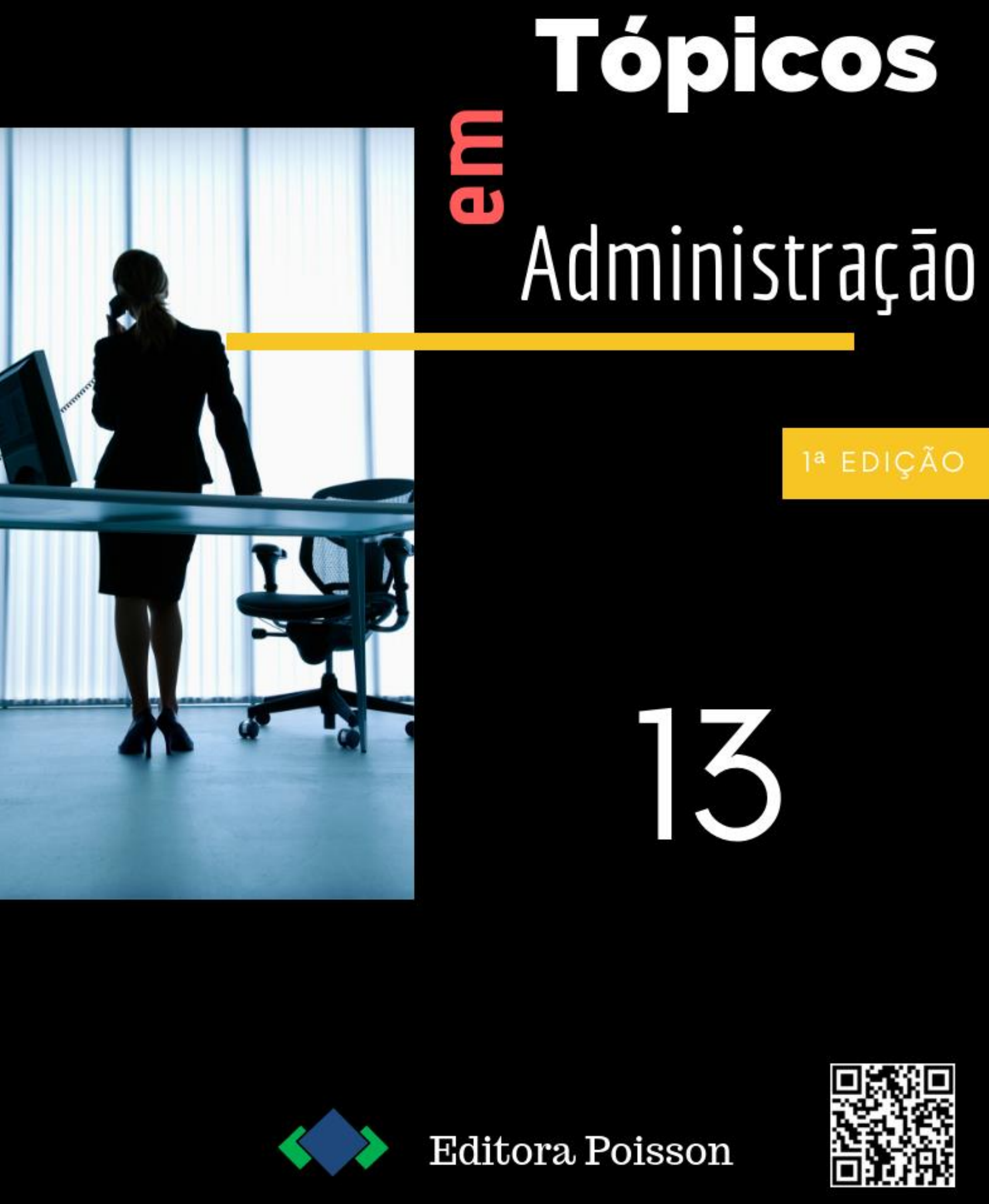


Editora Poisson

\title{
Tópicos em Administração Volume 13
}

\author{
1a Edição
}

Belo Horizonte

Poisson

2018 
Editor Chefe: Dr. Darly Fernando Andrade

Conselho Editorial

Dr. Antônio Artur de Souza - Universidade Federal de Minas Gerais

Dr. José Eduardo Ferreira Lopes - Universidade Federal de Uberlândia

Dr. Otaviano Francisco Neves - Pontifícia Universidade Católica de Minas Gerais

Dr. Luiz Cláudio de Lima - Universidade FUMEC

Dr. Nelson Ferreira Filho - Faculdades Kennedy

Ms. Valdiney Alves de Oliveira - Universidade Federal de Uberlândia

Dados Internacionais de Catalogação na Publicação (CIP) T674

Tópicos em Administração - Volume 13/

Organização Editora Poisson - Belo

Horizonte - MG: Poisson, 2018

293p

Formato: PDF

ISBN : $978-85-7042-021-3$

DOI : $10.5935 / 978-85-7042-021-3.2018$ B001

Modo de acesso: World Wide Web

Inclui bibliografia

1. Administração 2. Gestão. I. Título

CDD -658

O conteúdo dos artigos e seus dados em sua forma, correção e confiabilidade são de responsabilidade exclusiva dos seus respectivos autores.

www.poisson.com.br

contato@poisson.com.br 


\section{Sumário}

Capítulo 1: Custos políticos e políticas de controle ao tabagismo e resultados financeiros das empresas: um estudo de caso na empresa Souza Cruz S/A ..... 7

José Tiago Angélico da Silva, Gianinni Martins Pereira Cirne, Fabiano Ferreira Batista, Francisco Daênnio Casimiro de Oliveira, Francisco Jean Carlos de Souza Sampaio, José Ribamar Marques de Carvalho

Capítulo 2: Impacto no EVA® das distribuidoras de energia elétrica do Estado de São Paulo após a Lei 12.783/2013 ............................................................. 20

Thalisa Maria Jati Gilberto, Diego Vinícius Dias, Marinês Santana Justo Smith

Capítulo 3: Identificação dos custos ocultos no processo de fabricação de produtos de uma indústria de bebidas localizada na Paraíba.

Thaís Nicole Pereira Gomes, Isabelle Carlos Campos Rezende, Daniela Cintia de Carvalho Leite Menezes, Yara Magaly Albano Soares

Capítulo 4: Gestão de custos interorganizacionais: estudo sobre os fatores inibidores

Rafael Araújo Sousa Farias

Capítulo 5: A influência do tamanho do investimento realizado na intensidade do efeito custo afundado: quando mais é mais.

Denizar Leal, Guilherme Freitas Campos

Capítulo 6: Gestão de custos em pequenas propriedades rurais: um estudo aplicado no município de Marechal Cândido Rondon - PR.

Adriane Carine Maldaner Vorpagel, Elza Hofer, Anderson Giovane Sontag

Capítulo 7: The corporate sustainability index and legitimate theory: a correlation between market value and climate change.

Emerson Andrade Gibaut

Capítulo 8: Crise econômica e a evolução das despesas com pessoal nas administrações municipais do litoral de Santa Catarina

Francisco Xavier Soares Filho, José Simão de Paula Pinto, Ademir Clemente

Capítulo 9: Análise da política de dividendos: uma aplicação de regressão quantílica

Jéferson Rodrigo Ströher, Eric Fernando Boeck Daza, Igor Alexandre Clemente de Morais, Luiz Alberto Mangoni 


\section{Sumárīo}

Capítulo 10: Incentivos fiscais e competitividade: uma análise dos principais programas de incentivos utilizados pelo Rio Grande do Norte.

Richeliel Albert Rodrigues Silva, Rodrigo Mackssuel Silva de Melo, Genival Jardel Trajano Teixeira, Mônica Almeida Gavilan

Capítulo 11: A influência do ensino superior no planejamento financeiro pessoal dos acadêmicos ingressantes e concluintes do curso de administração da Universidade Federal de Mato Grosso do Sul - Campus de Nova Andradina

Thaís Nogueira da Silva, Vítor Cardoso da Silveira, Antonio Sérgio Eduardo, José Soares Ribeiro, Gemael Chaebo

Capítulo 12: Análise da estrutura produtiva da economia paranaense no contexto da economia brasileira: o caso da indústria 1995-2012

Márcio Luiz Ribeiro, Marcos Pedrinho Zuck, Sérgio Lopes

Capítulo 13: Incentivos fiscais à inovação no brasil: evolução da Lei do Bem no período de 2006 a 2014

Eder Angelo Sanches, Sanderson César Macêdo Barbalho, Adriana Regina Martin

Capítulo 14: Gestión de la innovación social como factor de competitividad

Sâmia Laíse Manthey Benevides, Flávio de São Pedro Filho, José Moreira da Silva Neto, Fábio

Biasotto Feitosa, Jackson José Sales Miranda Júnior

Capítulo 15: Desafios da captação de recursos para inovação: análise a partir do filme "Walt antes da Disney"

Sonia Regina Amorim Soares de Alcantara, Rafael Lucas Russo Daniel

Capítulo 16: A gestão do conhecimento aplicada no setor de corte diamantado -

Nível de similaridade 186

Daniel Brioschi Machado, Raoni Rocha Simões

Capítulo 17: Reflexões sobre os possíveis impactos do marketing religioso no município de Bom Jesus da Lapa.

Deyse Queiros Santos, Neivande Dias da Silva, Cassiana Santos da Silva Farias 


\section{Sumárīio}

Capítulo 18: A percepção dos clientes em relação ao atendimento aplicando-se a metodologia Disney em um Hotel

Layna de Azevedo Pereira da Silva, Ueliton da Costa Leonidio, Humberto Medrado Gomes Ferreira, Vanessa Cristina dos Santos

Capítulo 19: Diferenciação do produto: o caso Sapatos Lends

Camila Andrade Silva Souza, Camila Silva Damasceno, Stephania Aparecida Freitas Pedrosa, Joyce Gonçalves Altaf

Capítulo 20: Comportamento do consumidor: fatores que geram a necessidade da aquisição de cosméticos e de serviços estéticos

Tatiana Moreira Clemente, Hérica Landi de Brito, Gleidson Caetano da Silveira Pinto

Capítulo 21: O apelo ambiental como influência na decisão de compra do consumidor de produtos cosméticos

Eliane Santos Vargas, Lívia Maria de Pádua Ribeiro, Daniel Brianezi, Laércio Antônio Gonçalves Jacovine

Capítulo 22: Logística reversa como estratégia de fidelização no setor de produtos de beleza: uma revisão sistemática da literatura 265

Thaís Testoni, Patricia Guarnieri, Raphael Salviano de Souza, Amanda Cristina Gaban Filippi

Autores: 


\section{Gapítulo 1}

\section{CUSTOS POLITTICOS E POLÍTICAS DE CONTROLE AO TABAGISMO E RESULTADOS FINANCEIROS DAS EMPRESAS: UM ESTUDO DE CASO NA EMPRESA SOUZA CRUZ S/A}

\section{José Tiago Angélico da Silva}

Gianinni Martins Pereira Cirne

Fabiano Ferreira Batista

Francisco Daênnio Casimiro de Oliveira

Francisco Jean Carlos de Souza Sampaio

José Ribamar Marques de Carvalho

Resumo: O Brasil é um país atuante nas políticas públicas de combate ao tabagismo que impactam a demanda e a oferta do produto visando reduzir os danos causados à saúde pública, balanceando, desta forma, os males sociais causados por tais substâncias. Por outro lado, é o maior produtor e segundo maior exportador desse produto no mundo. O objetivo deste trabalho é analisar se os custos políticos advindos das políticas públicas exercem impacto no desempenho da empresa Souza Cruz S.A, para tanto foi estudado o período de 2000 a 2015. Através do estudo de eventos, foram analisadas as proxies: lucro líquido, comportamento de ações, volume de produção de vendas e representatividade no mercado, sob a ótica de que a referida interferência governamental teve impacto nessas variáveis. Encontraram-se evidências de que as políticas públicas de combate ao tabagismo não tiveram relação direta com a variação das ações. Observou-se ainda um aumento significativo do lucro líquido no decorrer dos anos, mesmo com o comportamento reverso da produção vendida, além do aumento da representatividade no mercado, indicando que as políticas públicas foram eficazes no combate ao tabagismo, sem influenciar negativamente no mercado. Mostrando que as interferências governamentais dos custos políticos advindos das políticas públicas foram eficientes sem trazer impactos financeiros negativos à empresa.

Palavras-Chave: Tabagismo. Políticas Públicas. Desempenho. 


\section{INTRODUÇÃO}

O setor fumageiro é de grande importância para a economia brasileira, uma vez que gera mais de 2,18 milhões de empregos diretos e indiretos, figurando no cenário mundial como o maior produtor do fumo no mundo e segundo maior exportador, ficando atrás somente da China (Afubra, 2013; Sinditabaco, 2013).

A estrutura do mercado tabagista se caracteriza como Oligopsônio, na qual poucas empresas são responsáveis pela compra e venda do produto. A representatividade do Brasil para a empresa é relevante, já que é o maior mercado latinoamericano do produto, com consumo correspondente a $42 \%$ do total vendido na América latina. Como em todo setor agrícola brasileiro, o desempenho depende de dois fatores determinantes: o mercado $e$ as políticas governamentais. Os fatores externos, como aumento da tributação, propagandas negativas, fim da publicidade e medidas educacionais contra o tabaco, mudam de forma direta a conjuntura e os resultados das empresas do ramo, que são atingidas diretamente por todos os aspectos da adoção das políticas internacionais (Limberger, 2013).

Segundo o Instituto Nacional do Câncer (INCA, 2014), a Convenção Quadro para Controle do Tabaco tem o objetivo de proteger gerações futuras, das conseqüências ambientais, sociais, sanitárias e econômicas geradas pela exposição à fumaça e pelo consumo do tabaco, desta maneira determinando ações intersetoriais em várias áreas como publicidade, patrocínio, propaganda, preço, impostos, advertências sanitárias e tratamentos de fumantes passivos e ativos.

Tais políticas interferem diretamente variáveis fundamentais para o setor de cigarros, a limitação ou proibição da publicidade, tal como a elevação dos preços, impostos e estabelecimento de preço mínimo de venda no varejo, podendo ter acarretado várias mudanças no setor nos últimos anos (Nascimento, 2011).

Segundo Luiz, Alberton e Silva (2014), as políticas públicas brasileiras implementadas no Brasil visando a retração do consumo, podem ter contribuído para determinar a trajetória de variáveis como preço, custo, volume de produção e receita em momentos distintos. Além dessas comprovações o índice de consumo de cigarros chegou ao seu menor índice em 2015, reduzindo em 35\% nos últimos nove anos (INCA, 2016).

Tendo em vista essa conjuntura, é necessário um diagnóstico sobre os impactos causados pela adoção do tratado internacional de saúde (CQCT), nos desempenhos financeiros das empresas tabagistas, evidenciando as variações de acordo com implementações de cada etapa do processo antitabagista.

\section{REFERENCIAL TEÓRICO \\ 2.1 POLÍTICAS PÚBLICAS}

Políticas públicas são consideradas um fluxo de decisões públicas que tem como finalidade manter o equilíbrio social ou introduzir desequilíbrios destinados a mudar a realidade. Essas decisões são condicionadas ao fluxo e às próprias reações e modificações que as mesmas causam no contexto social, estando diretamente envolvidas com valores, idéias e visões que envolvem a tomada de decisões (Saraiva \& Ferrarezi, 2007).

As Políticas Públicas tiveram seu surgimento nos EUA, como área de conhecimento, especificamente como disciplina acadêmica, avançando em relação à tradição européia de estudos nessa área, que tinham um foco de concentração no Estado e em suas instituições, surgindo, dessa forma, um desdobramento dos trabalhos baseados em Teorias de Correlação explicativas do papel em relação a excelência do governo no âmbito de políticas públicas, enquanto nos EUA, ao contrário, a área surge no próprio mundo acadêmico, sem estabelecer relações com bases teóricas do papel do estado, passando direto para ênfase nos estudos sobre a ação dos governos (Souza, 2006).

A forma intimista em que o estado está relacionado às suas funções, deslumbrandose sob os enfoques políticos, sociológicos, administrativos, filosóficos e jurídicos. Cada um desses enfoques teve sua prevalência no decorrer da história, sendo que os dois segmentos que tiveram maior relevância foram o jurídico, que teve longa hegemonia entre o século XIX estendendo-se até a segunda Guerra Mundial, e o administrativo, que despontou no começo do século $X X$, passando a ser dominante nos EUA onde, a partir de 1960, se alastrou e prevalece até os dias atuais (Saraiva \& Ferrarezi, 2006; Traldi, 2015). 
No quesito governamental, a introdução das Políticas Públicas como ferramenta foi produto da Guerra Fria. Nos EUA teve como introdutor Robert McNamara, em 1948, que estimulou sua criação, juntamente a RAND Corporation, organização não-governamental financiada por recursos públicos e considerada a precursora dos think tanks, organizações que atuam produzindo e difundindo conhecimento sobre assuntos estratégicos (Souza, 2006).

Tanto as políticas públicas em geral quanto, as políticas sociais se perfazem em campos multidisciplinares, buscando de certa maneira aplicar teorias construídas no campo de sociologia, da ciência política e da economia. As políticas públicas têm seu campo de atuação e operacionalidade, onde se destinam a demanda e a necessidade de entender as relações entre Estado, política, economia e sociedade, dividindo desta maneira interesses em comum com diversas áreas do conhecimento tais quais, economia, ciência política, sociologia, antropologia, geografia, planejamento, gestão e ciências sociais aplicadas (Hogwood, 1981).

\subsection{BRASIL E AS POLÍTICAS PÚBLICAS CONTRA O TABAGISMO}

O combate aos malefícios causados pelo tabagismo possui uma contextualização importante em aspectos fundamentais no decorrer de sua história política em âmbito internacional. A partir da década de 70 o hábito de fumar e o tabagismo se tornaram temas de discussão em Assembléias Mundiais de Saúde, órgão mais elevando na perspectiva de tomada de decisão da Organização Mundial da Saúde (OMS), que é constituído por representantes dos estados da organização (Rosemberg, 1981).

Encabeçando a articulação do movimento em combate ao tabagismo a OMS, definiu a situação como problemática e de extrema importância entre as prioridades da humanidade, na tentativa de redução dos impactos causados pelo tabagismo e as alarmantes conseqüências provocadas pelo seu consumo. Estes fatores configuraram a articulação e instauração do que seria o primeiro tratado em escala global de saúde pública da história. Nos dias atuais o tratado possui 180 assinaturas e 173 ratificações (Aliança de Controle ao Tabagismo [ACTBR], 2016).

A convenção é subdivida sobre os seguintes dispositivos gerais, subdivididos em dois subgrupos, redução da oferta e redução da demanda (ACTBR, 2016). Estruturados da seguinte forma:

Quadro 1- Dispositivos gerais da convenção

\begin{tabular}{|c|c|}
\hline Redução - Oferta: & Redução - Demanda \\
\hline $\begin{array}{l}\text { Mitigação do comércio ilegal dos produtos do tabaco } \\
\text { e contrabando; }\end{array}$ & Regular o teor substancial dos derivados de tabaco; \\
\hline $\begin{array}{l}\text { Restrição das vendas como um todo, principalmente } \\
\text { para menores de } 18 \text { anos; }\end{array}$ & $\begin{array}{c}\text { Regular e disponibilizar informações a respeito dos } \\
\text { produtos feitos de tabaco; }\end{array}$ \\
\hline \multirow{3}{*}{$\begin{array}{l}\text { Gera alternativas econômicas ao produtores de } \\
\text { tabaco estimulando seu desenvolvimento. }\end{array}$} & $\begin{array}{c}\text { Regular a proteção a exposição à fumaça ambiental } \\
\text { do tabaco; }\end{array}$ \\
\hline & $\begin{array}{l}\text { Controle dos anúncios, propagandas, e rótulos } \\
\text { embalagens; }\end{array}$ \\
\hline & $\begin{array}{l}\text { Comunicação, educação, difusão massiva de } \\
\text { informações ao público e treinamento. }\end{array}$ \\
\hline
\end{tabular}

Fonte: Dados da Pesquisa

No processo de desenvolvimento do tratado o Brasil destacou-se como um dos líderes do processo, que foi constituído em audiências públicas e seis rodadas de negociações envolvendo 192 países membros da OMS. O Programa Nacional de Controle do Tabagismo (PNCT) era apontado como visionário, explicando o protagonismo brasileiro no 
decorre do processo negociador do CQCT ao longo dos três anos do processo (ACTBR, 2016).

No entanto, mesmo estando nesta posição de liderança no acordo mundial, que ocorreu de 1999 a 2003, somente ratificou o acordo em outubro de 2005 sendo um dos últimos países a aderi-lo. Isso demonstra a força do setor fumageiro, principalmente da grande indústria tabaqueira que tentou coibir a ratificação do tratado gerando intensidade nas pressões contrárias à ratificação, tal atuação em meio ao processo negociador da ratificação Convenção Quadro, era foi nitidamente observada.

Segundo Aversa (2006), a indústria tabagista é tipicamente um negócio controverso, tem como grande preocupação a não manifestação de animosidade em relação à sociedade e sua imagem, que seus dirigentes preferem ver associada a iniciativas de responsabilidades.

$\mathrm{Na}$ esfera econômica as políticas públicas foram estabelecidas a partir do estímulo à taxação e à restrição do cigarro nos cálculos de índices de custo de vida. Já a ação médica social implementou programas de suporte ao tratamento do fumante por partes das organizações não governamentais e governamentais. Grande parte das ações recomendadas pela OMS, comprovadamente eficazes para o controle do tabagismo, foge da finalidade direta do Ministério da Saúde e sua governabilidade. Desta maneira, apesar do Ministério da Saúde não ter o poder direto para executar algumas ações, tem se empenhando para mobilizar ações intersetoriais de controle ao tabaco por meio de medidas econômicas e legislativas (ACTBR, 2016).

Duas etapas são consideradas fundamentais para descentralização. Primeiramente o estabelecimento de convênios que repassam os recursos financeiros para as Secretarias Estaduais de Saúde, que foram instituídos em 1996 pelo o Fundo Nacional de Saúde do Mistério da Saúde e as Secretarias Estaduais de Saúde, nas quais o INCA serve como mediador. Posteriormente, o processo de desenvolvimento e capacitação regional do programa, com foco nos recursos humanos dos Estados, Municípios e Secretária de Saúde. Essas etapas permitiram o desenvolvimento de uma terceira, na qual as Secretarias Estaduais, que tem como fornecedor de suporte técnico o INCA, alinhando a rede em torno do PNCT, que tem sido executado até o presente momento (Henrique, 2016).

O PNCT teve seu marco mais importante com a criação da Comissão Nacional para implementação da Convenção-Quadro para o Combate ao tabaco e seus Protocolos (CONICQ), em agosto de 2003, que possui até os dias atuais caráter permanente e é representada pela Casa Civil da Presidência da República, Agência Nacional de Vigilância Sanitária, Advocacia Geral de União, e por de 13 Ministérios: da Saúde; do Planejamento; das Relações Exteriores; da Agricultura, Pecuária e Abastecimento; da Fazenda; da Ciência, Tecnologia e Inovação; da Educação; Desenvolvimento, Indústria e Comércio Exterior; da Justiça, do Trabalho e Emprego; das Comunicações e do Meio Ambiente, tal comissão representou um importante avanço para o controle do tabaco no Brasil, realizando interligação necessária entre os setores para tratar de um assunto de tamanha magnitude (Cavalcante, 2005).

\subsection{AÇÕES DE REGULAÇÃO NO MERCADO}

Em 1995, o Ministério da Saúde enviou cinco amostras dos cigarros mais vendidos e produzidos no país ao Canadá, onde aconteceu a análise bioquímica das substâncias e teores tóxicos, a partir disso um importante passo foi dado pelo Ministério da Saúde, no sentido de mobilizar regulamentações através da legislação para coibir o uso dos derivados do tabaco (Silva et al., 2014).

No ano seguinte, os resultados foram revelados mostrando que os níveis de várias das substâncias estavam muito acima dos teores máximos estipulados em outros países. A partir disso, um documento foi elaborado, no qual foi tratada uma série de recomendações no sentido de criar mecanismos legislativos que regulamentassem e obrigassem os fabricantes e importadores de cigarros a informar ao Ministério da Saúde os conteúdos dos seus produtos e a divulgarem informações nas embalagens relativas a tais substancias. Nesse intuito foi recomendada a criação de mecanismos pelo governo para fiscalizar, normatizar e inspecionar esse seguimento, além de metodologias de análise específicas (Brasil, 2003). 
Segundo Silva et al. (2014), essas ações estão normatizadas e demonstradas de maneira sintética, onde o leque de políticas promulgadas pelo PCNT inicialmente foram mantidas e intensificadas após o surgimento da CONICQ.

Quadro 2 - Estratégia de atuação estatal no mercado do tabaco proposta pelo PNCT.

\begin{tabular}{|l|l|}
\hline \multicolumn{1}{|c|}{ ÁREAS } & \multicolumn{1}{c|}{ AÇÕES } \\
\hline Fiscalização & $\begin{array}{l}\text { A o controle, fiscalização e a regulamentação por } \\
\text { meio da ANVISA de todos os produtos derivados do } \\
\text { tabaco. }\end{array}$ \\
\hline Restrição à disponibilidade & $\begin{array}{l}\text { Manobras de carga tributária sobre a } \\
\text { comercialização dos produtos e proibição da venda } \\
\text { para menores de } 18 \text { e derivados de tabaco. }\end{array}$ \\
\hline Controle da Promoção e Comercialização & $\begin{array}{l}\text { Veto à propaganda comercial, inclusive Internet, bem } \\
\text { como distribuição de amostras; Restrição da } \\
\text { exposição dos produtos no interior dos } \\
\text { estabelecimentos, devendo estar acompanhada de } \\
\text { advertências; Proibição do uso de descritores como } \\
\text { light e suave nas embalagens; Inserção de } \\
\text { ilustrações com advertências sanitárias nas } \\
\text { embalagens, juntamente com o número do Disque - } \\
\text { Saúde - Pare de Fumar. }\end{array}$ \\
\hline Outras & $\begin{array}{l}\text { Suspensão do financiamento do Programa de } \\
\text { Fortalecimento da Agricultura Familiar à cultura do } \\
\text { fumo em regime de parceria ou integração com a } \\
\text { indústria do tabaco. }\end{array}$ \\
\hline
\end{tabular}

Fonte: Elaborado pelo autor, a partir de SILVA et. al (2014).

\subsection{RESTRIÇÕES À PUBLICIDADE}

A lei 9.294 foi editada em 1996 e suas disposições estabeleceram que as propagandas do setor tabagista só pudessem ser vinculadas em emissoras de rádio e televisão no horário entre 21h00min e 06h00min horas. Tal publicidade deveria está alinhada a vários princípios, entre eles o de não sugerir o consumo exagerado ou irresponsável do cigarro, a de não associação do produto com celebridades cívicas ou religiosas, o de não associar 0 produto à propriedades estimulantes e calmantes, o de não empregar imperativos que induzissem ao consumo e a não insinuação ao aumento de feminilidade ou virilidade a pessoas fumantes (Brasil, 1996).

Nesse sentindo, dois outros dispositivos foram estabelecidos pela lei 9.294/96, que foram alterados pela lei $10.167 / 00$, que proíbem a associação do fumo com prática esportiva, olímpicas ou não, e a indução de seu consumo em situações ou locais perigosos, ilegais ou abusivas, restringindo principalmente a utilização de crianças nas propagandas de rádio, difusão de sons e imagens (Brasil, 2000).
Essa mesma lei também estabeleceu a indispensabilidade de propagandas nos meios de comunicação com advertências aos malefícios do fumo através de frases como "Fumar pode causar câncer do pulmão, bronquite crônica e enfisema pulmonar". $\mathrm{Na}$ ocasião, a lei propôs uma lista de seis frases que teriam que ser veiculadas nas propagandas, trazendo a afirmação: "O ministério da Saúde adverte", obrigando as empresas tabagistas à vincularem diretamente nas embalagens dos produtos, salvo aqueles destinados à exportação. Em 2001, a medida provisória 2190-34 estabeleceu a obrigação da inserção de imagens ilustrativas que deveriam dar sentido às frases nas embalagens dos produtos (Brasil, 1996; Brasil, 2001).

Em 2000, com o intuito de alteração da lei 9.294 de 1996 , a lei 10.167/2000, restringiu a veiculação de qualquer propaganda de produto fumageiro a pôsteres, painéis e cartazes, na parte interna dos locais de venda. Novas regulamentações a partir da lei 10.702/2003 estabeleceram que na transmissão no Brasil de quaisquer eventos culturais ou esportivos, gerados no estrangeiro, patrocinadas por empresas 
tabagistas ou ligadas produtos fumageiros, deveriam ser vinculadas mensagens de advertências na abertura, encerramento e durante a transmissão a cada 15 minutos (Brasil, 2000; Brasil, 2003).

Por fim, disposição da lei 12.546/2011, vedouse em todo território nacional a propaganda de produtos tabagistas, excetuou-se, porém, a vedação a exposição dos produtos nos locais de vendas, desde que fossem acompanhadas de advertências sobre seus malefícios, incluindo a tabela de preço, preço mínimo de venda e no varejo. Também foram estabelecidos, que as imagens deveriam compor $100 \%$ da parte posterior e uma das laterais, além de uma advertência adicional na parte inferior e da face frontal equivalente a 30\% (Brasil, 2011).

A lei também proibiu todas as propagandas por meio eletrônicos, a realização de visitas promocionais, distribuição de qualquer tipo de amostra ou brinde, patrocínios em atividades esportivas e culturais, a propaganda móvel ou fixa em pista, palcos, estádios, ou local similar e merchandising em qualquer horário (Brasil, 2011).

\subsection{TEORIA POSITIVA DA CONTABILIDADE E A HIPÓTESE DOS CUSTOS POLÍTICOS}

A teoria positiva da contabilidade é classifica em duas perspectivas: (I) a perspectiva de eficiências, onde os envolvidos em um ambiente agem antes de um determinado fato acontecer, e a (II) perspectiva oportunística, em que os envolvidos agem defendendo seus próprios interesses utilizando-se de oportunismo (Dias Filho \& Machado, 2004).

Segundo Watts e Zimmerman (1986) a hipótese oportunística é formulada e centrada na ótica das seguintes hipóteses: hipótese do plano de incentivos, hipótese do grau de endividamento, hipótese dos custos políticos.

No que diz respeito a hipótese de custos políticos apresentados por Watts e Zimmerman (1986), presume-se que ao se inserir em setores mais sensíveis dos aspectos políticos as organizações, como a indústria farmacêutica, os serviços públicos, o setor florestal, a indústria de petróleo e outras, estão geralmente sujeitas a custos políticos, o que estão diretamente ligados com a divulgação de ganhos elevados, sendo tais custos decorrentes de aspectos contratuais, muitas vezes lobbies provindos da regulação do Estado para certos tipos de atividades.
Entre os fatores que podem impactar os custos políticos, está a regulação do mercado por órgão e autarquias públicas; os institucionais externos e internos, como a legislação societária atual; o tamanho da empresa; os sindicatos e o posicionamento estratégico, tais características aumentam as intervenções políticas (Gibbins, Richardson \& Waterhouse, 1990).

A regulação do mercado por órgão e autarquias públicas, seus custos e seus tipos podem ser compreendidas como uma junção de normas coercitivas, originadas do Estado ou de órgão com poderes para tanto, relativas à determinada área ou atividade do conhecimento. Outro método de compreensão é entendê-lo como processo de emissão de normas, a qualidade das mesmas, a sua aceitação ou eficácia, seus efeitos, necessidade ou pertinência (Pohlmann \& Alves, 2004).

Pode-se entender custos de regulação como um conjunto de gastos ou redução de receitas decorrentes de normas coercitivas, oriundas do estado ou de outro órgão com poderes de regulamentar determinado ramo de atividades. Os seus efeitos podem ser o aumento de tributos ou tarifas, despesas com atendimento das regulamentações, e despesas de adequação. Esses custos de regulação são caracterizados como custos políticos, como por exemplo, os custos de monitoramento, de lobbying, processual, de evidenciação e de atendimento (Pohlmann \& Alves, 2004).

Os custos políticos tributários foram propostos inicialmente por Gagnon (1967) como possível direcionador da escolha do método contábil a ser utilizado em fusões, transações e aquisições, de acordo com o - SFAS 141 Stament of Financial accounting Standard Combinação de negócios, emitido pelo Financial Accounting Standards Board (FASB). Tal escolha afetava levemente o mercado, por conta das informações que seriam disponibilizadas, bem como os resultados fiscais e da companhia sobre as operações.

Pode se identificar custos políticos tributários sobre a alíquota efetiva, antes que seja definido como percentual de impostos pagos sobre o lucro antes de impostos. Esse incremento é decorrente da assimetria do tratamento para fins contábeis e fiscais, visto que alguns dos mecanismos contábeis adotados para reduzir o lucro não geram 
impactos na esfera tributária, ocorrendo assim um deslocamento na alíquota total efetiva. Sendo assim, os grandes contribuintes que estão sujeitos aos custos políticos tributários devem apresentar alíquota maior aquela imposta aos outros contribuintes, que não precisam adotar tal procedimento por não estarem expostos aos custos políticos (Zimmerman, 1983).

Contudo, a alíquota tributária efetiva é apenas parte desses custos políticos, que pode ter outros aspectos como a regulação comercial, subsídios governamentais, quotas de importação, etc. (Lopes, 2012).

\subsection{ESTUDOS CORRELATOS}

Para embasar e dar respaldo a pesquisa, identificamos os seguintes estudos relacionados ao tema:

Silva et al. (2014), apresentou a pesquisa Com objetivo de apresentar as ações do PNCTOFR identificando as evidências de sua eficácia na redução da prevalência do tabagismo no Brasil, onde foi utilizada a metodologia do estudo bibliográfico, analisando as restrições da disponibilidade, controle do marketing, comercialização, atendimento na atenção primária, atividades educativas nas escolas, e coibição ao consumo, além de outras ações. Os resultados apontam a redução da prevalência de tabagismo no Brasil de 32,87 \% em 1997 para 14, 8 em 2014, demonstrando deste modo a eficiência das políticas e evidenciando a urgência do tabagismo como problema de saúde pública, devendo ser desnormatizado.

Boeira e Johns (2007), apresentaram a pesquisa com o objetivo de apresentar uma introdução à história da indústria de tabaco e do confronto entre sua rede social de stakeholders e a rede liderada pela Organização Mundial da Saúde, onde foi utilizada a metodologia documental, bibliográfica, teórica e de campo. Foram realizadas entrevistas abertas e gravadas com fumageiros, técnicos do setor de saúde e educacionais, líderes de ONGs e atores sociais. O artigo buscou correlacionar a problemática relação entre produção, exportação e combate ao consumo de cigarros e os resultados demonstraram o rompimento da confiança entre o governo brasileiro e o setor fumageiro, abrindo assim um novo período na história a partir do vigor do tratado internacional de saúde pública, Convenção-Quadro de controle ao tabaco (CQCT).

Luiz, Alberton e Silva (2014), apresentaram o trabalho cujo objetivo é estudar o comportamento das variáveis/custo, preço, receita e volume de produção do subsertor de fumo brasileiro diante das políticas antitabagistas entre os anos de 1994 e 2013. No qual foram evidenciadas as políticas de imposição do preço mínimo, majoração da carga tributária e restrição da publicidade, objetivando assim identificar o comportamento das variáveis custo, preço, receita e volume entre 1994 e 2013. A metodologia foi proposta a partir de pesquisa documental e bibliográfica. A análise representou o comportamento em três tendências: 1996 a 1999, 2000 a 2007 e 2008 a 2013, onde o primeiro é correlacionado com o fim da propaganda, o segundo com o aumento do IPI e o terceiro a instituição do preço mínimo que acarretaram uma sequência de reduções no volume de produção.

\section{PROCEDIMENTOS METODOLÓGICOS}

O estudo consiste em um estudo de caso na empresa Souza Cruz SA, que faz parte do setor tabagista, sendo a única empresa desse setor listada na BM\&FBovespa até o ano 2015. Quanto ao aspecto temporal, o estudo abrange os valores das ações no período correspondente entre 2000 e 2015.

Utilizou-se do estudo de eventos para medir o efeito de um evento econômico no desempenho de uma empresa. Sendo eficaz através da hipótese de que o efeito de um evento será refletido nos preços do ativo (Campbell, Lo \& Mackinley, 1997).

Segundo Binder (1998), na prática desse método é possível verificar o impacto de um determinado evento na riqueza dos acionistas de uma empresa, mantendo a hipótese de mercado eficiente referente a informação pública.

Os eventos de interesses foram as políticas públicas de combate ao tabagismo do período de 2000 a 2015, identificando as datas de suas respectivas vigências. A data da ocorrência do evento é o período de vigência das leis antitabagistas e correspondente a "data zero" a partir da qual se examinou os preços das ações em todo o período. 
Através da literatura foram elencados 37 eventos, dos quais foram selecionados 18 eventos, considerando como critério o impacto para os resultados da entidade e levando em consideração os dias dos eventos para os quais não houve negociação em bolsa. No quadro a seguir são elencados os eventos:

Quadro 3- Relação de Eventos

\begin{tabular}{|c|c|c|c|}
\hline ANO & DATA & EVENTO & EVENTOS \\
\hline 2002 & $07 /$ nov & EVENTO 1 & $\begin{array}{c}\text { Implementação do tratamento do fumante em todas as } \\
\text { unidades de saúde, com medicamentos }\end{array}$ \\
\hline 2002 & $01 / \mathrm{dez}$ & EVENTO 2 & $\begin{array}{c}\text { Alíquota do IPI alterada. Aumento dos preços de } \\
\text { cigarros de } 8 \% \text { a } 17 \%\end{array}$ \\
\hline 2004 & $01 /$ jan & EVENTO 3 & $\begin{array}{l}\text { Alíquota do IPI alterada. Aumento dos preços de } \\
\text { cigarros }\end{array}$ \\
\hline 2007 & $11 /$ jul & EVENTO 4 & $\begin{array}{l}\text { Alíquota do IPI aumenta em } 30 \% \text { para todas as classes } \\
\text { de cigarros }\end{array}$ \\
\hline 2009 & $30 / \mathrm{abr}$ & EVENTO 5 & Imposto aumenta em $65 \%$ para venda a varejo \\
\hline 2009 & 07/ago & EVENTO 6 & $\begin{array}{l}\text { São Paulo proíbe o fumo em recintos coletivos e os } \\
\text { fumódromos }\end{array}$ \\
\hline 2009 & 17/ago & EVENTO 7 & $\begin{array}{l}\text { Rio de Janeiro próbe o fumo em recintos coletivos e os } \\
\text { fumódromos }\end{array}$ \\
\hline & & & $\begin{array}{c}\text { Proíbe a comercialização, a importação e a propaganda } \\
\text { de quaisquer dispositivos eletrônicos para fumar, } \\
\text { conhecidos como }\end{array}$ \\
\hline 2009 & 28/ago & EVENTO 8 & cigarro eletrônico \\
\hline 2011 & 19/ago & EVENTO 9 & $\begin{array}{l}\text { É determinado que o Poder Executivo poderá fixar preço } \\
\text { mínimo de venda no varejo de cigarros abaixo do qual } \\
\text { fica proibida a sua comercialização }\end{array}$ \\
\hline 2012 & $01 / \mathrm{mai}$ & EVENTO 10 & Criação do preço mínimo dos cigarros \\
\hline 2012 & $01 / \mathrm{mai}$ & EVENTO 11 & Aumento do IPI \\
\hline 2013 & $01 /$ jan & EVENTO 12 & Aumento do preço mínimo dos cigarros \\
\hline 2013 & $01 /$ jan & EVENTO 13 & Aumento do IPI \\
\hline 2013 & $26 / \mathrm{dez}$ & EVENTO 14 & $\begin{array}{l}\text { Proibição da comercialização, a distribuição e a } \\
\text { propaganda de produtos nacionais e importados, e } \\
\text { embalagens, destinados ao público infanto-juvenil, } \\
\text { reproduzindo a forma de cigarros e similar }\end{array}$ \\
\hline 2014 & $01 /$ jan & EVENTO 15 & Aumento do IPI \\
\hline 2014 & $01 /$ jan & EVENTO 16 & Aumento do preço mínimo dos cigarros \\
\hline 2015 & $01 /$ jan & EVENTO 17 & Aumento do preço mínimo dos cigarros \\
\hline 2015 & $01 /$ jan & EVENTO 18 & Aumento do IPI \\
\hline
\end{tabular}

Fonte: Elaborada pelo autor

Desse modo, objetivando verificar a relação do evento com a variação do preço da ação utilizou-se como proxies para desempenho, o preço das ações, o volume de produção, a representatividade do mercado e resultados financeiros.

Foi analisada através de gráficos de linha para toda séria histórica, feita a verificação individual por anos.

\section{4 - APRESENTAÇÃO E ANÁLISE DOS DADOS}

Esta seção apresenta os dados e sua análise, retratando os eventos selecionados, que compreende a série histórica do período com o valor do fechamento das ações no decorrer do ano. 
Figura 1 - Série Histórica de Preço de Ações

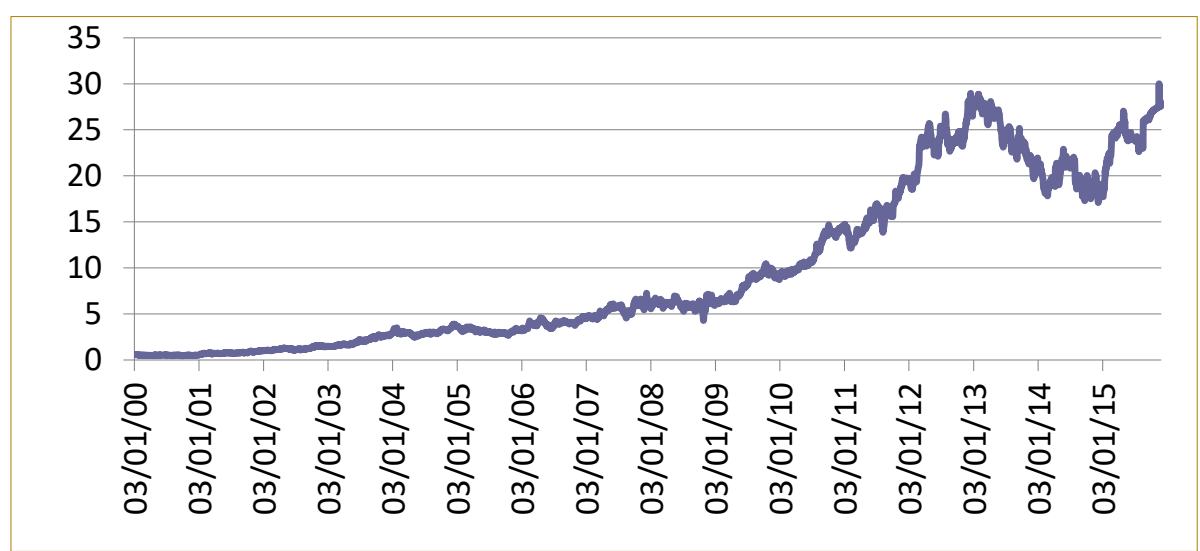

Fonte: Dados da Pesquisa

Contudo observando as ações e cruzando com os eventos relativos ao setor, e observando possíveis comportamentos atípicos, o estudo trouxe a visualização individual por ano com a finalidade de mostrar o desdobramento do comportamento do valor das ações e eventos ocorridos. Conforme
Figura 1, no ano de 2002, há o início do aumento da linha, e observa-se que nos anos 2013 e 2014, ocorre um declínio da linha, por isto traremos estes dados com 0 comportamento da série histórica e as políticas públicas implementadas:

Figura 2 - Preço das Ações ano 2002

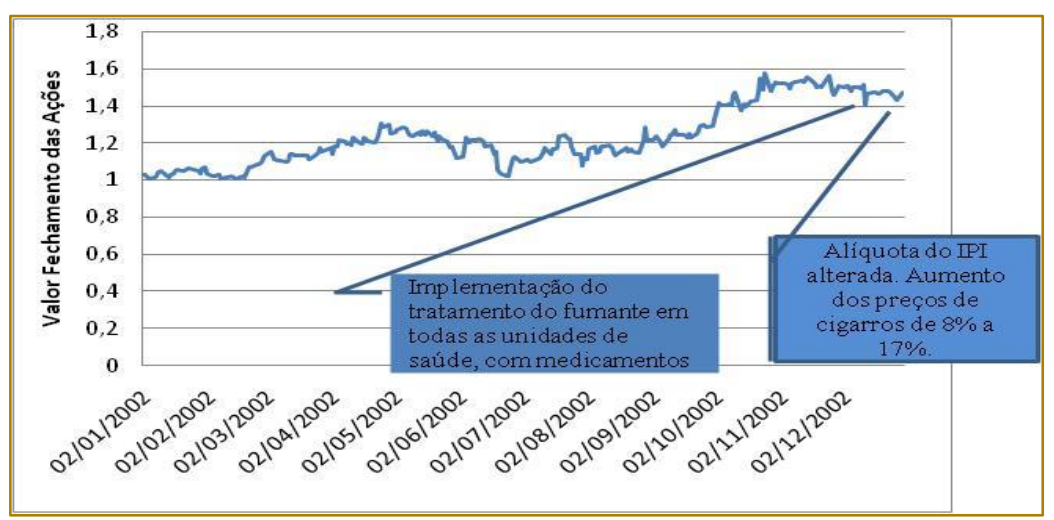

Fonte: Dados da Pesquisa.

Figura 3 - Preço das Ações ano 2014

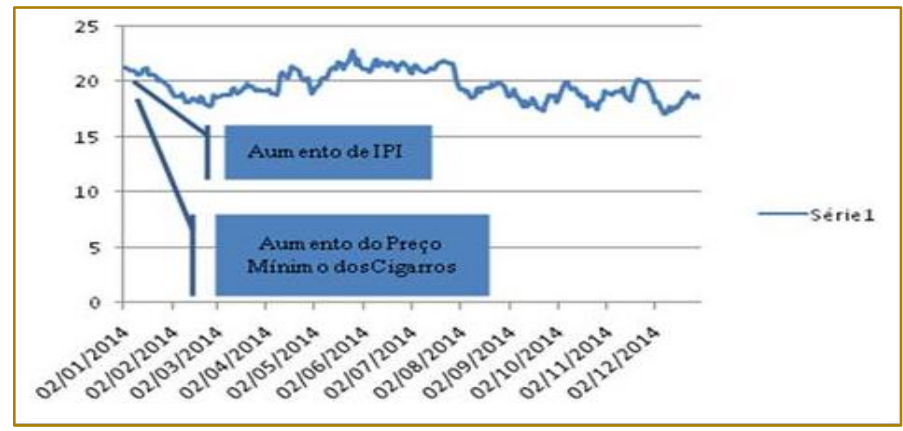

Fonte: Dados da Pesquisa. 
Figura 4 - Preço das Ações ano 2015



Fonte: Dados da Pesquisa.

Ao comparar as datas dos eventos com as maiores variações, viu-se que os mesmos não tiveram influência no comportamento das ações, no período. Embora os anos de 2014 e 2015 mostrem na série histórica uma queda na linha, não houve inferência em relação ao todo analisado, no período geral nos anos, sendo assim as políticas públicas não influenciaram no comportamento das ações no mercado.

Outra proxie que utilizamos para verificar a influência foi o Volume de Produção. A figura
5 traz o comportamento dos volumes de venda, e mesmo com a diminuição em 30,6\% das vendas entre os anos de 2000 e 2014, isso porque a Sousa Cruz, no ano 2000, possuía um volume de produção de 77,6 bilhões de unidades de cigarro, representando $58,8 \%$ do mercado tabagista, enquanto no ano de 2014 seu volume de produção foi de 56,8 bilhões de unidades de cigarro, detendo $74,40 \%$ do mercado.

Figura 5 - Volume de venda (Bilhões de unida) x Participação do Mercado



Fonte: Dados da Pesquisa.

Observa-se que o volume de produção teve descréscimos siginificativos após 2007, ano em que foi introduzida a nova regra de tributação do IPI pelo Decreto ํo 6.072, de 3 abril de 2007 instituindo um majoração de
$30 \%$ na sua alíquota, no mesmo período pode-se destacar o aumento progressivo da participação da Sousa Cruz no mercado brasileiro, chegando a $78,40 \%$ em 2014 , sendo 19,6\% a mais do que em 2003 quando 
possuia um volume de produção 30,6 \% maior.

Analisou-se o Lucro Líquido da empresa. No primeiro momento identifica-se a elevação do lucro líquido de 49,3\% entre 2000 e 2002, e decréscimo de 36\% de 2002 a 2005, vale destacar que em 2002 entrou em vigor os Decretos $n-4.448$ e $n-4542$ referente a políticas tributárias relacionadas ao $\mathrm{IPI}$, aumentando a TIPI, com uma majoração do IPI entre $8 \%$ a $17 \%$ em suas alíquotas, influenciando diretamente os impostos sobre venda do período e, uma vez que o volume de produção e representatividade dos mercado não apresentaram oscilações significativas, podendo-se inferir que esse custo político tributário pode ter influenciado a redução do lucro líquido da empresa.

Figura 6 - Valor do lucro líquido

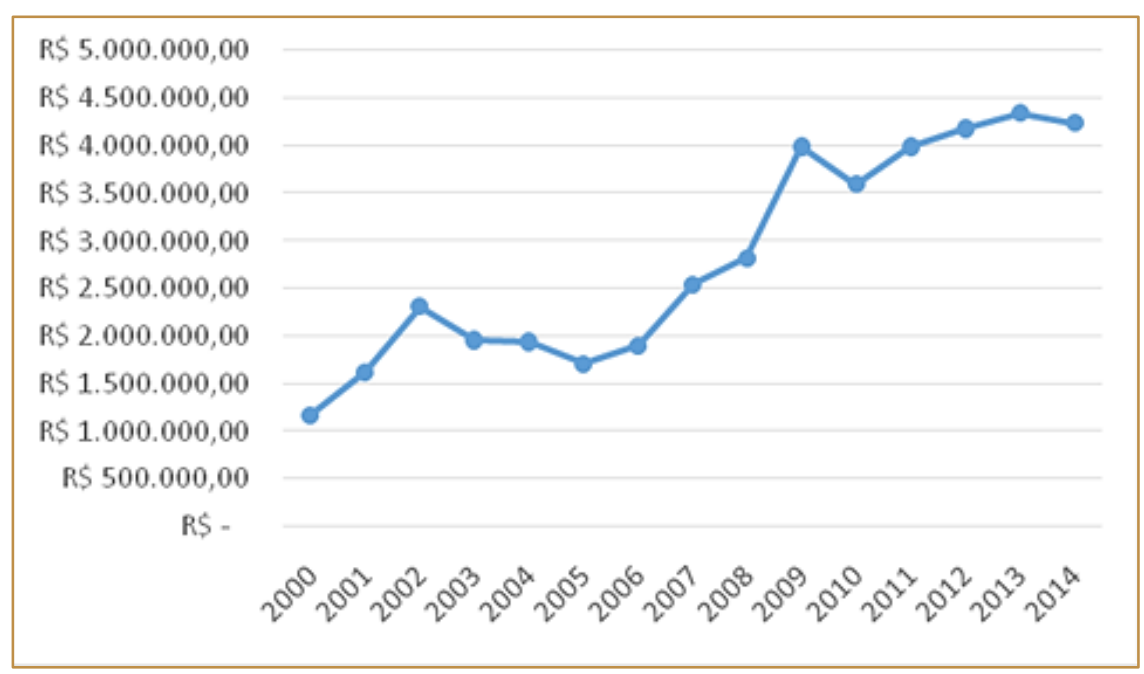

Fonte: Dados da Pesquisa.

De 2005 a 2009 o lucro líquido teve um aumento de $57 \%$, mesmo com uma queda de 6\% na produção. Entre 2009 e 2010 ocorreu proibição do fumo em recintos coletivos e nos fumódromos no estado de São Paulo e Rio de Janeiro, a proibição dos cigarros eletrônicos e o aumento do IPI que causou um aumento de $65 \%$ do preço de varejo, nesse mesmo período aconteceu uma diminuição no valor do lucro líquido em $10 \%$.

O lucro líquido de 2010 a 2014 teve um amento de $15 \%$, o volume da produção vendida um decréscimo de 27\%, e a participação no mercado uma elevação de $4 \%$. Cabe ressaltar que embora, houve 0 aumento do lucro, existiu diminuição dos produtos vendidos em quase $30 \%$.

\section{5- CONSIDERAÇÕES FINAIS}

A presente pesquisa tornou possível a contextualização e exposição das políticas públicas contra o Tabagismo implementadas no Brasil antes e depois da ConvençãoQuadro para combate ao Tabaco, sendo o primeiro tratado internacional de saúde pública. Foram feitas exposições dos principais eventos acontecidos entre 2000 e 2015, observando as diferentes políticas públicas em contextualizações distintas, que incidiram diretamente na demanda e na oferta dos produtos no Brasil, destacando as políticas públicas que geraram aumentos dos custos políticos tributários além de maneiras de proibir as diferentes formas de publicidade.

Objetivando analisar se o desempenho da Souza Cruz foi impactado pelas políticas públicas de combate ao tabagismo, analisouse a série histórica do preço da ação, o lucro líquido, representatividade do mercado e volume de vendas a partir da definição de 18 eventos que afetavam a empresa no corte temporal estudado.

Destarte, o aumento no lucro líquido no decorrer dos anos e a representatividade da empresa no setor, mesmo com redução do volume de vendas, evidencia que as políticas públicas que visam diretamente uma diminuição quantitativa do mercado 
consumidor, cumpriram sua função no sentido de reduzir o consumo dos produtos tabagistas no decorrer dos anos. Uma vez que a gestão pública implementa políticas públicas, não no sentido de interferência nos resultados financeiros da entidade, mas para que o consumidor final se conscientize dos malefícios do tabaco para a saúde e reduza o consumo.

Desta forma, no que se refere ao desempenho financeiro, em relação às políticas públicas, percebeu-se que não foram observadas

\section{REFERÊNCIAS}

[1]. ACTBR. Aliança de Controle ao Tabagismo. Disponível em http://actbr.org.br/tabaguismo/historico.asp. Acesso 13 de dezembro de 2016.

[2]. AFUBRA. Associação dos Fumicultores do Brasil. Mutualidade. 2013. Disponível em. Acesso em 31 ago 2016.

[3]. AVERSA, M. B. (2006). O processo de accountability como estratégia de negócio: o caso Souza Cruz e a implantação da norma AA 1000. (Dissertação Mestrado). Recuperado em 2017-0520,

http://www.tede.udesc.br/bitstream/handle/156/1/7 4208.pdf

[4]. BOEIRA, S., \& JOHNS, P. (2007). Indústria de Tabaco vs. Organização Mundial de Saúde: um confronto histórico entre redes sociais de stakeholders. Revista Internacional Interdisciplinar Interthesis, 4(1), 1-25.

[5]. BINDER, J. J. (1998). The Event Study Methodology Since 1969. Review of Quantitative Finance and Accounting, 11(2), 111-137.

[6]. BRASIL. Ministério da Saúde. Por Um Mundo Livre de Tabaco - Ação Global para Controle do Tabaco: 1음 Tratado Internacional de Saúde Pública. Brasília: Ministério da Saúde, 2003.

[71. Decreto $\mathrm{n}-\mathbf{7}$ 7.555, de 19 de agosto de 2011. Diário Oficial [da] República Federativa do Brasil, Poder Executivo, Brasília, DF, 22 ago. 2011. Seção 1, p. 1.

[8]. Lei o 5.172, de 25 de outubro de 1966. Diário Oficial [da] República Federativa do Brasil, Poder Legislativo, Brasília, DF, 27 out. 1966. Seção 1, p. 12452.

[9]. Lei no 9.294, de 15 de Julho de 1996. Diário Oficial [da] República Federativa do Brasil, Poder Legislativo, Brasília, DF, 16 jul. 1996. Seção 1, p. 13074.

[10]. Lei no 10.167, de 27 de Dezembro de 2000. Diário Oficial [da] República alterações significativas em relação às políticas públicas e elas foram eficazes no desincentivo do consumo sem afetar o mercado tabagista.

Observou-se ainda que o preço das ações não foi afetado pelos eventos analisados, assim como o lucro da empresa. Assim, podese inferir que os custos políticos advindos das políticas públicas podem ser eficazes, no sentido de inibir o consumo do cigarro sem interferir no desempenho da entidade.

Federativa do Brasil, Poder Executivo, Brasília, DF, 28 dez. 2000. Seção 1, p. 3.

[11]. Lei no 10.702, de 14 de julho de 2003. Diário Oficial [da] República Federativa do Brasil, Poder Executivo, Brasília, DF, 15 jul. 2003. Seção 1, p. 1. XXI Congresso Brasileiro de Custos - Natal, RN, Brasil, 17 a 19 de novembro de 2014

[12]. Lei no 12.546, de 14 de dezembro de 2011. Diário Oficial [da] República Federativa do Brasil, Poder Executivo, Brasília, DF, 15 dez. 2011. Seção 1, p. 3.

[13]. Medida Provisória ำ 540, de 2 de agosto de 2011. Diário Oficial [da] República Federativa do Brasil, Poder Executivo, Brasília, DF, 3 ago. 2011. Seção 1, p. 1.

[14]. Medida Provisória no 2190-34, de 23 de agosto de 2001. Diário Oficial [da] República Federativa do Brasil, Poder Executivo, Brasília, DF, 24 ago. 2001. Seção 1, p.

[15]. CAMPBELL, J. Y.; LO, A. W.; MACKINLAY, A. C. The econometrics of financial markets.

[16]. CAVALCANTE, Tânia Maria. O controle do tabagismo no Brasil: avanços e desafios. Rev psiquiatr clín, v. 32, n. 5, p. 283-300, 2005.

[17]. CORRÊA, P. C. As estratégias do marketing de responsabilidade social da Souza Cruz no Brasil: descrição e análise. Publicado em 2004 no website da Aliança de Controle do Tabagismo (ACTbr). Disponível em: http://www.actbr.org.br/ Acesso em: 30 ago 2016.

[18]. DIAS FILHO, José Maria; MACHADO, Luiz Henrique Baptista. Abordagens da pesquisa em contabilidade. In: IUDÍCIBUS, Sérgio de; LOPES, Alexsandro Broedel. (coord.). Teoria avançada da contabilidade. São Paulo: Atlas, 2004.

[19]. GAGNON, Jean-Marie. (1967). Purchase versus pooling of interests: The search for a predictor. Journal of Accounting Research.

[20]. GIBBINS, M., Richardson, A., WATERHOUSE, J. (1990). The management of 
corporate financial disclosure: opportunism, ritualism, policies, and processes. Journal of accounting research, 28, 121-143.

[21]. HOGWOOD, B. W.; Gunn, L. A. (1981). The policy orientation. Centre for the study of public policy, University of Strathclyde,

[22]. INCA. Instituto Nacional do Câncer.2014. Acesso em 02 de setembro de 2016.

[23]. LIMBERGER, V. S. (2013). Efeitos das políticas públicas do governo brasileiro sobre a produção de fumo. (Monografia). Recuperado em 2017-05-20

de

http://www.lume.ufrgs.br/bitstream/handle/10183/97 700/000915725.pdf?sequence $=1$

[24]. LOPES, T. (2012). Custos políticos tributários: o impacto do tamanho na alíquota tributária efetiva. (Tese Doutorado) Recuperado em 2017-05-20, de www.teses.usp.br

[25]. LUIZ, G.; ALBERTON, L.; SILVA, M. W. Comportamento das variáveis custo, preço, receita e volume de produção do subsetor de fumo brasileiro diante das políticas antitabagistas. In: Anais do Congresso Brasileiro de Custos-ABC. 2014.

[26]. NASCIMENTO, Leticia Lima do; TRENTIN, Fábia. Public policy for development of cultural tourismin the Praça XV de Novembro-Rio de Janeiro, RJ. Interações (Campo Grande), v. 12, n. 2, p. 161-173, 2011

[27]. POHLMANN, M. C., \& Alves, F. J. S. (2004). Regulamentação. In: IUDíCIBUS, Sérgio de;
LOPES, Alexsandro Broedel. (coord.). Teoria avançada da contabilidade. São Paulo: Atlas.

[28]. RICHARDSON, R. J. (1999). Pesquisa social: métodos e técnicas. ( $3^{\underline{a}}$ ed.) São Paulo: Atlas.

[29]. ROSEMBERG, J. (1981). Tabagismo. Sério Problema de Saúde Pública. São Paulo: Edusp.

[30]. SARAIVA, E.; FERRAREZI, E. Políticas públicas. Vol. 2. Brasília: ENAP, 2006.

[31]. SILVA, S. T., et. al. (2014). Combate ao Tabagismo no Brasil: a importância estratégica das ações governamentais. Ciência e saúde coletiva, 19(2), 539-52.

[32]. SINDITABACO. Dimensões do setor. Disponível em: http://sinditabaco.com.br/sobre-osetor/dimensoes-do-setor. Acesso em: 30 out 2016.

[33]. SOUZA, C. (2006). Políticas públicas: uma revisão da literatura. Sociologias, 8(16), 20-45.

[34]. TRALDI, M. T. F. (2015). O limite da atuação estatal na elaboração de políticas públicas de cunho proibicionista: o caso da Lei Antifumo do estado de São Paulo (Dissertação Mestrado). Recuperado em 2017-05-20, de http://repositorio.uniceub.br/bitstream/235/5770/1/6 0900548.pdf

[35]. WATTS, R. L., Zimmerman, J. L (1986). Positive Accounting Theory. Englewood Cliffs: Prentice-Hall.

[36]. ZIMMERMAN, J. L. (1983). Taxes and Firm Size. Journal of Accounting and Economics, 5(1), 119-149. 


\section{Papítulo 2}

\section{IMPACTO NO EVA® DAS DISTRIBUIDORAS DE ENERGIA ELÉTRICA DO ESTADO DE SÃO PAULO APÓS A LEI $12.783 / 2013$}

\section{Thalisa Maria Jati Gilberto}

Diego Vinícius Dias

\section{Marinês Santana Justo Smith}

Resumo: A questão energética é importante, seja sob a ótica da necessidade e busca de medidas sustentáveis, como também pela escassez de recursos e a questão das bandeiras tarifárias recentemente publicadas. A distribuição de energia elétrica no Brasil hoje, em sua maioria, é realizada através do regime de concessão e por isso, não possui livre tarifação e acaba por apresentar diversos aspectos políticos que influenciam a gestão das concessionárias. Tendo em vista que em 2012 houve a promulgação da medida provisória 579 de 2012, transformada em lei em 2013 (Lei 12.783) que implementou uma série de mudanças na regulamentação das concessões e em 2015 a criação das bandeiras tarifárias para resolver o problema da solvência das concessionárias, faz-se necessário analisar as questões financeiras na égide das principais concessionárias distribuidoras de energia elétrica do estado de São Paulo. Neste sentido, o presente artigo tem como objetivo verificar o impacto do EVA® das distribuidoras de energia elétrica do estado de São Paulo após a publicação da Lei 12.783/2013 e da criação das bandeiras tarifárias em 2015. Trata-se de uma pesquisa bibliográfica complementada por uma análise documental multicascos, ao se avaliar o EVA® das principais concessionárias de energia elétrica do estado de São Paulo entre os anos de 2011 a 2015.

Palavras-chave: Concessionárias de energia elétrica, EVA®, Lei 12.783/2013, Bandeiras tarifárias 


\section{INTRODUÇÃO}

O Brasil tem o maior sistema elétrico da América Latina com uma capacidade de potência instalada de 142GW. (Fernandes, 2016)

Desde 1995, no governo FHC (Fernando Henrique Cardoso), houve a concessão do serviço público de energia elétrica tanto no que concerne a geração quanto a distribuição e comercialização de energia elétrica no país. Atualmente, a maioria das empresas geradoras, distribuidoras e comercializadoras vivem a partir do regime de concessão e seguem normas e regras públicas.

A concessão do serviço público foi muito questionado e há quem seja contrário a esse tipo de atitude política dizendo que compromete a questão da oferta do serviço público à população. Ocorre que, com as atuais notícias acerca da corrupção nos serviços públicos, há quem acredite ser essa uma medida coerente. Independente do posicionamento, a realidade da questão energética no Brasil é que, em sua maioria, é regida pelo regime de concessão com suas leis e contratos deles oriundos.

Em 2012, foi promulgada a medida provisória 579 que modificou em grande parte o modelo de concessão para aquelas empresas que a ela queriam aderir com uma renovação antecipada de seus contratos, e impôs uma redução tarifária. O governo, na época, acreditava que, pelo fato de desde 1995 terem feito os investimentos em infraestrutura necessários dentro dos contratos de concessão e que esses já haviam sido amortizados, as concessionárias não sofreriam impactos e poderiam reduzir as tarifas. (Assunção, Takamatsu, \& Bressan, 2015). No entanto, tal medida "mais pareceu como uma política eleitoreira do que uma política pública em benefício do Estado Nacional" (Pinto, Perin, \& Duarte, 2015, p. 512)

Em 2015, após terem sido relatados diversos problemas financeiros das geradoras e distribuidoras e após o governo ter concedido diversos empréstimos para resolver as questões financeiras dessas empresas, foi divulgado um novo regime tarifário, denominado de bandeiras tarifárias. O anúncio das bandeiras tarifárias estava atrelado aos problemas na geração tendo em vista a redução das represas das hidrelétricas e a necessidade de geração a partir de termoelétricas (crise hídrica de 2014).
Diante desse cenário, no qual há alegações de ser permeado de questões de ordem pública essencial, de políticas eleitoreiras e de questões financeiras, surge a seguinte pergunta: "quais os impactos financeiros sofridos pelas empresas comercializadoras de energia elétrica no estado de São Paulo com a promulgação da redução tarifária da medida provisória 579/12 transformada na Lei $12.783 / 13$ e das bandeiras tarifárias?"

É, portanto objetivo do presente artigo analisar os impactos financeiros calculados a partir da análise do EVA® das principais empresas concessionárias comercializadoras de energia elétrica no estado de São Paulo que possuam capital aberto na BM\&FBOVESPA.

Para se atingir esse objetivo foi realizada uma pesquisa bibliográfica inicial para se verificar as questões energéticas no Brasil e as questões relativas a metodologia EVA $₫$ para análise financeira das empresas. O estudo foi complementado com uma análise multicasos a partir do cálculo do EVA® das empresas selecionadas para compor a amostra desta pesquisa.

O artigo está divido em três seções além desta introdução e da conclusão. Na primeira seção trata-se acerca da questão energética no Brasil, demonstrando como foram criadas as concessões, suas particularidades, a medida provisória 579 de 2012, convertida na Lei $12.783 / 13$ e a criação das bandeiras tarifárias em 2015. A segunda seção trata acerca do EVA®, sua importância, metodologia de cálculo e particularidades para análise Brasil. A terceira e última seção demonstra a metodologia de pesquisa utilizada e a demonstração dos cálculos do $E V A \circledast$ bem como o resultado da pesquisa.

\section{A QUESTÃO ENERGÉTICA NO BRASIL}

De 1879 até 1931, o setor energético no Brasil não dispunha de qualquer regulamentação legal e havia investimentos estrangeiros que detinham e forneciam energia elétrica as cidades e que também se encarregavam de gerar essa energia. Em 1931 foram suspensos todos os atos anteriores de concessões (que geralmente ocorriam via municipal) e em 1934, na era Vargas, o governo assumiu a indústria na sua totalidade. (Costa, 2013)

De 1934 em diante, inclusive no período militar, as distribuidoras de energia no Brasil 
eram totalmente estatais e o intuito do estado era obter economia de escala, superação das barreiras tecnológicas e de conhecimento. A partir da década de 1970 surgiu no Brasil o GCPS - Grupo Coordenador do Planejamento do Sistema - GCPS. Esse grupo tinha como objetivo obter ainda economias de escala e de escopo; regularidade tecnológica com a construção de grandes usinas hidrelétricas (até os anos 1970); aumento da capacidade instalada de geração e de transmissão crescentes, para atender a uma demanda crescente. Após a década de 1970, o setor energético passou por uma promoção de diversidade tecnológica e de fontes. (Mercedes, Rico, \& Pozzo, 2015)

Desde 1934 já havia a questão da concessão de energia nos casos de hidrelétricas, conforme melhor citado por Prado Jr e Silva (2011, p. 87):

Desde 1934, o aproveitamento dos recursos hídricos em usos múltiplos tinha passado a ser regulado pelo governo federal, sendo considerados como uso de bem público e facultada sua exploração sob regime de concessões, cuja outorga normalmente tinha conotações políticas. Na prática, a concessão de aproveitamentos hidroelétricos era sempre feita para empresas com sede na região onde fisicamente se localizava a queda d'água e apenas empresas federais do grupo Eletrobrás atuavam em múltiplos Estados. O artigo 175 da Constituição determinava, assim, a necessidade que todas as concessões de serviços públicos passassem a ser licitadas, o que, no entanto, somente ocorreria quando fosse publicada sua regulamentação pelo Congresso.

O sistema estatal perdurou até a era do governo Fernando Henrique Cardoso (FHC) que teve o seu início em 1995. Nesse período, para aumentar a eficiência energética foram feitas concessões que perdurariam por 30 anos.

O setor energético no Brasil divide-se em quatro segmentos: geração, transmissão, distribuição e comercialização. Entre as empresas geradoras de energia incluem-se as hidrelétricas, termoelétricas (em sua maioria proveniente de gás natural), e demais geradoras. As transmissoras são responsáveis por ligar o local de geração às distribuidoras por meio de corrente de alta potência. As empresas distribuidoras de energia elétrica são atualmente as concessionárias responsáveis por levar a energia do local de distribuição às residências dos consumidores finais, dentro do mercado cativo regulado pela ANEEL. A comercialização ocorre pelos agentes comercializadores que fazem parte do mercado livre de consumo de energia elétrica. (Pereira \& Campos, 2015)

"O setor de geração é majoritariamente dominado por empresas públicas tanto federais quanto estaduais. [...] $O$ setor privado corresponde a cerca de $15 \%$ da energia produzida no sistema". (Fernandes, 2016, p. 13) "Há um total de 63 distribuidoras no país, que representam cerca de $70 \%$ do consumo de energia no Brasil". (Fernandes, 2016, p. 15)

No Brasil, cerca de $45 \%$ de toda a energia elétrica produzida vem de fontes hidrelétricas, o que representa muito mais do que o resto do mundo, onde a média é de aproximadamente 13\%. (Costa, 2013) Em 2014, $73 \%$ da energia gerada no Brasil foram provenientes de fontes hidráulicas, biomassa e eólica, consideradas renováveis. (Fernandes, 2016)

\subsection{A CONCESSÃO ENERGÉTICA}

Conforme explicitado, o Brasil passou por distintos períodos em termos de concessão e estatização do setor energético. As geradoras de energia desde os seus inícios foram feitas por concessões conforme já citado por Prado Jr e Silva (2011). Já as distribuidoras passaram por um processo diferente: no início eram empresas privadas que investiam no país, mas no período militar, houve uma retomada do poder sobre essas empresas, estatizando-as. No entanto, após 1988, houve uma tentativa de transformar as distribuidoras em empresas concessionárias. Mas, haviam "dois empecilhos para a regularização da expansão da infraestrutura de energia elétrica no país: as condições inadequadas da inflação descontrolada [...] e a indefinição sobre regras futuras das concessões". (Prado Jr \& Silva, 2011, p. 87)

A Figura 1 mostra a evolução da capacidade instalada de distribuição de energia elétrica no Brasil. Verifica-se que no período compreendido em 1988 e 1994 foi o período de redução justamente pelo problema gerado com a não regulamentação das concessões, o que acarretou em retrocesso. 
Figura 1 - Evolução da capacidade instalada no Brasil

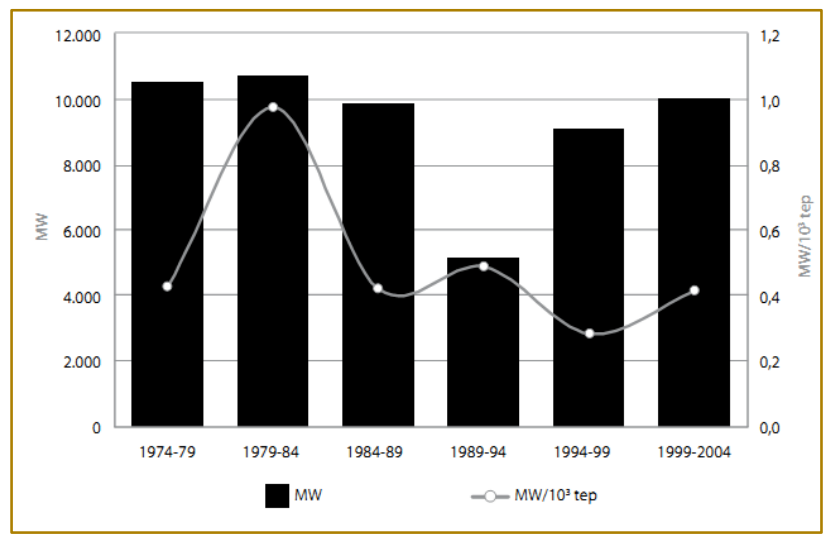

Fonte: Energia 2007

Após 2004, percebe-se que a capacidade instalada tem evoluído positivamente em todos os períodos, conforme visualiza-se pela Figura 2.

Figura 2 - Capacidade instalada de energia elétrica de 2004 a 2015

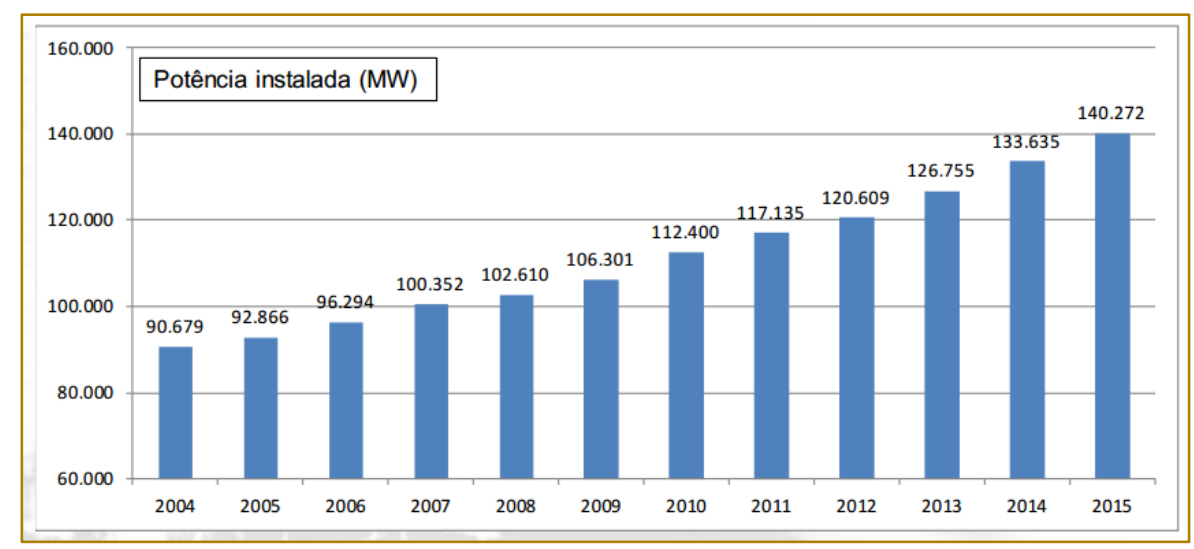

Fonte: (ANEEL, 2015, p. 7)

A concessão energética das distribuidoras é chamada por Mercedes, Rico e Pozzo (2015) de período mercantil do governo FHC. Nesse período de acordo com as autoras, a intenção era o planejamento energético indicativo com o incremento da participação do gás natural na matriz energética do país, e a meta principal era o desenvolvimento de recursos energéticos. Nesse período foi criado o Comitê Coordenador do Planejamento da Expansão - CCPE.

Foi em 1995 que foram promulgadas duas leis importantes regulamentando as questões acerca das concessões da distribuição de energia elétrica no país, possibilitando inclusive a criação de mercados competitivos para o setor. Para o governo foi positiva a regulamentação, pois era necessário suprimir a demanda energética, principalmente pelo fato do crescimento econômico que vinha ocorrendo pela estabilização gerada pelo
Plano Real. Deu-se início então à privatização das concessionárias distribuidoras de energia elétrica. "A privatização no Brasil [...] não foi ideológica e sim premida por necessidades financeiras". (Prado Jr \& Silva, 2011, p. 89)

Ainda do período do primeiro mandato de FHC foram criadas algumas entidades que serviam para apoiar, fiscalizar e regulamentar o sistema, a saber: o Operador Nacional do Sistema (ONS) - operador de atividades de Transmissão e Geração e formador preços, sem prejuízo à otimização do sistema - o Mercado Atacadista de Energia (MAE) agente de liquidação de contratos comerciais e a Agência Nacional de Energia Elétrica (ANEEL), entidade reguladora independente. Ao final da década de $90,80 \%$ do setor de distribuição já estava privatizado. (Prado Jr \& Silva, 2011) 
O racionamento de energia ocorrido em 2001 gerou duras críticas ao sistema e modelo implementado pelo governo FHC, e as principais críticas referiam-se a privatização ocorrida no setor. (Prado Jr \& Silva, 2011)

Os governos que sucederam a FHC (Lula e Dilma Rousseff) deram continuidade a esse chamado período mercantil e elaboraram um planejamento integrado e estratégico de pesquisa energética, aumentaram a participação pública com consultas e audiências e incluíram no plano energético fontes renováveis consideradas alternativas ao invés de simplesmente complementares como ocorreu no governo FHC. (Mercedes, Rico, \& Pozzo, 2015)

Com o início então, em 2003 do governo Lula, e tendo Dilma Rousseff como ministra de Minas e Energia, foram implementados novos modelos de gestão energética no país. De acordo com (Prado Jr \& Silva, 2011):

Entre as principais decisões estavam a da criação de uma Empresa de Planejamento para retomada do determinismo no planejamento da expansão da geração e da transmissão. As empresas Distribuidoras passaram a ter atividade exclusivamente de distribuição, ou seja, recebem remuneração pelo serviço de disponibilização de ativos (capital) e operação e manutenção da rede e bilhetagem. Estas empresas passaram a não mais ter riscos associados ao preço do suprimento de energia, mas receberam a obrigatoriedade de comprar $100 \%$ das suas necessidades energéticas, com cinco anos de antecedência. Com estas medidas foi separado o mercado regulado com tarifas definidas pela ANEEL e o mercado livre (no qual as distribuidoras passaram a ficar impedidas de atuar). Toda a energia necessária para atendimento ao mercado regulado das Distribuidoras passou a ser obrigatoriamente adquirida através de leilões organizados pelo regulador. (Prado Jr \& Silva, 2011, p. 93)

Com a mudança e a separação entre distribuição e geração de energia, obrigando as concessionárias a comprarem antecipadamente das geradoras a energia necessária de acordo com a demanda avaliada, criou-se uma "barreira" para que novos apagões viessem a ocorrer.

\subsection{MEDIDA PROVISORIA 579/2012, CONVERTIDA EM LEI 12.783/13}

Já no segundo mandato do governo Dilma Rousseff, foi tomada uma medida no setor energético, a MP 579 de 2012, que tinha como objetivo, ao reduzir o custo da tarifa energética, reduzir também o custo da indústria como um todo, aumentando a competitividade do setor. O objetivo era garantir um crescimento sustentável da indústria brasileira, inserida na política econômica do setor. (Castro, Brandão, Dantas, \& Rosental, 2013). Também era objetivo da medida provisória tornar o setor mais produtivo e competitivo contribuindo para o aumento de emprego e renda no país. (Costa, 2013)

Os custos do setor elétrico incluem a geração, a transmissão, a distribuição e a comercialização de energia elétrica no Brasil. Atualmente, a demanda é atendida em grande parte pelas hidrelétricas $e$ as necessidades não atendidas por essa geração são compradas previamente por leilões conforme já explicitado anteriormente. Os custos do setor energético não são tão elevados, todo o setor representa cerca de $60 \%$ do custo da tarifa. Os outros $40 \%$ são compostos de encargos e tributos que são utilizados para custear o sistema, ou seja, pagar todas as agências e entes regulamentadores e fiscalizadores e ainda custear os programas e projetos sociais, tal como o Luz para todos. (Castro, Brandão, Dantas, \& Rosental, 2013)

A medida provisória 579/12 teve como intuito reduzir os custos de energia elétrica no país, e também tentar regulamentar as renovações de concessões de forma a não deixar que as tarifas fossem negociadas livremente. Dessa forma, as geradoras não negociariam mais o valor no mercado da energia elétrica e passariam a ser prestadoras de serviços. As transmissoras de energia elétrica seriam remuneradas pelo valor que contempla o custo de manutenção e operação do sistema somente. Além disso, os programas sociais deveriam ser custeados pelo Tesouro Nacional e não pelos demais consumidores como acontecia até então. (Castro, Brandão, Dantas, \& Rosental, 2013)

[...] a MP 579 eliminou dois encargos setoriais (CCC e RGR) e reduziu outro (CDE), além de ter indenizado os investimentos que ainda não haviam sido totalmente amortizados das empresas que aceitaram os termos da 
renovação antecipada. O objetivo da indenização foi o de excluir os custos de capital (remuneração e depreciação), que representam em torno de 2/3 do custo da geração e transmissão de energia na receita final dessas concessões e, por consequência, da conta final de energia. (DIEESE, 2015, p. 5)

Após a promulgação da MP 579/12 o mercado de ações das transmissoras e das geradoras teve impacto imediato, pois percebeu-se as perdas iminentes que ocorreriam no setor com as medidas tomadas. Houve perda de $33 \%$ a quase $50 \%$ no valor das ações no período. Mesmo que a medida provisória tivesse auxiliando a manutenção dos contratos de concessão no futuro, as perdas que ocorreriam eram grandes, tanto que a CEMIG (aceitou parcialmente) e a CESP não aceitaram a renovação antecipada dos contratos de concessão nas condições da medida. Mesmo assim, as empresas amargaram perdas por sofrerem impactos negativos na sua rentabilidade e possibilidade futura de geração de dividendos. (Castro, Brandão, Dantas, \& Rosental, 2013)

A redução de custo que era o objetivo principal da Medida provisória, como foi percebido por alguns estudiosos, não veio de graça. A sua promulgação gerou "um cenário de insegurança jurídica, criou buracos bilionários nas contas das grandes empresas de energia elétrica e, também nas finanças públicas". (Costa, 2013, p. 54)

As geradoras de energia sofreram impacto em três aspectos: (1) tanto as que aderiam a renovação da concessão antecipada sofreram perdas pois tiveram redução de $60 \%$ no valor da tarifa; quanto as que não renovaram também, por reduzirem o seu período de concessão; (2) as empresas que não renovaram a concessão, embora não tenham tido perdas imediatas, deveriam aderir ao leilão para tentarem dar continuidade a concessão; além disso poderá haver um impacto no desemprego pois caso venham a perder a concessão provavelmente demitirão os funcionários e não há garantia de recontratação; (3) a Eletrobrás tem amargado perdas após a renovação da concessão e ela detém grande parte do mercado de geração e transmissão, embora seu resultado operacional tivesse se mantido e os investimentos também. (DIEESE, 2015)
De acordo com Castro, Brandão, et al. (2013), as transmissoras não sofreram tanto impacto pois seus contratos se assemelhavam aos contratos das distribuidoras, até então vantajosos.

Outro impacto negativo no setor de geração foi que a medida provisória privilegiou o mercado cativo de energia, impondo precificação a energia a quem aderia a medida. Dessa forma, havia restrições no mercado livre no qual os preços praticados são negociados livremente. (Castro, Brandão, Dantas, \& Rosental, 2013) As empresas do setor elétrico no geral (transmissoras, distribuidoras e geradoras) tiveram seu valor de mercado reduzido em 12\%. (Costa, 2013)

Com relação as empresas comercializadoras de energia, foco deste estudo, verifica-se que estas sofreram impacto também. É possível verificar através do estudo de Silva (2015) que em 2012 (período de crise) houve um primeiro impacto negativo na rentabilidade dessas empresas. A autora verificou com dados de 2009 a 2013 que a crise de 2012 provocou "variações negativas nos indicadores de endividamento e rentabilidade, enquanto que os indicadores de liquidez e atividades apresentaram variações positivas, que podem ser justificadas pelas indenizações pagas pelo Governo Federal pela renovação das concessões". No entanto, em 2013 os indicadores de rentabilidade voltaram a apresentar variações positivas que pode demonstrar uma reação à crise. (Silva P. Z., 2015, p. 67)

Um estudo de Kurtz e Rosemberg (2014) demonstrou, através de um estudo de caso, que a medida provisória afetou a CPFL, tendo sido demonstrado que a renovação da concessão por parte de dois empreendimentos de geração da empresa não foi uma boa estratégia tendo em vista a disparada de preços de energia no mercado no curto prazo. Os autores ainda argumentam que as empresas do setor elétrico tiveram a sua saúde financeira comprometida, visto que a viabilidade econômica de seus empreendimentos se viu ameaçada pela medida provisória convertida em lei que foi decretada.

De acordo com DIEESE (2015) o que ocorreu em 2014 foi que a crise hídrica fez com que a energia das termoelétricas e demais gerações tivessem que ser ativadas, pois houve uma queda na geração das hidrelétricas. Com 
isso, as distribuidoras viram-se obrigadas a comprar a energia no mercado comum, já que poucas geradoras haviam aderido a MP descrita e com isso não venderiam a energia por leilão (o que baratearia o custo para a distribuidoras).

Pela lei de mercado, como a oferta de energia era pouca e a procura pelas distribuidora muito grande, o preço de compra dessa energia de gerações secundárias (termoelétricas) elevou-se consideravelmete e as reduções tarifárias que haviam sido feitas em 2013 não puderam ser mantidas, ocasionndo um aumento nos preços e a necessidade da criação das bandeiras tarifárias, pois em 2015 a situação dos aumento dos preços de compra de energia se agravou. (DIEESE, 2015)

A forte estiagem e a lógica mercantil do modelo de comercialização de energia atuaram no sentido contrário a medida adotada em 2013, anulando já em 2014 todo esforço da política de redução das tarifas adotada pelo governo (as tarifas aumentaram $17 \%$ em 2014). A crise hídrica explicitou as contradições de um modelo que pretende ser mercantil, mas que é vinculado a uma estrutura de mercado que tende ao monopólio. Nesse sentido, qualquer viés restritivo de oferta tende a criar ganhadores e perdedores, sempre transferindo a conta ao consumidor final. (DIEESE, 2015, pp. 17-18)

Após a promulgação da medida provisória, por um período de tempo verificou-se uma significativa redução das tarifas de energia elétrica, que, no entanto, tiveram elevações decorrentes do aumento do custo de aquisição de energia, afetando diretamente os consumidores. (Fachini, 2015)

A medida provisória que a princípio tinha o objetivo de reduzir o custo de energia elétrica aos consumidores finais, acabou promovendo uma tendência de reestatização, visto que parte das empresas não aceitou as novas regras. Tais fatos adicionados a crise hídrica de 2013 e 2014, geraram uma crise aguda no setor e a necessidade de que o Tesouro realizasse empréstimos para garantir a liquidez das empresas. (Kurtz \& Rosemberg, 2014)

\subsection{BANDEIRAS TARIFÁRIAS DE 2015}

Diante desse cenário de regulamentações e modificações constantes, é importante entender de que forma se comportam as tarifas energéticas no Brasil. Quem regula o setor e autoriza aumentos de energia é a agencia reguladora, ANEEL. Na tarifa paga pelo consumidor há duas partes que a compõe, a parte $A$ que é não gerenciável pelas distribuidoras e incluem a compra, a transmissão e os encargos setoriais e a parte $B$ que engloba custos operacionais, depreciação e a remuneração dos investimentos realizados, estes últimos são chamados de custos gerenciáveis. A parte A, não gerenciável é a que compõe a maior parte dos custos do setor. (DIEESE, 2015)

Em 2014, a crise hídrica fez com que as hidrelétricas gerassem menos energia, sendo que as tarifas então de geração se tornaram mais caras, pois foram acionadas as termoelétricas e como grande parte da tarifa é composta pela geração e transmissão esse reajuste tarifário teve que ser repassado ao consumidor final. Muito embora, o governo tenha tomado certas medidas para conter o repasse, utilizando os fundos de reservas financeiras destinados ao setor, ainda assim o reajuste tarifário se tornou necessário. (DIEESE, 2015)

A geração de energia por meio das termelétricas cresceu 57\%, entre 2013 e 2014: a geração de energia por meio de fonte térmica convencional (excluindo térmicas nucleares) passou de 7.227 GWh, em dezembro de 2013, para $11.371 \mathrm{GWh}$, em dezembro de 2014. Como consequência, a participação da geração por meio de fontes térmicas na capacidade instalada total no país aumentou de $22 \%$, em 2008 , para $30 \%$, em 2013, enquanto a participação das hidroelétricas caiu de $75 \%$ para $68 \%$, em 2013. (DIEESE, 2015, p. 8)

O aumento dos preços já descritos na seção anterior ocasionado pela necessidade de compra de energia no mercado aberto se intensificou em 2015 e houve a necessidade da implementação pela ANEEL das bandeiras tarifárias. Tal medida serviu para sinalizar ao consumidor que estava ocorrendo um aumento de preço na tentativa de frear o consumo de energia que também aumentou no período. Criou-se então cores de bandeiras verde, amarela e vermelha. Com isso, o governo deixou de custear parte desse custo e repassou ao consumidor. (DIEESE, 2015)

Os patamares da bandeira indicam 0 seguinte: (1) bandeira verde determina que o Custo variável de energia for inferior a 
$\mathrm{R} \$ 211,28$ por $\mathrm{MWh}$; (2) bandeira amarela quando o valor foi maior que o máximo da verde e inferior ao teto do Preço de Liquidação de Diferenças; (3) Bandeira Vermelha; quando o valor estiver acima do Preço de Liquidação de Diferenças. A cada bandeira há uma adicional tarifário repassado ao consumidor que varia de $R \$ 15,00$ por MWh a R\$ 45 por MWh. (Silva R. M., 2016)

Dessa forma, ainda de acordo com Silva (2016), as bandeiras tarifárias são um adicional cobrado dos consumidores visando cobrir os custos variáveis de geração de energia elétrica no momento em que estes estão maiores devido a mudança da matriz de geração de energia.

\section{ECONOMIC VALUE ADDED: EVA®}

"O EVA® procura medir a adição de valor ao acionista, a geração de riqueza a partir das atividades operacionais da empresa, após a cobertura de todos os custos, inclusive o custo do capital próprio." (Tavares \& Oliveira, Adicionando valor aos investimentos em distribuição de energia elétrica, 2007, p. 2). Os autores ainda mencionam que o EVA® é uma metodologia capaz de medir o lucro econômico e atende à obsolescência das avaliações baseadas unicamente em índices financeiros, pois passam a levar em consideração o custo de capital.

De acordo com o Instituto Acende Brasil (2011, p.1) "O EVA® se mostra apropriado para avaliar a rentabilidade de um setor - especialmente se tal setor for intensivo em capital - porque ele quantifica os custos de todos os insumos utilizados na produção, incluindo o custo de oportunidade do capital"

O principal objetivo das empresas é a geração de riqueza, e a metodologia do EVA® é uma das medidas mais completas, pois considera todos os custos de capital envolvidos no investimento. O $E V A \AA$ representa a diferença entre o lucro operacional e o custo de todo o capital empregado para produzir esse lucro. (Sampaio, Machado, \& Machado, 2006)

Esses pensamentos corroboram com 0 de Assaf Neto (2014, p. 111):

O EVA expressa quanto uma empresa ganhou de lucro acima de seu custo de capital, sendo entendido, de forma mais ampla, como um parâmetro de desempenho econômico e sistema de gestão. É uma medida de lucro genuíno, do resultado econômico apurado por uma empresa que excede a remuneração mínima exigida pelos proprietario de capital (credores e acionistas). Indica, em outras palavras, se a empresa está criando ou destruindo valor aos acionistas.

O Instituto Acende Brasil realizou em 2011 em conjunto com Stern Stewart \& Co. um estudo de empresas privadas brasileiras do setor elétrico e verificou que de 1998 a 2006 o EVA® dessas empresas encontravam-se negativos, ou seja, essas empresas estavam destruindo valor. Apenas em 2007 houve um sinal de melhora no EVA®, conforme pode ser verificado na Figura 3.

Figura 3 - EVA de amostra de empresas privadas do setor elétrico brasileiro (1998-2009)

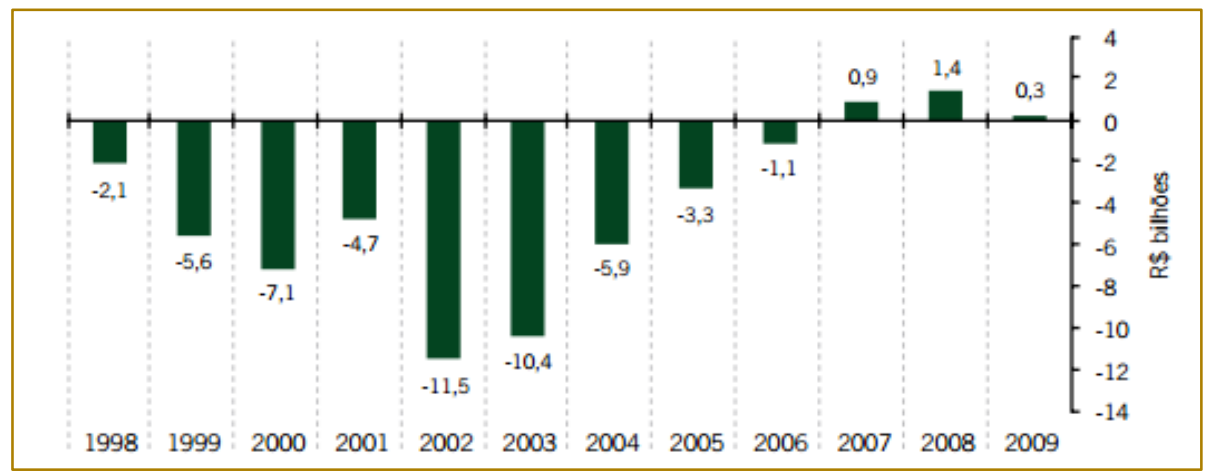

Fonte: (Instituto Acende Brasil, 2011, p. 15)

É importante então, que se verifique o que ocorre no comportamento do EVA® atualmente e por isso esse estudo vem analisar este indicador de três comercializadoras de energia elétrica do estado de São Paulo. 
A fórmula que será utilizada para o cálculo do EVA® neste trabalho é o da Equação 1.

\section{Equação 1 - Cálculo EVA}

$E V A=$ NOPAT $-($ WACC $x$ Investimentos $)$, onde, (1) NOPAT representa o resultado operacional restrito no qual são considerados como não operacionais, além das despesas com juros, as receitas financeiras e 0 resultado da equivalência patrimonial. (2) Investimento é a soma dos recursos próprios e de terceiros onerosos que são aplicados no negócio da empresa. (3) WACC é o custo total do capital investido exigido pelas fontes de financiamento próprio e de terceiros, calculado de acordo com a Equação 2.

\section{Equação 2 - Cálculo WACC}

$W A C C=\left(K_{e} x \frac{P L}{P+P L}\right)+\left[K_{i} x(1-I R) x \frac{P}{P L}, \quad\right.$ onde Ke é o custo do capital próprio; Ki o custo do capital de terceiros; IR o imposto de renda; $\mathrm{P}$ é o capital oneroso de terceiros e PL é o capital próprio. (Assaf Neto, Valuation: métricas de valor e avaliação de empresas, 2014)

O valor do custo de capital próprio não será calculado e será utilizado o cálculo setorial anual extraído do Instituto Assaf (Assaf Neto, instituto assaf, 2016). Tal fato se dá pois de acordo com Assaf Neto, Lima e Araújo (2008) os aspectos restritivos presentes na realidade brasileira não permitem o cálculo do custo de capital próprio pelos fundamentos do CAPM devendo haver um benckmark com uma economia mais estável, além da inclusão do fator risco país no cálculo de seu valor. Esta metodologia descrita pelos autores é utilizada no instituto citado de onde se irá extrair o custo do capital próprio.

Com isso, os valores de custo de capital próprio que serão aplicados são os descritos na Tabela 1.

Tabela 1 - Custo do capital próprio anual para o setor elétrico

\begin{tabular}{|c|c|}
\hline Ano & Ke para o setor elétrico \\
\hline 2011 & $15,5 \%$ \\
\hline 2012 & $15,5 \%$ \\
\hline 2013 & $12,8 \%$ \\
\hline 2014 & $14,9 \%$ \\
\hline 2015 & $20,4 \%$ \\
\hline
\end{tabular}

Fonte: Baseado em dados do instituto Assaf (Assaf Neto, instituto assaf, 2016)

Os demais valores serão calculados a partir dos dados de Balanço Patrimonial das empresas pesquisadas.

\section{ANÁLISE DO EVA DAS CONCESSIONÁRIAS DISTRIBUIDORAS DE ENERGIA ELÉTRICA DO ESTADO DE SÃO PAULO}

Trata-se de uma pesquisa bibliográfica que é complementada pela análise documental dos balanços patrimoniais das comercializadoras de energia elétrica do Estado de São Paulo escolhidas para compor a amostra da pesquisa, que servirão de base para o cálculo do EVA cuja metodologia foi explicada no item 3.

A técnica de amostragem é por conveniências e as empresas escolhidas correspondem as comercializadoras de energia elétrica do estado de São Paulo que estão entre os dez maiores agentes de distribuição de energia elétrica de acordo com o boletim energético da Aneel de 2015, conforme Tabela 2 (ANEEL, 2015) 
Tabela 2 - Dez maiores distribuidoras de energia elétrica no Brasil

\begin{tabular}{|c|c|c|c|c|}
\hline $\mathrm{N}^{\circ}$ & Agente & $\begin{array}{c}\text { Receita do } \\
\text { Fornecimento de } \\
\text { Energia Elétrica (R\$) }\end{array}$ & \multicolumn{2}{|r|}{ \% em relação ao total nacional } \\
\hline $1^{\circ}$ & Eletropaulo Metropolitana Eletricidade de São Paulo & 13.872.037.352,29 & $10,4 \%$ & \multirow{11}{*}{ CPFL } \\
\hline $2^{\circ}$ & Cemig Distribuiçăo & $11.306 .018 .102,97$ & $8,5 \%$ & \\
\hline $3^{\circ}$ & Copel Distribuição & $9.109 .519 .854,09$ & $6,8 \%$ & \\
\hline $4^{\circ}$ & Companhia Paulista de Força e Luz & 8.948.673.150,74 & $6,7 \%$ & \\
\hline $5^{\circ}$ & Light Serviços de Eletricidade & $8.773 .945 .429,68$ & $6,6 \%$ & \\
\hline $6^{\circ}$ & Celesc Distribuição & $5.955 .387 .473,12$ & $4,5 \%$ & \\
\hline $7^{\circ}$ & Elektro Eletricidade e Serviços & $5.376 .264 .466,84$ & $4,0 \%$ & \\
\hline $8^{\circ}$ & Companhia de Eletricidade do Estado da Bahia & 5.186.023.329,95 & $3,9 \%$ & \\
\hline $9^{\circ}$ & Ampla Energia e Serviços & 4.617.506.723,59 & $3,5 \%$ & \\
\hline \multirow[t]{2}{*}{$10^{\circ}$} & Celg Distribuição & $4.575 .097 .772,56$ & $3,4 \%$ & \\
\hline & Soma & $77.720 .473 .655,83$ & $58,2 \%$ & \\
\hline
\end{tabular}

Fonte: (ANEEL, 2015)

Dessa forma a amostra da pesquisa foi composta por três empresas das dez, presentes no relatório da ANEEL, que são consideradas as dez maiores que se situam no Estado de São Paulo. Fazem parte da amostra a Eletropaulo, a Companhia Paulista de Força e Luz (CPFL) e a Elektro. As demais são de outros estados, a saber: Cemig de Minas Gerais; Copel do Paraná; Light e Ampla do Rio de Janeiro; Coelba da Bahia e Celg de Goiás.

A metodologia de cálculo do EVA® utilizada no artigo é a descrita no item 2 e foram realizados os ajustes necessários no Balanço Patrimonial e DRE (Demonstração do resultado do exercício) para que os cálculos pudessem ser realizados.
Os dados da empresa Eletropaulo foram coletados do Instituto Assaf pois não foram encontrados no site da empresa os balanços patrimoniais, apenas os dados relativos ao relatório da administração. Da empresa CPFL, foram coletados no site da empresa, os dados apenas relativos ao Estado de São Paulo, ou seja, da CPFL Paulista, já que diferentemente das outras duas pesquisadas, esta possui atuação também em outros estados. Em relação à Elektro os dados foram coletados no site da empresa.

A empresa Eletropaulo que apresenta o maior percentual de receita auferida conforme, demonstrou o seguinte comportamento do EVA®, verificado no Gráfico 1.

Gráfico 1- Gráfico EVA Eletropaulo

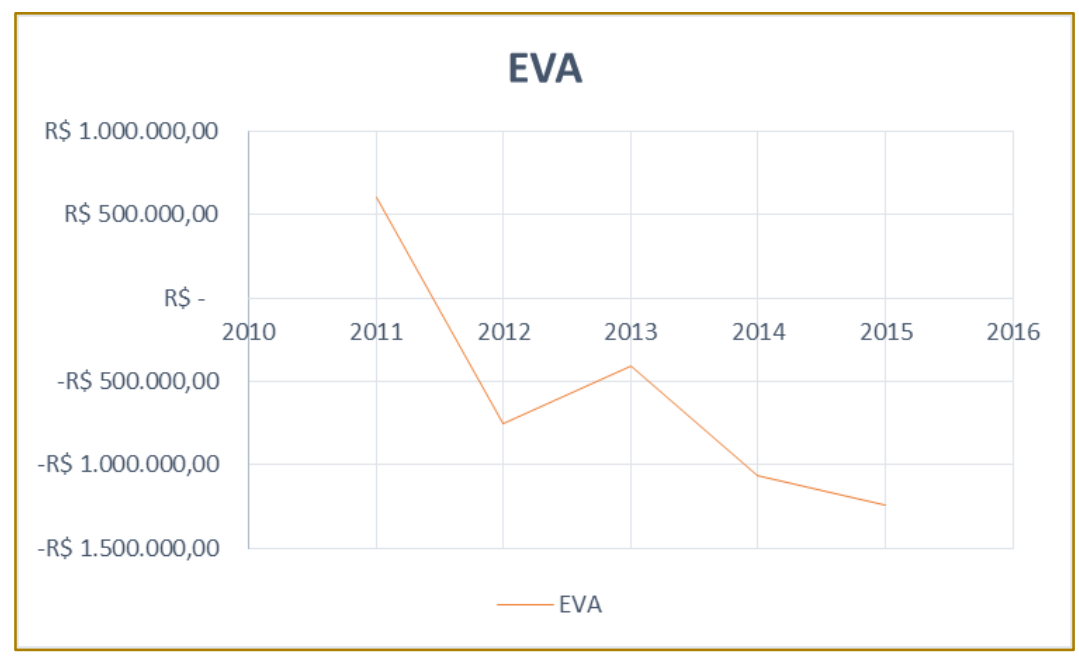

Fonte: elaborado pelos autores 
Pelos dados analisados, verifica-se que a Eletropaulo de 2012 a 2015 apresentou destruição de valor. Houve uma melhora no resultado de 2013, mas este ainda não resultou em agregação de valor.
O comportamento da empresa CPFL Paulista, com relação a sua agregação de valor, tem resultados um pouco melhores que da Eletropaulo, embora também apresente períodos de destruição de valor, conforme o Gráfico 2.

Gráfico 2 - EVA CPFL Paulista

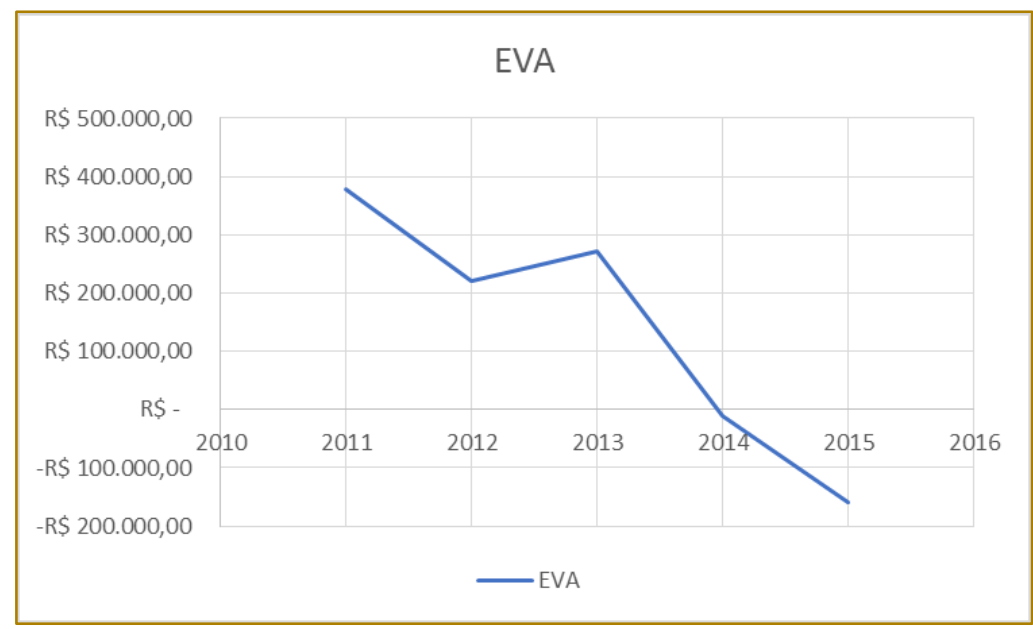

Fonte: elaborado pelos autores

Verifica-se na CPFL Paulista que houve uma queda na agregação de valor em 2012 e uma retomada, em 2013, mas não nos patamares de 2011. Nestes períodos, a empresa agregou valor. Já em 2014 a empresa tem um novo pico de queda e há neste caso destruição de valor o que continua ocorrendo em 2015, apresentado uma continuidade de queda.

A empresa Elektro, foi a que apresentou melhores resultados de geração de valor em todo o período analisado, mas também apresentou período de destruição de valor, conforme pode ser analisado no Gráfico 3.

Gráfico 3 - EVA Elektro

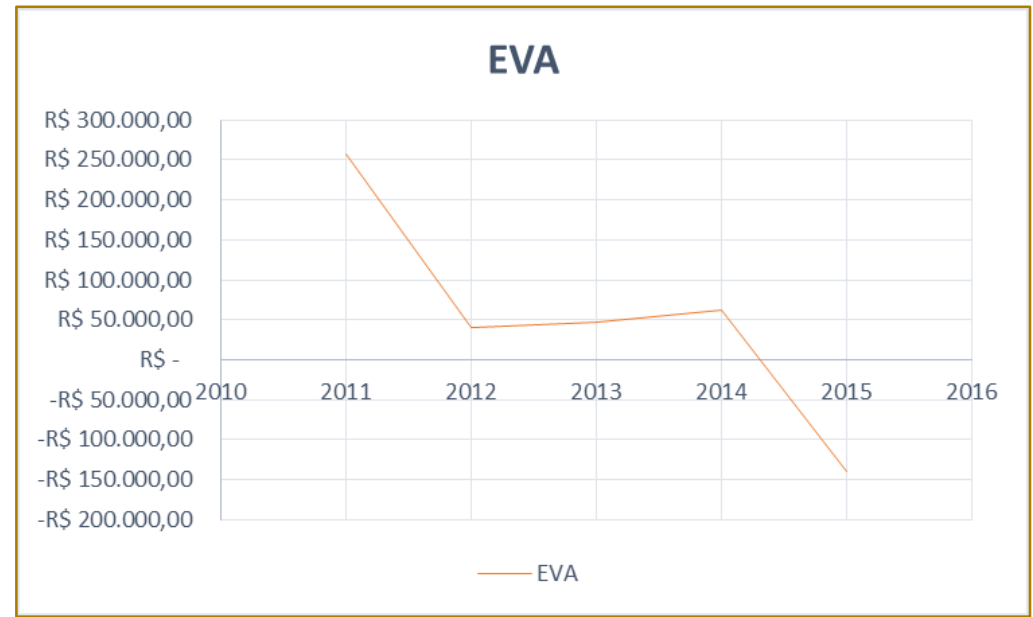

Fonte: elaborado pelos autores

A Elektro também apresentou em 2012 uma queda acentuada não chegando a destruir valor. Houve uma pequena recuperação em 2013 e 2014 (podendo-se dizer que os 
valores se apresentaram praticamente iguais nesses dois períodos). Já em 2015 a empresa apresenta um novo pico de queda gerando a destruição de valor.

Pelos resultados apresentados, verifica-se que embora a Eletropaulo tenha destruído valor em 2012 o que não ocorreu na CPFL Paulista e na Elektro, todas tiveram picos de queda neste período. Pode-se atribuir esse fator à Medida provisória convertida em Lei que foi implementada corroborando com a literatura que demonstrou que tal medida afetou negativamente o setor.

A melhoria apresentada em 2013 nas três empresas deve-se ao fato de que as empresas conseguiram adequar as suas operações as novas regulamentações trazidas pela medida provisória. No entanto, percebe-se que a recuperação é pequena e não se retoma o patamar conseguido em 2011.

O fator que pode ter contribuído para a queda novamente da geração de valor na Eletropaulo e CPFL Paulista em 2014 gerando uma destruição de valor na última empresa citada, é a crise hídrica que fez com que as empresas tivessem que comprar energia mais cara, e não puderam repassar esses valores ao consumidor devido aos programas de incentivo do governo. Nesse período de 2014, a Eletropaulo foi a única empresa analisada que apresentou prejuízo (DRE) no período pesquisado dentre as três empresas.

O que poderia explicar o fato dessa queda se acentuar em 2015 é o fator crise econômica e política do país que aumentou o risco Brasil fator este que está incluído no cálculo do custo do capital próprio elaborado pelo Instituto Assaf. Percebe-se que em 2015 o Ke é de 20,5\%, sendo que em 2014 esse fator apresentava valor de $14,9 \%$.

Verifica-se então que a atual conjuntura financeira das comercializadoras de energia do estado de São Paulo pesquisadas encontra-se com problemas, pois pela análise do EVA®, no último ano todas elas destruíram valor. O governo deverá então tomar novas medidas para que esse cenário se modifique de forma que os consumidores não sejam afetados por tais valores negativos.

\section{CONCLUSÃO}

A questão energética preocupa o Brasil não só pela necessidade de se pensar em alternativas sustentáveis, mas também pela questão financeira apresentada pela indústria de energia elétrica que se vê à mercê de decisões governamentais muitas vezes mais pautadas dentro das questões políticas do que econômicas e que visem o bem-estar da população.

Verificou-se que desde as primeiras empresas que começaram a trabalhar no Brasil com energia elétrica, houve uma série de modificações na regulamentação e até na forma como essas empresas se compõe (estatais ou privadas) que afetam todo o setor e inclusive os investimentos em melhoria e expansão.

Neste sentido, este artigo visou demonstrar quais foram os impactos financeiros gerados às distribuidoras de energia elétrica do estado de São Paulo após a promulgação da Lei 12.783/13. Esses impactos foram apurados analisando-se o EVA® das distribuidoras de energia elétrica do estado de São Paulo entre os anos de 2011 (anteriormente a promulgação da redução tarifária) à 2015 (ano em que foram implementadas as bandeiras tarifárias e houve um reajuste no valor da tarifa cobrado).

Pela análise feita dos valores de EVA® das três maiores comercializadoras de energia elétrica do Estado de São Paulo (Eletropaulo, CPFL Paulista e Elektro), verificou-se que a MP de 2012 afetou negativamente as empresas, em especial a Eletropaulo que em 2012 passou a destruir valor. Embora com uma aparência de melhoria nos valores em 2013, 2014 as empresas demonstraram nova queda, não tão acentuada como a primeira na Elektro, mas acentuada nas demais causando na CPFL Paulista destruição de valor. Esse aspecto pode ser explicado pela crise hídrica que fez com que a compra de energia ficasse mais cara no período, reflexo também das mudanças na regulamentação que aconteceram na MP 579/12 convertida na Lei 12.783/13.

Em 2015, embora tenha havido a promulgação das bandeiras tarifárias na tentativa de melhorar a condição econômica no setor e também de reduzir o consumo de energia elétrica para que não houvesse mais impactos negativos com a crise hídrica, tais medidas não foram suficientes. Verificou-se nas três empresas pesquisadas a destruição de valor. Tal fato pode ter sido agravado pela crise política e econômica do país que aumentou o risco Brasil, fator este que 
contribui para a elevação do custo do capital próprio que é considerado no cálculo do EVA®.

Estes resultados diferem dos apresentados em 2006 (Sampaio, Machado, \& Machado, 2006) e 2007 (Tavares \& Oliveira, Adicionando valor aos investimentos em distribuição de energia elétrica, 2007); nos quais os autores demonstraram em seus estudos que empresas de energia elétrica, em sua maioria, apresentaram aumento de valor na ótica do EVA®. Isto vem reforçar o fato de que as mudanças na regulamentação e legislação apresentada após 2006 contribuíram para a

\section{REFERÊNCIAS}

[8]: ANEEL. Informações gerenciais. Agência Nacional de Energia Elétrica, Dezembro 2015.

[3]. ASSAF NETO, A. Valuation: métricas de valor e avaliação de empresas. São Paulo: Atlas, 2014.

[4]. ASSAF NETO, A. instituto assaf. Instituto Assaf, 2016. Disponivel em: <http://www.institutoassaf.com.br/2012/painel.aspx >. Acesso em: 20 junho 2016.

[5]. ASSAF NeTO, A.; LIMA, F. G.; ARAÚJO, A. M. P. Uma proposta metodológica para o cálculo do custo de capital no Brasil. Revista de Administração, São Paulo, v. 43, p. 72-83, jan/fev/mar 2008. ISSN 1.

[6]. ASSUNÇÃO, T. N.; TAKAMATSU, R. T.; BRESSAN, V. G. F. Os impactos da medida provisória 579 nos retornos das ações de companhias de energia elétrica. Revista gestão, finanças e contabilidade, UNEB, Salvador, v. 5, p. 38-53, jan-abr. 2015. ISSN 2.

[7]. CASTRO, N. J. D. et al. O Processo de reestruturação so setor elétrico brasileiro e os impactos da MP 579. Texto de discussão do setor elétrico n. 51, Rio de Janeiro, p. 23, Janeiro 2013.

[8]. COSTA, L. R. Atuação e intervenção estatal: instabilidade regulatória no setor elétrico brasileiro sob a perspectiva da MP 579/2012. Monografia de Direito do Centro Universitário de Brasília, Brasilia, p. 53, 2013.

[9]. CYRILLO, I. O. Dissertação de mestrado em sistema de potências - POLI USP, São Paulo, p. 123, 2011.

[10]. DIEESE, D. I. D. E. E. E. S. Comportamento das tarifas de energia elétrica no Brasil. Nota técnica Número 147, p. 20, Agosto 2015. ISSN 147.

[11]. ENERGIA, M. D. M. E., 2007.

[12]. FACHINI, F. Crise no setor elétrico brasileiro após a medida provisória no. 579 . mudança de cenário e os resultados apresentados neste artigo.

Como sugestões de pesquisas futuras, podese replicar tal estudo para verificar como irão se comportar as empresas deste momento em diante, bem como ampliar o estudo para uma área de atuação fora do estado de São Paulo. Além disso, também é possível replicar este estudo com o cálculo do custo do capital próprio por empresa, e não com a utilização de um único valor no setor, embora seus cálculos tenham sido extraídos de um Instituto confiável e que possui metodologia apropriada.

Monografia de Ciências Econômicas da Universidade Federal de Santa Catarina, Florianópolis, p. 69, 2015.

[13]. FELíCIO, J. R. et al. Researchgate. Researchgate, 2014. Disponivel em: <https://www.researchgate.net/publication/2426118 03_Uma_Analise_Socio-

Economica_da_Tarifacao_Diferenciada_da_Energia _Eletrica>. Acesso em: 07/01/2016 Janeiro 2016.

[14]. FERNANDES, L. A. G. Impactos da MP 578 na gestão de riscos dos contratos das distribuidoras brasileiras de energia. Monografia de Enegenharia de produção da Escola Politécnica da UFRJ, Rio de Janeiro, p. 81, 2016.

[15]. FILHO, M. M.; SILVEIRA, F. S. V. provedor.nuca.ie.ufrj.br. Provedor de Informações Econômico-Financeiras do Setor de Energia Elétrica, $1998 . \quad$ Disponivel em: <http://www.provedor.nuca.ie.ufrj.br/eletrobras/estu dos/silveira4.zips. Acesso em: 07/01/2016 Janeiro 2016.

[16]. FISCHMANN, A. A.; ZILBER, M. A. Utilização de indicadores de desempenho como instrumento de suporte à gestão estratégica. XXIII Encontro da ANPAD, Foz do Iguaçu, p. 14, Setembro 1999. http://www.anpad.org.br/diversos/trabalhos/EnANP AD/enanpad_1999/AE/1999_AE11.pdf.

[17]. GUZELLA, M.; RODRIGUES, A. Avaliação do poder preditivo do desmpenho operacional a partir da situação econômico-financeira das distribuidoras de energia elétrica. VI Congresso Nacional de Administração e Contabilidade AdCont 2015, Rio de Janeiro , p. 17, Outubro 2015.

[18]. INSTITUTO ACENDE BRASIL. Uma avaliação da rentabilidade do setor elétrico. White Paper, n. 4, p. 20, fevereiro 2011.

[19]. KURTZ, C. R.; ROSEMBERG, L. O. A. L. Os impactos da MP 579/2012 no setor elétrico 
brasileiro: um estudo de caso. Trabalho de Graduação de Engenharia de Produção da UFRJ, Rio de Janeiro, p. 90, 2014.

[20]. LOPES, C. F. B. Regulação e credibilidade: $O$ caso do reajuste das tarifas de energia elétrica. Brasil Energy Frontiers 2013, São Paulo, p. 15-28, Outubro 2013.

[21]. MELO, S. et al. Demonstrações contaábeis sem efeios inflacionários: Uma abordagem relativa às empresas distribuidoras de energia elétrica. Contabilidade, Gestão e Governança, Brasília, v. 15, p. 63-77, Maio/Agosto 2012. ISSN 2. ISSN: 1984-3925.

[22]. MERCEDES, S. S. P.; RICO, J. A. P.; POZZO, L. D. Y. Uma revisão histórica do planejamento do setor elétrico brasileiro. Revista USP, São Paulo, p. 13-36, Janeiro/Fevereiro/Março 2015. ISSN 104.

[23]. NASCIMENTO, A. C. C. Regulação no setor de distribuição de energia elétrica no Brasil: Análise de metodologias alternativas para a definição dos custos operacionais eficientes. Tese em economia aplicada - Universidade Fedral de Viçosa, Viçosa, p. 137, 2013.

[24]. PEREIRA, E. R.; CAMPOS, A. F. Análise de dez concessionárias do segmento de distribuição de energia elétrica da região sudeste, no período 2001-2013, a partir de indicadores de rentabilidade selecionados. Revista Augustus, Rio de Janeiro, v. 20, n. 40, p. 124-142, jul-dez 2015. Disponivel em: <http://dx.doi.org/10.15202/19811896.2015v20n40 p124>.

[25]. PINTO, A. G. D. A. V. E.; PERIN, G. R.; DUARTE, F. C. Direito econômico da energia elétrica: a variação da tarifa e as falhas de mercado. Revista Juridica Cesumar, v. 15, p. 493515, jul-dez 2015. ISSN 2.
[26]. PRADO JR, F. A. D. A.; SILVA, A. L. R. D. Sobre reformas e concessões no setor elétrico brasileiro: uma análise crítica. Estratégica, v. 11, p. 85-115, Dezembro 2011. ISSN 2.

[27]. SAITO, A. T.; SAVOIA, J. R. F.; ANGELO, C. F. D. Mensuração dos custos econômicos do setor de distribuição de gás canalizado do estado de São Paulo com o emprego do EVA: o caso da Comgás. Revista de Administração Pública, Rio de Janeiro, v. 45, p. 1055-1067, Julho/Agosto 2011. ISSN 4. ISSN 0034-7612.

[28]. SAMPAIO, J. P. A.; MACHADO, M. A. V.; MACHADO, M. R. A Utilização do EVA como medida de desmpenho econômico: Estudo de caso na SAELPA. XIII Congresso Brasileiro de Custos, Belo Horizonte, p. 15, Outubro/Novembro 2006.

[29]. SILVA, A. M. G. E. et al. Análise da relação entre os preços das ações na bolsa de valores e indicadores contábeis: Um estudo aplicado a empresas do setor de energia elétrica. Revista de Negócios, Blumenau, v. 14, p. 52-70, Abril/Junho 2009. ISSN 2. ISSN 1980-4431.

[30]. SILVA, P. Z. P. D. Análise da crise de 2012 no desempenho econômico financeiro das indústrias de energia elétrica listadas na BM\&FBovespa. ConTexto, Porto Alegre, v. 15, p. 67-80, set-dez 2015. ISSN 31.

[31]. SILVA, R. M. D. Bandeiras tarifárias: benefícios ou prejuízo ao consumidor? Textos para discussão - Núcleo de estudos e pesquisas da consultoria legislativa, Senado Federal, n. 191, p. 24, março 2016.

[32]. TAVARES, A. D. L.; OLIVEIRA, A. F. D. Adicionando valor aos investimentos em distribuição de energia elétrica. XIV Congresso Brasileiro de Custos, João Pessoa, p. 1-15, Dezembro 2007. 


\section{Capítulo 3}

\section{IDENTIFICACÃO DOS CUSTOS OCULTOS NO PROCESSO DE FABRICACCÃO DE PRODUTOS DE UMA INDÚSTRIA DE BEBIDAS LOCALIZADA NA PARAÍBA}

\section{Thaís Nicole Pereira Gomes}

Isabelle Carlos Campos Rezende

Daniela Cintia de Carvalho Leite Menezes

Yara Magaly Albano Soares

Resumo: Tratar sobre custos ocultos significa ter conhecimento da funcionalidade da entidade como um todo, pois os mesmos apresentam difícil mensuração. Assim, este estudo teve como objetivo geral identificar os custos ocultos no processo de fabricação de produtos de uma indústria de bebidas localizada na Paraíba. Como metodologia foi utilizada a pesquisa descritiva e o estudo de caso. Os produtos estudados foram o refrigerante guaraná $250 \mathrm{ml}$ e água mineral $500 \mathrm{ml}$. Para coletar os dados utilizou-se dos relatórios gerenciais do período de abril a dezembro de 2013 e do ano de 2014. Para calcular os custos ocultos a pesquisa baseou-se na metodologia de estudo usada por Pedrosa Neto (2009), optando-se por utilizar o modelo IMPM. As variáreis envolvidas no modelo e utilizadas na pesquisa foram: (a) Ociosidade; (b) Estoque de produto acabado; (c) Absenteísmo e (d) Atestado Médico. Foram calculadas as medidas de tendência centra e de dispersão. Os resultados demonstraram que os custos ocultos calculados nesta pesquisa durante o período estudado totalizaram $\mathrm{R} \$ 21.320 .760,20$, sendo que o refrigerante guaraná $250 \mathrm{ml}$ foi o produto que mais agregou tais custos. Os custos ocultos em seu total representam um valor relevante e que não é efetivamente controlado pela empresa pelo fato de a mesma não os mensurar, revelando a importância da mensuração dos referidos custos, pois os mesmos implicam nos resultados e consequentemente na geração de riqueza para a empresa.

Palavras-chave: Custos ocultos. Processo de fabricação. Indústria. 


\section{INTRODUÇÃO}

A contabilidade de custos, nas últimas décadas, vem se apresentando como uma ferramenta relevante de controle e decisões gerenciais deixando apenas de ser instrumento de avaliação de estoques e mensuração de lucros. Esse novo campo de atuação da contabilidade de custos permitiu o seu auxílio na contabilidade gerencial (MARTINS, 2010).

Dessa forma, a contabilidade de custos produz informações relevantes para os usuários internos que as utilizam no processo de tomada de decisão. Esses usuários, principalmente gestores, precisam levar em consideração que os custos surgem das atividades, independentemente de serem apenas relacionadas aos custos do produto final, porque segundo Megliorini (2001) os custos refletem o comportamento da empresa e quando estruturados contribuem para a otimização dos resultados empresariais. Entretanto, se as informações sobre custos não forem confiáveis, os resultados encontrados serão deficientes. É relevante destacar que a preocupação não é apenas com a forma de escrituração dos fatos contábeis, porque uma vez identificado, mensurado os custos de um determinado produto o gestor é o detentor de informações úteis para à tomada de decisão que também auxilia no desempenho empresarial.

Trazendo para a realidade do estudo tratar sobre custos ocultos significa ter conhecimento da funcionalidade da entidade como um todo, porque além dos outros custos já conhecidos como os fixos e os variáveis, os diretos e os indiretos, saber identificar, mensurar e reconhecer os custos ocultos é de fundamental importância, pois o mesmo pode ser definido como um gasto referente à atividade de produção, no qual a principal característica é ser de difícil mensuração (SAVAL; ZARDET, 1991 apud FREITAS; SEVERIANO FILHO, 2007), como também, segundo Furedy (2005, apud Melo et al, 2006) "custo oculto é qualquer custo que não seja aparente na contabilidade padrão, ou, em termos gerais, que não esteja imediatamente aparente, mas que seja importante para o processo de produção". Dessa maneira surgiu o seguinte problema de pesquisa: Quais os custos ocultos identificados no processo de fabricação de produtos de uma indústria de bebidas localizada na Paraíba?
Sendo assim, o objetivo geral visou identificar os custos ocultos do processo de fabricação de produtos de uma indústria de bebidas localizada na Paraíba. Torna-se essencial destacar que o termo custo oculto, é tratado por alguns autores como custo indireto, intangível, invisível, escondido, imensurável, de difícil identificação, mas neste trabalho foi utilizado como custo oculto. Estudo realizado por Pedrosa Neto (2009) procurou mostrar se as metodologias SAPROV e IMPM foram adequadas para identificar os custos ocultos em uma planta industrial produtiva de cerâmica sendo constatado que é possível por meio destes métodos mensurar os custos ocultos.

Outro fato relevante é que o segmento estudado é uma indústria de bebidas com foco na água mineral que é líder desde a sua implantação e hoje a indústria ocupa o sétimo lugar no ranking mundial de águas minerais. Considerando o problema da existência dos custos ocultos nas empresas e que também impactam diretamente no desempenho econômico das mesmas, resolveu-se estudar os custos ocultos envolvidos no processo de fabricação dos produtos de uma indústria de bebidas já que tais custos influenciam a lucratividade.

\section{REFERENCIAL TEÓRICO}

\subsection{CONTABILIDADE DE CUSTOS E A CONTABILIDADE GERENCIAL}

De acordo com Atrile e McLaney (2014, p.43) em um primeiro momento a medição de custos parece um processo simples. Pois, trata-se da quantia paga pelo bem ou serviço prestado. Porém, ainda segundo os mesmos autores, quando parte para o processo de tomada de decisão, não parece tão simples assim. O autor afirma que um custo deve ser olhado como um elemento que tenha efeito sobre a riqueza da empresa. Sendo assim, todos os elementos que possam alterar essa opulência, como os sacrifícios financeiros, as oportunidades de negócios dispensadas em detrimentos de outras opções, as perdas de recursos e os possíveis gastos futuros, serão objetos de estudo da contabilidade de custos. Dessa forma, observa-se que a função predominante da contabilidade de custos é a sua aplicabilidade no campo gerencial, gerando informações para tomada de decisão. De acordo com Martins (2010) e Leone (2010) a contabilidade de custos passou a assumir um papel marcante, de 
importância nas empresas, a de dar suporte, de fornecer dados gerenciais para que a administração ampare suas tomadas de decisão, já que os mesmos influenciam diretamente na lucratividade.

Observa-se então que a contabilidade de custos reconhece, registra e mensura os elementos que se caracterizam como custos e que esses venham a alterar o patrimônio de uma entidade e a contabilidade gerencial organiza as informações de acordo como o usuário que dela venha precisar.

\subsection{CLASSIFICAÇÃO DOS CUSTOS}

Para Bruni (2008) custo é um gasto relativo à bem ou serviço utilizado na produção de outros bens ou serviços. Estão associados aos produtos ou serviços produzidos pela entidade. São consumidos pelos estoques. Como exemplo podem citados salários de pessoal da produção, aluguéis e seguros do período da fabricação, matérias primas e embalagens.

Portanto, os custos podem ser classificados em: diretos, indiretos, variáveis, fixos, tangíveis ou explícitos ou "mensuráveis" e custos intangíveis ou implícitos ou ocultos. Os custos diretos são aqueles que podem ser diretamente apropriados a cada tipo de bem ou órgão, no momento da sua ocorrência, isto é, estão ligados diretamente a cada tipo de bem ou função de custo, são aqueles incluídos de forma objetiva no cálculo dos produtos ou serviços comercializados (BRUNI, 2008; MARTINS, 2010).

Os custos indiretos são aqueles que não se pode apropriar diretamente a cada tipo de bem ou função de custo no momento da sua ocorrência. Atribui-se parcela deles a cada tipo de bem ou função de custo através de um critério de rateio. São aqueles custos que não são facilmente identificados com o objeto e custeio (SEVERIANO FILHO, 2007; LEONE, 2010).

De acordo com a variabilidade os custos variáveis são aqueles que se altera, em termos de valor total, com variações do nível de entidade. Se não houver quantidade produzida, o custo variável será nulo. Observa-se que os custos variáveis devem ser analisados com respeito às quantidades consumidas na produção e não às quantidades adquiridas ou às estocadas (BREWER; GARRISON; NOREEN, 2007; LEONE, 2010). Já os custos fixos não variam, em termos totais, qualquer que seja 0 comportamento do nível de atividade dentro de um intervalo relevante de observação. (BREWER; GARRISON; NOREEN, 2007).

De acordo com a sua natureza os custos tangíveis ou explícitos ou "mensuráveis" são os que se podem calcular com critérios convencionais de custos, em muitos casos de acordo com princípios de contabilidade geralmente aceitos, e normalmente vão acompanhados de um desembolso efetivo por parte da empresa (AECA, 1995, apud Severiano Filho e Freitas, 2007).

Os custos intangíveis, implícitos ou ocultos é qualquer custo que não seja aparente na contabilidade padrão, ou, em termos gerais, que não esteja imediatamente aparente, mas que seja importante para o processo de produção (FUREDY, 2005, apud Severiano Filho e Freitas, 2007). Para Leone (2007) são custos que não estão explicitados porque se encontram "escondidos" nas operações, são custos não contabilizados, não registrados não possuem documentos que demonstrem sua autenticidade porque são subjetivos, são estabelecidos para ajudar na tomada de decisão.

\subsection{CUSTOS OCULTOS}

É importante para todo o tipo e tamanho de empresas, independente do setor econômico (indústria, comércio, serviços públicos, hospitais, bancos, escritórios de consultoria) o estudo dos custos ocultos (SEVERIANO FILHO; SILVA, 2011). Algumas empresas já vêm dando atenção para esses custos que podem ser classificados como indiretos e que não são precisos e proporcionam um ambiente empresarial inseguro baseado em estimativas.

Uma vez mensurado corretamente esses custos servem como um guia gerencial para as tomadas de decisão, porque apresentam o custo industrial evitando custos desnecessários e garantem a competitividade futura (FREITAS; SEVERIANO FILHO, 2007).

Pode-se afirmar que os custos ocultos têm origem externa e outros se desenvolvem dentro da organização e uma de suas características é o fato de não serem detectados não serem reconhecidos nos relatórios gerenciais, contábeis e nem medidos pelos sistemas tradicionais de custeio. Quando não mensurados esses custos serão dificilmente controláveis. E uma 
vez reconhecidos agregam valores no ponto de vista gerencial, pois fornecem dados que influenciam nos aspectos administrativo, de planejamento, controle e de investimentos da empresa (FEMENICK, 2004; MELO; FREITAS; COSTA, 2006).

Para Savall e Zardet (1991, apud Melo et al, 2006) os custos ocultos são "o resultado de uma interação permanente e complexa entre as estruturas da empresa e os comportamentos humanos, aqueles criados a partir do "funcionamento adequado" e dos disfuncionamentos, "funcionamento inadequado" da organização".
Segundo Herculano (2009) a ocorrência do custo oculto refere-se à incerteza nas escolhas dos métodos de custeios para mensuração monetária de uma atividade por parte das empresas. Pode-se dizer que os custos ocultos surgem de disfunções, perdas, maus funcionamentos, da má organização, má gestão, falhas, da má mensuração, ou não mensuração adequada, má aplicabilidade nas escolhas para uma tomada de decisão errada, pode ocasionar numa disfunção que gera custos e na maioria das vezes ocultos e afetam a saúde econômica da empresa, nesse sentido podem relacionar a seguinte equação.

Custos Oculto $=$ Funcionamento Esperado - Funcionamento Atingido

A empresa no seu ciclo operacional planeja e controla as suas atividades cotidianas para que obtenha o lucro esperado, ou seja, consiga receber a mais para cobrir o que se investiu, mas nem sempre o que se planejou é atingido. A implantação nas rotinas operacionais da empresa do acompanhamento dos custos oculto é difícil, mas em contrapartida relevante. A identificação de tais custos é importante para tentar diminuí-los e, se possível, evitá-los, para que possa haver a possibilidade de aumento no investimento e a obtenção da otimização de resultados financeiros como também aumentar a eficiência operacional.

Segundo Miller e Vollman (1985 apud Corso et al, 2009) considera-se custos ocultos "a existência de uma "fábrica oculta" no âmbito organizacional interno", ou seja, custos de transações, que ocorrem, mas não são visíveis para a contabilidade.

\subsubsection{CLASSIFICAÇÃO DOS CUSTOS OCULTOS}

O custo oculto é algo subjetivo, intangível, de difícil identificação para mensurar no momento em que efetivamente ocorrem como excesso de hora extra, tempo perdido para analisar as causas das falhas. Assim, é relevante apresentar o quadro $1 \mathrm{com}$ a classificação dos custos. 
Quadro 1 Classificação dos custos ocultos

\begin{tabular}{|c|c|c|}
\hline $\begin{array}{c}\text { Classificação dos custos } \\
\text { ocultos }\end{array}$ & Descrição & Exemplos \\
\hline Má gestão & $\begin{array}{l}\text { Ausência de planejamento, gerando perda de } \\
\text { oportunidade ou sacrifício pelo abandono de } \\
\text { uma ação. São gastos decorrentes de decisões } \\
\text { baseadas em análises superficiais, utilização } \\
\text { de sistemas e processos obsoletos, existência } \\
\text { de liderança omissa e ausente. }\end{array}$ & $\begin{array}{l}\text { Custos com projetos } \\
\text { inacabados; Custos com a } \\
\text { desistência de projetos mal } \\
\text { planejados. }\end{array}$ \\
\hline Não qualidade & $\begin{array}{l}\text { Decorre do refazer, do corrigir, dos } \\
\text { desperdícios dos itens produzidos. São } \\
\text { considerados: gastos com devoluções, trocas } \\
\text { de produtos defeituosos; retoques, disposição } \\
\text { de refugos. }\end{array}$ & $\begin{array}{l}\text { Retrabalho em peças } \\
\text { produzidas; Substituição de } \\
\text { peças ou produtos. }\end{array}$ \\
\hline Rotatividade de Pessoas & $\begin{array}{l}\text { Resulta da falta de direcionamento adequado } \\
\text { para os talentos internos e um clima } \\
\text { organizacional ruim. Compreende gasto da } \\
\text { formação, investimentos efetuados em pessoal, } \\
\text { contratações. }\end{array}$ & $\begin{array}{l}\text { Treinamentos de novos } \\
\text { funcionários, substitutos. }\end{array}$ \\
\hline Mau controle & $\begin{array}{l}\text { Custos decorrentes do excesso de informações } \\
\text { e dados que não agregam valor. São gastos } \\
\text { gerados pela desconfiança e criação de } \\
\text { controles em excesso, inexistência ou falta de } \\
\text { controles. }\end{array}$ & $\begin{array}{l}\text { Controles duplos feitos por } \\
\text { setores diferentes. }\end{array}$ \\
\hline Acidente de trabalho & $\begin{array}{l}\text { Normalmente decorrente do não uso de } \\
\text { equipamentos de proteção ou de } \\
\text { procedimentos inadequados de segurança } \\
\text { para a execução das atividades. }\end{array}$ & $\begin{array}{l}\text { Custos com funcionários } \\
\text { afastados e funcionário para } \\
\text { reposição. }\end{array}$ \\
\hline Set-up & $\begin{array}{l}\text { Custo do set-up relacionado às falhas e ao mau } \\
\text { uso do tempo de preparação do processo } \\
\text { produtivo. }\end{array}$ & $\begin{array}{l}\text { Custo com pessoal parado, } \\
\text { tempo extra para regulação } \\
\text { das máquinas. }\end{array}$ \\
\hline Espera & $\begin{array}{l}\text { Ocasionado por procedimentos e métodos não } \\
\text { integrados às dimensões das demandas do } \\
\text { processo produtivo. }\end{array}$ & $\begin{array}{l}\text { Custo com paradas por falta } \\
\text { de matéria-prima. }\end{array}$ \\
\hline Ociosidade & $\begin{array}{l}\text { Refere-se ao não funcionamento no tempo certo } \\
\text { ou da capacidade disponível de determinado } \\
\text { processo. }\end{array}$ & $\begin{array}{l}\text { Custos por lentidão com } \\
\text { máquinas sem manutenção; } \\
\text { capacidade subutilizada. }\end{array}$ \\
\hline Estoque & $\begin{array}{l}\text { Fruto do armazenamento do produto acabado } \\
\text { sem necessidade, gerando gastos adicionais } \\
\text { com manutenção e acondicionamento. }\end{array}$ & $\begin{array}{l}\text { Custo com manutenção e } \\
\text { seguro de estoques } \\
\text { desnecessários. }\end{array}$ \\
\hline Obsolescência & $\begin{array}{l}\text { Resulta do uso de máquinas e equipamentos } \\
\text { que tiveram o tempo de vida expirado, exigindo } \\
\text { manutenção corretiva adicional. }\end{array}$ & $\begin{array}{l}\text { Custos com tempo extra por } \\
\text { máquinas de tecnologia } \\
\text { defasada. }\end{array}$ \\
\hline
\end{tabular}

Fonte: Lima (1991), Savall e Zardet (1991) e Zaffani (2005, apud Becher et al, 2011)

Tais classificações dos custos ocultos contextualizam o cenário da contabilidade juntamente com ambiente interno das empresas, para então diminuir ou evitar essas distorções da apuração dos custos e as ocorrências das falhas. Assim, Femenick (2004) tratou dessas classificações de duas formas: custos invisíveis, aqueles presentes nas organizações, mas não mensurados e desenvolve-se dentro ou fora da empresa dividindo em três grupos: (1) custos tributários; (2) custos operacionais externos; e (3) custos operacionais internos e custo oculto aqueles demonstrados pelo resultado da equação (Custo Oculto = Desempenho Real Desempenho Ideal) que separou em três categorias: (1) custos referentes a reformas; 
(2) manutenção ineficiente; e (3) mão-de-obra não capacitada.

Para Corso et al (2009) os custos ocultos surgem de disfunções que possam ser criadas devido as transações logísticas (movimentação do material por ordem dos funcionários), transações de nivelamento (envolvem recursos financeiros, materiais e humanos no processo de aquisição de materiais, planejamento e controle da produção e expedição), transações referentes à qualidade (controle de qualidade, incluindo a engenharia indireta e o suprimento) e transações de alterações (custos que atualizam sistemas de informação de produção para acomodar mudanças nos projetos de engenharia, estabelecimento de padrões, programações da produção e especificação de materiais).

Ainda se observa a possibilidade de classificar como custos ocultos aqueles que diminuem a qualidade dos produtos/serviços. Esses custos são decorrentes de incidência de defeitos e desperdícios (CORSO et al, 2009).

\section{PROCEDIMENTOS METODOLÓGICOS}

Conforme Sampieri, Collado e Lúcio (2006) o alcance de um estudo depende da estratégia de investigação. Assim, a presente pesquisa foi caracterizada como descritiva, pois teve como finalidade identificar os custos ocultos no processo de fabricação dos produtos de uma indústria de bebidas localizada na Paraíba, bem como quantitativa por utilizar técnicas de coleta e análise de dados que a caracterizam. Os estudos descritivos objetivam detalhar como se manifestam fenômenos, situações, contextos e eventos (GIL, 2002). E para descrever o estado da arte foi usada a pesquisa bibliográfica.

É importante ressaltar que a pesquisa documental foi utilizada para auxiliar a coleta de dados que foi realizada in loco, tendo acesso as planilhas de custos e relatórios gerenciais do período de abril de 2013 a dezembro de 2013 e do ano de 2014, dos produtos estudados que foram refrigerante guaraná $250 \mathrm{ml}$ e água mineral $500 \mathrm{ml}$ sem gás. Deste modo, é importante enfatizar duas situações: (1) os dados do exercício de 2013 foram a partir do mês de abril, porque a empresa alegou que os dados de janeiro a março de 2013 foram perdidos devido a mudança no sistema operacional; e (2) a escolha desses produtos se motivou, pois além de serem fabricados (produzidos na própria empresa) são os mais vendidos, de acordo com informações do responsável pelo setor de vendas. Além dos documentos, foi necessário realizar uma entrevista estruturada com a gerente filial para coletar mais informações necessárias para identificar os custos ocultos.

Em seguida, foram organizadas tabelas com as variáveis custos diretos, custos indiretos e custos totais de cada produto por período e foi calculado a média e o desvio padrão (medida de tendência centra e de dispersão, respectivamente). Para identificar os custos ocultos foi usada a metodologia que partiu do estudo realizado por Pedrosa Neto (2009) o qual utilizou dois modelos para avaliar os custos ocultos. Porém, neste estudo optou-se por utilizar o modelo IMPM, visto que pelos dados que o pesquisador teve acesso era possível fazer a mensuração dos custos ocultos. Deste modo, as variáreis envolvidas no modelo e utilizadas na pesquisa de Pedrosa Neto (2009) foram: (a) Ociosidade; (b) Estoque de produto acabado; (c) Absenteísmo e (d) Atestado Médico. E importante destacar que foi realizado o cálculo para cada produto estudado, em seguida foram expostos em tabelas e feito a comparação de qual produto apresenta maiores custos ocultos.

\section{APRESENTAÇÃO E ANÁLISE DOS RESULTADOS}

Nesta seção foi apresentada a estrutura de custos de fabricação dos produtos analisados, que são água mineral $500 \mathrm{ml}$ sem gás e refrigerante guaraná $250 \mathrm{ml}$, embasados nos relatórios disponibilizados pela empresa e entrevista feita com o gerente filial.

\subsection{CUSTOS DIRETOS DOS PRODUTOS POR PACOTE}

As tabelas 1 e 2 apresentam sinteticamente os custos diretos, que são aqueles que estão diretamente ligados ao processo de fabricação dos produtos, por pacote e a variação existente em relação ao valor total do período de 2013 e 2014, respectivamente, dos produtos água mineral $500 \mathrm{ml}$ sem gás e refrigerante guaraná $250 \mathrm{ml}$. Vale salientar que essa análise de 2013 inicia-se a partir de abril, pois a empresa passou por mudança de sistema operacional, a qual ocasionou a 
perda dos relatórios dos meses anteriores (janeiro a março).

Através dos relatórios gerenciais disponibilizados pela empresa destaca-se no processo produtivo dos respectivos produtos os custos diretos com matéria prima, mão de obra, produto acabado, despesa com manutenção de máquinas e equipamentos, embalagens, frete, despesa com frota e mercadoria de revenda.

Tabela 1 Total dos custos diretos dos produtos por pacote no período de 2013

\begin{tabular}{|c|c|c|c|c|}
\hline \multirow{2}{*}{ Período } & \multicolumn{2}{|c|}{ Produtos/Custos diretos } & \multirow{2}{*}{$\begin{array}{c}\text { Variação Água } \\
(\%)\end{array}$} & \multirow{2}{*}{$\begin{array}{c}\text { Variação Refrig. } \\
(\%)\end{array}$} \\
\hline & Água Mineral S/G 500ml & Refrigerante $250 \mathrm{ml}$ & & \\
\hline Abril/2013 & $\mathrm{R} \$ 1,33$ & $\mathrm{R} \$ 1,82$ & $9,04 \%$ & $10,56 \%$ \\
\hline Maio/2013 & $\mathrm{R} \$ 1,81$ & $\mathrm{R} \$ 1,87$ & $12,30 \%$ & $10,83 \%$ \\
\hline Jun/2013 & $\mathrm{R} \$ 1,40$ & $\mathrm{R} \$ 1,75$ & $9,51 \%$ & $10,16 \%$ \\
\hline Jul/2013 & $\mathrm{R} \$ 1,66$ & $\mathrm{R} \$ 1,89$ & $11,28 \%$ & $10,97 \%$ \\
\hline Agost/2013 & $\mathrm{R} \$ 1,53$ & $\mathrm{R} \$ 1,95$ & $10,39 \%$ & $11,32 \%$ \\
\hline Set/2013 & $\mathrm{R} \$ 1,90$ & $\mathrm{R} \$ 2,00$ & $12,91 \%$ & $11,61 \%$ \\
\hline Out/2013 & $\mathrm{R} \$ 1,71$ & $\mathrm{R} \$ 2,08$ & $11,62 \%$ & $12,07 \%$ \\
\hline Nov/2013 & $\mathrm{R} \$ 1,63$ & $R \$ 1,95$ & $11,07 \%$ & $11,32 \%$ \\
\hline Dez/2013 & $\mathrm{R} \$ 1,75$ & $\mathrm{R} \$ 1,92$ & $11,89 \%$ & $11,14 \%$ \\
\hline Total dos CD & $\mathrm{R} \$ 14,72$ & $\mathrm{R} \$ 17,23$ & $100 \%$ & $100 \%$ \\
\hline
\end{tabular}

Fonte: Elaboração própria a partir da coleta de dados (2015)

Na produção da água, o mês que apresentou os maiores custos diretos foi o de setembro, sendo igual a $R \$ 1,90$, o que representa $12,91 \%$ do total dos custos diretos incorridos no período analisado ( $R \$ 14,72)$. A justificativa para esse maior custo observado no relatório gerencial é o acréscimo no valor da embalagem e da matéria-prima do referido produto. Já o mês que apresentou os menores custos diretos foi o de abril, que totalizou $R \$ 1,33$, o que representa $9,04 \%$ do total. Essa diminuição se deu aos itens envolvidos de produto acabado e mão de obra. A média mensal de custos diretos nesta produção no período analisado foi igual a 1,64 , e apresentou desvio padrão igual a $\mathrm{R} \$ 0,19$.
Entretanto, na produção de refrigerante observam-se maiores custos no mês de outubro de $R \$ 2,08$, o que representa $12,07 \%$ do total dos custos diretos sendo igual a $\mathrm{R} \$ 17,23$. Esse alto valor se deu também em relação aos aumentos dos itens de matéria prima e embalagens. Enquanto o mês que representou o menor custo foi de junho com um custo mensal de $\mathrm{R} \$ 1,75$, proporcionalmente, $10,16 \%$ da produção total, e também os itens de mão de obra e produto acabado. A média mensal de custos diretos é de $R \$ 1,91$, e desvio padrão em torno dela igual a $R \$ 0,10$. Apresenta-se na tabela 2 os custos diretos da água mineral e refrigerante incorridos no período de 2014 e suas variações em relação ao valor total. 
Tabela 2 Total dos custos diretos dos produtos por pacote no período de 2014

\begin{tabular}{|c|c|c|c|c|}
\hline \multirow{2}{*}{ Período } & \multicolumn{2}{|c|}{ Produtos/Custos diretos } & \multirow{2}{*}{$\begin{array}{c}\text { Variação Água } \\
(\%)\end{array}$} & \multirow{2}{*}{$\begin{array}{c}\text { Variação Refrig. } \\
(\%)\end{array}$} \\
\hline & Água Mineral S/G 500ml & Refrigerante $250 \mathrm{ml}$ & & \\
\hline Janeiro/2014 & $\mathrm{R} \$ 1,62$ & 1,81 & $7,99 \%$ & $8,17 \%$ \\
\hline Fevereiro/2014 & $\mathrm{R} \$ 1,68$ & 1,91 & $8,29 \%$ & $8,61 \%$ \\
\hline Março/2014 & $\mathrm{R} \$ 1,77$ & 1,94 & $8,73 \%$ & $8,75 \%$ \\
\hline Abril/2014 & $\mathrm{R} \$ 1,72$ & 1,88 & $8,49 \%$ & $8,48 \%$ \\
\hline Maio/2014 & $\mathrm{R} \$ 1,69$ & 1,83 & $8,34 \%$ & $8,26 \%$ \\
\hline Junho/2014 & $\mathrm{R} \$ 1,71$ & 1,73 & $8,44 \%$ & $7,81 \%$ \\
\hline Julho/2014 & $\mathrm{R} \$ 1,64$ & 1,85 & $8,09 \%$ & $8,35 \%$ \\
\hline Agosto/2014 & $\mathrm{R} \$ 1,65$ & 1,89 & $8,14 \%$ & $8,53 \%$ \\
\hline Setembro2014 & $\mathrm{R} \$ 1,76$ & 1,91 & $8,68 \%$ & $8,62 \%$ \\
\hline Outubro/2014 & $\mathrm{R} \$ 1,60$ & 1,75 & $7,89 \%$ & $7,90 \%$ \\
\hline Novembro/2014 & $\mathrm{R} \$ 1,67$ & 1,75 & $8,24 \%$ & $7,90 \%$ \\
\hline Dezembro/2014 & $\mathrm{R} \$ 1,76$ & 1,91 & $8,68 \%$ & $8,62 \%$ \\
\hline Total dos CD & $\mathrm{R} \$ 20,27$ & $\mathrm{R} \$ 22,16$ & $100 \%$ & $100 \%$ \\
\hline
\end{tabular}

Fonte: Elaboração própria a partir da coleta de dados (2015)

Avaliando a tabela 2 observa-se que os custos diretos da água mineral no período de 2014 nos mês de março sobressaíram em relação aos demais meses, com o custo de $\mathrm{R} \$ 1,77$ isso se deu ao fato dos valores da matéria prima e da embalagem estarem mais elevados, conforme constatação nos relatórios gerenciais. O que constitui $8,73 \%$ dos custos diretos produzidos $R \$ 20,27$. E o menor mês foi o de outubro em que os custos foi de $R \$ 1,60$ porque houve uma redução de $13 \%$ no valor na matéria prima. E totalizou $7,89 \%$ da produção total. A média dos custos no período de 2014 é de $R \$ 1,69$ e o desvio padrão de $R \$ 0,06$.

Já em relação aos custos do refrigerante no mês de Março foi o que mostrou o maior custo de $\mathrm{R} \$ 1,94$, demonstrando $8,75 \%$ dos custos produzidos num total de $R \$ 22,16$. E mais uma vez destaca-se os itens da matéria prima e embalagem com altos custos. E o menor mês foi o de junho com $R \$ 1,73$ de custo por pacote num total de $7,81 \%$. A média dos custos é de $\mathrm{R} \$ 1,85$ por pacote e o desvio padrão dela é $\mathrm{R} \$ 0,07$.

\subsection{CUSTOS INDIRETOS DOS PRODUTOS POR PACOTE}

Nas tabelas 3 e 4 apresentam sinteticamente os custos indiretos, que são aqueles que não são diretamente alocados a um produto, por pacote e a variação existente em relação ao valor total do período de 2013 e 2014, respectivamente, dos produtos água mineral $500 \mathrm{ml}$ sem gás e refrigerante guaraná $250 \mathrm{ml}$. 
Tabela 3 Total dos custos indiretos dos produtos por pacote no período de 2013

\begin{tabular}{|c|c|c|c|c|}
\hline \multirow{2}{*}{ Período } & \multicolumn{3}{c}{ Produtos/Custos indiretos } \\
\hline Abril/2013 & $\mathrm{R} \$ 0,36$ & 0,19 & $9,04 \%$ & $5,18 \%$ \\
\hline Maio/2013 & $\mathrm{R} \$ 0,79$ & 0,20 & $12,30 \%$ & $5,45 \%$ \\
\hline Jun/2013 & $\mathrm{R} \$ 0,58$ & 0,63 & $9,51 \%$ & $17,17 \%$ \\
\hline Jul/2013 & $\mathrm{R} \$ 0,51$ & 0,45 & $11,28 \%$ & $12,26 \%$ \\
\hline Agost/2013 & $\mathrm{R} \$ 0,45$ & 0,41 & $10,39 \%$ & $11,17 \%$ \\
\hline Set/2013 & $\mathrm{R} \$ 0,58$ & 0,48 & $12,91 \%$ & $13,08 \%$ \\
\hline Out/2013 & $\mathrm{R} \$ 0,46$ & 0,41 & $11,62 \%$ & $11,17 \%$ \\
\hline Nov/2013 & $\mathrm{R} \$ 0,67$ & 0,40 & $11,07 \%$ & $10,90 \%$ \\
\hline Dez/2013 & $\mathrm{R} \$ 0,63$ & 0,50 & $11,89 \%$ & $13,63 \%$ \\
\hline Total dos CD & $\mathrm{R} \$ 5,03$ & $\mathrm{R} \$ 3,67$ & $100 \%$ & $100 \%$ \\
\hline
\end{tabular}

Fonte: Elaboração própria a partir da coleta de dados (2015)

A tabela 3 evidencia no mês de maio o maior custo indireto de $\mathrm{R} \$ 0,79$, ocasionando $12,30 \%$ do custo total de $R \$ R \$ 5,03$. Verificase nos itens mão de obra e despesas gerais valores maiores. Enquanto que no mês abril o custo foi menor de $\mathrm{R} \$ 0,36$, resultando $9,04 \%$ do valor total. A média dos custos é de $\mathrm{R} \$ 0,56$ e o desvio padrão de $\mathrm{R} \$ 0,13$.

$\mathrm{Na}$ tabela 3 evidencia também os custos maiores de refrigerante, no mês de junho de
$R \$ 0,63$, e $17,17 \%$ do valor total de $R \$ 3,67$. Que nesse mês os custos que sobressaíram foram despesa com energia e mão de obra. E o mês com o custo menor foi o de abril por $\mathrm{R} \$ 0,19$ por pacote com a variação de $5,18 \%$ em relação ao valor total. A média do custo por pacote é de $\mathrm{R} \$ 0,40$ com desvio padrão de $\mathrm{R} \$ 0,14$.

Tabela 4 Total dos custos indiretos dos produtos por pacote no período de 2014

\begin{tabular}{|c|c|c|c|c|}
\hline \multicolumn{2}{|c|}{ Período } & \multicolumn{2}{c}{ Produtos/Custos indiretos } & \multicolumn{2}{c|}{ Variação } & Variação (\%) \\
\hline Janeiro/2014 & $\mathrm{R} \$ 0,53$ & 0,50 & $6,68 \%$ & $8,77 \%$ \\
\hline Fevereiro/2014 & $\mathrm{R} \$ 0,52$ & 0,53 & $6,56 \%$ & $9,30 \%$ \\
\hline Março/2014 & $\mathrm{R} \$ 0,51$ & 0,46 & $6,43 \%$ & $8,07 \%$ \\
\hline Abril/2014 & $\mathrm{R} \$ 0,52$ & 0,40 & $6,56 \%$ & $7,02 \%$ \\
\hline Maio/2014 & $\mathrm{R} \$ 0,77$ & 0,38 & $9,71 \%$ & $6,67 \%$ \\
\hline Junho/2014 & $\mathrm{R} \$ 0,56$ & 0,36 & $7,06 \%$ & $6,32 \%$ \\
\hline Julho/2014 & $\mathrm{R} \$ 0,84$ & 0,46 & $10,59 \%$ & $8,07 \%$ \\
\hline Agosto/2014 & $\mathrm{R} \$ 0,79$ & 0,55 & $9,96 \%$ & $9,65 \%$ \\
\hline Setembro2014 & $\mathrm{R} \$ 0,80$ & 0,51 & $10,09 \%$ & $8,95 \%$ \\
\hline Outubro/2014 & $\mathrm{R} \$ 0,54$ & 0,44 & $6,81 \%$ & $7,72 \%$ \\
\hline Novembro/2014 & $\mathrm{R} \$ 0,62$ & 0,51 & $7,82 \%$ & $8,95 \%$ \\
\hline Dezembro/2014 & $\mathrm{R} \$ 0,93$ & 0,60 & $11,73 \%$ & $10,53 \%$ \\
\hline Total dos CD & $\mathrm{R} \$ 7,93$ & $\mathrm{R} \$ 5,70$ & $100 \%$ & $100 \%$ \\
\hline
\end{tabular}

Fonte: Elaboração própria a partir da coleta de dados (2015) 
A tabela 4 mostra que no mês de dezembro teve o maior custo indireto de $\mathrm{R} \$ 0,93$ de fabricação da água. Resultando de um total de $11,73 \%$ de $\mathrm{R} \$ 7,93$. E os maiores custos envolvidos foi com mão de obra e despesa com manutenção de máquinas e equipamentos. E o menor custo observado foi no mês de março com valor igual a $R \$ 0,51$. Representando $6,43 \%$ do valor total. Essa diminuição se deu por causa dos itens despesa com frota e despesa com imóveis estarem a menor. A média é $R \$ 0.66$ e o desvio padrão de $\mathrm{R} \$ 0,15$.

A tabela 4 mostra também os custos do refrigerante. Que no mês de dezembro apresentou um maior custo de $\mathrm{R} \$ 0,60$, realizando $10,53 \%$ do valor total de $R \$ 5,70$. $E$ os itens com maiores valores foram o de mão de obra e manutenção de máquinas. E no mês de junho foi o mês que apresentou o menor custo de $\mathrm{R} \$ 0,36$, de um total de $\mathrm{R} \$ 6,32 \%$. E os itens com menores valores foram energia e despesa com frota. A média dos custos é de $R \$ 0,48$ e desvio padrão dela igual a $R \$ 0,07$.

\subsection{CUSTO TOTAL DOS PRODUTOS POR PACOTE}

Segue a análise das tabelas 5 e 6 , onde apresentam os custos totais dos produtos, representado pelo somatório das tabelas anteriores ( 1 e 3 ), dos custos diretos e indiretos.

Tabela 5 Custos totais dos produtos por pacote no período de 2013

\begin{tabular}{|c|c|c|c|c|}
\hline \multirow{2}{*}{ Período } & \multicolumn{2}{c}{ Produtos/Custo total } & Variação Água & Variação Refrig. \\
$(\%)$
\end{tabular}

Fonte: Elaboração própria a partir da coleta de dados (2015)

A tabela 5 mostra o custo total de 2013 da água mineral que é o somatório das tabelas 1 e 3, em que trata da soma dos custos diretos e indiretos do período de 2013. Observa-se que o mês de maio teve o custo a maior de $R \$ 2,58$, representando $13,31 \%$ do total de $\mathrm{R} \$$ 19,38. A média por pacote de $\mathrm{R} \$ 2,15$ e desvio padrão dela igual a $R \$ 0,26$. Enquanto que na produção do refrigerante o mês que demonstrou maior custo foi o de outubro com $\mathrm{R} \$ 2,50$, apresentando $12,07 \%$ do total de $\mathrm{R} \$ 20,71$. E o menor custo no mês de abril com $R \$ 2,01$ e $9,71 \%$ do valor total. 
Tabela 6 Custos totais dos produtos por pacote no período de 2014

\begin{tabular}{|c|c|c|c|c|}
\hline \multirow{2}{*}{ Período } & \multicolumn{2}{|c|}{ Produtos/Custo total } & \multirow{2}{*}{$\begin{array}{c}\text { Variação Água } \\
(\%)\end{array}$} & \multirow{2}{*}{$\begin{array}{c}\text { Variação Refrig. } \\
(\%)\end{array}$} \\
\hline & Água Mineral S/G 500ml & Refrigerante $250 \mathrm{ml}$ & & \\
\hline Janeiro/2014 & $\mathrm{R} \$ 2,15$ & $\mathrm{R} \$ 2,31$ & $7,63 \%$ & $8,29 \%$ \\
\hline Fevereiro/2014 & $\mathrm{R} \$ 2,20$ & $\mathrm{R} \$ 2,44$ & $7,81 \%$ & $8,75 \%$ \\
\hline Março/2014 & $\mathrm{R} \$ 2,28$ & $\mathrm{R} \$ 2,41$ & $8,09 \%$ & $8,64 \%$ \\
\hline Abril/2014 & $R \$ 2,24$ & $\mathrm{R} \$ 2,29$ & $7,95 \%$ & $8,21 \%$ \\
\hline Maio/2014 & $\mathrm{R} \$ 2,45$ & $\mathrm{R} \$ 2,21$ & $8,70 \%$ & $7,93 \%$ \\
\hline Junho/2014 & $\mathrm{R} \$ 2,26$ & $\mathrm{R} \$ 2,09$ & $8,02 \%$ & $7,50 \%$ \\
\hline Julho/2014 & $\mathrm{R} \$ 2,48$ & $\mathrm{R} \$ 2,31$ & $8,80 \%$ & $8,29 \%$ \\
\hline Agosto/2014 & $\mathrm{R} \$ 2,44$ & $\mathrm{R} \$ 2,44$ & $8,66 \%$ & $8,75 \%$ \\
\hline Setembro2014 & $\mathrm{R} \$ 2,56$ & $\mathrm{R} \$ 2,42$ & $9,09 \%$ & $8,68 \%$ \\
\hline Outubro/2014 & $\mathrm{R} \$ 2,14$ & $\mathrm{R} \$ 2,20$ & $7,60 \%$ & $7,89 \%$ \\
\hline Novembro/2014 & $\mathrm{R} \$ 2,28$ & $\mathrm{R} \$ 2,25$ & $8,09 \%$ & $8,07 \%$ \\
\hline Dezembro/2014 & $\mathrm{R} \$ 2,69$ & $\mathrm{R} \$ 2,51$ & $9,55 \%$ & $9 \%$ \\
\hline Total dos CD & $\mathrm{R} \$ 28,17$ & $\mathrm{R} \$ 27,88$ & $100 \%$ & $100 \%$ \\
\hline
\end{tabular}

Fonte: Elaboração própria a partir da coleta de dados (2015)

A tabela 6 do custo total de 2014 da água mineral é o somatório das tabelas 2 e 4 , em que trata da soma dos custos diretos e indiretos do período de 2014. Em que mostra que nos mês de dezembro teve o custo a maior de $R \$ 2,69$, representando $9,5 \%$ do total de $\mathrm{R} \$ 28,17$. E o menor custo foi no mês de outubro com $R \$ 2,14$, e $7,60 \%$ do total. $A$ média por pacote de $R \$ 2,35$ e desvio padrão dela igual a $R \$ 0,17$.

E na produção de refrigerante, demonstrou no mês de dezembro o maior custo de $\mathrm{R} \$ 2,51$, $9 \%$ do valor total de $R \$ 27,88$. E no mês de junho, o menor custo de $R \$ 2,09$, resultando $7,50 \%$ dos custos totais. A média é $R \$ 2,32$ e o desvio padrão é igual a $\mathrm{R} \$ 0,12$.

\subsection{CUSTOS OCULTOS DOS PRODUTOS}

A empresa mostrou-se prestativa dando-lhe total acesso para que a pesquisa fosse realizada, disponibilizando relatórios, bem como dando entrevista pela parte da gerência filial, demonstrando assim interesse em conhecer e quantificar seus possíveis custos ocultos.

Em entrevista com o gerente filial da empresa, o mesmo afirmou que está ciente dos custos ocultos existentes na fábrica e procura a cada ano reduzi-los, da seguinte forma: não ultrapassando a meta projetada para o referido ano, como também sempre reduzir a meta para o ano posterior em relação à do ano anterior e assim sucessivamente, através de planejamentos anuais em reunião conjunta com os administradores da empresa.

Ao falar dos tipos de custos ocultos o mesmo destacou a perda de matéria prima, perdas de produto acabado, produtividade baixa, o tempo ocioso devido à parada/falhas das máquinas, o estoque de produto acabado, o absenteísmo, e a hora extra gerada desses absenteísmos, atestados médicos que ocasiona a uma enorme rotatividade de pessoal.

Em relação à perda da matéria prima o mesmo afirma está ciente por causa da qualificação da mão de obra, matéria prima defeituosa. Falando de perda de produto acabado se deriva da previsão de vendas erradas, PEPS (FIFO) não realizado, como também o erro da não qualidade.

Ao se referir da ociosidade devido às paradas ou falhas das máquinas o gerente relata que o setor de manutenção realiza as manutenções preventivas e corretivas, mas algumas vezes é detectada a falta de peças adequadas. Tais peças demoram a chegar à empresa devido a distância do local de onde foi solicitado, pois as máquinas têm tecnologias avançadas, assim sua reposição de peças é bastante rara. 
Em relação ao estoque de produto acabado o responsável do setor da empresa afirma que $98 \%$ dos problemas está relacionado a parte de logística, na maioria das vezes a demanda é considerável e não tem transporte suficiente para atender as necessidades das outras filiais e dos clientes.

Outro item é o custo existente da má gestão, os supervisores imediatos dos colaboradores, que alguns têm problema pessoal com o colaborador e não ser profissional, para o atingimento de alguma meta, trata o funcionário de maneira agressiva verbalmente.

O custo do acidente de trabalho é ocasionado pela falta de atenção dos colaboradores para desempenhar a função, descumprimento dos procedimentos corretos de operar a máquina, autoconfiança pela parte dos mesmos ou por irresponsabilidade.

O absenteísmo e atestados médicos e a rotatividade do pessoal ocasionado pela rescisão sem justa causa, pela nova diretriz da empresa, não pode mais existir, deixando apenas a possibilidade do pedido de demissão para os colaboradores, pois os mesmos faziam por onde serem demitidos, faltando sem justificativa e colocando atestados, algumas vezes até falsos, onde foi detectado e o colaborador foi demitido por justa causa. Entretanto, havia outra insatisfação clara para todos os gerentes da empresa, inclusive para o gerente filial, acerca de benefícios e salários, onde os funcionários não eram satisfeitos. Ocorriam comentários de que em outras empresas pagavam melhores salários e benefícios. Em decorrência dessas faltas sem justificativas e atestados surgia a demanda de serviço e a necessidade de hora extra para os outros colaboradores, onde gerava uma insatisfação geral, porque tinham alguns que se recusavam a fazer hora extra e eram praticamente obrigados a fazer.

A solução para este caso é que foram detectados os colaboradores que estavam gerando essa insatisfação e foram todos demitidos e até o momento da entrevista tinha diminuído consideravelmente o número de faltas e atestados. Já que a empresa, na alternativa de diminuir essas faltas não justificadas em acordo com o sindicato iniciou a entrega de ticket alimentação por assiduidade.

\subsubsection{CÁLCULO DOS CUSTOS OCULTOS}

Esta análise foi feita acerca de quatro elementos: ociosidade, estoques de produto acabado, absenteísmo e atestado médico, devido ao levantamento e possibilidade de mensuração desses custos ocultos, para cada produto, fazendo-se um comparativo entre os dois produtos e evidenciando o produto com o maior custo oculto.

\section{Ociosidade}

Partindo-se da metodologia aplicada por Pedrosa Neto (2009) o cálculo a ociosidade demonstrado foi obtido utilizando como variável o tempo parado em horas das máquinas para cada dia, com fatores referentes a lapsos de falhas, os quais se referem à interrupção do processo produtivo por motivos não programados ou programados, conforme mostra a tabela 7 . Tornase relevante destacar que o tempo parado diário forma um percentual que é denominado ineficiência industrial. Assim, a empresa pesquisada teve em seu processo produtivo ociosidade de $40 \% \quad(0,4)$, valor fornecido pela gerência filial e gerência de produção. 
Tabela 7 Custos Ocultos dos produtos com ociosidade 2013 e 2014

\begin{tabular}{|c|c|c|c|c|}
\hline \multirow{2}{*}{ DADOS } & \multicolumn{2}{|c|}{ Custos Ocultos da Água com Ociosidade } & \multicolumn{2}{|c|}{$\begin{array}{l}\text { Custos Ocultos do Refrigerante com } \\
\text { Ociosidade }\end{array}$} \\
\hline & 2013 & 2014 & 2013 & 2014 \\
\hline $\begin{array}{l}\text { Volume médio da } \\
\text { produção diária } \\
\text { (VMPd) }\end{array}$ & $R \$ 13.067,09$ & $R \$ 17.013,65$ & $\mathrm{R} \$ 7.174,07$ & $\mathrm{R} \$ 9.364,07$ \\
\hline $\begin{array}{l}\text { Custo médio de } \\
\text { produção unitário } \\
\text { (CMPun) }\end{array}$ & $\mathrm{R} \$ 2,14$ & $R \$ 1,69$ & $R \$ 2,30$ & $R \$ 1,85$ \\
\hline $\begin{array}{l}\text { Tempo médio } \\
\text { trabalhado no ano } \\
\text { (TMTa) }\end{array}$ & 198,83 & 169,01 & 190,2835 & 163,64381 \\
\hline $\begin{array}{c}\text { Ineficiência } \\
\text { Industrial (I.Ind.) }\end{array}$ & 0,4 & 0,4 & 0,4 & 0,4 \\
\hline Ociosidade & $\mathrm{R} \$ 2.224 .036,14$ & $\mathrm{R} \$ 1.943 .803,27$ & $\mathrm{R} \$ 1.255 .898,58$ & $\mathrm{R} \$ 1.133 .955,35$ \\
\hline & Ociosidade & Pd) $\times($ CMPun $) \times(T$ & $x($ (I.Ind.) & \\
\hline
\end{tabular}

Fonte: Elaboração própria a partir da coleta de dados (2015)

Percebe-se que os custos com ociosidade da produção da água são superiores aos do refrigerante e que no ano de 2014 tais custos foram reduzidos. Embora a análise de 2013 tenha contemplado apenas 9 meses, devido à falta de relatórios referentes aos meses de janeiro a março, como o cálculo é médio, deixando as grandezas de cada variável na mesma proporção, é possível esta análise comparativa entre os anos. b) Estoque de produto acabado

O cálculo do custo com estoque se refere ao fato de que ao estocar são implicados outros custos. Para o cálculo foi necessário o valor médio dos estoques de produto acabado, aplicado ao índice de 9,8\% para amortização, que conforme Freitas (2007, apud Pedrosa Neto, 2009, p.74) representa o valor imobilizado do estoque.

Tabela 8 Custos Ocultos de Estoque dos Produtos Acabados 2013 e 2014

\begin{tabular}{|c|c|c|c|c|}
\hline \multicolumn{5}{|c|}{ Custos Ocultos de Estoques de Produtos Acabados } \\
\hline \multirow{2}{*}{ DADOS } & \multicolumn{2}{|c|}{ Custos de Estoque da Água } & \multicolumn{2}{|c|}{ Custos Estoque do Refrigerante } \\
\hline & 2013 & 2014 & 2013 & 2014 \\
\hline $\begin{array}{l}\text { Vol. médio dos est. de } \\
\text { prod. acabado (VMEPA) }\end{array}$ & $\mathrm{R} \$ 10.333 .29$ & $\mathrm{R} \$ 12.568,58$ & $R \$ 20.334,96$ & $\mathrm{R} \$ 23.034,34$ \\
\hline $\begin{array}{l}\text { Índice para o valor de } \\
\text { amortização (Ind. Am.) }\end{array}$ & $9,8 \%$ & $9,8 \%$ & $9,8 \%$ & $9,8 \%$ \\
\hline $\begin{aligned} \text { Estoque }= & (\text { VMEPA }) \times(\text { Ind } . \\
& \text { Am. })\end{aligned}$ & $R \$ 1.012,66$ & $\mathrm{R} \$ 1.231,72$ & $\mathrm{R} \$ 1.992,83$ & $\mathrm{R} \$ 2.257,37$ \\
\hline
\end{tabular}

Fonte: Elaboração própria a partir da coleta de dados (2015)

De acordo com a Tabela 8 verifica-se que os custos dos estoques do refrigerante também representam valores maiores em relação à água, embora o custo do estoque da água oscilou mais que o com refrigerante aumentando 22\% de 2013 para 2014, enquanto que o de refrigerante oscilou em $13 \%$.

c) Cálculo do absenteísmo 
O cálculo do custo oculto com absenteísmo foi realizado através do valor do custo médio do dia trabalhado dos colaboradores das respectivas linhas de produção em relação ao número médio de faltas ocorridas durante o período de estudo.

Tabela 9 Custos Ocultos de Estoque dos Produtos Acabados 2013 e 2014

\begin{tabular}{|c|c|c|c|c|}
\hline \multicolumn{2}{c}{ Custos Ocultos com Absenteísmo } \\
\multicolumn{2}{c}{ Custos com Absenteísmo da Água } & $\begin{array}{c}\text { Custos com Absenteísmo do } \\
\text { Refrigerante }\end{array}$ \\
\hline $\begin{array}{c}\text { VIr. do custo médio diário } \\
\text { do trabalhador (VCMDT) }\end{array}$ & $\mathrm{R} \$ 95.256,00$ & $\mathrm{R} \$ 99.360,00$ & $\mathrm{R} \$ 132.300,00$ & $\mathrm{R} \$ 138.000$ \\
\hline $\begin{array}{c}\text { Número médio de faltas } \\
\text { não justificadas (NMFNJ) }\end{array}$ & 4,03 & 6,69 & 4,53 & 5,59 \\
\hline $\begin{array}{c}\text { Faltas = (VCMDT) } \\
\text { (NMFNJ) }\end{array}$ & $\mathrm{R} \$ 383.881,68$ & $\mathrm{R} \$ 664.718,40$ & $\mathrm{R} \$ 599.310,00$ & $\mathrm{R} \$ 771.420$ \\
\hline
\end{tabular}

Fonte: Elaboração própria a partir da coleta de dados (2015)

A Tabela 9 evidencia que os custos com absenteísmo da água apesar de terem sido inferiores em 2013, apresentou um crescimento de $73 \%$ no ano de 2014 , tornando-se maiores que os mesmos custos com refrigerante o qual oscilou $29 \%$ durante o período analisado. d) Cálculo do Atestado Médico

O cálculo deste item é igual ao do item anterior sendo a única diferença que se utiliza apenas as faltas atestadas por motivos médicos e não outros como doação de sangue.

Tabela 10 Custos Ocultos do Atestado Médico 2013 e 2014

\begin{tabular}{|c|c|c|c|c|}
\hline \multicolumn{5}{|c|}{ Custos Ocultos com Atestado Médico } \\
\hline \multirow[t]{2}{*}{ DADOS } & \multicolumn{2}{|c|}{ Custos Atestado Médico da Água } & \multicolumn{2}{|c|}{$\begin{array}{c}\text { Custos Atestado Médico do } \\
\text { Refrigerante }\end{array}$} \\
\hline & 2013 & 2014 & 2013 & 2014 \\
\hline $\begin{array}{c}\text { Valor do custo médio } \\
\text { diário do trabalhador } \\
\text { (VCMDT) }\end{array}$ & $\mathrm{R} \$ 95.256,00$ & $\mathrm{R} \$ 99.360,00$ & $\mathrm{R} \$ 132.300,00$ & $R \$ 138.000$ \\
\hline $\begin{array}{l}\text { Tempo médio de } \\
\text { afastamento em dia } \\
\text { trabalhado (TMADT) }\end{array}$ & 24,59 & 28,02 & 22,70 & 30,49 \\
\hline $\begin{array}{c}\text { Atestado Médico = } \\
(\text { VCMDT }) \times(\text { TMADT })\end{array}$ & $R \$ 2.342 .345$ & $\mathrm{R} \$ 2.784 .067,20$ & $R \$ 3.003 .210$ & $\mathrm{R} \$ 4.207 .620$ \\
\hline
\end{tabular}

A Tabela 10 mostra que os custos com atestado médico foram superiores com os colaboradores das linhas de produção do refrigerante, tendo um aumento considerável de $40 \%$ de 2013 para 2014, entretanto os colaboradores da produção da água variaram de 2013 para 2014 em 19\%.

\subsubsection{CUSTOS OCULTOS ANUAIS}

Para uma análise da representatividade total dos custos ocultos calculados neste trabalho é apresentada na Tabela 11 a soma dos custos com ociosidade, estoque de produtos acabados, absenteísmo e atestado médico. 
Tabela 11 Custos ocultos anuais dos produtos

\begin{tabular}{|c|c|c|c|c|}
\hline \multirow[b]{2}{*}{ Custos ocultos } & \multicolumn{2}{|c|}{ Produtos/Período de 2013} & \multicolumn{2}{|c|}{ Produtos/Período de 2014} \\
\hline & $\begin{array}{c}\text { Água Mineral S/G } \\
500 \mathrm{ml}\end{array}$ & $\begin{array}{l}\text { Refrigerante } \\
250 \mathrm{ml}\end{array}$ & $\begin{array}{c}\text { Água Mineral S/G } \\
500 \mathrm{ml}\end{array}$ & Refrigerante $250 \mathrm{ml}$ \\
\hline Ociosidade & $R \$ 2.224 .036,14$ & $R \$ 1.255 .898,58$ & $R \$ 1.943 .803,27$ & $R \$ 1.133 .955,35$ \\
\hline $\begin{array}{c}\text { Estoque de Produtos } \\
\text { Acabados }\end{array}$ & $R \$ 1.012,66$ & $\mathrm{R} \$ 1.992,83$ & $\mathrm{R} \$ 1.231,72$ & $\mathrm{R} \$ 2.257,37$ \\
\hline Absenteísmo & $\mathrm{R} \$ 383.881,68$ & $\mathrm{R} \$ 599.310,00$ & $\mathrm{R} \$ 664.718,40$ & $\mathrm{R} \$ 771.420$ \\
\hline Atestado Médico & $\mathrm{R} \$ 2.342 .345$ & $\mathrm{R} \$ 3.003 .210$ & $\mathrm{R} \$ 2.784 .067,20$ & $\mathrm{R} \$ 4.207 .620$ \\
\hline TOTAL & $\mathrm{R} \$ 4.951 .275,48$ & $\mathrm{R} \$ 4.860 .411,41$ & $R \$ 5.393 .820,59$ & $\mathrm{R} \$ 6.115 .252,72$ \\
\hline
\end{tabular}

Fonte: Elaboração própria a partir da coleta de dados (2015)

Em suma, os custos ocultos totais analisados neste estudo mostraram que os custos da produção de refrigerante sobressaíram em relação a produção da água. De 2013 para 2014 os custos da água oscilaram em 9\% e do refrigerante aumentou em 26\%, o que resultou em uma situação de custos ocultos com refrigerante maior que com água em 2014, situação diferente da apresentada em 2013. Neste sentido, em 2013 os custos ocultos calculados nesta pesquisa com o refrigerante foram $2 \%$ inferiores aos com a água, enquanto que em 2014 os mesmos foram $13 \%$ superiores.

Percebe-se ainda, através da Tabela 11, que o refrigerante apresentou maiores valores em todas as variáveis calculadas, com exceção apenas do custo da ociosidade, que com a água, o somatório dos anos de 2013 e 2014 evidenciou que o mesmo foi de $43 \%$ maior que o mesmo custo com o refrigerante.

\section{CONSIDERAÇÕES FINAIS}

A presente pesquisa teve como objetivo identificar os custos ocultos ocorridos no processo de fabricação de produtos de uma indústria de bebidas localizada na Paraíba. Para o alcance do mesmo foram calculados os custos ocultos com Ociosidade, Estoque de Produtos Prontos, Absenteísmo e Atestado Médico de dois produtos integrantes do portfólio da empresa estudada, água mineral $500 \mathrm{ml}$ e refrigerante guaraná $250 \mathrm{ml}$, durante o período de abril de 2013 a dezembro de 2014 sendo utilizados os relatórios gerenciais e entrevista pela parte da gerência geral da empresa.

Vários custos ocultos foram identificados e todos de ciência por parte da empresa, mas foram mensurados alguns, que até então eram desconhecidos monetariamente pela parte administrativa da empresa. Como explanado no item custos ocultos, foi verificado que na maioria das vezes eles existem pela deficiência dos próprios setores da empresa. Como o caso da ociosidade das máquinas, pela não realização de maneira eficiente da manutenção preventiva das máquinas, porque se fosse detectado em tempo hábil a necessidade da reposição das peças, não ocorreria a parada das máquinas. Já em relação ao absenteísmo os próprios colaboradores expõem a sua insatisfação causando uma desmotivação devido a não ter benefícios e possuir salários menores em relação a outras indústrias do ramo.

Com relação à má gestão dos supervisores a empresa poderia oferecer cursos, treinamento de liderança comportamental para sanar essas pendências, como também se houvesse por tarte desses supervisores um maior empenho e exigência para assim evitar os acidentes de trabalho. Os resultados demonstraram também que os custos ocultos calculados nesta pesquisa durante o período estudado totalizaram em $\mathrm{R} \$ 21.320 .760,20$, o que representa um valor relevante e que não é efetivamente controlado pela empresa estudada pelo fato de a mesma não o mensurar, revelando a importância da mensuração dos referidos custos.

O estudo teve como principal limitação à falta de dados disponíveis, pela mudança de sistema operacional da empresa. O sistema não atende a todas as necessidades, como fornecer relatórios detalhados por linha de produção específica. Para futuras pesquisas, sugere-se realizar novas pesquisas na mesma temática, podendo ser em outro segmento da economia industrial e verificar a lucratividade 
da empresa com e sem os custos ocultos, de maneira a melhorar e garantir a continuidade das empresas no âmbito industrial.

[10]. FEMENICK, Tomislav R. A Problemática e a solução para os "custos invisíveis" e "custos ocultos". Revista da FARN, Natal, v.4,n. 1/2, p. 4961, jul. 2004/dez. 2005

[11]. FREITAS, João Batista de; SEVERIANO FILHO, Cosmo. Apreciação dos custos ocultos do processo sucroalcooleiro em uma usina de álcool na Paraíba. Revista Gestão Industrial. Universidade Tecnológica Federal do Paraná - UTFPR Campus Ponta Grossa - Paraná - Brasil ISSN 1808-0448 / v. 03, n. 01: p. 52-63, 2007.

[12]. GIL, A. C. Como elaborar projetos de pesquisa. 4 Edição. São Paulo: Atlas, 2002.

[13]. HERCULANO, Adriano Souto. Mensuração e avaliação dos custos ocultos no setor de manutenção industrial de uma mineração: impacto gerencial no ciclo de vida. Dissertação (Mestrado em Engenharia de Produção)-Universidade Federal da Paraíba, João Pessoa, 2009.

[14]. LEONE, George Sebastião Guerra; LEONE, Rodrigo José Guerra. Curso de Contabilidade de Custos. Ed. Atlas, $4^{\underline{a}}$ ed. São Paulo, 2010.

[15]. MARTINS, Eliseu. Contabilidade de custos. 10 ed. São Paulo: Atlas, 2010.

[16]. MEGLIORINI, Evandir. Custos. São Paulo: MAKRON Books, 2001.

[17]. PEDROSA NETO, Carlos. Uma contribuição na identificação dos custos ocultos na produção de uma indústria de cerâmica. Dissertação (Mestrado em Ciências Contábeis) Universidade de Brasília, Universidade Federal da Paraíba e da Universidade Federal do Rio Grande do Norte, João Pessoa, 2009.

[18]. SAMPIERI, R. H.; COLLADO, C. F.; LUCIO, P. B. Metodologia de la investigación. 4 Edición. Iztapalapa: McGraw-Hill, 2006.

[19]. SEVERIANO FILHO, Cosmo; SILVA, Paulo César Pereira da. Ocorrência de custos ocultos em operações de serviços: insights sobre observação em uma sociedade de economia mista no Brasil. Revista Gest. Prod., São Carlos, v. 18, n. 3, p. 499508, 2011. 


\section{Eapítulo 4}

\section{GESTÃO DE CUSTOS INTERORGANIZACIONAIS: ESTUDO SOBRE OS FATORES INIBIDORES}

\section{Rafael Araújo Sousa Farias}

Resumo: A gestão estratégica de custos nas cadeias de suprimento não é um conceito novo. As ações coordenadas entre empresas da mesma cadeia com o intuito de reduzir custos e o preço ao consumidor final apresentam oportunidades de melhoria de resultados. Gestão de Custos Interorganizacionais (GCl) é uma abordagem estruturada com visão ampla, além das fronteiras da organização, que visa a redução de custos em âmbito interno e externo. De fato, a gestão de custos é uma questão complexa, que perpassa por todas as áreas da organização, podendo apresentar uma série de dificuldades para ser implantada e continuada. Desse modo, este trabalho tem o objetivo geral de identificar na literatura os fatores e situações que inibem a aplicabilidade da abordagem da Gestão de Custos Interorganizacionais. Para atingir os objetivos, foram analisadas 35 pesquisas acadêmicas disponibilizadas pela literatura, que demonstraram as dificuldades enfrentadas pelas empresas para gerenciar os custos de maneira cooperada. A análise desses trabalhos permitiu observar as percepções de diferentes empresas, sendo possivel listar as dificuldades enfrentadas por elas, assim, este estudo possui objetivo exploratório e caráter qualitativo. Os fatores que inibem a $\mathrm{GCl}$ foram agrupados em: (i) Estratégia das empresas; (ii) integração entre as empresas; (iii) pessoas; (iv) processos intra e interorganizacionais; (v) treinamento e educação corporativa; (vi) conflitos entre empresas; e (vii) falta de confiança entre empresas.

Palavras-chave: Gestão de Custos Interorganizacionais. Fatores Inibidores. Cadeias de Suprimento. 


\section{INTRODUÇÃO}

A evolução dos mercados e a complexidade crescente nas cadeias de suprimento levaram ao surgimento de novas técnicas de gestão e novos sistemas de troca de informações entre as empresas, perpassando pelo ambiente interno e alcançando as relações interorganizacionais (KULMALA; PARANKO; UUSI-RAUVA, 2002). Wincent (2008) afirma que as redes interorganizacionais surgiram como uma alternativa para as necessidades das empresas, e que a inter-relação é tendência para o futuro. Para Drucker (1997), cabe às empresas se posicionarem e articular relações que as ajudem em suas atividades, de modo a enfrentar os desafios, como por exemplo, a globalização, como uma oportunidade.

As empresas podem obter vantagem competitiva por meio da Gestão de Custos Interorgaizacionais (GCl), cujo objetivo é encontrar soluções que apresentem custos mais baixos, quando comparados à soma dos custos das empresas agindo individualmente (KULMALA; PARANKO; UUSI-RAUVA, 2002). Cooper e Slagmulder (1999) explicam que Gestão de Custos Interorganizacionais é uma abordagem estruturada para a coordenação das atividades das empresas em uma rede de fornecimento, visando a redução de custos totais da rede.

Estudos acerca do relacionamento interorganizacional afirmam que esta abordagem é um instrumento para as empresas crescerem no mercado em que atuam, gerando benefícios para todos os envolvidos (BORIN; FARRIS, 1990; ELLRAM, 1994; ELLRAM; SIFERD, 1998; COOPER; SLAGMULDER, 1999; FERRIN; PLANK, 2002; LALONDE, 2003), entretanto, do ponto de vista empírico, há um número significativo de empresas que deixam de participar de processos cooperativos, sendo que muitas redes são incapazes de consolidar as suas estruturas e modelos de gestão (PEREIRA; ALVES; SILVA, 2010).

É possível observar, analisando a opinião dos autores citados, que a $\mathrm{GCl}$ se apresenta como uma oportunidade nesse cenário, mas que sua aplicação pode ser uma tarefa difícil. Observa-se ainda que, visto as vantagens proporcionadas, seria normal que a maioria das empresas a aplicasse, paradoxalmente, ocorre o oposto (KULMALA; PARANKO; UUSI-RAUVA, 2002).
Desse modo, há de se questionar, já que o inter-relacionamento pode proporcionar benefícios e competitividade ante o mercado, quais são as causas que levam as empresas a abandonar as parcerias e quais motivos e razões levam às dificuldades e, posteriormente, à retirada da relação.

Essa situação é vista como uma oportunidade de pesquisa, desse modo, questiona-se: quais são os fatores ou situações que inibem a aplicabilidade da abordagem da Gestão de Custos Interorganizacionais?

Para responder a questão de pesquisa, o presente estudo determinou o objetivo geral de identificar na literatura os fatores e situações que inibem a aplicabilidade da abordagem da Gestão de Custos Interorganizacionais.

Estudos que auxiliem as empresas implementar de forma bem-sucedida os programas interorganizacionais de custos podem gerar benefícios ao passo que aumentam o conhecimento dos processos da empresa e custos relacionados (STAPLETON; PATI; BEACH; JULMANICHOTI, 2004). De fato, o diagnóstico das razões pelas quais os relacionamentos interorganizacionais falham pode contribuir em todas as fases do relacionamento, ressaltando a importância na fase inicial, permitindo que se analise se sua empresa possui muitos fatores que inibem os relacionamentos com outras empresas da sua cadeia de suprimentos.

Pereira, Alves e Silva (2010) explicam que essa análise inicial pode auxiliar os gestores desde a criação do seu estatuto, formalização de contratos e seleção dos membros da cadeia (especialmente fornecedores), podendo inclusive impossibilitar a entrada de algum membro para evitar problemas posteriores, o que poderia causar certa turbulência para as partes. Para estes autores, descobrir as razões pelas quais as empresas deixam as redes pode significar uma melhoria no seu processo de gestão.

Bastl et al. (2010) explicam que os gerentes estão enfrentando novos desafios na busca de vantagem competitiva fora de suas organizações, entretanto, eles possuem pouca orientação sobre os potenciais desafios relacionados com a implementação das abordagens da Gestão de Custos Interorganizacionais. Os autores explicam que os gerentes encontram dificuldades em lidar com a complexidade dos problemas que 
impendem que as organizações obtenham êxito em suas ações cooperadas.

\section{FUNDAMENTAÇÃO TEÓRICA}

\subsection{ABORDAGENS TRADICIONAIS DA CONTABILIDADE PARA A GESTÃO INTERORGANIZACIONAL DE CUSTOS}

As funções que a contabilidade deve exercer para o contexto interorganizacional são diferentes daquelas realizadas para apenas uma empresa. Bastl et al. (2010) explicam que as práticas contábeis tradicionais muitas vezes não cumprem o papel de gerenciar as relações interorganizacionais. Seal et al. (1999) e Tomkins (2001) afirmam que a contabilidade voltada para os relacionamentos interorganizacionais deve gerar informações que auxiliem os gestores a tomar decisões nesse cenário. As informações agora geradas pela contabilidade devem abranger não apenas uma empresa, mas deve considerar os membros das cadeias das quais ela faz parte.

O Custo Padrão, por exemplo, pode ser reconhecido como uma prática contábil eficiente quando aplicado por uma empresa em seu ambiente interno. Entretanto, Gupta e Unasekaran (2004) são pontuais ao afirmar que o Custo Padrão não incentiva melhorias na cadeia de suprimentos.

\subsection{FORMAÇÃO DE REDES INTERORGANIZACIONAIS}

O que leva as empresas a formarem redes interorganizacionais? Amato Neto (2000) afirma que as empresas buscam vantagens competitivas, entre outras, a possibilidade de haver combinação de competências, utilização de know-how das outras empresas, divisão do ônus ao realizar pesquisas tecnológicas, divisão dos riscos e custos de explorar novas oportunidades, compartilhamento dos recursos e fortalecimento do poder de compra.

De fato, o interesse em formar alianças estratégicas deve vir acompanhado de preocupações iniciais acerca da proteção das empresas. Pereira, Alves e Silva (2010) afirmam que o processo de formação de redes interorganizacionais exige, na maioria dos casos, a aplicação de mecanismos que auxiliem na regulação do relacionamento entre as empresas.
Janowicz-Panjaitan e Noorderhaven (2009) explicam que esses mecanismos são destinados, entre outras finalidades, a punir o comportamento oportunista, e explicam que a rede deve possuir regras, código de ética e uma comissão que fiscalize o cumprimento das regras estipuladas aos participantes.

Abbade (2005) aponta que as empresas devem tomar algumas medidas para precaver-se de ações oportunistas, dentre as quais devem determinar qual será o papel de cada membro da cadeia, especificando seus direitos e obrigações, devem proteger seus recursos estratégicos que não podem ser violados ou descobertos e conhecer a história dos possíveis parceiros de cadeia.

\subsection{OS PROBLEMAS DO INTER- RELACIONAMENTO}

$\mathrm{Na}$ Teoria dos Custos de Transação, Williamson (1985) explica que em um cenário perfeito, o que seria irreal, onde não houvesse oportunismo entre os membros de uma cadeia e as informações estivessem disponíveis a todos e a todo o momento, a possibilidade de operações com falhas seria baixa. Desse modo, a teoria afirma que o receio de comportamento oportunista e a ausência, ou intempestividade, das informações para os membros da cadeia faz com que a rede necessite estabelecer fortes mecanismos de controle e tenha que aumentar a burocracia e complexidade das transações realizadas entre os seus membros. Williamson (1985) cita que a incerteza quanto aos benefícios e obrigações atribuídos a cada empresa da rede é considerada um fator que inibe o interesse das empresas em entrar em relações de cooperação.

De fato, a literatura afirma que as empresas podem obter muitos benefícios coordenando esforços e agindo colaborativamente com os membros da cadeia, e que são muitos os benefícios oferecidos que justificam a formação de redes interorganizacionais (COOPER; SLAGMULDER 1999). Entretanto, muitos problemas podem ocorrer durante este processo, o que pode dificultar ou impossibilitar a obtenção dos objetivos aspirados pelas empresas.

\section{ASPECTOS METODOLÓGICOS}

Inicialmente foi delimitado o campo de exploração, sendo as bases de dados selecionadas após as seguintes etapas: (i) 
foram selecionadas as bases que constavam no Portal de Periódicos Capes (501 bases); (ii) no campo "Áreas do Conhecimento" foi especificada a opção "Ciências Sociais Aplicadas", e escolhida a subárea "Administração de empresas - Administração Pública - Contabilidade", o que resultou em 73 Bases; (iii) foram selecionadas as bases que disponibilizavam "Textos Completos" (24 Bases); e (iv) foram selecionadas as bases que permitiam buscas em "Todos os campos do texto", e permitiam a utilização de pelo menos dois eixos com a utilização de expressões booleanas. O processo resultou em 13 bases: ANNUAL REVIEWS; CAMBRIDGE JOURNALS ONLINE; EMERALD INSIGHT; JSTOR; OECD LILIBRARY; SAGE JOURNALS ONLINE; APA PSYCARTICLES; WILEY ONLINE LIBRARY; PROQUEST; WEB OF SCIENCE; SCIENCEDIRECT; SCOPUS; e EBSCO.

Nas bases de dados selecionadas, foram realizadas buscas com termos em língua inglesa, utilizando 2 eixos. O Eixo 1 contém palavras com o significado semelhante a "inibidor", ou seja, aquelas palavras que se referem a ideia de "barreira", algo que fica no caminho, que atrapalha. O Eixo 2 contém termos relacionados a "gestão de custos interorganizacionais".

As buscas foram formuladas com a seguinte combinação de palavras-chave para os eixos: Eixo 1 - "inhibit" OR "barrier*" OR "problem*" OR "disturb" OR "difficult". Eixo 2 "interorganizational cost" OR "interorganizational cost" OR "interorganisational cost" OR "inter-organisational cost"

As buscas foram realizadas no mês de janeiro de 2015, selecionando a opção "todos os campos do texto", utilizando o booleano "AND" entre os eixos, o booleano "OR" entre os termos, e sem delimitação de período.

A busca foi realizada nas 13 bases selecionadas, entretanto, apenas em sete bases foi encontrado pelo menos um trabalho. As bases que disponibilizaram trabalhos foram: EMERALD INSIGHT; WILEY ONLINE LIBRARY; PROQUEST; WEB OF SCIENCE; SCIENCEDIRECT; SCOPUS; e EBSCO. A pesquisa gerou, ao todo, 418 resultados.

Com o intuito de garantir a relevância dos trabalhos encontrados, o conteúdo foi filtrado por meio dos seguintes passos: (i) buscou realizar o download dos 418 trabalhos advindos das buscas, entretanto, apenas 225 trabalhos estavam disponíveis integramente e gratuitamente; (ii) os 225 trabalhos foram importados para um software de gerenciamento bibliográfico, o Mendeley ${ }^{\circledR}$, onde ocorreu a exclusão de 134 trabalhos repetidos ou desalinhados, restando assim, 91 trabalhos; (iii) foi realizada a leitura dos títulos e resumos, realizando a exclusão daqueles trabalhos que não estavam alinhando com os critérios da busca, ou seja, para ser mantido no portfólio os trabalhos deveriam: a) abordar o tema de contabilidade gerencial no contexto interorganizacional; e b) colaborar para o debate acerca de fatores inibidores e barreiras à Gestão de Custos Interorganizacionais. Após a filtragem, foram selecionados 35 trabalhos para compor o portfólio bibliográfico a ser analisado.

Em seguida, foi realizada a leitura integral de todos os trabalhos. A leitura de cada trabalho permitiu identificar os fatores que atrapalharam/dificultaram a Gestão de Custos Interorganizacionais em cada ambiência, o que permitiu a criação de um relatório com todos os fatores identificados. Foram identificados 25 fatores inibidores às práticas da $\mathrm{GCl}$ e, com o intuito de facilitar o debate acerca dos fatores, eles foram agrupados em fatores inibidores relacionados: (i) estratégia das empresas; (ii) integração entre as empresas; (iii) pessoas; (iv) processos intra e interorganizacionais; $(v)$ treinamento e a educação corporativa; (vi) conflitos entre empresas; e (vii) falta de confiança entre empresas.

\section{APRESENTAÇÃO DOS RESULTADOS}

\subsection{ESTRATÉGIA DAS EMPRESAS}

Porter (1989) explica que "estratégia" pode ser vista como a construção de defesas contra as forças concorrentes, ou como a determinação de posições para que a empresa atinja seus objetivos. Conforme Rocha (1999), estratégia qualifica o que é absolutamente necessário ao alcance de um objetivo, sendo que o objetivo maior de uma organização é o cumprimento de sua missão, para garantir a continuidade do negócio.

A forma como as organizações determinam e executam suas estratégias influencia, decisivamente, em como as partes julgam o equilíbrio e a eficiência da cooperação e, influencia a motivação das organizações para continuar ou finalizar a cooperação ao longo do tempo (GUTH; SCHMITTBERGER; SCHWARZ, 1982). 
Quadro 1 - Fatores inibidores relacionados à estratégia das empresas

\begin{tabular}{|c|c|}
\hline Fatores inibidores & Autores \\
\hline $\begin{array}{c}\text { Diferenças entre os planejamentos estratégicos } \\
\text { das empresas }\end{array}$ & Hitt et al. (2000); Ojala e Hallikas (2007) \\
\hline $\begin{array}{l}\text { Falta de gerenciamento voltado para o longo } \\
\text { prazo }\end{array}$ & Ferrin e Plank (2002); Möller et al. (2011) \\
\hline $\begin{array}{l}\text { Desequilíbrio entre os ganhos de curto e longo } \\
\text { prazo }\end{array}$ & Pereira et al. (2010) \\
\hline Perda de foco no cliente & Lin et al. (2001); Himme (2012) \\
\hline
\end{tabular}

Fonte: Dados da pesquisa (2015)

Uma das barreiras ao sucesso das parcerias entre as empresas é a diferença entre as estratégias dos parceiros, ou seja, motivos diferentes que levaram as empresas a entrar nas alianças. A compreensão dos objetivos dos parceiros e a compatibilidade com estes, pode melhorar o desempenho das parcerias, de modo que as características das empresas e suas metas individuais tem um papel significativo na construção dos relacionamentos (OJALA; HALLIKAS, 2007; HITT; DANCIN; LEVITAS; ARREGLE; BORZA, 2000).

Ferrin e Plank (2002) explicam que o custo deve ser examinado a partir de uma perspectiva de longo prazo e deve incluir outros elementos além do preço inicial de compra, argumentam ainda. As empresas parceiras precisam sinalizar de forma credível as suas intenções para a continuidade das relações em longo prazo quando se pretende implantar a GCl (MÖLLER; WINDOLPH; ISBRUCH, 2011; FERRIN; PLANK, 2002).

$O$ fato de as parcerias serem voltadas para o longo prazo, não significa que a estratégia de auferir ganhos deva ser de longo prazo. Pereira, Alves e Silva (2010) explicam que o desequilíbrio entre ganhos de curto e longo prazo pode ser um fator inibidor da relação interorganizacional, sendo um ponto de tensão para muitos relacionamentos.
Lin et al. (2001) explicam que as empresas não podem perder o foco no cliente. Para os autores, as elas devem arquitetar suas relações em função dos clientes, bem como melhorar o potencial de lucro. No entanto, a administração pode tornar-se demasiadamente atenta às questões relacionadas aos custos, de tal forma que venha a perder o foco em seus clientes. Himme (2012) afirma que um plano de gestão estratégica de custos requer uma visão holística, de modo que mantenha o foco no cliente, já que, segundo o autor, o trabalho se torna inútil quando a visão orientada para o cliente se perde.

\subsection{INTEGRAÇÃO ENTRE AS EMPRESAS}

No processo de cooperação entre as empresas, novas características surgem, como por exemplo, o aumento da complexidade e a necessidade de trabalhar dentro e fora das fronteiras da organização. Desse modo a dinâmica do mercado exige que as empresas compartilhem e integrem suas informações rapidamente. É importante que as empresas possam se comunicar e analisar de maneira dinâmica os processos que ocorrem entre elas.

O Quadro 2 demonstra os fatores inibidores relacionados à integração entre as empresas. 
Quadro 2 - Fatores inibidores relacionados à integração entre as empresas

\begin{tabular}{|c|c|}
\hline Fatores inibidores & Autores \\
\hline $\begin{array}{l}\text { Dificuldades relacionadas à integração de } \\
\text { informações entre as empresas }\end{array}$ & $\begin{array}{c}\text { Ellram (2002); Ramos (2004); Mouritsen e Thrane } \\
\text { (2006) }\end{array}$ \\
\hline
\end{tabular}

Fonte: Dados da pesquisa (2015)

Um fator que inibe o sucesso do relacionamento cooperado é a ausência de equipes multifuncionais nas empresas. A gestão das compras (por parte dos compradores) e a gestão do fornecimento (por parte dos fornecedores) precisam de apoio específico de especialistas de gestão de custos, que são designados para apoiar estes processos (ELLRAM, 2002).

A administração das relações estreitas entre fornecedores e compradores requer atenção adicional sobre as questões da cadeia de suprimento e a inclusão de mais dados da organização e do ambiente externo. A relação entre as empresas parceiras dificilmente pode fluir sem a ajuda de certas tecnologias de gestão que, mesmo que imperfeitamente, ajudam os gestores a gerenciar as relações entre os parceiros (RAMOS, 2004; MOURITSEN; THRANE, 2006).

\subsection{PESSOAS}

A determinação das estratégias das empresas deve levar em consideração as características das pessoas envolvidas na mudança, do prazo em que se pretende implementar esta mudança, da profundidade da mudança e duração desejada para seus efeitos (LOPES; STADLER; KOVALESKI, 2003).

De fato, as pessoas podem não estar preparadas ou aptas para as mudanças que vão ocorrer quando as empresas implementam a Gestão de Custos Interorganizacionais.

O Quadro 3 demonstra os fatores inibidores relacionados às pessoas.

Quadro 3 - Fatores inibidores relacionados às pessoas

\begin{tabular}{|c|c|}
\hline $\begin{array}{c}\text { Fatores inibidores } \\
\text { Resistência à mudança por parte dos membros } \\
\text { das organizações }\end{array}$ & $\begin{array}{c}\text { Autores } \\
\text { Axelsson, et al. (2002); Ellram (1994); Ellram e } \\
\text { Siferd (1998) }\end{array}$ \\
\hline $\begin{array}{c}\text { Falta de apoio à gerência, por parte dos } \\
\text { membros das empresas }\end{array}$ & Ellram (2002); Seal et al. (2004); Himme (2012) \\
\hline
\end{tabular}

Fonte: Dados da pesquisa (2015)

Axelsson et al. (2002) explicam que a mudança no comportamento organizacional não se refere apenas à questão de desenhar sistemas de gestão, mas sim, ser um esforço sistêmico. Com o objetivo de alcançar as mudanças organizacionais necessárias para que as empresas possam desenvolver o interrelacionamento, elas devem observar o quanto as pessoas estão interessadas nas mudanças, e se isso pode ser uma barreira.

Ellram (1994) ressalta que a flexibilidade para a mudança é um fator importante para o sucesso da implementação de programas de gestão. Assim, a mudança cultural da organização pode ser um desafio duplo, dependendo do nível de resistência apresentada por seus funcionários e a complexidade da abordagem de gestão estratégica de custos. Elrram e Siferd (1998) ressaltam que, sempre que uma organização tenta uma mudança em suas operações, a natureza e extensão desta precisa ser claramente definida.

A cultura interna e estrutura organizacional da empresa devem ser caracterizadas pelo apoio da alta administração para a gestão de custos. Além de recursos destinados a apoiar a gestão de custos da cadeia, equipes multifuncionais devem ser incentivadas a identificar e implementar abordagens de gerenciamento de custos. Os responsáveis pela gestão de custos são prejudicados 
quando não recebem apoio por parte dos membros da empresa (SEAL; CULLEN; DUNLOP; BERRY; AHMED, 2004; ELLRAM, 2002).

Himme (2012) explica que não é suficiente a empresa ter apenas os gestores comprometidos com a redução de custos na organização. A empresa deve buscar desenvolver e incentivar seus funcionários de modo que todos adotem a filosofia de redução de custos. Himme (2012) explica que o desenvolvimento de uma cultura corporativa é um processo de longo prazo, e persistência é um pré-requisito.

\subsection{PROCESSOS \\ INTRA \\ INTERORGANIZACIONAIS}

Os processos a serem executados pelas empresas para agirem colaborativamente pode ser um fator determinante para 0 sucesso da $\mathrm{GCl}$. A literatura demonstra alguns fatores que podem inibir a Gestão de Custos Interorganizacionais no tocante aos processos.

O Quadro 4 demonstra os fatores inibidores relacionados aos processos intra e interorganizacionais.

Quadro 4 - Fatores inibidores relacionados aos processos intra e interorganizacionais

\begin{tabular}{|c|c|}
\hline Fatores inibidores & Autores \\
\hline Design do modelo da GCI mal elaborado & Waeytens e Bruggeman (1994) \\
\hline Sistemas de GCI muito complexos & Kaplan e Anderson (2004) \\
\hline Rigidez na GCl & Dubois (2003) \\
\hline Falta de revisões periódicas de desempenho & Gareth (2005) \\
\hline $\begin{array}{c}\text { Incapacidade de gerenciamento por parte da } \\
\text { organização dominante da cadeia }\end{array}$ & Caker (2008); Carr e Ng (1995); Dekker (2003) \\
\hline
\end{tabular}

Fonte: Dados da pesquisa (2015)

Waeytens e Bruggeman (1994) apontam que problemas no design dos modelos relacionados à gestão de custos podem impedir que as empresas consigam apurar seus custos corretamente e, então, tenham dificuldades em colaborar com os membros de sua cadeia. Um modelo complexo, com atividades mal formuladas, que não fornece o real custo das atividades da empresa é visto como uma barreira para a $\mathrm{GCl}$.

Kaplan e Anderson (2004) alertam que modelos de gestão de custos muito complexos podem inibir a sua aplicabilidade. Os autores explicam que os modelos implementados pelas empresas tendem a evoluir ao passo que elas aprendem sobre a variedade e a complexidade de seus processos, pedidos, fornecedores e clientes. Segundo Kaplan e Anderson (2004), com o intuito de aumentar a precisão e o detalhamento das informações, os modelos podem ficar demasiadamente complexos, o que pode ser uma barreira para 0 funcionamento da cadeia.

Segundo Dubois (2003) quando a gestão de custos está sujeita a interação entre comprador e fornecedor, não é possível predeterminar o que deve ser incluído no "custo total", dos produtos ou serviços, no início da relação. O autor explica que um custo total predefinido poderia limitar desnecessariamente as oportunidades de redução de custos.

Dubois (2003) explica que ao passo que a gestão conjunta dos custos acontece, ocorre o aprendizado do comportamento dos custos, podendo ocorrer, então, melhorias contínuas. Desse modo, a ideia de um custo total predefinido por um modelo pode ser problemática, devido à dinâmica e à evolução das necessidades de ambos os parceiros.

Gareth (2005) afirma que as alianças formadas por empresas que são demasiadamente rígidas ou demasiadamente flexíveis não podem alcançar o sucesso. Para o autor, o equilíbrio é a chave do sucesso, de modo que os parceiros devem desenvolver um relacionamento no qual consigam se moldar às mudanças que ocorram na ambiência na qual estão inseridos, sem perder a rigidez necessária para manter a estrutura conforme acordado entre as partes. 
Gareth (2005) explica que as relações entre as empresas devem passar por avaliações regulares, de modo a realizar ajustes necessários para que as empresas superem as dificuldades que aparecerão.

Caker (2008) ressalta que a capacidade da empresa dominante em gerenciar a cadeia é uma questão decisiva para o desenvolvimento das relações interorganizacionais, ponto de vista compartilhado por outros autores (CARR; NG, 1995; DEKKER, 2003).

\subsection{TREINAMENTO E A EDUCAÇÃO CORPORATIVA}

Bohlander, Snell e Sherman (2003), explicam que "treinamento" é o esforço desprendido pela empresa para estimular o aprendizado de seus empregados. O treinamento e a educação corporativa fazem parte de uma ação da organização de modo que possibilite o desenvolvimento de habilidades que podem tornar o indivíduo mais apto a desempenhar suas funções atuais ou futuras (BORGESANDRADE, 2002).

O Quadro 5 demonstra os fatores inibidores relacionados ao treinamento e educação corporativa.

Quadro 5 - fatores inibidores relacionados a treinamento e educação corporativa

\begin{tabular}{|c|c|}
\hline Fatores inibidores & Autores \\
\hline $\begin{array}{c}\text { Ausência de conhecimento especializado e } \\
\text { programas de educação voltados aos } \\
\text { funcionários }\end{array}$ & $\begin{array}{l}\text { LaLonde e Pohlen (1996); Ramos (2004); Kulmala et } \\
\text { al. (2002); Ellram (2002); Thomson e Gurowka (2005); } \\
\text { Himme (2012) }\end{array}$ \\
\hline Taxonomias inconsistentes & Thomson e Gurowka (2005) \\
\hline $\begin{array}{l}\text { Falta de compreensão de custos ao longo da } \\
\text { cadeia }\end{array}$ & Nicolini et al. (2000) \\
\hline $\begin{array}{c}\text { Ausência de percepção de valor gerado pela } \\
\text { relação }\end{array}$ & Cannon e Homburg (2001) \\
\hline
\end{tabular}

LaLonde e Pohlen (1996) explicam que o conhecimento especializado pode superar muitos problemas associados com as atividades de custeio através das fronteiras das empresas. Para os autores, o conhecimento especializado pode ajudar no processo de Gestão de Custos Interorganizacionais, identificando as atividades "não eficientes" realizadas por outras empresas.

Ramos (2004) explica que uma das barreiras à aplicação de abordagens de Gestão de Custos Interorganizacionais é a ausência de competência por parte dos gestores de custos das empresas. O autor afirma que as relações estreitas entre fornecedores e compradores exigem relatórios adicionais sobre os problemas das cadeias de suprimento e a necessidade de mais dados sobre a organização e o ambiente externo.

Kulmala et al. (2002) afirmam que as empresas devem avaliar se as relações com os fornecedores são benéficas para o seu negócio ou não. Desse modo, as empresas devem ser capazes de calcular a quantidade de redução de custo que as relações vão the oferecer, assim, precisa ter compreensão do comportamento dos custos de seus produtos.

A educação tem se revelado uma das ferramentas mais valiosas na melhoria do desempenho da cadeia de suprimentos e da gestão de custos. As empresas podem criar programas de treinamento para que as pessoas envolvidas, como funcionários e fornecedores, aprendam os conceitos e princípios do inter-relacionamento (ELLRAM, 2002; THOMSON; GUROWKA, 2005).

Himme (2012) explica que para reduzir a resistência à mudança e preparar os funcionários para os programas de redução de custos, as empresas devem oferecer formação e educação para descrever as mudanças que podem ocorrer. Para o autor, é fundamental que os as instruções sejam dadas antes das mudanças surgirem.

Thomson e Gurowka (2005) ressaltam a importância da taxonomia dos termos 
utilizados na gestão de custos, já que terminologia e padrões inconsistentes e/ou inexistente pode ser uma barreira para o cotidiano das relações entre empresas. Os autores explicam que as empresas parceiras devem evitar ruídos na comunicação, e que a formação e educação são capacitores fundamentais para o sucesso de qualquer metodologia de custeio estratégico.

Nicolini et al. (2000) sugerem que uma das barreiras para a Gestão de Custos Interorganizacionais aparece pelo fato das empresas, muitas vezes, operarem sem uma compreensão completa dos custos ao longo da cadeia de suprimentos. De maneira geral, as empresas desenvolvem os projetos e posteriormente contatam os preços dos fornecedores, que não foram envolvidos no desenvolvimento do design do projeto.

As empresas analisam a continuação ou não das relações por meio da capacidade de tais relações gerarem valor demonstrável aos participantes (CANNON; HOMBURG, 2001). De fato, a redução do valor total do produto disponibilizado ao consumidor final é um indicador da eficiência dos relacionamentos interorganizacionais, mas não é o único. A falta de percepção de valor gerado pelas relações entre as empresas é apontada por Cannon e Homburg (2001) como um fator que pode comprometer a continuidade das relações em longo prazo.

A mensuração do valor gerado, ou do intangível gerado, pelas relações entre as empresas é uma tarefa difícil. Cannon e Homburg (2001) explicam que, para a criação de modelos que avaliem a geração de valor, os pesquisadores precisarão recorrer a uma variedade de perspectivas.

\subsection{CONFLITOS ENTRE EMPRESAS}

Cooper e Slagmulder (1999) explicam que os conflitos decorrentes das relações pode ser um empecilho para atingir metas estabelecidas entre os parceiros de rede. De fato, os conflitos e divergências são fatores que, segunda a literatura, inibem a prática da $\mathrm{GCl}$.

O Quadro 6 demonstra os fatores inibidores relacionados aos conflitos entre as empresas.

Quadro 6 - Fatores inibidores relacionados aos conflitos entre as empresas

\begin{tabular}{|c|c|}
\hline Fatores inibidores & Autores \\
\hline Partilha desigual dos benefícios & $\begin{array}{c}\text { Kulmala (2004); Kajüter e Kulmala (2005); } \\
\text { Chistopher (1998) }\end{array}$ \\
\hline Dificuldade em definir benefícios mútuos & $\begin{array}{c}\text { Dekker (2003); Kajüter, Kulmala (2005); Kulmala } \\
\text { et al. (2007) }\end{array}$ \\
\hline $\begin{array}{l}\text { Incapacidade de determinar os preços de } \\
\text { mercado }\end{array}$ & Nicolini et al. (2000) \\
\hline Conflitos constantes & Ariño e De La Torre (1998); Lui (2009) \\
\hline $\begin{array}{l}\text { Fornecedores reconhecem benefícios apenas } \\
\text { para os compradores }\end{array}$ & Agndal e Nilsson (2008) \\
\hline
\end{tabular}

Fonte: Dados da pesquisa (2015)

Kulmala (2004) explica que um dos obstáculos para as relações interorganizacionais é a divergência sobre a partilha dos benefícios. As empresas tentem a não querer cooperar e compartilhar informações de custos quando os benefícios não forem partilhados de maneira justa. Kajüter e Kulmala (2005) afirmam que não há uma regra geral sobre a forma como as economias geradas pelo inter-relacionamento devam ser partilhadas, o que se justifica pelo fato das situações variarem de caso a caso. Chistopher (1998) ressalta que isso não significa que os benefícios devam sempre ser divididos em partes iguais, mas que os envolvidos estejam de comum acordo e satisfeitos com os benefícios referentes a cada um.

Nicolini et al. (2000) ressaltam que a determinação dos preços de mercados dos produtos advindos das inter-relações pode ser difícil de ser executada. Segundo os autores, para alguns produtos, como por exemplo, as commodities, a determinação dos preços praticados ao consumidor final é mais fácil, já que os preços são estipulados 
pelo mercado, entretanto, as empresas podem ter dificuldades em determinar os preços de outros produtos.

Problemas e dificuldades são esperados nas redes interorganizacionais, de modo que os conflitos entre as partes é um componente normal para o desenvolvimento da rede. Entretanto, segundo Ariño e De La Torre (1998), conflitos constantes podem conduzir à terminação do relacionamento. Lui (2009) explica que os relacionamentos podem terminar após o desgaste causado por conflitos, mesmo que o relacionamento tenha se iniciado pautado na confiança, boa vontade das partes, recursos financeiro e compromisso.

Agndal e Nilsson (2008) afirmam que uma política de contabilidade de livros abertos não é necessariamente algo implementada pelo comprador, exclusivamente para benefício do comprador. Os autores explicam que é possível encontrar livros abertos em um ambiente de colaboração, onde são reconhecidos efeitos benéficos para ambas as partes. Desse modo, os fornecedores devem estar cientes de que o compartilhamento de informações, com o intuito de realizar uma gestão estratégica de custos pode trazer benefícios para toda a cadeia, caso isso não seja percebido pelos fornecedores, pode gerar falta de interesse em entrar em inter-relações, fato visto como uma barreira à Gestão de Custos Interorganizacionais.

\subsection{FALTA DE CONFIANÇA ENTRE EMPRESAS}

Cooper e Slagmulder (1999) explicam que a confiança é a base da $\mathrm{GCl}$, pois permite uma interação maior entre os agentes envolvidos na rede. Autores concordam que fatores podem favorecer ou inibir a formação de parcerias entre as empresas, entre eles, a confiança é um fator de destaque (COOPER; SLAGMULDER, 1999; KAJÜTER; KULMALA, 2005; SOUZA, 2008; SOUZA; ROCHA, 2009).

A falta de confiança pode desencadear uma série de fatores inibidores da prática da GCl. O Quadro 7 demonstra os fatores inibidores relacionados à falta de confiança entre as empresas.

Quadro 7 - Fatores inibidores relacionados à falta de confiança entre as empresas

\begin{tabular}{|c|c|}
\hline Fatores inibidores & Autores \\
\hline $\begin{array}{l}\text { Desinteresse, por parte das empresas parceiras, } \\
\text { em compartilhar informações }\end{array}$ & $\begin{array}{c}\text { Cooper e Slagmulder (2003); LaLonde e Pohlen } \\
\text { (1996); Kulmala (2002); Kulmala et al. (2002); } \\
\text { Kulmada (2004) }\end{array}$ \\
\hline $\begin{array}{l}\text { Desinteresse do fornecedor em usar o Open } \\
\text { Book Accounting }\end{array}$ & $\begin{array}{c}\text { Caker (2008); Windolph e Moeller (2012); Mcivor } \\
\text { (2001); Munday (1992) }\end{array}$ \\
\hline $\begin{array}{l}\text { Incerteza acerca do relacionamento com os } \\
\text { parceiros }\end{array}$ & Barney e Hesterly (1996) \\
\hline A falta de confiança entre os parceiros de $\mathrm{GCl}$ & Dekker (2004) \\
\hline
\end{tabular}

Fonte: Dados da pesquisa (2015)

Cooper e Slagmulder (2003) explicam que a cooperação entre as empresas deve buscar a diminuição do custo total e, assim, buscar aumentar os lucros das empresas. As redes formadas por compradores e fornecedores devem ser pautadas em confiança e em grande compartilhamento de informações. Entretanto, as empresas podem não estar dispostas a compartilhar informações, movidas principalmente por incertezas.

LaLonde e Pohlen (1996) explicam que a relutância em compartilhar informações de custos pode ser um obstáculo significativo para a determinação dos custos da cadeia de suprimentos. Como resultado, as empresas podem continuar a se comportar de forma independente, e assim, inadvertidamente, aumentar os custos de toda a cadeia de suprimento.

O compartilhamento de informações deve ser bidirecional e a falta de interesse em compartilhar informações por um dos membros da cadeia pode ser uma barreira para a relação inerorganizacional (KULMALA, 2002).

Windolph e Möeller (2012) explicam que pode haver desinteresse por parte dos 
fornecedores em compartilhar informações com os membros da cadeia. Segundo os autores, os fornecedores podem recusar a ideia de utilização da contabilidade de livro aberto devido ao receio de que os compradores utilizem os dados para aumentar a pressão sobre as suas margens de lucro.

Barney e Hesterly (1996) afirmam que quanto maior as incertezas nos acordos e parcerias entre as empresas, mais mecanismos de controle, como por exemplo, a utilização de contratos, será necessária, o que aumenta a complexidade das relações. Os autores explicam que as empresas podem adorar medidas de governança e estabelecer estruturas hierárquicas com o intuito de dirimir possíveis desentendimentos.

Dekker (2004) aponta que os mecanismos de controle ajudam na diminuição das incertezas e riscos, de modo que melhoram a confiança entre as empresas. Por fim, o autor afirma que as empresas devem buscar formas de garantir a estabilidade e continuidade da aliança no futuro, de modo a evitar que a falta de confiança entre as empresas seja uma barreira para o gerenciamento estratégico de custos.

\section{CONCLUSÕES E RECOMENDAÇÕES}

Agir colaborativamente com os membros da cadeia de suprimento, com o intuito de reduzir os custos totais do produto, pode gerar significativas vantagens perante as cadeias concorrentes. De fato, a rede de relacionamentos da empresa pode exercer um papel fundamental em sua sobrevivência e desenvolvimento.

As vantagens em formar parcerias entre as empresas são muitas, entretanto, são inúmeras as dificuldades e fatores que dificultam e inibem as relações que objetivam reduzir custos na cadeia. Nicolini et al. (2000) e Norek e Pohlen (2001) explicam que as abordagens de Gestão de Custos Interorganizacionais, para serem bemsucedidas, depende do desenvolvimento interno das empresas, como por exemplo, o conhecimento e compreensão dos custos, o conhecimento da cultura organizacional e a educação e formação dos funcionários. Para os autores, primeiro as empresas devem superar as barreiras internas para posteriormente dispensar esforços para obter vantagens da gestão externas de custos.

Ao entrar em parcerias, as empresas possuem, como expectativas, o desenvolvimento e fortalecimento diante do mercado. Entretanto, quando as parcerias não obtêm êxito, por vezes devido à falta de preparo dos gestores, pode gerar decepção entre as empresas envolvidas. Pereira, Alves e Silva (2010) explicam que o processo de remoção ou exclusão de uma rede corporativa pode gerar desconforto entre as partes, entre outros motivos, devido ao cancelamento de contratos que possam ter sido assinados no início das parcerias.

Quanto aos fatores inibidores identificados, observa-se que a Gestão de Custos Interorganizacionais é um fenômeno interdisciplinar que envolve pessoas, cultura da empresa, tecnologia e processos. Argumenta-se, baseado nos achados, que a aplicação de práticas de Gestão de Custos Interorganizacionais não pode ser visto como uma abordagem técnica, apenas pautada em tecnologia e programas de gestão.

Como limitação de pesquisa, aponta-se que o fato da utilização de trabalhos de diferentes fontes e em diferentes contextos tenha permitido a identificação de fatores demasiadamente genéricos e abrangentes, sem ser específicos de determinado ramo ou setor econômico.

Por fim, como sugestão para trabalhos futuros: a) analisar se o foco estratégico das empresas interfere na decisão de entrar em alianças estratégicas; e b) conduzir pesquisas, com enfoque interdisciplinar, que busquem sanar os fatores inibidores quando surgirem no relacionamento entre as empresas. De fato, o estudo relacionado à Gestão de Custo Interorganicionais e os desafios encontrados em sua abordagem apresentam uma grande oportunidade para pesquisas futuras que visem auxiliar os gestores a lidar com a complexa tarefa de gerenciar custos externos às empresas. 


\section{REFERÊNCIAS}

[1]. AGNDAL, Henrik; NILSSON, Ulf. Supply chain decision-making supported by an open books policy. International Journal of Production Economics, v. 116, n. 1, p. 154-167, 2008.

[2]. AMATO NETO, J. Redes de cooperação produtiva e clusters regionais: oportunidades para as pequenas e médias empresas. São Paulo: Atlas, 2000.

[3]. ARIÑO, Africa; DE LA TORRE, José. Learning from failure: Towards an evolutionary model of collaborative ventures. Organization Science, v. 9, n. 3, p. 306-325, 1998.

[4]. AXELSSON, Björn; LAAGE-HELLMAN, Jens; NILSSON, Ulf. Modern management accounting for modern purchasing. European Journal of Purchasing \& Supply Chain Management, v. 8, n. 1, p. 53-62, 2002.

[5]. BARNEY, Jay B.; HESTERLY, William. Organizational economics: understanding the relationship between organizations and economic analysis. London: Sage, 1996.

[6]. BORGES-ANDRADE, Jairo Eduardo. Desenvolvimento de medidas em avaliação de treinamento. Estudos de Psicologia, v. 7, n. 1, p. 31-43, 2002.

[7]. BORIN, Norm; FARRIS, Paul. An Empirical Comparison of Direct Product Profit and Existing Measures of SKU Productivity. Journal of Retailing, v. 66, n. 3, p. 297- 314, 1990.

[8]. BURRELL, Gibson; MORGAN Gareth. Sociological Paradigms and Organizational Analysis. 1. ed. London: Heinemann Educational Books, 1979.

[9]. CAKER, Mikael. Intertwined coordination mechanisms in interorganisational relationships with dominated suppliers. Management Accounting Research, v. 19, n. 3, p. 231- 251, 2008.

[10]. CANNON, Joseph. P.; HOMBURG, Chistian. Buyer-supplier relationships and customer firm costs. Journal of Marketing, v. 65, n. 1, p. 2943, 2001

[11]. CARR, C.; NG, J. Total Cost Control: Nissan and its U.K. Supplier Partnerships. Management Accounting Research, v. 6, n. 4, p. 347-365, 1995

[12]. CARVALHO, Maria Cecília M. (Org.) Construindo o saber: técnicas de metodologia científica. São Paulo: Papirus, 1988.

[13]. CHRISTOPHER, Martin. Logistics and Supply Chain Management: Strategies for Reducing Cost and Improving Service. London: Pitman Publishing, 1998.

[14]. CHURCHILL, Gilbert A. Marketing research: methodological foundations. Chicago: The Dryden Press, 1987.
[15]. COOPER, Robin; SLAGMULDER, Regine. Cost management beyond the boundaries of the firm, Management Accounting, v. 79, n. 9, p. 18-20, 1998.

[16]. COOPER, Robin; SLAGMULDER, Regine. Interorganizational costing - Part 1. Cost Management, v. 17, n. 5, p. 14-21, 2003.

[17]. COOPER, Robin; SLAGMULDER, Regine. Supply chain development for the lean enterprise: interorganizational cost management. New Jersey: The IMA Foundation for Applied Research, 1999.

[18]. DEKKER, Henri C. Control of interorganizational relationships: evidence on appropriation concerns and coordination requirements. Accounting, Organizations and Society, v. 29, n. 1, p. 27-49, 2004.

[19]. DEKKER, Henri C. Value chain analysis in interfirm relationships: A field study. Management Accounting Research, v. 14, n. 1, p. 1-23, 2003.

[20]. DRUCKER, Peter F. Toward the new organization. Executive Excellence, v. 14, n. 2, p. 78, 1997.

[21]. DUBOIS, Anna. Strategic cost management across boundaries of firms. Industrial Marketing Management, v. 32, n. 5, p. 365-374, 2003.

[22]. ELLRAM, Lisa M. A Taxonomy of Total Cost of Ownership Models. Journal of Business Logistics, v. 15, n. 1, p. 171-191, 1994.

[23]. ELLRAM, Lisa M. Strategic Cost Management in the Supply Chain: A Purchasing and Supply Management Perspective. Arizona: CAPS Research, 2002

[24]. ELLRAM, Lisa M.; SIFERD, Sue Parrott. Total cost of ownership: a key concept in strategic cost management decisions. Journal of Business Logistics, v. 19, n. 1, p. 55-84, 1998.

[25]. FERRIN, Bruce G.; PLANK, Richard E. Total Cost of Ownership Models: An Exploratory Study. Journal of Supply Chain Management, v. 38, n. 3, p. 18-29, 2002.

[26]. GARETH, Beazant; Perfecting partnerships. Professional Engineering, v. 17, n. 21, p. 34, 2005.

[27]. GIL, Antonio Carlos. Métodos e técnicas de pesquisa social. 5. ed. São Paulo: Atlas, 1999.

[28]. GODOY, Arilda Schmidt. Introdução à pesquisa qualitativa e suas possibilidades. Revista de Administração de Empresas, v. 35, n. 2, p. 5763, 1995.

[29]. HITT, Michael A.; DANCIN, M. Tina; LEVITAS, E.; ARREGLE, Jean-Luc; BORZA, Anca. Partner Selection in Emerging and developed market contexts: resource-based and 
organizational learning perspectives. Academy of Management Journal, v. 43, n. 3, p. 449-467, 2000.

[30]. KAJÜTER, Peter; KULMALA, Harri. Open book accounting in networks: Potencial achievements and reasons for failures. Management Accounting Reserarch, v. 16, n. 2, p. 179-204, 2005.

[31]. KULMALA, Harri. Developing cost management in cutomer-supplier relationships: three case studies. Journal of Purchasing \& Supply Management, v. 10, n. 2, p. 65-77, 2004.

[32]. KULMALA, Harri. Open-book accounting in networks. Finnish Journal of Business Economics, v. 52, n. 2, p. 157-177, 2002.

[33]. KULMALA, Harri; PARANKO, Jari; UUSIRAUVA, Erkki. The role of cost management in network relationships. International Journal of Production Economics, v. 79, n. 1, p. 33-43, 2002.

[34]. LALONDE, Bernard. Three Problems that Linger. Supply Chain Management Review, v. 7, n. 2, p. 7-8, 2003

[35]. LALONDE, Bernard; POHLEN, Tarrance. Issues in Supply Chain Costing. The International Journal of Logistics Management, v. 7, n. 1, p. 111,1996

[36]. LIN, Binshan; COLLINS, James; SU, Robert K. Supply chain costing: an activity-based perspective. International Journal of Physical Distribution \& Logistics Management, v. 31, n. 9/10, p. 702-713, 2001

[37]. LUI, Steven S. The Roles of Competence Trust, Formal Contract, and Time Horizon in Interorganizational Learning. Organization Studies, v. 30, n. 4 , p. 333-353, 2009.

[38]. MARTINS, Gilberto de A. Estudo de caso: uma estratégia de pesquisa. 2. ed. São Paulo: Atlas, 2008

[39]. MCIVOR, Ronan. Lean supply: the design and cost reduction dimensions. European Journal of Purchasing and Supply Management, v. 7, n. 4, p. 227-242, 2001.

[40]. MEDEIROS, João Bosco. Redação Científica: a prática de fichamentos, resumos e resenhas. São Paulo: Atlas, 2010

[41]. MOURITSEN, Jan; THRANE, Sof. Accounting, network complementarities and the development of inter- organisational relations. Accounting, Organizations and Society, v. 31, n. 3, p. 241-275, 2006.

[42]. MUNDAY, Max. Accounting cost data disclosure and buyer-supplier partnerships - A research note. Management Accounting Research, v. 3, n. 3, p. 245-250, 1992.

[43]. NASCIMENTO, Artur Roberto; JUNQUEIRA, Emanuel; MARTINS, Gilberto de Andrade. Pesquisa acadêmica em contabilidade gerencial no Brasil: análise e reflexões sobre teorias, metodologias e paradigmas. Revista de Administração Contemporânea, v. 14, n. 6, p. 11131133, 2010

[44]. OJALA, Mika; HALLIKAS, Jukka. Financial Decision Risks in Supplier Networks. Managing Supply Chain Risks, v. 8, n. 2, p. 80-91, 2007.

[45]. PEREIRA, Breno Augusto Diniz. Estruturação de relacionamentos horizontais em rede. 2005. 219 f. Tese (Doutorado em Administração) - Programa de Pós-Graduação em Administração da Universidade Federal do Rio Grande do Sul, Porto Alegre, 2005

[46]. PEREIRA, Breno Augusto Diniz; ALVES, Juliano Nunes; SILVA, Patricia Ennes. O lado obscuro dos relacionamentos interorganizacionais: por que as empresas saem dos processos cooperativos? Espacios, v. 31, n. 4, p. 25-27, 2010

[47]. POPPER, Karl. A Lógica da Pesquisa Científica. São Paulo: Cultrix, 1993.

[48]. PORTER, Michael. Estratégia Competitiva: Técnicas Para Análise da Indústria e da Concorrência. São Paulo: Campus, 1980.

[49]. RAMOS, Miguel Martinez. Interaction between management accounting and supply chain management. Supply Chain Management: An International Journal, v. 9, n. 2, p. 134-138, 2004

[50]. RICHARDSON, Roberto Jarry. Pesquisa social: métodos e técnicas. 3. ed. São Paulo: Atlas, 1999

[51]. SEAL, Willie; BERRY, Anthony; CULLEN, John. Disembedding the supply chain: institutionalized reflexivity and inter-firm accounting. Accounting, Organization and Society, v. 29, n. 1, p. 73-92, 2004

[52]. SOUZA, Bruno Carlos de.; ROCHA, Welington. Gestão de Custos Interorganizacionais: Ações coordenadas entre clientes e fornecedores para otimizar resultados. São Paulo: Atlas, 2009.

[53]. THOMSON, Jeff; GUROWKA, Jim. Sorting out the clutter. Strategic Finance, v. 87, n. 2, p. $27-$ 33, 2005.

[54]. TOMKINS, Cyril. Interdependencies, trust and information in relationships, alliances and networks. Accounting, Organizations and Society, v. 26, n. 2, p. 161-191, 2001

[55]. WAEYTENS, Dominique; BRUGGEMAN, Werner. Barriers to successful implementation of $A B C$ for continuous improvement: A case study. International Journal of Production Economics, v. 36, n. 2, p. 39-52, 1994.

[56]. WILLIAMSON, Oliver E. The economic institutions of capitalism. New York: Free Press, 1985.

[57]. WINDOLPH, Melanie; MOELLER, Klaus. Open-book accounting: Reason for failure of interfirm cooperation? Management Accounting Research, v. 23, n. 1, p. 47-60, 2012. 


\section{Bapítulo 5}

\section{A INFLUENCIA DO TAMANHO DO INVESTIMENTO REALIZADO NA INTENSIDADE DO EFEITO CUSTO AFUNDADO: QUANDO MAIS E MAIS.}

\section{Denizar Leal}

\section{Guilherme Freitas Campos}

Resumo: O efeito custo afundado caracteriza-se pela atenção indevida das pessoas a custos passados (THALER, 1980) e tem sido, por essa razão, estudado como um viés cognitivo em decisões envolvendo alocação de recursos ou a escolha de um caminho em detrimento de outro (ARKES; BLUMER, 1985). Este trabalho investigou se a intensidade do efeito custo afundado sofre influência do tamanho do investimento inicial realizado e foi motivado pelo fato de estudos anteriores apresentarem níveis diferentes de intensidade do efeito custo afundado em experimentos neles realizados. Em algumas situações tal diferença foi justificada pelo tipo de decisão a ser tomada (SILVA; SOUZA; DOMINGOS; 2008), após análise dos resultados de experimentos distintos e realizados com diferentes cenários. Para investigar a questão de pesquisa foi realizada uma pesquisa experimental, na modalidade entressujeitos, que contou com a participação de estudantes de graduação como sujeitos da pesquisa. A partir da manipulação do tamanho do investimento realizado os resultados demonstraram que os participantes submetidos ao cenário em que o valor do investimento realizado era maior, foram mais propensos a honrar os custos afundados e optar pelo caminho em que haviam investido mais recursos do que os demais sujeitos participantes do experimento (que tomaram decisões envolvendo investimentos de valor inferior ao primeiro grupo).

Palavras-chave: Efeito custo afundado. Julgamento e tomada de decisão. 


\section{INTRODUÇÃO}

As pessoas diariamente são levadas a tomar decisões, muitas delas envolvendo investimentos (gastos) efetuados de dinheiro, de tempo ou de esforço, às vezes um conjunto destes. No entanto, em muitos casos, elas são influenciadas pelo fato de já terem investido recursos e decidem honrar o investimento que fizeram. Ocorre que tais investimentos deveriam ser irrelevantes em decisões futuras, quando tais recursos não podem ser recuperados, independentemente da decisão a ser tomada (THALER, 1980).

A atenção indevida aos investimentos realizados (custos perdidos ou afundados), caracteriza um fenômeno denominado efeito custo afundado (ARKES; BLUMER, 1985).

De acordo com Kahneman e Tversky (1979), em muitas situações as pessoas agem de forma diversa do que prevê a teoria econômica. A atenção equivocada aos custos afundados é uma dessas situações e tem recebido grande atenção de pesquisadores nos últimos anos. Por exemplo Thaler (1980), Arkes e Blumer (1985), Prelec e Loewenstein (1998) e Gourville e Soman (1998) e diversos outros estudos têm se dedicado a investigar diversos aspectos do fenômeno atribuído à atenção indevida aos custos afundados, que é denominado the sunk cost effect (efeito custo afundado). Paralelamente, Soman (2001), Okada e Hoch (2004), De Voe e Pfeffer (2007), Leclerc, Shmitt e Dubé (1995), dentre outros, avaliam a questão de como as pessoas tomam decisões a partir do investimento do tempo.

No Brasil, embora tenham sido encontrados estudos que abordam a questão do efeito custo afundado, como os de Borba e Murcia (2005), Murcia e Borba (2006), Silva, Souza e Domingos (2008) e Rover, Werges, Tomazzia e Borba (2009), Leal (2014), Leal e Holz (2015) em alguns casos não ocorreu o efeito em experimentos realizados. Por exemplo, no estudo de Rover et. al. (2009), enquanto no segundo cenário por eles utilizado, que envolvia um custo afundado de $\mathrm{R} \$ 500,00$, os participantes fizeram suas escolhas influenciados pelo valor investido, no quarto cenário, cujo investimento foi de apenas $R \$ 10,00$, o efeito custo afundado não ocorreu. Também no estudo de Silva, Souza e Domingos (2008), o efeito não ocorreu na comparação entre investimentos de $R \$ 1.000,00$ e $R \$ 500,00$ (para passeios a dois eventos distintos).
Rover et. al. (2009) sugeriram que o efeito custo afundado pode não ter ocorrido em seu estudo devido à maior relevância de outros fatores que foram considerados no contexto apresentado e consideram que o efeito só ocorre quando não há outras informações mais salientes que possam influenciar as pessoas em suas escolhas. Já Silva, Souza e Domingos (2008) consideram que o efeito pode não ter ocorrido em seu estudo devido à pequena importância do valor apresentado.

Nesse sentido, esta pesquisa pretende responder à seguinte questão: $A$ intensidade do efeito custo afundado é influenciada pelo tamanho do investimento inicial realizado?

Assim, o objetivo deste trabalho é avaliar se o tamanho dos custos afundados pode provocar uma maior tendência à escolha de uma opção em que se tenha investido mais recursos do que em outra. Para isso, o cenário nele utilizado foi construído de forma a eliminar a possibilidade de outras variáveis não controladas no experimento influenciarem os tomadores de decisão, como por exemplo as diferenças entre tipos de eventos ou nomes de cidades.

Dessa forma, pretende-se contribuir para um maior conhecimento de como o efeito custo afundado se manifesta no Brasil, em questões envolvendo decisões pessoais.

\section{REFERENCIAL TEÓRICO}

A aversão à perda é um dos pontos chave da teoria dos prospectos de Kahneman e Tversky (1979) e para Thaler (1999) um dos elementos essenciais dos estudos de mental accounting (contabilidade mental). Para ele a contabilidade mental é um conjunto de operações mentais utilizado pelos indivíduos e pelas famílias para organizar, avaliar e controlar suas atividades financeiras.

Thaler (1999), ao descrever alguns aspectos da tomada de decisão em contabilidade mental, lista os três componentes do processo que recebem maior atenção em seu estudo: como os resultados são percebidos e sentidos pelas pessoas e como as decisões são tomadas e, posteriormente, avaliadas; a alocação das atividades em contas específicas; a frequência com que as contas são avaliadas. Thaler (1999) destaca que as pessoas mentalmente abrem uma conta para cada operação que fazem, procuram relacionar o custo (gasto de dinheiro) com o benefício decorrente do gasto e têm 
relutância em fechar uma conta no vermelho, pois, para ele, as pessoas têm aversão à perda.

Adicionalmente, Cheema e Soman (2006) afirmam que a contabilidade mental em determinadas condições é maleável, ou seja, os consumidores têm flexibilidade na alocação de despesas em diferentes contas mentais, principalmente quando uma despesa pode ser classificada de mais de uma forma (por exemplo: ir ao shopping lanchar pode ser do grupo lazer ou do grupo alimentação).

Prelec e Loewenstein (1998) também abordam a questão da contabilidade mental e propõem uma teoria de dupla entrada, que prevê a interação entre o prazer do consumo e a dor do pagamento. Esses autores sugerem a existência de uma aversão à dívida, o que faz com que as pessoas sintam mais prazer em consumir aquilo que foi pago antes, ou seja, as pessoas sentem mais prazer quando pagam antes e consomem depois.

Thaler (1999) declara que uma das questões que o fazem ter interesse pela contabilidade mental é a tentativa de entender porque as pessoas dão atenção aos custos afundados. Para Thaler (1980) o efeito custo afundado tem origem no sistema psíquico de contabilidade das pessoas, para o qual o equivalente a débito e crédito são, respectivamente, a dor do pagamento e o prazer do benefício que se espera ao se realizar um investimento. Para ele, embora a teoria econômica estabeleça que apenas custos incrementais e benefícios deveriam afetar as decisões, ou seja, os custos históricos deveriam ser irrelevantes, os consumidores não ignoram os custos afundados, sugerindo que o fato de uma pessoa pagar por um produto ou serviço aumenta a probabilidade de que tal produto ou serviço seja utilizado.

Nessa mesma linha, Friedman, Pommerenke, Lukose, Milam e Huberman (2007) consideram que um custo é afundado quando ele não pode ser recuperado, não devendo ter efeito em pagamentos incrementais de decisões futuras e, consequentemente, não deve ser considerado em escolhas racionais. Eles argumentam que embora os economistas considerem que as pessoas são racionais, esses devotam um considerável tempo das aulas e um significativo número de páginas dos livros para ensinar estudantes de graduação e de MBA a ignorarem os custos afundados.

Ainda de acordo com Friedman et al. (2007) há dois mecanismos psicológicos distintos que podem ter relação com o efeito custo afundado: a autojustificativa, pois as pessoas não quererem assumir que fizeram um investimento (gasto) errado; e a aversão à perda, que faz com que os indivíduos apliquem mais recursos para tentar "salvar" um investimento já realizado.

Já na visão de Arkes e Blumer (1996), uma das razões para que o efeito custo afundado ocorra é o fato de que as pessoas não querem ser consideradas "desperdiçadoras", o que faz com que busquem investir novos recursos na tentativa de recuperar custos afundados.

As pesquisas relacionadas ao efeito, em sua grande maioria, utilizam experimentos baseados em cenários hipotéticos, em diferentes linhas de investigação. Enquanto alguns estudos avaliam se os participantes levarão em conta os custos afundados ao decidir se vão a um ou outro evento - um final de semana em diferentes estações de esqui (ARKES; BLUMER, 1985); uma peça de teatro ou um concerto de rock (SOMAN, 2001) -, outros avaliam se as pessoas persistirão em determinado investimento iniciado, mas que não tem grandes perspectivas de êxito projeto do avião invisível (ARKES; BLUMER, 1985); equipamento para fuga de radar (GARLAND, 1990). Ainda há outros estudos que avaliam a persistência das pessoas na aplicação de novos recursos em um objetivo, comparando-se contas mentais diferentes ticket de teatro (KAHNEMAN; TVERSKY, 1984).

Nesse sentido, Gourville e Soman (1998) analisaram o impacto no comportamento dos consumidores causado pelo distanciamento entre o custo e o benefício (o pagamento e o consumo), verificando que o efeito custo afundado se dilui ao longo do tempo.

A partir de adaptação do exemplo do ticket de teatro de Kahneman e Tversky (1984), com a inclusão de valores diferentes de gasto adicional, experimentos realizados por Thames (1996) indicam que a contabilidade mental, juntamente com o tamanho do investimento incremental necessário para recuperar eventual custo perdido, tem influência na tendência das pessoas em honrar custos afundados, realçando a 
importância da contabilidade mental no processo de tomada de decisão.

No Brasil poucos trabalhos que se dedicam ao estudo do efeito foram divulgados. Borba e Murcia (2005) e Murcia e Borba (2006) constataram a ocorrência do fenômeno em estudos realizados com alunos de graduação dos cursos de Ciências Contábeis, Administração e Economia de uma Universidade Federal, concluindo que o ensino da contabilidade gerencial não é suficiente para fazer os estudantes do curso de Ciências Contábeis ignorarem os custos afundados no processo de tomada de decisão.

Silva, Souza e Domingos (2008), que aplicaram questionários a alunos de graduação dos cursos de Ciências Contábeis, Administração, Economia e Estatística de uma Universidade Brasileira, investigaram, em um dos problemas por eles proposto, se a existência de informação sobre o valor do investimento passado interfere na tomada de decisão. Esses autores constataram que a maioria dos respondentes escolheu a opção que Ihes foi sugerida como preferível (dentre duas escolhas possíveis) com ou sem a evidenciação do valor do investimento anterior. Embora não tenha ficado caracterizado um forte efeito do custo afundado, para as pessoas que sofreram influência do efeito não havia diferença significativa com ou sem a evidenciação do valor gasto.

Rover et. al. (2009) confirmaram a existência do efeito custo afundado em alguns dos experimentos por eles realizados com alunos de nove cursos de graduação, em três universidades de Santa Catarina e não conseguiram confirmar a hipótese que investigaram, que sugeria que os alunos dos cursos da área de negócios seriam menos propensos ao viés cognitivo causado pelo efeito.

Outros trabalhos buscaram investigar o efeito em atividades específicas, como o de Leal (2014), que constatou que em situação de incerteza, até mesmo pessoas com experiência anterior na decisão a ser tomada, foram influenciadas pelos custos afundados em suas escolhas. Por outro lado, Leal e Holz (2015) verificaram que essa influência pode ser mitigada na presença de um custo de oportunidade, quando os tomadores de decisão já possuem experiência de escolhas semelhantes realizadas anteriormente.
Na sequência é apresentada a metodologia utilizada neste estudo, com a discussão sobre os resultados obtidos.

\section{METODOLOGIA E RESULTADOS}

Como o objetivo da pesquisa foi verificar se o tamanho do investimento realizado provoca uma maior tendência à ocorrência do efeito custo afundado, utilizou-se da pesquisa experimental. Essa metodologia permite avaliar a influência da manipulação de uma variável (variável independente) sobre outra (variável dependente), a partir da observação dos resultados dessa manipulação entre os grupos estudados (GIL, 2002).

Assim, foi realizado um experimento, dividido em duas fases, com utilização da modalidade entressujeitos, uma vez que cada componente de cada grupo estudado foi submetido a apenas um cenário dentre os utilizados. O experimento foi realizado com estudantes de graduação de diversos cursos de uma universidade brasileira, com abordagem em sala de aula e preenchimento do instrumento de pesquisa na presença de um dos pesquisadores. A variável manipulada no experimento (variável independente) foi o tamanho do investimento realizado e a variável de observação (variável dependente) foi a escolha dos participantes entre duas opções existentes.

Na primeira fase do experimento foi utilizado um cenário adaptado de Soman (2001), com base em cenário utilizado por Arkes e Blumer (1985), porém sem identificação do evento que seria objeto da decisão, de forma a evitar a influência do gosto do participante por um ou outro tipo de atividade. Por exemplo, pode haver preferência das pessoas entre assistir a uma peça de teatro ou ir a um show de uma banda de rock (SOMAN, 2001). No experimento realizado por Soman (2001) o cenário apresentado aos participantes indicou que eles gostariam de assistir aos dois eventos, mas tinham expectativas de que gostariam mais do concerto de rock. O autor indicou que $61,7 \%$ dos participantes de seu experimento consideram o custo afundado em sua decisão, isto é, escolheram ir ao evento que custou mais caro, mesmo com indicação no cenário de que o outro evento deveria ser melhor.

Neste estudo, essa etapa do experimento contou com a participação de 74 sujeitos, sendo 40 submetidos à versão em que havia 
diferença entre os valores investidos (grupo experimental) e 34 que fizeram sua escolha entre dois eventos de mesmo valor (grupo de controle). Assim, a ocorrência do efeito custo afundado se caracterizaria se houvesse diferença significativa entre as escolhas dos dois grupos.

O cenário descrito indicava que os participantes haviam comprado ingressos para dois eventos culturais distintos, pagando valores diferentes (um evento quatro vezes mais caro que o outro) e depois ficaram sabendo que somente poderiam assistir a um deles. Foi indicado também que os respondentes gostariam de assistir aos dois eventos, mas que tinham expectativa de que o que custou mais barato seria melhor do que o outro.

Como mencionado anteriormente, diferentemente dos estudos de Arkes e Blumer (1985), de Soman (2001) e de outros autores que adaptaram o mesmo cenário, que especificaram os tipos de eventos (um passeio para esquiar em Michigan $X$ um passeio para esquiar em Wisconsin, no primeiro; uma peça de teatro $X$ um concerto de uma banda de rock, no segundo) optou-se aqui por não indicar o tipo de evento, para evitar o viés decorrente das preferências pessoais (gostar mais de teatro ou de show musical, por exemplo). Outras modificações foram a alteração da proporção entre o maior e o menor gasto de dinheiro de $3 \times 1$ para $4 \times 1$.

Cenário com valores diferentes - grupo experimental

Considere o seguinte cenário: você trabalha e seus rendimentos são suficientes para seus gastos usuais e para suas atividades de lazer. Nos últimos dias, você ficou sabendo que haverá dois eventos culturais de seu interesse, mas em datas diferentes. Assim, você adquiriu ingressos para os dois. O ingresso para o primeiro evento custou $R \$ 200,00$, enquanto 0 ingresso para 0 segundo custou $R \$ 50,00$. Você gostaria de assistir aos dois eventos, embora tenha expectativa de que o segundo deverá ser melhor que o primeiro.

Neste momento você recebe a informação de que um dos eventos teve a data alterada, de forma que os dois ocorrerão no mesmo dia e horário. Em outras palavras, você só poderá assistir a um deles. Assuma que os ingressos são intransferíveis (eles vêm com seu nome impresso) e não reembolsáveis, ou seja, você só poderá usar um dos ingressos e, assim, perderá o outro.

A qual dos eventos você irá?

( ) - Irei ao primeiro

( ) - Irei ao segundo

Cenário com valores iguais - grupo de controle

Considere o seguinte cenário: você trabalha e seus rendimentos são suficientes para seus gastos usuais e para suas atividades de lazer. Nos últimos dias, você ficou sabendo que haverá dois eventos culturais de seu interesse, mas em datas diferentes. Assim, você adquiriu ingressos para os dois, a $\mathrm{R} \$ 200,00$ cada um. Você gostaria de assistir aos dois eventos, embora tenha expectativa de que o segundo deverá ser melhor que o primeiro.

Neste momento você recebe a informação de que um dos eventos teve a data alterada, de forma que os dois ocorrerão no mesmo dia e horário. Em outras palavras, você só poderá assistir a um deles. Assuma que os ingressos são intransferíveis (eles vêm com seu nome impresso) e não reembolsáveis, ou seja, você só poderá usar um dos ingressos e, assim, perderá o outro.

A qual dos eventos você irá?

( ) - Irei ao primeiro

( ) - Irei ao segundo

A tabela 1, a seguir, apresenta os resultados obtidos na primeira fase do experimento: 
Tabela 1 - Resumo das decisões na primeira fase do experimento

\begin{tabular}{|c|c|c|c|c|c|c|}
\hline \multicolumn{2}{c}{ Cenário } & \multicolumn{2}{c|}{ Ir ao primeiro evento } & \multicolumn{2}{c|}{ Ir ao segundo evento } & \multicolumn{2}{c|}{ Total } \\
\cline { 2 - 6 } & Quantidade & $\%$. & Quantidade & $\%$ & Quantidade & $\%$ \\
\hline Valores diferentes & 12 & $35,3 \%$ & 22 & $64,7 \%$ & 34 & $100 \%$ \\
\hline Valores iguais & 6 & $15,0 \%$ & 34 & $85,0 \%$ & 40 & $100 \%$ \\
\hline
\end{tabular}

Foi utilizado o teste qui-quadrado para verificar a significância das diferenças entre as proporções de sujeitos que escolheram cada uma das duas opções disponíveis. A diferença do padrão de respostas dos dois grupos foi significativa, $x^{2}(1)=3,97, p<0,05$, indicando a existência do efeito custo afundado. No primeiro cenário, vários respondentes (35,3\% dos participantes) afirmaram que iriam ao primeiro evento, mesmo imaginando que o segundo fosse melhor. No entanto, a grande maioria dos participantes $(64,7 \%)$ da versão com investimentos diferentes não foi influenciada pelos custos afundados, isto é, mesmo tendo pagado mais pelo ingresso do primeiro evento, afirmaram que escolheriam ir ao segundo.

$\mathrm{Na}$ segunda fase do experimento, realizada com mais dois grupos de participantes, foi aumentado o valor do investimento realizado e, por essa razão, foi necessário alterar também o tipo de atividade que seria realizada. Neste caso, optou-se por uma viagem, o que possibilitaria a utilização de valores superiores aos apresentados no cenário da primeira fase. A seguir são apresentadas as duas versões e os resultados obtidos. Nessa etapa foram utilizados 50 participantes em cada uma das versões, também com aplicação dos instrumentos de pesquisa em sala de aula, na presença de um dos pesquisadores.

Cenário com valores diferentes - grupo experimental

Considere o seguinte cenário: Você trabalha e seus rendimentos são suficientes para seus gastos usuais e para suas atividades de lazer. Nos últimos dias, você adquiriu dois pacotes de viagens para dois finais de semana distintos. O pacote para o primeiro passeio custou $R \$ 4.000,00$, enquanto o pacote para o segundo passeio custou $R \$ 1.000,00$. Você está muito interessado nos dois passeios, embora tenha expectativa de que o segundo deverá ser melhor que o primeiro.

Neste momento percebe que, por um erro seu, marcou os dois passeios para o mesmo final de semana, de forma que você só poderá ir a um deles. Assuma que os pacotes são intrasferíveis (as passagens e estadias estão em seu nome) e não reembolsáveis, ou seja, você só poderá usufruir de um dos passeios e, assim, perderá o outro.

Pergunta: A qual passeio você irá?

( ) - Irei ao primeiro

( ) - Irei ao segundo

Cenário com valores iguais - grupo de controle

Considere o seguinte cenário: Você trabalha e seus rendimentos são suficientes para seus gastos usuais e para suas atividades de lazer. Nos últimos dias, você adquiriu dois pacotes de viagens para dois finais de semana distintos. Ambos os pacotes custaram $\mathrm{R} \$ 1.000,00$. Você está muito interessado nos dois passeios, embora tenha expectativa de que o segundo deverá ser melhor que o primeiro.

Neste momento percebe que, por um erro seu, marcou os dois passeios para o mesmo final de semana, de forma que você só poderá ir a um deles. Assuma que os pacotes são intrasferíveis (as passagens e estadias estão em seu nome) e não reembolsáveis, ou seja, você só poderá usufruir de um dos passeios e, assim, perderá o outro.

Pergunta: A qual passeio você irá?

( ) - Irei ao primeiro

( ) - Irei ao segundo

A tabela 2, a seguir, apresenta os resultados obtidos nessa fase, cujos valores foram maiores que os da primeira: 
Tabela 2 - Resumo das decisões na segunda fase do experimento

\begin{tabular}{|c|c|c|c|c|c|c|}
\hline \multicolumn{5}{|c|}{ Decisão } & & \\
\hline \multirow[t]{2}{*}{ Cenário } & \multicolumn{2}{|c|}{ Ir ao primeiro evento } & \multicolumn{2}{|c|}{ Ir ao segundo evento } & \multicolumn{2}{|c|}{ Total } \\
\hline & Quantidade & $\%$ & Quantidade & $\%$ & Quantidade & $\%$ \\
\hline Valores diferentes & 28 & $56,0 \%$ & 22 & $44,0 \%$ & 50 & $100 \%$ \\
\hline Valores iguais & 7 & $14,0 \%$ & 43 & $86,0 \%$ & 50 & $100 \%$ \\
\hline
\end{tabular}

Fonte: elaborado pelos autores

Novamente o efeito custo afundado ocorreu, $x^{2}(1)=19,385, p>0,05$. No entanto, com o aumento do valor do investimento realizado, ocorreu também o aumento do percentual de participantes que foram influenciados pelos custos afundados em suas escolhas. Quando o cenário apresentou valores de $R$ \$200,00 e $\mathrm{R} \$ 50,00$, apenas $35 \%$ dos participantes escolheram a opção que havia custado mais caro. Esse percentual aumentou para 56\% quando os valores foram elevados para $\mathrm{R} \$ 4.000,00$ e $\mathrm{R} \$ 1.000,00$.

Comparadas as respostas desses dois cenários com valores diferentes, também houve diferença significativa $x^{2}(1)=4,889, p$ $<0,05$, o que demonstra que o aumento do valor investido provocou aumento significativo na tendência em levar os custos afundados em consideração na escolha.

No estudo de Silva, Souza e Domingos (2008), enquanto no grupo que foi submetido a uma questão envolvendo um investimento de $\mathrm{R} \$ 1.000,00$, apenas $40 \%$ dos respondentes sofreram o efeito dos custos afundados, no grupo ao qual foi apresentada a outra questão, envolvendo investimento de $\mathrm{R} \$$ 1.000.000,00, o percentual de participantes que ficou preso aos custos afundados foi de $80 \%$. Os autores atribuíram a diferença ao fato de o primeiro investimento ter sido de natureza pessoal, enquanto o segundo foi de natureza profissional. Entretanto, como ocorreu neste estudo, tal variação nos percentuais pode ter sido ocasionada pela diferença entre os valores envolvidos.

O comportamento diferente em função do valor investido por ser ilustrado por uma questão cotidiana. Por exemplo, quando uma pessoa compra cinco balas, pagando por elas o total de $R \$ 0,50$ e não gosta do sabor, após experimentar a primeira, será que ela insiste no consumo das demais, da mesma forma que insistiria se, em vez de cinco balas, tivesse adquirido cinco garrafas de vinho por $\mathrm{R} \$$ 500,00? Provavelmente, nesta última situação, a pessoa iria consumir as demais garrafas, tentando identificar sabores e aromas no vinho que justificassem o investimento efetuado.

\section{CONCLUSÕES}

Esta pesquisa teve como objetivo investigar, no contexto de decisões relacionadas às finanças pessoais, se a intensidade do efeito custo afundado é influenciada pelo tamanho do investimento inicial realizado. Os resultados do experimento aqui apresentado demonstraram que o aumento do investimento inicial promoveu um aumento significativo do efeito custo afundado entre os pesquisados. Em outras palavras, as escolhas dos sujeitos pesquisados foram influenciadas pelo tamanho do investimento inicialmente realizado.

Quer seja para não parecerem desperdiçadores de recursos, ou para não considerarem que erraram em uma atitude anterior, ou ainda, quer seja pelo medo da perda de um recurso que investiram, dentre outras possíveis razões, os participantes da pesquisa apresentaram o viés cognitivo de serem influenciados pelos custos passados. Nesse caso, as decisões equivocadas dos que optariam pelo caminho em que haviam investido mais, mesmo com a indicação da expectativa de que a outra opção seria melhor, não resultariam em graves consequências, a não ser o fato de estarem em um lugar, quando talvez preferissem estar em outro. No entanto, quando as escolhas envolvem outros tipos de investimentos, principalmente relacionados à gestão empresarial, esse tipo de escolha enviesada pode provocar sérios prejuízos às pessoas e às organizações. 
Embora o estudo não tenha sido realizado em um contexto organizacional, mas pessoal, a influência dos custos afundados nas decisões das pessoas (o efeito custo afundado) merece atenção especial dos gestores.

Estudos anteriores, mencionados no referencial teórico deste trabalho, comprovaram que o efeito também ocorre em decisões relacionadas ao ambiente organizacional. Nesse caso, decisões equivocadas, baseadas em investimentos expressivos podem provocar prejuízos significativos às organizações.

Nesse sentido, é necessário que os cursos de formação de gestores e de profissionais de áreas afins tratem de questões relacionadas ao julgamento e tomada de decisão, em especial situações envolvendo custos afundados.

Este estudo eliminou o efeito de eventual preferência do grupo de respondentes por um outro tipo de evento, já que, diferentemente dos estudos de Arkes e Blumer (1985) escolha entre duas estações de esqui -, Soman (2001) - escolha era entre peça de teatro e show musical - e de Silva, Souza e Domingos (2008) - escolha entre dois festivais de cinema diferentes -, neste trabalho não foram especificadas atividades diferentes entre as opções a serem escolhidas. No entanto, ele ainda tem limitações relacionadas

\section{REFERÊNCIAS}

[1]. ARKES, H. R.; BLUMER, C. The Psychology of sunk-costs. Organizational Behavior \& Human Decision Processes. V. 25, p. 124-140, 1985.

[2]. The Psychology of waste. Journal of Behavioral Decision Making. V. 9, p. 213224, 1996.

[3]. BORBA, J. A.; MURCIA, F. A influência dos custos perdidos (sunk costs) no processo de tomada de decisão: um estudo empírico baseado em cenários de decisão. In. IX Congresso Internacional de Custos. Florianópolis-SC, novembro de 2005.

[4]. CHEEMA, A.; SOMAN, D. Malleable mental accounting: the effect of flexibility on the justification of attractive spending and consumption decisions. Journal of Consumer Psychology. V. 16(1), p. 33-44, 2006.

[5]. DE VOE; S. E.; PFEFFER, J. When time is money: the effect of hourly payment on the à utilização de estudantes como amostra do experimento realizado, fato comum à maioria dos estudos que investigam efeito custo afundado.

Sugere-se que sejam realizados estudos que comparem a postura dos brasileiros com outras culturas, já que os resultados sinalizam indícios de que os brasileiros são menos propensos a considerar os custos afundados de valores pequenos em suas decisões. Enquanto no estudo inicial de Arkes e Blumer (1985), realizado com estudantes dos Estados Unidos, 54\% dos sujeitos foram influenciados pelos custos afundados, e no de Soman (2001) - realizado com estudantes de Hong Kong -, o efeito se manifestou em mais de $60 \%$, para investimento inicial máximo de U\$ 100.00 no primeiro e de U\$ 57.00, no segundo, a pesquisa de Silva, Souza e Domingos (2008), com valor de $R \$ 1.000$, observou um efeito de $40 \%$ e o presente estudo, com investimento de $\mathrm{R} \$ 200$, um efeito de $35 \%$.

Também é importante estudar diferentes parâmetros de comparação entre investimentos para a análise da ocorrência do efeito. Por exemplo, no trabalho de Arkes e Blumer (1985) e no de Silva, Souza e Domingos (2008) o maior investimento era o dobro do menor, enquanto que no de Soman (2001) era o triplo e nesta pesquisa o quádruplo.

evaluation of time. Organization Behavior and Human Decision Processes. V. 104, p. 1-13, 2007.

[6]. FRIEDMAN, D.; POMMERENKE, K.; LUKOSE, R.; MILAM. G.; HUBERMAN, B. Searching for the sunk cost fallacy. Experimental Economics. V. 10(1), p.79-104, 2007.

[7]. GARLAND, H. Throwing good money after bad: the effect of sunk costs on the decision to escalate commitment to an ongoing project - short notes. Journal of Applied Psychology. V 75, n. 6, p. 728-731, 1990.

[8]. GIL, A. C. Como elaborar projetos de pesquisa. 4. ed. São Paulo: Atlas, 2002.

[9]. GOURVILLE, J. T.; SOMAN, D. Payment depreciation: the behavioral effects of temporally separating payments from consumption. Journal of Consumer Research. V. 25, p. 160-174, September 1998. 
[10]. KAHNEMAN, D.; TVERSKY, A. Prospect theory: an analysis of decision under risk. Econometrica. V. 47, p. 263-291, 1979.

[11]. KAHNEMAN, D.; TVERSKY, A. Choices, Values and Frames. The American Psychologist. V. 39, p. 341-350, (1984).

[12]. LEAL, D. O papel de custos afundados em decisões de alocação de recursos. Tese (Doutorado em Administração) - Instituto COPPEAD de Administração, Universidade Federal do Rio de Janeiro. Rio de Janeiro, 2014.

[13]. LEAL, D.; HOLZ, F. L. A influência da experiência sobre o efeito custo afundado. In: ANPCONT, 9., 2015, Curitiba. Anais... Curitiba: ANPCONT, 2015.

[14]. LECLERC, F.; SCHIMITT, B. H.; DUBÉ, L. Waiting time and decision making: is time like money? Journal of Consumer Research. V. 22, p 110-119, June 1995.

[15]. MURCIA, F. D.; BORBA, J. A. Um estudo empírico sobre os efeitos dos sunk costs no processo decisório dos indivíduos: evidências dos estudantes de graduação de uma universidade federal. UNB Contábil. V. 9, n. 2, jul-dez 2006.

[16]. OKADA, E. M.; HOCH, S. J. Spending time versus spending money. Journal of Consumer Research. V. 31, p 313-322, September 2004.

[17]. PRELEC, D.; LOEWENSTEIN, G. The red and the black: mental accounting of savings and debt. Marketing Science. V. 17, n.1, p. 4-28, 1998.
[18]. RAJAGOPAL, P.; RHA, J. Y. The mental accounting of time. Journal of Economic Psychology. V. 30, p. 772-781, 2009.

[19]. ROVER, S.; WUERGES, A. F. E.; TOMAZZIA, E. C.; BORBA, J. A. Efeito sunk costs: o conhecimento teórico influencia no processo decisório de discentes? Brazilian Business Review. V. 6, n. 3, p. 247-263, set-dez 2009.

[20]. SILVA, C. A. T.; SOUZA, F. A.; DOMINGOS, N. T. Efeito do custo perdido: a influência do custo perdido na decisão de investimento. Revista de Contabilidade e Organizações - FEARP/USP. V. 2, n. 2, p. 87-99, jan/abr 2008

[21]. SOMAN, D. The mental accounting of sunk time costs: Why time is not like money. Journal of Behavioral Decision Making. V. 14, p. 169-186, 2001.

[22]. THALER, R. H. Toward a positive theory of consumer choice. Journal of Economic Behavior and Organization. V. 1, p. 39-60, 1980.

[23]. Mental accounting matters. Journal of Behavioral Decision Making. V. 12, p. 183-206, 1999.

[24]. THAMES, E. A. The Sunk-Cost Effect: The Importance of Context. Journal of social Behavior and Personality. V. 11, n. 4, p. 817-826. 


\section{Bapítulo 6}

\section{GESTÃO DE CUSTOS EM PEQUENAS PROPRIEDADES RURAIS: UM ESTUDO APLICADO NO MUNICIPIO DE MARECHAL CÂNDIDO RONDON - PR}

\section{Adriane Carine Maldaner Vorpagel}

Elza Hofer

Anderson Giovane Sontag

Resumo: Toda atividade empresarial necessita de planejamento, controle e gestão. Os empresários utilizam-se do conhecimento da administração, contabilidade e economia para gerenciar seus empreendimentos e a tomar decisões. No agronegócio e na agricultura familiar não pode ser diferente, embora muitas vezes não constituído de uma empresa formal, mas na própria pessoa física no exercício de suas atividades, precisa-se de ferramentas gerenciais. Este estudo tem como objetivo verificar se os produtores de Marechal Cândido Rondon - PR utilizam controle de custos no gerenciamento de suas atividades, identificando o perfil, o porte das propriedades e de que maneira essas variáveis podem interferir na gestão e controle das atividades rurais. A pesquisa caracteriza-se por um estudo descritivo, de levantamento e a coleta de dados desenvolveu-se com a aplicação de questionário. Os resultados da pesquisa foram submetidos a tratamento quantitativo, com análise descritiva. Constatou-se que os produtores possuem muita experiência no desenvolvimento das atividades rurais, mas encontram dificuldades na gestão da sua propriedade. A grande maioria adota um controle de custos informal, com anotações em caderno, sendo que modelos de gestão mais sofisticados são adotados por uma minoria de produtores rurais. O tamanho da propriedade e o faturamento influenciam na gestão, uma vez que, de acordo com o cruzamento de dados, verificou-se que quanto maior for a propriedade e o faturamento, melhor será o controle de custos das atividades desenvolvidas.

Palavras-chave: Controles Contábeis. Gestão de Custos. Atividades Rurais. 


\section{INTRODUÇÃO}

O agronegócio brasileiro contribui significativamente para 0 desenvolvimento econômico de nosso país, "[...] produz um quarto do Produto Interno Bruto (PIB) nacional e aproximadamente um quinto do emprego total" (Buainain et al., 2013). O agronegócio é fator importante para o desenvolvimento regional e fortalecimento da economia. No entanto, diante das dificuldades enfrentadas pelos produtores, fica cada vez mais difícil se manterem na atividade, principalmente devido às constantes oscilações de preços dos produtos, a lei da oferta e da procura, além dos fatores ambientais, como estiagens, geadas e temporais. Além destes fatores, manter-se na atividade rural requer um grande número de investimentos, seja para manter-se na atividade, ampliar a receita ou até mesmo para facilitar o manejo das atividades (Araújo, 2013).

Existe uma série de fatores que afetam significativamente 0 desempenho dos empreendimentos rurais, como a elaboração de projetos agrícolas para solicitação de crédito, a tomada de decisão sobre o que produzir, da tecnologia a ser adquirida, processo de compra de insumos e venda dos produtos, entre outros, exigindo capacitações gerenciais, ausentes na maioria dos produtores rurais, inclusive os familiares, provocando impactos negativos no desenvolvimento desse segmento e, consequentemente, na sua integração aos mercados mais dinâmicos (Lourenzani, 2006).

Toda atividade empresarial necessita de planejamento, controle e gestão. Os empresários utilizam-se do conhecimento da administração, contabilidade e economia para gerenciar seus empreendimentos e a tomar decisões. No agronegócio e na agricultura familiar não pode ser diferente, embora muitas vezes não constituído de uma empresa formal, mas na própria pessoa física no exercício de suas atividades, precisa-se de ferramentas gerenciais.

O agricultor está se transformando em empresário rural, um administrador profissional, que além de se preocupar com a produção, busca a produtividade e a lucratividade; produzindo mais com menos recursos e necessitando para isso informações para avaliar, controlar e decidir. Ainda, as propriedades no futuro tendem a ser verticalizadas e integradas à agroindústria, havendo a transição da fazenda familiar para a empresa familiar (Marion e Segatti, 2005). O suporte para o gerenciamento do negócio rural pode ser obtido por meio da contabilidade. No entanto, conforme Hofer et al. (2011), a grande maioria dos produtores rurais administra suas atividades na informalidade, utilizando-se apenas de simples anotações.

Considerando a relevância das atividades desenvolvidas no meio rural para o desenvolvimento econômico e as vantagens oferecidas pela contabilidade aos seus usuários, busca-se responder o seguinte questionamento: os produtores rurais do município de Marechal Cândido Rondon - PR utilizam de algum controle de custos na gestão de suas atividades? O objetivo da pesquisa é verificar em que medida os produtores rurais utilizam as informações da contabilidade de custos no gerenciamento de suas atividades. Busca-se ainda identificar o perfil dos entrevistados, qual o porte das propriedades pesquisadas e de que maneira essas variáveis podem interferir na gestão e controle das atividades rurais.

O presente trabalho justifica-se na importância do agronegócio para o sustento da população, de sua relevância para o bom andamento da economia, geração de emprego e renda, obtendo maior acompanhamento das atividades rurais, a fim de auxiliar o produtor rural na gestão de seus negócios, de forma que este possa obter bons resultados financeiros, que permitam a continuidade de suas atividades.

A pesquisa está organizada em mais quatro seções além desta introdução. Na sequência é apresentado a fundamentação teórica, abordando a contabilidade rural e de custos, na terceira seção, descrevem-se os procedimentos metodológicos, na quarta, a análise dos dados e resultados; por fim, as considerações finais e as referências que sustentaram a justificativa e argumentação do trabalho.

\section{FUNDAMENTAÇÃO TEÓRICA}

A Contabilidade Rural, apesar de sua extrema importância, ainda é pouco utilizada no Brasil. Isto se deve principalmente, pelo desconhecimento das vantagens proporcionadas pelo seu uso no desenvolvimento das atividades rurais, além de que, muitos empresários desse ramo primam pelos controles baseados na 
experiência adquirida e passam a abrir mão das informações reais (Crepaldi, 2009).

A contabilidade é peça fundamental na gestão dos empreendimentos rurais, uma vez que, o empreendedor rural, agricultor ou pecuarista deve possuir em mãos, ferramentas que o auxiliam na tomada de decisão. Com o uso da contabilidade o empresário rural poderá dispor de informações financeiras de sua atividade, se o desempenho de sua produção é rentável e qual a melhor forma para otimizar seus resultados. De modo geral, terá em mãos dados que the permitam estabelecer relações entre diferentes departamentos, de forma que possa tomar decisões acertadas quanto a novos investimentos e quanto ao futuro da organização (Barbosa, 2008).

Na gestão realizada pelos empresários rurais, estes na maioria das vezes, sequer fazem anotações sobre suas operações financeiras, guardando os registros em sua memória, e com o tempo são esquecidos. De modo geral, não há separação das despesas particulares e das atividades da empresa, logo não se faz apuração de lucro, o que impossibilita a verificação da rentabilidade do negócio e impede a minimização de custos de produção (Crepaldi, 2009).

Existem alguns obstáculos para o uso da contabilidade no meio rural, os quais se referem principalmente ao elevado custo de manutenção dos serviços contábeis, a dificuldade de separar os custos de produção dos gastos do próprio empresário, desrespeitando o princípio da entidade, além da ausência de recibos, notas fiscais, cópias de cheques ou extratos de contas bancárias (Crepaldi, 2009).

A administração ou uso de técnicas de gerenciamento, controle ou organização da propriedade rural ainda são pouco aceitas pelos produtores, pois muitos deles pensam que, dedicar-se a qualquer atividade que não seja a atividade pecuária e agrícola seria perca de tempo. Os produtores que utilizam algum tipo de controle, que geralmente ocorre por meio de anotações em papel ou apenas guardam as informações na própria memória, dispensando qualquer tipo de anotação. Poucos são aqueles que utilizam métodos mais sofisticados, como planilhas eletrônicas, ou sistemas computadorizados. Casos do tipo podem ser explicados pela idade avançada e baixa escolaridade dos gestores, que por vezes, não sabem utilizar um computador, ou sequer possuem este equipamento em sua propriedade (Souza Filho e Batalha, 2005).

O empresário rural carece do uso de métodos de planejamento de suas atividades, observar quais seus pontos fortes e fracos, comparando o desempenho de cada uma delas com períodos anteriores, fazer o controle de suas receitas e despesas, além de fazer estimativas de custos e da rentabilidade que poderia ser obtida em possíveis investimentos (Barbosa, 2008).

Para Crepaldi (2009), o empresário rural necessita do auxílio de um profissional para a contabilização de suas atividades. Em posse dos relatórios, o administrador terá em mãos ferramentas que indicaram quais as melhores tendências do mercado, podendo explorar de maneira adequada o seu ciclo produtivo, além de realizar um controle efetivo dos insumos utilizados na produção, diminuindo desperdícios e maximizando o lucro.

A adoção de ferramentas de gestão nas propriedades rurais não é tão simples assim, já que para solucionar essa questão precisase mudar a cultura dos produtores e dos consultores técnicos que Ihes dão assistência, pois o desleixo ao uso das ferramentas de gestão pode comprometer a sustentabilidade e competitividade desses empreendimentos rurais (Souza Filho e Batalha, 2005). Para Debertolis et al. (2005, p. 36), "a gestão rural pode ser [...], o uso de forma eficiente e eficaz dos recursos naturais, humanos, físicos e financeiros, [...], de todas as atividades desenvolvidas, mediante planejamento, a organização, a direção, o controle, [...]".

Para Callado e Moraes Filho (2011), o gerenciamento e controle das empresas rurais pode ser classificado quanto ao porte das propriedades. As pequenas empresas, em sua maioria, controlam suas contas a pagar e a receber, além dos serviços e outros registros, por meio de anotações em uma simples caderneta. Enquanto que as médias empresas utilizam de registros não somente das contas pendentes, como em todas as operações e negócios realizados, dispõe do livro diário, registros dos empregados e das contas correntes. E por fim, as grandes empresas, que utilizam a contabilidade financeira completa e de rigorosos registros para o controle das transações.

O gestor rural, conhecedor de seu negócio, toma decisões com base nos dados reais das operações desenvolvidas na propriedade, 
busca conhecer as atividades para poder trabalhar com riscos calculados e tomar decisões acertadas (Debertolis et al., 2005).

De acordo com Callado e Moraes Filho (2011), o administrador rural deve ser capaz de tomar decisões acertadas diante das diversas alternativas que o mercado the oferece, optando pela possibilidade que traga benefícios a sua empresa, sem infringir a legislação. Decisões importantes na gestão da entidade estão relacionadas ao controle de custos, o que significa que o gestor deve estar atento aos custos relevantes, buscando sempre reduzir seus custos, maximizar sua produção, sem que o produto final perca sua qualidade.

Segundo Crepaldi (2009), a boa gestão é realizada quando se tem informações confiáveis e concretas para serem analisadas, o que permite a tomada de decisões acertadas, no entanto, esta é justamente a maior dificuldade dos produtores rurais, que pela falta de instrução não sabem lidar com certas informações. Para Debertolis et al. (2005), os principais aspectos a serem observados no gerenciamento de uma propriedade rural são: controle de custos, receitas e a margem de lucro de cada uma das atividades.

Desse modo, diante das diversas especificidades das atividades agrícolas e pecuárias, o gestor rural deve capacitar-se, de modo que seja capaz de fazer análises quanto à viabilidade da realização de investimentos em determinada atividade. Para isso, o administrador rural disporá de técnicas de análise financeira, de investimento e de risco (Simprini e Lopes, 2012).

\subsection{CUSTOS NA AGROPECUÁRIA}

Toda administração de qualidade requer um bom planejamento. A gestão de custos ideal inicia-se com uma previsão de custos, estimando-se custos e receitas, buscando aproximá-los da realidade para ter um prognóstico sobre gastos e lucros. O controle de gastos da propriedade deve ser observado e tabulado diariamente, e ao final da semana e do mês elaborado resultado parcial, para poder constantemente acompanhar o comportamento dos custos e gastos das atividades e prever antecipadamente a ocorrência de possíveis prejuízos (Araújo, 2013).
Ainda a maioria dos pequenos produtores rurais trabalham no sistema de integração ou comercializam sua produção por intermédio de cooperativas, logo não demonstram interesse em saber qual o verdadeiro custo de sua produção ou criação, considerando que possuem a garantia de venda de seus produtos (Batalha et al., 2005). No entanto, se o produtor soubesse o custo real de seus produtos, poderia aumentar o seu poder de barganha (Souza Filho e Batalha, 2005).

É imprescindível que os empresários rurais realizem a gestão de custos, facilitando o acompanhamento das alterações patrimoniais ocorridas. Assim, a aplicação de uma contabilidade, mesmo que simplificada, permite o acompanhamento e registro dos valores de sua propriedade e de todas as operações realizadas no exercício, possibilitando a análise das causas que concorrem para os lucros ou prejuízos (Callado e Callado, 2011).

Nessa perspectiva, Simprini e Lopes (2012) complementam que um empreendimento rural se torna competitivo no mercado, a partir do momento que estiver a frente dos concorrentes, para atingir esse propósito deve produzir produtos com mais qualidade do que os do concorrente, a um custo melhor, além de transmitir confiabilidade aos clientes, e de possuir uma boa localização geográfica de seu empreendimento.

Ainda, Godinho et al. (2013) identificaram e correlacionaram aspectos relevantes da gestão empresarial em sistemas de produção de leite de um município do Sudoeste de Minas Gerais. Em pesquisa realizada junto aos produtores rurais e profissionais da assistência técnica com vínculo com a produção leiteira, avaliou-se as percepções quanto ao entendimento de gestão, a prática do planejamento, organização, direção e controle. Constatou-se que o baixo uso de técnicas de gestão nos sistemas de produção leiteira, possui uma relação com o baixo envolvimento dos profissionais da assistência técnica com as questões administrativas dessas empresas que exploram estes sistemas.

Na mesma linha, Breitenbach et al. (2016), buscaram identificar o perfil gerencial de agricultores familiares produtores de soja do Rio Grande do Sul, definindo o nível de administração e o conhecimento em relação aos custos relacionados a atividade que desenvolvem. Os resultados apontaram que 
99,5\% dos agricultores têm pouca noção dos lucros das atividades, $87,3 \%$ têm conhecimento aproximado de custos das atividades e apenas 30\% consideram-se "organizado" e "muito organizado" nos controles da propriedade.

\section{PROCEDIMENTOS METODOLÓGICOS}

A presente pesquisa quanto aos objetivos enquadra-se como descritiva, sendo utilizada principalmente quando se objetiva realizar aplicação de questionários, ou quando se deseja realizar uma observação sistemática (Andrade, 2003). Quanto aos procedimentos trata-se de uma pesquisa survey ou levantamento, caracterizado pela interrogação direta as pessoas, extraindo-lhes as informações que se deseja conhecer (Raupp e Beuren, 2012). Em relação a abordagem do problema, trata-se de uma pesquisa quantitativa com uso de métodos estatísticos na análise dos dados.

A população são os produtores rurais do município de Marechal Cândido Rondon - PR, que de acordo com o IBGE (2006), somam 2.423 empreendimentos rurais. A amostra são 130 produtores rurais entrevistados, ou seja, $5,36 \%$ da população. A amostra foi selecionada de forma não probabilística, por acessibilidade e erro amostral de 8,5\%.

Para fins desta pesquisa, a coleta dos dados foi realizada por meio de questionário estruturado, seguindo um roteiro de perguntas pré-determinadas para atender os objetivos previamente propostos, compreendendo 35 questões fechadas. Além de seguir um roteiro com questionamentos previamente estabelecidos, a interrogação direta, possibilitou o contato aberto com os entrevistados, o que permitiu que estes expusessem o seu ponto de vista sobre os questionamentos realizados e sobre a situação da gestão da propriedade.

O questionário foi organizado em três partes, a primeira possui 10 questões que identificam o perfil dos produtores rurais, sua idade, escolaridade, se possui filhos e tempo de atividade rural. No segundo tópico verificamse as características da propriedade, elencando 17 questões a respeito de faturamento, o tamanho da propriedade, forma de aquisição do patrimônio e quais as culturas desenvolvidas. Na terceira parte referiu-se à gestão da propriedade e controle de custos das atividades rurais. Este último tópico procurou, por meio de 8 questões, constatar se os produtores utilizam algum método de controle, como é realizado, os benefícios percebidos e se tem interesse em adotar a contabilidade em suas atividades.

Para a aplicação da pesquisa realizou-se a abordagem dos produtores que frequentavam a unidade sede de uma cooperativa agropecuária do município, no dia escolhido para fazer as entrevistas. Além disso, realizaram-se visitas às propriedades rurais, entrevistando produtores de diversas regiões do município. A coleta dos dados foi realizada entre os dias 03/06/2014 à 19/07/2014, em dias aleatórios, tanto no período matutino, vespertino, quanto noturno, dependendo da disponibilidade do entrevistador em fazer as visitas.

Após coletados os dados, as respostas foram tabuladas em planilhas de Excel, compiladas em tabelas, alguns dados foram submetidos ao cruzamento de dados por meio do Software SPSS Versão 22 permitindo por meio de tabela cruzada verificar como uma variável se comporta em relação à outra. A análise estabeleceu a relação entre os controles de custos com a faixa etária dos pesquisados, o tamanho da propriedade, o faturamento, o financiamento e as informações de mercado.

\section{ANÁLISE DOS DADOS E DISCUSSÃO DOS RESULTADOS}

Nesta seção é abordado o perfil dos produtores rurais, as características das propriedades rurais e as ferramentas de controle e gestão utilizadas na atividade rural.

\subsection{PERFIL DOS PRODUTORES RURAIS}

Nessa seção é apresentado o perfil dos produtores rurais entrevistados. Em relação ao gênero $80 \%$ são do sexo masculino e $20 \%$ feminino. Essa disparidade de gênero leva a crer que o homem está mais envolvido na atividade rural que a mulher, seja no serviço braçal, seja na gestão dos negócios. Percebeu-se também, durante a aplicação das entrevistas que as mulheres acompanham seus maridos na gestão, mas quem ainda toma a frente nas contas da família é o homem. Esses dados refletem a realidade nacional em que $87 \%$ dos estabelecimentos são dirigidos por homens (IBGE, 2006).

No que se refere à idade dos respondentes, constatou-se que a população jovem na qual estão incluídas pessoas com menos de 20 
anos até os 30 anos, representam juntos, apenas $8 \%$ da população de produtores rurais, a faixa que compreende agricultores de 31 a 40 anos é representada por $7 \%$. Dos produtores entrevistados $31 \%$ disseram enquadrar-se na faixa etária dos 41 aos 50 anos, $33 \%$ dos 51 aos 60 , enquanto que os produtores acima de 61 anos representaram $21 \%$. Percebe-se que uma das características dessa atividade é possuir profissionais com maior maturidade, pois como observado, são poucos os profissionais jovens neste setor, e que a maioria dos produtores rurais possui de 41 a 60 anos de idade, ou seja, 86\%.

Em relação ao estado civil observa-se $88 \%$ dos produtores rurais são casados, $6 \%$ são solteiros, $2 \%$ viúvos e $4 \%$ não fazem parte destes estados civis, que em sua maioria, são os casais em união estável, os quais decidem viver juntos, mas não são casados perante a lei.

Quanto ao grau de instrução durante a entrevista nenhum dos entrevistados se manifestou como sendo analfabeto, por outro lado, verificou-se que $29 \%$ dos pesquisados possuem apenas 0 1ำ grau de ensino incompleto, 35\% completaram o 10 grau, $4 \%$ disseram não ter concluído o 2 o grau e $22 \%$ dos 130 entrevistados disseram possuir o $2^{\circ}$ grau completo. Fato importante é que 10\% dos produtores estão cursando ou concluíram o ensino superior demonstrando que, mesmo ainda sendo poucos, existem produtores que estão interessados no crescimento profissional do homem do campo.

No que se refere ao tempo que atua na atividade rural quase a totalidade dos produtores atua mais de 20 anos na atividade rural, de modo que, $87 \%$ afirmaram atuar a vida toda nesta atividade e os demais 13\% estão distribuídos entre os profissionais que atuam de 5 a 20 anos no setor.

\subsection{CARACTERÍSTICAS DA PROPRIEDADE RURAL}

A caracterização da propriedade é de fundamental importância para a compreensão da gestão de custos e do controle das atividades. Assim, 94\% dos produtores rurais são proprietários da área em que desenvolvem as suas atividades, alguns destes, também arrendam terras de terceiros. Apenas 6\% não possuem área própria e operam por meio da exploração de propriedades de terceiros.
Comparativamente, os dados do censo agropecuário indicavam que município apresentava uma concentração de $86 \%$ de estabelecimentos rurais próprios em 2006 (IBGE, 2006; IPARDES, 2017).

Dos 130 produtores entrevistados, 94\% possuem área própria, sendo que, 31\% obtiveram sua área de terra por meio de herança, $1 \%$ adquiriu parte da propriedade com herança e parte com financiamento, $47 \%$ obtiveram a sua área por meio de herança e com a renda da própria atividade. Ainda 15\% não tiveram nenhum incentivo, ou seja, adquiriram suas terras utilizando-se de recursos próprios. Os demais 6\% são representados pelos produtores que não possuem área própria, já que arrendam terras de terceiros.

Além da terra, o desenvolvimento das atividades rurais requer inúmeros investimentos, tais como: construção de infraestrutura, maquinários, equipamentos e insumos. Para conseguir manter a atividade, muitos produtores necessitam utilizar-se de incentivos financeiros, outros, porém, por possuir um bom capital de giro realizam investimentos por meio de recursos próprios, geralmente oriundos da renda da própria atividade. Neste sentido, Buainain et al. (2013) comentam que a produção e as rendas agropecuárias passam a depender, crescentemente, de investimentos e capital de giro para introduzir no sistema produtivo os insumos que viabilizam as inovações para manter-se rentável em ambientes de crescente tensionamento concorrencial.

Em relação à forma de aumento patrimonial nos últimos 10 anos: $20 \%$ justificam que o aumento patrimonial se deve pela renda das próprias atividades, $42 \%$ pela obtenção de financiamentos e pela renda própria, 7\% somente utilizaram financiamento, $20 \%$ pela diversificação de culturas agrícolas e pecuárias, $10 \%$ por meio de herança e 1\% que utilizaram outros meios para aumentar o patrimônio. Os produtores podem utilizar-se de diferentes formas de aumento de patrimônio.

A renda da propriedade aliada ao financiamento são os elementos que mais contribuem para aumentar os investimentos e como consequência o patrimônio. A renda própria e os financiamentos são recursos que estão intimamente ligados, tanto que, para a obtenção de financiamento, o usuário deverá 
possuir renda para que consiga honrar os seus empréstimos.

De 130 produtores entrevistados, 52 exploram propriedades de terceiros, seja na forma de arrendamento, parceria rural ou comodato. Isso em termos percentuais significa que do total de entrevistados, $40 \%$ dos produtores obtém renda por meio da exploração de propriedades de terceiros, enquanto que 60\% cultivam apenas área própria.

Considerando apenas os produtores que utilizam terras de terceiros, 73\% dos produtores que exploram terras de terceiros, por meio do regime de arrendamento (contrato agrário por determinado período de tempo), 25\% adotam a parceria rural (associação com terceiros), e apenas 2\% utilizam o comodato (empréstimo gratuito da área para cultivo).

Durante a realização das entrevistas percebeu-se que muitos agricultores com idade avançada, que estão sozinhos na atividade, pois seus filhos deixaram o campo em busca de estudos ou realização profissional, tem no arrendamento a única alternativa para a continuidade da atividade. Estes pequenos produtores, geralmente arrendam suas terras para produtores maiores, que possuem maquinário e infraestrutura para o cultivo da mesma.

Em relação ao tamanho da propriedade, a amostra de 130 produtores rurais do município de Marechal Candido Rondon - PR é constituída por pequenos produtores rurais. A pesquisa demonstra que $45 \%$ das propriedades do município são classificadas como minifúndio, ou seja, possuem área inferior a um módulo fiscal, o que equivale a 18 hectares, 44\% das propriedades são classificadas como pequena propriedade rural possuindo de 1 a 4 módulos fiscais (18 a 72 hectares), $11 \%$ incluem-se na média propriedade por possuírem de 4 a 15 módulos (72 a 270 hectares) e por fim, 1 produtor entrevistado se classifica como grande propriedade rural, por possuir mais de quinze módulos fiscais, mais precisamente uma área superior a 270 hectares.

Quanto às culturas desenvolvidas nas propriedades, verificou-se que a maioria dos entrevistados possui mais de uma atividade como fonte de renda da propriedade. Isso se explica principalmente pelas oscilações de preços, pelas intempéries e porque muitas vezes uma atividade complementa a outra, tornando-se viável o desenvolvimento em conjunto. Ressalta-se que essa questão permitia a opção de várias alternativas. Os agricultores entrevistados: 91\% cultivam milho, $75 \%$ soja, $62 \%$ atividade leiteira, $19 \%$ suinocultura, $12 \%$ piscicultura, $13 \%$ gado de corte, $9 \%$ trigo, $8 \%$ aviários e $31 \%$ praticam outras atividades.

Em relação a "outras atividades" destaca-se a horticultura, fruticultura, pastagem, mandioca, plantio de chia, feno, embutidos de carne animal, plantação de eucalipto, aveia, sorgo e cultivo de orquídeas. Destas atividades citadas, a que teve maior relevância, por ter sido mencionada por vários agricultores, é o cultivo da mandioca, seguido da pastagem, porém esta última serve como complemento a produção leiteira, não sendo uma fonte de geração de receita isolada.

Quanto às atividades rurais que representam maiores receitas nas propriedades mencionam-se: 29\% milho, 27\% soja, 22\% pecuária de leite, e na sequência produtos que não tiveram uma representatividade tão significativa, a suinocultura com $7 \%$, avicultura $3 \%$, piscicultura $2 \%$, pecuária de corte $2 \%$, e por último o cultivo de trigo $1 \%$. O censo agropecuário de 2006 apresentava como principal renda dos estabelecimentos rurais as lavouras temporárias com $44 \%$ e a pecuária com 53\% no município (IBGE, 2006; IPARDES, 2017).

Considerando que uma característica das propriedades é a diversificação de culturas, $50 \%$ dos produtores optam pela diversificação de culturas devido à maior rentabilidade (resultados financeiros obtidos), 19\% considera que a diversificação gera menor demanda por mão de obra.

Ainda $14 \%$ optam pela diversificação devido à linha de financiamento oferecida, 36\% preocupam-se com a preservação do solo, $38 \%$ possuem afinidade e experiência pessoal, ou seja, tratam-se de atividades das quais os produtores gostam e possuem experiência. Além de 35\% que desenvolvem as atividades para aproveitar a estrutura já existente e $8 \%$ restantes que possuem outros motivos como o desenvolvimento conjunto de várias culturas por se complementarem. O desenvolvimento de diferentes atividades proporciona maior segurança quanto à renda do produtor, pois quando uma atividade está em crise, a outra gera renda.

Analisando a relação entre o tamanho da propriedade e o faturamento anual percebese que apesar do município possuir um 
número significativo de minifúndios e pequenas propriedades, a receita obtida na exploração das atividades é significativa. Isso pode ser explicado pelos períodos de geração de receita de cada atividade. Uma propriedade que pratica a atividade leiteira tem geração de receita durante os doze meses do ano, enquanto que um produtor de milho obtém receita apenas duas vezes ao ano, e da soja, apenas uma vez.

Desse modo, os dados obtidos demonstram que $26 \%$ dos produtores possuem geração de receita bruta anual de 25.000,00 a $50.000,00$ reais, $23 \%$ arrecadam de $50.000,00$ a $100.000,00$ reais anualmente, $36 \%$ faturam de $100.000,00$ a $250.000,00$ reais. Os valores mais significativos como de 250.000,00 a $500.000,00$ reais provem de $10 \%$ dos produtores, de $500.000,00$ a 1.000.000,00 2\%, e acima de $1.000 .000,00$ somente $3 \%$.

Os proprietários rurais necessitam de recursos financeiros para o desenvolvimento de suas atividades, sendo utilizados no custeio de atividades produtivas, em projetos de investimento, em atividades de comercialização da produção e no suprimento das necessidades familiares. Os gastos incorridos durante o ciclo de produção e as receitas provenientes das vendas dos produtos, por vezes, apresenta uma defasagem que precisa ser equacionada com recursos próprios ou captados externamente (Mundo Neto e Souza Filho, 2005). Neste sentido, dos 130 produtores entrevistados 93\% já efetuaram algum tipo de financiamento, contra $7 \%$ que nunca realizaram este tipo de operação.

Para 64\% dos produtores a contratação de financiamento foi necessária para melhorar a atividade, na substituição de maquinários e equipamentos, $61 \%$ consideraram que os recursos apresentavam taxas de juros atraentes, 48\% como uma alternativa para ampliar a receita da família e diversificação. Ainda, $45 \%$ buscaram recursos por necessidade e como uma alternativa para o desenvolvimento das atividades, 29\% realizaram investimentos em nova atividade, com os recursos financiados e 59\% buscaram financiamentos para bancar o custeio dos insumos.

Os financiamentos contratados foram investidos em diversos setores: máquinas e equipamentos em $66 \%$ dos casos, custeio dos insumos $50 \%$, pecuária de leite $38 \%$, suinocultura $16 \%$, avicultura $8 \%$ e piscicultura
$5 \%$, sendo a área que menos recebeu investimentos. Outras áreas que receberam investimentos foram: fruticultura, horticultura, pecuária de corte, instalações e estufas.

De acordo com a pesquisa $89 \%$ dos respondentes que realizaram financiamentos para investimentos, obtiveram lucro devido aos investimentos que realizaram, apenas $4 \%$ não obtiveram lucros. Vale ressaltar que 9 produtores alegaram nunca ter realizado financiamentos, isso não significa que não tenham investido em suas atividades, apenas não utilizaram recursos de terceiros para realizá-los. Destaca-se que as linhas de financiamento, como Pronaf e microcrédito rural utilizadas não foram questionadas na pesquisa.

Ainda 97\% dos pesquisados utilizam mão de obra familiar. Destes, $85 \%$ de forma exclusiva, $3 \%$ não utilizam, ou seja, 4 pessoas desenvolvem a agricultura exclusivamente patronal. Em relação ao número de funcionários $10 \%$ possuem de 1 a 2, 3\% de 3 a 5 e $2 \%$ acima de 10 funcionários.

Embora não possuam funcionários, 93\% dos produtores rurais utilizam de serviços de terceiros. Isso ocorre geralmente em períodos de plantio e colheita, pois nem todos os produtores rurais possuem equipamentos e maquinários para tal fim, optando em terceirizar este serviço. O uso de serviços de terceiros também ocorre quando há um acúmulo ou um grande volume de trabalhos a serem desenvolvidos e quando há a necessidade de assessoramento da produção por um profissional especializado. Dos serviços mencionados, os serviços gerais representam apenas $26 \%$, enquanto que o plantio, colheita e preparação do solo correspondem a $71 \%$ e o que possui maior demanda dos produtores é a assistência técnica agronômica e veterinária com $87 \%$ dos respondentes.

Os produtores ainda foram questionados quanto à participação em entidades associativas: $85 \%$ participam em cooperativas agropecuárias, $72 \%$ cooperativas de crédito, $64 \%$ cooperativa de eletrificação rural, 52\% associação de moradores, $45 \%$ sindicato de trabalhadores rurais, $17 \%$ associação de produtores de leite, $8 \%$ associação de suinocultores e $1 \%$ associação de piscicultores. 


\subsection{FERRAMENTAS DE CONTROLE E GESTÃO UTILIZADAS NA ATIVIDADE RURAL}

Nessa seção são apresentadas as principais ferramentas de controle e gestão utilizados pelos pesquisados na atividade rural. Questionados sobre acesso à internet, 66\% têm acesso na propriedade. A rede mundial de computadores, apesar de não exercer influência direta sobre a gestão das atividades rurais, desempenha um papel fundamental, que é a informação e a comunicação. Por meio da internet o produtor pode inteirar-se sobre as tendências de seu negócio, como anda a agricultura em termos mundiais e nacionais entre outros benefícios.

Dos 86 produtores que disseram possuir acesso à internet em suas propriedades, nem todos utilizam este recurso. Alguns afirmaram que, o uso da internet é realizado exclusivamente pelos filhos, principalmente para fins acadêmicos. Por outro lado, percebeu-se que alguns produtores realmente demonstram interesse em atualizarse, seja para conectar-se virtualmente, seja para manusear o computador para a realização de controles de gestão.

Em relação ao acesso às informações 58\% dos produtores baseiam-se em informações como o preço das commodities no mercado agrícola e cotação do dólar, para a tomada de decisão quanto a comercialização dos seus produtos. Os $42 \%$ dos produtores que não utilizam de informações de mercado, por vezes, vendem seus produtos por necessidade para honrar seus compromissos financeiros de custeio, não possuindo capital de giro para aguardar o melhor momento de venda.

Questionados se os respondentes realizam controle de custos, despesas e receitas na propriedade, $89 \%$ dos produtores da amostra utilizam algum método de controle, contra $11 \%$ dos entrevistados que não fazem. Ideal seria que este procedimento fosse utilizado por todos os profissionais, seja da área rural ou não, por mais simples e rudimentar que fosse.

Os controles contábeis e de custos, revelam o andamento da atividade, se está dando lucro, se o negócio é viável, quando ocorrem as entradas e saídas de dinheiro. Enfim, são as ferramentas e/ou melhor maneira para controlar o patrimônio.

Quanto à forma que é realizado o controle na propriedade $21 \%$ afirma fazer o controle informal, sem anotações apenas mentalmente, o que leva a crer que, por vezes, alguns controles passam despercebidos. $63 \%$ dos produtores fazem o controle manual de suas atividades, por meio de anotações em um caderno. Além destes controles, $13 \%$ dos produtores administram suas atividades com apoio de planilhas no Excel. E 3\% possuem sistemas informatizados próprios ou realizam contabilidade em escritório terceirizado. Alguns produtores alegaram utilizar mais de um tipo de controle, como o informal associado ao controle manual ou controle manual juntamente com planilhas informatizadas em Excel.

No entendimento dos produtores rurais entrevistados os objetivos da gestão da propriedade são: controle de custos 63\%, planejamento futuro das atividades $55 \%$, apuração do lucro $48 \%$, controle do fluxo de caixa $47 \%$ e para atender exigências fiscais $19 \%$. Em se tratando do uso da contabilidade na gestão rural, a pesquisa buscou saber se os produtores a utilizam para planejar e projetar investimentos futuros. Assim, 77\% dos respondentes utilizam a contabilidade de custos para planejamento de investimentos futuros, enquanto que $23 \%$ não a utilizam.

Os produtores que planejam o futuro de suas atividades baseando-se na contabilidade de custos possuem bem definidos os seus objetivos: $42 \%$ desejam construir ou ampliar a infraestrutura, $41 \%$ em maquinários e equipamentos, 33\% buscam investir em novas áreas e atividades, $31 \%$ para realização de financiamentos, $18 \%$ querem investir em aquisição de terras e 13\% planejam viabilidade para a contratação de serviços de terceiros. Quanto aos benefícios percebidos pelos entrevistados que optam pelo controle de custos e despesas da atividade foram: redução dos custos de produção e aumento dos lucros $48 \%$, tomada de decisão com maior precisão $44 \%$, planejamento com base na lucratividade $40 \%$ e melhor controle $35 \%$. Ressalta-se que $12 \%$ consideram que não obtiveram nenhum benefício. Foram enquadrados neste último grupo os produtores que não realizam nenhum controle de custos ou porque realmente o produtor considera que a atividade não gerou benefício.

A pesquisa revelou que apenas 34\% dos produtores possuem interesse em adotar assessoria contábil rural, e melhorar a sua gestão amparada pelos serviços da contabilidade, enquanto $66 \%$ não querem 
utilizar esse tipo de serviço. Entre as justificativas dos produtores para não aderir à assessoria contábil, estão os altos custos que isso geraria aos usuários, destacando que não seria viável. Segundo os produtores as atividades rurais nem sempre são lucrativas, e por vezes, pela interferência de intempéries resultam em prejuízo, e a contratação da assessoria seria um custo desnecessário a ser honrado.

Outros ainda afirmaram que possuem poucas atividades e pouca movimentação financeira, e até o presente momento, estão conseguindo gerenciar os seus negócios sem necessitar do auxílio de profissionais especializados. Alguns produtores com idade mais avançada justificaram que, continuam na atividade apenas para se manter, já que, depois de se aposentarem vão mudar-se para a cidade, e quem ficará responsável por esses serviços serão os filhos, além de possuírem muita dificuldade no manuseio de sistemas informatizados. Outros, porém, destacaram a importância destes serviços, mas não possuem interesse, pois são qualificados na área, ou possuem profissional especializado na família para a execução de trabalhos relacionados a esse fim. Ou ainda, porque já possuem sistema informatizado e profissional encarregado da gestão dos negócios.

Quanto à contratação de escritórios contábeis para realização do imposto de renda pessoa física, contatou-se que são poucos os produtores que fazem a declaração de imposto nessa modalidade, apenas $47 \%$ do total de entrevistados. No entanto, nem todos os 53\% que optaram pela resposta negativa, deixam de fazer a declaração, já que alguns se enquadram na isenção e outros que cumprem a obrigação por intermédio do sindicato rural, além daqueles que não realizam a declaração do imposto por negligência.

\subsection{ANÁLISE CRUZADA DOS DADOS}

Os dados apresentados na Tabela 1 abaixo revelam que dos produtores entrevistados que se enquadram na faixa etária de até 20 anos, bem como daqueles que estão entre os 21 e 30 anos, todos eles fazem controle de custos. Enquanto, os produtores classificados entre os 31 e 40 anos de idade, apenas $55,6 \%$ fazem gestão de custos contra 44,4\% que não a fazem. A faixa etária com maior relevância foi a que enquadrou os produtores de 41 a 50 anos, na qual estão inclusos 40 produtores, sendo que $100 \%$ destes afirmam gerenciar seus custos. Os produtores da faixa etária seguinte, entre 51 a 60 anos, apesar de ser o grupo que compreende o maior número de entrevistados, não apresentou unanimidade na aderência à gestão de custos, de modo que $90,7 \%$ realizam controle de seus custos, enquanto 9,3\% não o fazem. Ao passo que, dos produtores acima de 61 anos $78,6 \%$ realiza algum tipo de controle de custos em oposição a 21,4\% que não fazem controle algum.

Tabela 1 - Faixa etária x Controle custos - Tabulação cruzada

\begin{tabular}{|c|c|c|c|c|c|}
\hline & & & Controle & le custos & Total \\
\hline & & & Não & Sim & \\
\hline & Até 20 anos & Contagem & 0 & 2 & 2 \\
\hline & & \% dentro de Faixa etária & $0,00 \%$ & $100,00 \%$ & $100,00 \%$ \\
\hline & De 21 a 30 anos & Contagem & 0 & 8 & 8 \\
\hline & & \% dentro de Faixa etária & $0,00 \%$ & $100,00 \%$ & $100,00 \%$ \\
\hline & De 31 a 40 anos & Contagem & 4 & 5 & 9 \\
\hline Faixa etária & & \% dentro de Faixa etária & $44,40 \%$ & $55,60 \%$ & $100,00 \%$ \\
\hline & De 41 a 50 anos & Contagem & 0 & 40 & 40 \\
\hline & & \% dentro de Faixa etária & $0,00 \%$ & $100,00 \%$ & $100,00 \%$ \\
\hline & De 51 a 60 anos & Contagem & 4 & 39 & 43 \\
\hline & & \% dentro de Faixa etária & $9,30 \%$ & $90,70 \%$ & $100,00 \%$ \\
\hline & Acima de 61 anos & Contagem & 6 & 22 & 28 \\
\hline & & \% dentro de Faixa etária & $21,40 \%$ & $78,60 \%$ & $100,00 \%$ \\
\hline Total & & Contagem & 14 & 116 & 130 \\
\hline & & \% dentro de Faixa etária & $10,80 \%$ & $89,20 \%$ & $100,00 \%$ \\
\hline
\end{tabular}

FONTE: Elaborado pelos autores (2015) 
$\mathrm{Na}$ Tabela 2 tem-se o cruzamento de informação quanto à faixa etária dos produtores rurais e o tipo de controle que utilizam para gerenciar suas atividades. Diante das informações, os produtores com idade até 20 anos tal como os produtores de 21 a 30 anos de idade, 50\% utilizam o controle de custos manual e $50 \%$ utiliza mais de um método, fazendo a associação entre os dois controles, como por exemplo, o controle manual associado ao controle por meio de tabelas no Excel.

Os produtores inseridos na faixa entre 31 aos 40 anos está subdividida em controle informal $20 \%$, controle manual $60 \%$ e tabelas informatizadas também 20\%. Daqueles com idade entre 41 a 50 anos, 20\% administra de maneira informal, sem anotações, 67,5\% efetua anotações por meio de controle manual, 5\% utilizam tabelas e planilhas informatizadas, e também 5\% são representados por aqueles que utilizam dois sistemas de controle simultaneamente. Enquanto que apenas 2,5\% possuem um sistema informatizado próprio para efetuar 0 controle de seus custos.
Por outro lado, os entrevistados enquadrados na faixa etária entre 51 aos 60 anos apresentam um percentual razoável de usuários do controle informal, o que representa $30,8 \%$. No entanto, a maioria opta pelo controle manual, ou seja, 54,5\%, enquanto que $17,9 \%$ utilizam dois tipos de controle simultaneamente. E por fim, produtores com idade superior aos 61 anos, $27,3 \%$ aderem ao controle informal e $54,5 \%$ ao manual, as tabelas informatizadas $4,5 \%$ e $13,6 \%$ utilizam dos controles de maneira conjunta.

Com base nestas informações notou-se que o controle informal é crescente, acompanhando o aumento das faixas etárias, e que o controle informal é mais frequente na gestão realizada pelos produtores de idade mais avançada. No entanto, estas análises não podem ser generalizadas, pois de acordo com a pesquisa, a maior parte dos produtores entrevistados enquadra-se nas maiores faixas etárias, representando a maioria no total da amostra.

Tabela 2 - Faixa etária x Tipo controle - Tabulação cruzada

\begin{tabular}{|c|c|c|c|c|c|c|c|}
\hline \multirow{2}{*}{\multicolumn{2}{|c|}{ Faixa etária }} & \multicolumn{5}{|c|}{ Tipo controle } & \multirow{2}{*}{ Total } \\
\hline & & Informal & Manual & Tabelas & Sistema & Mais de um & \\
\hline \multirow{2}{*}{ Até 20 anos } & Contagem & 0 & 1 & 0 & 0 & 1 & 2 \\
\hline & \% dentro da Faixa & $0,00 \%$ & $50,00 \%$ & $0,00 \%$ & $0,00 \%$ & $50,00 \%$ & $100,00 \%$ \\
\hline \multirow{2}{*}{21 a 30 anos } & Contagem & 0 & 4 & 0 & 0 & 4 & 8 \\
\hline & \% dentro da Faixa & $0,00 \%$ & $50,00 \%$ & $0,00 \%$ & $0,00 \%$ & $50,00 \%$ & $100,00 \%$ \\
\hline \multirow{2}{*}{31 a 40 anos } & Contagem & 1 & 3 & 1 & 0 & 0 & 5 \\
\hline & \% dentro da Faixa & $20,00 \%$ & $60,00 \%$ & $20,00 \%$ & $0,00 \%$ & $0,00 \%$ & $100,00 \%$ \\
\hline \multirow{2}{*}{41 a 50 anos } & Contagem & 8 & 27 & 2 & 1 & 2 & 40 \\
\hline & $\%$ dentro da Faixa & $20,00 \%$ & $67,50 \%$ & $5,00 \%$ & $2,50 \%$ & $5,00 \%$ & $100,00 \%$ \\
\hline \multirow{2}{*}{51 a 60 anos } & Contagem & 12 & 20 & 0 & 0 & 7 & 39 \\
\hline & \% dentro da Faixa & $30,80 \%$ & $51,30 \%$ & $0,00 \%$ & $0,00 \%$ & $17,90 \%$ & $100,00 \%$ \\
\hline \multirow{2}{*}{ Acima 61 anos } & Contagem & 6 & 12 & 1 & 0 & 3 & 22 \\
\hline & $\%$ dentro da Faixa & $27,30 \%$ & $54,50 \%$ & $4,50 \%$ & $0,00 \%$ & $13,60 \%$ & $100,00 \%$ \\
\hline \multirow{2}{*}{ Total } & Contagem & 27 & 67 & 4 & 1 & 17 & 116 \\
\hline & \% dentro da Faixa & $23,30 \%$ & $57,80 \%$ & $3,40 \%$ & $0,90 \%$ & $14,70 \%$ & $100,00 \%$ \\
\hline
\end{tabular}

FONTE: Elaborado pelos autores (2015)

A Tabela 3 disposta abaixo demonstra 0 cruzamento de informações entre o tamanho das propriedades rurais dos entrevistados com a informação dos produtores que fazem ou não o controle de custos evidenciando que dos produtores classificados como minifúndios, ou seja, que possuem área inferior a 18 hectares de terra, 86,2\% realizam 
algum tipo de controle de custos, em confronto com 13,8\% que não o fazem.

Dos produtores que detém de 18 a 72 hectares de terra, $89,5 \%$ faz gestão de custos, contra 10,5\% que não a faz. Enquanto os produtores classificados como médios produtores rurais, por possuírem área de $72 \mathrm{a}$ 270 hectares, todos eles adotam algum tipo de gestão de seus custos, o mesmo ocorre com os grandes produtores rurais, os quais possuem área superior a 270 hectares de terra. Observa-se claramente que os produtores que possuem maiores áreas de terra, fazem a gestão de custos de suas atividades, pois quanto menor o tamanho da propriedade menor foi o percentual de produtores que afirmaram realizarem a gestão de seus custos.

Tabela 3 - Tamanho propriedade x Controle custos - Tabulação cruzada

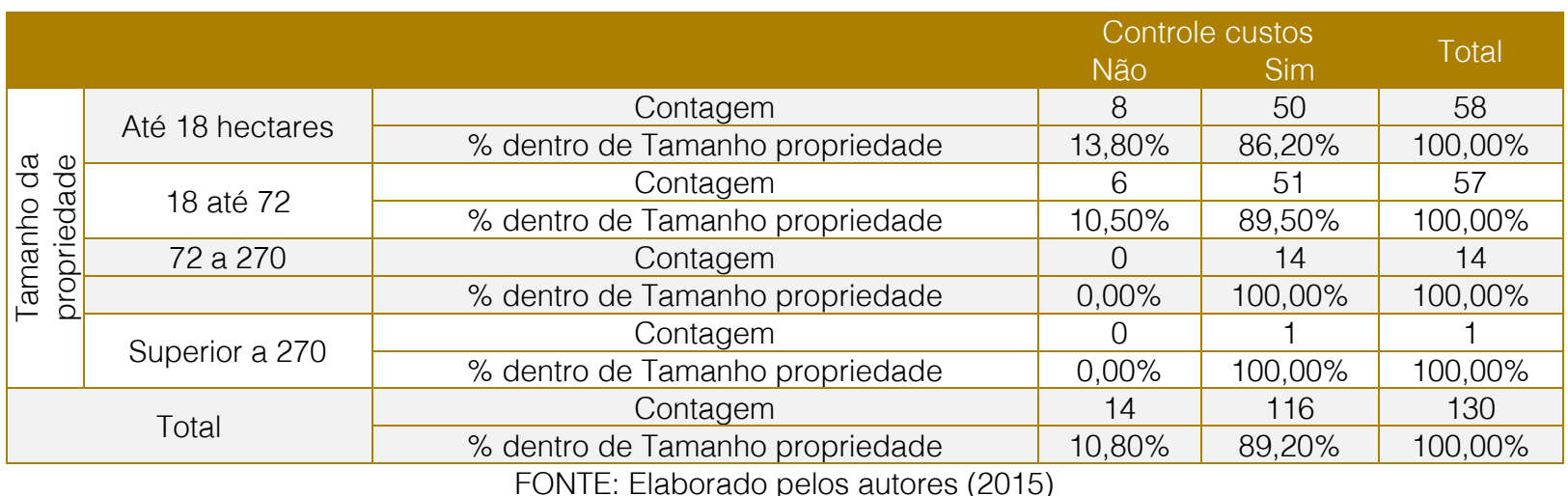

A Tabela 4 evidencia os resultados entre 0 cruzamento de dados referentes ao faturamento da propriedade, em comparação com o uso ou não de controle de custos. Os dados revelam que os produtores que possuem faturamento bruto anual de 25 a 50 mil reais, $76,5 \%$ gerenciam seus custos, e 23,5\% não faz nenhum tipo de controle. Dos produtores com faturamento de 50 a 100 mil, $86,2 \%$ fazem gestão de custos contra $13,8 \%$ que adota tais procedimentos. Daqueles que se enquadram na receita entre 250 a 500 mil reais $100 \%$ afirmaram gerenciar seus custos, assim como ocorre com os produtores que possuem 500 mil a 1 milhão de faturamento, ou acima de um milhão.

Assim como ocorre na relação à área da propriedade com a gestão de custos, a gestão de custos também acompanha o faturamento, quanto maior o faturamento, maior a preocupação dos produtores em relação ao gerenciamento dos custos.

Tabela 4 - Faturamento x Controle custos - Tabulação cruzada

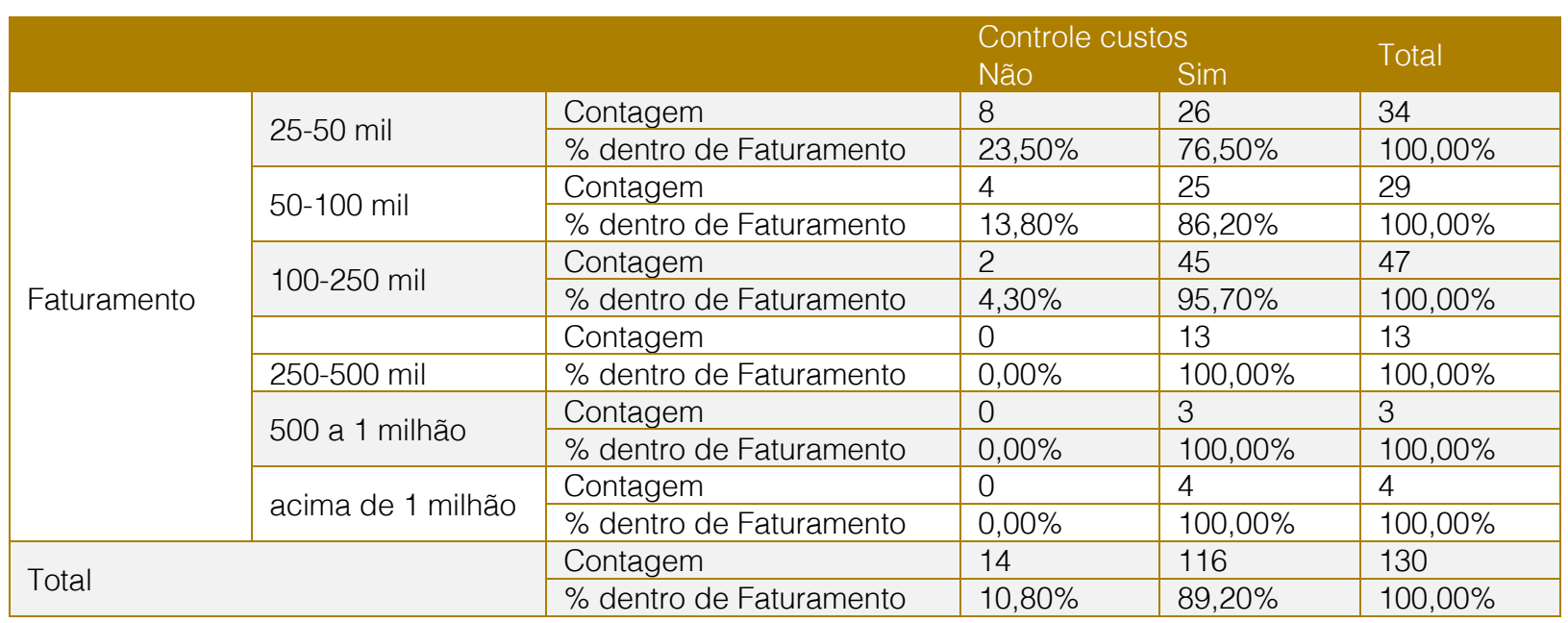

FONTE: Elaborado pelos autores (2015) 
Na Tabela 5 apresenta-se o cruzamento de informações entre controle de custos e a contratação de financiamentos. Pôde-se observar que os produtores que nunca contrataram financiamento $77,8 \%$ controlam os seus custos, enquanto que $22,2 \%$ não utilizam controle algum. Já daqueles que já utilizaram de contratação de financiamentos em suas atividades, 90,1\% fazem a gestão de custos, e 9,9\% não adotam tal procedimento.
Estas informações revelam que os produtores que financiam suas atividades ou fazem investimentos, praticam melhor controle de custos. Pode-se inferir, que isto se deve, principalmente para conseguir controlar as atividades e possuir recursos suficientes para honrar com seus compromissos.

Tabela 5 - Financiamento x Controle custos - Tabulação cruzada

\begin{tabular}{|c|c|c|c|c|c|}
\hline & & & \multicolumn{2}{|c|}{ Controle custos } & \multirow{2}{*}{ Total } \\
\hline & & & Não & Sim & \\
\hline \multirow{4}{*}{ Financiamento } & \multirow{2}{*}{ Não } & Contagem & 2 & 7 & 9 \\
\hline & & $\%$ dentro de Financiamento & $22,20 \%$ & $77,80 \%$ & $100,00 \%$ \\
\hline & \multirow{2}{*}{ Sim } & Contagem & 12 & 109 & 121 \\
\hline & & $\%$ dentro de Financiamento & $9,90 \%$ & $90,10 \%$ & $100,00 \%$ \\
\hline \multirow{2}{*}{\multicolumn{2}{|c|}{ Total }} & Contagem & 14 & 116 & 130 \\
\hline & & $\%$ dentro de Financiamento & $10,80 \%$ & $89,20 \%$ & $100,00 \%$ \\
\hline
\end{tabular}

FONTE: Elaborado pelos autores (2015)

A Tabela 6 apresenta informações semelhantes, porém, levam em consideração aqueles que se baseiam em informações de mercado para comercializarem seus produtos, em comparação com a gestão que adotam.

Tabela 6 - Informações de mercado x Controle custos

\begin{tabular}{|c|c|c|c|c|c|}
\hline & & & Controle & tos & Total \\
\hline & & & Não & Sim & $10 t c$ \\
\hline & & Contagem & 8 & 47 & 55 \\
\hline informações & IVau & \% dentro de Base informações mercado & $14,50 \%$ & $85,50 \%$ & $100,00 \%$ \\
\hline & & Contagem & 6 & 69 & 75 \\
\hline & (111 & \% dentro de Base informações mercado & $8,00 \%$ & $92,00 \%$ & $100,00 \%$ \\
\hline & & Contagem & 14 & 116 & 130 \\
\hline & & \% dentro de Base informações mercado & $10,80 \%$ & $89,20 \%$ & $100,00 \%$ \\
\hline
\end{tabular}

A Tabela 6 evidencia que dos produtores que não se baseiam em informações de mercado, como preço das commodities na bolsa de valores, cotação do dólar e outros, 85,5\% controlam seus custos e 14,5\% não controlam. Por outro lado, esses números melhoram no caso dos produtores que levam em consideração as informações de mercado para comercializarem os seus produtos. Dos que consideram essas informações, 92\% controla os seus custos e apenas $8 \%$ não faz controle algum. De modo geral, notou-se que quanto maior o produtor, maior o faturamento, sendo que, aqueles que utilizam de financiamentos e utilizam informações de mercado para comercializarem seus produtos, realizam um melhor controle de seus custos. 


\section{CONSIDERAÇÕES FINAIS}

O objetivo desta pesquisa foi verificar em que medida os produtores rurais de Marechal Cândido Rondon - PR utilizam as informações contábeis no gerenciamento de suas atividades. Os resultados indicam que a maioria $89 \%$ dos produtores utilizam algum tipo controle de custos na sua propriedade, mesmo que seja informal, sem nenhum tipo de anotações. O controle manual com $57 \%$ é o mais utilizado, poucos produtores utilizam controles mais sofisticados, como planilhas de Excel, sistema informatizado ou assessoria contábil por meio de escritório de contabilidade. No cruzamento de dados, constatou-se que os controles mais sofisticados são utilizados pelos produtores

\section{REFERÊNCIAS}

[1]. ANDRADE, M. M. (2003). Introdução a metodologia do trabalho científico: elaboração de trabalhos de graduação. (6a. ed.). São Paulo, Atlas, $174 \mathrm{p}$.

[2]. ARAÚJO, M. J. (2013). Fundamentos do agronegócio. (4a. ed.). São Paulo, Atlas, 175 p.

[3]. BARBOSA, C. A. (2008). Manual de Administração e Escrituração Rural. Viçosa, Minas Gerais, Agrojuris, 185 p.

[4]. BATALHA, M. O.; BUAINAIN, A. M. e SOUZA FILHO, H. M. (2005). Tecnologia de gestão e agricultura familiar. In: SOUZA FILHO, H. M. e BATALHA, M. O. (orgs.), Gestão integrada a agricultura familiar. São Carlos, Edufscar, 359 p.

[5]. BREITENBACH, R.; BRANDÃO, J. B. e VITALI, D. J. (2016). Gestão de custos em unidades de produção familiares especializadas no cultivo de soja no Norte do Rio Grande do Sul, Brasil. Revista Espacios. 37(23):22.

[6]. BUAINAIN, A. M.; ALVES; E.; SILVEIRA, J. M. e NAVARRO, Z. (2013). Sete teses sobre o mundo rural brasileiro. Revista de Política Agrícola. 22(2): 105-121.

[7]. CAllado, A. A. C. e CAlladO, A. L. C. (2011). Gestão de custos no agronegócio. In: CALLADO, A. A. C. (org.), Agronegócio. (3a. ed.). São Paulo, Atlas, 2011, p. 86-104.

[8]. CALLADO, A. A. C. e MORAES FILHO, R. A. (2011). Gestão empresarial no agronegócio. In: CALLADO, A. A. C. (org.), Agronegócio. (3a. ed.). São Paulo, Atlas, 2011, p. 20-29.

[9]. CREPALDI, S. A. (2009). Contabilidade Rural: uma abordagem decisorial. (5a. ed.) São Paulo, Atlas, 376 p. mais jovens, enquanto os produtores mais velhos utilizam os controles informais.

Conclui-se que o controle realizado pelos produtores tem como objetivo principal controlar os custos de produção e planejar o futuro das suas atividades. Assim, os controles proporcionam a redução dos custos, aumento dos lucros e auxiliam na tomada de decisão. O tamanho da propriedade e o faturamento obtido influenciam na gestão de custos, uma vez que, de acordo com o cruzamento de dados efetuado, verificou-se que quanto maior for a propriedade e o faturamento, melhor será o controle de custos das atividades desenvolvidos na propriedade.

[10]. DEBERTOLIS, A. J.; ALEXIUS M. L. e DOSSA, D. (2005). Trabalhador na administração de propriedades em regime de economia familiar. 2. ed. Curitiba, SENAR- PR, $119 \mathrm{p}$.

[11]. GODINHO, R. F.; SOARES, V. E.; BERTIPAGLIA, L. M. A. e DIAN, P. H. M. (2013). Gestão empresarial em sistemas de produção de leite na microregião de São João Batista do Glória/MG. Revista Ciência Et Praxis, 6(12):39-50.

[12]. HOFER, E.; PACHECO, V.; SOUZA, A. e PROTIL, R. M. (2011). A relevância do controle contábil para o desenvolvimento do agronegócio em pequenas e médias propriedades rurais. Revista Contabilidade e Controladoria, 3(1):27-42.

[13]. Instituto Brasileiro de Geografia e Estatística [IBGE]. (2006). Síntese de informações de Marechal Cândido Rondon - PR. Disponível em: http://biblioteca.ibge.gov.br/visualizacao/periodicos /51/agro_2006.pdf, Acesso em: 27/05/2017.

[14]. Instituto Paranaense de Desenvolvimento Econômico e Social [IPARDES]. (2017). Perfil avançado dos municípios: Marechal Cândido Rondon - PR. Disponível em: http://www.ipardes.gov.br/cadernos/MontaCadPdf1 .php?Municipio=85960\&btOk=ok, Acesso em: 27/05/2017.

[15]. LOURENZANI, W. L. (2006). Capacitação gerencial de agricultores familiares: uma proposta metodológica de extensão rural. Organizações Rurais \& Agroindustriais, 8(3):313-322

[16]. MARION, J. C. e SEGATTI, S. (2005). Gerenciando custos agropecuários. Custos e @gronegócio on line,1(1):2-8.

[17]. MUNDO NETO, M. e SOUZA FILHO, H. M. (2005). Problemas do crédito rural sob a ótica da 
Nova Economia Institucional. Revista de Ciências Gerenciais, 9(11):92-99.

[18]. RAUPP, F. M. e BEUREN, I. M. (2012). Metodologia da pesquisa aplicável às ciências sociais. In. BEUREN, I. M. (org). Como elaborar trabalhos monográficos em contabilidade: teoria e prática. (3a. ed.). São Paulo, Atlas, 195 p.

[19]. SIMPRINI, E. S. e LOPES, F. F. (2012).

Análise Interna. In: LOPES, F. F. (org).
Agroperformance: um método de planejamento e gestão estratégica para empreendimento agro visando alta performance. São Paulo, Atlas, p. 2748.

[20]. SOUZA FILHO, H. M. e BATALHA, M. O. (2005). Gestão Integrada da Agricultura Familiar. São Carlos, Edufscar, 2005. 359 p. 


\section{Capítulo 7}

\section{THE CORPORATE SUSTAINABILITY INDEX AND LEGITIMATE THEORY: A CORRELATION BETWEEN MARKET VALUE AND CLIMATE CHANGE}

\section{Emerson Andrade Gibaut}

Abstract: The study aims to analyze whether the practices of climate change are influenced by the market value of the companies that participate in the Corporate Sustainability Index (CSI). Were analyzed participating companies in the year 2015 and evaluated all your answers to climate change compared with its market value. To justify this relationship was presented the legitimate theory as a source to provide clarification to the stakeholders. In the field of sample were used 32 consolidated companies that responded to the questionnaire of CSI in 2015, according to the BM\&FBOVESPA. With the objective of testing the assumptions used in the study, we used the Mann Whitney test with the comparison of averages of several companies. The conclusion was that the companies that have higher market value have the best environmental practices.

Keywords: Market Value. Legitimate Theory. Climate Change. 


\section{INTRODUCTION}

The perception of a new market that directs your attention to the problems of sustainability, the environment and the preservation of the planet, is related not only with the economy, but also with the survival of humanity. The logic of the global economy that fosters the tireless pursuit for profit above all else, you can derive impacts on environment catastrophic. This happens because the products and goods produced are removed from the environment, pollute, degrade and negatively impact the ecosystem.

The consequence of this impact is global warming, the melting of glaciers and the extinction of thousands of species that contribute to the balance of the lives in the world. The central problem is that companies do not want to reduce their profits in exchange for a more balanced life and this logic of decompensated profit causes serious damage to the environment.

Due to a strong popular pressure and gradual awareness of society, the strength of recoveries of companies more transparent, less polluting and that are in tune with the politics of preserving the environment, has been suggested as a way forward in the business world. The formatting of a new time was able to observe that the requirement of the investor turned not only for profit, but to the ethics of businesses, to an awareness of business methods and of a minimal speech harmful to the environment.

The companies now respond to questionnaires that facilitate the assessment of the investor, because these issues reveal their environmental practices used. From there, the investor can analyze your criteria for the approval or disapproval of environmental policies used by the companies. In this scenario, one may ask: what is the impact of the efficiency of entrepreneurial attitudes that contribute to the preservation of the environment? What attitudes can be representative in the face of environmental actions of companies in the stock market?

These issues represent a new global trend of interpretation and a new sense of demand of enterprises, effective policies capable of interfering with the condition of the environment. The research is justified using disclosures that directly interfere in the actions of the environmental dimension. The effects of these actions reflect directly on the company's image, in expectation of the consumer and in the general opinion of the market. Seek to analyze how the market value has a decisive influence on the actions of the policies of efficiency of climate change is the primary objective of the study that investigated the wallets of theoretical year of 2015 .

\section{THEORETICAL FRAMEWORK}

\subsection{LEGITIMATE THEORY}

For Dias Filho (2008), the legitimate theory is derived from the theory of contracts and begins to be used in the accounting area, particularly in studies that seek explanations for the adoption of certain mechanisms for disclosure. Therefore, it is based on the idea that there is a contract between the organizations the society in which they operate based on the system of beliefs and values. In this way, even second Dias Filho (2007), it is assumed that the companies are legitimate to the extent that they align their practices with the norms and standards of behavior advocated in the environment in which they operate.

The legitimate theory has been widely used to explain the motivation of organizations to disseminate environmental information volunteers, especially in industries more environmentally polluting. The legitimacy is a widespread perception that part of the judgment on the appropriateness of the actions of an entity within a system is socially constructed norms, values, beliefs and definitions (Suchman, 1995, p. 574).

The disclosure of information related to the actions of the organization facing the environment aims to reduce the pressures of society and demonstrates that it is corporate social responsibility, and this makes their acceptance and approval by the stakeholders. In this way, it becomes clear that the accounting practices related to disclosure of information, environmental influence and are influenced by the social demands, to seek alignment with these to survive in the market where do all their activities.

In this sense, Hopwood and Miller (1994) claim that, from the point of view of institutional theory, the accounting practices cannot be understood with neutrality, but from the interactions that performs with society. It can be said that the environmental disclosure is a mechanism for enterprises to legitimize the market environment of companies. 
In this context, Meyer and Rowan (1977, p. 340) believe in organizations adopt practices and procedures to achieve legitimacy, reaching your goals of continuity in the market, regardless of these practices are or are not efficient. Therefore, the adoption of certain accounting practices, techniques and structures institutionalized by some companies and regarded as legitimate by society, influences other companies to adopt, without a rational analysis of the instruments that are incorporating. It is, therefore, that the structures are coated with social character and that can influence the internal public and external to the organization.

For Gibaut and Dias Filho (2015), the participation of business indicators related to the environment can be used as a mechanism of response to the requirements of stakeholders. The aim is to ensure that the company is aligned with the expectations of the market, from this context, the actions company policies are geared toward the support of the social visibility and the ability to manage responsible policies.

It is clear, therefore, that the good performance of the organization is not bound only to the efficiency of technical factors adopted by the same, but also the ability to develop processes isomorphic in scenarios of similar conditions. Businesses gain or maintain legitimacy by means of incentives in the strategy of the use of business communications, including in addition to financial information, environmental information that serve as an instrument of legitimacy.

Thus, one of the instruments of legitimacy used by organizations is the disclosure of information, environmental volunteers, since these types of information are aligned with the demands of society. However, despite the growth in the volume of such information, it is necessary to improve the quality and quantity of information reported. In this scenario, the discussion of the impossibility of decisionmaking more reliable, since the disclosure of this information does not accurately reflect the risks inherent in the development of the activities of enterprises.

\section{METHODOLOGICAL PROCEDURES}

The methodology adopted from the sectors accounted for analysis, in accordance with the instrument of responses of climate change. The Corporate Sustainability Index (CSI) encourages an analysis of investments aimed at sustainability. The CSI aims to provide the actions adopted by the companies that participate in the stock market and who use practices related to the environment.

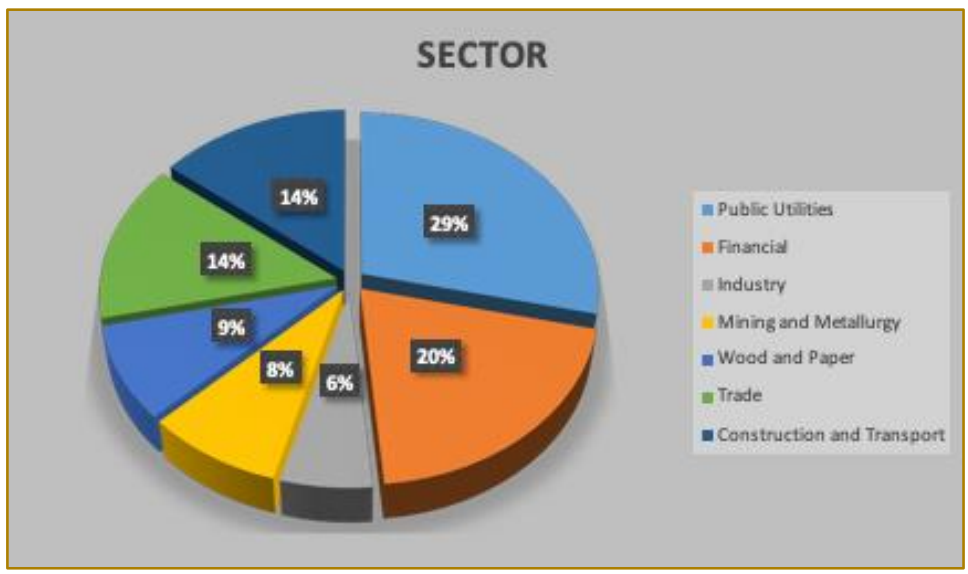

Source: own elaboration

The companies accounted for by the CSI represented 32 consolidated companies that participated in the questionnaire. The answers are political actions toward the environment and its resolutions according to their attitudes toward the preservation of the environment. The survey divided across seven sectors that have contributed to the discussion and technical analysis of the customers who participate in CSI.

The questions address issues within the sustainability and the actions that companies develop to preserve the environment, for the balance of the ecosystem and combat the extinction of species. The efficiency of an 
environmental planning of enterprise not only serves to contribute to the medium, but with the legitimacy of the company and social recognition to the world. It is logical that companies seek to maximize their profits, but this must be done with responsibility.

There are companies that, by presenting profits higher, consequently, become more visible on the pressures of the media, the local population and especially the government. The stakeholders are more attentive to this fact, because they are businesses that attract attention through it financial size and cost. This impact interferes directly in the actions of the climate change policies and actions that companies develop for your well being and improving its visibility to stabilize the market.

To legitimize the market, companies invest in social programs, sport in underserved communities, with the aim of obtaining the feeling of responsibility called by society. These actions correspond to a process of positive visibility of the company to get better appreciation of the society, ease of credit in banks, recognition of consumers, continued growth of profit, constant increase of consumers, adhesion of the mark to the product. All these acts constitute encouragements to the stability of the company and perpetuation in the enterprise market.

The process of devastation of the environment does not necessarily by the process of increasing awareness of the people and especially of attitudes of businesses to halt the advance of the degradation of the world. Sustainable actions are increasingly necessary to contribute to a healthy life on the planet. With the crisis of global warming, companies seek to differentiate them in the market through further elaboration of processes of consumption, with the goal of achieving its competitive advantage. Environmental responsibility must be seen as a necessity for survival and also constitutes a promising market, because the moment of crisis, companies are distinguished by their ability to manage and innovation.

Sustainability is a concept that relates the continuity of economic aspects and the preservation of the environment. For an economy that can support is required the participation of companies whose shares are reversible and of control of non-renewable resources, such as water and energy.

The study was segregated in various sectors to lend credibility the characteristics of utility each company. The asset of the company is potentially influenced by its market value, despite that, sometimes, companies with active low have high market value. This is due mainly in technology companies like Google, Microsoft, Apple and others. The debate on the companies that have a higher market value as a function of effective actions for sustainability condition its proportionality in accordance with the visibility evaluated on the stock market. The application of resources geared to environmental area is related with the financial growth the company's future and the expectation of growth in the coming years the company based on cash flow.

The study aims to analyze the responses that companies have implemented based on the Corporate Sustainability Index in the portfolio in 2015, listed on BM\&FBOVESPA. The composition of the sample was 32 companies for their replies to the questionnaire on climate change.

The politics of efficiency was considered based on responses of the questionnaire of Corporate Sustainability Index that companies must respond. This disclosure of responses of corporate actions are conditioned the legitimacy that the company has with respect to the market.

From an analysis that determines the market value based on political action on climate change, whose theme refers the prospects that companies have in the face of environmental responsibility, reducing environmental costs, preservation of natural resources and possible legal proceedings involving the company.

HO: The market value of companies is not related to best practice of climate change.

$\mathrm{H1}$ : The market value of companies is related to best practice of climate change.

The construction of these hypotheses has come through the understanding that companies with higher market value have more strength to cope with climate change and select the best responses in the light of his character. 


\section{1}

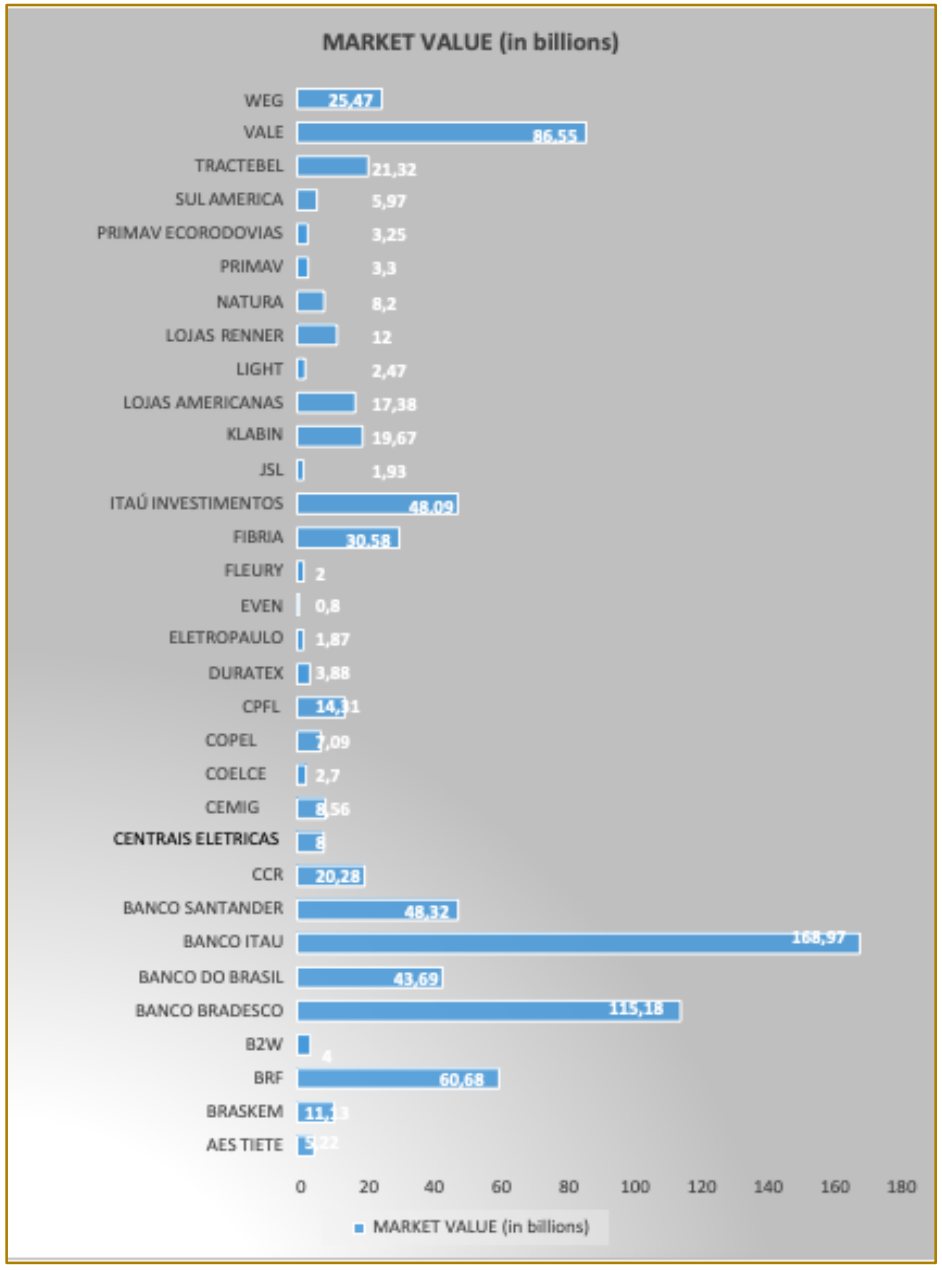

The issues addressed in the CSI, match the

management of the company within the guidelines for the planning process and politics of climate change the following:

\begin{tabular}{|c|c|}
\hline A & $\begin{array}{l}\text { Incorporating the analysis of GHG emissions in the selection and development of suppliers } \\
\text { and service providers }\end{array}$ \\
\hline B & Promotion and encouragement of energy efficiency \\
\hline C & Promoting and encouraging the use of renewable energy \\
\hline D & $\begin{array}{l}\text { Promoting and encouraging the reduction of GHG emissions associated with the transport and } \\
\text { Logistics }\end{array}$ \\
\hline$E$ & $\begin{array}{l}\text { Promotion and encouragement of technological innovation and R\&D for the reduction of GHG } \\
\text { emissions in the production and marketing of goods or services }\end{array}$ \\
\hline $\mathrm{F}$ & $\begin{array}{l}\text { Promoting and encouraging the development of new products, services and/or business models } \\
\text { that allow for the reduction in GHG emissions }\end{array}$ \\
\hline G & Establishment of goals for the reduction of GHG emissions \\
\hline $\mathrm{H}$ & Compensation of GHG emissions \\
\hline 1 & $\begin{array}{l}\text { Establishment of variable remuneration linked to performance in the reduction of GHG } \\
\text { emissions to its executives and employees }\end{array}$ \\
\hline J & Identification of risks and vulnerabilities, in order to adapt to climate change \\
\hline K & None of the above \\
\hline
\end{tabular}

Source: own elaboration 
These guidelines contribute to coping with climate change through the encouragement of renewable energy, reducing pollutant gases and other compensatory measures that promote a considerable improvement to the environment. From this table, we dealt with which companies have contributed effectively to revert this situation. From the analysis of the data, was the construction of a framework that measured the efficiency of each company promoting the allocation of points for this system.

The following chart delineated the condition of efficiency of each company participating in the CSI. To do this, assign points to each answer. The score was given a point for each positive response and no point for each negative response, in other words, the absence of a response does not applied to loss of score, but just not marking the same. In a system of percentage, was given the charge of $100 \%$ if the marking of all the answers. The company that does not marked no response, therefore, get zero, demonstrated its inefficiency of the fight against climate change.

\section{ANALYSIS OF RESULTS}

Taking as a basis the resolution of alternatives given by CSI, it can be noticed that there is a greater interest on the part of public utility companies and mining companies in dealing with the management of incentives for renewable energy and offset the greenhouse gases.

The rule of hypothesis test used was the test of median of independent samples from the measurement of the test for the comparison between medium, with the objective of checking if the market value is or is not associated with the practices of effective sustainability proposal by CSI. It is important to understand that only one aspect of the Corporate Sustainability Index, within the responses of climate change, was considered, in this case, the politics criterion.

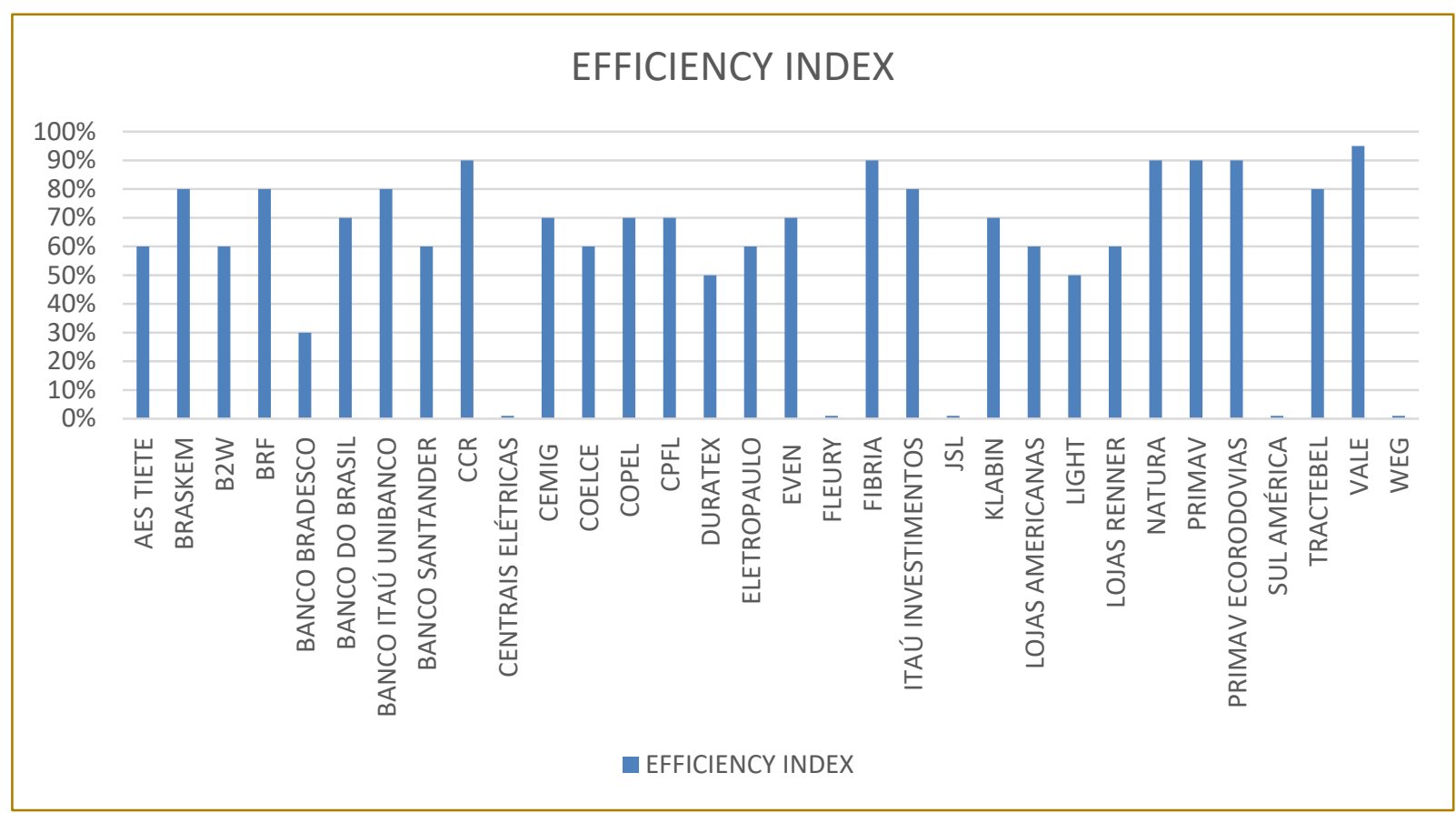

Source: own elaboration

Through this graph you can see that, among the banks, only the Banco Itaú Unibanco S.A. and Banco do Brasil S.A. have an efficiency of $80 \%$ and $70 \%$, respectively. Making it clear that the Financial sector does not have a commitment to climate change. Unlike the industry Mining and Metallurgy, where Vale S.A. and CCR S.A. have $95 \%$ and $90 \%$, respectively, for the operation of the politics of climate change.

This demonstrates that the businesses that deal directly with the environment, by means of machinery, mining, transport, fuel, are more prone to have attention in relation to environmental problems. Already the entities 
that are "far away" the activity of commercial products, there is little concern with the problems of nature.

Even under this perspective, you can make it clear that the corporations of Public Utilities also have a concern with this chaotic scenario environmental, with an average of $70 \%$ between them. This occurs because there is a visibility marked since these corporations provide services for the whole of society, then the collection of government and other interested parties are active and constant.
Companies with the highest market value are not efficient in politics of climate change and that varies in each sector for its performance. The hypothesis $\mathrm{HO}$ must be rejected, because "the market value of companies is not related to best practice of climate change" corresponds to a hypothesis false. Therefore, it is confirmed the hypothesis $\mathrm{H} 1$ to show that the market value of companies is related to best practice of climate change.

Test of Hypotheses

\begin{tabular}{|c|c|c|c|}
\hline \multicolumn{1}{|c|}{ Tull Hypothesis } & Significance & Decision \\
\hline $\begin{array}{c}\text { The market value of the } \\
\text { company is associated } \\
\text { with the best efficiency of } \\
\text { planning and management } \\
\text { of the ISE. }\end{array}$ & $\begin{array}{c}\text { Test of median of } \\
\text { independent samples }\end{array}$ &, 0133 & $\begin{array}{c}\text { Reject the null } \\
\text { hypothesis }\end{array}$ \\
\hline
\end{tabular}

Through a measurement by Statistical Package for the Social Sciences, it was possible to verify the rejection of the null hypothesis. The best practices are associated with the market value due to a requirement of large companies caused by the strong social visibility and governmental pressure. Companies seek, therefore, presenting the best possible image, avoid the mistakes, with the permanent objective of maximizing their profits. The environmental actions are useful for improving practices that preserve the environment, however, these practices are used as a mechanism to ensure the legitimacy.

\section{FINAL CONSIDERATIONS}

The objective of this study was to diagnose as the market value influences the capacity to react to actions that would reduce the environmental improvement. These actions are directly linked to its ability to representativeness through the legitimacy that favor the good image.

It can be said that there is a relationship between the market value and the actions of environmental policies. This can be considered favorable due to the resources that large companies have to invest in the conditions of preservation of the environment.
Small businesses are more concerned with their immediate survival and the appearance of the environment is far from being a discussion on the life of these companies. However, in larger companies this discussion serves as an instrument to legitimize the market and be able to differentiate from the others with the goal of obtaining attention.

The entities that have lower market value are more concerned with the politics of the ISE, this can be explained because the smaller companies tend to have a greater interest in its growth and sell directly with materials that entail higher costs and damage to the environment. The interesting thing is that the larger companies do not act with management politics and planning for climate change, but you can have an idea that they legitimize the market through of the constant use of marketing.

The most significant of the stakeholders is because of the larger firms, because companies are large, therefore, all their attention on their respective actions are on their behalf. As a suggestion, is the using other indices of accounts, such as for example, active, passive, level of indebtedness, earnings per share, degree of financial leverage, operating margin and the indices of liquidity. 


\section{REFERENCES}

[1]. BOLSA DE VALORES DE SÃO PAULO (BM\&FBOVESPA). Índice de Sustentabilidade Empresarial (ISE). 2015. Availabe in: $<$ http://www.bmfbovespa.com.br/Pdf/Indices/ISE.p df>. Acesso em: 13. Set. 2016.

[2]. DIAS FILHO, José Maria. 2008. A Pesquisa Qualitativa sob a Perspectiva da Teoria da Legitimidade: Uma Alternativa para Explicar e Predizer Políticas de Evidenciação Contábil. Enanpad.

[3]. DIAS FILHO, José Maria. 2007. Políticas de Evidenciação Contábil: Um Estudo do Poder Preditivo e Explicativo da Teoria da Legitimidade. ANPAD.
[4]. GIBAUT, Emerson A; DIAS FILHO, José Maria. 2015. As Respostas das Empresas Brasileiras às Mudanças Climáticas: uma Análise à Luz da Teoria da Legitimidade. ENGEMA, Universidade de São Paulo.

[5]. HOPWOOD, Anthony G.; MILLER, Peter. Accounting as social and institutional practice. New York: Cambridge University Press, 1994.

[6]. MEYER, John; ROWAN, Brian. Institutionalized organizations: formal structure as myth and cerimony. In: American Journal of Sociology, 1977.

[7]. SUCHMAN, Mark C. Managing legitimacy: strategic and institutional approaches. Academy of Management Review, v. 20, n. 3, p. 571-610, 1995. 


\section{Capítulo 8}

\section{CRISE ECONÔMICA E A EVOLUCÃO DAS DESPESAS COM PESSOAL NAS ADMINISTRAÇÕES MUNICIPAIS DO LITORAL DE SANTA CATARINA}

\section{Francisco Xavier Soares Filho}

José Simão de Paula Pinto

Ademir Clemente

Resumo: Apresenta a contextualização com o momento político e econômico do Brasil no $2^{\circ}$ semestre do ano de 2015 , e a questão do agravamento da crise política e principalmente econômica. Analisa as finanças públicas na crise e a perspectiva de reduções salariais dos agentes políticos, dos cargos comissionados, diminuições de funções gratificadas, entre outras medidas da austeridade fiscal. A justificativa está relacionada com a necessidade de redução de custos de pessoal para equilibrar as contas públicas, a partir de uma queda nas arrecadações em função da crise econômica. O trabalho busca analisar o comportamento da série histórica da Receita Corrente Líquida (RCL) nos 31 Municípios do litoral catarinense, e verifica o grau de comprometimento de gastos de pessoal com a RCL, com fulcro na Lei Complementar no 101/2000. Utilizou-se informações da base de dados do site "Portal Cidadão", mantido pelo Tribunal de Contas de Santa Catarina (TCE-SC), e alimentado pelos próprios Municípios catarinenses por meio do software denominado "E-Sfinge". O período da análise ocorreu entre o $1^{\circ}$ quadrimestre de 2008 até o $3^{\circ}$ quadrimestre de 2014. Por fim, com base nos dados da pesquisa, foi possível constatar que a RCL, apesar da crise, apresentou crescimento em todos os municípios analisados no período da pesquisa, especialmente no litoral norte de SC. Os quatro municípios com maior crescimento percentual da RCL foram, respectivamente, Araquari, Palhoça, Navegantes e Itapoá. O município da Penha apresentou a maior redução do comprometimento de gastos de pessoal com a RCL no Poder Executivo Municipal. E a Câmara Municipal de Barra do Sul apresentou a maior redução do comprometimento percentual da $\mathrm{RCL}$ com despesas de pessoal.

Palavras-chave: gastos de pessoal. contabilidade pública. litoral de Santa Catarina. 


\section{INTRODUÇÃO}

O presente artigo traz uma análise da evolução dos gastos de pessoal nas Prefeituras e Câmaras Municipais do litoral de Santa Catarina, a partir do ano de 2008, com dados extraídos do site portal cidadão, disponibilizado pelo Tribunal de Contas de Santa Catarina, de acordo com dados remetidos pelos próprios Municípios através do sistema denominado e-Sfinge.

A análise dos gastos com pessoal dos servidores públicos, tanto do Poder Executivo quanto do Poder Legislativo, é um tema oportuno, de grande relevância contemporânea, tendo em vista a crise política e econômica vivenciada pelo Brasil a partir do primeiro ano de gestão do $2^{\circ}$ mandato da Presidente reeleita Dilma Rousseff (G1, 2015).

A partir da ação do Poder Judiciário, na operação denominada "Lava Jato", em que estão sendo revelados esquemas de corrupção, com o pagamento de propina e outros delitos envolvendo políticos, especialmente os integrantes da base governista, no escândalo denominado de "Petrolão", na empresa de economia mista federal Petróleo Brasileiro S.A. (FOLHA, 2015), e diante de uma insatisfação generalizada com os Governos, a sociedade brasileira passou a organizar protestos nas ruas, fiscalizar e cobrar com mais rigor a justa retribuição dos impostos confiados aos Governos, com a expectativa de uma melhora na prestação dos serviços públicos tanto do Governo Federal, quanto dos Governos Estaduais e Municipais (EXAME, 2015). Tratase de um movimento de indignação generalizada contra os agentes políticos, e com reflexos em todas as esferas e níveis de Governo, inclusive na economia brasileira.

Nos últimos meses, diversos Prefeitos e Presidentes de Câmaras Municipais de Santa Catarina, na expectativa de reagirem ao crescimento da insatisfação generalizada da sociedade com os agentes políticos e diante do agravamento da crise econômica nacional, passaram a anunciar medidas de redução salarial, exonerações de cargos comissionados e consequente redução de despesas com pessoal (DIA, 2015). É um movimento que ocorre em vários municípios do Brasil, e também em Santa Catarina, e que além da iniciativa dos agentes políticos, notase a iniciativa da redução dos gastos de pessoal a partir dos Projetos de Lei de iniciativa popular, nos termos do inciso XIII, art. 29 da Constituição Federal de 1988.

Nesse sentido, diante do cenário apresentado acima, suscita-se alguns questionamentos: Quais os municípios que apresentam os maiores comprometimentos de suas receitas públicas próprias para pagamento das despesas de pessoal, e que em tese, mais precisam reduzir suas despesas; qual o comportamento da arrecadação de impostos nos municípios; e quais os municípios que mais aumentaram e mais reduziram seus gastos de pessoal da administração municipal nos últimos anos.

Como forma de colaborar com o debate qualificado de redução dos gastos de pessoal em Santa Catarina, a presente pesquisa busca trazer informações relevantes e fidedignas com o objetivo de tabular, classificar e comparar os gastos com pessoal, com o recorte para análise dos municípios do litoral de Santa Catarina, para verificar a evolução histórica e para oferecer subsídios informacionais para a tomada de decisão dos gestores públicos municipais e sociedade.

Foram analisados apenas os gastos de pessoal dos Poderes Executivo e Legislativo municipais do litoral de Santa Catarina. Portanto, trata-se de uma amostra intencional e que aconteceu em função da decisão do pesquisador. A motivação da escolha aconteceu tendo em vista o tempo para a coleta, tabulação e análise dos dados, e também diante da semelhança no perfil econômico do litoral catarinense, com exceção das duas maiores cidades do Estado, Joinville e Florianópolis, além do crescimento populacional acima da média estadual localizado principalmente ao longo da rodovia BR 101, que corta o território catarinense no sentido norte-sul, acompanhando a linha costeira. O litoral catarinense possui uma vocação natural para o turismo e prestação de serviço, e de modo geral apresenta pouca atividade industrial e um perfil econômico de certa forma semelhante (PEREIRA, 2011).

\section{GASTOS DE PESSOAL NA ADMINISTRAÇÃO MUNICIPAL}

A partir da Lei Complementar no 101/2000, popularmente conhecida como Lei de Responsabilidade Fiscal (LRF), foi regulamentado a fixação de despesa total com pessoal, em cada período de apuração, 
para os Municípios, com a determinação que os gastos com pessoal não podem exceder o percentual de 60\% (sessenta por cento) da receita corrente líquida (artigo 19), sendo distribuídos (artigo 20) o limite de 6\% para o Poder Legislativo e 54\% para o Poder Executivo (BRASIL, 2000).

O artigo 169 da Constituição Federal de 1988 dispõe que "a despesa com pessoal ativo e inativo da União, dos Estados, do Distrito Federal e dos Municípios não poderá exceder os limites estabelecidos em lei complementar". Portanto, por determinação expressa constitucional, criou-se no Brasil uma limitação dos gastos de pessoal da administração pública direta (BRASIL, 1988).

A LRF trouxe um importante avanço para uma gestão fiscal equilibrada nas contas públicas, sendo responsável por uma das legislações mais importantes da história política do Brasil e que contribuiu e continua contribuindo para o equilíbrio fiscal e progresso ordenado em todos os níveis e esferas da administração pública do Brasil (COELHO; FARIA, 2000; LUQUE; SILVA, 2004; GERIGK; CLEMENTE, 2011; GOULART, 2012).

\subsection{DESPESAS COM PESSOAL DA ADMINISTRAÇÃO MUNICIPAL NO LITORAL CATARINENSE}

Historicamente, a ocupação do litoral catarinense e o seu desenvolvimento seguiram um progresso distinto do restante do Estado devido ao processo de ocupação e da condição geográfica de divisão do Estado pela Serra do Mar. Os municípios litorâneos apresentam semelhanças em seus perfis de atividade econômica, com destaque para o perfil turístico, sazonalidade da população na alta temporada, e predominância da prestação de serviços como principal atividade econômica (MARIA; PEREIRA, 2003; PEREIRA, 2011)

Nesse sentido, a análise e comparação de dados fiscais e econômicos das despesas entre os municípios da faixa litorânea de Santa Catarina são relevantes para a sociedade e para os Governos, pois permitem importantes comparações no desempenho dos gastos públicos municipais. Comparar as contas de Araquari, Itapoá e Porto Belo, por exemplo, é algo relevante, pois há um perfil econômico semelhante entre esses municípios e é possível criar e comparar importantes indicadores de gestão pública para subsidiar tomadas de decisões pelos administradores e pela sociedade.

O objetivo geral do trabalho é de analisar o comportamento da série histórica do percentual de comprometimento da Receita Corrente Líquida (LRF) com as despesas de pessoal, conforme definido no art. 19 inciso III e no art. 20, alíneas a e b do inciso III, da LRF, nos Poderes Executivo e Legislativo dos municípios do litoral de Santa Catarina, de 2008 até 2014. O ano de 2008 foi escolhido, tendo em vista a disponibilidade somente a partir desse ano das informações disponíveis para consulta no Portal Cidadão do TCE-SC. A análise foi baseada no dispositivo da LRF, conforme segue:

"Art. 19. Para os fins do disposto no caput do art. 169 da Constituição, a despesa total com pessoal, em cada período de apuração e em cada ente da Federação, não poderá exceder os percentuais da receita corrente líquida, a seguir discriminados:

[...]

III - Municípios: 60\% (sessenta por cento).

[...]

Art. 20. A repartição dos limites globais do art. 19 não poderá exceder os seguintes percentuais:

[...] III - na esfera municipal:

a) $6 \%$ (seis por cento) para o Legislativo, incluído o Tribunal de Contas do Município, quando houver;

b) $54 \%$ (cinquenta e quatro por cento) para o Executivo." (BRASIL, 2000).

\subsection{METODOLOGIA}

A metodologia expõe os caminhos que foram percorridos no levantamento dos dados do estudo, quais e como as informações foram pesquisadas e coletadas, qual o método adotado, como objetivo final de responder ao problema de pesquisa (GIL, 1999). A metodologia deste trabalho foi dividida na descrição da variável "Percentual de Gastos de Pessoal", população e amostra, delimitação da pesquisa, técnicas de coleta, análise e tratamento adotado e limitação da pesquisa. 


\subsubsection{VARIÁVEL PESQUISADA}

O foco da pesquisa é a análise da variável "Percentual de Gastos com Pessoal", que remete ao grau de comprometimento das administrações municipais. O percentual de gastos de pessoal é a razão do montante total de gastos das despesas da folha de pagamento e patronal, com o montante da Receita Corrente Líquida executada nos últimos 12 meses.

A variável serve para impor os limites máximos de despesas com pessoal definidos na LRF, e para sinalizar os limites prudenciais de novas vinculações de despesas (aumentos salariais para os servidores, novas contratações de cargos comissionados, despesas com funções gratificadas, abonos, horas extras, contrato temporário de prestadores de serviço, entre outras despesas relacionadas com pessoal).

\subsubsection{POPULAÇÃO E AMOSTRA}

Quanto aos materiais utilizados, trata-se de uma pesquisa computacional, com a utilização exclusiva de dados e softwares livres disponíveis para consulta pública na internet, especificamente no site denominado "Portal Cidadão", mantido pelo Tribunal de Contas de Santa Catarina (TCE-SC), e alimentado pelos próprios Municípios Catarinenses por meio do software denominado "E-Sfinge". Foram utilizados os softwares do sistema operacional Ubuntu Linux versão 15.04, planilha eletrônica Libre Office Calc versão 4.2.8.2, visualizador de documentos Portable Document Format (PDF) Evince versão 3.10.3 para ambiente Network Object Model Environment (GNOME), editor de texto leve Gedit versão 3.10.4. Os softwares foram utilizados na coleta, tabulação, tratamento e análise dos dados da pesquisa.

Foram pesquisados 31 Municípios catarinenses, sendo do norte para o sul, os municípios de Itapoá, Garuva, Joinville, São Francisco do Sul, Barra do Sul, Araquari, Barra Velha, Piçarras, Penha, Navegantes, Itajaí, Balneário Camboriú, Itapema, Porto Belo, Bombinhas, Tijucas, Governados Celso Ramos, Biguaçu, São José, Florianópolis, Palhoça, Paulo Lopes, Garopaba, Imbituba, Laguna, Jaguaruna, Içara, Araranguá, Balneário Arroio da Silva, Balneário Gaivota e Passo de Torres.

Figura 1. Lista dos 31 Municípios do litoral catarinenses analisadas (em vermelho).

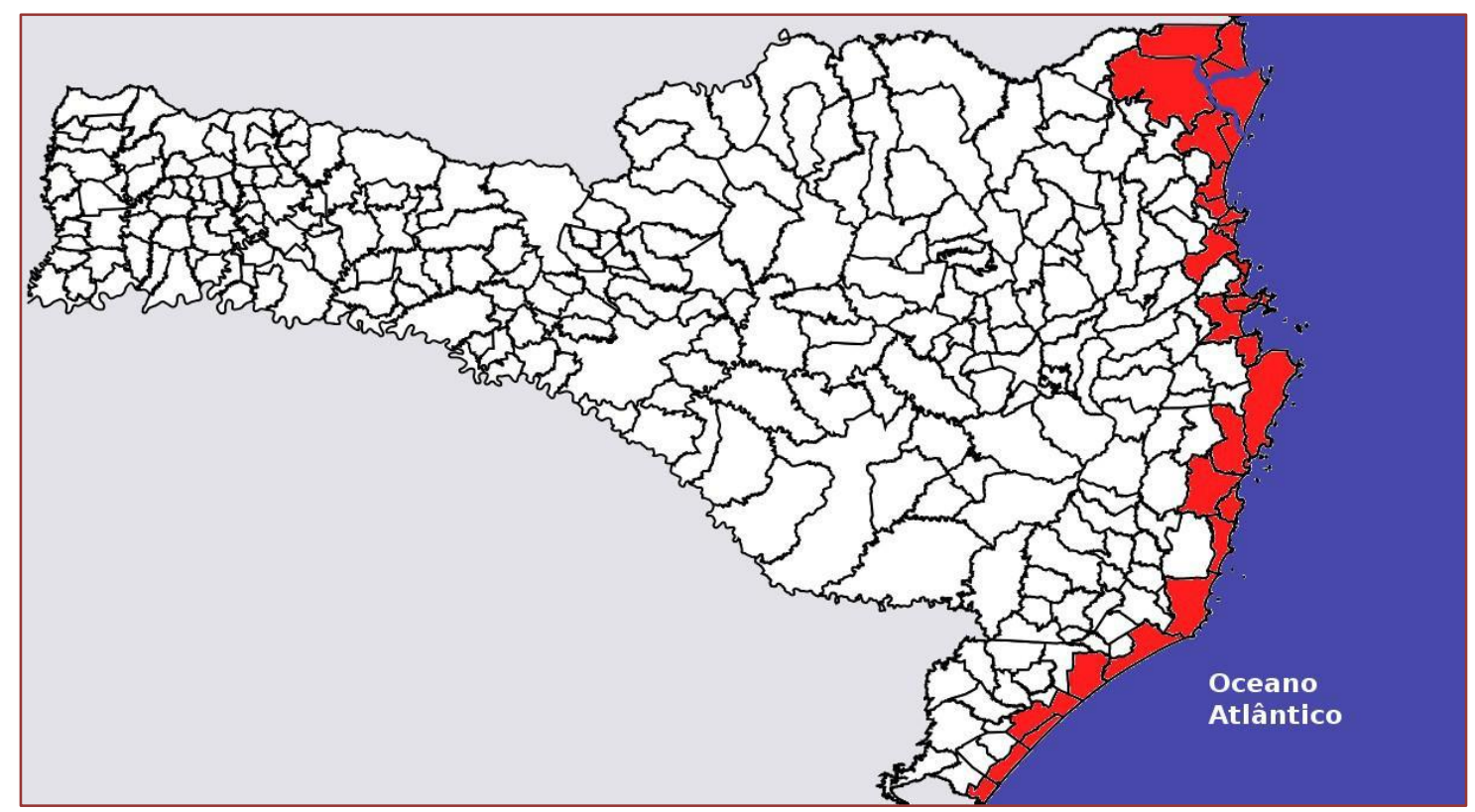

Fonte: O Autor (2015). 
Os municípios de Garuva e Joinville foram considerados litorâneos, tendo em vista estarem situados no entorno da Baía da Babitonga (VIEIRA et al., 2008).

\subsubsection{COLETA DE DADOS}

Inicialmente, foi realizado a criação de uma planilha com dados dos próprios Municípios catarinenses consultados por meio do software denominado "E-Sfinge". O período da análise ocorreu entre o 1 quadrimestre de 2008 até o 3ㅇquadrimestre de 2014. Por fim, com base nos dados da pesquisa, foi possível constatar que a RCL apresentou forte crescimento em todos os municípios analisados, especialmente no $\lim 31$ abas no Libre Office Calc, e com a denominação dos 31 municípios do litoral catarinense. A listagem de municípios catarinenses foi obtida no site do Instituto Brasileiro de Geografia e Estatística (IBGE).

Na sequência, as seguintes informações para cada município foram coletadas a partir do Portal Cidadão, endereço http://portaldocidadao.tce.sc.gov.br/, conforme segue:

a) Valor da RCL do 1ㅇ quadrimestre de 2008 até o 3ㅇq quadrimestre de 2014;

b) Despesa total realizada pelo Poder Executivo Municipal do $1^{\circ}$ quadrimestre de 2008 até o 3o quadrimestre de 2014, e o cálculo da respectiva porcentagem; e

c) Despesa total realizada pelo Poder Legislativo Municipal do $1^{\circ}$ quadrimestre de 2008 até o 3o quadrimestre de 2014, e o cálculo da respectiva porcentagem.

\subsubsection{TRATAMENTO DOS DADOS}

Após a alimentação e tabulação dos dados, foi realizado o cruzamento de informações, classificações e comparações entre os 31 municípios pesquisados, com o propósito de verificar a evolução dos gastos de pessoal dos Poderes Executivo e Legislativo dos municípios do litoral de Santa Catarina nos últimos 6 anos.

Foi identificado que alguns municípios repassam informações sobre o percentual de comprometimento de gastos de pessoal no ESfinge a cada quadrimestre ou a cada semestre. Assim, para padronizar e permitir a classificação e comparação dos dados entre os municípios, optou-se em considerar o $1^{\circ}$ 은 semestre como $1^{\circ}$ quadrimestre, $02^{\circ}$ semestre como $3^{\circ}$ quadrimestre, $\begin{array}{lllll} & 0 & 2^{\circ}\end{array}$ quadrimestre como a média do $1^{\circ}$ e $2^{\circ}$ semestres. O procedimento de adequação foi realizado nos municípios de Garuva, Barra do Sul, Araquari, Barra Velha, Piçarras, Penha, Porto Belo, Bombinhas, Tijucas, Governador Celso Ramos, Paulo Lopes, Garopaba, Imbituba, Balneário Gaivota e Passo de Torres. Tal procedimento não compromete a análise, pois os resultados foram realizados com a média anual da RCL de cada município.

Na análise, também foram criados gráficos, para verificar o comportamento das séries históricas da RCL e dos percentuais de gastos de pessoal dos Poderes Executivo e Legislativo nos três quadrimestres de cada ano, de 2008 até 2014, dos municípios do litoral de Santa Catarina.

$\mathrm{Na}$ sequência, foi realizada a classificação e comparação dos gastos de pessoal, a partir do aumento ou redução do percentual de comprometimento de gastos de pessoal com a RCL, no período de análise de 2008 até 2014.

Por fim, foi verificado se há correlação entre os gastos de pessoal com o valor da RCL e se, no ano de 2010, que coincidiu com o CENSO Demográfico do IBGE, há correlação entre os gastos de pessoal nas administrações municipais com a quantidade de habitantes residentes do Município no ano de 2010.

\subsection{APRESENTAÇÃO DOS DADOS COLETADOS E COMPORTAMENTO DA RCL}

A RCL dos municípios do litoral de Santa Catarina apresentou entre os anos de 2008 e 2014, um comportamento de forte crescimento, com uma clara tendência de alta observada nos 31 municípios pesquisados. Tal expansão permitiu o aumento dos gastos de pessoal, já que a RCL estabelece os limites das despesas de pessoal nas administrações públicas municipais, estaduais e federais.

Para exemplificar, foi proposto um gráfico com o crescimento percentual da RCL a partir do 1o quadrimestre de 2008, com a seleção dos 4 (quatro) Municípios que apresentaram os maiores crescimentos e os 4 (quatro) Municípios que apresentaram a pior evolução da RCL, conforme Figura 2. 
$\mathrm{Na}$ análise da Figura 2, observa-se um comportamento de crescimento médio para a RCL de todos os 31 municípios analisados. Foi considerado $100 \%$ o valor da RCL no ano de 2008, e adotado um gráfico de porcentagem de crescimento, com o objetivo de permitir a comparação de desempenho da capacidade de arrecadação e consequente incremento das receitas municipais entre todos os 31 Municípios.

Para exemplificar, podemos analisar que Joinville registrou no ano de 2014 uma RCL em torno de 1,49 bilhão de reais. Já o município de São Francisco do Sul apresentou no ano de 2014 uma RCL aproximada de 214 milhões de reais. Assim, nota-se que os dois municípios apresentam economias bem diferentes, todavia a capacidade de crescimento da RCL em porcentagem é um indicador comum aos dois municípios, independente do valor da RCL. O procedimento permitiu demostrar o desempenho individual dos Municípios, e permitiu propor comparações na taxa de crescimento das arrecadações com a RCL.

Figura 2. Gráfico de evolução percentual da RCL a partir do 1ำ quadrimestre do ano de 2008, dos 4 maiores crescimentos e 4 menores crescimentos da RCL.

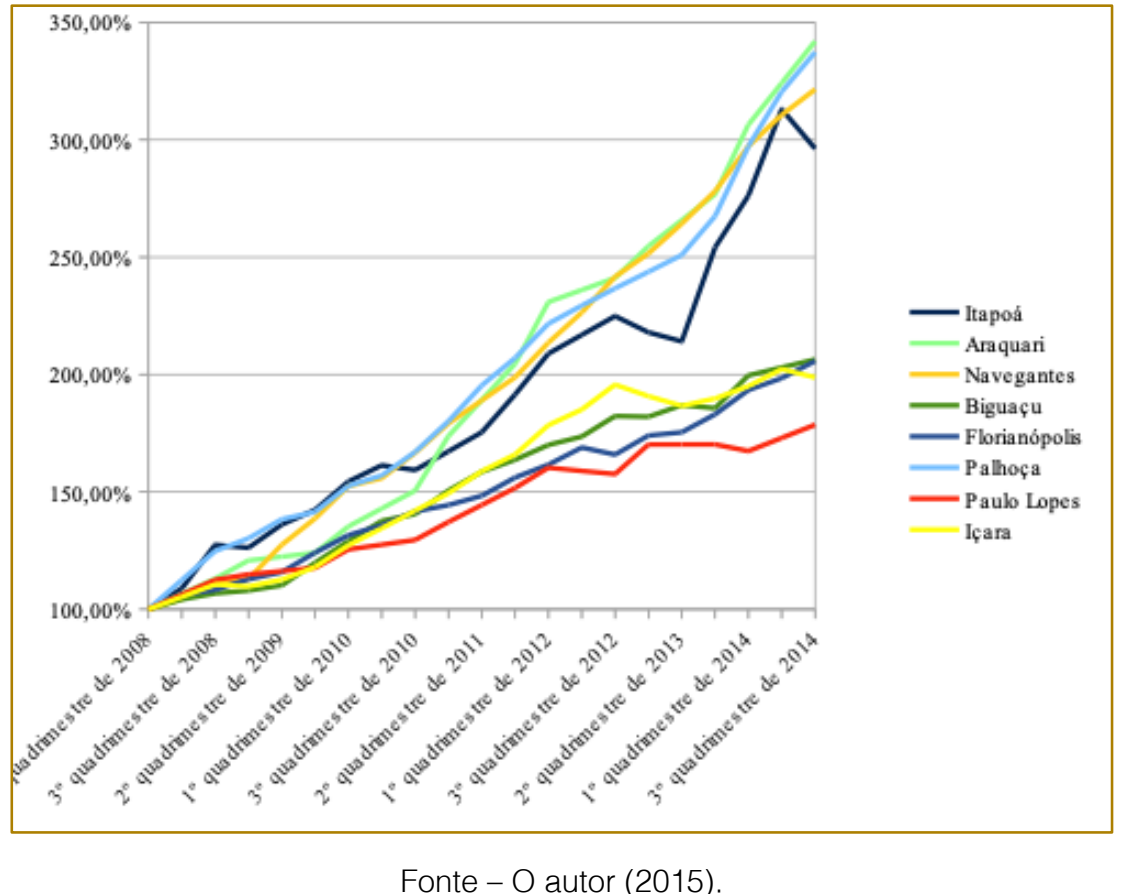

Pode-se observar na Tabela 1, que os 4 (quatro) municípios com maior crescimento percentual da RCL foram, respectivamente, Araquari, Palhoça, Navegantes e Itapoá. Já os quatro piores desempenhos foram, respectivamente, Paulo Lopes, Içara, Florianópolis e Biguaçu. 
Tabela 1. Lista dos 31 municípios classificados pelo crescimento da RCL no período.

\begin{tabular}{|c|c|c|c|c|}
\hline Posiçẫo & Municipio & $\begin{array}{c}\text { RCL no } 1^{\circ} \text { quadrimestre } \\
2008\end{array}$ & $\begin{array}{c}\text { RCL no } 3^{\circ} \text { quadrimes tre } \\
2015\end{array}$ & $\begin{array}{c}\text { Porcentagem de } \\
\text { crescimento da RCL } \\
\text { no periodo }\end{array}$ \\
\hline $1^{\circ}$ & Araquari & RS 20.606.705,71 & RS 70.477.662,64 & $242,01 \%$ \\
\hline $2^{\circ}$ & Pzthesa & RS $93.537 .870,31$ & RS $314.925 .819,16$ & $237,53 \%$ \\
\hline $3^{\circ}$ & Navegaates & RS $56.156 .340,76$ & RS $180.536 .494,46$ & $221,49 \%$ \\
\hline $4^{\circ}$ & Itapot & RS $22.514 .706,40$ & RS $66.700 .961,82$ & $196,26 \%$ \\
\hline $5^{\circ}$ & Garuva & RS $15.616 .616,50$ & RS 44.874 .803 .50 & $187.35 \%$ \\
\hline $6^{\circ}$ & Penha & RS $22.879,392,72$ & RS $65.178 .383,94$ & $184,88 \%$ \\
\hline $7^{\circ}$ & Porto Beb & RS $17.538 .598,73$ & RS 49.785 .742 .28 & $183.86 \%$ \\
\hline $8^{\circ}$ & Bombinhas & RS $24,677.362,34$ & RS $69.040 .254,16$ & $179.77 \%$ \\
\hline 90 & Tüess & RS $32.664 .853,21$ & RS 88.485 .789 .65 & $170,89 \%$ \\
\hline $10^{\circ}$ & Baheárin Gainots & RS $8.925 .866,15$ & RS $23.892 .905,60$ & $167,68 \%$ \\
\hline $11^{\circ}$ & Governador Celso Ramos & RS $14.960 .582,88$ & RS $38.887 .479,12$ & $159,93 \%$ \\
\hline $12^{\circ}$ & Ilapema & RS $61.740 .303,09$ & RS $158.369 .295,54$ & $156,51 \%$ \\
\hline $13^{\circ}$ & Pigarras & RS $23.750 .551,17$ & RS $60.655 .895,17$ & $155,59 \%$ \\
\hline $14^{\circ}$ & Barra Veha & RS 24.648.785,80 & RS $62.049 .238,18$ & $151,73 \%$ \\
\hline $15^{\circ}$ & S1o Francis co do Sul & RS $84.960 .166,11$ & RS $213.816 .719,58$ & $151,67 \%$ \\
\hline $16^{\circ}$ & Bama do Sul & RS $11.075 .002,07$ & RS $27.205 .292,12$ & $145,65 \%$ \\
\hline $17^{\circ}$ & Imbàubz & RS $38.950 .141,51$ & RS 92.423.667,01 & $137,29 \%$ \\
\hline $18^{\circ}$ & Jiaji & RS $392.947,369,24$ & RS 924.077 .978 .22 & $135.17 \%$ \\
\hline $19^{\circ}$ & São Josê & RS $190.048 .278,99$ & RS 446.203 .314 .86 & $134.78 \%$ \\
\hline $20^{\circ}$ & Bu inejirio Arroio da Siva & RS $10.669 .164,82$ & RS 24.822 .286 .13 & $132.65 \%$ \\
\hline $21^{\circ}$ & Jonvile & RS $644,476.180,53$ & RS $1.489 .701,362,68$ & $131,15 \%$ \\
\hline $22^{\prime}$ & Laguna & RS $39.571 .230,11$ & RS 89.803 .829 .00 & $126,94 \%$ \\
\hline $23^{\prime}$ & Passo de Turses & RS 7.804 .745 .88 & RS $17.282 .018,07$ & $121,43 \%$ \\
\hline $24^{\circ}$ & Ararangui & RS $49.481 .164,32$ & Rs $108.580 .608,53$ & $119,44 \%$ \\
\hline $25^{\circ}$ & Bsheirio Camburii & RS $226.911 .452,54$ & RS $491.838 .815,74$ & $116,73 \%$ \\
\hline $26^{\circ}$ & Jaguaruna & RS 19.503.313.46 & RS 41.008.944,39 & $112,45 \%$ \\
\hline $25^{\circ}$ & Garopabz & RS $21.793 .011,18$ & RS $45.854 .404,15$ & $110,41 \%$ \\
\hline $28^{\circ}$ & Bigua & RS $57.699 .614,71$ & RS $119.100 .950,96$ & $106,42 \%$ \\
\hline $29^{\circ}$ & Fbriasopolis & RS 576.235_585,66 & RS $1.185 .469 .025,05$ & $105,73 \%$ \\
\hline $30^{\circ}$ & Içara & RS $55.943 .564,80$ & RS $111.191 .579,94$ & $98,74 \%$ \\
\hline $31^{*}$ & Paub Lopes & RS 8.328 .469 .44 & RS $14.875 .196,44$ & $78,61 \%$ \\
\hline
\end{tabular}

Fonte: O Autor (2015).

Nota-se que o pior desempenho de crescimento da RCL foi verificado no município de Paulo Lopes, com o crescimento total de $78,61 \%$ em 8 anos. Mesmo assim, o município apresentou uma média anual de crescimento de 9,83\%, portanto com uma taxa de crescimento superior à inflação média anual no período.

De modo geral, pode-se constatar que a totalidade da amostra analisada, ou seja, os 31 municípios do litoral catarinense, apresentaram forte crescimento da RCL no período entre 2008 e 2014, o que demonstra força das economias locais, aumento nas arrecadações próprias, gestão fiscal eficiente e, principalmente, a margem de expansão das despesas com pessoal das administrações municipais.

Outra análise que merece destaque é o melhor desempenho na evolução da RCL nos municípios do litoral norte em comparação aos do litoral sul. Em média, observa-se um crescimento da RCL mais acentuado no litoral norte em comparação ao litoral sul do Estado de Santa Catarina, no período entre 2008 e 2014. Tal fato pode ser explicado pela análise do PIB per capita, por Município, do Estado de Santa Catarina, conforme Figura 3. É possível notar uma relação entre o PIB per capita com a arrecadação da RCL municipal. 
Figura 3. PIB per capita a preços correntes do Estado de SC, no ano de 2012.

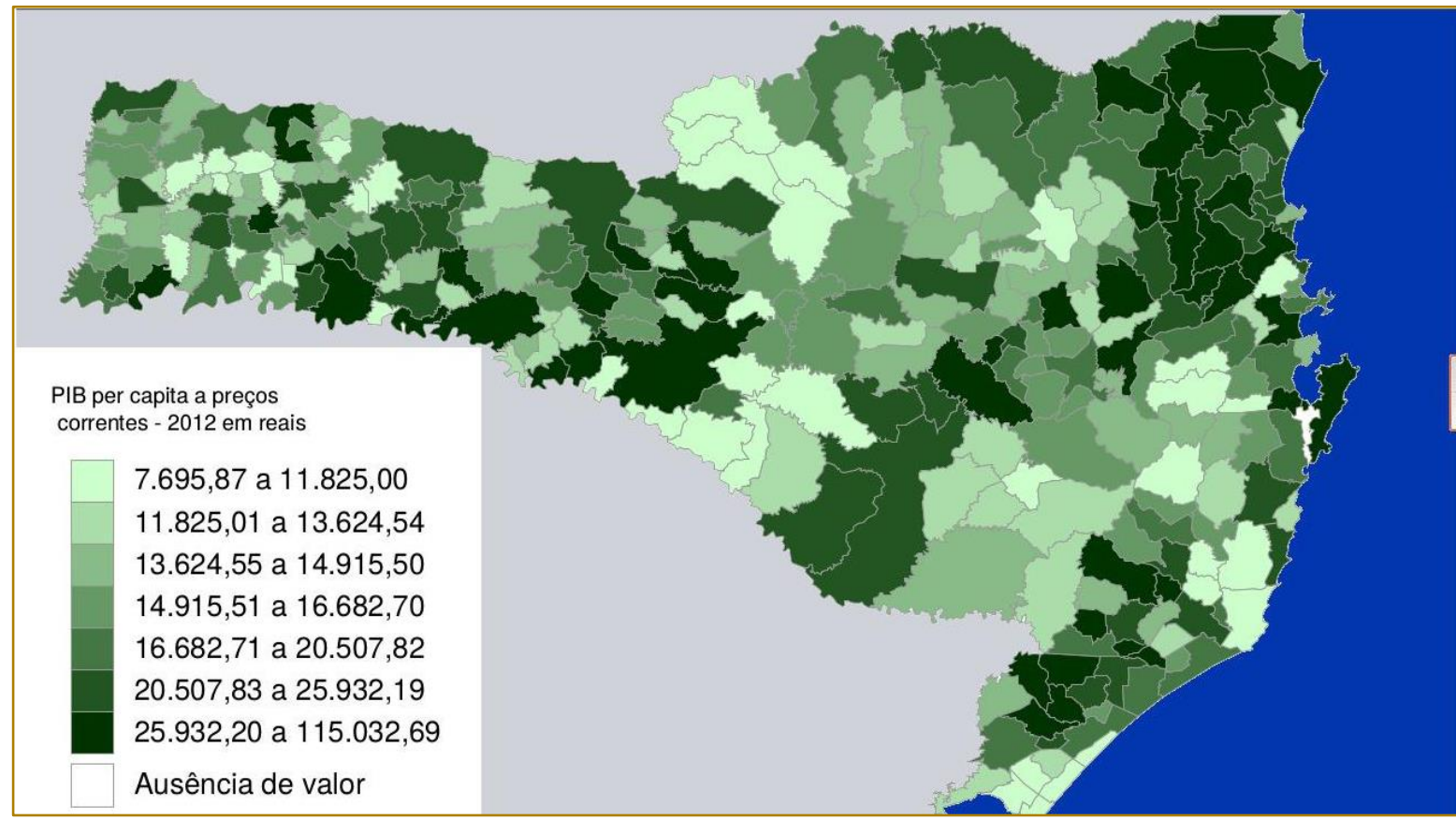

Fonte: Instituto Brasileiro de Geografia e Estatística (2015).

\subsection{CLASSIFICAÇÃO DOS MUNICÍPIOS COM O MAIOR COMPROMETIMENTO EM GASTOS COM PESSOAL NO PODER EXECUTIVO}

A partir da tabulação das informações sobre o comprometimento percentual dos gastos de pessoal (art. 20, alíneas a e b do inciso III da
LRF) nos Poderes Executivos Municipais no litoral de Santa Catarina, com dados extraídos do $1^{\circ}$ quadrimestre de 2008 e $3^{\circ}$ quadrimestre de 2014, foi possível classificar os municípios que apresentaram os maiores crescimentos e reduções do comprometimento da RCL com as despesas com pessoal, conforme tabela 2.

Tabela 2. Lista dos 31 municípios do litoral catarinense, classificados em ordem decrescente, em relação a diferença do percentual de comprometimento da RCL com gastos de pessoal no Poder Executivo, entre o 1ㅇ quadrimestre de 2008 e 3o quadrimestre de 2014.

\begin{tabular}{|c|c|c|c|c|c|}
\hline $\begin{array}{c}\text { Municipio do litoral de Santa } \\
\text { Catarina }\end{array}$ & $\begin{array}{c}\text { Gastos de Pessoal no } \\
1^{\circ} \text { quadrimestre de } \\
2008\end{array}$ & $\begin{array}{c}\text { Porcentagem } \\
\text { da RCL } \\
\text { Gastos de } \\
\text { Pessoal 1 } \\
\text { quad de 2008 }\end{array}$ & $\begin{array}{c}\text { Gastos de Pessoal no } \\
3^{\circ} \text { quadrimestre de } \\
2014\end{array}$ &  & $\begin{array}{l}\text { Diferença } \\
\text { Percentual de } \\
2008 \text { para } \\
2013 \\
\end{array}$ \\
\hline Penha & RS $10.945 .904,95$ & $47,84 \%$ & RS $18.229 .591,52$ & $27,97 \%$ & $-19,87 \%$ \\
\hline Bombinhas & RS $13.184 .266,34$ & $53,43 \%$ & RS $30.134 .975,92$ & $43,65 \%$ & $-9,78 \%$ \\
\hline Tijucas & RS $16.845 .082,52$ & $51,57 \%$ & RS $37.762 .138,19$ & $42,68 \%$ & $-8,89 \%$ \\
\hline Araranguá & RS 21.908.329,83 & $44,28 \%$ & RS $46.109 .047,82$ & $42,47 \%$ & $-1,81 \%$ \\
\hline Biguaçu & RS 25.439.718,66 & $44,09 \%$ & RS $51.180 .706,13$ & $42,97 \%$ & $-1,12 \%$ \\
\hline Itapod & RS $10.736 .008,22$ & $47,68 \%$ & RS $31.533 .865,43$ & $47,28 \%$ & $-0,41 \%$ \\
\hline Joinville & RS $299.640 .713,83$ & $46,49 \%$ & RS $688.314 .775,42$ & $46,20 \%$ & $-0,29 \%$ \\
\hline Laguna & RS $17.394 .969,85$ & $43,96 \%$ & RS $39.228 .065,28$ & $43,68 \%$ & $-0,28 \%$ \\
\hline Paulo Lopes & RS $3.941 .343,21$ & $47,32 \%$ & RS 7.059.401,09 & $47,46 \%$ & $0,13 \%$ \\
\hline Palhoça & RS $42.606 .218,25$ & $45,64 \%$ & RS $146.097 .319,19$ & $46,39 \%$ & $0,75 \%$ \\
\hline Itapema & RS 31.639.858,68 & $51,25 \%$ & RS $82.599 .299,46$ & $52,16 \%$ & $0,91 \%$ \\
\hline Såo Francisco do Sul & RS $36.140 .803,48$ & $42,54 \%$ & RS $95.524 .796,23$ & $44,68 \%$ & $2,14 \%$ \\
\hline Navegantes & RS 27.325.712,23 & $48,66 \%$ & RS $92.232 .736,86$ & $51,09 \%$ & $2,43 \%$ \\
\hline São José & RS $89.428 .494,06$ & $47,06 \%$ & RS $221.875 .472,88$ & $49,73 \%$ & $2,67 \%$ \\
\hline Itajai & RS 137.695.178,33 & $35,04 \%$ & R\$352.884.296,58 & $38,19 \%$ & $3,15 \%$ \\
\hline Porto Belo & RS 7.995.7985,59 & $45,59 \%$ & RS $24.603 .432,33$ & $49,42 \%$ & $3,83 \%$ \\
\hline Piçamas & RS $11.286 .271,52$ & $47,52 \%$ & RS 31.198.696,49 & $51,44 \%$ & $3,92 \%$ \\
\hline Passo de Torres & RS 3.616.774,00 & $46,34 \%$ & RS 8.709.524,90 & $\frac{5,44 \%}{50,40 \%}$ & $\frac{3,276}{4,06 \%}$ \\
\hline Imbituba & RS $16.930 .576,72$ & $43,47 \%$ & RS $43.958 .910,40$ & $47,56 \%$ & $4,10 \%$ \\
\hline Barra do Sul & R\$ $4.833 .675,91$ & $43,64 \%$ & RS $13.072 .894,87$ & $48,05 \%$ & $4,41 \%$ \\
\hline Balneário Arroio do Silva & RS $4.039 .225,64$ & $37,86 \%$ & RS $10.855 .489,54$ & $43,73 \%$ & $5,87 \%$ \\
\hline Balneário Gaivota & RS 3.649.906,82 & $40,89 \%$ & RS $11.181 .276,93$ & $46,80 \%$ & $5,91 \%$ \\
\hline Ganuva & RS 6.658.491,13 & $42,64 \%$ & RS $22.863 .800,13$ & $50,95 \%$ & $8,31 \%$ \\
\hline Araquari & RS $9.257 .524,05$ & $44,92 \%$ & RS $37.727 .220,59$ & $53,53 \%$ & $8,61 \%$ \\
\hline Jaguaruna & RS $7.718 .509,14$ & $39,99 \%$ & RS $20.738 .820,54$ & $50,57 \%$ & $10,59 \%$ \\
\hline Garopaba & RS 8.451.239,77 & $38,78 \%$ & RS 23.267.948,34 & $50,74 \%$ & $11,96 \%$ \\
\hline Balneánio Camboría & RS $72.385 .416,45$ & $31,90 \%$ & RS216.492.248,95 & $44,02 \%$ & $12,12 \%$ \\
\hline Florianópolis & RS 227.422.295,99 & $39,47 \%$ & RS $633.449 .074,63$ & $53,43 \%$ & $13,97 \%$ \\
\hline Bama Velha & RS $9.200 .414,18$ & $37,33 \%$ & RS $32.989 .854,48$ & $53,17 \%$ & $15,84 \%$ \\
\hline Içara & RS 21.082.079,06 & $37,68 \%$ & RS $59.558 .217,15$ & $53,56 \%$ & $15,88 \%$ \\
\hline Govemador Celso Ramos & RS $4.475537,33$ & $29,92 \%$ & RS 19.145.617,90 & $49,23 \%$ & $19,32 \%$ \\
\hline
\end{tabular}

Fonte: O Autor (2015). 
Nota-se, por exemplo, que o município de Penha apresentou a maior redução do comprometimento de gastos de pessoal com a RCL no Poder Executivo Municipal do ano de 2008 para 2014. É possível verificar que apesar de acontecer um incremento no valor absoluto dos gastos de pessoal de 10,94 milhões para 18,23 milhões em 7 anos, ou aproximadamente um aumento percentual de $66,5 \%$, porém o crescimento da arrecadação própria do município (RCL) apresentou um crescimento ainda maior. Conforme a Tabela 1, a RCL do município de Penha no $1^{\circ}$ quadrimestre de 2008 foi de aproximadamente 22,2 milhões de reais. Já no $3^{\circ}$ quadrimestre de 2014 a $\mathrm{RCL}$ realizada foi do montante total de 65,2 milhões de reais, ou seja, um crescimento percentual de aproximadamente 193\% em 7 anos.

Portanto, a análise da variação percentual do comprometimento da RCL de um município traz um melhor indicador da gestão fiscal com os gastos de pessoal, pois reflete se o aumento das despesas está em conformidade com o crescimento da RCL. A LRF veio justamente para incentivar esta gestão fiscal responsável, em que permite aos municípios somente incrementares as despesas com pessoal se a RCL também aumentar. Trata-se de um ciclo virtuoso e responsável de administração dos recursos públicos.

Ainda conforme análise da Tabela 2, nota-se de o município Governador Celso Ramos apresentou um crescimento significativo no grau de comprometimento percentual das despesas com pessoal no período de análise da pesquisa. O Poder Executivo Municipal apresentava uma despesa com pessoal no $1^{\circ}$ quadrimestre de 2008 de aproximadamente 4,5 milhões de reais. Entretanto, no 3은 quadrimestre de 2014 o município informou ao Tribunal de Contas de SC um gastos de pessoal de cerca de 19,1 milhões de reais. No mais, o aumento da RCL não acompanhou o aumento da vinculação das despesas com pessoal. Como consequência, o Município apresentou o pior resultado de aumento no comprometimento de gastos de pessoal do Poder Executivo em relação aos demais Municípios do litoral catarinenses analisados.
2.5 CLASSIFICAÇÃO DOS MUNICÍPIOS COM O MAIOR COMPROMETIMENTO EM GASTOS COM PESSOAL NO PODER LEGISLATIVO

O comprometimento com despesas de pessoal das Câmaras Municipais do litoral catarinense em relação à $R C L$ também foi evidenciado nessa pesquisa. De forma semelhante à análise do Poder Executivo, conforme Tabela 3 , é possível verificar a classificação dos municípios em relação ao aumento ou diminuição dos gastos de pessoal em relação à $\mathrm{RCL}$ no período do $1^{\circ}$ quadrimestre de 2008 e $3^{\circ}$ quadrimestre de 2014.

Conforme análise da Tabela 3, nota-se uma importante redução do comprometimento da RCL no município de Barra do Sul. EM 2008, a Câmara Municipal de Barra do Sul informou ao TCE-SC uma despesa com pessoal de cerca de R\$ 431 mil reais. No ano de 2014, o gasto com pessoal ficou contabilizado em cerca de $\mathrm{R} \$ 794$ mil reais. Apesar do aumento, a RCL de Barra do Sul cresceu muito acima do aumento das despesas com pessoal da Câmara Municipal no período analisado. Como consequência, o comprometimento percentual da RCL que era de $3,90 \%$ em 2008, acabou diminuindo para 2,92\% no ano de 2014. Portanto, fica evidenciado que a Câmara Municipal de Barra do Sul apresentou a maior redução das despesas com pessoal à Luz da Lei de Responsabilidade Fiscal.

Por outro lado, a Câmara Municipal de Biguaçu apresentou o pior na evolução do comprometimento da RCL em relação aos gastos com pessoal. De um montante de aproximadamente $R \$ 1,68$ milhão de reais contabilizados em 2008, passou para cerca de $R \$$ 5,6 milhões de reais no ano de 2014 . Nota-se um aumento de aproximadamente 233\% do comprometimento da RCL para pagamento das despesas com pessoal na Câmara Municipal. Uma das explicações está justamente no fraco desempenho da evolução da RCL do município de Biguaçu, que conforme a Tabela 1, o Município apresentou o $4^{\circ}$ pior desempenho no crescimento da $R C L$, de $R \$ 57,7$ milhões em 2008 para $\mathrm{R} \$ 119,1$ milhões no ano de 2014 . 
Tabela 3. Lista dos 31 municípios do litoral catarinense, classificados em ordem decrescente, em relação a diferença do percentual de comprometimento da RCL com gastos de pessoal no Poder Legislativo, entre o 1ㅇquadrimestre de 2008 e 3ํquadrimestre de 2014.

\begin{tabular}{|c|c|c|c|c|c|}
\hline $\begin{array}{l}\text { Município do litoral de } \\
\text { Santa Catarina }\end{array}$ & $\begin{array}{c}\text { Gastos de Pessoal } \\
\text { no } 1^{\circ} \text { quadrimestre } \\
\text { de } 2008\end{array}$ & $\begin{array}{c}\text { Porcentagem da } \\
\text { RCL Gastos de } \\
\text { Pessoal 1* quad de } \\
2008 \\
\end{array}$ & \begin{tabular}{|c|}
$\begin{array}{c}\text { Gastos de Pessoal } \\
\text { no } 3^{\circ} \text { quadrimestre } \\
\text { de } 2014\end{array}$ \\
\end{tabular} & $\begin{array}{c}\text { Porcentagem da } \\
\text { RCL Gastos de } \\
\text { Pessoal } 3^{\circ} \text { quad } \\
\text { de } 214 \\
\end{array}$ & $\begin{array}{c}\text { Diferença } \\
\text { Percentual } \\
\text { de } 2008 \\
\text { para } 2013\end{array}$ \\
\hline Barra do Sul & R\$ $431.533,14$ & $3,90 \%$ & RS $794.292,12$ & $2,92 \%$ & $-0,98 \%$ \\
\hline Tijucas & RS $1.053 .272,01$ & $3,22 \%$ & RS 2.153.584,79 & $2,43 \%$ & $-0,79 \%$ \\
\hline Itapoá & RS 630.133,19 & $2,80 \%$ & RS $1.457,285,66$ & $2,18 \%$ & $-0,61 \%$ \\
\hline São José & RS 4.834.462,79 & $2,54 \%$ & RS 9.019.952,04 & $2,02 \%$ & $-0,52 \%$ \\
\hline Imbituba & RS $1.173 .427,68$ & $3,01 \%$ & RS 2.323.049,52 & $2,51 \%$ & $-0,50 \%$ \\
\hline Porto Belo & R\$ $395.899,71$ & $2,26 \%$ & RS $892.061,83$ & $1,79 \%$ & $-0,47 \%$ \\
\hline Joinville & RS $12.429 .896,12$ & $1,93 \%$ & RS $21.893 .513,70$ & $1,47 \%$ & $-0,46 \%$ \\
\hline Passo de Tomes & R\$317.728,81 & $4,07 \%$ & RS $629.527,50$ & $3,64 \%$ & $-0,43 \%$ \\
\hline Palhoça & RS $2.540 .868,35$ & $2,72 \%$ & RS 7.431.145,41 & $2,36 \%$ & $-0,36 \%$ \\
\hline Florianópolis & RS $19.046 .127,54$ & $3,31 \%$ & RS $36.542 .927,64$ & $3,08 \%$ & $-0,22 \%$ \\
\hline Bombinhas & RS $869.564,11$ & $3,52 \%$ & RS $2.287 .127,02$ & $3,31 \%$ & $-0,21 \%$ \\
\hline Barra Velha & R\$ $648.466,20$ & $2,63 \%$ & RS $1.533 .112,30$ & $2,47 \%$ & $-0,16 \%$ \\
\hline São Francis co do Sul & RS $2.177 .221,66$ & $2,56 \%$ & RS $5.426 .765,11$ & $2,54 \%$ & $-0,02 \%$ \\
\hline Navegantes & $\mathrm{R} \$ 700.704,06$ & $1,25 \%$ & RS 2.451.602,68 & $1,36 \%$ & $0,11 \%$ \\
\hline Ganuva & RS $420.601,14$ & $2,69 \%$ & RS $1.260 .000,00$ & $2,81 \%$ & $0,11 \%$ \\
\hline Govemador Ceko Ramos & $\mathrm{R} \$ 385.316,92$ & $2,58 \%$ & RS $1.065 .189,26$ & $2,74 \%$ & $0,16 \%$ \\
\hline Balneário Camboriú & RS 3.094.933,19 & $1,36 \%$ & RS 7.975.436,35 & $1,62 \%$ & $0,26 \%$ \\
\hline Garopaba & R\$ $612.959,29$ & $2,81 \%$ & RS $1.438 .020,79$ & $3,14 \%$ & $0,32 \%$ \\
\hline Laguna & RS $1.016 .867,94$ & $2,57 \%$ & RS 2.646.675,39 & $2,95 \%$ & $0,38 \%$ \\
\hline Balneário Amoio do Silva & R\$ $297.894,13$ & $2,79 \%$ & RS $789.232,95$ & $3,18 \%$ & $0,39 \%$ \\
\hline Balneário Gaivota & $\mathrm{R} \$ 251.993,96$ & $2,82 \%$ & RS $767.239,14$ & $3,21 \%$ & $0,39 \%$ \\
\hline Itajai & RS $5.220 .354,13$ & $1,33 \%$ & RS $16.055 .741,80$ & $1,74 \%$ & $0,41 \%$ \\
\hline Piçarras & $\mathrm{R} \$ 613.494,02$ & $2,58 \%$ & RS $1.835 .222,60$ & $3,03 \%$ & $0,44 \%$ \\
\hline Içara & RS $1.482 .564,07$ & $2,65 \%$ & RS $3.479 .197,18$ & $3,13 \%$ & $0,48 \%$ \\
\hline Araranguá & RS $1.500 .814,96$ & $3,03 \%$ & RS $3.841209,45$ & $3,54 \%$ & $0,50 \%$ \\
\hline Araquari & R\$ $470.604,88$ & $2,28 \%$ & RS 1.978.194,05 & $2,81 \%$ & $0,52 \%$ \\
\hline Penha & R\$ $442.902,34$ & $1,94 \%$ & RS $1.645 .248,66$ & $2,52 \%$ & $0,59 \%$ \\
\hline Paulo Lopes & $\mathrm{R} \$ 293.425,06$ & $3,52 \%$ & RS 643.547,11 & $4,33 \%$ & $0,80 \%$ \\
\hline Jaguaruna & R\$ 443.016,87 & $2,30 \%$ & RS 1.338.988,22 & $3,27 \%$ & $0,97 \%$ \\
\hline Itapema & RS $1.332 .416,00$ & $2,16 \%$ & RS 5.407.034,73 & $3,41 \%$ & $1,26 \%$ \\
\hline Biguaçu & RS $1.680 .471,89$ & $2,91 \%$ & RS 5.569.962,20 & $4,68 \%$ & $1,76 \%$ \\
\hline
\end{tabular}

Fonte: O Autor (2015).

\section{CONSIDERAÇÕES FINAIS}

A LRF proporciona aos municípios brasileiros um importante mecanismo de fiscalização e controle da gestão fiscal, e passou a exigir dos governantes uma administração dos recursos públicos de forma responsável, transparente e democrática.

Um dos aspectos da LRF é a responsabilização dos governantes pelo orçamento e pelas previsões de arrecadação de modo a prevenir riscos para o equilíbrio das contas públicas e garantir o desenvolvimento econômico sustentável. Para atingir os objetivos propostos na LRF foi criado a RCL como indexador de determinados gastos públicos, com destaque para o limite de dívida em 1,2 vezes do valor da RCL anual para os municípios, garantias para obrigações financeiras e contratuais a partir da RCL, limites de endividamento em operações de crédito em 16\% da RCL anual, e por fim o limite de despesas com pessoal definidos no art. 19, inciso III e no art. 20, alíneas $a$ e b do inciso III da LRF, conforme segue:

Na pesquisa foi possível identificar a evolução das despesas com pessoal nos 31 municípios do litoral de Santa Catarina, definidos conforme a Figura 1. A Tabela 1 é possível verificar um forte crescimento da RCL em todos os municípios analisados, especialmente no litoral norte catarinense. Já as Tabelas 2 e 3 explicitaram a evolução do comprometimento da RCL a partir do ano de 2008 com o ano de 2014, para verificar e classificar os municípios do litoral catarinense a partir da sua respectiva evolução no grau de comprometimento das despesas com pessoal. Tais informações podem ajudar na avaliação e tomada de decisão dos governos e da sociedade, para definir eventuais ações no sentido de redução ou aumento dos gastos com pessoal diante de um cenário de crise política e econômica nacional.

Por fim, foi possível verificar que o município de Itapoá apresentou, na relação de gastos de pessoal e crescimento de RCL, o melhor desempenho do litoral catarinense. Itapoá apresentou o 4 maior crescimento da RCL de 2008 para 2014, saltando de cerca de $\mathrm{R} \$ 22,5$ milhões para $\mathrm{R} \$ 66,7$ milhões. Além disso, o município apresentou a $3^{\underline{a}}$ (terceira) maior redução do comprometimento de gastos com pessoal no Poder Legislativo e a 6몰 (sexta) maior redução do percentual de 
gastos com pessoal no Poder Executivo, no período do $1^{\text {a }}$ quadrimestre de 2008 até o $3^{\circ}$ quadrimestre de 2014. Portanto, a associação de forte crescimento da RCL com o crescimento prudente dos gastos de pessoal, posicionam o Município com o melhor desempenho para os critérios metodológicos adotados nessa pesquisa.

A pesquisa aplica os princípios gerenciais relacionados à coleta, tratamento, análise,

\section{REFERÊNCIAS}

[1]. BRASIL. Constituição Federal do Brasil. , 1988. Brasil: Senado Federal. Disponível em: $<$ http://www.planalto.gov.br/ccivil_03/constituicao/c onstituicao.htm>. .

[2]. BRASIL. Lei Complementar n. 101, de 4 de maio de 2000. Diário Oficial [da] República Federativa do Brasil, p. 18261, 2000. Disponível em:

<http://www.planalto.gov.br/ccivil_03/leis/LCP/Lcp1 01.htm>.

[3]. COELHO, A. K. S.; FARIA, J. C. DE. A Lei de Responsabilidade Fiscal e o seu Impacto na Gestão Pública. XIII Encontro Latino Americano de Iniciação Científica e IX Encontro Latino Americano de Pós-Graduação. Anais... . p.1-6, 2000. Paraíba: Universidade do Vale do Paraíba.

[4]. DIA, N. DO. Prefeitos catarinenses cortam o próprio salário e adotam medidas para conter a crise econômica. Disponível em: <http://ndonline.com.br/florianopolis/noticias/28022 3-prefeitos-catarinenses-cortam- o-proprio-salarioe-adotam-medidas-para-conter-a-criseeconomica.html>. Acesso em: 8/9/2015.

[5]. EXAME. Impostos lá em cima, serviços públicos lá embaixo. Disponível em: <http://exame.abril.com.br/revista-

exame/edicoes/104402/noticias/impostos-la-emcima-servicos-publicos-la-embaixo>. Acesso em: 8/9/2015.

[6]. FOLHA, S. P. Entenda a Operação Lava Jato - Poder. Disponível em: $<$ http://arte.folha.uol.com.br/poder/operacao-lavajato/>. Acesso em: 8/9/2015.

[7]. G1. Todos os estados e o DF têm protestos contra o governo Dilma. Disponível em: <http://g1.globo.com/politica/noticia/2015/08/manif estantes-protestam-contra-o-governo-dilma-emcidades-do-brasil.html>. Acesso em: 8/9/2015.

[8]. GERIGK, W.; CLEMENTE, A. Influência da LRF sobre a gestão financeira: espaço de manobra dos municípios paranaenses extremamente pequenos. Revista de Administração Contemporânea, v. 15, n. 3, p. 513-537, 2011. disseminação e uso da informação e do conhecimento em organizações públicas como fator determinante na concepção e melhoria de processos, produtos e serviços. É possível verificar uma importante contribuição acadêmica para as pesquisas nas áreas de administração pública, através da comparação dos resultados tabulados, previstos e analisados, com a disponibilidade da base de dados desenvolvida na pesquisa.

Curitiba: Revista de Administração Contemporânea. Disponível em: $<$ http://www.scielo.br/scielo.php?script=sci_arttext \&pid=S1415$65552011000300009 \& \operatorname{lng}=e n \& n r m=i s o \& t \mid n g=p t>$. Acesso em: 21/3/2014.

[9]. GIL, A. C. Métodos e técnicas de pesquisa social. 1999.

[10]. GOULART, S. O. Lei de Responsabilidade Fiscal: um enfoque sobre o controle das despesas com pessoal nos Poderes Executivo e Legislativo em municípios da região central do RS. Revista Eletrônica de Contabilidade, v. 6, n. 1, p. 91, 2012. Santa Maria. Disponível em: <http://cascavel.ufsm.br/revistas/ojs2.2.2/index.php/contabilidade/article/view/81>. Acesso em: 31/3/2014.

[11]. LUQUE, C. A.; SILVA, V. M. DA. A Lei de Responsabilidade na Gestão Fiscal : combatendo falhas de governo à Brasileira. Revista de Economia Política, v. 24, n. 3, p. 404-421, 2004

[12]. MARIA, R.; PEREIRA, A. Formação sócioespacial do litoral de Santa Catarina Resumo.

[13]. Geosul, v. 18, n. 35, p. 99-129, 2003.

[14]. PEREIRA, R. M. F. DO A. Expansão urbana e turismo no litoral de Santa Catarina: o caso das microrregiões de Itajaí e Florianópolis. Interações (Campo Grande), v. 12, n. 1, p. 101111 ,

[15]. 2011. Editora da Universidade Católica $<$ http://www.scielo.br/scielo.php?script=sci_arttext \&pid $=$ S1518-

$70122011000100010 \& \operatorname{lng}=e n \& n r m=i s o \& t \operatorname{lng}=p t>$. Acesso em: 27/9/2015.

[16]. VIEIRA, C. V.; FILHO, N. O. H.; BONETTI, C. D. H. C. VAN; BONETTI, J. Caracterização morfosedimentar e setorização do complexo estuarino da Baía da Babitonga/SC. Boletim Paranaense de Geosciencias, , n. 62-63, p. 85105, 2008. 


\section{Bapítulo 9}

\section{ANÁLISE DA POLÍTICA DE DIVIDENDOS: APLICAÇÃO DE REGRESSÃO QUANTÍLICA}

\section{Jéferson Rodrigo Ströher}

Eric Fernando Boeck Daza

Igor Alexandre Clemente de Morais

Luiz Alberto Mangoni

Resumo: A política de dividendos é importante por envolver a tomada de decisão de distribuir ou não volumes de recursos financeiros através de dividendos ou de juros sobre capital próprio em percentuais diferenciados e formas de tributação diferenciadas no caso Brasileiro. O objetivo deste trabalho foi identificar quais os fatores impactam o índice Payout, como tamanho, liquidez, rentabilidade, endividamento, investimento, lucro, receita e concentração. Para analisar estes aspectos, utilizou-se a técnica de regressão quantílica, com dados da base da Economática e empresas representadas na BM\&FBOVESPA no período de 2009 a 2013, compreendendo 3.073 observações. As estimativas permitem concluir as variáveis tamanho, liquidez, rentabilidade, dívida bruta, investimento e receita são fatores que impactam de forma relevante a variável payout em tamanho e sinal diferenciadas, principalmente a partir da mediana, aumentando em magnitude nos quantis superiores. Todas as relações descritas mostram como a variável payout variou de acordo com modificações das variáveis descritas acima nos quantis amostrais da variável payout.

Palavras-chave: Política de Dividendos. Payout. Regressão Quantílica. 


\section{INTRODUÇÃO}

A política de dividendos trata de um dos pontos mais importantes para as empresas de capital aberto. A política adotada pela empresa envolve a tomada de decisões que não deve se restringir apenas à visão do conselho, mas ao contexto do mercado no qual a empresa está inserida, atendendo ou não à expectativa dos investidores.

O assunto relativo à distribuição do lucro ainda hoje gera controvérsia dentro do campo das finanças corporativas, apesar da intensa investigação que tem sido produzida após o trabalho de Miller e Modigliani (1961), o qual trata da matéria concluindo ser esta irrelevante, ao passo que os investidores teriam preferência a receber o dividendo a ganho de capital, conforme apontam estudos de Lintner (1956) e Gordon (1959).

Artigos clássicos, como o de Black (1976), remetem à política de dividendos como um quebra-cabeça em que as peças não se encaixam, sendo que, duas décadas depois, Black (1990), pesquisando a motivação das empresas que pagam dividendos, conclui: nós não sabemos o que leva à conclusão de que a dúvida em relação ao tema persiste.

De acordo com Ross et al. (2013), a política de dividendos é o padrão de tempo da distribuição de dividendos, e a reflexão que permeia esse tema é se a empresa deve pagar um percentual maior ou menor de seus lucros no momento presente.

Há dois aspectos da decisão da política de dividendos que devem ser considerados: em que magnitude irá ocorrer a distribuição de proventos e de que forma isso será feito. Ambos têm o poder de definir o futuro da empresa no que diz respeito à disponibilidade de recursos para fazer frente a novos investimentos ou então para remunerar os acionistas.

Nos EUA os dividendos são desvantajosos em termos fiscais e a incógnita é porque as empresas distribuem dividendos. No Brasil, conforme os limites da legislação pertinente, os dividendos não são tributados, enquanto o ganho de capital, sim. Também existem o dividendo mínimo obrigatório e a possibilidade de pagamento de juros sobre capital próprio, que limitam as conclusões comparadas aos estudos internacionais como nos EUA.

Diversos são os fatores que influenciam a política de dividendos, tais como legislação, concentração de propriedade, endividamento, investimento, disponibilidade de recursos, nível de endividamento, tributação, entre outros, que variam consoante cada país.

Com o propósito de se obter maior clareza sobre o tema política de dividendos, esse estudo tem por objetivo identificar os fatores determinantes que impactam o índice Payout Para tal propósito, utiliza-se a técnica de Regressão Quantílica.

Esta pesquisa utilizará dados públicos das companhias brasileiras de capital aberto listadas na BM\&F BOVESPA nos anos de 2009 a 2013 extraídos do banco de dados da


Valores Mobiliários e na área de relacionamento com investidores. O software Eviews será utilizado para tratamento dos dados e análise estatística.

As principais conclusões são que as variáveis tamanho, liquidez, rentabilidade, dívida bruta, investimento e receita são fatores que impactam de forma relevante a variável payout em tamanho e sinal diferenciadas, principalmente a partir da mediana.

A próxima seção apresenta uma breve revisão de literatura. A seção 3 descreve os dados e as variáveis, bem como a técnica utilizada para estimação dos dados. As análises, interpretações e resultados das regressões na seção 4, e, por fim, na seção 5, têm-se considerações finais do estudo.

\section{REVISÃO DA LITERATURA}

\subsection{TEORIAS SOBRE POLÍTICA DE DIVIDENDOS}

\subsubsection{RELEVÂNCIA OU IRRELEVÂNCIA DE DIVIDENDOS}

A teoria da Relevância de Lintner (1956), posteriormente complementada por Gordon (1959) afirma que o preço de mercado das ações de uma empresa é diretamente proporcional ao aumento da distribuição de dividendos. Em sentido oposto, o preço das ações também pode ser dado de forma inversamente proporcional à taxa de retorno exigida pelos acionistas ou proprietários. Dessa forma o investidor tende a valorizar mais as ações de empresas que distribuem seus resultados. A preposição fundamental é chamada de "bird in the hand" onde investidores avessos ao risco preferem dividendos correntes a dividendos futuros ou 
ganho de capital, onde mais vale um dividendo na mão do que um ganho de capital incerto. Nesse sentido, o pagamento de dividendos correntes reduz a incerteza dos investidores, elevando consequentemente o preço das ações. De forma oposta, se os dividendos forem reduzidos ou não pagos, irá gerar incerteza nos investidores e, com isso, o retorno exigido aumentaria, tendo como consequência a queda no preço das ações.

Dividendo é o pagamento parcelado que o investidor espera receber onde a causa mais importante e previsível do crescimento dos dividendos de uma empresa são os lucros retidos. (GORDON, 1959).

Dessa forma, acreditava-se que o pagamento de dividendo iria reduzir a incerteza do investidor, induzindo o mesmo a descontar os resultados da empresa a uma taxa menor e a precificar suas ações a um valor maior. Nesse caso, quanto maior forem os dividendos pagos, maior será o valor da empresa.

Existem dois dados básicos para o modelo: os dividendos esperados e a taxa de retorno exigida sobre o patrimônio líquido. Para os dividendos esperados são estipuladas hipóteses sobre as futuras taxas de crescimento, dos lucros e índices payout em relação ao lucro. A taxa de retorno exigida é determinada pelo grau de risco, de acordo com o modelo utilizado, o beta do CAPM ou os betas dos fatores no APM. (DAMODARAN, 2010).

Vale destacar que, o dividendo é uma parcela do lucro da empresa e quanto menor o dividendo, mais recursos estarão disponíveis para reinvestir. Ao passo que se esse investimento for maior, é provável que os lucros futuros sejam maiores, possibilitando maiores dividendos futuros. Dessa forma Gordon (1959) acredita que esses dividendos futuros são mais arriscados e a taxa de retorno exigida pelos investidores é uma função crescente do índice de lucros retidos e tenderá a ser maior que a taxa de crescimento. (DECOURT, 2009).

Por outro lado, Modigliani e Miller (1961), questionam a relevância dos dividendos considerando algumas hipóteses básicas como: (a) o mercado é perfeito e nenhum agente é capaz de afetar a cotação com compras e vendas; (b) não existem impostos ou corretagem; (c) os comportamentos dos agentes são racionais e idênticos, e; (d) investimentos são definidos antecipadamente e não se alteram por mudanças na política de dividendos.

A literatura também apresenta a teoria do dividendo residual sustentada pelo fato de que uma administração competente deve se certificar que a empresa tenha recursos para competir satisfatoriamente no mercado e consequentemente elevar o valor de suas ações. Nessa visão é sugerido que a taxa de retorno dos investidores, não é influenciada pela política de dividendos da empresa premissa essa que sugere, por sua vez, que a política de dividendos é irrelevante. (GITMAN, 1997).

\subsubsection{CONTEÚDO INFORMACIONAL E SINALIZAÇÃO}

O efeito do conteúdo informacional refere-se ao fato de que os investidores associam uma mudança inesperada de dividendos como um sinal de previsão da administração dos lucros futuros. (BRIGHAM; GAPENSKI; EHRHARDT, 2001).

A mudança na política de dividendos transmite informação ao mercado, que é assimilado no preço das ações. Essas informações podem ser dividendos como sinal positivo ou negativo. (BRUNI et al., 2003).

Algumas teorias relacionam a política de dividendos com a de investimentos ou orçamento de capital. É chamada de pecking order theory, teoria da hierarquia das fontes, que pressupõe que as empresas preferem usar os lucros retidos e acumulados em detrimento da contração de dívidas e, em caso dos investimentos ultrapassarem tais recursos, a preferência é a emissão de ações ou títulos de dívidas. Nessa situação, a distribuição de lucros varia positivamente com a lucratividade e negativamente com o investimento. (FAMÁ; MARTINS, 2012).

\subsubsection{EFEITO CLIENTELA E TRIBUTOS}

Inicialmente a hipótese do efeito clientela foi apontada por Miller e Modigliani (1961), em que, após demonstrarem a irrelevância dos dividendos, em situações perfeitas, passam a incluir algumas imperfeições do mercado. A análise apontou a existência do efeito clientela, que consiste na preferência dos investidores por determinadas ações com o nível de pagamento de dividendo mais benéfico em relação à faixa de tributação. 0 
referido efeito foi testado por vários autores, sendo os primeiros Elton e Gruber (1970).

O Efeito Clientela leva os acionistas a receberem os dividendos que eles próprios esperam. Os investidores que preferem investimentos estáveis e previsíveis como fonte de renda, deteriam de ações que pagassem o mesmo montante a títulos de dividendos em cada período. Enquanto que aqueles investidores que preferissem ganhos de capital seriam atraídos preferencialmente por empresas em fase de crescimento que reinvestissem uma grande parcela de seus lucros e, portanto, revelassem um padrão instável no pagamento dos dividendos. (SANTANA, 2006).

O Efeito Clientela sugere que uma empresa atrairá investidores que estejam de acordo com a política de distribuição de dividendos da empresa. (BRIGHAM; GAPENSKI; EHRHARDT, 2001).

\subsubsection{CUSTOS DE AGÊNCIA}

A teoria da agência busca analisar os conflitos existentes nas organizações devido aos interesses entre os atores que influenciam as decisões nas organizações. Jensen e Meckling (1976) definem uma relação de agência como um contrato quando uma ou mais pessoas (principal) conferem a outra pessoa (agente) delegação de autoridade e atribuições para realizar algum serviço ou trabalho em seu favor.

Os conflitos entre acionistas e gestores assumem relevância quando as empresas geram fluxos de caixa excedentários. Embora os gestores tendam a preferir a retenção dos resultados gerados pela empresa, esta decisão pode não ir ao encontro da maximização do valor da empresa, como é desejado pelos acionistas. Nesta situação, a retenção de resultados implica a existência de fluxos de caixa disponíveis, o que contribui para alargar o montante de recursos que podem ter utilização discricionária gerando problemas sobre os investimentos e potencializando os conflitos de interesses da relação de agência entre acionistas e gestores cuja implicação é um reflexo negativo no valor da empresa. Numa perspectiva de custos de agência, o acréscimo (decréscimo) de dividendos contribui para a redução (aumento) dos fluxos de caixa disponíveis e, consequentemente, pra o acréscimo (decréscimo) da cotação das ações da empresa. (JENSEN, 1986).

Segundo Eisenhardt (1989) os problemas de agência ocorrem quando há a separação da propriedade e da gestão das organizações. Para minimizar os conflitos de interesses e a assimetria da informação entre acionistas e gestores houve a necessidade da delegação de poder, surgindo assim os mecanismos da governança corporativa. (GÜTTLER, 2011).

\subsection{LEGISLAÇÃO BRASILEIRA}

\subsubsection{DIVIDENDOS}

$\mathrm{Na}$ Legislação Brasileira, a distribuição de dividendos consta no artigo 199 da Lei no 11.638, de 28 de dezembro de 2007, e nos artigos 17 e 202 da Lei no 10.303, de 31 de outubro de 2001, que altera, revoga ou acrescenta dispositivos na Lei no 6.404, de 15 de dezembro de 1976, dispõem sobre o mercado de valores mobiliários e cria a Comissão de Valores Mobiliários. A lei estabelece um dividendo mínimo obrigatório de $25 \%$ sobre o lucro líquido ajustado ou a parcela dos lucros ou percentual estabelecido no estatuto. E em caso de omissão metade do lucro líquido do exercício com os devidos ajustes.

O Brasil vale-se do inciso I do "caput" do art. 202, da Lei das Sociedades por Ações, que compõem uma fórmula híbrida de cálculo do dividendo mínimo obrigatório de cada exercício social e considerando o disposto no artigo 195 da constituição a base de cálculo para aplicação do percentual do dividendo é dada pela equação $B C=L L-R L-R C+R R C$ - RIC, onde: BC, base de cálculo; LL, lucro líquido do exercício; $R L$, quota destinada à reserva legal; $R C$, destinação à reserva de contingências; RRC, reversão de reserva para contingências; RIC, destinação à reserva de incentivos fiscais.

O artigo 193 da Lei das Sociedades Anônimas diz que, antes de qualquer outra destinação, 5\% do lucro líquido do exercício será aplicado na constituição da reserva, e não poderá exceder $20 \%$ do capital social. O artigo 194 da mesma lei, determina que a assembleia geral poderá destinar parte do lucro líquido para reservas, bem como, seus limites.

A reserva de lucros a realizar poderá ser constituída no exercício em que o montante do dividendo obrigatório ultrapassar a parcela 
realizada do lucro líquido do exercício, porém, a distribuição dos lucros para a constituição de reservas ou a retenção deles não pode prejudicar a distribuição do dividendo obrigatório, conforme artigo 198 da Lei $6.404 / 76$

O artigo 202 da Lei 6.404/76 estabelece que o dividendo obrigatório pode ser fixado como uma percentagem do lucro líquido ou do capital social e os acionistas têm o direito de receber como dividendo obrigatório, a parcela dos lucros estabelecida no estatuto, ou, se este não demonstrar preocupação com a matéria em questão, metade do lucro líquido do exercício diminuído ou acrescido das seguintes reservas: legal, contingências e lucros a realizar.

O quarto inciso do artigo 202 da mesma lei estabelece que o dividendo mínimo não será obrigatório no exercício social em que os órgãos da administração informarem à assembleia geral ordinária ser ele incompatível com a situação financeira da empresa.

O pagamento deverá ser pago, salvo deliberação ao contrário da assembleia geral, no prazo de 60 dias da data em que for declarado e, em qualquer caso, dentro do exercício social. (MAMEDE, 2004; ROBERT, 2011).

\subsubsection{JUROS SOBRE CAPITAL PRÓPRIO}

A partir de 1996, no Brasil, a Lei no 9.249, de dezembro de 1995 criou um novo mecanismo de pagamento de proventos, sob a forma de juros sobre capital próprio, classificado contabilmente como despesa dedutível da base de cálculo do imposto de renda da pessoa jurídica, gerando um benefício fiscal à empresa pagadora.

O lançamento dos Juros sobre Capital Próprio agrega valor à empresa, reduzindo a carga tributária e por essa razão são considerados um importante fator de economia fiscal e de preservação do patrimônio empresarial. (NESS JÚNIOR; ZANI, 2001).

A Lei no 9.430, de 27 de dezembro de 1996, estendeu essa dedução à base de cálculo da contribuição social sobre o lucro líquido, a partir de 1997, condicionado a dedução ao efetivo pagamento ou crédito ao acionista. Os Juros sobre Capital Próprio podem ser calculados pela taxa que a empresa entender adequada; porém, para que possa considerar como despesa dedutível da base do imposto de renda e contribuição social, deve ser levado em consideração os seguintes limites estabelecidos na mesma lei.

A alíquota do imposto de renda sobre os Juros sobre o Capital Próprio é de $15 \%$ e o imposto é tributado na fonte para as pessoas físicas e pode ser compensado pela pessoa jurídica.

\subsubsection{GANHO DE CAPITAL}

A incidência do Imposto de Renda sobre ganhos de capital, que se verificam na valorização das ações, já chegaram a ser tributados em 25\% nos anos de 1993 e 1994, reduzindo para $10 \%$ em 1995, aumentando novamente para 15\% em 2000 e $20 \%$ em 2001. Desde dezembro de 2004, o Imposto de Renda sobre ganhos de capital é de 15\%, devendo ser pago no momento da venda dos títulos, se possuir realização dos ganhos, conforme o artigo 117 do regulamento do Imposto de Renda de 1999.

\section{DADOS E VARIÁVEIS}

\subsection{VARIÁVEL DEPENDENTE}

Diversos estudos utilizam como variável dependente o índice payout, justificado pela razão dos proventos sobre o lucro líquido. (ALLI; KHAN; RAMIREZ, 1993; FERREIRA JUNIOR; NAKAMURA; MARTIN, 2007; LA PORTA et al., 2000; LINTNER, 1956; ROZEFF, 1982).

As empresas que optarem por pagar proventos aos acionistas em forma de juros sobre capital próprio, dividendos ou ambos, o fazem na maioria das vezes levando em consideração sua dedutibilidade fiscal. As razões que levam as empresas a optarem pela proporção da composição de ambos é objeto de estudo de diversas pesquisas, não cabendo a este realizar esta análise. Da mesma forma cabe salientar que não será realizado distinção entre ação $\mathrm{ON}$ e PN. Neste sentido, serão tratadas indistintamente estas duas formas, investigando o total de proventos conforme deliberação da AGO.

A variável dependente, razão dos proventos sobre o lucro líquido, onde, Payout (PAY) = índice de pagamento de provento da empresa para o ano "a", representando a proporção do resultado enviado para os acionistas na forma de dividendos e/ou juros 
sobre o capital próprio do lucro líquido no ano "a"; Div $_{a}=$ Dividendo pago + Juros sobre capital próprio pagos da empresa para o ano "a" e $L L_{a}=$ Lucro líquido por ação da empresa para o ano "a".

\subsection{VARIÁVEIS INDEPENDENTES}

Para viabilizar a aplicação do método estatístico, foram utilizadas proxies representativas dos aspectos teóricos cuja expectativa é identificar os fatores determinantes que impactam o índice Payout (PAY). Todas as variáveis identificadas nas diversas pesquisas e utilizadas foram relativizadas pelo Ativo Total e seguem:

AT_LN - A variável tamanho será utilizada para testar sua relação com a variável dependente e será dado pelo logaritmo neperiano do ativo total. É esperada uma relação positiva. (ALMEIDA; SANTOS, 2011; FAMA; FRENCH, 2001).

LIQGR - O índice de liquidez é calculado pela razão do ativo circulante pelo passivo circulante. A folga de recursos é representada pela presença de liquidez, associado ao menor risco de insolvência. Dessa forma, quanto maior a liquidez, maior a taxa de pagamento de proventos. (HO, 2003; LEMES JÚNIOR; CHEROBIM; RIGO, 2002; ROSS et al., 2013).

RENPAT - Return on Equity - índice de lucratividade das empresas. É o retorno sobre o patrimônio líquido, indicativo de quanto a empresa consegue gerar lucro em relação ao capital investido. (MARTINS; IUDICIBUS; ERNESTO, 2013; ROSS et al., 2013). É esperado uma relação positiva entre lucratividade e a quantidade de dividendos distribuídos. (AIVAZIAN; BOOTH; CLEARY, 2003; HEINEBERG; HO, 2003).

DIVB_AT - Endividamento. O maior nível de alavancagem em algumas empresas acarreta na realização de pagamentos sobre as dívidas (ALLI; KHAN; RAMIREZ, 1993), restringindo a disponibilidade de recursos em detrimento do pagamento de proventos. (ROZEFF, 1982; LA PORTA, et al. 2000). É a divisão entre o passivo circulante mais o exigível de longo prazo dividido pelo ativo total. É esperada uma relação negativa entre a variável e a distribuição de dividendos.
CAPEX - (capital expenditure) - é o montante de investimentos realizados em equipamentos e instalações de forma a manter a produção de um produto ou serviço. Sendo assim, caso existam projetos rentáveis, a empresa optaria pela priorização da destinação dos fundos gerados internamente para financiamento dos mesmos, conforme teoria preconizada do Pecking Order. (PORTAL; ZANI; SCHÖNERWALD, 2012). É esperada uma relação negativa entre a variável e a distribuição de dividendos.

LL_AT - Lucro Líquido que mensura a eficiência global da empresa em gerar lucros com seus ativos disponíveis; também chamado de retorno sobre o ativo (ROA). Quanto maior for o rendimento da empresa sobre o total dos ativos, melhor.

REC_AT - Receita do ano. Empresas com estabilidade nos ganhos provavelmente terão maior comprometimento com a distribuição de proventos devido ao risco menor das receitas esperadas não ocorrerem. (AIVAZIAN; BOOTH; CLEARY, 2003).

CON1 - Concentração de propriedade. É medido pelo percentual do acionista majoritário. Empresas com propriedade mais concentrada pagam menos dividendos do que empresas com propriedade menos concentrada, pois possuem condições mais favoráveis para expropriar os minoritários, gerando um problema de agência. Os dividendos podem ser usados para reduzir o problema de agência entre a administração e os acionistas. (ASSAF NETO, 2010).

DUMFIN - Dummy para o Setor Financeiro em detrimento das particularidades específicas de contabilização.

DUMNEG - Dummy para empresas que possuíram resultado negativo e distribuíram proventos pela constituição de reservas legais dos anos anteriores.

Para este trabalho foram utilizadas variáveis anuais e a partir disso foram testadas 10 variáveis independentes que buscassem explicar a variável dependente, PAY, classificadas da seguinte maneira, conforme o quadro 1: 
Quadro 1 - Análise das variáveis

\begin{tabular}{|c|c|c|c|}
\hline VARIÁVEL & IMPORTÂNCIA / SIGNIFICADO & CLASSIFICAÇÃO & $\begin{array}{l}\text { SINAL } \\
\text { ESPERADO }\end{array}$ \\
\hline PAY (Payout) & $\begin{array}{l}\text { Percentual de distribuição de } \\
\text { proventos }\end{array}$ & Distribuição e proventos & - \\
\hline AT_LN: Tamanho & Tamanho da empresa & $\begin{array}{l}\text { Relacionado ao tamanho } \\
\text { da empresa }\end{array}$ & Positiva \\
\hline LIQGR: Liquidez Geral & $\begin{array}{l}\text { Capacidade de pagamento da } \\
\text { empresa }\end{array}$ & Relacionada à liquidez & Positiva \\
\hline $\begin{array}{l}\text { RENPAT: (Returno on } \\
\text { Equity): }\end{array}$ & $\begin{array}{l}\text { Lucro em relação ao capital } \\
\text { investido }\end{array}$ & $\begin{array}{l}\text { Relacionada a } \\
\text { lucratividade }\end{array}$ & Positiva \\
\hline DIVB_AT: Endividamento & $\begin{array}{l}\text { Nível de endividamento das } \\
\text { empresas }\end{array}$ & $\begin{array}{l}\text { Relacionada ao custo } \\
\text { financeiro }\end{array}$ & Negativa \\
\hline CAPEX & $\begin{array}{l}\text { Investimentos em bens } \\
\text { imobilizados }\end{array}$ & $\begin{array}{l}\text { Relacionada à estrutura } \\
\text { de Ativos }\end{array}$ & Negativa \\
\hline LL_AT & Lucro Líquido no ano & $\begin{array}{l}\text { Relacionado a } \\
\text { rentabilidade }\end{array}$ & Positiva \\
\hline REC_AT & Receita no ano & Volume de vendas & Positiva \\
\hline CON1: Propriedade & $\begin{array}{l}\text { Percentual de concentração do } \\
\text { acionista majoritário }\end{array}$ & Estrutura de propriedade & Negativa \\
\hline $\begin{array}{l}\text { DAMFIN: Dummy } \\
\text { Financeira }\end{array}$ & Empresas do setor financeiro & Setor financeiro & Positiva \\
\hline $\begin{array}{l}\text { DAMNEG: Dummy } \\
\text { Negativa }\end{array}$ & $\begin{array}{l}\text { Empresas com resultado } \\
\text { negativo que distribuíram } \\
\text { proventos }\end{array}$ & Distribuição de proventos & Negativa \\
\hline
\end{tabular}

Fonte: Elaborado pelo autor.

Assim a função matemática do modelo proposto pode ser definida como:

$$
\begin{gathered}
\text { PAY }\rangle_{i}=\beta_{0}+\beta_{1} \mathrm{AT}_{-} \mathrm{LN}_{i}+\beta_{2} \mathrm{LIQGR}_{i}+\beta_{3} \mathrm{RENPAT}_{i}+\beta_{4} \mathrm{DIVB}_{-} \mathrm{AT}_{i}+\beta_{5} \mathrm{CAPEX}_{i}+\beta_{6} \mathrm{LL}_{-} \mathrm{AT}_{i}+\beta_{7} \mathrm{REC}_{-} \mathrm{AT}_{i} \\
+\beta_{8} \mathrm{CON}_{i}+\beta_{9} \text { DUMFIN }_{i}+\beta_{10} \text { DUMNEG }_{i}+\varepsilon_{i}
\end{gathered}
$$

Onde: $\beta_{0-10}=$ é o coeficiente que relaciona a variável independente $n$ com a variavel dependente; AT_LN = variável tamanho; LIQGR = Liquidez Geral; RENPAT = lucratividade; DIVB_ATT = endividamento; CAPEX = investimentos; LL_AT = Lucro líquido; REC_AT = Receita; CON1 = controle da propriedade; DUMFIN = setor financeiro; DUMNEG = empresas com resultado negativo e distribuíram dividendo.

\subsection{REGRESSÃO QUANTÍLICA}

Para tal propósito, utiliza-se a técnica de Regressão Quantílica, a qual permite analisar a associação entre a variável resposta com as variáveis explicativas nos diversos quantis da distribuição condicional. Dessa forma, obtém- se um mapeamento mais amplo dos determinantes que impactam o índice Payout, analisando as respostas de como cada quantil responde, em vez de se obter somente uma reta de regressão para o caso da média (KOENKER; BASSETT, 1978).

Outro aspecto que evidencia a utilização da regressão quantílica é que apesar de ser aplicada a mais de três décadas, são poucos os trabalhos que utilizam esta técnica, evidenciando o grande potencial ainda não explorado. (SILVA; PÔRTO JÚNIOR, 2006). Além disso, em dividendos, a distribuição não é igual para todos os quantis sendo muito pequena a utilização de regressão quantílica. 


\subsection{AMOSTRA}

A amostra é composta por companhias brasileiras listadas na BMF\&BOVESPA que pagaram ou não dividendos ou juros sobre capital próprio no ano de 2009 a 2013. Os dados foram extraídos do banco de dados da Economática ${ }^{\circledR}$, das informações publicadas no site da CVM, no site da BMF\&BOVESPA e na área de relações com 0 investidor das empresas.

No site da BMF\&BOVESPA, atualizado em 01 de fevereiro de 2015, constam listadas 442 empresas. Da amostra total de empresas, foram retiradas as que não continham informações suficientes no banco de dados e as observações consideradas outliers, resultando em 425, 420, 419, 415 e 406 empresas de 2009 a 2013 respectivamente e um total de 3073 observações. Também não foi excluído nenhum setor específico.

Ressalta-se que a definição da amostra dessa forma alcança um número maior de empresas do que os demais trabalhos na área em um mercado mais amadurecido do que o encontrado pelos pesquisadores pioneiros no País. Por exemplo, Heineberg e Procianoy (2003) analisaram 7 anos, entre 1994 e 2000, 196 empresas e 951 observações. Posteriormente Ferreira Junior, Nakamura e Martin (2007) analisaram 8 anos, de 1997 a 2004, 108 empresas (setor bancário), perfazendo 864 observações. Recentemente estudos de Procianoy e Vancin (2014) analisaram 5 anos, de 2007 a 2011, e com 1.118 observações.

Cabe salientar que a variável dependente, o indicador financeiro PAY, considera os dividendos pagos no ano. Dessa forma existe uma limitação quanto a competência do pagamento de dividendos mais juros sobre capital próprio do último trimestre do ano, uma vez que este é pago no ano seguinte.

Outra limitação encontrada foi quanto à validação de alguns dados apresentados na base de dados que estavam como número índice, no entanto, era apresentado em forma de valor por algumas empresas. Esses dados tiveram que ser corrigidos analisando as informações contábeis dos relatórios no site das empresas.

\section{ANÁLISE E INTERPRETAÇÃO DOS RESULTADOS}

\subsection{ANÁLISE DESCRITIVA}

Da amostra total de 3073 observações da variável PAY, 1.331 empresas não distribuíram nenhum tipo de provento, enquanto que 1.607 empresas distribuíram proventos e outras 135 empresas possuíram Payouts menores do que zero. Este último grupo possui distribuição de proventos com resultado negativo ou prejuízo, sendo considerado como fato atípico decorrente de fatores pontuais e extraordinários. Os dados foram testados em logaritmo, considerando somente os payouts maiores que zero. No entanto o modelo não apresentou diferença significante sobre os resultados.

$\mathrm{Na}$ análise é interessante observar que as variáveis desse estudo não possuem distribuição normal. Também é observado na maior parte das variáveis uma discrepância entre o valor médio e a mediana, bem como, no coeficiente de assimetria (Skewness), indicando uma análise que leva em conta as assimetrias da base de dados e a regressão quantílica leva em consideração essa particularidade. Pelo teste de JaqueBera observamos que a distribuição das variáveis não se aproxima da distribuição normal.

Na tabela 1 são apresentadas as estatísticas descritivas de todas as variáveis para todos os anos. Observa-se que a média da variável PAY ficou em 0.40 e a mediana em 0.07 no período de análise. A média do AT_LN ficou próximo da mediana. A LIQGR ficou com média 2.24 e mediana 0.9. A RENPAT com média 8.22 e mediana em 7.4. O endividamento, DIVB_AT, com média de $25.7 \%$ e mediana de $21.9 \%$ do ativo total. Os níveis de investimento CAPEX ficou em média $5.2 \%$ e para mediana $2.8 \%$ do ativo total. O LL_AT apresenta em média um resultado abaixo do esperado de $-12 \%$ do ativo total, ficando a mediana em 2\%. A REC_AT ficou com média de $56 \%$ e mediana de $45 \%$ do ativo total. Todas as variáveis não apresentam distribuição normal de dados. 
Tabela 1 - Estatística Descritiva de todos os anos (2009 a 2013)

\begin{tabular}{|c|c|c|c|c|c|c|c|c|c|}
\hline Média & 0,4082 & 13,9145 & 2,4367 & 8,2267 & 25,7896 & 0,0529 & - $\quad 0,1257$ & 0,5656 & 58,1434 \\
\hline Mediana & 0,0735 & 14,2745 & 0,9000 & 7,4000 & 21,9000 & 0,0286 & 0,0257 & 0,4516 & 55,1000 \\
\hline Mínimo & - 14,1800 & 1,3863 & 0,0010 & $-339,0000$ & 0,0010 & 1,5017 & - 26,7500 & 0,0001 & 0,1000 \\
\hline Desvio Padrão & 2,4425 & 2,7253 & 11,5758 & 33,3036 & 31,4204 & 0,1954 & 1,4223 & 0,5790 & 29,0810 \\
\hline Assimetria & 20,7849 & - $\quad 1,1297$ & 14,2554 & - $\quad 0,1276$ & 4,7622 & 20,2281 & - 12,8351 & 1,9894 & 0,0368 \\
\hline Probabilidade & 0,00 & 0,00 & 0,00 & 0,00 & 0,00 & 0,00 & 0,00 & 0,00 & 0,00 \\
\hline Observações & 3.073 & 3.073 & 3.073 & 3.073 & 3.073 & 3.073 & 3.073 & 3.073 & 3.073 \\
\hline Ações ON & 2.080 & & & & & & & & \\
\hline Ações PN & 993 & & & & & & & & \\
\hline Empresas & 471 & & & & & & & & \\
\hline
\end{tabular}

Fonte: Elaborado pelo autor a partir de dados da Economática® (2009-2013).

\subsection{CORRELAÇÕES ENTRE AS VARIÁVEIS}

Nesse estudo, observa-se que as variáveis independentes não são altamente correlacionadas, indicando ausência de vieses na estimativa dos coeficientes e do modelo apresentado por problemas de correlação. Para esse estudo é comentado a correlação entre as variáveis com valor acima de 0.2. A maior correlação foi entre as variáveis LL_AT e AT_LN com uma relação moderada e positiva em todos os anos, sendo que a maior foi no ano de 2013 (0.58).

A RENPAT apresentou uma correlação positiva em todos os anos com o AT_LN.
A DUMFIN e AT_LN apresentou correlação positiva no período. As variáveis DIVB_AT e REC_AT a DUMFIN apresentou correlação negativa em todo o período.

A tabela 2 apresenta a correlação entre todas as variáveis e de todo o período. Houve uma correlação positiva entre LL_AT e AT_LN. Também observa-se uma correlação positiva, porém menos intensa entre DUMFIN e AT_LN. As principais correlações negativas ocorrem entre DUMFIN, DIVB_AT e REC_AT, LIQGR e AT_LN.

Tabela 2 - Correlação Todos os anos (2009 a 2013)

\begin{tabular}{|c|c|c|c|c|c|c|c|c|c|c|c|}
\hline $\begin{array}{c}2009: \\
2013\end{array}$ & PAY & AT_LN & LIQGR & RENPAT & DIVB_AT & CAPEX & LL_AT & REC_AT & CON1 & DUMFIN & DUMNEG \\
\hline PAY & 1 & $\begin{array}{c}0,0335 \\
1 \\
\end{array}$ & 0,01587 & 0,03050 & 0,02748 & 0,01409 & 0,02335 & 0,00901 & 0,01225 & 0,01956 & 0,14618 \\
\hline AT_LN & & 1 & 0,22688 & 0,18175 & 0,02275 & 0,02909 & 0,42474 & 0,01025 & 0,15673 & 0,24826 & 0,04004 \\
\hline LIQGR & & & 1 & $\begin{array}{c}- \\
0,10114\end{array}$ & 0,12075 & 0,04738 & 0,00070 & $\begin{array}{c}- \\
0,09694\end{array}$ & 0,08932 & $\begin{array}{c}- \\
0,02509\end{array}$ & $\begin{array}{c}- \\
0,02332\end{array}$ \\
\hline RENPAT & & & & 1 & $\begin{array}{c}- \\
0,08189\end{array}$ & $\begin{array}{c}- \\
0,03673\end{array}$ & 0,13799 & 0,08134 & $\begin{array}{c}- \\
0,03459\end{array}$ & 0,07496 & $\begin{array}{c}- \\
0,16109\end{array}$ \\
\hline DIVB_AT & & & & & 1 & 0,02925 & 0,04843 & 0,10167 & 0,05963 & 0,25703 & 0,01974 \\
\hline CAPEX & & & & & & 1 & $\begin{array}{c}- \\
0,02397\end{array}$ & 0,06633 & 0,00933 & 0,08195 & $\stackrel{-}{-} 0,02107$ \\
\hline LL_AT & & & & & & & 1 & 0,10272 & 0,12185 & 0,03807 & 0,00894 \\
\hline REC_AT & & & & & & & & 1 & $\begin{array}{c}- \\
0,07940\end{array}$ & $\begin{array}{c}- \\
0,28378\end{array}$ & $\begin{array}{c}- \\
0,00523\end{array}$ \\
\hline CON1 & & & & & & & & & 1 & 0,02974 & $0, \overline{-} 790$ \\
\hline DUMFIN & & & & & & & & & & 1 & 0,01467 \\
\hline DUMNEG & & & & & & & & & & & 1 \\
\hline
\end{tabular}

Fonte: Elaborado pelo autor a partir de dados da Economática® (2009-2013). 


\subsection{RESULTADOS DAS REGRESSÕES}

O passo inicial foi determinar quais das variáveis independentes são estatisticamente significantes para explicar a variável dependente PAY. Para tanto através do software Eviews se obteve o t-Statistic para cada uma das variáveis e a probabilidade destas serem estatisticamente iguais a zero, conforme diversas modelagens.

Inicialmente é proposta a estimação via mínimos quadrados ordinários (MQO). No entanto, esta abordagem não foi adequada para a base de dados utilizada. Sendo assim, foi realizado a estimação utilizando o método de regressão quantílica, para os quantis .10, .25, .50, .75, .90.

No modelo de MQO estimado foi possível observar que as variáveis independentes são capazes de explicar $2.47 \%$ da variação de PAY. Optou-se pela estimação utilizando as variáveis em logaritmo, com exceção das variáveis dummy. As diferenças entre 0 modelo em nível e o modelo em logaritmo foram muito pequenas. Além disso, quando foi analisado que o valor dos coeficientes e sua significância estatística, a maioria deles é estatisticamente igual a zero. Somente a variável AT_LN apresentou uma relação positiva e significativa a $5 \%$ com a variável PAY. Ao aumento de 1 ponto da variável AT_LN a variável PAY aumentou 3.96\%. Já a variável indicativa de valores negativos que distribuíram proventos apresentou uma relação negativa e significativa com a variável PAY. As demais variáveis não apresentaram relação estatisticamente significante.

Dessa forma, é possível que as variáveis independentes tenham relações distintas com a variável PAY de acordo com sua distribuição, ou seja, no início da distribuição haja uma relação de magnitude e sinal distinto do restante da distribuição. Para tentar observar se existe relevância nesta suposição foram realizados alguns testes para verificar a estabilidade dos parâmetros de MQO e também para observar se há um processo quantílico na base de dados.

Pelo teste de estimativa do processo quantílico a maior parte das variáveis possui alguma relação com a variável PAY. Contudo, na maioria dos casos esta relação claramente não é linear, nem igual para todos os pontos da distribuição, sendo assim, é possível que seja necessário a utilização de uma metodologia distinta da de MQO.

Um fato a ser observado é o aumento do desvio padrão após o quartil 0.5, no intervalo de confiança de 95\%. Este fato reitera o uso de metodologia capaz de analisar a base de dados nos seus diversos pontos de acordo com as características da mesma.

No teste de igualdade de inclinação via MQO e para alguns quantis específicos, vemos que há pelo menos quatro variáveis onde seus coeficientes diferem estatisticamente da estimação de MQO. Podemos observar que duas variáveis apresentaram igualdade, sendo elas, a variável LIQGR e CAPEX. Como optou-se pela utilização de mais variáveis, não é indicado a utilização de MQO. O teste de Wald para igualdade de inclinação nos quantis foi de $X_{(40)}^{2}=2040$ [0.0000].

Visando utilizar um modelo que seja mais adequado para a base de dados, optou-se pelo método de regressão quantílica. A diferença entre a estimação via MQO e esta são os pesos atribuídos para cada observação. Inicialmente, os valores da variável PAY são ordenados de forma crescente. Então, a minimização dos erros ocorre em diversos pontos da distribuição de PAY, e não apenas nos seus valores centrais como ocorre no MQO.

A estimação via regressão quantílica é bastante similar a de MQO. Porém, ao realizar a minimização em mais de um ponto, devido ao quantil escolhido, é como se ponderasse as observações, dando mais peso àquelas próximas ao ponto de escolha. Ou seja, ao escolher o quantil 0.1 estaremos minimizando o erro nas proximidades dos 10\% menores valores de PAY. Sendo assim, as observações ao redor deste quantil terão uma ponderação maior.

Pelo teste de estimativa do processo quantílico foi possível observar que as relações entre as variáveis são distintas de acordo com a distribuição de PAY. Neste sentido, consideramos válido realizar a estimação de cinco quantis: .10, .25, .50, .75, .90.

Serão expostos na tabela 3 os resultados conforme o modelo apresentado. 
Tabela 3- Estimação da relação entre a variável PAY (em logaritmo) e outras variáveis independentes (em logaritmo) nos diferentes quantis de 2009 a 2013

\begin{tabular}{|c|c|c|c|c|c|c|c|}
\hline Quartil & & MQO & Q 0.1 & Q 0.25 & Q 0.50 & Q 0.75 & Q 0.90 \\
\hline \multirow[t]{2}{*}{ AT_LN } & * & 3.96E-02 & 2.25E-20 & 1.87E-20 & 2.08E-02 & 3.71E-02 & $6.54 \mathrm{E}-02$ \\
\hline & ** & $(0.0395)$ & $(1.0000)$ & $(1.0000)$ & $(0.0000)$ & $(0.0000)$ & $(0.0000)$ \\
\hline \multirow[t]{2}{*}{ LIQGR } & & 4.30E-03 & $-3.79 \mathrm{E}-22$ & $-6.09 \mathrm{E}-22$ & 5.92E-04 & 7.01E-03 & $1.80 \mathrm{E}-02$ \\
\hline & & $(0.2782)$ & $(1.0000)$ & $(1.0000)$ & $(0.0016)$ & $(0.0000)$ & $(0.6024)$ \\
\hline \multirow[t]{2}{*}{ RENPAT } & & $-2.79 \mathrm{E}-04$ & 3.19E-22 & $1.53 \mathrm{E}-21$ & 1.43E-03 & 2.41E-03 & $1.99 \mathrm{E}-03$ \\
\hline & & $(0.8385)$ & $(1.0000)$ & $(1.0000)$ & $(0.0000)$ & $(0.0000)$ & $(0.0000)$ \\
\hline \multirow[t]{2}{*}{ DIVB_AT } & & $-1.79 \mathrm{E}-03$ & $-1.35 \mathrm{E}-21$ & $-7.42 \mathrm{E}-22$ & $-3.33 E-04$ & -8.87E-04 & $-1.73 \mathrm{E}-03$ \\
\hline & & $(0.2212)$ & $(1.0000)$ & $(1.0000)$ & $(0.0001)$ & $(0.0000)$ & $(0.0000)$ \\
\hline \multirow[t]{2}{*}{ CAPEX } & & $-2.45 \mathrm{E}-01$ & 7.33E-20 & $-7.27 \mathrm{E}-20$ & 1.45E-03 & -5.59E-02 & -1.56E-01 \\
\hline & & $(0.2765)$ & $(1.0000)$ & $(1.0000)$ & $(0.9432)$ & $(0.0000)$ & $(0.0000)$ \\
\hline \multirow[t]{2}{*}{ LL_AT } & & 1.25E-02 & $-3.07 E-21$ & $-1.57 \mathrm{E}-20$ & $-1.01 \mathrm{E}-02$ & -5.09E-03 & $6.30 \mathrm{E}-03$ \\
\hline & & $(0.7188)$ & $(1.0000)$ & $(1.0000)$ & $(0.0000)$ & $(0.1524)$ & $(0.4736)$ \\
\hline \multirow[t]{2}{*}{ REC_AT } & & 6.37E-02 & 5.38E-20 & 1.09E-19 & 3.89E-02 & 2.84E-02 & -9.88E-02 \\
\hline & & $(0.4262)$ & $(1.0000)$ & $(1.0000)$ & $(0.0001)$ & $(0.1577)$ & $(0.0039)$ \\
\hline \multirow[t]{2}{*}{ CON1 } & & 1.29E-03 & $-2.18 \mathrm{E}-22$ & 5.76E-22 & $-2.73 E-04$ & 3.28E-04 & $1.70 \mathrm{E}-03$ \\
\hline & & $(0.3985)$ & $(1.0000)$ & $(1.0000)$ & $(0.1776)$ & $(0.5056)$ & $(0.0858)$ \\
\hline \multirow[t]{2}{*}{ DUMFIN } & & 2.72E-02 & 1.35E-01 & 2.95E-01 & $2.21 \mathrm{E}-01$ & 1.02E-01 & $-1.37 \mathrm{E}-02$ \\
\hline & & $(0.8710)$ & $(0.0007)$ & $(0.0000)$ & $(0.0000)$ & $(0.0651)$ & $(0.8861)$ \\
\hline \multirow[t]{2}{*}{ DUMNEG } & & $-1.76 \mathrm{E}+00$ & $-3.88 \mathrm{E}+00$ & $-1.35 \mathrm{E}+00$ & $-4.73 \mathrm{E}-01$ & $-4.66 \mathrm{E}-01$ & $-6.90 \mathrm{E}-01$ \\
\hline & & $(0.0000)$ & $(0.0000)$ & $(0.0000)$ & $(0.0000)$ & $(0.0000)$ & $(0.0000)$ \\
\hline \multirow[t]{2}{*}{ C } & & $-1.27 \mathrm{E}-01$ & 9.45E-03 & 1.00E-03 & -1.76E-01 & $-1.62 \mathrm{E}-01$ & $-1.02 \mathrm{E}-01$ \\
\hline & & $(0.6714)$ & $(0.9157)$ & $(0.9376)$ & $(0.0000)$ & $(0.0334)$ & $(0.5914)$ \\
\hline \multicolumn{2}{|c|}{ R-quadrado } & 0.0247 & 0.2537 & 0.0827 & 0.0774 & 0.0510 & 0.0353 \\
\hline \multicolumn{2}{|c|}{ R-quadrado ajustado } & 0.0216 & 0.2512 & 0.0797 & 0.0744 & 0.0479 & 0.0321 \\
\hline \multicolumn{2}{|c|}{ № Observações } & 3,073 & & & & & \\
\hline
\end{tabular}

**Segunda linha: Probabilidade. Significância estatística.

Fonte: Elaborado pelo autor a partir de dados da Economática® (2009-2013).

Observa-se que realmente ocorrem modificações de acordo com o quantil estimado. Também podemos observar que ao utilizar a regressão quantílica houve um incremento do R-quadrado para todos os quantis, com o mínimo de 0.0353 no quantil 0.9 e um máximo de 0.2537 no quantil 0.1 . Podemos observar que essa relação foi decrescente nos quantís.

De forma distinta da estimação via $\mathrm{MQO}$ temos muitas variáveis que são estatisticamente significantes. A variável
AT_LN, que já tinha apresentado significância estatística na estimação de MQO, manteve essa particularidade com exceção dos dois primeiros quartis. A relação desta variável com a variável PAY foi significativa e positiva, sendo mais forte no quartil 0.9 onde um aumento de 1 ponto no AT_LN aumentou 6.54\%. Resultado semelhante foi encontrado por Fama e French (2001), Iquiapaza, Barbosa e Bressan (2005), Iquiapaza, Lamounier e Amaral (2006), Ferreira Junior, Nakamura e Martin (2007), Mota e Eid Junior 
(2010), Procianoy e Vancin (2014), com utilização de outros métodos estatísticos como dados em painel, regressão linear múltipla, regressões tobit ou logit.

A variável LIQGR foi positiva e significativa apenas para os quantis 0.5 e 0.75. Já a variável RENPAT apresentou significância a partir do quantil $0.5 \mathrm{em}$ diante, com uma relação positiva de aproximadamente $0.2 \%$ com a variável PAY. Maiores valores de LIQGR geram um aumento na variável PAY. Resultado semelhante foi encontrado por Lemes Júnior, Cherobim, Rigo (2002), Ho (2003), Iquiapaza, Lamounier e Amaral (2006), Decourt e Procianoy (2006), Mota e Eid Junior (2010), Ross et al. (2013), Procianoy e Vancin (2014) com utilização de outros métodos estatísticos como dados em painel, médias de variáveis, regressão linear múltipla, regressões tobit ou logit.

A DIVB_AT também apresentou significância apenas a partir do quantil 0.5, com uma relação negativa com a variável PAY. Maiores valores de DIVB_AT geram uma redução na dependente PAY. Essa relação aumentou em magnitude com o aumento dos quantis. Estudos de lquiapaza, Barbosa e Bressan (2005) e Mota e Eid Junior (2010) concluem que o menor endividamento influencia positivamente o pagamento de dividendos. A relação negativa é confirmada por estudos de Rozeff (1982) e La Porta et al. (2000).

A variável CAPEX foi significativa apenas nos quantis 0.75 e 0.9. A relação foi negativa, onde um aumento de 1 ponto desta variável representou uma queda de $5.59 \%$ e $15.58 \%$ respectivamente em PAY. A variável LL_AT apresentou uma relação significativa apenas no quantil 0.5 (mediana) com uma relação negativa de $1.01 \%$ com a variável PAY ao aumento de 1 ponto na variável LL_AT. Essa relação é confirmada com o estudo de Procianoy e Vancin (2014) no período de 2007 a 2011 com utilização de regressão múltipla.

Em relação a variável REC_AT apenas houve significância estatística na mediana e no quantil de 0.9. No primeiro caso a relação foi positiva. Maiores valores de REC_AT geram um aumento na dependente PAY. O aumento de 1 ponto na variável REC_AT representou um incremento na variável PAY de 3.89\%, no quantil 0.5 , enquanto no quantil 0.9 o aumento de 1\% em REC_AT reduziu o PAY em 9.88\%.

A variável CON1 não apresentou significância estatística a $1 \%$ para nenhum dos quantis. Estudos de Iquiapaza, Lamounier e Amaral
(2006) e Mota e Eid Junior (2010) encontraram relação negativa entre nível de concentração e Payout. Nesse estudo verifica-se uma relação negativa no quartil .50. Procianoy e Vancin (2014) confirmaram uma relação positiva com utilização de regressão multivariada no período de 2007 a 2011.

A DUMFIN foi significativa nos quantis 0.1 a 0.5 e positiva. Já a DUMNEG foi significativa para todos os quantis, estando associada com uma relação negativa e cada vez mais forte com a variável PAY.

Para todos os casos da análise quantílica a significância estatística utilizada foi de 1\%.

Neste trabalho podemos observar alguns resultados bastante distintos dos tradicionais. Alguns dos fatores que levaram a isso foram a não exclusão de nenhum setor econômico da base de dados, além da utilização de diversos anos. Sendo assim, a amostra total, que obteve 3.073 observações, foi uma das maiores dentre os estudos da política de dividendos.

Outro fator que modifica os resultados é a modelagem. A escolha por analisar de acordo com os quantis da distribuição, ao invés de ponderar todas as observações com o mesmo peso é capaz de se destacar, uma vez que o comportamento das variáveis não é homogêneo durante a sua distribuição.

\section{CONSIDERAÇÕES FINAIS}

A política de dividendos tem destaque em diversos estudos visando esclarecer a sua importância e os fatores que a determinam. A forma como são distribuídos os proventos é um tema central e não se trata apenas de uma decisão sobre o quanto pagar aos acionistas, mas também do quanto de lucro permanecerá na companhia e de que forma será utilizado.

Neste sentido, o propósito deste trabalho foi identificar os fatores determinantes que impactam o índice Payout. A abordagem teórica levou em consideração a relevância e irrelevância dos dividendos, o conteúdo informacional e sinalização, o efeito clientela e tributos, os custos de agência e a legislação brasileira.

Contudo, foi observado que para todos os fatores mencionados, as conclusões dos estudos empíricos realizados não reúnem um consenso. Alguns autores obtiveram 
resultados semelhantes e outros não, seja pelo período amostral diferenciado, escolha de segmento específico ou técnica de análise utilizada.

A técnica de regressão quantílica foi aplicada e produziu um mapeamento mais completo do impacto gerado na distribuição condicional da variável resposta (PAY) para a base de dados e o período analisado. Pelo teste de igualdade de inclinação dos quantis, pelo menos os coeficientes de quatro variáveis diferem da estimação MQO.

As estimativas produzidas pela regressão quantílica permitem concluir que as variáveis que impactam a Payout são: a) AT_LN com relação positiva e significativa em todos os quantis; b) a variável LIGGR foi positiva e significativa nos quantis 0.5 e 0.75 ; c) a RENPAT apresentou significância a partir do quantil 0.5 e positiva; d) relação negativa da DIVB_AT a partir do quantil $0.5 \mathrm{com}$ a variável PAY; e) há uma relação significativa e negativa nos quartis 0.75 e 0.9 entre a variável CAPEX e PAY; f) A variável LL_AT apresentou uma relação significativa e negativa no quartil $0.5 ; \mathrm{g}$ ) a variável REC_AT apresentou uma relação positiva $\mathrm{e}$

\section{REFERÊNCIAS}

[1]. AIVAZIAN, Varouj; BOOTH, Laurence; CLEARY, Sean. Do emerging market firms follow different dividend policies from U.S. firms? Journal of Financial Research, v. 26, n. 3, p. 371-387, 2003.

[2]. ALLI, Kasim L.; KHAN, Abdul Q.; RAMIREZ, Gabriel G. Determinants of corporate dividend policy: a factorial analysis. The Financial Review, v. 28, n. 4, p. 523-547, nov. 1993.

[3]. ASSAF NETO, Alexandre. Finanças corporativas e valor. 5. ed. São Paulo: Atlas, 2010.

[4]. BLACK, Fischer. The Dividend Puzzle. Journal of Portfolio Management, vol. 2, n. 2, p. 5-8, 1976.

[5]. BLACK, Fischer. Why firms pay dividends? Financial Analysis Journal, n. 46, p. 5, 1990.

[6]. BRIGHAM, Eugene F.; GAPENSKI, Louis C.; EHRHARDT, Michael C. Administração financeira: teoria e prática. Tradução Alexandre Loureiro Guimarães Alcântara e José Nicolas Albuja Salazar. São Paulo. Atlas, 2001.

[7]. BRUNI, Adriano Leal; FAMÁ, Rubens; FIRMINO, Adilson; GAMA, Alex. O anúncio da distribuição de dividendos e seu efeito sobre os preços das ações: um estudo empírico do Brasil. In: III Congresso USP de Controladoria e Contabilidade (Faculdade de Economia, Administração e Contabilidade da Universidade de significativa na mediana e no quartil 0.9 ; h) a variável CON1 não apresentou significância estatística a 1\%, no entanto verifica-se uma relação positiva no quartil 0.75 e 0.9 e negativa nos outros quartis; i) as variáveis DUMFIN foram significativas e positivas no quartil 0.1 a 0.5 e a DUMNEG apresentou uma associação negativa e cada vez mais forte.

Nesse sentido, o estudo atingiu seu objetivo ao verificar que as variáveis tamanho, liquidez, rentabilidade, dívida bruta, investimento e receita são fatores que impactam de forma relevante a variável payout em tamanho e sinal diferenciadas, principalmente a partir da mediana, aumentando em magnitude nos quantis superiores.

Com base nos resultados obtidos neste trabalho, recomenda-se que outros estudos aprofundem outras proxys, outras técnicas econométricas, a análise por setores, os fatores que impactam empresas que distribuem dividendos além dos limites definidos pela legislação ou estatuto, Dummy para governança e com variáveis deflacionadas.

São Paulo), 2003. Anais. São Paulo: USP, p. 1-20, 2003.

[8]. DAMODARAN, Aswath. Avaliação de Investimentos - Ferramentas e Técnicas para a Determinação do Valor de Qualquer Ativo. 2. ed. Rio de Janeiro: Qualitymark, 2010.

[9]. DECOURT, Roberto F. O Processo Decisório da Distribuição de Lucros das Empresas Listadas na Bovespa. 2009. 130 f. Tese. PósGraduação em Administração da Universidade Federal do Rio Grande do Sul (UFRGS), Porto Alegre, 2009.

[10]. EISENHARDT, Kathleen. Agency Theory: An Assessment and Review. The Academy of Management Review, v. 14, n. 1, p. 57-74, jan, 1989.

[11]. FAMA, Eugene, F.; FRENCH, Kenneth R. Disappearing dividends: changing firm characteristics or lower propensity to pay? Journal of Financial Economics, v. 60, n. 1, p. 3-43, 2001.

[12]. FAMÁ, Rubens; MARTINS, Andressa I. O que revelam os estudos realizados no Brasil sobre Política de Dividendos? Revista ERA, São Paulo. v. 52, n. 1 p. 24-39, 2012

[13]. FERREIRA JUNIOR, Wanderley Ottoni; NAKAMURA, Wilson Toshiro; MARTIN, Diogenes Manoel Leiva. Evidências empíricas dos fatores 
determinantes das políticas de dividendos das firmas listadas na bolsa de valores de São Paulo. In: Sétimo Encontro Brasileiro de Finanças. Rio de Janeiro, 2007.

[14]. GITMAN, Lawrence J. Princípios de Administração Financeira. 7. ed. São Paulo: Atlas, 1997.

[15]. GLADWELL, Malcolm. Fora de Serie Outliers. Rio de Janeiro. Sextante, 2008.

[16]. GORDON, Myron J. Dividends, earnings, and stock prices. The Review of Economics and Statistics, v. 41, n. 2, p. 99-105, 1959.

[17]. GÜTTLER, Cláudio. Governança corporativa: avaliação qualitativa das práticas em uma empresa de energia elétrica. In: VII Congresso Nacional de Excelência em Gestão. Agosto, 2011.

[18]. HEINEBERG, Ricardo; PROCIANOY, Jairo L. Aspectos determinantes do pagamento de proventos em dinheiro das empresas com ações negociadas na Bovespa. In: Encontro Nacional da Associação Nacional dos Programas de PósGraduação, 27. 2003. Atibaia. Anais Atibaia: ANPAD, 2003.

[19]. HO, Horace. Dividend policies in Australian and Japan. International advances in Economic Research, v. 9, n. 2, p. 91-100, may 2003.

[20]. IQUIAPAZA, Roberto A; BARBOSA, Francisco V; BRESSAN, Aureliano A. Dividendos: plano real, imposto de renda e sinalização nas empresas listadas na Bovespa: 1986 a 2003. In: Encontro brasileiro de Financças. 5. 2005. São Paulo. Anais eletrônicos. São Paulo: SBFIN, 2005. Disponível em: <http://www.sbfin.org.br/encontros/2005>. Acesso em: 15 ago. 2014.

[21]. IQUIAPAZA, Roberto A; LAMOUNIER, Wagner M; AMARAL, Hudson F. Assimetria de informações e pagamento de proventos em dinheiro na Bovespa. 2006. Salvador. Anais eletrônicos de Salvador: ANPAD, 2006. Disponível em

<http://www.anpad.org.br/enanpad/2006/enanpad2 006>. Acesso em: 08 set. 2014.

[22]. JENSEN, Michael C.; MECKLING, William $\mathrm{H}$. Theory of the Firm: Managerial Behavior, Agency Costs and Ownership Structure. Journal of Financial Economics, v. 3, n. 4, p. 305-360, out. 1976.

[23]. JENSEN, Michael. Agency Costs of Free Cash Flow: Corporate Finance and Takeovers. American Economic Review, v. 76, n. 2, p. 323-363, 1986.

[24]. KOENKER, Roger; BASSETT, Gilbert. Regression quantile. Econometrica, 46, p. 33-50, jan. 1978.

[25]. LA PORTA, Rafael; LOPEZ-DE-SILANES, Florencio; SHLEIFER, Andrei; VISHNY, Robert W.
Agency problems and dividend policies around the world. Journal of Finance, v. 55, n. 1, p. 01-33, feb. 2000 .

[26]. LEMES JÚNIOR, Antônio B.; CHEROBIM, Ana Paula; RIGO, Claudio M. Administração financeira: princípios, fundamentos e práticas brasileiras. Rio de Janeiro: Campus, 2002.

[27]. LINTNER, John. Distribution of incomes of corporations among dividends, retained earnings and taxes. American Economic Review, v. 46, n. 2, p. 97-113, 1956.

[28]. MILLER, Merton H; MODIGLIANI, F. Dividend policy, growth and the valuation of shares. Journal of Business, v. 34, n. 4, p. 411-433, 1961.

[29]. MOTA, Daniel C; EID JUNIOR, Willian. Dividendos, juros sobre capital próprio e recompra de ações: um estudo empírico sobre a política de distribuição no Brasil. Anais eletrônicos. Rio de Janeiro: ANPAD, 2010. Disponível em: <http://www.anpad.org.br/admin/pdf/FINB609.pdf>. Acesso em: 02 out. 2014.

[30]. NETO, Augusto Novis Jorge. Dividend yield e persistência de retornos anormais das ações: evidência do mercado brasileiro. 2002. 66 f. Dissertação (Mestrado em Administração de Empresas) - Pós-Graduação da EAESP/FGV, São Paulo, 2002.

[31]. PORTAL, Márcio Telles; ZANI, João; SCHÖNERWALD, da Silva Carlos Eduardo. Fricções financeiras e a substituição entre fundos internos e externos em companhias brasileiras de capital aberto. Revista contabilidade e finanças, São Paulo, v. 23, n. 58, jan./apr, 2012.

[32]. PROCIANOY, Jairo L. A política de dividendos e o preço das ações. In: VARGA, Gyorgy; LEAL, Ricardo. Gestão de Investimentos e Fundos. Rio de Janeiro: FCE, 2006.

[33]. PROCIANOY, Jairo L; VANCIN, Daniel F. Os fatores determinantes do pagamento de dividendos: um Approach Inovador. Congresso: ENAMPAD. Rio de Janeiro, 2014.

[34]. ROSS, S. A.; WESTERFIELD, R. W.; JORDAN, B. D.; LAMB, Roberto. Fundamentos de Administração Financeira. 9. ed. São Paulo: Bookman, 2013.

[35]. ROZEFF, Michael S. Growth. Beta and agency costs as determinants of dividend payout ratios. Journal of Financial Research, v. 5, n. 3, 1982.

[36]. SANTANA, Luciene. Relação entre dividendo e retorno das ações abordando aspectos determinantes da política de dividendos: um estudo empírico em empresas com ações negociadas na BOVESPA. 2006. 82 f. Dissertação (Mestrado) - Instituto Pesquisas em Contabilidade, Economia e Finanças, Vitória, 2006.

[37]. SANTOS, Sandrine I. G. M. Os determinantes da política de distribuição de 
dividendos: o caso das empresas não financeiras do índice PSI-20. 2011. 37 f. Dissertação (Mestrado em Finanças Empresariais) - Universidade de Cabo Verde, 2011.
[38]. SILVA, Everton Nunes da; PÔRTO JÚNIOR, S. Sabino. Sistema Financeiro e Crescimento Econômico: Uma aplicação de regressão quantílica. Economia Aplicada. São Paulo, v. 10, n. 3, p. 425-442, jul./set. 2006. 


\section{Bapítulo 10}

\section{INCENTIVOS FISCAIS E COMPETITIVIDADE: UMA ANÁLISE DOS PRINCIPAIS PROGRAMAS DE INCENTIVOS UTILIZADOS PELO RIO GRANDE DO NORTE}

\section{Richeliel Albert Rodrigues Silva}

Rodrigo Mackssuel Silva de Melo

Genival Jardel Trajano Teixeira

Mônica Almeida Gavilan

Resumo: O presente estudo teve como objetivo compreender como se dá a consecução dos programas fiscais, como também analisar os benefícios concedidos através desses programas contribui para a competitividade da indústria do Rio Grande do Norte. Para isso, foram utilizados dados secundários, acessados por meio da legislação instituidora dos programas, além de dados oficiais do Estado do RN, no que se refere à sua execução. Ademais, trata-se de uma pesquisa exploratória, aplicada e com viés de pesquisa bibliográfica. $\mathrm{Na}$ análise foi perceptível que os programas analisados possuem intensa fonte na isenção e/ou financiamento do Imposto de Circulação de Mercadorias e Serviços ICMS, concluindo-se que o Estado para atrair a competitividade utiliza-se, praticamente, desse mecanismo em todos os programas analisados, podendo 0 mesmo reestruturar algumas políticas voltadas para determinados segmentos econômicos que são pilares da sua economia.

Palavras-chave: Economia. Atratividade. Tributação. 


\section{INTRODUÇÃO}

O Brasil é um país emergente e em constante desenvolvimento. Neste cenário, as questões tributárias do regime brasileiro ainda afetam as empresas em seus processos produtivos e comerciais, tanto no mercado interno como no externo, fazendo com que muitas dessas organizações descontinuem no mercado.

Neste sentido, é certo que a carga tributária está diretamente relacionada a evolução do Produto Interno Bruto - PIB - e uma expansão ou retração econômica acarreta mutações na carga de tributos brasileira. Conforme dados da Receita Federal, a carga tributária brasileira em 2015 ficou em 32,66\%, oscilando positivamente em comparação ao ano de 2014.

Com isso, percebe-se que na evolução constante na figura acima, a carga de tributos no Brasil continua num patamar alto, sendo considerada uma das cargas mais altas do mundo, se comparado com nações altamente desenvolvidas. Porém, de acordo com a Receita Federal (2015), o Brasil apresentou uma redução da carga tributária, ao passo que a média dos países que fazem parte da Organização para a Cooperação e Desenvolvimento Econômico (OCDE) apresentou aumento de sua carga.

Adicionalmente, conforme o Instituto Brasileiro de Planejamento Tributário (IBPT), desde a promulgação da Constituição Federal em 1988 até o ano de 2015, um total de 15 emendas constitucionais com teor tributário e inúmeros tributos foram criados, o que demonstra que o aumento tem acontecido de forma gradativa em consonância com a criação de novos meios de arrecadação.

No que tange a produção e comércio brasileiro, em suas relações domésticas e internacionais, os altos tributos cobrados ainda continuam sendo empecilho no que se refere a competitividade no mercado. Ainda que os tributos aduaneiros, especialmente os impostos, tenham como característica essencial a extrafiscalidade há excessiva cobrança tributária em diversos momentos da cadeia produtiva.

Com base nisso, esse estudo tem por finalidade entender como funcionam os mecanismos tributários de extrafiscalidade utilização dos recursos para finalidade diversa à arrecadatória -, focando nos programas de incentivos fiscais criados e utilizados como ferramenta para a busca da competitividade, pelo estado do Rio Grande do Norte, no período de 2010 a 2017.

\section{METODOLOGIA}

O estudo classifica-se, quanto a sua abordagem como uma pesquisa qualitativa, uma vez que não se preocupa ou restringe-se à representatividade numérica, mas, sim, com o aprofundamento da compreensão de um grupo social, de uma organização, etc. Referente à natureza, a pesquisa é aplicada, visto que, objetiva gerar conhecimentos para aplicação prática, dirigidos à solução de problemas específicos. Envolve verdades e interesses locais. Também é uma pesquisa exploratória, pois tem como objetivo proporcionar maior familiaridade com o problema, com vistas a torná-lo mais explícito, sem a pretensão de produzir verdades absolutas (SILVEIRA e CORDOVA, 2009).

Quanto aos procedimentos adotados para coleta de dados, dar-se-á, por meio de intensa fonte bibliográfica e análise documental a dados oficiais do estado, o que faz com que a pesquisa seja predominantemente uma pesquisa bibliográfica. Tratase ainda de um estudo de caso de realidade específica, apontando os programas de incentivos fiscais do Rio Grande do Norte como possíveis propulsores de competitividade no estado.

\section{RESULTADOS E DISCUSSÕES}

A Constituição Estadual do Rio Grande do Norte, assim, como os dispositivos legais complementares à Carta Magna Estadual versam, dentre outros assuntos, sobre questões pertinentes aos tributos e suas formas de exclusão, anistia e remissão. É comum que os estados utilizem-se da extrafiscalidade para o alcance de melhores resultados dentro do seu potencial econômico. Desta forma, apresentam-se, a seguir, os principais programas de incentivos fiscais do Rio Grande do Norte, a saber, o Programa de Apoio às Importações do Exterior e Desenvolvimento Portuário e Aeroportuário do Rio Grande do Norte (IMPORT - RN ou PROIMPORT), o Programa de Apoio ao Desenvolvimento Industrial do Rio Grande do Norte (PROADI) e o Programa de Apoio ao Desenvolvimento Industrial pelo Incentivo do Gás Natural (antigo PROGÁS, atualmente RN GÁS +). 


\subsection{PROGRAMA DE APOIO ÀS IMPORTAÇÕES DO EXTERIOR E DESENVOLVIMENTO PORTUÁRIO E AEROPORTUÁRIO DO RIO GRANDE DO NORTE (IMPORT - RN OU PROIMPORT)}

A principal fonte de receita estadual é o ICMS e sobre esse tributo, a lei máxima do $\mathrm{RN}$, em seu art. 98, $\S 2^{\circ}$, inciso IX, alínea a, evoca que o mesmo incide quando da entrada de mercadoria importada do exterior, ainda quando se tratar de bem destinado a consumo ou ativo fixo do estabelecimento, assim como sobre serviço prestado no exterior, 83 desde que o estabelecimento destinatário da mercadoria ou serviço esteja localizado no Estado". Dentro dessa incidência, o Programa de Apoio às Importações do Exterior e Desenvolvimento Portuário e Aeroportuário do Rio Grande do Norte - PROIMPORT - foi instituído através da Lei Estadual 9.592/11 e regulamentado pelo Decreto n. 22.567/12.

$\mathrm{O}$ art. $2^{\circ}$, da Lei instituidora define que $\mathrm{O}$ IMPORT - RN destina-se a assegurar o apoio, através da concessão de financiamento, a empresas importadoras cuja atividade seja desenvolvida através da estrutura portuária ou aeroportuária do Estado do Rio Grande do Norte, sob a forma de contrato de mútuo de execução periódica, através de instituição financeira oficial credenciada pelo Governo do Estado.

É válido frisar que é de competência exclusiva do Governador (a) do Estado o consentimento do financiamento, após manifestação de uma Câmara de Gestão responsável pela análise - art. 9o da Lei Estadual 9.592/11 - ainda sendo, importante destacar que as empresas beneficiadas pelo IMPORT - RN não poderão participar, de forma cumulativa, de outro programa de isenção ou benefício fiscal concedido pelo Rio Grande do Norte.

Para obtenção do financiamento do ICMS através do IMPORT - RN, a Câmara de Gestão analisa volume de absorção de mãode-obra e/ou aperfeiçoamento tecnológico, aumento de capacidade de geração de tributos estaduais, contribuição para a ampliação e modernização da estrutura portuária e aeroportuária em função da atividade a ser desenvolvida, montante das operações a serem realizadas pela empresa e também a inexistência de produto similar produzido por empresa localizada no território do Estado do Rio Grande do Norte. Esse último denota a proteção à indústria potiguar diante dos produtos advindos do Exterior.

Entrementes, analisando o dispositivo, há uma inadequação quanto ao nome do programa, visto que o mesmo enuncia que é voltado para o desenvolvimento portuário e aeroportuário do estado do Rio Grande do Norte. No entanto, a lei e o decreto que regulamentam o benefício não discriminam de que forma serão desenvolvidos os portos e o aeroporto internacional do estado em face do programa, merecendo a lei um detalhamento melhor.

\subsection{PROGRAMA DE APOIO AO DESENVOLVIMENTO INDUSTRIAL DO RIO GRANDE DO NORTE (PROADI)}

O Programa de Apoio ao Desenvolvimento Industrial do Rio Grande do Norte - PROADI foi instituído pela Lei n. 5.397, de 11 de outubro de 1985, tendo como objetivo apoiar e incrementar o desenvolvimento industrial do estado e sendo um dos programas mais antigos de incentivo ao desenvolvimento econômico do Rio Grande do Norte.

O PROADI constitui-se no programa de maior importância no que tange à incentivo fiscal através de isenção tributária. Neste caso, versa sobre o Imposto sobre Circulação de Mercadorias e Serviços. Com essa atualização, as sociedades de fruticultura do estado - muitas vezes implantadas por Cooperativas - podem aderir ao PROADI, aumentando sua produtividade, diminuindo seus custos e tornando-se cada vez mais competitivas diante outras concorrentes.

Ao ampliar o rol de sociedades que podem se beneficiar desse incentivo, elenca as empresas que não podem aderir ao PROADI, a Lei 9.995/2015 não atualizou o rol das empresas que, por atividade econômica, estão excluídas da possibilidade de adesão do programa. Os dados mais recentes sobre - quantitativo de recursos são datados de 2015. Pode-se verificar que no ano de 2015 os recursos do PROADI alcançaram $\mathrm{R} \$$ 276.863.946,30, tendo sido concebidos 955 benefícios fiscais através do programa.

Atualmente, com base nos dados de março de 2017, de acordo com dados da Agência de Fomento do RN S.A - AGN existem 102 empresas ativas, $88 \mathrm{em}$ processo de instalação e 14 em ampliação que estão aptas ao recebimento desse benefício fiscal. Empresas em instalações têm direito de $60 \%$ 
a $75 \%$ do incentivo do ICMS devido, mês a mês. Já as empresas em ampliação têm direito ao incentivo em razão de $75 \%$ ou $60 \%$ do ICMS que ultrapassa da produção que ultrapassa o teto. O teto é tido como a produção acima da capacidade inicial, o que pode ser entendido como uma forma mais ampla de incentivo, fazendo com que as indústrias beneficiadas possam focar mais em seus resultados e com isso ter maiores incentivos por parte do estado.

É importante frisar que uma das obrigações que as empresas que gozaram do benefício fiscal em estudo, é que as mesmas, após o período de concessão do programa, devem permanecer suas atividades no Estado, no que equivale a $20 \%$ do tempo que gozou dos incentivos. Esta medida parece positiva, pois é uma tentativa de retornar ao Estado o investimento disponibilizado as indústrias. Exemplificando, se a empresa recebeu os benefícios do PROADI durante 10 anos, a mesma deve permanecer dois anos a mais com suas atividades no Estado. Assim, como se a mesma quiser prorrogar o período de participação no programa deve ampliar no mínimo em $20 \%$ a sua capacidade produtiva, mediante apresentação de projeto de viabilidade econômica, podendo ainda prorrogar a sua participação até 31 de dezembro de 2014, de acordo com a nova lei que atualizou o programa (Lei n. 9.995/2015).

\subsection{PROGRAMA DE APOIO AO DESENVOLVIMENTO INDUSTRIAL DO RIO GRANDE DO NORTE PELO INCENTIVO DO GÁS NATURAL (RN GÁS +)}

O Programa de Apoio ao Desenvolvimento Industrial do Rio Grande do Norte pelo incentivo do Gás Natural - operacionalizado pela POTIGÁS - é um incentivo concebido através da redução do preço de venda de gás natural. Instituído pela Lei n. 7.059, de 18 de setembro de 1997, o programa concede subsídios às indústrias que utilizam o gás natural e que sejam consideradas prioritárias para o desenvolvimento do Estado (grifo nosso), conforme critérios estabelecidos em regulamento (art. 2oda Lei 7.059/97).

Cabe observação quanto à consideração, por parte do Poder Público das indústrias que sejam prioritárias para o desenvolvimento do Estado. Apesar de a Lei instituidora frisar que critérios estariam estabelecidos no regulamento posterior (Dec. n. 13.957/98), o mesmo não elenca de forma clara, quais atividades econômicas são tidas como prioridade para o Estado, deixando uma lacuna na legislação vigente, podendo inclusive, a mesma ser objeto de divergência entre os operadores e aos que estão ligados diretamente ao Programa.

Ainda conforme o art. 3ㅜㅡ, caput da lei que o institui, o prazo para concessão do subsídio é de cinco anos, podendo ser prorrogados duas vezes, por igual período. Ao verificar o Decreto n. 13.957, de 11 de maio de 1998 regulamentador do programa - percebe-se que o mesmo segue a mesma linha do PROADI quanto a definição das sociedades que podem ser beneficiadas pelo incentivo. No ano de 2016, através do Decreto n. $25.846 / 2016$ se fixou o limite máximo de $R \$ 20$ milhões de reais para o exercício orçamentário-financeiro do ano em questão, não tendo sido publicado decreto similar no corrente ano. De forma similar, não há publicação quanto aos benefícios concedidos no ano de 2015, 2016 e 2017. Apenas os dados mais recentes - setembro de 2017 apontam que a Companhia Potiguar de Gás possui 33 clientes industriais, sem apontamentos de quais e quantos atualmente gozam do subsídio, o que impossibilita uma melhor análise sobre eventuais benefícios do programa.

Além disso, Freitas (2017) frisa que o RN Gás + apresenta-se como diferencial potiguar para atração de empresas, tendo em vista que os programas de incentivos fiscais sob o ICMS já se equiparam na maioria dos estados brasileiros. Sendo o estado do RN, o único no Brasil com incentivos de gás natural para indústrias.

Os incentivos de gás natural podem ter descontos de $36 \%$ em relação à tarifa normal para uma quantidade consumida de até 1.000 $\mathrm{m}^{3} /$ dia e máxima de $52,8 \%$ para consumos superiores a $400.000 \mathrm{~m}^{3} / \mathrm{dia}$ e ambas as referências não levam em conta a incidência de ICMS em $17 \%$ e do imposto PIS/COFINS em $9,25 \%$.

\subsection{PROIMPORT E PROADI: BREVE ANÁLISE À LUZ DOS PRINCÍPIOS CONSTITUCIONAIS TRIBUTÁRIOS DA UNIFORMIDADE GEOGRÁFICA E DA ISONOMIA OU IGUALIDADE TRIBUTÁRIA}

Por se tratar de formas de incentivos que devem ser concedidas em estrita observância aos princípios que regem o Estado 
Democrático, em breve análise, aponta-se a consonância dos mecanismos instituídos com os princípios constitucionais tributários da Uniformidade Geográfica e da Isonomia ou Igualdade Tributária. Tem-se que, princípio, portanto, pode ser entendido como linhas gerais aplicadas a determinada área do direito, constituindo as bases e determinando as estruturas em que se assentam institutos e normas jurídicas (MIRANDA 2009, p. 3).

Nesse aspecto a Constituição está clara, quando exclui do inciso I, a concessão de incentivos fiscais, pois os mesmos têm caráter extrafiscal com vistas à promoção do desenvolvimento regional e redução de desigualdade, conforme objetivo fundamental da República Federativa do Brasil (art. 3ํㅡ. III). Ressalta-se, ainda que, a concessão de incentivos não fere o disposto no art. 19 da CF, inciso III, in fine: "Art. 19. É vedado à União, aos Estados, ao Distrito Federal e aos Municípios: III - criar distinções entre brasileiros ou preferências entre si". Portanto, pode-se afirmar que os programas de incentivos - PROIMPORT e PROADI - se comportam em estreita concordância com o princípio da uniformidade geográfica.

Não há no caso do PROIMPORT e PROADI desobediência ao disposto na CF, uma vez que, ao analisar de forma teleológica, com o princípio da isonomia, a CF determinou como finalidade o tratamento desigual à medida de sua desigualdade. Portanto, visto que os incentivos fiscais têm como objetivo principal reduzir os desequilíbrios regionais, os mesmos são utilizados como mecanismos para o alcance da isonomia.

Importa pontuar, que em caso de descumprimento aos princípios constitucionais e ou extrapolação dos limites legais, programas de incentivos fiscais podem ser invalidados pelo Supremo Tribunal Federal (STF), mesmo com o entendimento pacificado de que os incentivos são atos administrativos discricionários, ou seja, atos praticados por conveniência ou oportunidade pela Administração Pública.

\subsection{BREVE ANÁLISE DO PROIMPORT, PROADI E RN GÁS + EM DETRIMENTO COM O RANKING DE COMPETITIVIDADE DO CLP}

Anualmente, desde o ano de 2015, é publicado pelo Centro de Liderança Pública (CLP), o ranking de competitividade entre os estados brasileiros. Para a construção do ranking são analisados 10 pilares, considerados primordiais para o alcance da competitividade. São eles: potencial de mercado, sustentabilidade ambiental, inovação, eficiência da máquina pública (grifo nisso), solidez fiscal, segurança pública, sustentabilidade social, educação, capital humano e infraestrutura.

Cada um dos itens subdivide-se em vários outros aspectos. $\mathrm{Na}$ presente análise, interessa destaque aos pilares de potencial de mercado, da eficiência da máquina pública e solidez fiscal, por terem subitens mais diretamente ligados as questões tributárias e fiscais.

Ao analisar o potencial de mercado, entendese que, pragmaticamente, incentivo fiscal visa também crescimento de número de empregos gerados, o indicador gerado no ranking demonstra que de 2016 para 2017, o RN caiu uma posição - de 13으 para 14ำ lugar. Destaca-se também que a taxa de crescimento caiu da posição 14ำ para a posição 19º, deixando evidente que o mercado potiguar não está conseguindo expandir-se e/ou está se expandido em velocidade inferior à média dos outros estados brasileiros, mesmo diante os incentivos e subsídios concedidos.

Quando interpretados os dados pertinentes à eficiência da máquina pública, tem-se como base alocação de recursos da forma eficiente, trazendo eficácia aos atos praticados pela Administração Pública. O subitem da transparência aponta o RN na posição 16을 deixando evidente que o Estado precisa ser mais claro e objetivo, bem como apresentar com maior frequência os dados pertinentes a economia potiguar, bem como demonstrar estatisticamente os dados pertinentes, inclusive aos incentivos fiscais, onde ficam evidenciadas nesse trabalho, também a dificuldade de obtenção de dados dos programas do PROIMPORT, PROADI e RN Gás + pela ausência de publicação dos mesmos nos Portais de Transparência.

A transparência é de suma importância, uma vez que norteia os agentes econômicos na consecução dos objetivos e possíveis empreendimentos, cabendo ao poder público atualizar dados que fomentem 0 desenvolvimento das atividades industriais e comerciais do Estado, passando confiabilidade aos possíveis investidores. Por fim, uma máquina pública que não é 
transparente, acaba não passando confiança ao empresariado.

No exame dos dados do ranking que tangem sobre a solidez fiscal, os subitens destacam por serem os mais próximos do crivo fiscal/tributário. O RN é o $2^{\circ}$ no quesito solvência fiscal, isto é, contabilmente, referese à capacidade de possuir um ativo maior que o passivo. Porém, no que concerne a capacidade de investimento, o RN posicionase em 19 , demonstrando que o Estado ainda é tímido nesse aspecto. Pode-se perceber que os dados são divergentes, deduzindo-se que os incentivos fiscais e subsídios concebidos podem auxiliar para redução de custos, porém não são suficientemente capazes de melhorar a capacidade de investimento das indústrias potiguares.

Em síntese geral, no ano de 2017, o RN é apresentado como o 15으 mais competitivo do Brasil. No ano de 2016, o mesmo ranking posicionou o Estado em 18으 e em 2015, o RN figurava a $23^{\circ}$ posição.

\section{CONCLUSÕES}

Em alusão a análise da legislação pertinente à instituição e regulamentação dos programas de incentivos fiscais e subsídios do Rio Grande do Norte examinados nesse estudo, verifica-se fragilidade, do ponto de vista, que alguns aspectos pertinentes à forma como a lei está escrita, deixa várias lacunas, que

\section{REFERÊNCIAS}

[1]. BRASIL. Constituição Federal da República Federativa do Brasil. Disponível em http://www.planalto.gov.br/ccivil_03/constituicao/co nstituicao.htm Acesso em 05 de março de 2017.

[2]. BRASIL. Código Tributário Nacional. Lei $\mathrm{n}$ 5.172 de 25 de outubro de 1966. Disponível em http://www.planalto.gov.br/ccivil_03/leis/L5172.htm Acesso em 09 de março de 2017.

[3]. BRASIL. Lei de Responsabilidade Fiscal. Lei complementar n. 101 de 04 de maio de 2000. Disponível em http://www.planalto.gov.br/ccivil_03/leis/LCP/Lcp10 1.htm Acesso em 25 de março de 2017. podem ser interpretadas com divergências, podendo culminar em entraves em instâncias judiciais. Cabendo, a nível sugestivo, a atualização dos dispositivos que apresentem tais características.

Referente à consonância dos princípios constitucionais tributários (princípio da isonomia tributária e princípio da uniformidade geográfica), os programas de incentivos e subsídios estudados apresentam total congruência com o disposto na Constituição Federal e também na legislação ordinária, a citar, a Lei de Responsabilidade Fiscal.

Pertinente aos índices de competitividade apontados com base no Ranking de Competitividade 2017 produzido pela CLP é perceptível que o RN tem se posicionado em situação de ascendência. Porém, a escassez de dados dificulta atrelar as melhorias demonstradas no ranking aos programas de incentivos e subsídios estudados nesse trabalho.

Por fim, é perceptível que os programas trazem benefícios para a indústria potiguar, principalmente no que se refere à redução de custos (estratégia genérica de Porter). Porém é necessário o aprofundamento através de novos estudos para analisar de forma mais contundente a efetividade desses mecanismos que visam o desenvolvimento do Estado. Cabe destacar que a pouca disponibilidade de dados limitou a pesquisa.

[4]. BRASIL. Receita Federal do Brasil. Carga Tributária no Brasil em 2015: Análise por tributos e bases de incidência. Disponível em < http://idg.receita.fazenda.gov.br/dados/receitadata/ estudos-etributarios-e-aduaneiros/estudos-eestatisticas/carga-tributaria-no-brasil/ctb2015.pdf > Acesso em 25 de março de 2017.

[5]. SILVEIRA, D. T. CÓRDOVA, F. P. Métodos de Pesquisa. UFRGS. 2009. Disponível em < http://www.ufrgs.br/cursopgdr/downloadsSerie/der ad005.pdf > Acesso em 26 de março de 2017. 


\section{Bapítulo 11}

\section{A INFLUENCIA DO ENSINO SUPERIOR NO PLANEJAMENTO FINANCEIRO PESSOAL DOS ACADEMICOS INGRESSANTES E CONCLUINTES DO CURSO DE ADMINISTRAÇÃO DA UNIVERSIDADE FEDERAL DE MATO GROSSO DO SUL - CAMPUS DE NOVA ANDRADINA}

\section{Thaís Nogueira da Silva \\ Vitor Cardoso da Silveira \\ Antonio Sérgio Eduardo \\ José Soares Ribeiro}

Gemael Chaebo

Resumo: O planejamento financeiro pessoal é um instrumento essencial para qualquer indivíduo, visto que o nível de endividamento dos brasileiros tem aumentado nos últimos anos. Diante de tal fato o conhecimento de um controle financeiro é capaz de prover um auxílio nas decisões financeiras da população. Neste cenário é importante realçar o papel de uma educação financeira eficaz. Este artigo tem como objetivo principal verificar o grau de influência que o ensino superior exerce sobre o planejamento financeiro dos acadêmicos do curso de administração da Universidade Federal de Mato Grosso do Sul - Campus de Nova Andradina, para tal foi empregado um questionário composto por 9 (nove) questões fechadas, aplicado para 67 acadêmicos distribuídos entre ingressantes e concluintes. A pesquisa se caracterizou como exploratória e descritiva, e com relação aos dados estes tiveram uma abordagem qualitativa e quantitativa. Dentre os resultados encontrados, observou-se que os discentes se sentem seguros com relação ao gerenciamento de seus recursos, porém não são todos que efetuam um planejamento financeiro. Destacou-se ainda assuntos relativos à temática além de ferramentas como o orçamento e fluxo de caixa, capazes de serem aplicados para uma boa gestão financeira pessoal.

Palavras-chave: Planejamento Financeiro Pessoal, Orçamento Pessoal, Fluxo de Caixa. 


\section{INTRODUÇÃO}

De acordo com dados divulgados pela Pesquisa de Endividamento e Inadimplência do Consumidor (PEIC), e apurada pela Confederação Nacional do Comércio de Bens, Serviços e Turismo (CNC), as famílias brasileiras estão consumindo menos e o endividamento também é menor, fato que se dá pela crise que afeta o país. O total de endividados caiu de $61,9 \%$ de janeiro de 2015 para $57,7 \%$ no mês de julho de 2016, porém ainda não deixa de ser um resultado preocupante. O percentual de famílias que se encontram com dívidas ou conta em atraso teve uma diminuição em relação ao mês de junho caindo de $23,5 \%$ para $22,9 \%$, no entanto houve alta com relação ao ano passado, o percentual era de $21,9 \%$. Houve uma queda também das famílias que não terão condições de pagar suas dívidas em comparação com o mês anterior caindo de $9,1 \%$ para $8,7 \%$, entretanto realizada a comparação com o ano de 2015 este percentual aumentou, o total do ano anterior era de $8,1 \%$. A pesquisa ainda demonstra que os principais causadores de dívida são o cartão de crédito, carnês, crédito pessoal, financiamento de carro e de casa, cheque pré-datado e especial.

Em situações assim, nota-se que um planejamento financeiro auxiliará tanto indivíduos quanto empresas a manterem uma posição mais favorável, e serem menos afetados pelo endividamento que mesmo diante da crise ainda se encontra em um nível alto.

No que diz respeito ao Planejamento Financeiro, Macedo Jr. (2013, p. 43) aponta que "Um erro que a maioria das pessoas comete é fazer o planejamento financeiro somente quando está endividada. Nessa situação, o planejamento necessariamente implica cortes e gera situação de desgaste familiar".

Caso não se tenha um controle efetivo, a situação ficará cada vez mais precária, de outra forma o planejamento é uma ótima ferramenta para que se alcance grandes resultados na vida pessoal financeira.

De acordo com Chiavenato (2014, p. 169) "o planejamento define aonde se pretende chegar, o que deve ser feito, quando, como e em que sequência". Planejar é essencial, sendo responsável por determinar objetivos e a maneira de alcançá-los, tornando-se uma necessidade a ser adotada urgentemente pela população em geral.
O comportamento financeiro das pessoas reflete nas decisões financeiras futuras, porém o conhecimento inadequado de como lidar com o dinheiro, acaba por deixar o futuro incerto dessas decisões.

Macedo Jr. (2013, p. 77) enfatiza que:

O planejamento deve estar direcionado a objetivos que estejam de acordo com seus valores pessoais, propiciem melhoria na qualidade de vida e the permitam obter tranquilidade financeira. Pior do que não se preocupar com dinheiro é viver apenas para ganhá-lo.

Um indivíduo que possui conhecimentos financeiros e que se mantém informado é capaz de vir a tomar decisões mais corretas e conscientes, neste sentido a educação financeira é de grande relevância dentro da sociedade, auxiliando as pessoas em seu processo de decisão.

Diante disto, esta pesquisa busca responder o seguinte questionamento: Os acadêmicos ingressantes e concluintes do curso de Administração da Universidade Federal de Mato Grosso do Sul - Campus de Nova Andradina (UFMS - CPNA) são influenciados pela graduação para a elaboração de seu planejamento financeiro?

Assim, o objetivo do presente artigo consiste em identificar o grau de influência da graduação no processo de planejamento financeiro dos acadêmicos ingressantes e concluintes de Administração da Universidade Federal de Mato Grosso do SulCampus de Nova Andradina (UFMS - CPNA).

A abordagem do tema foi escolhida por ser um assunto de extrema relevância, contribuindo não só para acadêmicos, mas também para toda a sociedade, visto que o planejamento executado de forma coerente é uma ferramenta eficaz para o controle financeiro pessoal.

A estrutura do artigo, além desta introdução, contempla o referencial teórico acerca dos conceitos de finanças pessoais e educação financeira, planejamento financeiro, orçamento pessoal e fluxo de caixa, na sequência são apresentados os procedimentos metodológicos utilizados para a resolução da problemática, em seguida foi proposto um breve questionário, respondido pelos discentes, sendo realizada uma análise posteriormente. Por último são apresentadas as considerações finais. 


\section{REFERENCIAL TEÓRICO}

Este capítulo apresenta os principais conceitos que se relacionam com o estudo em questão, os mesmos fazem referência às finanças pessoais, educação financeira, planejamento financeiro, orçamento pessoal, fluxo de caixa e a demonstração de resultado de exercício (DRE).

Segundo Gitman (2010, p. 3), finanças pode ser definida como "a arte e ciência de administrar dinheiro. Praticamente todas as pessoas físicas e jurídicas, ganham ou levantam, gastam ou investem dinheiro".

Quando se tem pouco conhecimento sobre finanças as pessoas muitas vezes gastam toda sua renda de forma inadequada, podendo gastar além do que recebem, quando esse conhecimento começa a ser aprimorado, é possível seguir um novo caminho, aumentando a qualidade de vida e melhorando o processo de tomada de decisões financeiras.

A boa gestão das finanças pessoais pressupõe a existência da educação financeira. Indivíduos educados financeiramente lidam de maneira mais satisfatória com o dinheiro.

Segundo o Banco Central do Brasil (2013, p.12):

A educação financeira pode trazer diversos benefícios, entre os quais, possibilitar o equilíbrio das finanças pessoais, preparar para o enfrentamento de imprevistos financeiros e para a aposentadoria, qualificar para o bom uso do sistema financeiro, reduzir a possibilidade de o indivíduo cair em fraudes, preparar o caminho para a realização de sonhos, enfim, tornar a vida melhor.

A instrução financeira é essencial na hora de gerir as finanças, quando não se tem tal conhecimento, as habilidades para administrar as próprias finanças ficam comprometidas.

Silvestre (2010) relata que as áreas de maior preocupação e ação no que diz respeito às finanças pessoais são: os investimentos, os gastos e as dívidas. Quando se tem conhecimento nessas áreas às pessoas passam a gerir seus recursos financeiros de forma mais coerente, investindo melhor, controlando os gastos e evitando o endividamento.

De acordo com o Banco Central do Brasil (2013), os cidadãos conseguem melhorar sua qualidade de vida e a de seus familiares, desenvolvendo habilidades com base em suas atitudes e nos conhecimentos básicos de finanças pessoais aplicados no cotidiano.

O conhecimento básico de finanças pessoais corrobora com o alcance de objetivos individuais. Para Tosseti e Gibbons (2012, p. 29) "administrar bem as suas finanças diárias é apenas uma questão de criar e manter hábitos e rotinas fiscais saudáveis".

A organização das finanças pessoais possui reflexos na qualidade de vida dos indivíduos. Ao dar início a um planejamento financeiro, que seja condizente com a realidade, a visão dos disponíveis e também dos gastos necessários acarretará em ganhos na vida financeira das pessoas.

Maximiano (2011) argumenta que é o planejamento quem administra as relações com o futuro, sendo uma ferramenta essencial do processo de tomada de decisão, para este autor as decisões de planejamento, são aquelas decisões que influenciam o futuro ou que serão postas em práticas no futuro.

O planejamento financeiro é uma ferramenta de grande relevância, é ele quem estabelece como os alvos financeiros serão atingidos. Chiavenato (2014) elucida que planejamento é o ato de estabelecer objetivos e estipular de forma antecipada o melhor caminho para que sejam alcançados.

Para Frezatti (2009, p. 18) "Planejar sem controlar é uma falácia e desperdício de tempo e energia. Significaria que energia foi despendida pelos gestores decidindo 0 futuro, sem que se possa saber se os objetivos estão sendo atingidos".

A partir destas visões, pode-se afirmar que quando se aprende a administrar e planejar os recursos que se encontram disponíveis se obtém melhores resultados no reconhecimento de oportunidades, na limitação dos gastos, independência financeira e qualidade de vida, etc. Para que os objetivos sejam alcançados, o planejamento tem que ser elaborado de forma séria e executado com disciplina, sendo capaz de orientar o processo de tomada de decisão.

De acordo com Braga (2011, p. 228) "Planejar significa definir antecipadamente":

Os objetivos das ações preestabelecidas (o que se deseja alcançar); 
A forma pela qual as ações serão desenvolvidas (como será feito);

Os meios físicos, tecnológicos, humanos etc. e os recursos financeiros necessários (com que e por quanto será feito);

Os prazos de execução e as épocas de conclusão de cada etapa do plano (quando será feito); e

Os responsáveis pela execução das etapas do plano (por quem será feito).

Semelhantemente às empresas (pessoa jurídica), as pessoas físicas também devem utilizar o planejamento financeiro a fim de conquistar seus objetivos e metas, aumento de seus patrimônios, dentre outros.

Cerbasi (2009, p. 21) aponta que "O primeiro passo de qualquer planejamento é garimpar suas contas em busca de sobras de recursos. Investir mal é melhor do que não investir. Com o tempo e algum estudo, você começará a selecionar melhor suas alternativas".

Para atingir os objetivos propostos de forma mais fácil e prática o melhor caminho a se seguir é dividir seu planejamento em curto e longo prazo. O planejamento de curto prazo busca suprir as necessidades mais imediatas dos indivíduos enquanto que o planejamento de longo prazo envolve planos maiores, com investimentos mais altos e que demandam mais tempo para realizar as ações, além de ser exigir mais disciplina em sua elaboração.

Os aliados básicos do planejamento são o orçamento e fluxo de caixa, ferramentas que se apresentam com o intuito de obter dados precisos e auxiliar no processo de tomada de decisões, e assim atingir os objetivos de maneira eficiente.

Os cidadãos não conseguem ter um controle sobre os seus diversos gastos, com isso acabam gastando mais do que ganham, neste sentido a ação em conjunto de um orçamento pessoal e um fluxo de caixa, é capaz de harmonizar as despesas e receitas das pessoas.

Pires (2007, p.37) salienta que:

O orçamento é essencialmente um instrumento de planejamento, semestral, anual ou plurianual. Fisicamente falando, ele nada mais é do que uma planilha em que são listadas todas as receitas e despesas esperadas e previstos os valores correspondentes para cada um dos meses de um ano (supondo-se que o período escolhido seja anual).

Ainda de acordo com Pires (2007), o orçamento possui uma estrutura básica que é sempre a mesma, com linhas e colunas, na coluna que são listadas as receitas e despesas, contudo, diverge de indivíduo para indivíduo, pois não possuem os mesmo gastos e nem apresentam a mesma origem de receita.

O orçamento pessoal é como um orçamento empresarial, ou seja, está ligado ao comportamento e à cultura que pertencem. É um mecanismo indispensável para gerenciar a vida financeira do indivíduo e do grupo familiar, capaz de auxiliar no controle dos gastos e verificar a necessidade de mudança de comportamento.

A execução de um orçamento colabora para correção de eventuais impasses durante a realização do planejamento financeiro, apresenta informações úteis transformando-o em um grande mecanismo de controle, além de ser uma ferramenta de fácil utilização.

Gitman (2010) aponta que orçamento pessoal é um diagnóstico do planejamento financeiro de curto prazo que auxilia as pessoas a atingirem os seus objetivos financeiros de curto prazo.

Assim que elaborado o orçamento é necessário a realização de um fluxo de caixa, que segundo Hoji (2012) é uma ferramenta que representa as entradas e saídas de dinheiro do caixa ao longo do período.

O fluxo de caixa é um instrumento de gestão que possibilita o planejamento e o controle dos recursos financeiros dos consumidores, permitindo visualizar os caminhos que serão seguidos para a sobrevivência dos mesmos.

Pires (2007, p. 44,45) enfatiza que:

Enquanto o orçamento é um instrumento de gestão que geralmente leva em conta um ano, permitindo acompanhar as variações mensais, o fluxo de caixa é uma planilha de acompanhamento do saldo diário, com o intuito de evitar desencaixes, ou falta de dinheiro para os pagamentos necessários. Sua lógica e estrutura são as mesmas do canhoto de um talão de cheques: saldo inicial + créditos - débitos $=$ saldo final.

Nesta situação quando gastar mais do que se ganha, o fluxo de caixa será encaminhado para um resultado negativo, isso significa que é necessário de imediato alguma entrada de 
recursos para honrar com seus compromissos, de maneira oposta, quando se entra mais recursos do que sai, o fluxo de caixa é considerado positivo, portanto o indivíduo está conseguindo cumprir com suas obrigações.

Com o fluxo de caixa é possível perceber se haverá caixa considerável para manter suas contas em dia, verificando de forma detalhada suas receitas e despesas que ocorrem frequentemente, mostrando a real situação financeira dos indivíduos.

Portanto, a partir do momento em que os sujeitos adotarem um modelo que atenda suas necessidades e características, contribuirá para manter as obrigações em dia e uma vida financeira saudável e sem preocupações.

Outro ferramenta que torna-se importante a sua implementação é a chamada DRE (demonstração do resultado do exercício).

Padoveze (2004, p. 123) explica que "a finalidade da Demonstração de Resultado é uma melhor evidenciação do ganho, [...]". A DRE nada mais é do que um relatório que tem como função apurar todas as receitas e despesas do período, tendo assim uma análise mais clara e objetiva dessas contas.

E nas finanças pessoais não é diferente, este instrumento evidenciará os ganhos e os desembolsos realizados pelos indivíduos. A partir do momento que são analisados quais foram as receitas (ganhos) e despesas (desembolsos), é possível verificar se o resultado foi positivo, ou seja, se o indivíduo obteve lucro, ou foi negativo, gerando assim um prejuízo.

\section{METODOLOGIA}

Este capítulo destina-se a classificar o artigo diante dos procedimentos metodológicos efetuados. A metodologia é o processo onde o pesquisador atingirá seu objetivo através da utilização de um método de pesquisa.

Thiollent (2009, p. 35) enfatiza que:

Quando a ideia de encontrar a solução para um problema de uma respectiva área de atuação surge, é preciso ter, além de motivação, um bom plano de pesquisa em cima do assunto estudado. Para isso é utilizada a metodologia que dá o delineamento do estudo para que o objetivo principal seja cumprido.
No que diz respeito à abordagem da pesquisa, Vergara (1998, p. 57) ressalta o seguinte:

Os dados podem ser tratados de forma quantitativa, isto é, utilizando-se procedimentos estatísticos, como o teste de hipóteses. Os dados também podem ser tratados de forma qualitativa como, por exemplo, codificando-os, apresentando-os de forma mais estruturada e analisando-os.

O estudo possui cunho quantitativo, visto que se configura por resultados que possam ser quantificados, isto é, reproduz em números as informações obtidas para utilizá-las na análise dos dados; e cunho qualitativo por constituir interpretações e conclusões a cerca dos fenômenos.

Os métodos de procedimento se classificam como uma pesquisa exploratória e descritiva. De acordo com os autores Teixeira, Zamberlan e Rasia (2009), a pesquisa exploratória permite uma maior familiaridade e aproximação com o tema abordado, ocasionando um melhor entendimento do mesmo.

Além de exploratória, é classificada também como descritiva, pois segundo Teixeira, Zamberlan e Rasia (2009, p. 116 e 117) "a pesquisa descritiva visa a identificar, expor e descrever os fatos ou fenômenos de determinada realidade em estudo, características de um grupo, comunidade, população ou contexto social".

Para a coleta de dados foi utilizado como dados primários um questionário, que de acordo com Gil (2008), é um método de averiguação formado por um conjunto de questões que são aplicadas aos indivíduos para que se adquiram informações sobre os mesmos.

E como dados secundários, empregou-se a pesquisa bibliográfica, que conforme Lakatos e Marconi (2010, p. 166):

Abrange toda bibliografia já tornada pública em relação ao tema de estudo, desde publicações avulsas, boletins, jornais, revistas, livros, pesquisas, monografias, teses, material cartográfico etc., até meios de comunicação oral: rádio, gravações em fita magnética e audiovisuais: filmes e televisão.

O público alvo desse trabalho foram os acadêmicos regularmente matriculados no curso de Administração da Universidade 
Federal de Mato Grosso do Sul - Campus de Nova Andradina (UFMS/CPNA).

O método de amostragem da pesquisa foi a não probabilística intencional, que segundo Gressler (2003, p. 44) "é aquela que se baseia em julgamentos feitos pelo pesquisador, isto é, aquela que, segundo ele, é a melhor para o estudo".

A amostra direcionou-se para os estudantes que estão no primeiro semestre do curso e os que já se encontram no penúltimo semestre, com o intuito de avaliar o grau de influência proporcionado pelo ensino superior no conhecimento financeiro de quem entrou e de quem está saindo da universidade. Portanto, a amostra se constituiu por 67 alunos do curso de administração, com 40 acadêmicos do primeiro semestre e 27 acadêmicos do penúltimo semestre.

O questionário aplicado aos discentes foi composto por nove questões objetivas, indicando sobre idade, faixa salarial, influência da graduação e outros assuntos relativos à pesquisa, a aplicação do questionário ocorreu no dia 27 de julho de 2016 e para a análise dos dados obtidos e elaboração dos quadros utilizou-se o software Microsoft Excel 2007.

\section{APRESENTAÇÃO E ANÁLISE DOS DADOS}

Neste capítulo são apresentados os resultados obtidos com a pesquisa, que buscou evidenciar a influência do ensino superior para os acadêmicos de Administração ingressantes e concluintes da Universidade Federal de Mato Grosso do Sul - Campus de Nova Andradina (UFMS/CPNA).

As primeiras questões fazem referência aos dados pessoais dos discentes, buscou-se levantar a idade e estado civil.

Quadro 1 - Idade dos Discentes

\begin{tabular}{|c|c|c|}
\hline & Semes & 7은 Semestre \\
\hline Até 20 anos & $50 \%$ & $15 \%$ \\
\hline Entre 21 e 25 anos & $33 \%$ & $33 \%$ \\
\hline Entre 26 e 30 anos & $8 \%$ & $26 \%$ \\
\hline Acima de 30 anos & $10 \%$ & $26 \%$ \\
\hline
\end{tabular}

Fonte: Elaborado pelos autores.

Foi constatado dentre os respondentes ingressantes que $50 \%$ possuem idade de até 20 anos, 33\% tem entre 21 e 25 anos, $8 \%$ entre 26 e 30 anos e 10\% tem idade superior a 30 anos.

Quanto aos acadêmicos concluintes verificouse que $15 \%$ dos respondentes têm até 20 anos, 33\% entre 21 e 25 anos, $26 \%$ entre 26 e 30 anos, ocorrendo o mesmo percentual pra os indivíduos acima de 30 anos de idade.

Em seguida indagou-se a respeito da situação dos indivíduos em relação à sociedade conjugal, como pode ser percebido logo abaixo:

\section{Quadro 2 - Estado Civil}

\begin{tabular}{|c|c|c|}
\hline \multicolumn{2}{|c|}{} & \multicolumn{2}{|c|}{1 Semestre } & 7 Semestre \\
\hline Solteiro & $88 \%$ & $59 \%$ \\
\hline Casado & $8 \%$ & $37 \%$ \\
\hline Divorciado & $5 \%$ & $4 \%$ \\
\hline
\end{tabular}

Fonte: Elaborado pelos autores. 
Com relação ao estado civil dos estudantes verificou-se que quase $90 \%$ dos ingressantes estão solteiros, enquanto que, uma minoria de $8 \%$ e $5 \%$, estão casados e divorciados respectivamente.

No caso dos universitários concluintes, foi observado que mais da metade (60\%) se encontram solteiros, 37\% são casados e apenas $4 \%$ dos concluintes são divorciados.

Na sequência foi questionado sobre a área de atuação de cada discente, obtendo-se como resultado o que está evidenciado no quadro abaixo:

Quadro 3 - Área de atuação no mercado

\begin{tabular}{|c|c|c|}
\hline & 1o Semest & $7^{\circ}$ Semestre \\
\hline Indústria & $8 \%$ & $15 \%$ \\
\hline Comércio & $43 \%$ & $19 \%$ \\
\hline Prestação de Serviços & $18 \%$ & $26 \%$ \\
\hline Autônomo & $8 \%$ & $7 \%$ \\
\hline Outro & $28 \%$ & $33 \%$ \\
\hline
\end{tabular}

Fonte: Elaborado pelos autores.

Nota-se que mais de $40 \%$ (quase a metade) dos ingressantes atuam no comércio, de outra forma, no que diz respeito aos concluintes a atuação concentra-se em setores diversos não apresentados na questão. Como opção "outro" é válido falar sobre os indivíduos que não estão atuando no mercado de trabalho no momento.

Como consequência ao quadro anterior, foi realizada uma pergunta sobre a faixa salarial dos alunos, segue resumo abaixo do resultado obtido:

Quadro 4 - Faixa Salarial

\begin{tabular}{|c|c|c|}
\hline \multicolumn{2}{|c|}{} & \multicolumn{2}{|c|}{ 10 Semestre } & 70 Semestre \\
\hline 0 a 2 salários mínimos & $100 \%$ & $56 \%$ \\
\hline 3 a 4 salários mínimos & - & $33 \%$ \\
\hline 5 a 6 salários mínimos & - & $7 \%$ \\
\hline Acima de 6 salários mínimos & - & $4 \%$ \\
\hline
\end{tabular}

Fonte: Elaborado pelos autores.

O nível salarial de todos os alunos ingressantes corresponde de 0 a 2 salários mínimos, é importante frisar que a opção 0 (zero) de salário é para os acadêmicos que não estão inseridos no momento no mercado de trabalho ou não possuem uma outra fonte de recursos. Quanto aos alunos concluintes observou-se que mais de $50 \%$ estão na faixa salarial de 0 a 2 salários mínimos, 33\% na faixa de 3 a 4 salários mínimos, e os demais $11 \%$ dividem-se na faixa de 5 a 6 salários mínimos e acima de 6 salários mínimos.

As questões que se seguiram faziam referência à resolução da problemática proposta inicialmente. O quadro a seguir 
evidencia se os discentes possuem ou não segurança em seus conhecimentos para administrar os recursos financeiros.

Quadro 5 - Segurança em seus conhecimentos para gerir o dinheiro

\begin{tabular}{|l|c|c|}
\multicolumn{1}{|c|}{1 10 Semestre } & 70 Semestre \\
\hline Sim & $90 \%$ & $93 \%$ \\
\hline Não & $10 \%$ & $7 \%$ \\
\hline
\end{tabular}

Fonte: Elaborado pelos autores.

Nota-se que $90 \%$ dos discentes do 1 으 semestre e $93 \%$ dos discentes do $7^{\circ}$ - semestre afirmam ter segurança em seus próprios conhecimentos para controlar seu dinheiro, enquanto que uma minoria de $10 \%$ do 1 은 semestre e $7 \%$ do $7^{\circ}$ semestre discordam a respeito do caso.
Fato é que a segurança nos conhecimentos financeiros nem sempre significa uma prática de planejamento financeiro no cotidiano. O quadro 6 mostra as respostas a respeito desta prática.

Quadro 6 - Praticam o planejamento financeiro pessoal no cotidiano

\begin{tabular}{|c|c|c|}
\multicolumn{2}{|c|}{ 1\% Semestre } & 7 Semestre \\
\hline Sim & $73 \%$ & $81 \%$ \\
\hline Não & $28 \%$ & $19 \%$ \\
\hline
\end{tabular}

Fonte: Elaborado pelos autores.

No que diz respeito ao desenvolvimento do planejamento financeiro pessoal, verificou-se que dentre os acadêmicos ingressantes mais de $70 \%$ o realizam, já em relação aos acadêmicos concluintes $81 \%$ efetuam 0 planejamento financeiro no dia-a-dia. Questionou-se ainda quais seriam as ferramentas que os discentes fazem uso no planejamento financeiro, as respostas estão evidenciadas no quadro a seguir:

Quadro 7 - Ferramentas utilizadas para elaboração do planejamento financeiro

\begin{tabular}{|c|c|c|}
\hline \multicolumn{1}{|c|}{} & 10 Semestre & 7 Semestre \\
\hline Orçamento & $40 \%$ & $74 \%$ \\
\hline Fluxo de Caixa & $13 \%$ & $26 \%$ \\
\hline DRE & $15 \%$ & $15 \%$ \\
\hline $\begin{array}{l}\text { Não utiliza, o planejamento } \\
\text { está gravado mentalmente }\end{array}$ & $28 \%$ & $11 \%$ \\
\hline Outro & $10 \%$ & - \\
\hline
\end{tabular}

Fonte: Elaborado pelos autores. 
Observou-se que dos alunos ingressantes e concluintes quase a metade $(40 \%)$ e mais de $70 \%$ respectivamente, utilizam o orçamento como ferramenta de elaboração do planejamento financeiro, vale salientar que $28 \%$ dos ingressantes e 15\% dos concluintes asseguram que seu planejamento financeiro está gravado mentalmente, não sendo necessária a utilização de qualquer ferramenta. Na questão apresentada aos alunos, foi possível marcar mais de uma opção.

A oitava pergunta feita aos discentes estava relacionada à influência do curso de administração na gestão financeira pessoal, os resultados estão descritos abaixo:

Quadro 8 - A influência da graduação em administração no planejamento financeiro pessoal

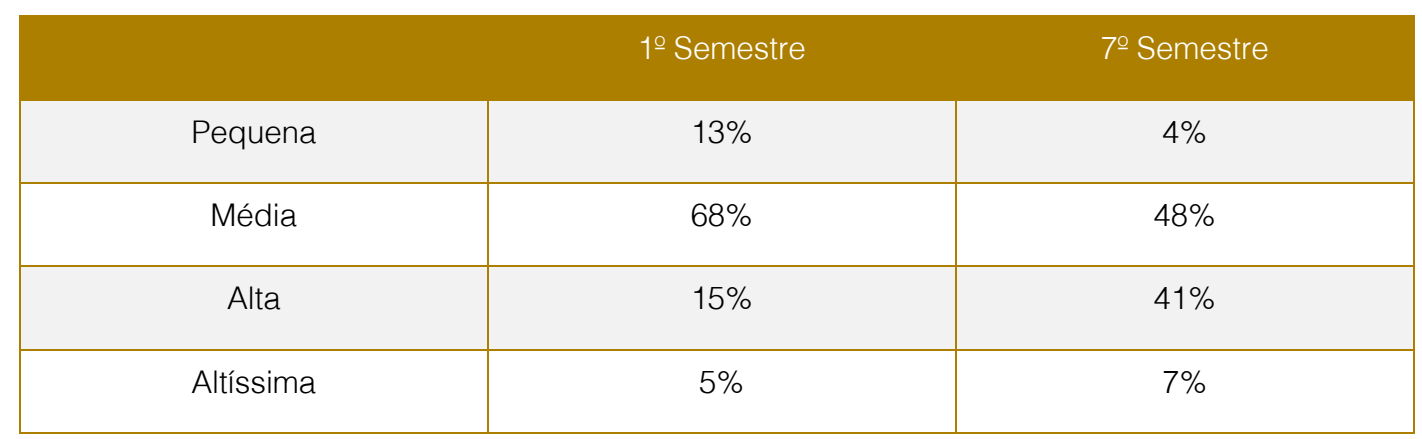

Fonte: Elaborado pelos autores.

Constatou-se que $68 \%$ dos ingressantes consideraram que a graduação exerce uma influência média em seu planejamento financeiro pessoal, $15 \%$ e $5 \%$ afirmaram respectivamente que a graduação influenciou de uma maneira alta e altíssima em seu processo de planejamento, enquanto $13 \%$ declararam que a influência foi pequena.

No que diz respeito aos concluintes, $48 \%$ dos indivíduos julgaram média a atuação do ensino superior em seus planejamentos, $41 \%$ opinaram que a graduação teve uma alta atuação, $7 \%$ desses alunos acreditam que a influência foi altíssima e apenas $4 \%$ a consideraram de pequeno peso para 0 planejamento financeiro pessoal.

Considerando a relevância de um bom planejamento financeiro pessoal, a última pergunta fez referência ao grau de satisfação com este planejamento. O quadro 9 mostra os resultados para a pergunta.

Quadro 9 - Grau de satisfação do planejamento financeiro pessoal

\begin{tabular}{|c|c|c|}
\hline \multicolumn{2}{|c|}{1 10 Semestre } & 70 Semestre \\
\hline Insatisfeito & $10 \%$ & $4 \%$ \\
\hline Mediano & $43 \%$ & $44 \%$ \\
\hline Satisfeito & $38 \%$ & $52 \%$ \\
\hline Totalmente satisfeito & $10 \%$ & - \\
\hline
\end{tabular}

Fonte: Elaborado pelos autores.

Verificou-se que dentre os acadêmicos ingressantes $38 \%$ estão satisfeitos com seu planejamento financeiro e $43 \%$ atestam que o seu grau de satisfação está mediano, 10\% estão totalmente satisfeitos, ocorrendo o mesmo percentual para os que se consideram insatisfeitos.

Em relação aos concluintes 52\% (mais da metade) se dizem satisfeitos com o próprio planejamento financeiro, em contrapartida 
44\% alegam que o nível de satisfação está numa fase média, e $4 \%$ se encontram insatisfeitos.

\section{CONSIDERAÇÕES FINAIS}

O tema de estudo deste trabalho é a influência que o ensino superior possui sobre o planejamento financeiro pessoal dos acadêmicos ingressantes e concluintes que estão cursando Administração na Universidade Federal de Mato Grosso do Sul - Campus de Nova Andradina (UFMS/CPNA).

A partir da análise de dados pode ser verificado que nem todos que alegam ter segurança em seus conhecimentos para controlar o próprio dinheiro praticam 0 planejamento financeiro, indicando que estes fatores nem sempre estão relacionados.

Nota-se um percentual alto de respondentes ingressantes que se sentem seguros para gerir seus recursos, fator considerado favorável já que a maioria dos indivíduos são jovens e ainda estão em níveis iniciais do curso em questão, identificando-se assim que não há uma fase certa para se adquirir segurança. Observou-se também uma porcentagem considerável de acadêmicos de ambos os semestres que não fazem uso de uma gestão financeira pessoal.

No que diz respeito às técnicas utilizadas para elaborar o planejamento financeiro, os acadêmicos tanto ingressantes quanto concluintes aplicam ferramentas de controle para o mesmo, porém uma parcela significativa argumentou que o planejamento se encontra gravado mentalmente não sendo necessário o emprego de qualquer outro instrumento de controle.

\section{REFERÊNCIAS}

[1]. BANCO CENTRAL DO BRASIL, Caderno de Educação Financeira - Gestão de Finanças pessoais (Conteúdo Básico). Brasília: 2013.

[2]. BRAGA, Roberto. Fundamentos e Técnicas de Administração Financeira. São Paulo: Atlas, 2011

[3]. CERBASI, Gustavo. Como Organizar sua vida financeira. Rio de Janeiro: Elsevier, 2009.

[4]. CHIAVENATO, Idalberto. Introdução teoria geral da administração. 9o ed. Barueri-SP: Manole, 2014.
Nem todos os discentes concluintes identificaram que o curso de administração tem uma influência significativa em seu processo de gestão financeira pessoal, o fato talvez se deva pela forma que os conteúdos relacionados às finanças tenham sido aplicados em sala, sugere-se ainda a realização de projetos voltados para o planejamento financeiro pessoal.

Em relação aos discentes ingressantes, a grande maioria apontou um grau médio de influência da graduação, fator promissor já que porventura tenham a expectativa de que o curso irá agregar de forma positiva o seu processo de construção de conhecimento.

Ademais, percebeu-se que a satisfação do planejamento financeiro pessoal dos acadêmicos ingressantes e concluintes oscilou entre uma satisfação média e alta, poucos são os que estão insatisfeitos quanto a este fato.

O estudo realizado teve limitações relevantes quanto ao tamanho da amostra, não foi possível fazer um estudo mais aprofundado com indivíduos desde a série primária até os egressos da universidade, sendo assim permite considerar os resultados obtidos apenas para a população do estudo. Outra limitação se deve a não consideração de um acompanhamento mais intenso com os respondentes da pesquisa.

Outrossim, o artigo teve o propósito de contribuir aos diversos temas relacionados ao planejamento financeiro pessoal, um assunto amplo e de extrema relevância para os indivíduos que buscam um controle financeiro eficaz e uma sobrevivência econômicofinanceira.

[5]. FREZATTI, Fábio. Orçamento empresarial - Planejamento e Controle Gerencial. 5o ed. São Paulo: Atlas, 2009

[6]. GADELHA, Kalyne Amara Di Lorenzo. Decisões financeiras x Formação acadêmica: uma contribuição com base na educação financeira. Revista de Administração e Negócios da Amazônia, V.7, n.1, jan/abr. 2015 ISSN: 2176-8366.

[7]. GIL, Antonio Carlos. Métodos e Técnicas de Pesquisa Social. 6o ed. São Paulo: Atlas, 2008. 
[8]. GITMAN, Lawrence J. Princípios da Administração Financeira. $12^{\circ}$ ed. São Paulo: Pearson. 2010.

[9]. GRESSLER, Lori Alice. Introdução à Pesquisa - Projetos e Relatórios. São Paulo: Loyola, 2003.

[10]. HOJI, Masakazu. Administração Financeira e orçamentária. 10ำed. São Paulo: Atlas, 2012.

[11]. LAKATOS, Eva Maria; MARCONI, Marina de Andrade. Fundamentos de Metodologia Científica. 7ํe ed. São Paulo: Atlas, 2010.

[12]. MACEDO JUNIOR, J. S. A árvore de dinheiro - Guia para cultivar a sua independência financeira. Florianópolis: Insular, 2013.

[13]. MAXIMIANO, Antônio César Amaru. Teoria Geral da Administração. 6ำ ed., São Paulo: Atlas, 2011.

[14]. PADILHA, Maria Celi Damasceno. A influência do planejamento financeiro pessoal na consecução dos resultados: indivíduo/organização. Revista Científica FacMais, Volume. II, Número 1. Ano 2012/2은 Semestre. ISSN 2238-8427.

[15]. PADOVEZE, Clóvis Luís. Manual de Contabilidade básica: Uma Introdução à Prática Contábil. 5a ed. São Paulo: Atlas, 2004.
[16]. PESQUISA CNC. Endividamento e Inadimplência do Consumidor. Disponível em: <http://www.cnc.org.br/sites/default/files/arquivos/a nalise_peic_julho_2016.pdf > Acesso em: 19/08/2016.

[17]. PIRES, Valdemir. Finanças pessoais: fundamentos e dicas. Piracicaba-SP: Editora Equilíbrio, 2007.

[18]. SILVESTRE, Marcos. 12 Meses para enriquecer: O plano da virada. São Paulo: Lua de Papel, 2010.

[19]. TEIXEIRA, Enise Barth; ZAMBERLAN, Luciano; RASIA, Pedro Carlos. Pesquisa em Administração. ljuí, Rio Grande do Sul: Unijuí, 2009.

[20]. THIOLLENT, Michel. Metodologia da pesquisa-ação. São Paulo: Saraiva, 2009.

[21]. TOSSETI, Melissa; GIBBONS, Kevin. Gaste com estilo e inteligência: o guia prático para você ter tudo o que quer na vida. São Paulo: Editora Gente, 2012.

[22]. VERGARA, Sylvia Constant. Projetos e Relatórios de Pesquisa em administração. 2으. ed. São Paulo: Atlas, 1998. 


\section{Bapítulo 12}

\section{ANÁLISE DA ESTRUTURA PRODUTIVA DA ECONOMIA PARANAENSE NO CONTEXTO DA ECONOMIA BRASILEIRA: O CASO DA INDÚSTRIA 1995-2012}

\section{Márcio Luiz Ribeiro}

Marcos Pedrinho Zuck

Sérgio Lopes

Resumo: O objetivo desse trabalho foi avaliar disparidades da estrutura produtiva da economia paranaense no contexto da economia brasileira. Num primeiro momento identificaram-se as características históricas do desenvolvimento da estrutura produtiva brasileira e paranaense. Caracterizou-se de maneira geral a indústria paranaense de 1960 até meados da década de 1990 e, por fim, comparou-se o comportamento da indústria e de outros setores econômicos do Paraná com o de outros estados brasileiros para os anos de 1995 e 2012 utilizandose dos dados do Instituto Brasileiro de Geografia e Estatística (IBGE). Os resultados sugerem que tanto o setor industrial, como a agropecuária e o setor serviços estão fortemente concentrados na região Sudeste. O Paraná, ainda que seja a quarta maior economia do país, representa aproximadamente, a sexta parte do Produto Interno Bruto (PIB) da economia paulista. Além disso, a participação da economia paranaense no PIB praticamente não variou no período analisado e o estado tende a elevar a produção agropecuária, seguindo a tendência das economias menos desenvolvidas do país.

Palavras-chave: Economia paranaense, Economia brasileira, Disparidades regionais. 


\section{INTRODUÇÃO}

O desenvolvimento industrial pode ser um dos caminhos mais promissores para 0 desenvolvimento econômico e social. Para alguns teóricos, este é o único meio de superar o subdesenvolvimento. Nesse sentido, desenvolveram-se diferentes visões teóricas, por exemplo: a teoria da base exportadora, o processo de substituição de importações, teoria do centro-periferia, e política industrial.

Segundo Gremaud (2010), desde a época colonial até a República Velha, o Brasil dependeu quase que exclusivamente do desempenho das commodities como principais produtos exportados, variando apenas o produto demandado pelo mercado internacional (minerais, açúcar, algodão, café, borracha).

De acordo com Souza (2008), no Brasil houve surtos industriais ainda no século XVIII na etapa da mineração, no século XIX com a instituição da Tarifa Alves Branco (aumento dos impostos sobre produtos importados) e com um programa de industrialização na década de 1890. Na I Guerra Mundial, o conflito naturalmente trouxe certo protecionismo à economia brasileira. Contudo, o autor afirma que nenhum desses processos se consolidou. Nesse sentido, segundo Baer (2002), em 1919, a produção industrial brasileira de bens de produção era de 16,6\%, enquanto os bens de consumo (principalmente alimentos, roupas e calçados, e têxteis) representavam $83,4 \%$.

Para Tavares (1973), a industrialização brasileira se deu efetivamente no período pós-

1930, com a substituição de importações, ou seja, passou-se a produzir internamente o que antes se importava. Em outras palavras, havia uma reorientação da economia brasileira passando de um modelo agroexportador para um urbano-industrial. Ou seja, era preciso crescer independentemente da dinâmica econômica mundial.

De acordo com Furtado (1979), a industrialização induzida pela exportação de produtos primários foi importante para diversificar o mercado interno entre 1900 a 1929 quando a elasticidade de crescimento da indústria em função do aumento da renda per capita sugeriu que a exportação de produtos primários promoveria a indústria. Para o autor, isso ocorreu não apenas no Brasil como em outros países latino- americanos. Contudo, mostra também que o modelo agroexportador apresenta limites como: flutuações do produto global, necessidade de aumento contínuo da produtividade da pauta exportadora e aumento da concorrência.

Gremaud (2010) afirma que a indústria não teve origens devido à crise cafeeira, pois o capital industrial surgiu do vazamento do capital cafeeiro, e para atender às necessidades da economia cafeeira. Conforme Villela et al. (1971), entre 1929 e 1939, o índice da produção industrial total passou da base 100 para 224,6 por meio do mecanismo de "confisco cambial", transferindo renda do café para a indústria.

Por outro lado, Suzigan (2010) mostra que o processo de substituição de importações foi relevante apenas entre 1930 e 1950, uma vez que apresentou sinais de saturação em uma fase de industrialização mais avançada. 0 coeficiente de importações permanecia estável ao passo que caía a elasticidade renda do crescimento da produção industrial e a produção industrial, em relação ao produto global, permanecia constante. Para o autor, isto implica que após atingir um limite da redução das importações, para que seja possível aumentar os investimentos industriais tem de elevar também os preços relativos dos importados que têm margem reduzida. Além disso, com as importações reduzidas apenas a itens essenciais, um simples aumento dos preços relativos de bens de capital importados prejudicaria os investimentos na economia.

Assim sendo, esgotado esse processo, a industrialização prosseguiria apenas se, principalmente o setor industrial, tivesse se diversificado a ponto de alterar a estrutura da economia. Diante disso, o papel do Estado em modificar o perfil da demanda (bens de luxo para bens de consumo e bens de capital) ganha relevância, bem como os esforços em termos de políticas de desenvolvimento industrial e a autonomia da economia brasileira. Dessa maneira, obter-se-ia independência econômica através da implantação de uma indústria de base. Nesse sentido, Pignaton (1973) afirma que no pósguerra a industrialização se deu, principalmente, com base na produção de bens essenciais que passou a dinamizar 0 setor de bens de capital, os quais quase não eram produzidos internamente. Mas foi com Vargas (1951-1954) que houve maior dinamismo interno dentro da concepção do 
nacional desenvolvimentismo. Foram criadas importantes empresas estatais em setores estratégicos como: setor de energia, metalurgia, química e transporte. No contexto do Plano de Metas de JK e da abertura da economia, entre 1957 e 1961, a indústria brasileira cresceu a uma taxa anual de $11,5 \%$, alavancando o PIB que cresceu 9,3\% no período (OLIVEIRA, 1977).

Segundo Abreu (1995), a industrialização da fase pós-substituição foi definitiva para a inserção internacional da economia nacional. Também foi nesse contexto de industrialização da economia brasileira que, para Padis (1981), São Paulo, principal centro industrial dinâmico, estabeleceu vínculos de dependência com as demais regiões do país que passaram a contribuir para o centro da economia nacional agravando as disparidades regionais que deu origem às economias periféricas. Em outras palavras, dada a inserção da economia brasileira no cenário internacional, passa-se a questionar a inserção das unidades federativas no setor industrial dinâmico que era praticamente restrito à economia de São Paulo.

Para Trintin (2006), diante dos problemas de integração da economia nacional para o desenvolvimento industrial, o governo federal deu privilégios aos estados do polo dinâmico da economia nacional, São Paulo. Dessa maneira, o Paraná e os demais estados teriam sidos excluídos do processo de industrialização brasileira. Ou seja, estaria se reproduzindo relações de dominaçãodependência baseada na troca de produtos industriais paulistas por produção de matérias-primas e alimentos de outras partes do país, que condicionava as economias periféricas à especialização produtiva que poderia barrar o seu desenvolvimento industrial. Ainda que, para o autor, isso não significa que a acumulação de capital na periferia fosse impedida, apenas a partir de meados de 1960 houve certa desconcentração da estrutura produtiva nacional por meio do espraiamento da indústria paulista.

No entanto, Furtado (1979) argumenta que, partindo do pressuposto que a diversificação da demanda e o aumento da produtividade constituem o motor do desenvolvimento, estados que se especializam em bens com maior vantagem comparativa tendem a importar novos bens de consumo. Nesse sentido, a industrialização torna-se mera desconcentração geográfica de atividade industrial. Contudo, a desconcentração não necessariamente significa autonomia para criar produtos industriais. Mas localizar na periferia artigos que são criados no centro.

Considerando esse histórico de concentração industrial em torno de São Paulo, e de economia nacional agroexportadora, pode-se fazer o seguinte questionamento: qual é a participação da economia paranaense e de outros estados na economia nacional no período mais recente (1995 e 2012)? Isto porque, conforme se tentou expor, o problema paranaense parece ser também histórico e nacional, cuja natureza é mais ampla, conforme Padis:

... os problemas econômicos do Paraná não poderão ser superados apenas em âmbito estadual. Para serem viáveis, as soluções terão que ser propostas no quadro de uma política de desenvolvimento nacional que tenha por objetivo explícito e específico a diminuição das desigualdades regionais. Ou seja, de uma política que vise não à integração em torno de um polo de crescimento, mas a formação de novos polos, capazes de promover e sustentar o desenvolvimento da economia nacional (PADIS, 1981 p. 216).

Nesse contexto, esse artigo tem por objetivo geral avaliar as possíveis disparidades da estrutura produtiva da economia paranaense no contexto da economia nacional. Especificamente pretende-se: a) apresentar um breve histórico da formação da economia paranaense e seus principais ciclos econômicos até o surgimento da indústria; b) caracterizar de maneira geral, a indústria paranaense de 1960 até meados da década de 1990; c) comparar o comportamento da indústria e de outros setores econômicos da economia paranaense com a de outros estados brasileiros entre 1995 e 2012. Utilizou-se como fonte, os dados produzidos e disponibilizados pelo Instituto Brasileiro de Geografia e Estatística (IBGE).

Além desta introdução, em que se apresentou um contexto geral da indústria nacional, primeiramente é apresentado o contexto histórico da economia paranaense atentandose para os seus ciclos econômicos. Em segundo lugar, caracteriza-se a indústria paranaense, do seu surgimento até meados de 1990. Por fim, a estrutura da economia paranaense será comparada com as demais economias estaduais para que se possa verificar se, de fato, a economia paranaense e 
a indústria paranaense tem se desenvolvido de maneira mais autônoma comparativamente ao centro, no período de 1995 a 2012.

\section{FUNDAMENTAÇÃO TEÓRICA \\ 2.1 A ECONOMIA PARANAENSE: DO SÉC. XVI A CRISE DO MATE}

Segundo Magalhães Filho (1996), a evolução histórica da economia do Paraná tem início no século XVI com a ocupação dos espanhóis e portugueses em busca de metais preciosos. O comércio de escravos indígenas e o tropeirismo deram origem às primeiras atividades agrícolas de subsistência. Para o autor, o ouro passa a ter uma representatividade econômica somente no século XVII. A mineração que se iniciava no Paraná, que na época pertencia à província de São Paulo, atraiu pessoas que formaram pequenos arraiais que mais tarde se transformaram em vilarejos. Na busca pelo ouro, os colonizadores se deslocaram do litoral até o planalto de Curitiba. Com a expansão da mineração, outras atividades se desenvolveram, principalmente a atividade agrícola, para abastecer os vilarejos. Nessa época, tanto a importação como a exportação dos produtos eram feitas com a utilização de animais até o principal porto brasileiro no Rio de Janeiro. Por meio desse mecanismo de transporte de carga, surgiu o tropeirismo em função do abastecimento pecuário em Sorocaba, onde se realizavam grandes feiras de vendas de animais que em seguida eram distribuídos para outras regiões. Nos locais de paradas das tropas foram se formando pequenas pousadas que se transformaram em vilas, algumas se tornaram grandes cidades, tal como a atual Ponta Grossa.

No último quartel do século XVIII, iniciou a decadência da economia do ouro que, por conseguinte refletiu na queda da atividade pecuária. Mais tarde, com a expansão do café em nível nacional e com a separação do Paraná de São Paulo, em 1853, a venda de animais voltou a crescer. Com o surgimento das estradas de ferro, ligando o centro-sul, o tropeirismo foi sendo eliminado. Ao se aproximar do final do século XVIII a agricultura de subsistência novamente se expande para a região oeste com a ocupação do terceiro planalto (MAGALHÃES FILHO, 1996; PADIS, 1981).

A extração do mate teve origem em 1867, devido à possibilidade de exportação para os mercados platinos (Argentina, Paraguai e Uruguai) e para o Chile. Conforme Padis (1981), o Paraguai e Corrientes, província Argentina, eram os principais abastecedores do mercado platino, porém, devido a uma série de conflitos, o fluxo de abastecimento foi prejudicado, o que propiciou a exportação do mate paranaense. No entanto, o mate entrou em crise nos anos 1930 devido à baixa qualidade do produto e do aumento da concorrência externa, da carência de meios de comunicação e da política livre-cambista do governo federal. Paralelamente ao mate, a procura por madeira aumentou em razão da construção da estrada de ferro e outras ligações estabelecidas entre o comércio do centro-sul do Brasil e o Paraná que propiciam a exportação da madeira. Isso viabilizou a entrada de investimentos estrangeiros, algo que a produção ervateira não havia estimulado.

Em resumo, num primeiro momento a economia paranaense se desenvolveu por meio da extração de metais preciosos, anterior ao ciclo de mineração de Minas Gerais, surgindo os primeiros núcleos urbanos no litoral. Encerrada a mineração, surgiu a incipiente pecuária que pouco contribuiu para o Paraná, pois a atividade criatória estava mais ligada a São Paulo. A economia paranaense por muito tempo esteve ligada à subsistência. Foi somente a partir de 1820 que devido às condições internacionais foi possível a extração e beneficiamento do mate que se manteve até a I Guerra Mundial, quando passou a declinar em função da baixa qualidade do produto, da deficiência na infraestrutura do Estado, da dependência do mercado internacional e da crença no livre mercado. A atividade madeireira pouco se distinguiu da extração do mate. Ressalta-se ainda a importância do tropeirismo para a ocupação territorial com o surgimento de vários núcleos urbanos, mas que era apenas um reflexo da mineração.

Assim sendo, essa fase compõe o primeiro ciclo primário-exportador da economia paranaense (mate, madeira e pecuária). Portanto, até 1930 essa economia era principalmente exportadora de produtos primários que tenderia a levar a economia à concentração de investimentos, pouca capacidade de capitalização e variações externas que determinariam a produção. De acordo com a teoria centro-periferia, isso no longo prazo tornaria a economia paranaense dependente e periférica em relação ao centro 
dinâmico da economia brasileira. Passa-se, pois, a análise da economia cafeeira no estado à luz dessa teoria.

\subsection{A EXPANSÃO CAFEEIRA NA ECONOMIA PERIFÉRICA: O SURGIMENTO DA INDÚSTRIA}

De acordo com Trintin (2006), a teoria centroperiferia mostra que os estados periféricos tenderiam a manter uma estrutura produtiva especializada que os impossibilitaria de se desenvolver. De maneira geral, a tese era que - Paraná em particular, bem como outros estados brasileiros foram excluídos do processo de industrialização devido aos maiores estímulos à indústria paulista por parte do governo. Nesse sentido, a industrialização seria o principal caminho para a autonomia do Paraná em relação ao centro dinâmico: São Paulo.

Segundo Padis (1981), a partir de 1945, a produção de café se torna expressiva no Paraná, porém houve outro vínculo de dependência e periferia com São Paulo, pois ao passo que o Paraná aumentava a produção de café, o centro desenvolvia o setor industrial e apropriava as divisas paranaenses por meio da transferência de renda, que ocorria principalmente, devido à deficiência do Paraná em termos de infraestrutura, e um setor industrial ainda inexpressivo. O progresso da atividade cafeeira no Paraná nos anos de 1940 ocorreu muito mais em função do desenvolvimento da cafeicultura paulista do que pelo esforço paranaense. De certa maneira, o Paraná contribuiu para subsidiar o parque industrial de São Paulo, uma vez que a partir do surto industrial da economia brasileira, a partir de 1947, parte da renda da cafeicultura paranaense foi transferida em favor do setor industrial por meio do aumento da sua produção de café relativamente à produção paulista, e da desvalorização interna da moeda.

Nesse sentido, outro aspecto das economias exportadoras de produtos primários, como era a economia paranaense até sua diversificação agrícola em meados de 1960, é que geralmente se importa manufaturas. No entanto, a tendência à deterioração dos preços dos produtos primários no exterior, relativamente à valorização crescente dos produtos manufaturados, acentua o problema das economias periféricas, dada uma redução de sua capacidade de capitalização.
Nesse sentido, Padis (1981) com base nos dados da Fundação Getúlio Vargas (FGV) mostra que, entre 1944 a 1953 houve uma tendência ao aumento do preço do café numa proporção maior que o aumento dos preços dos produtos agrícolas (exclusive o café) e dos produtos industriais. De maneira geral, de 1944 até 1954 o café lidera em termos de preço. Mas, já em 1955, os produtos industriais assumiram a dianteira. Entre 1955 e 1968, os produtos manufaturados superaram o preço dos produtos agrícolas e do café (com exceção de 1962 quando os produtos agrícolas tiveram um índice superior aos produtos da indústria e do café). Já no ano de 1968, o índice de preços dos produtos industriais era 2,85 vezes superior ao do café.

Por outro lado, segundo o Instituto Brasileiro do Café (1968), ao passo que os preços do café caiam em relação aos produtos manufaturados, o Paraná aumenta a produção cafeeira e São Paulo se industrializava. Entre 1943 e 1944, São Paulo era responsável por $48,8 \%$ da produção de café brasileiro enquanto o Paraná produzia apenas 1,3\% do total nacional. Entre 1953/1954 São Paulo havia reduzido sua produção para $40,1 \%$ e o Paraná aumentou para 21,1\%. E finalmente, entre 1967/68 o Paraná, que já havia superada a produção paulista em 1960, foi responsável por $46,7 \%$ da produção de café no Brasil e a economia paulista apenas $38,6 \%$.

Contudo, a atividade cafeeira trouxe também benefícios para o estado, mesmo que com isso o Paraná de certa forma abrisse mão do seu processo de industrialização. Para Trintin (2006), o café foi responsável por introduzir novas atividades e produzir efeitos dinâmicos para a economia. A renda da cafeicultura foi importante para o financiamento da infraestrutura econômica e social diante do crescimento populacional e do aumento da produção. Entre 1940 e finais dos anos 1960, a população paranaense quintuplicou devido ao grande número de migrantes interessados em comprar terra. Como consequência do aumento do número de pequenas propriedades rurais e da população, o autor argumenta que a economia passou a ser impulsionada pelo setor agrícola cuja pauta de produtos foi se diversificando gradativamente. Os setores industrial e terciário continuaram sendo apenas complementares ao setor principal, a agricultura. 
Ainda para Trintin (2006), a indústria que até os anos 1940 estava estagnada passou a expandir-se e, embora fosse rudimentar, deu sinais que estava a se desenvolver. Até a década de 1960, a produção industrial limitava-se a alguns gêneros: principalmente produtos alimentares e madeira que eram responsáveis por cerca de $60 \%$ da transformação industrial. Então, surgiram também indústrias de beneficiamento de café, de fibras têxteis e fábricas de tábuas e compensados. Vale frisar que devido à diversificação da pauta de produtos agrícolas, em meados de 1960, quando a cafeicultura entra em decadência, não havia mais uma monocultura do café.

No entanto, Trintin (2006) também afirma que o processo de industrialização da economia brasileira, principalmente em meados de 1960, barrou o crescimento das economias regionais, dado o predomínio de estruturas de mercado concentradas (na contramão da política estadual com ênfase na concorrência). Diante disso, o Paraná pôde desenvolver apenas alguns setores industriais tendo de optar pelo fortalecimento do setor agropecuário para cumprir seu papel de fornecedor de alimentos para o centro dinâmico. O autor conclui que a ideia de Paraná autônomo foi esquecida em detrimento da tese da complementaridade, ou seja, o Paraná tinha um papel industrial complementar.

\subsection{A INDÚSTRIA PARANAENSE ENTRE 1960 ATÉ MEADOS DE 1990}

A partir de 1960, a estrutura produtiva do Paraná passou por grandes transformações. Segundo o Ipardes (1981), o estado tornou-se um dos mais dinâmicos do Brasil, cuja base do processo é a modernização da agricultura e a diversificação da produção agrícola. A organização da produção ocorre por meio das cooperativas que impulsionam a agroindústria. A rentabilidade do setor conta grande influência de políticas, como a extinção do imposto sobre exportação de soja. Ou seja, surgem movimentos políticos que garantem melhor rentabilidade à sua produção. Além disso, ainda de acordo com o Instituto, em 1980, o Paraná foi o 3o estado que mais obteve crédito rural e $\circ 2^{\circ}$ que mais realizou operações junto ao Banco do Brasil. Ressalta-se ainda que no mesmo ano, os mini e pequenos produtores captaram apenas $21,5 \%$ do valor total dos empréstimos, enquanto que os grandes proprietários receberam $45,9 \%$ do crédito total concedido ao Paraná.

Ainda para o Ipardes (1981), a dinâmica da economia paranaense no período refere-se à reinversão dos lucros numa economia capitalista agrícola, e que permite a transferir recursos para setores como o industrial, comercial, financeiro, infraestrutura. Assim sendo, o próprio desenvolvimento da economia agrícola promoveria sua diversificação e modernização.

De acordo com Trintin (2006), a década de 1970 foi um marco para o Paraná, uma vez que houve políticas de integração nacional que contribuíram para desconcentrar a indústria paulista; e também políticas de modernização e diversificação no setor agropecuário em nível nacional. Embora a agricultura moderna tenha se consolidado no período, sua participação na renda do estado diminuiu. Era de 25,27\%, em 1970 e caiu para $18,53 \%$, em 1980. Todavia a indústria passou de $16,6 \%$ para $28,07 \%$. Ou seja, a agricultura contribuiu com menos $6,74 \%$ da renda no período, enquanto a indústria aumentou a renda estadual em 11,47\%. Ressalte-se a instalação da Cidade Industrial de Curitiba (CIC) trouxe vantagens locacionais aos investidores, bem como os incentivos fiscais que atraíram o capital estrangeiro. Isso levou ao autor concluir que o setor industrial sofreu significativas transformações, com destaque para a queda da importância de gêneros tradicionais como a produção de alimentos e a madeira, e o crescimento do ramo da química e metal mecânico. Vale frisar também, o significativo crescimento da indústria de produtos alimentares e dos complexos agroindustriais de transformação da soja e do milho.

O conjunto dessas mudanças contribuiu para que em 1985, a economia paranaense estivesse integrada à economia nacional, tanto para escoar sua produção quanto para a compra dos insumos necessários à indústria. Conforme Guimarães Neto (1995), o Paraná passou de um sistema articulado apenas comercialmente, para um sistema com características únicas e integrado à economia brasileira.

Na década de 1990, diante da maior abertura econômica e da estabilização econômica a partir do Plano Real, novamente há uma retomada dos investimentos industriais. Por exemplo, por meio de incentivos fiscais e 
financeiros, o estado atraiu um polo automobilístico (Volkswagen/Audi, Chrysler e Renault), bem como conglomerados para alavancar a industrialização. Entre 1985 e 1998, o setor industrial paranaense cresceu mais que o nacional, tornando-se o quarto maior parque industrial brasileiro. Em síntese, - Paraná utilizou outro padrão de tecnologia na sua produção que o tornou menos dependente dos gêneros tradicionais (química e produtos alimentares), e desenvolve produtos industriais ligados, principalmente, ao ramo de material de transporte, elétrico, comunicação e mecânica (TRINTIN, 2006).

Portanto, após essa breve discussão acerca do desenvolvimento histórico da indústria paranaense, pretende-se analisar se, de fato, a economia do estado tem certa autonomia e importância do cenário nacional, e ainda, um setor industrial consolidado e competitivo num período mais recente (1995-2012).

\section{METODOLOGIA}

A fim de que se possa comparar o comportamento da indústria e de outros setores econômicos da economia paranaense com a de outros estados brasileiros, e avaliar possíveis disparidades no desenvolvimento da economia do estado em relação as outras unidades federativas; utilizou-se uma série do IBGE de 1995 a 2012. De acordo com o IBGE (2016), de 1995 a 2001 essa série das Contas Regionais teve por referência 2002 e admitiuse que as variações em volume e preço foram constantes. Vale ressaltar que a partir de 2002 a série foi ajustada e estimada, porém foram feitas atualizações no ano de 2014.

Num primeiro momento, analisou-se a participação das grandes regiões e Unidades da Federação (UF) no produto interno bruto (PIB), destacando a economia paranaense e paulista.

Com isso se busca apresentar a magnitude da renda, em percentual, que cada estado e região concentram, bem como as possíveis disparidades regionais, evidenciando o quadro da economia do Paraná ao longo do período em relação a outros estados, ou seja, a economia do estado no cenário nacional.

Como um desdobramento do passo anterior, avaliou-se a participação das grandes regiões e unidades da federação no Valor Adicionado Bruto (VAB) da agropecuária, a indústria e serviços, lembrando que o VAB é a diferença entre o PIB e os impostos sobre produtos (líquidos de subsídios). Em outras palavras, isso mostra a participação que cada estado ou grande região tem no VAB de cada setor, ou seja, indica a contribuição de cada estado no valor gerado por cada setor econômico no contexto da economia brasileira. Portanto, isso dá uma visão geral da estrutura produtiva brasileira e qual a relevância que os estados têm em cada atividade econômica. Evidentemente, destacou-se também a economia paranaense nesse contexto e, a participação da indústria e da agropecuária paranaense em relação a São Paulo, por exemplo. Contudo, vale frisar que a análise do VAB por setor e UF só faz sentido se considerada a participação de cada UF no PIB. Por exemplo, São Paulo ao longo do período analisado, teve uma participação média na agropecuária de apenas 10,8\%. No entanto, esse estado gerou, em média, mais de um terço do PIB brasileiro (34,6\%) de 1995 a 2012, mantendo-se acima dos 30\%.

Finalmente, observou-se a participação das atividades econômicas no VAB, por UF.

Em outras palavras, volta-se para a estrutura produtiva das economias estaduais em relação a elas mesmas. De fato, determinada atividade econômica pode ser pouco significante quando analisada agregadamente. Porém, determinado estado, cujo setor pode ser insignificante em relação à economia brasileira, pode ser fundamental para gerar renda em nível desta UF. Por exemplo, o VAB da indústria paranaense em relação à indústria brasileira foi de 5,5\% em 2012. Mas representou, nesse mesmo ano, $24,5 \%$ do VAB da indústria estadual, valor próximo da participação do VAB da indústria brasileira (26\%) no referido ano. Portanto, essa análise indica tendências setoriais ao longo do tempo dentro da estrutura produtiva de cada estado. Contudo, mesmo que a indústria paranaense tenha representado quase $25 \%$ do $V A B$ do estado, em nível nacional ela é relativamente pequena.

Além disso, os dados serão apresentados por meio de análise gráfica, tabular e estatísticas descritivas básicas. Trata-se de dados secundários das Contas Regionais do IBGE e órgãos parceiros. Por meio dessas informações, procura-se entender alguns aspectos referentes à estrutura produtiva paranaense no contexto da economia brasileira e, especificamente, o caso da indústria, bem como o comportamento do desenvolvimento regional no Brasil. 


\section{APRESENTAÇÃO E ANÁLISE DOS} RESULTADOS

\subsection{PARTICIPAÇÃO DAS GRANDES REGIÕES E UF NO PIB, 1995-2012}

A partir da análise da proporção que cada Grande Região contribui para o PIB, podem ser identificadas importantes disparidades regionais em termos de geração de renda no Brasil no período de 1995 e 2012, conforme sugere a Figura 1.

Embora a região Sudeste tenha diminuído sua participação na renda como proporção do PIB no período, é a região que se manteve, ao longo dos 17 anos, objeto deste estudo, como a região mais dinâmica do país gerando acima de $55 \%$ de toda a riqueza brasileira. A região Sul, $2^{\underline{a}}$ região mais produtiva, não gerou nem um terço do que é gerado no Sudeste. Quando se volta para as regiões Nordeste, Centro-oeste e Norte, observa-se que estas tiveram crescimento relativo considerável, se se considera que foram as únicas grandes regiões que não reduziram sua participação na geração do produto global. Parece haver uma tendência de transferência de renda entre regiões, pois os $3,9 \%$ de queda da região Sudeste se traduziram no desenvolvimento das outras regiões. De 1995 para 2012, o percentual da região Norte, menor do país, aumentou apenas 1,1\%; enquanto a região Centro-oeste e Nordeste, $1,4 \%$ e 1,6\%, respectivamente.

Figura 1 - Participação das Grandes Regiões (\%) no Produto Interno Bruto 1995/2012

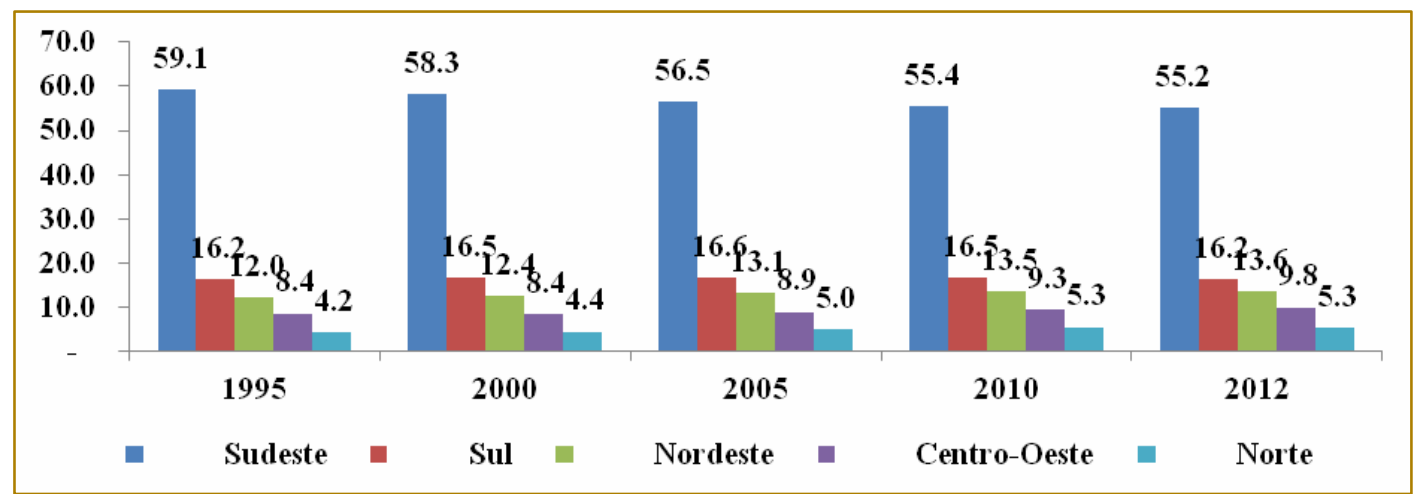

Fonte: elaborado pelos autores a partir de IBGE (2016)

Contudo, nesse processo a região Sul simplesmente estagnou, já que não aumentou nem diminuiu sua participação no PIB no ano de 2012 em relação a 1995.

Portanto, neste cenário das grandes regiões brasileiras, a região Sul, inclui-se evidentemente o Paraná, ainda que seja a $2^{\text {a }}$ região mais desenvolvida (por exemplo, é quase três vezes maior que a economia nordestina) tem quase esse mesmo grau de disparidade de três para um, em relação ao Sudeste. Além disso, não pareceu crescer em termos de importância para a economia nacional no período analisado. O ANEXO A permite um exame, mais minucioso e ao longo do referido período, das desigualdades regionais em termos de renda por grande região e unidade da federação. Contudo, foi feito uma análise resumida relacionada às duas principais maiores economias estaduais das grandes regiões conforme a Figura 2. 
Figura 2 - Participação de UF selecionadas (\%) no Produto Interno Bruto - 1995/2012

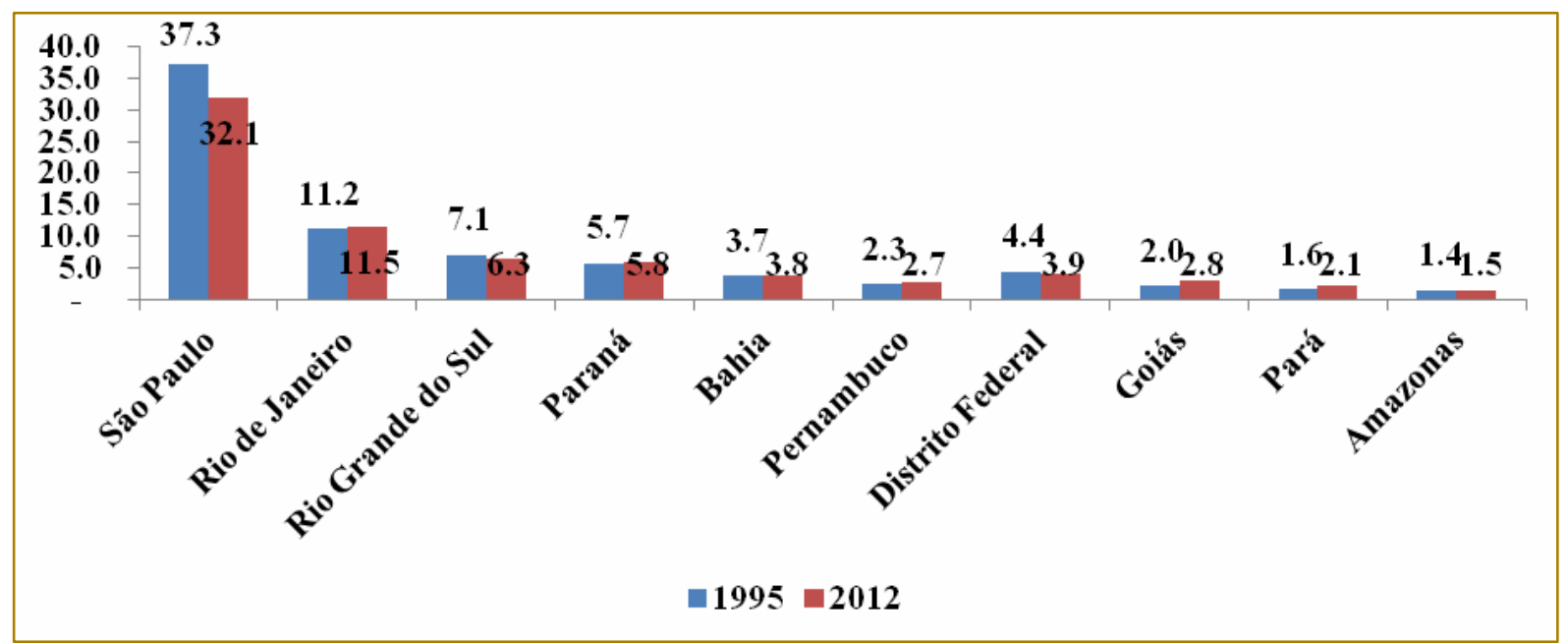

Fonte: elaborado pelos autores a partir de IBGE (2016)

Como se observou, a região Sudeste é a mais rica do país. No entanto, uma análise intrarregional contínua a mostrar importantes disparidades. São Paulo, maior economia dessa grande região, respondeu por mais de $32 \%$ da renda gerada no Brasil no período. Há uma grande margem em relação à segunda e terceiras maiores economias do Sudeste, o Rio de Janeiro (manteve-se acima de quase $11 \%$ no período) e Minas Gerais (participação média de 8,9\% na renda do país de 1995 a 2012).

A região Sul é a segunda grande região mais rica do Brasil. No entanto, o Rio Grande do Sul, a principal economia da região perdeu importância no cenário nacional no período selecionado, e o Paraná aumentou sua participação na renda em 0,1\%. Embora dentre os 27 estados, em 2012, a economia do Paraná fosse a quinta maior do país, (atrás de São Paulo, Rio de Janeiro, Minas Gerias e Rio Grande do Sul) conclui-se também que era 5,5 vezes menor que a economia paulista.

De maneira geral, todas as economias das regiões Norte, Nordeste e Centro-Oeste responderam por menos de $5 \%$ da renda brasileira ao longo do período analisado, com destaque para vários estados do Norte e do Nordeste que não atingiram nem 1\% do PIB nacional.

Em resumo, não apenas algumas grandes regiões concentram a maior parte da renda no país, como se observa que apenas alguns estados também o fazem. O que chama a atenção é a magnitude dessas desigualdades intrarregionais, que pouco contribuiu para o desenvolvimento homogêneo da nação.

\subsection{PARTICIPAÇÃO DAS GRANDES REGIÕES E UF NO VAB A PREÇOS BÁSICOS, POR ATIVIDADE ECONÔMICA, 1995/2012}

Outra maneira de analisar a renda gerada por cada estado é desmembrá-la por atividade econômica para verificar a importância de cada setor econômico estadual na geração da renda brasileira, conforme mostra a Tabela 1. 
Tabela 1 - Participação das Grandes Regiões e UF no VAB a preços básicos, por atividade econômica 1995/2012

\begin{tabular}{|c|c|c|c|c|c|c|c|c|}
\hline \multirow{2}{*}{$\begin{array}{c}\text { Grandes Regiões e } \\
\text { UF }\end{array}$} & \multicolumn{2}{|c|}{ VAB Total } & \multicolumn{2}{|c|}{ Agropecuária } & \multicolumn{2}{|c|}{ Indústria } & \multicolumn{2}{|c|}{ Serviços } \\
\hline & 1995 & 2012 & 1995 & 2012 & 1995 & 2012 & 1995 & 2012 \\
\hline Brasil & 100.0 & 100.0 & 100.0 & 100.0 & 100.0 & 100.0 & 100.0 & 100.0 \\
\hline Norte & 4.3 & 5.4 & 8.8 & 10.2 & 4.4 & 6.3 & 3.9 & 4.8 \\
\hline Rondônia & 0.5 & 0.7 & 1.3 & 2.7 & 0.2 & 0.5 & 0.5 & 0.6 \\
\hline Acre & 0.2 & 0.2 & 0.6 & 0.8 & 0.1 & 0.1 & 0.2 & 0.2 \\
\hline Amazonas & 1.3 & 1.4 & 0.8 & 2.0 & 2.1 & 2.0 & 1.1 & 1.1 \\
\hline Roraima & 0.2 & 0.2 & 0.2 & 0.2 & 0.1 & 0.1 & 0.2 & 0.2 \\
\hline Pará & 1.6 & 2.2 & 4.2 & 3.0 & 1.8 & 3.2 & 1.3 & 1.8 \\
\hline Amapá & 0.2 & 0.3 & 0.2 & 0.2 & 0.1 & 0.1 & 0.3 & 0.3 \\
\hline Tocantins & 0.3 & 0.5 & 1.4 & 1.5 & 0.0 & 0.4 & 0.3 & 0.4 \\
\hline Nordeste & 12.3 & 13.9 & 22.9 & 15.0 & 10.0 & 12.6 & 12.4 & 14.3 \\
\hline Maranhão & 1.0 & 1.4 & 3.2 & 3.9 & 0.5 & 0.9 & 1.0 & 1.4 \\
\hline Piauí & 0.5 & 0.6 & 1.4 & 0.5 & 0.2 & 0.4 & 0.6 & 0.7 \\
\hline Ceará & 2.0 & 2.1 & 4.0 & 1.3 & 1.6 & 1.8 & 2.0 & 2.3 \\
\hline Rio Grande do Norte & 0.7 & 0.9 & 0.9 & 0.6 & 0.5 & 0.9 & 0.8 & 1.0 \\
\hline Paraíba & 0.8 & 0.9 & 1.8 & 0.6 & 0.5 & 0.8 & 0.8 & 1.0 \\
\hline Pernambuco & 2.3 & 2.7 & 2.0 & 1.4 & 2.0 & 2.6 & 2.5 & 2.8 \\
\hline Alagoas & 0.7 & 0.7 & 2.1 & 0.7 & 0.5 & 0.6 & 0.6 & 0.7 \\
\hline Sergipe & 0.6 & 0.7 & 0.6 & 0.5 & 0.5 & 0.7 & 0.6 & 0.6 \\
\hline Bahia & 3.8 & 3.9 & 6.8 & 5.4 & 3.5 & 3.8 & 3.6 & 3.8 \\
\hline Sudeste & 58.1 & 54.3 & 33.7 & 29.8 & 63.3 & 58.2 & 58.0 & 54.7 \\
\hline Minas Gerais & 8.6 & 9.4 & 17.3 & 15.2 & 9.1 & 10.7 & 7.6 & 8.5 \\
\hline Espírito Santo & 1.7 & 2.4 & 4.5 & 2.6 & 1.8 & 3.5 & 1.4 & 1.9 \\
\hline Rio de Janeiro & 11.2 & 11.5 & 1.6 & 0.9 & 8.0 & 14.3 & 13.4 & 11.3 \\
\hline São Paulo & 36.6 & 31.0 & 10.4 & 11.0 & 44.4 & 29.8 & 35.6 & 33.0 \\
\hline Sul & 16.4 & 16.2 & 23.2 & 23.5 & 18.4 & 16.9 & 14.9 & 15.4 \\
\hline Paraná & 5.8 & 5.8 & 5.8 & 10.1 & 6.2 & 5.5 & 5.6 & 5.6 \\
\hline Santa Catarina & 3.5 & 4.0 & 5.5 & 3.2 & 4.4 & 5.2 & 2.9 & 3.6 \\
\hline Rio Grande do Sul & 7.1 & 6.4 & 12.0 & 10.1 & 7.8 & 6.2 & 6.4 & 6.2 \\
\hline Centro-Oeste & 8.9 & 10.1 & 11.4 & 21.5 & 3.8 & 6.0 & 10.8 & 10.8 \\
\hline Mato Grosso do Sul & 0.9 & 1.3 & 3.2 & 3.7 & 0.6 & 1.1 & 0.9 & 1.2 \\
\hline Mato Grosso & 1.0 & 1.9 & 2.9 & 10.4 & 0.7 & 1.2 & 1.0 & 1.6 \\
\hline Goiás & 2.1 & 2.9 & 5.0 & 7.2 & 1.6 & 2.9 & 2.1 & 2.6 \\
\hline Distrito Federal & 4.9 & 4.0 & 0.2 & 0.3 & 0.9 & 0.9 & 6.9 & 5.5 \\
\hline
\end{tabular}

Fonte: elaborado pelos autores a partir de IBGE (2016)

Os dados indicam que a região Sudeste não só concentra a maior parcela do VAB total, como também tem a maior participação nas três atividades econômicas: agropecuária, indústria e serviços. São Paulo lidera a participação na indústria e no setor serviços, todavia perde para outros estados na agropecuária.

Com relação à agropecuária, ressalta-se que em Minas Gerais e Rio Grande Sul ela perdeu participação e aumentou apenas 0,6\% em São Paulo. Porém, no estado do Paraná passou de 5,8\% em 1995, para 10,1\% em 2012. Contudo, o Paraná não aumentou sua participação em relação ao $\mathrm{VAB}$ total no período. A mesma atividade também aumentou sua participação em todos os quatro estados do Centro-Oeste. De maneira geral, a agropecuária aumentou pouco a sua participação no Norte; já no Centro-Oeste quase dobrou se se compara 1995 e 2012, destacando-se o estado de Mato Grosso que passou de 2,9\% para 10,4\%. No Nordeste apenas a Bahia teve uma participação mais expressiva, 5,4\% em 2012, mas também caiu considerando os 6,8\% de 1995.

Em síntese, São Paulo é o quarto maior responsável pela produção agropecuária e o estado que tem maior participação na indústria e serviços. Nas outras economias mais ricas que o Paraná há uma tendência de queda na agropecuária, ao passo no Paraná essa atividade quase dobrou sua participação comparando 1995 com 2012. Além disso, 
existe uma forte expansão da agropecuária no Mato Grosso e outros estados do CentroOeste, regiões relativamente menos desenvolvidas.

Com relação à indústria, se por um lado a agropecuária cresceu no Centro-Oeste, por outro lado, a região é a menos industrializada do país, mantendo-se nessa situação em 1995 e 2012. Os estados que se destacaram na indústria em 2012 foram: o estado de Goiás (2,9\%), Mato Grosso do Sul $(1,1 \%)$ e Mato Grosso (1,2\%), todavia, alguns dos seus estados são mais industrializados que estados da região Norte e Nordeste. Nessas duas últimas regiões, destacaram-se também em 2012, Amazonas (2\%), Pará (3,2\%), Ceará $(1,8 \%)$, Pernambuco $(2,6 \%)$ e Bahia $(3,8 \%)$. Todos os demais estados do Norte e Nordeste não atingiram 1\% no VAB da indústria, tanto em 1995 como em 2012. Em geral, todos os estados do Centro-Oeste, Norte e Nordeste tiveram algum aumento de participação na indústria (exceção do Distrito Federal, Roraima e Acre, pois a participação não variou). Essas regiões juntas responderam por aproximadamente 1/4 da participação no VAB da indústria em 2012.

Por outro lado, observa-se uma queda na participação das regiões mais industrializadas do país, pois em 1995 o Sudeste respondia por $63,3 \%$ e em 2012 caiu para $58,2 \%$, o Sul passou de 18,4\% em 1995 para 16,9\%. No Sudeste, possivelmente isso refletiu a queda da indústria paulista que representava 44,4\% em 1995 e caiu para 29,8\% em 2012, pois nos demais estados aumentou a participação na indústria. $\mathrm{Na}$ região Sul, a indústria paranaense passou de 6,2\% para 5,5\% e no Rio Grande do Sul passou de 7,8\% para $6,2 \%$. Apenas a indústria catarinense aumentou sua parcela do VAB da indústria de $4,4 \%$ para $5,2 \%$.

Em suma, a região Centro-Oeste manteve-se relativamente pouco industrializada, mas parece que o crescimento da agropecuária nessa região, possa ter influenciado um ligeiro aumento da parcela da indústria. Aumento esse que também ocorreu em quase todos os estados do Nordeste e Norte, com exceção daqueles estados cujo quinhão da indústria não se alterou. Vale ressaltar que essas três regiões juntas não representam a quarta parte da participação na indústria nacional, já que em 2012, quase $60 \%$ pertencia ao Sudeste e $16,9 \%$ ao Sul. É verdade que houve considerável queda na parcela da indústria paulista, mas o estado que mais aumentou sua participação na indústria foi o vizinho Rio de Janeiro. As maiores economias do Sul tiveram queda na sua porção da indústria. Portanto, o Paraná diminuiu sua fração na indústria e aumentou a agropecuária entre 1995 e 2012. O resultado disso para esse estado foi que manteve sua parcela no VAB no referido período e aumentou em apenas $0,1 \%$ sua parcela no PIB.

No que tange aos serviços, a região Norte é a que tem menor participação no VAB. Os estados que tiveram maior parcela em 2012 foram o Amazonas $(1,1 \%)$ e Pará $(1,8 \%)$. No Nordeste, a parcela dos serviços superou o Norte e Centro-Oeste, 14,3\% em 2012 contra $4,8 \%$ do Norte e 10,8\% do Centro-Oeste. Os estados que também se destacaram no Nordeste em 2012 foram: Pernambuco (2,8\%) e Bahia (3,8\%). E no Centro-Oeste, o Distrito Federal (5,5\%) e Goiás (2,6\%). As regiões Sul e Sudeste lideraram o setor serviços, $15,4 \%$ e $54,7 \%$, respectivamente no ano de 2012 . Os estados que mais contribuíram para gerar esse resultado no Sudeste foram: São Paulo (33\%), Rio de Janeiro (11,3\%) e Minas Gerais (11,5\%). No Sul, foram os estados do Rio Grande do Sul (6,2\%) e Paraná (5,6\%). Vale frisar que, enquanto no Nordeste e Norte a participação desse setor aumentou em 2012, se comparado a 1995, no Centro-Oeste permaneceu constante, ao passo que diminuiu na região Sudeste e aumentou 0,5\% na região Sul. No entanto, essa "desconcentração" do setor serviços não é tão significativa quando se considera um período de 17 anos. Até porque o setor de serviços continuou majoritariamente forte nas regiões mais industrializadas do país.

De maneira geral, a maior parcela do VAB total coube à região Sudeste $(54,3 \%)$ em 2012, a frente da segunda colocada, a região Sul (16,2\%). Análise semelhante a da participação das regiões e estados no PIB. Com base no VAB total da região Norte, observa- se que, embora esta tenha aumentado no período, ainda é a região menos desenvolvida do país. Esse aumento do VAB total também ocorreu no Nordeste e Centro-Oeste, mas ainda é relativamente pouco significativo, contudo parece se desenvolver. Ressalta-se ainda que, em 2012, a região Sudeste foi responsável por 29,8\% da produção agropecuária brasileira, 58,2\% da indústria e $54,7 \%$ do setor serviços. 


\subsection{PARTICIPAÇÃO DAS ATIVIDADES} ECONÔMICAS NO VAB NO BRASIL, 1995/2012: COMPARAÇÃO ENTRE AS REGIÕES SUL E SUDESTE

Como se pode notar pela análise da estrutura produtiva brasileira, os estados da região Sul e principalmente da região Sudeste, concentram a maior parte da riqueza do país e são mais dinâmicos na indústria e serviços. Além disso, observou-se também um alto grau de disparidade entre estados de uma mesma região em nível nacional. Nesta seção, o objetivo é comparar a estrutura produtiva dos estados da região Sul e Sudeste e verificar possíveis disparidades apenas nas regiões mais ricas do país, destacando-se a economia paranaense. Porém, primeiramente é importante avaliar a estrutura produtiva nacional para um parâmetro de comparação, conforme a Tabela 2.

Em termos agregados, ou seja, para o Brasil, - VAB da agropecuária e indústria teve uma queda entre 1995 e 2012, ao passo que o setor de serviços aumentou $2 \%$. De maneira geral, a estrutura produtiva nacional pouco se modificou e tem grandes discrepâncias entre as atividades.

Tabela 2 - Estrutura produtiva do Brasil, 1995/2012 (\% do VAB por atividade econômica)

\begin{tabular}{|c|c|c|}
\hline Atividades & 1995 & 2012 \\
\hline Total & 100.0 & 100.0 \\
\hline Agropecuária & 5.8 & 5.3 \\
\hline Indústria & 27.5 & 26.0 \\
\hline Serviços & 66.7 & 68.7 \\
\hline
\end{tabular}

Fonte: elaborado pelos autores a partir de IBGE (2016)

Na região Sul, apenas o Paraná aumentou a parcela da agropecuária (3,4\%). A indústria caiu nos três estados, tendo queda considerável de 1995 para 2012 no Rio
Grande do Sul e Paraná. Já o setor serviços foi o que mais cresceu, conforme mostra a Tabela 3.

Tabela 3 - Estrutura produtiva dos estados da região Sul 1995/2012 (\% do VAB por atividade econômica)

\begin{tabular}{|c|c|c|c|c|c|c|}
\hline \multicolumn{2}{c}{ Região Sul } & \multicolumn{2}{c}{ Paraná } & \multicolumn{2}{c|}{ Santa Catarina } & \multicolumn{2}{c|}{ Rio Grande do Sul } \\
\multirow{2}{*}{ Atividades } & 1995 & 2012 & 1995 & 2012 & 1995 & 2012 \\
\hline Total & 100.0 & 100.0 & 100.0 & 100.0 & 100.0 & 100.0 \\
\hline Agropecuária & 5.8 & 9.2 & 9.1 & 4.3 & 9.7 & 8.4 \\
\hline Indústria & 29.7 & 24.5 & 34.7 & 33.7 & 30.2 & 25.2 \\
\hline Serviços & 64.6 & 66.2 & 56.2 & 62.1 & 60.1 & 66.3 \\
\hline
\end{tabular}

Fonte: elaborado pelos autores a partir de IBGE (2016)

Na região Sudeste, o setor agropecuário somente não caiu em São Paulo. No entanto, a parcela da agropecuária deste estado foi de apenas $1,9 \%$ e cresceu $0,3 \%$ em relação a 1995. Por outro lado, a indústria nesse estado caiu 8,5\% comparando o ano de 2012 com 1995. Nos demais estados do Sudeste a indústria cresceu significativamente. No Espírito Santo, aumentou 9,5\% e no Rio de Janeiro, $12,6 \%$. Isso pode ter refletido a queda da participação da indústria paulista no seu cenário de "desconcentração". $\mathrm{Na}$ verdade a indústria continuou concentrada na região Sudeste. O setor serviços aumentou sua participação apenas nos estados de São Paulo (8,2\%) e Minas Gerais (2,7\%); no Espírito Santo e Rio de Janeiro houve queda do setor, $0,1 \%$ e $12,2 \%$, respectivamente. Observe-se a Tabela 4. 
Tabela 4 - Estrutura produtiva dos estados da região Sudeste 1995/2012 (\% do VAB por atividade econômica)

\begin{tabular}{|c|c|c|c|c|c|c|c|c|}
\hline \multicolumn{9}{|c|}{ Região sudeste } \\
\hline \multirow{2}{*}{ Atividades } & \multicolumn{2}{|c|}{ Minas Gerais } & \multicolumn{2}{|c|}{ Espírito Santo } & \multicolumn{2}{|c|}{ Rio de Janeiro } & \multicolumn{2}{|c|}{ São Paulo } \\
\hline & 1995 & 2012 & 1995 & 2012 & 1995 & 2012 & 1995 & 2012 \\
\hline Total & 100.0 & 100.0 & 100.0 & 100.0 & 100.0 & 100.0 & 100.0 & 100.0 \\
\hline Agropecuária & 11.6 & 8.6 & 15.3 & 6.0 & 0.8 & 0.4 & 1.6 & 1.9 \\
\hline Indústria & 29.1 & 29.4 & 29.7 & 39.2 & 19.6 & 32.2 & 33.5 & 25.0 \\
\hline Serviços & 59.3 & 62.0 & 55.0 & 54.9 & 79.6 & 67.4 & 64.9 & 73.1 \\
\hline
\end{tabular}

De maneira geral, quando se analisa a estrutura produtiva dos estados mais ricos, comparativamente, observa-se que a agropecuária no estado do Paraná, Rio Grande do Sul, Minas Gerais e Espírito Santo teve valores maiores, de 1995 para 2012, que os do Brasil (na verdade, para o Brasil houve queda da agropecuária no período). Nos demais estados do Sul e Sudeste, a agropecuária ficou abaixo dos valores de referência para o Brasil, 5,8\% (1995) e 5,3\% (2012). Ou seja, nos estados citados, a agropecuária desenvolveu-se mais que no Brasil como um todo. No caso da indústria, os estados que ficaram abaixo dos valores referentes ao Brasil foram: Paraná, Rio Grande do Sul e São Paulo. Ou seja, o Paraná apresentou mais uma desvantagem no seu crescimento industrial entre os estados das duas regiões comparadas. Com relação ao setor serviços, com exceção de São Paulo, todos os estados do Sul e Sudeste ficaram abaixo do valor referente ao Brasil, comparando 1995 com 2012.

\section{CONSIDERAÇÕES FINAIS}

O objetivo desse trabalho foi analisar a estrutura produtiva paranaense no contexto nacional, destacando-se o comportamento da indústria e das disparidades regionais da economia brasileira do ponto de vista histórico e empírico.

Até 1930 a economia paranaense era exportadora de produtos primários: houve 0 ciclo do mate, o ciclo da madeira e da pecuária. Isso não a diferenciou naquele momento do que ocorria na economia brasileira. A partir de 1945, a produção de café se torna expressiva no Paraná, e com certo vínculo de dependência em relação a
São Paulo, o Paraná passou a desenvolver alguns setores industriais tendo de optar pelo fortalecimento do setor agropecuário para cumprir seu papel de fornecedor de alimentos para o centro dinâmico. Com isso, a indústria, que até os anos 1940 estava estagnada, passou a expandir-se. Além disso, ao término da década de 1960, quando o café declinou, não havia mais uma monocultura do café e a indústria ainda rudimentar, deu sinais de desenvolvimento. Em 1985, a economia paranaense de fato integrou-se a economia nacional, pois já havia se modernizado e se diversificado. Na década de 1990, outro surto industrial concentrou as indústrias em torno da capital do estado e ocorreu um aumento significativo da produtividade agrícola.

No período mais recente (1995 e 2012), a análise da estrutura produtiva da economia brasileira e paranaense, mostrou que, de maneira geral, apenas algumas grandes regiões concentram a maior parte da renda do país, como também se observa que apenas alguns estados também o fazem. Ou seja, há uma grande desigualdade regional e intrarregional que pouco promoveu 0 desenvolvimento homogêneo da nação. O estado de São Paulo, por exemplo, concentra quase um terço do PIB. Nesse cenário, o Paraná contribuiu com apenas 5,8\% do PIB brasileiro em 2012. A agropecuária do Paraná representou $10,1 \%$ do total do setor no Brasil, a indústria $5,5 \%$ e o setor serviços $5,6 \%$, em 2012.

Por meio da análise da distribuição do VAB por atividade econômica, mais uma vez concluiu-se que os estados da região Sul e Sudeste concentram demasiadamente quase todas as atividades. A participação do Norte e Nordeste na indústria, por exemplo, é quase insignificante. Nesse contexto, o Paraná 
diminuiu sua fração na indústria e aumentou a agropecuária, comparando 1995 com 2012. Com isso, esse estado manteve sua parcela no VAB total no referido período e aumentou em apenas $0,1 \%$ sua parcela no PIB. Observou-se ainda que, há certa tendência dos estados que têm menor parcela na renda em elevar a participação da agropecuária.

Finalmente, a comparação da estrutura produtiva entre os estados da região Sul e Sudeste indicou que a queda da indústria

\section{REFERÊNCIAS}

[1]. ABREU, Marcelo de Paiva. Crise, crescimento e modernização autoritária: 19301945. In: ABREU, Marcelo de Paiva (Org.). A ordem do progresso: cem anos de política econômica republicana (1889-1989). Rio de Janeiro: Campus, 1995.

[2]. BAER, Werner. A economia brasileira. Tradução de Edite Sciulli. 2. São Paulo: Nobel, 2002.

[3]. FURTADO, Celso. Teoria e política do desenvolvimento econômico. 7. São Paulo: Nacional, 1979. 344 p.

[4]. GREMAUD, Amaury Patrick. Economia brasileira. São Paulo: Atlas, 2010.

[5]. GUIMARÃES NETO, Leonardo. Dinâmica recente das economias regionais brasileiras.

[6]. Revista Paranaense de Desenvolvimento, Curitiba, n. 86, p. 123-152, set./dez. 1995.

[7]. IBGE (Instituto Brasileiro de Geografia e Estatística). Contas Regionais do Brasil. Disponível

em:<http://www.ibge.gov.br/home/estatistica/econo mia/contasregionais/2012/defa

ult_xls_1995_2012.shtm>. Acesso em: 31/06/2016.

[8]. INSTITUTO BRASILEIRO DO CAFÉ (IBC). Anuário Estatístico do Café, 1968. In: PADIS, Pedro Calil. Formação de uma Economia Periférica: o caso do Paraná. São Paulo; Hucitec; Curitiba: Secretaria da Cultura e do Esporte do Governo do Estado do Paraná, 1981.

[9]. IPARDES (Instituto Paranaense de Desenvolvimento Econômico e Social) - Fundação Édison Vieira. O Paraná: economia e sociedade. Curitiba, 1981. 72p.

[10]. MAGALHÃES FILHO, Francisco. Evolução histórica da economia paranaense. In: Revista paulista pode ter contribuído significativamente para o crescimento da indústria do Rio de Janeiro e Espírito Santo. No entanto, as maiores economia da região Sul, Paraná e Rio Grande do Sul, reduziram a parcela da indústria no VAB total desse setor no Brasil, no período analisado. Os resultados também sugerem uma forte desigualdade na estrutura produtiva dos estados das duas regiões mais ricas do país, em termos de participação no PIB e na própria estrutura produtiva desses estados.

paranaense de desenvolvimento, Curitiba, $n^{\circ} 87$, jan/abr. 1996, p. 131-148.

[11]. OLIVEIRA, Francisco de. A economia da dependência imperfeita. Rio de Janeiro: Graal, 1977.

[12]. PADIS, Pedro Calil. Formação de uma Economia Periférica: o caso do Paraná. São Paulo; Hucitec; Curitiba: Secretaria da Cultura e do Esporte do Governo do Estado do Paraná, 1981. (Economia e planejamento: Série teses e pesquisas).

[13]. PIGNATON, A. G. Álvaro. Capital estrangeiro e expansão industrial no Brasil. Brasília: UNB, Departamento de Economia, set. 1973, p.50.

[14]. SOUZA, Nilson Araújo de. Economia brasileira contemporânea: de Getúlio a Lula. São Paulo: Atlas, 2008.

[15]. SUZIGAN, Wilson. Celso furtado e o processo histórico de industrialização na América Latina. In: CAMARGO, José Marangoni; CORSI, Francisco Luiz (Org). Celso Furtado: os desafios do desenvolvimento. São Paulo: Cultura Acadêmica, 2010. 260 p.

[16]. TAVARES, Maria da Conceição. Da substituição de importações ao capitalismo financeiro: ensaios sobre a economia brasileira. Rio de Janeiro: Zahar, 1973.

[17]. TRINTIN, Jaime Graciano. A nova economia paranaense: 1970-2000. Maringá, PR: Eduem, 2006

[18]. VILLELA, Annibal; SILVA, Sérgio da; SUZIGAN, Wilson, SANTOS, Mario J. Aspectos do crescimento da economia brasileira. Rio de Janeiro: Fundação Getúlio Vargas, 1971. 


\section{2}

ANEXO A - PARTICIPAÇÃO DAS GRANDES REGIÕES E UNIDADES DA FEDERAÇÃO NO PRODUTO INTERNO BRUTO (\%), 1995-2012

\begin{tabular}{|c|c|c|c|c|c|c|c|c|c|c|c|c|c|c|c|c|c|c|}
\hline \multicolumn{19}{|l|}{$\begin{array}{c}\text { Grandes Regiōes } \\
\text { e UFs }\end{array}$} \\
\hline & 1995 & 1996 & 1997 & 1998 & 1999 & 2000 & 2001 & 2002 & 2003 & 2004 & 2005 & 2006 & 2007 & 2008 & 2009 & 2010 & 2011 & 2012 \\
\hline Brasil & 100.0 & 100.0 & 100.0 & 100.0 & 100.0 & 100.0 & 100.0 & 100.0 & 100.0 & 100.0 & 100.0 & 100.0 & 100.0 & 100.0 & 100.0 & 100.0 & 100.0 & 100.0 \\
\hline Norte & 4.2 & 4.3 & 4.1 & 4.2 & 4.2 & 4.4 & 4.5 & 4.7 & 4.8 & 4.9 & 5.0 & 5.1 & 5.0 & 5.1 & 5.0 & 5.3 & 5.4 & 5.3 \\
\hline Rondônia & 0.4 & 0.5 & 0.5 & 0.5 & 0.5 & 0.5 & 0.5 & 0.5 & 0.6 & 0.6 & 0.6 & 0.6 & 0.6 & 0.6 & 0.6 & 0.6 & 0.7 & 0.7 \\
\hline Acre & 0.2 & 0.2 & 0.2 & 0.2 & 0.2 & 0.2 & 0.2 & 0.2 & 0.2 & 0.2 & 0.2 & 0.2 & 0.2 & 0.2 & 0.2 & 0.2 & 0.2 & 0.2 \\
\hline Amazonas & 1.4 & 1.5 & 1.3 & 1.3 & 1.3 & 1.4 & 1.4 & 1.5 & 1.5 & 1.6 & 1.6 & 1.7 & 1.6 & 1.5 & 1.5 & 1.6 & 1.6 & 1.5 \\
\hline Roraima & 0.1 & 0.1 & 0.1 & 0.1 & 0.1 & 0.2 & 0.2 & 0.2 & 0.2 & 0.1 & 0.1 & 0.2 & 0.2 & 0.2 & 0.2 & 0.2 & 0.2 & 0.2 \\
\hline Pará & 1.6 & 1.6 & 1.5 & 1.5 & 1.5 & 1.6 & 1.7 & 1.7 & 1.8 & 1.8 & 1.8 & 1.9 & 1.9 & 1.9 & 1.8 & 2.1 & 2.1 & 2.1 \\
\hline Amapá & 0.2 & 0.2 & 0.2 & 0.2 & 0.2 & 0.2 & 0.2 & 0.2 & 0.2 & 0.2 & 0.2 & 0.2 & 0.2 & 0.2 & 0.2 & 0.2 & 0.2 & 0.2 \\
\hline Tocantins & 0.3 & 0.3 & 0.3 & 0.3 & 0.3 & 0.3 & 0.4 & 0.4 & 0.4 & 0.4 & 0.4 & 0.4 & 0.4 & 0.4 & 0.4 & 0.5 & 0.4 & 0.4 \\
\hline Nordeste & 12.0 & 12.5 & 12.5 & 12.4 & 12.4 & 12.4 & 12.6 & 13.0 & 12.8 & 12.7 & 13.1 & 13.1 & 13.1 & 13.1 & 13.5 & 13.5 & 13.4 & 13.6 \\
\hline Maranhão & 0.9 & 1.0 & 1.0 & 1.0 & 1.0 & 1.0 & 1.0 & 1.0 & 1.1 & 1.1 & 1.2 & 1.2 & 1.2 & 1.3 & 1.2 & 1.2 & 1.3 & 1.3 \\
\hline Piauí & 0.5 & 0.5 & 0.5 & 0.5 & 0.5 & 0.5 & 0.5 & 0.5 & 0.5 & 0.5 & 0.5 & 0.5 & 0.5 & 0.6 & 0.6 & 0.6 & 0.6 & 0.6 \\
\hline Ceará & 1.9 & 2.0 & 2.0 & 2.0 & 1.9 & 1.9 & 1.9 & 2.0 & 1.9 & 1.9 & 1.9 & 2.0 & 1.9 & 2.0 & 2.0 & 2.1 & 2.1 & 2.1 \\
\hline $\begin{array}{c}\text { Rio Grande do } \\
\text { Norte. }\end{array}$ & 0.7 & 0.7 & 0.8 & 0.7 & 0.8 & 0.8 & 0.8 & 0.8 & 0.8 & 0.8 & 0.8 & 0.9 & 0.9 & 0.8 & 0.9 & 0.9 & 0.9 & 0.9 \\
\hline Paraíba & 0.7 & 0.8 & 0.8 & 0.8 & 0.8 & 0.8 & 0.8 & 0.8 & 0.8 & 0.8 & 0.8 & 0.8 & 0.8 & 0.8 & 0.9 & 0.8 & 0.9 & 0.9 \\
\hline Pernambuco & 2.3 & 2.4 & 2.3 & 2.4 & 2.3 & 2.3 & 2.3 & 2.4 & 2.3 & 2.3 & 2.3 & 2.3 & 2.3 & 2.3 & 2.4 & 2.5 & 2.5 & 2.7 \\
\hline Alagoas & 0.7 & 0.6 & 0.7 & 0.7 & 0.7 & 0.7 & 0.7 & 0.7 & 0.7 & 0.7 & 0.7 & 0.7 & 0.7 & 0.6 & 0.7 & 0.7 & 0.7 & 0.7 \\
\hline Sergipe & 0.5 & 0.6 & 0.6 & 0.6 & 0.6 & 0.6 & 0.6 & 0.6 & 0.6 & 0.6 & 0.6 & 0.6 & 0.6 & 0.6 & 0.6 & 0.6 & 0.6 & 0.6 \\
\hline Bahia & 3.7 & 3.8 & 3.9 & 3.9 & 3.9 & 3.9 & 3.9 & 4.1 & 4.0 & 4.1 & 4.2 & 4.1 & 4.1 & 4.0 & 4.2 & 4.1 & 3.9 & 3.8 \\
\hline Sudeste & 59.1 & 58.4 & 58.5 & 58.2 & 58.2 & 58.3 & 57.7 & 56.7 & 55.8 & 55.8 & 56.5 & 56.8 & 56.4 & 56.0 & 55.3 & 55.4 & 55.4 & 55.2 \\
\hline Minas Gerais & 8.6 & 8.8 & 8.8 & 8.6 & 8.4 & 8.5 & 8.5 & 8.6 & 8.8 & 9.1 & 9.0 & 9.1 & 9.1 & 9.3 & 8.9 & 9.3 & 9.3 & 9.2 \\
\hline Espírito Santo & 2.0 & 1.9 & 1.9 & 1.9 & 1.9 & 2.0 & 1.9 & 1.8 & 1.8 & 2.1 & 2.2 & 2.2 & 2.3 & 2.3 & 2.1 & 2.2 & 2.4 & 2.4 \\
\hline Rio de Janeiro & 11.2 & 11.2 & 11.1 & 11.7 & 11.9 & 11.8 & 11.7 & 11.6 & 11.1 & 11.5 & 11.5 & 11.6 & 11.2 & 11.3 & 10.9 & 10.8 & 11.2 & 11.5 \\
\hline São Paulo & 37.3 & 36.5 & 36.7 & $\begin{array}{c}36 . \\
1\end{array}$ & 36.0 & 36.0 & 35.6 & 34.6 & 34.1 & 33.1 & 33.9 & 33.9 & 33.9 & 33.1 & 33.5 & 33.1 & 32.6 & 32.1 \\
\hline Sul & 16.2 & 16.2 & 16.1 & $\begin{array}{c}16 . \\
2\end{array}$ & 16.4 & 16.5 & 16.7 & 16.9 & 17.7 & 17.4 & 16.6 & 16.3 & 16.6 & 16.6 & 16.5 & 16.5 & 16.2 & 16.2 \\
\hline Paraná & 5.7 & 5.7 & 5.6 & 5.8 & 6.0 & 5.9 & 5.9 & 6.0 & 6.4 & 6.3 & 5.9 & 5.8 & 6.1 & 5.9 & 5.9 & 5.8 & 5.8 & 5.8 \\
\hline Santa Catarina & 3.4 & 3.5 & 3.5 & 3.5 & 3.5 & 3.7 & 3.7 & 3.8 & 3.9 & 4.0 & 4.0 & 3.9 & 3.9 & 4.1 & 4.0 & 4.0 & 4.1 & 4.0 \\
\hline $\begin{array}{c}\text { Rio Grande do } \\
\text { Sull }\end{array}$ & 7.1 & 7.0 & 6.9 & 6.9 & 6.9 & 6.9 & 7.1 & 7.1 & 7.3 & 7.1 & 6.7 & 6.6 & 6.6 & 6.6 & 6.7 & 6.7 & 6.4 & 6.3 \\
\hline Centro-Oeste & 8.4 & 8.6 & 8.8 & 9.0 & 8.8 & 8.4 & 8.5 & 8.8 & 9.0 & 9.1 & 8.9 & 8.7 & 8.9 & 9.2 & 9.6 & 9.3 & 9.6 & 9.8 \\
\hline $\begin{array}{c}\text { Mato Grosso do } \\
\text { Sull }\end{array}$ & 0.9 & 0.9 & 0.9 & 0.9 & 1.0 & 1.0 & 1.0 & 1.0 & 1.1 & 1.1 & 1.0 & 1.0 & 1.1 & 1.1 & 1.1 & 1.2 & 1.2 & 1.2 \\
\hline Mato Grosso & 1.0 & 1.0 & 1.1 & 1.1 & 1.2 & 1.3 & 1.3 & 1.4 & 1.6 & 1.9 & 1.7 & 1.5 & 1.6 & 1.8 & 1.8 & 1.6 & 1.7 & 1.8 \\
\hline Goiás & 2.0 & 2.1 & 2.1 & 2.2 & 2.1 & 2.2 & 2.3 & 2.5 & 2.5 & 2.5 & 2.4 & 2.4 & 2.5 & 2.5 & 2.6 & 2.6 & 2.7 & 2.8 \\
\hline Distrito Federal & 4.4 & 4.6 & 4.7 & 4.8 & 4.6 & 3.9 & 4.0 & 3.8 & 3.7 & 3.6 & 3.8 & 3.8 & 3.8 & 3.9 & 4.1 & 4.0 & 4.0 & 3.9 \\
\hline
\end{tabular}

Fonte: elaborado pelos autores a partir de IBGE (2016) 


\section{Gapítulo 13}

\section{INCENTIVOS FISCAIS À INOVAÇÃO NO BRASIL: EVOLUÇÃO DA LEI DO BEM NO PERÍODO DE 2006 A 2014}

\section{Eder Angelo Sanches}

Sanderson César Macêdo Barbalho

\section{Adriana Regina Martin}

Resumo. A Lei do Bem é considerada na atualidade uma das mais importantes e recentes políticas de fomento à inovação tecnológica para o setor industrial no país. Seus incentivos colocam-se como um dos mais importantes instrumentos fiscais para fortalecer e estimular as empresas privadas a realizarem atividades de inovação, com destaque às atividades de Pesquisa e Desenvolvimento (P\&D). Apesar dos esforços empreendidos pelo governo Brasileiro, desde o final dos anos 90, para estimular a inovação no cenário econômico e ampliar a participação empresarial nos aspectos tecnológicos, indicadores mostram que é preciso fazer mais. O uso dessa lei apresenta discussão e dúvida sobre a capacidade de estimular a utilização e aumentar a base de empresas beneficiárias. No período de 2006 a 2014 de utilização da Lei do Bem no país, o objetivo deste artigo é apresentar sua evolução histórica e seus efeitos à inovação tecnológica. Embora pesem as dificuldades metodológicas à utilização, é possível associar efeitos positivos ao desempenho das empresas e a seus esforços tecnológicos. Por meio da observação direta de alguns indicadores de resultados do MCTIC, serão apresentadas as principais características da lei e sua evolução para orientação das empresas, principalmente àquelas nãobeneficiárias. Os resultados apontam para uma evolução histórica positiva no período de 2006 a 2014, registrando aumento dos gastos em P\&D e da renúncia fiscal apurada, mas, uma situação antagônica em relação ao número empresas beneficiárias. Apesar dos efeitos positivos da lei, é sinalizado a necessidade de aperfeiçoar o mecanismo fiscal para aumentar a efetividade e evitar o antagonismo apontado. 


\section{INTRODUÇÃO}

A política tecnológica representa, na atualidade, parte central da agenda econômica nos países desenvolvidos e nos países emergentes como o Brasil. A partir dos anos 90, foi possível observar iniciativas do governo brasileiro em transformar o discurso da inovação em ações efetivas, principalmente com a entrada em vigor da Lei da Inovação $n^{\circ}$ 10.973, promulgada em 2 de dezembro de 2004, criada com objetivo de fornecer incentivos fiscais à inovação e à pesquisa científica e tecnológica. A recente Lei $n^{\circ} 13.243$, de 11 de janeiro de 2016, que representa o marco legal da inovação, fortalece o motor da inovação no país.

Com intuito de acelerar o desenvolvimento tecnológico no país e criar uma infraestrutura estratégica de fomento à inovação em PD\&I na indústria nacional, foi criada a Lei $n^{\circ} 11.196$, de 21 de novembro de 2005, conhecida como Lei do Bem (LB), que fornece incentivos fiscais para as empresas realizarem atividades de PD\&l no país, por meio de projetos de P\&D, em contrapartida, o governo oferece isenção fiscal (renúncia) baseada no total de gastos realizados e variações no custo de uso do capital.

Os incentivos fiscais da Lei do Bem estruturam-se a partir da dedução da base do imposto a pagar (base de tributação do $\operatorname{IRPJ}^{1}$ e $\mathrm{CSLL}^{2}$ ), sobre o investimento total realizado pela empresa na execução de suas atividades de P\&D, em determinado período (ano- calendário). As informações técnicas e financeiras dos projetos desenvolvidos são enviadas anualmente por meio do FORMP\&D ${ }^{3}$ ao MCTIC ${ }^{4}$. Além dos incentivos fiscais representarem menor custo de administração para o governo, em comparação ao mecanismo de financiamento direto, permitem que o mercado, não o governo, defina a alocação dos investimentos em P\&D (GUIMARÃES, 2008).

Segundo Izique (2007), mecanismos fiscais indiretos - como da Lei do Bem - ainda são desconhecidos por muitas empresas. A falta de informação e a insegurança jurídica - associadas a possíveis penalidades decorrentes da aplicação incorreta dos incentivos fiscais à inovação tecnológica prevista na Lei do Bem - são fatores que restringem a aplicação efetiva dos incentivos fiscais em muitas empresas. Essa situação é preocupante, uma vez que o desconhecimento e a falta de informação sobre como utilizar os incentivos fiscais previstos na lei comprometem a continuidade e ampliação dos investimentos em inovação nas empresas, reduzindo consequentemente o avanço científico, tecnológico e econômico do país.

Este artigo apresenta uma avaliação qualitativa-quantitativa da utilização da Lei do Bem e o impacto dos incentivos fiscais de P\&D sobre o investimento e a renúncia fiscal gerada. O principal objetivo é apresentar uma visão dos efeitos da Lei do Bem à inovação no Brasil considerando a sua evolução histórica em 10 anos de existência.

\section{INOVAÇÃO TECNOLÓGICA}

Segundo Pardo (1994), a origem da palavra "tecnologia" vem do grego, onde tekne significa que pertence a uma ciência ou arte e logos quer dizer estudo. Dessa forma, pode-se dizer que tecnologia é o estudo da ciência ou artes, sejam elas práticas ou, na atualidade, industriais. A tecnologia caracteriza-se por uma evolução controlada do uso do conhecimento científico e empírico, com fins de aperfeiçoamento ou desenvolvimento de novos produtos ou processos industriais.

Para Schumpeter (1988), o conceito de inovação envolve cinco situações: a) a introdução de um novo produto (bem), que pode ser novo para os consumidores ou uma nova qualidade de um produto já existente; b) introdução de um novo método de produção, que ainda não foi testado pelo setor em que a empresa está inserida, não sendo necessariamente uma descoberta científica; c) a abertura de um novo mercado, em que outras empresas do mesmo setor ainda não tenham entrado; d) a conquista de uma nova fonte de insumos (matérias-primas ou produtos semimanufaturados); e) o estabelecimento de uma nova organização industrial seja pela criação de um monopólio ou por sua fragmentação. De acordo com Zucoloto (2012), na ótica neoschumpeteriana, as inovações - não somente tecnológicas - são consideradas o motor do desenvolvimento econômico e o principal veículo de transformação do conhecimento em valor.

Jugend et al. (2013) afirma que a inovação significa introduzir novidades por meio de mudanças e possibilidades de fazer as 
coisas de maneiras novas ou diferentes, ou seja, é a exploração bem-sucedida de novas ideias. Já Christensen (2012) refere-se à inovação como à mudança em uma tecnologia capaz transformar a mão-deobra, o capital, os materiais e a informação em produtos e serviços.

De acordo com o Manual de Oslo ${ }^{5}$ publicado pela OECD (1997), a inovação tecnológica de produto ou processo (TPP) corresponde a implantações de produtos (bem ou serviço) e processos tecnologicamente novos ou substancialmente aprimorados e, precisa ser distinguida de inovação organizacional e de outras mudanças em produtos e processos realizados por métodos convencionais. Inovação tecnológica de produto pode assumir duas formas abrangentes, o produto tecnologicamente novo e produto tecnologicamente melhorado. Inovação tecnológica de processo é a adoção de métodos de produção novos ou significativamente melhorados, como uma simples mudança em um equipamento ou na organização como um todo, incluindo métodos de entrega dos produtos.

Para a empresa, a inovação tecnológica deve abranger produto ou processo novo (ou significativamente melhorado) que aproxime o conhecimento dos negócios resultando em caráter comercial e aplicado (Fig. 1), não sendo necessário que seja novo para o mundo (OCDE, 1997).

Fig. 1. Inovação tecnológica para a empresa.

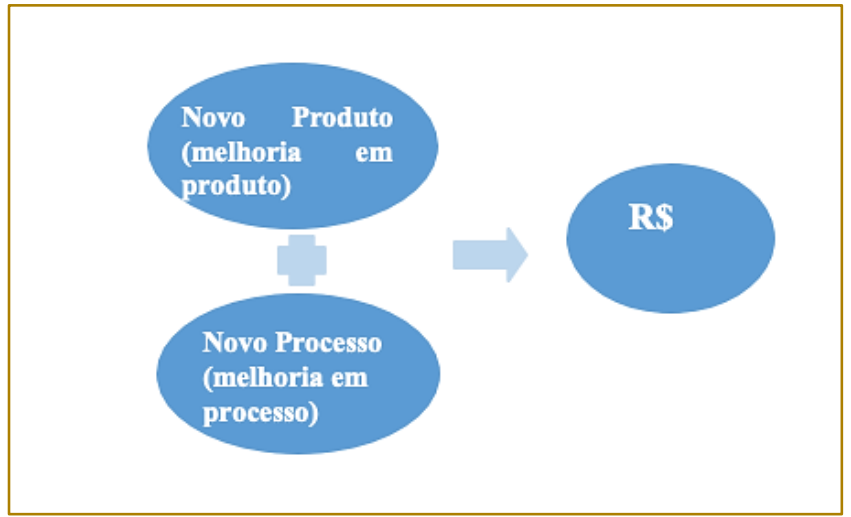

Fonte: Autores (2018). Adaptado do estudo de diversos autores na revisão da literatura.

Uma inovação tecnológica é considerada implantada se tiver introduzida no mercado ou usada no processo de produção. Pode ser entendida como o principal determinante do crescimento econômico no mundo industrializado (BUENO E TORKOMIAN, 2014). Enquanto a tecnologia tem sido a direcionadora do crescimento dos países industrializados e, consequentemente, ao crescimento de suas empresas.

De acordo com o $\S 1^{\circ}$, art. 17 da Lei do Bem (2005):

"Considera-se inovação tecnológica a concepção de novo produto ou processo de fabricação, bem como a agregação de novas funcionalidades ou características ao produto ou processo que implique melhorias incrementais e efetivo ganho de qualidade ou produtividade, resultando maior competitividade no mercado (Lei $\mathrm{n}^{\circ} 11.196$, $\mathrm{p}$. 9, 2005)".
As atividades de P\&D incentivadas pela Lei do Bem são: pesquisa básica, pesquisa aplicada, desenvolvimento experimental, tecnologia industrial básica e serviço de apoio técnico. São atividades desenvolvidas pelas empresas na forma de projetos inovadores classificados como beneficiáveis pelo MCTIC. Essas atividades são definidas tecnicamente e padronizadas pelo Manual de Frascati.

\section{LEI DO BEM NO BRASIL}

\subsection{INCENTIVOS FISCAIS}

Os incentivos fiscais (ou tributários) são instrumentos de estímulo ao desenvolvimento da inovação tecnológica e têm sido utilizados por aproximadamente 2/3 dos países (OCDE, 2015). Em alguns casos, como no Estados Unidos, o mecanismo foi totalmente consolidado na década de 1990, 
sendo implementado ainda na década de 1980. Em outros a iniciativa é mais recente, como a Irlanda em 2004 e o Brasil, que apesar de não ser um país membro da OCDE, implantou em 2005. No início da década anterior, cerca de $19 \%$ das empresas inovadoras no Brasil haviam declarado terem recebido algum tipo de apoio governamental para inovar, esse número cresceu para mais de 34\% em 2011 e para mais de 46\% em 2014 (IPEA, 2016).

No Brasil, os incentivos fiscais da Lei do Bem apresentam as formas: indireta para despesas de custeio (operacional), reduzindo (por exclusão) as despesas da empresa com atividades de P\&D da base de cálculo de incidência tributária (CSLL e IRPJ); direta para despesas de bens de capital, diminuindo pela metade o imposto incidente sobre a aquisição de produtos industrializados como máquinas e equipamentos nacionais ou importados (IPI); direta para despesa geral, reduzindo a zero o imposto devido incidente sobre registro e manutenção de marcas e patentes no exterior (IRRF); e temporal para despesas de bens de capital, acelerando a amortização de bens intangíveis ou acelerando a depreciação de máquinas e equipamentos nacionais ou importados (de 10 para 1 ano).

São os mecanismos de apoio financeiro de concessão de benefícios ou isenções fiscais (renúncia fiscal) para as empresas que realizam dispêndios em PD\&l (Tabela 1), por conta própria ou mediante cooperação com Institutos de Ciência e Tecnologia (ICT) ou empresa de pequeno porte.

Tabela 1: Formas e modalidades de incentivos fiscais de P\&D.

\begin{tabular}{|c|c|c|c|}
\hline Benefícios & Gasto & Recuperação & Significado econômico \\
\hline $\begin{array}{l}\text { Exclusão (dedução) adicional do Lucro } \\
\text { Real e da base cálculo da tributação } \\
\text { (IRPJ e CSLL) dos dispêndios em } \\
\text { atividades de inovação (PD\&I) } \\
60 \% \text { (simples), 80\% (especial), } 100 \% \\
\text { (especial). (indireto) }\end{array}$ & $\begin{array}{l}\text { Despesas de custeio } \\
\text { (operacional) }\end{array}$ & $\begin{array}{l}20,4 \% \text { a } 34 \% \text { do } \\
\text { gasto com } \\
\text { PD\&I por meio } \\
\text { do CSLL e IRPJ }\end{array}$ & $\begin{array}{l}\text { O custo do PD\&I privado diminui, } \\
\text { incentivando sua realização }\end{array}$ \\
\hline $\begin{array}{l}\text { Exclusão (dedução) adicional do Lucro } \\
\text { Real e da base cálculo da tributação } \\
\text { (IRPJ e CSLL) dos dispêndios em } \\
\text { atividades de inovação (PD\&I) } \\
\text { executadas por ICTs (Art. 19-A). } \\
50 \% \text { a } 250 \% \text { (simples), escalonamento } \\
\text { por opção da empresa. (indireto) }\end{array}$ & $\begin{array}{l}\text { Despesas de custeio } \\
\text { (operacional) }\end{array}$ & $\begin{array}{l}17 \% \text { a } 85 \% \text { do } \\
\text { gasto com } \\
\text { PD\&I } \\
\text { executadas por } \\
\text { ICTs por meio } \\
\text { do CSLL e IRPJ }\end{array}$ & $\begin{array}{l}\text { O custo do PD\&I privado diminui, } \\
\text { incentivando sua realização. A } \\
\text { cooperação das organizações do SNI, } \\
\text { gerando sinergia para a troca de } \\
\text { conhecimento local, mútuo e } \\
\text { interativo }\end{array}$ \\
\hline $\begin{array}{l}\text { Redução de } 50 \% \text { da alíquota do IPI } \\
\text { incidente sobre máquinas e equipamentos } \\
\text { destinados à PD\&I. (direto) }\end{array}$ & $\begin{array}{l}\text { Despesas de capital } \\
\text { Máquinas e } \\
\text { equipamentos para } \\
\text { PD\&I. }\end{array}$ & $50 \%$ do IPI & $\begin{array}{l}\text { O custo (preço) dos bens de capital } \\
\text { destinados ao PD\&I diminui, } \\
\text { incentivando sua aquisição }\end{array}$ \\
\hline $\begin{array}{l}\text { Redução a } 0 \text { (zero) da alíquota do } \\
\text { Imposto de Renda Retido na Fonte } \\
\text { (IRRF) incidente sobre remessas ao } \\
\text { exterior para o registro e manutenção de } \\
\text { marcas, patentes e cultivares. (direto) }\end{array}$ & $\begin{array}{l}\text { Despesa geral } \\
\text { Registro e } \\
\text { manutenção de } \\
\text { marcas, patentes e } \\
\text { cultivares. }\end{array}$ & $100 \%$ do IRRF & $\begin{array}{l}\text { O gasto com registro e manutenção } \\
\text { de marcas, patentes e cultivares no } \\
\text { exterior são isentos, incentivando sua } \\
\text { realização }\end{array}$ \\
\hline $\begin{array}{l}\text { Depreciação Acelerada Integral incidente } \\
\text { sobre máquinas e equipamentos } \\
\text { destinados à PD\&I, no próprio ano de } \\
\text { aquisição destes bens. (temporal) }\end{array}$ & \begin{tabular}{l}
\multicolumn{3}{l}{ Despesas de capital } \\
Máquinas r e \\
equipamentos para \\
PD\&I.
\end{tabular} & $\begin{array}{l}100 \% \text { de } \\
\text { Depreciação no } \\
\text { ano da aquisição } \\
\text { do bem }\end{array}$ & $\begin{array}{l}\text { Beneficio temporário financeiro que } \\
\text { melhora o caixa da empresa por meio } \\
\text { de redução de IRPJ e CSLL no } \\
\text { momento do investimento em bens de } \\
\text { capital. }\end{array}$ \\
\hline $\begin{array}{l}\text { Amortização Acelerada incidente sobre } \\
\text { bens intangíveis destinados à PD\&I, no } \\
\text { próprio ano de aquisição destes bens. } \\
\text { (temporal) }\end{array}$ & $\begin{array}{l}\text { Despesas de capital } \\
\text { Bens intangiveis } \\
\text { para PD\&I. }\end{array}$ & $\begin{array}{l}100 \% \text { de } \\
\text { Amortização no } \\
\text { ano da aquisição } \\
\text { do bem }\end{array}$ & $\begin{array}{l}\text { Beneficio temporário financeiro que } \\
\text { melhora o caixa da empresa por meio } \\
\text { de redução de IRPJ e CSLL no } \\
\text { momento do investimento em bens } \\
\text { intangíveis }\end{array}$ \\
\hline
\end{tabular}

Fonte: Adaptado da Lei do Bem (Lei n 11.196/2005).

Nota: Os incentivos fiscais incluem despesas de custeio (operacional) e despesas de capital. O total das despesas operacionais com atividades de P\&D são deduzidas da base de cálculo da tributação do IRPJ e CSLL de forma proporcional ao tipo de gasto. 
Nota-se que os incentivos fiscais reduzem o custo com P\&D privado atuando tanto sobre os investimentos em bens de capital como despesa operacional (P\&D puro), que é o principal alvo da política devido a sua menor capacidade de crédito e ao maior risco. Há ainda a flexibilização de regras contábeis como a depreciação acelerada integral e amortização acelerada (Kannembley Jr. et al., 2016). Além dos dispêndios normais do processo de desenvolvimento de produto, é permitido que as empresas deduzam, parcialmente, despesas com mão-de-obra relacionada com a contratação de capital humano qualificado exclusivo para suas atividades de P\&D e gastos com registro ou manutenção de marcas e patentes no Brasil e no exterior (ativos intangíveis).

Para se beneficiar dos incentivos fiscais de forma automática em cada ano- calendário, as empresas devem primeiro realizar O P\&D e financiar seus projetos durante $\mathrm{o}$ ano e, no ano subsequente, enviar as informações para análise do MCTIC (ex post) por meio do FORMP\&D eletrônico.

No Brasil, o Ministério da Fazenda (MF/SRF) é o órgão responsável pela fiscalização tributária das empresas em campo, análise e aprovação dos gastos financeiros dos projetos de P\&D relacionados com os incentivos fiscais da Lei do Bem.

\subsection{EVOLUÇÃO HISTÓRICA}

A Lei do Bem é uma política de fomento à inovação que faz parte das políticas expansionistas estratégicas do governo para o desenvolvimento científico e tecnológico do Brasil. É um mecanismo de apoio fiscal para redução de impostos nas empresas (nacionais ou multinacionais) visando estimular à inovação tecnológica através da produção de projetos de P\&D no país. Com vigência a partir de 2005, a Lei do Bem completa em 2015 uma década de existência. Os indicadores da evolução apresentados nesta pesquisa são baseados na análise do

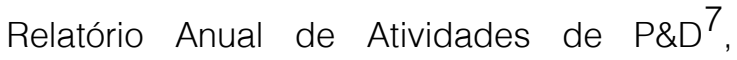
divulgados anualmente pelo MCTIC.

Na Tabela 2 apresenta-se uma síntese dos pré-requisitos e das principais características necessárias para conhecimento e informação prévia das empresas privadas que buscam a inovação com suporte da Lei do Bem.

Tabela 2: Pré-requisitos e características da Lei do Bem.

\begin{tabular}{|ll}
\hline \multicolumn{1}{c}{ Pré-requisito } & \multicolumn{1}{c}{ Característica } \\
\hline $\begin{array}{l}\text { Empresas (nacional ou multinacional) de qualquer porte } \\
\text { ou setor econômico em qualquer parte do país }\end{array}$ & Desoneração tributária \\
\hline $\begin{array}{l}\text { Empresas sujeitas ao regime de tributação com base no } \\
\text { Lucro Real }\end{array}$ & Não precisa de aprovação prévia (sem habilitação) \\
\hline $\begin{array}{l}\text { Apurar lucro fiscal tributável no ano-base de referência } \\
\text { (vigente) }\end{array}$ & Fruição automática dos incentivos fiscais (direto) \\
\hline Possuir regularidade fiscal & Não afeta o resultado operacional da empresa \\
\hline $\begin{array}{l}\text { Ter realizado investimento (dispêndios) em P\&D no } \\
\text { país }\end{array}$ & $\begin{array}{l}\text { Não pode haver cumulação destes benefícios com o } \\
\text { benefício do Art. 19-A (ICTs) }\end{array}$ \\
\hline
\end{tabular}

Fonte: Adaptado da Lei do Bem (2005)

A Lei do Bem é uma lei amigável, pois além de beneficiar qualquer empresa, independente da atividade ou do setor econômico, pode ser utilizada de forma direta (automática) sem necessidade de habilitação prévia para fruição dos incentivos fiscais. Entre as vantagens dos incentivos fiscais estão o baixo custo administrativo para o governo, a facilidade de acesso e a independência do setor público nas decisões sobre os projetos a serem desenvolvidos e do montante a ser aplicado pelas empresas. Porém, sofre desvantagem na limitação do uso, onde somente as empresas enquadradas no regime de tributação do lucro real e que possuem regularidade fiscal e lucro tributável no ano vigente para apuração do benefício podem utilizar, pois a base de cálculo para tributação é o lucro.

$\mathrm{Na}$ Fig. 2 apresenta-se os segmentos da cadeia produtiva que incidem os incentivos fiscais e quais os tipos de atividades consideradas como P\&D na Lei do Bem. 
Fig. 2. Atividades de P\&D incentivadas na Lei do Bem.

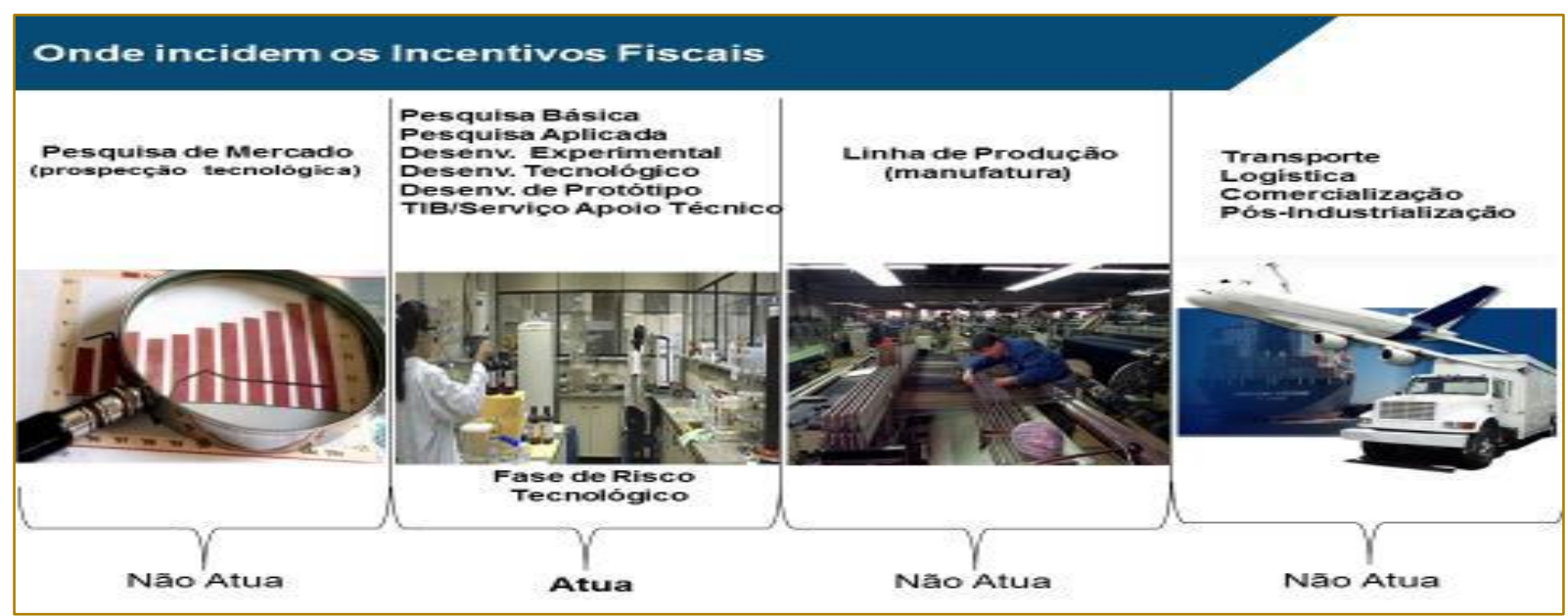

Fonte: MCTIC/SETEC (2014).

De acordo com o Decreto $n^{\circ} 5.798 / 2006^{8}$ os incentivos fiscais incidem somente nos segmentos onde ocorrem as atividades de pesquisa básica dirigida (PB), pesquisa aplicada (PA), desenvolvimento experimental (DE) (até a fase de desenvolvimento tecnológico e de protótipo), tecnologia industrial básica (TIB) e serviços de apoio técnico (SAT), que é a fase do risco tecnológico, não sendo incentivadas as etapas de introdução de novas tecnologias em escala comercial, manufatura e comercialização/logística.

Em seus 10 anos de existência, pode-se demonstrar (Fig. 3) a evolução histórica das empresas participantes (que entregaram o FORMP\&D ao MCTIC) pelas recomendadas (beneficiadas após a análise do MCTIC) na Lei do Bem.

Fig. 3. Evolução histórica das empresas participantes vs recomendadas na Lei do Bem.



Adaptado do "Relatório Anual Lei 11.196/05" publicado no site do MCTIC.

Nota: desconsidera-se 2005 (ano de início) e as empresas recomendadas de 2015 (dados ainda não computados pelo MCTIC).

O número de empresas que aderiram à lei entre 2006 (130) e 2014 (1.206) cresceu em torno de 9,28 vezes. Em 2014 as empresas participantes apresentaram 13.733 projetos inovadores, dentre os quais, 856 (6\%) de pesquisa básica dirigida (PB), 4.120 (30\%) de pesquisa aplicada (PA) e 8.757 (64\%) de desenvolvimento experimental (DE).

Em termos de distribuição de empresas participantes declaradas (D) e recomendadas $(R)$ por região no Brasil, na Fig. 4 apresenta-se uma evolução histórica (em um período de 3 anos de atuação). 
Fig. 4. Evolução histórica das empresas participantes vs recomendadas por região.

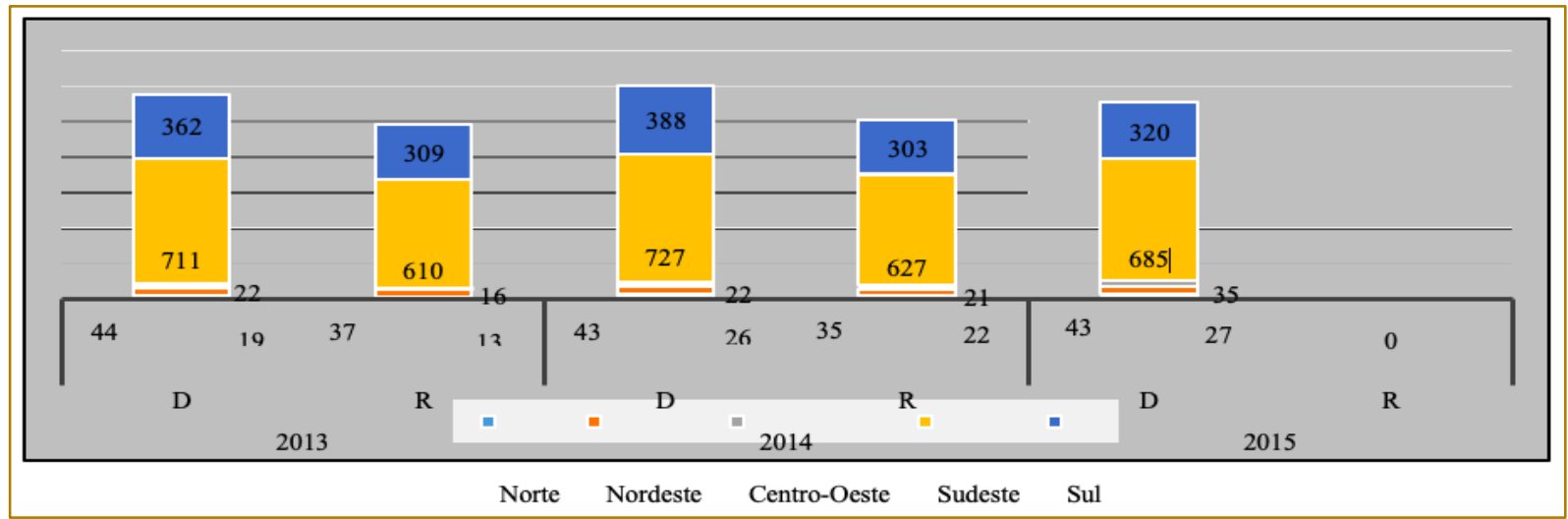

Fonte: Adaptado do "Relatório Anual Lei 11.196/05" publicado no site do MCTIC.

Este é um retrato do comportamento que se mantém desde o início da vigência da lei (2005). As regiões Sudeste e Sul apresentam-se como as maiores demandantes de empresas participantes no Brasil (94\%), principalmente pelo fato de concentrarem a maior intensidade industrial e o maior PIB per capita do país. As regiões Norte, Nordeste e Centro-Oeste apresentam demanda baixa de empresas, o que sugere a necessidade de aprimoramentos na lei para reduzir as desigualdades regionais.

$\mathrm{Na}$ Fig. 5 apresenta-se um indicador divulgado anualmente pelo MCTIC (com base no FORMP\&D enviado pelas empresas), sumarizando 0 investimento (gastos) em P\&D, de todos os setores industriais beneficiados pela lei, a renúncia fiscal e a proporção percentual da renúncia fiscal, para o ano-base de 2014.

Fig. 5. Investimento em P\&D vs renúncia fiscal por setores industriais em 2014.

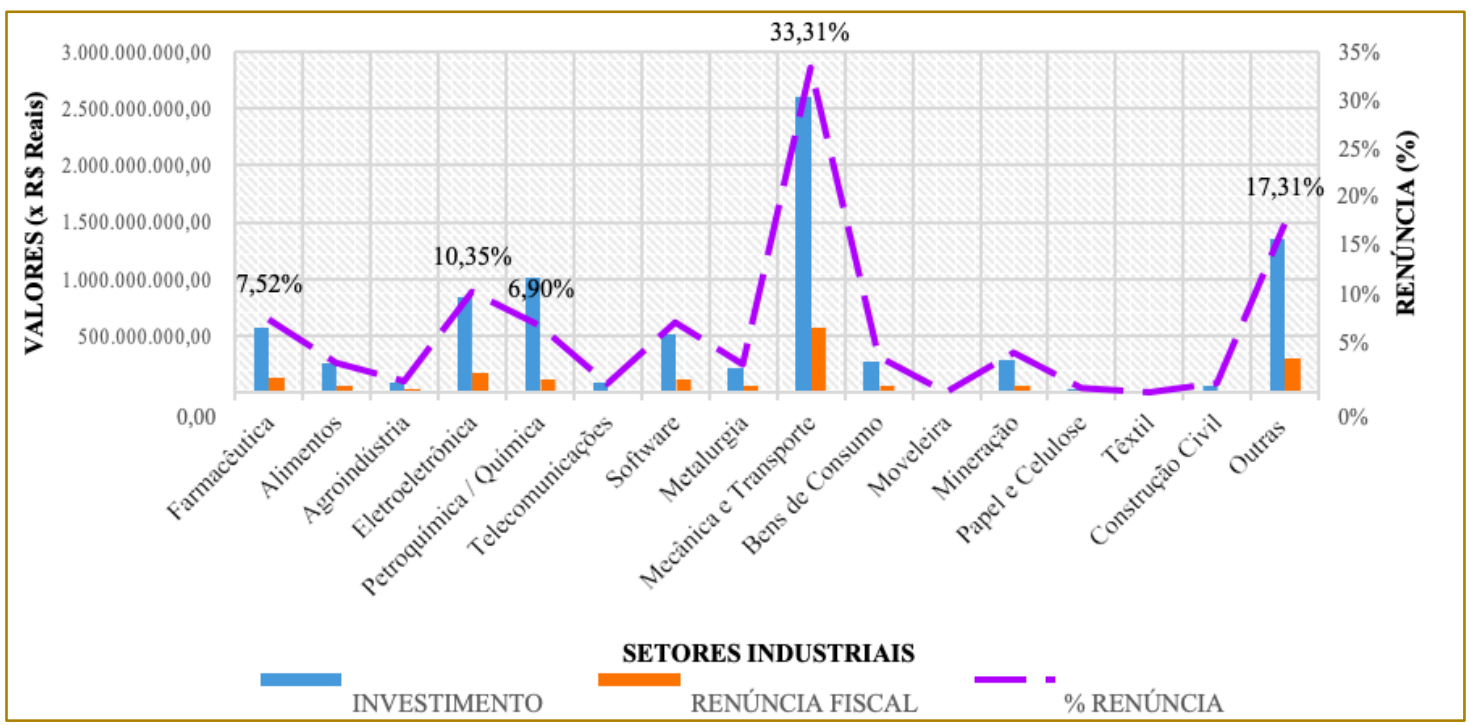

Fonte: Adaptado do "Relatório Anual Lei 11.196/05 - Ano-Base 2014" publicado no site do MCTIC. Nota: os valores são recomendados após análise do MCTIC.

Nota-se que os setores Mecânica e Transporte (33,31\%), Eletroeletrônica $(10,35 \%)$, Farmacêutica (7,52\%) e Petroquímica/Química (6,90\%), foram os que mais investiram em pesquisa tecnológica e desenvolvimento de inovação tecnológica e, consequentemente, os que mais demandaram incentivos fiscais de P\&D neste ano. 
Na Fig. 6 apresenta-se a evolução histórica do investimento total em P\&D (custeio e capital) pela renúncia fiscal às empresas incentivadas na Lei do Bem nos últimos 10 anos de vigência da lei.

Fig. 6. Evolução histórica do investimento vs renúncia fiscal.

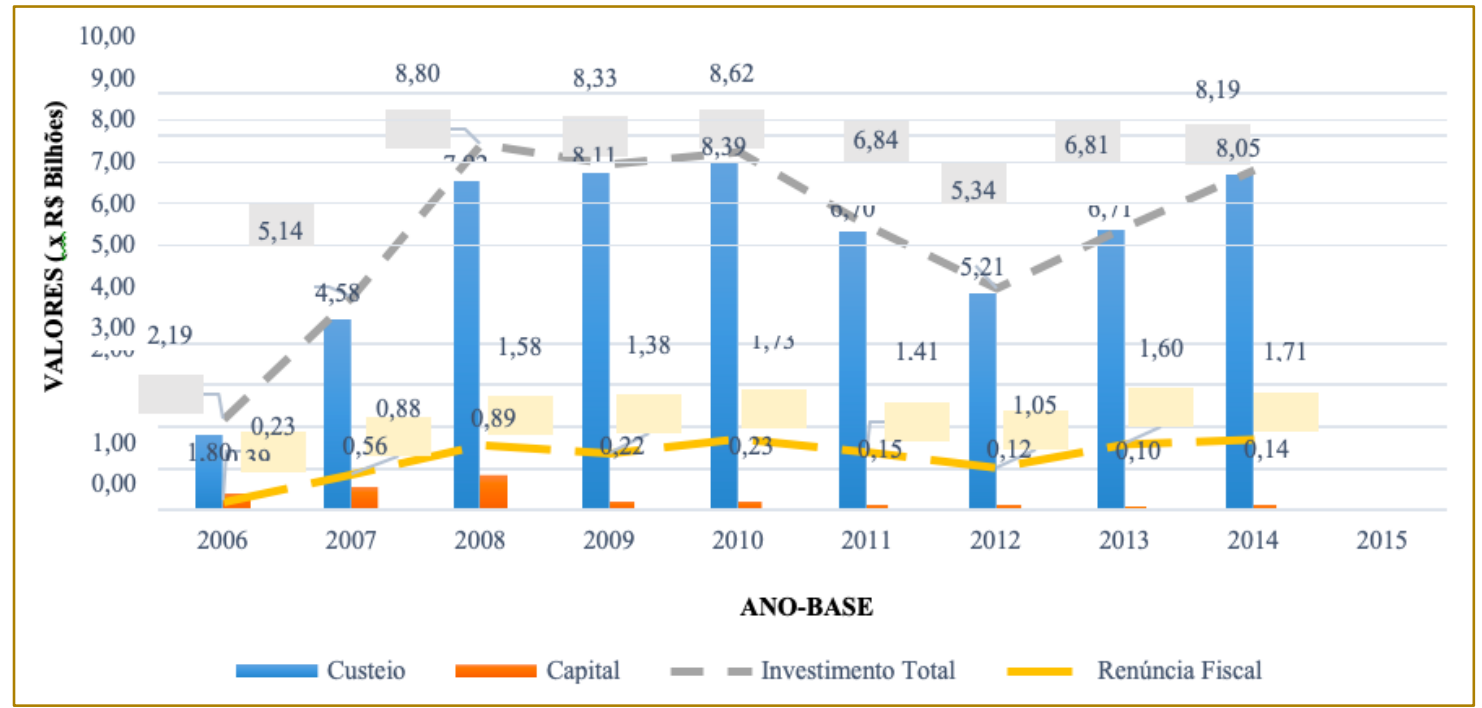

Fonte: Adaptado do "Relatório Anual Lei 11.196/05" publicado no site do MCTIC.

Nota: os valores são recomendados após análise do MCTIC.

Percebe-se uma variação significativa do investimento das empresas e da renúncia fiscal do governo federal em todo período. O incentivo fiscal de $P \& D$ público exerce uma influência positiva no aumento do investimento privado. Entre 2006 e 2010 o investimento se manteve com variações crescentes, mas a partir de 2011 observase uma queda anual que pode ser justificada pelo aumento significativo do número de empresas participantes, i. e, cerca de 58\% no período de 2010 a 2014 (Fig. 2). Como os investimentos não acompanham o mesmo crescimento proporcional de empresas, registrou-se queda neste período de $-4,92 \%$. A retração do investimento também está relacionada com sucessivas instabilidades no cenário macroeconômico neste período.

Comparando os anos de 2006 e 2014, os dispêndios privados em P\&D aumentaram da ordem de 3,74 vezes (374\%) e a renúncia fiscal aumentou da ordem de 7,43 vezes (743\%). O aumento do investimento em P\&D demonstra um esforço tecnológico bastante relevante das empresas, que nesse caso, os benefícios gerados compensaram os custos das perdas de receita (renúncia fiscal) do governo. Em consonância com pensamento de Zucoloto (2012), as empresas nacionais estão acreditando no diferencial da inovação como o principal determinante do aumento da produtividade e da geração de novas oportunidades de investimento no país.

\subsection{O DESAFIO}

Apesar dos indicadores de resultado apresentarem evidências positivas do impacto dos incentivos fiscais de P\&D sobre o aumento dos investimentos privados em inovação, o resultado tem sido antagônico e não muito satisfatório ainda. A Fig. 5 notadamente comprova que a Lei do Bem reduziu obstáculos à inovação no Brasil e simplificou o acesso aos incentivos fiscais aplicáveis a qualquer pessoa jurídica que desenvolva, por si ou mediante contrato com ICT ou empresa de pequeno porte, atividades de P\&D. Assim como trouxe uma diversificação do número de empresas usuárias dos incentivos dentre os mais variados setores e portes, um dos principais pré-requisitos da lei (Tabela 2) é favorecer de forma mais eletiva as grandes empresas que optaram pelo sistema de tributação com base no Lucro Real.

Neste sentido, considerando apenas as empresas da modalidade de Lucro Real no país, o número de empresas incentivadas é 
ainda considerado muito baixo em relação ao total de empresas que deduzem IRPJ e CSLL, conforme demonstrado na Fig. 7.

Fig. 7. Número de empresas por modalidade de tributação no Brasil.

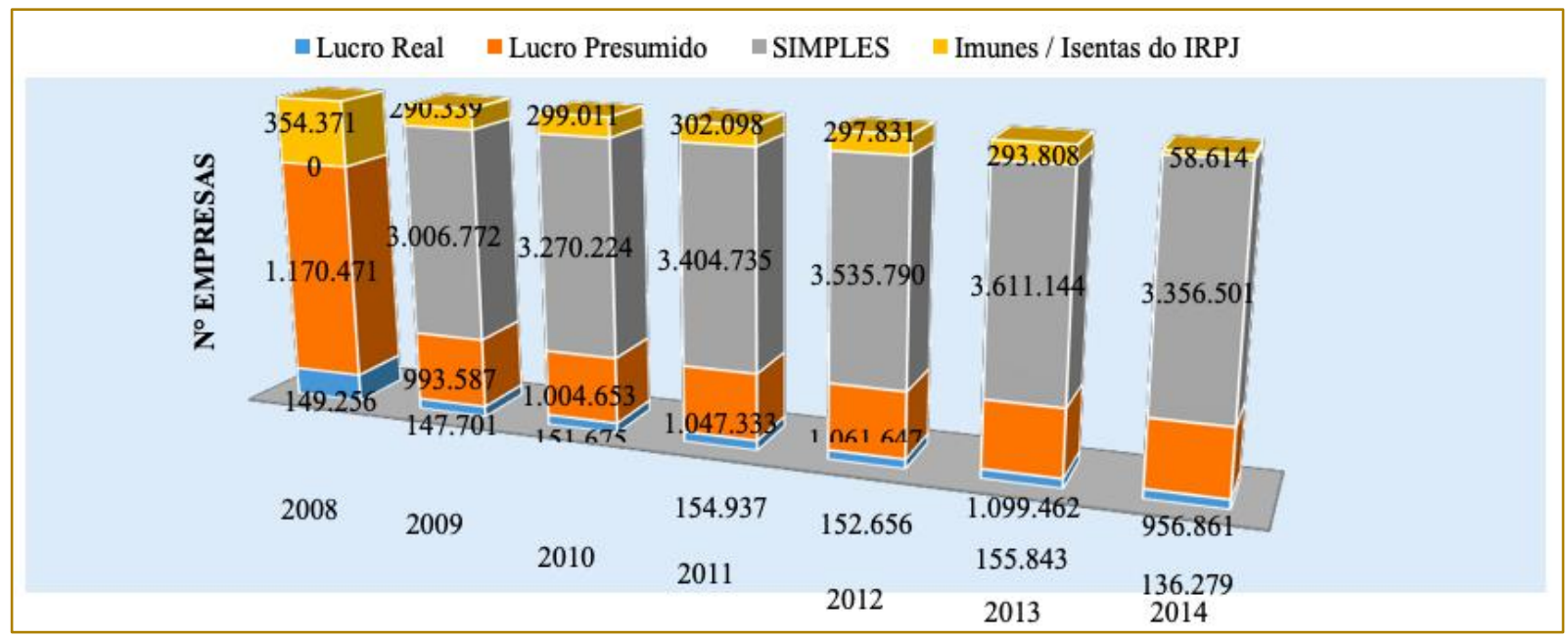

Fonte: Adaptado da CETAD (Estudos diversos - 2008 a 2014) da SRF/MF (2016).

Nota: 2014 são dados preliminares.

Nota-se no ano de 2014 que aproximadamente $136 \mathrm{mil}$ empresas deduziram IRPJ e CSLL na modalidade de Lucro Real no Brasil. Chama atenção o fato de um pequeno número de empresas declararem usuárias da Lei do Bem (1.158 em 2013 e 1.206 em 2014, conforme Fig. 3), representando um percentual muito abaixo de utilização da lei (Fig. 8) sobre o total de empresas.

Fig. 8. Número de Empresas no Regime Lucro Real e Incentivadas pela Lei do Bem

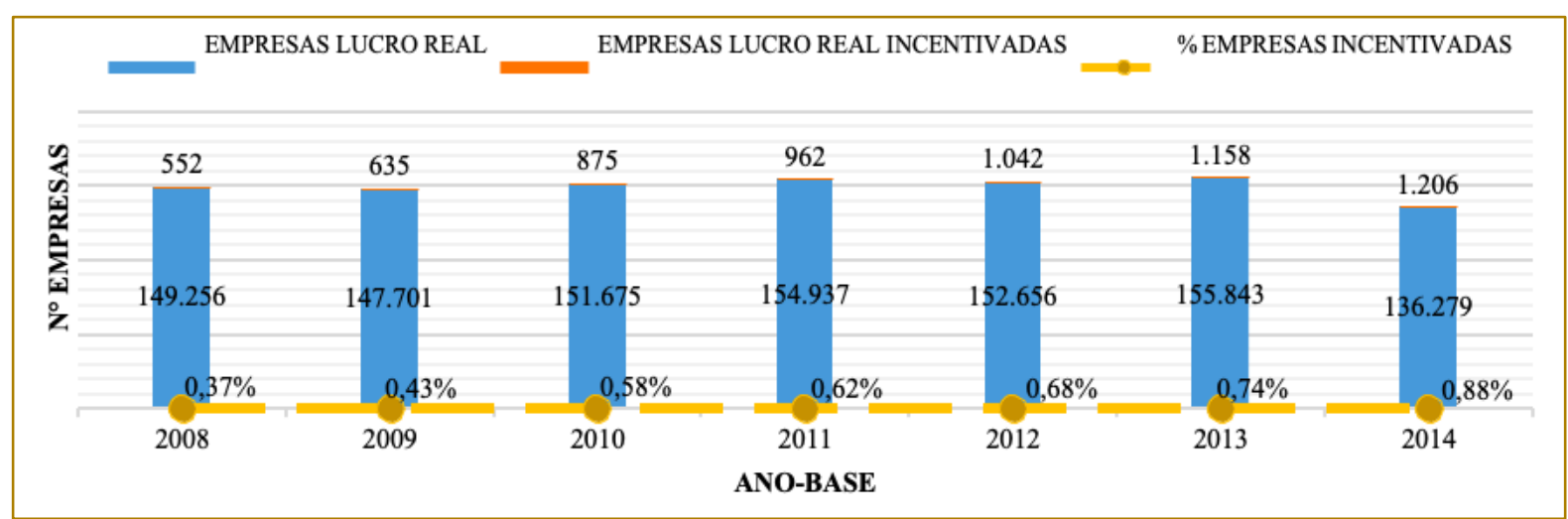

Fonte: Adaptado da CETAD (Estudos Diversos - 2008 a 2014) da SRF/MF (2016) e do MCTIC/SETEC (2016)

O percentual de aproximadamente $1 \%$ de empresas beneficiárias dos incentivos fiscais representa um valor muito baixo em termos de estratégia de uma política pública de fomento à inovação. Excluindo as empresas que não adotam o regime de lucro real, dentre os principais fatores relacionados à baixa utilização da lei, podemos citar alguns relevantes: a falta de conhecimento da legislação; a localização de $94 \%$ das empresas demandantes nas regiões Sudeste e Sul constituí um fator limitante para que os incentivos fiscais possam alcançar um melhor desempenho a nível nacional; a insegurança jurídica da análise ex post do MCTIC - pode haver devolução do incentivo com multa, no caso de não aprovação; impossibilidade de apoiar empresas em situação de prejuízo fiscal no 
ano-base, custos de conformidade pela contratação de consultorias.

A falta de conhecimento acerca da legislação torna-se um dos principais motivos justificados pelas empresas para não utilizarem os incentivos fiscais. Trata-se de uma variável não complexa sensível à alteração, ou seja, com pouco esforço na divulgação do instrumento a demanda de empresas usuárias pode aumentar consideravelmente. Neste sentido, o MCTIC/SETEC vem fazendo um trabalho de divulgação e informação da Lei do Bem entre os mais variados setores produtivos, além de melhorias na transparência de dados no site, incrementos nas informações do FORMP\&D para melhorar a descrição dos projetos e atividades integradas com entidades representativas das indústrias.

Por outro lado, o desafio de ampliar a utilização dos incentivos fiscais de P\&D, por meio do aumento da base de empresas beneficiárias, implica em ações do governo com vistas à consecução deste objetivo. Isto envolve desde a divulgação da Lei do Bem, como o aprimoramento das regras de utilização para aumentar o estímulo das empresas à inovação.

\section{CONSIDERAÇÕES FINAIS}

Após uma década de utilização da Lei do Bem no fomento à inovação no Brasil, apresentamos uma avaliação aparente de sua evolução histórica no período de 2006-2014. Foi analisado o impacto dos incentivos fiscais de P\&D sobre o investimento em inovação no país e, ainda, explorado o resultado da renúncia fiscal e a capacidade de utilização da lei pelas empresas brasileiras no regime de lucro real. A base de dados utilizada foi o

\section{NOTAS}

[1]. IRPJ - Imposto de Renda da Pessoa Jurídica.

[2]. CSLL - Contribuição Social sobre o Lucro Líquido.

[3]. FORMP\&D - Formulário eletrônico de prestação de informações técnicas e financeiras das empresas. É individual e apresenta informações técnicas dos projetos e atividades de P\&D desenvolvidos pelas empresas, bem como os valores de dispêndios em P\&D e os incentivos fiscais apurados no ano calendário. O FORMPD
Relatório Anual dos projetos apresentados no FORMP\&D das empresas ao MCTIC.

Os resultados apresentaram impactos positivos tanto para os dispêndios privados em P\&D, que aumentaram na faixa de 3,74 vezes, quanto para renúncia fiscal do governo, que aumentou na faixa de 7,43 vezes, mas, pouco significativo na utilização da lei pelas empresas, que chegou a registrar um aumento na faixa de 9,28 vezes, representando uma evolução crescente de empresas participantes, porém, quando comparado com a quantidade de empresas que operam no regime de lucro real no Brasil, esse número representa aproximadamente $1 \%$ de utilização, demonstrando um impacto pouco significativo.

No geral, os resultados desta pesquisa demonstram que há uma efetividade da Lei do Bem para o setor industrial em geral e uma percepção de que as empresas estão acreditando que à inovação é o diferencial e a oportunidade de crescimento diante das dificuldades econômicas de mercado, mas que ainda precisa ser aperfeiçoada para alavancar sua utilização e, sobretudo, o fomento à inovação no país.

O maior desafio será criar um ambiente com uma "cultura de inovação empresarial" que favoreça a competição e ao mesmo tempo estimule o aumento da plena utilização da lei no país. A perspectiva é positiva, já que as empresas incentivadas apresentam várias vantagens em relação as não incentivadas, como: melhoria da produtividade, recursos humanos mais qualificados, maior eficiência em projetos, melhor desempenho financeiro, possibilidade de apresentar maior rentabilidade, efetividade no custo-benefício e aumento do estímulo à inovação.

pode ser acessado diretamente no site do MCTIC: http://www.mctic.gov.br/mctic/opencms/tecnologia/ incentivo_desenvolvimento/lei_bem/Lei_do_Bem.ht $\mathrm{ml}$.

[4]. MCTIC - Ministério da Ciência, Tecnologia, Inovações e Comunicações, é o órgão governamental responsável pela gestão da Lei do Bem.

[5]. Manual de Oslo - principal documento de referência internacional para análise de dados relacionados às atividades de inovação. Em 2005 
expandiu o conceito de inovação incluindo o setor de serviços.

[6]. Manual de Frascati (2015) - 1a versão criada em 1963 na Itália e 7a versão publicada em 2015 pela OECD - é fonte de referência internacional para a padronização dos conceitos de inovação, como as terminologias utilizadas pelos pesquisadores de diversos países membros da OECD. Auxilia o entendimento geral da importância da PD\&l como elementos-chave das economias baseadas em conhecimento, possibilitando a comparação e o monitoramento estatístico econômico das ações de inovação de diversos países.

\section{REFERÊNCIAS}

[9]. BRASIL. Presidência da República. Lei Federal n 10.973, de 2 de dezembro de 2004. Dispõe sobre a lei da inovação. Disponível em: $<$ http//www.planalto.gov.br>. $\quad$ Acesso em: 21/12/2016

[10]. BRASIL. Presidência da República. Lei Federal no 13.243, de 11 de janeiro de 2016. Dispõe sobre o marco legal da CT\&I. Disponível em: <http//www. planalto.gov.br>. Acesso em: 21/12/2016

[11]. BRASIL. Presidência da República. Lei Federal $n^{\circ}$ 11.196, de 21 de novembro de 2005. Dispõe sobre a Lei do Bem, Incentivos Fiscais à Inovação Tecnológica, Cap. III, arts. 17 a 26. Disponível

em:<http://www.mctic.gov.br/mctic/opencms/tecnolog ia/incentivo_desenvolvimento/lei_bem/Lei_do_Bem.ht $\mathrm{ml}$. Acesso em: 21/12/2017.

[12]. BRASIL. Presidência da República. Decreto Federal $n^{\circ}$ 5.798, de 7 de junho de 2006. Regulamenta os incentivos fiscais da Lei do Bem. Disponivel em: $<$ http://www.mctic.gov.br/mctic/opencms/tecnologia/in centivo_desenvolvimento/lei_bem/Lei_do_Bem.html >. Acesso em: 21/12/2017.

[13]. BRASIL. Presidência da República. IN RFB $n^{\circ} 1.187$, de 29 de agosto de 2011. Disciplina os arts. 17 a 26 da Lei do Bem. Disponível em: $<$ http://www.mctic.gov.br/mctic/opencms/tecnologia/in centivo_desenvolvimento/lei_bem/Lei_do_Bem.html > . Acesso em: 21/12/2017.

[14]. BRASIL. Presidência da República. Decreto Federal $n^{\circ} 3.000$, de 26 de março de 1999. Regulamenta o Imposto sobre a Renda. Disponível em: <http//www.planalto.gov.br>. Acesso em: 21/12/2016.

[15]. BUENO, A.; TORKOMIAN, A. L. V. Financiamentos à inovação tecnológica: reembolsáveis, não reembolsáveis e incentivos fiscais. RAl - Revista de Administração e Inovação, São Paulo, v.11, n.4, pp. 135- 158, out./dez. 2014. ISS 1809-2039. Disponível em:
[7]. Relatório Anual de Atividades de P\&D - é o relatório anual da avaliação ex post das informações técnicas e financeiras dos projetos desenvolvidos pelas empresas no ano-base de referência, com indicadores de resultado e de incentivos concedidos, divulgado pelo MCTIC no site:

http://www.mctic.gov.br/mctic/opencms/tecnologia/ incentivo_desenvolvimento/lei_bem/Lei_do_Bem.ht $\mathrm{ml}$.

[8]. Decreto $n^{\circ} 5.798$, de 07 de junho de 2006, que regulamenta o Capítulo III da Lei do Bem, que é esclarecido pela IN RFB $n^{\circ} 1.187$, de 29 de agosto de 2011.

https://doi.org/10.11606/rai.v11i4.100276. Acesso em 06 fev 2018.

[16]. CETAD - Centro de Estudos Tributários e Aduaneiros. Estudos e Estatísticas - Estudos Diversos. Ministério da Fazenda (MF) - Secretaria da Receita Federal do Brasil (SRF). Brasília-DF, $2016 . \quad$ Disponivel em: <http://idg.receita.fazenda.gov.br/dados/receitadata/e studos-e-tributarios-e-aduaneiros/estudos-eestatisticas/estudos-diversos>. Acesso em: 22/12/2016.

[17]. CHRISTENSEN, C. M. O Dilema da Inovação: quando as novas tecnologias levam empresas ao fracasso. São Paulo: Makron Books, 2012.

[18]. EUROPEAN COMMISSION. A Study on R\&D Tax Incentives - Final Reports. TAXATION PAPERS. Taxation and Customs Union. Working Paper N. 52-2014. Holanda, 2014.

[19]. GUIMARÃES, E. A. Políticas de inovação: financiamento e incentivos. Em J. A. De Negri; L. C. Kubota (Eds). Políticas de incentivo à inovação tecnológica no Brasil. Brasília: IPEA, p. 149-228, 2008.

[20]. INSTITUTO DE PESQUISA ECONÔMICA APLICADA - IPEA. Inovação no Brasil: Crescimento Marginal no Período Recente. Nota Técnica $n^{\circ} 34$. Brasília, dezembro de 2016. Disponível em: $<$ http//www.ipea.gov.br/portal/images/stories/PDFs/ nota_tecnica/20161209_nt_34.pdf>. Acesso em: 22/12/2016

[21]. IZIQUE, C. Pedras no caminho - falta de informação compromete investimentos de empresas em inovação. Pesquisa FAPESP. São Paulo, Ed. 139, Setembro 2007. Disponível em: <http://revistapesquisa.fapesp.br/=>. Acesso em: 27/11/2015

[22]. JUGEND, D.; DA SILVA, S. L. Inovação e Desenvolvimento de Produtos: práticas de gestão e casos brasileiros. Rio de Janeiro: LTC, 2013. 
[23]. KANNEBLEY JR., S.; SHIMADA, E.; DE NEGRI, F. Efetividade da Lei do Bem no Estímulo aos Dispêndios em P\&D: uma análise com dados em painel. Pesquisa e Planejamento Econômico PPE, v. 46, n. 3, dez. 2016.

[24]. KANNEBLEY JR., S.; PORTO, G. S. Incentivos Fiscais à Pesquisa, Desenvolvimento e Inovação no Brasil: uma avaliação das políticas recentes. Washington: IDB, 2012. (IDB Publications, n. 326). Banco Interamericano de Desenvolvimento - BID. São Paulo, 2012. (Documento para Discussão BID, IDB-DP-236).

[25]. MINISTÉRIO

$\mathrm{DA}$

CIÊNCIA, TECNOLOGIA E INOVAÇÃO - MCTI. Estratégia Nacional de Ciência, Tecnologia e Inovação 2012-2015. Brasília: MCTI, 2011. Disponível em: <http://www.mct.gov.br/upd_blob/0218/218981.pdf >. Acesso em: 22/12/2016.

[26]. MINISTÉRIO DA CIÊNCIA, TECNOLOGIA, INOVAÇÕES E COMUNICAÇÕES - MCTIC. Relatório Anual de Atividades de P\&D e Utilização dos Incentivos Fiscais. Anos de 2006 a 2014. Brasília: MCTIC, 2016. Disponível em: <http://www.mctic.gov.br/mctic/opencms/tecnologia/in centivo_desenvolvimento/lei_bem/Lei_do_Bem.html.>. Acesso em: 22/12/2017.

[27]. MINISTÉRIO DA CIÊNCIA, TECNOLOGIA E INOVAÇÃO - MCTI. Indicadores selecionados de Ciência, Tecnologia e Inovação. Brasil 2015. Disponível em: <http://www.mct.gov.br/upd_blob/0237/237254.pdf >. Acesso em: 22/12/2016.

[28]. OECD - Organization for Economic Cooperation and Development. Manual de Oslo Proposta de Diretrizes para Coleta e Interpretação de Dados sobre Inovação Tecnológica. European Commission, 1997. Disponível em: <http://www.finep.gov.br/imagens/apoio-efinanciamento/manualoslo.pdf $>$. Acesso em: 22/12/2016.

[29]. OECD - Organization for Economic Cooperation and Development. Oslo Manual Guidelines for Collecting and Interpreting Innovation Date, 3rd Edition Organization for Economic Cooperation and Development (OECD), European Commission, 2005. Acesso em: 22/12/2016

[30]. OECD - Organization for Economic Cooperation and Development. OECD Science, Technology and Industry Scoreboard 2015. Innovation for Growth and Society. OECD publishing. Paris, 2015. DOI: Disponível em: <http://dx.doi.org/10.1787/sti_outlook-2014-en>. Acesso em: 22/12/2016.

[31]. OECD - Organization for Economic Cooperation and Development. OECD Science, Technology and Industry Outlook 2014. OECD publishing. Paris, 2014. DOI: Disponível em: <http://dx.doi.org/10.1787/sti_scoreboard- 2015en.> Acesso em: 22/12/2016.

[32]. PARDO, M. Competición y Gestión Tecnológica. In: XVIII Simpósio de Gestão da Inovação Tecnológica, São Paulo, 1994.

[33]. SCHUMPETER, J. A teoria do desenvolvimento econômico: uma investigação sobre os lucros, capital, crédito, juro e o ciclo econômico. Coleção os Economistas. 3ª . ed. São Paulo: Nova Cultural, 168p., 1988.

[34]. ZUCOLOTO, G. F. Origem de capital e acesso aos incentivos fiscais e financeiros à inovação no Brasil. Texto para Discussão. IPEA, ed. 1753. Brasília, 2012. Disponível em: <http://www.ipea.gov.br/portal/images/stories/PDFs /TDs/td_1753.pdf>. Acesso em: 23/12/2016. 


\section{Gapítulo 14}

\section{GESTIÓN DE LA INNOVACIÓN SOCIAL COMO FACTOR DE COMPETITIVIDAD}

Sâmia Laíse Manthey Benevides

Flávio de São Pedro Filho

José Moreira da Silva Neto

Fábio Biasotto Feitosa

Jackson José Sales Miranda Júnior

Resumen: Esta investigación pretende comprender la relación existente entre la innovación social y la competitividad. Para tanto, evaluó la gestión de la innovación social como factor de promoción de la competitividad en una organización de economía mixta ubicada en Rondonia. El problema planteado fue: ¿Como la gestión de la innovación social puede contribuir para la promoción de la competitividad organizacional? Como objetivos específicos: Identificar las dimensiones de la gestión de la innovación social frente a los factores de competitividad organizacional (1); Analizar críticamente las dimensiones de la gestión de la innovación social válidas para el alcance de la competitividad organizacional (2) Proponer directrices para la gestión de la innovación social válidas para la competitividad organizacional (3). El eje teórico fue la teoría del Desarrollo Organizacional. Se trata de una investigación exploratoria, cuyo problema se abordó mediante el método mixto y la aplicación del método de estudio de caso con el uso del cuestionario, observación que participante y análisis de documentos para la colecta de datos. El análisis paraconsistente fue basado en el análisis de contenido de la interpretación de datos cualitativos. La Trabajo identificado, describió y determinó las dimensiones de la innovación social y los factores de competitividad. Propuso como pautas la gestión de los factores internos y externos de forma participativa; La adopción de una estrategia flexible con inclusión de la responsabilidad social de la responsabilidad empresarial, promoción del valor compartido; o la gestión de la innovación.

Palabras clave: Gestión; Innovación; Innovación social; Competitividad. 


\section{INTRODUCCIÓN}

El enfoque de las estrategias organizativas ha disminuido en la competitividad y la innovación tecnológica con fines económicos. Sin embargo, la investigación en Bignetti (2011) señala la importancia de una gestión que contempla aspectos del desarrollo social. Estudios en Gabriele (2012) indican que la inversión en acciones socioambientales reduce costes y riesgos, aumenta la calidad, identifica oportunidades y desarrolla ventajas competitivas. La indicación es que las empresas adopten una postura proactiva en cuanto a a la sostenibilidad, buscando más allá del retorno financiero, una imagen positiva y un diferencial competitivo. A pesar de la inversión para incorporar la sostenibilidad en la estructura, el aspecto social sigue siendo minimizado en la gestión. Para Porter y Kramer (2006), Munck, Munck y Souza (2011), la inclusión del aspecto social en la estrategia, la gestión y las acciones organizativas es todavía compleja. Para João (2014) la innovación social contribuye al desarrollo del aspecto social en el ámbito académico, gubernamental y empresarial; es capaz de desarrollar actividades y servicios motivados por objetivos sociales en respuesta a la demanda de la sociedad de resolver los problemas de manera sustentable.

\section{REVISIÓN TEÓRICO-CONCEPTUAL}

Para Dias, Zack y Cassar (2013) la Teoría del Desarrollo Organizacional tiene como objetivo armonizar los métodos de producción a las personas, desarrollar la formación y crear patrones de rendimiento que favorezcan el alcance de la flexibilidad y la adaptación a los cambios de la sociedad. El mantenimiento de la competitividad organizacional requiere organizacionales a través de la inversión en la estructura, el comportamiento de las personas o ambos. Para promover la interdependencia, realizar el diagnóstico, intervenir en estructura y comportamiento, promover el cambio y cumplir los objetivos es necesario: (1) centrarse en los factores ambientales e identificar los impactos para la organización y sus valores sociales; (2) absorber el impacto ambiental y desarrollar características tales como dinamismo y flexibilidad; (3) identificar y considerar al grupo social en aspectos como el liderazgo, la comunicación, las relaciones interpersonales, los conflictos; y (4) destacar las motivaciones, actitudes, necesidades y objetivos de las personas.

\subsection{CONCEPTOS DE COMPETITIVIDAD INNOVACIÓN E INNOVACIÓN SOCIAL}

Según Castro, Santos, Silva (2008) y Roman et al. (2012) el factor de competitividad es la base de la acción; son aspectos que contribuyen a la mejora organizacional y aumento de la performance, por lo cual la organización necesita destacarse. Para Roman et al. (2012), la ventaja competitiva se adquiere mediante la relación de conocimientos con la innovación, la estructura organizativa flexible y adaptable a los cambios de entorno.

Para Sanmartin (2012), la innovación es el resultado de un proceso sistematizado, organizado, controlado y medido. La gestión estratégica de la innovación debe tener objetivos claros y concretos, con plazos, responsabilidades, acciones y métricas o criterios para evaluar el proceso. Para Tidd y Bessat (2015) las fases de gestión de la innovación incluyen: (1) la búsqueda de nuevas ideas en el escenario interno y externo con signos de amenazas y oportunidades; (2) selección y elección estratégica de ideas centradas en la competitividad; (3) Implementación o transformación de la idea en realidad; (4) captura de valor que garantice la justificación de los esfuerzos y a través de este modelo se pretende gestionar el proceso de innovación. Los fracasos están en cómo se gestiona el proceso de innovación, estando el suceso relacionado tanto con las fuentes técnicas y las competencias de la organización para gestionarla.

Murray, Grice y Mulgan (2010) definen la innovación social como nuevas y/o adaptadas ideas, prácticas, enfoques o intervenciones traducidas en productos, servicios $\mathrm{O}$ modelos que satisfagan una necesidad, resuelvan problemas, transformen o creen relaciones sociales y redes de colaboración. Innovaciones que surgen de mejorar la capacidad de actuar en la sociedad, transformar las relaciones sociales a través de la inclusión, generación de Trabajar y mejorar las condiciones de vida. La innovación social presentada en Cañete-Santana (2014) está relacionada con el cambio de rutina, los recursos, las relaciones de poder, las creencias del sistema social, no se caracterizan como un instrumento de estandarización. 
Conforme Maurer (2011) y Maurer y Silva (2014) la dimensión de transformación se refiere al entorno cuya innovación social se desarrolla en respuesta a la situación de crisis en un determinado sector. La dimensión innovadora del carácter se refiere a la acción social que impulsa la innovación y sus modelos derivados de la implementación y difusión. El contexto con sus crisis impulsa la acción de los actores para remediar el problema. La solución debe ser sin precedentes, pasar por pruebas, experimentos. Pueden ser representantes de la sociedad civil, empresas, organizaciones de economía social, emprendimientos colectivos y beneficiarios de empresas. Y finalmente la dimensión del proceso es según los autores, de los modos de coordinación, los medios involucrados y restricciones a la implementación de una innovación social.

\section{METODOLOGIA}

Estudio en Gil (2010) indicó tratarse de una investigación exploratoria, cuyo problema fue abordado por el método mixto como Creswel (2010) y por la aplicación del método de estudio de caso como indicado en Creswell (2014) y Yin (2010). Los procedimientos utilizados para la recopilación de datos fueron el cuestionario, la observación de los participantes y el análisis de los documentos. El análisis basado en el análisis cuantitativo de los datos y la validación del instrumento como indicaciones de Sanches, Meireles, Sordi (2011) y el análisis de contenido de la interpretación de los datos cualitativos como puntuado en Bauer y Gaskell (2010). También se empleó el método de análisis de contenido, como pontuado en Bauer y Gaskell (2011). Se adoptó para Escala Likert de cinco puntos en los que los encuestados presentaron su grado de acuerdo o desacuerdo. Para análisis de documentos se empleó la evaluación de resoluciones manuales, normas, reglamentos y el informe socioambiental.

Basado en Oliveira (2001) la muestra fue clasificada como no-probabilítica para la conveniencia. Los encuestados eran los 384 empleados de Porto Velho del cual se obtuvieron 69 respuestas; 42 empleados externalizados siendo 23 asistentes, 14 Limpieza y 5 del mantenimiento del edificio obteniendo 42 respuestas; De los 140.000 clientes de Porto Velho aplicó 100 cuestionarios con respuesta a 69 de ellos; de 437 proveedores con contratos existentes en el país, se remitió un cuestionario a 100 con una respuesta de 10; Contactó a los 34 representantes sindicales del estado con una respuesta de 10.

\section{RESULTADO}

En la organización estudiada el Consejo Ejecutivo es responsable de la orientación estratégica, definición de objetivos y metas, estandarización y normalización de procedimientos, control de gestión de 17 departamentos, 58 oficinas comerciales, 694 empleados propios y estimados 1.500 empleados externalizados en el estado. Se constató que en relación con los elementos institucionales que las estrategias de 2014 a 2018 contemplan acciones que visan el alcance alcance económico, no se prevén las cuestiones sociales y medioambientales, que están en divergencia con la misión, visión y valores y la propia política de responsabilidad social corporativa de la empresa, siguiendo el camino contrario de lo que recomiendan Porter y Kramer (2006) y Gabriele et al (2012).

\subsection{IDENTIFICACIÓN DE LAS DIMENSIONES EN EL CONTEXTO DE LA GESTIÓN DE LA INNOVACIÓN SOCIAL EN LA CARA DE LOS FACTORES DE COMPETITIVIDAD ORGANIZACIONAL}

Después de la aplicación se analizaron las proposiciones con menor grado de concordancia, indicando las características que la organización necesita para mejorar en cada dimensión para promover la innovación social. Los datos detallados por dimensión y stalkeholder están presentes en Benevides (2017). Los resultados sintetizados se encuentran en el Cuadro 1. 
Cuadro 1- El menor grado de acuerdo Respondedores en relación a las dimensiones de la innovación social

\section{Transformación}

1.1 identificar un problema del cliente y de los contratistas;

1.2 Satisfacer la expectativa del cliente;

1.3 Ofrecer a empleado motivado para satisfacer al cliente;

1.4 Minimizar los procesos de exclusión y marginación (contratistas);

1.5 Reconocer el papel de los individuos (contratistas);

1.6 Conocer y satisfacer las necesidades de los representantes sindicales y de los proveedores;

\section{Carácter innovador}

Satisfacer a los clientes en relación con el costo del servicio, la velocidad de asistencia y la resolución del problema;

Desarrollar modelos e innovaciones para remediar los problemas del empleado y de terceros;

Innovar para satisfacer una necesidad de los contratistas;

Adoptar un modelo de gestión de la innovación;

Cumplir los plazos con el sindicato;

\section{Innovación}

Garantizar la seguridad de lo que se cobra en relación con el servicio prestado;

Garantizar la seguridad en los servicios al cliente;

Innovar para cubrir la necesidad del cliente;

Difundir políticas de responsabilidad social entre los clientes;

Innovar utilizando recursos comunitarios locales;

Invirtiendo en las condiciones de trabajo de contratistas;

Mejorar los servicios para cumplir objetivos individuales;

Desarrollar la innovación conjunta con la Unión.

\section{Actores}

Establecer una relación de confianza y cooperación con los clientes y el sindicato;

Garantizar la seguridad de los datos de los clientes;

Difundir la visión futura de la organización entre los contratistas;

Considerar la cultura organizacional de la Interesadas En la toma de decisiones;

Gestionar conflictos de intereses; Establecer la confianza, el respeto a la ideología con la Unión;

\section{Proceso}

Interactuar y coordinar innovaciones conjuntamente con el cliente y la Unión;

Buscar flexibilidad para modificar las normas y estándares en relación con los clientes, empleados, sindicatos y proveedores;

Un espacio en la organización para la reflexión.

Fuente: Elaborado por los autores (2017).

El mismo criterio se llevó a cabo para identificar los más pequeños grados de acuerdo de los factores de competitividad indicados por Roman et al. (2012). la síntesis está en el Cuadro 2. 
Cuadro 2- Menor grado de Acuerdo de Respuesta a los factores de competitividad

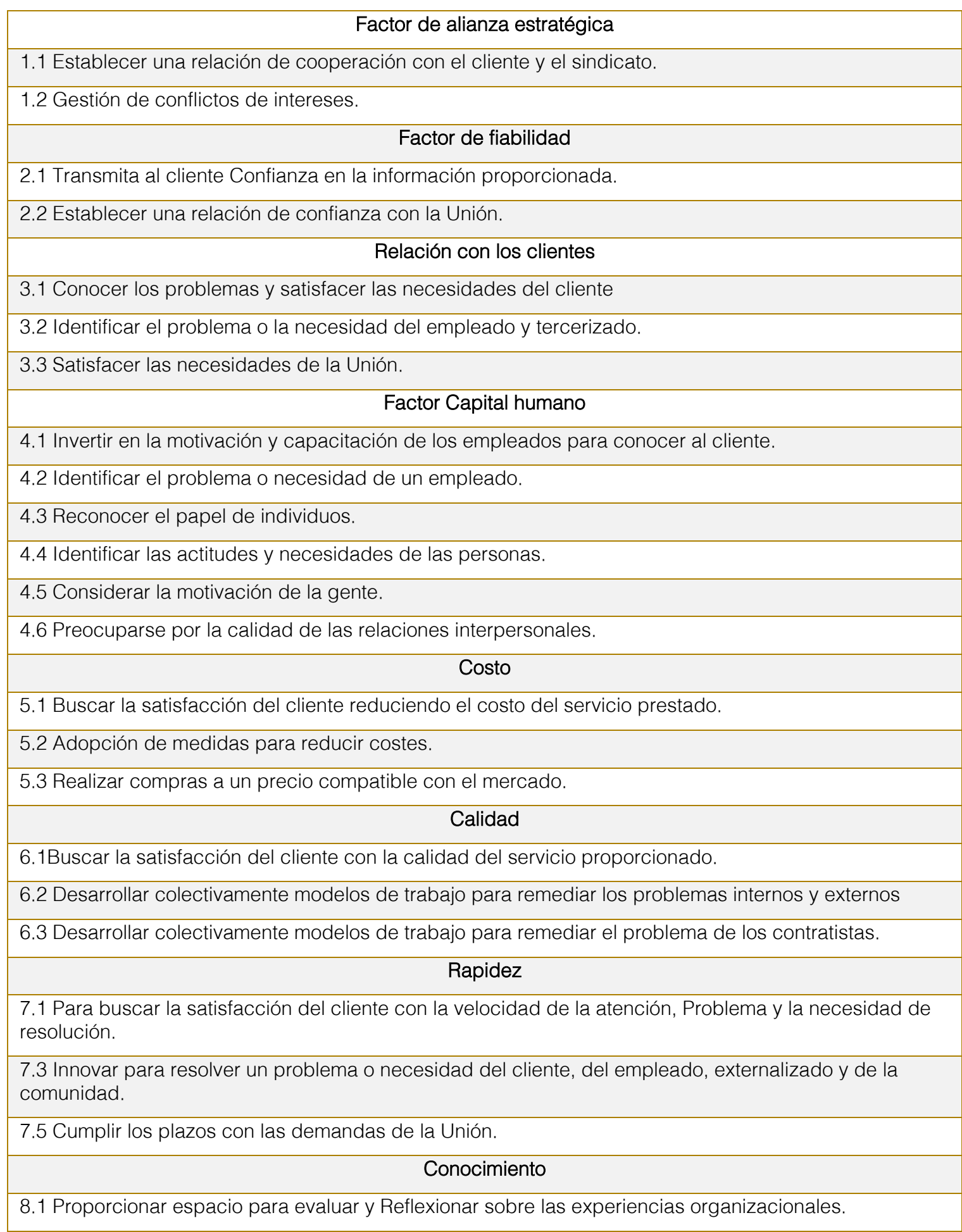


Continuação...

\begin{tabular}{|c|}
\hline Flexibilidad \\
\hline 9.1 Mantener una postura flexible ante el medio ambiente para lograr sus objetivos. \\
\hline 9.2 Buscar flexibilidad para negociar con el sindicato, el cliente y el empleado. \\
\hline Innovación \\
\hline 10.1 Desarrollar innovaciones para satisfacer las necesidades de los clientes. \\
\hline 10.2 Desarrollar un modelo para gestionar la innovación de forma integrada. \\
\hline 10.3 Desarrollar innovaciones en conjunción con la Unión para interesar ambas. \\
\hline Factores culturales \\
\hline 11.1 Establecer una relación de cooperación con el cliente. \\
\hline 11.2 Modificar o reconstruir su cultura a nivel regional para enfrentar problemas. \\
\hline 11.3 Respetar la ideología y los valores de la Unión. \\
\hline Responsabilidad social \\
\hline $\begin{array}{l}\text { 12.1 Sensibilizar a los clientes sobre la importancia de invertir en cuestiones sociales o } \\
\text { medioambientales. }\end{array}$ \\
\hline 12.2 Priorizar la compra de recursos y suministros de la comunidad local. \\
\hline Tecnologías de la información y la comunicación-TIC \\
\hline 13.1 Disponer de tecnología Para facilitar el servicio al cliente y la comunicación. \\
\hline
\end{tabular}

Fuente: Elaborado por los autores (2017).

\subsection{ANÁLISIS CRÍTICO DE LAS DIMENSIONES DE LA GESTIÓN DE LA INNOVACIÓN SOCIAL QUE SON VÁLIDAS PARA EL ALCANCE DE LA COMPETITIVIDAD ORGANIZACIONAL}

En esta sección las dimensiones de la innovación social serán comparadas con los factores de competitividad que apuntan a identificar características e investigar la relación entre los conceptos. Esta correlación se llevó a cabo mediante análisis de contenido basado en Bauer y Gaskell (2010). Así, las dimensiones de la innovación social y los factores de competitividad fueron sistemáticamente identificadas y relacionadas por la correlación de significados y conceptos presentados en el cuadro 8.

La relación descrita es la capacidad de la organización para identificar problemas, crisis sociales o económicas que requieren cambios para la atención de los clientes y empleados. Capacidad de adaptarse, modificar, cambiar las relaciones de trabajo, producción o consumo para satisfacer los intereses de ambos, minimizando la exclusión y la marginación. Cuando la organización crea mecanismos estructurales, procedimentales o culturales que incluyan al interesado, promoverá acciones que conduzcan a la innovación y la competitividad como en el Cuadro. 
Cuadro 3- Relación de la dimensión innovadora del carácter con los factores de la competitividad

\begin{tabular}{|c|c|c|}
\hline $\begin{array}{c}\text { Descripción de la } \\
\text { dimensión innovadora } \\
\text { del carácter }\end{array}$ & $\begin{array}{l}\text { Factores de } \\
\text { competitividad }\end{array}$ & Descripción de los factores de competitividad \\
\hline \multirow{4}{*}{$\begin{array}{l}\text { Crear modelos de } \\
\text { trabajo, desarrollo y } \\
\text { gobernanza, generando } \\
\text { Un know-how y un } \\
\text { conocimiento conjunto y } \\
\text { social capaces de ser } \\
\text { probados, } \\
\text { experimentados y si } \\
\text { favorables, extendidos a } \\
\text { través de políticas, } \\
\text { programas, arreglos } \\
\text { institucionales y } \\
\text { regulación social. }\end{array}$} & Costo & $\begin{array}{l}\text { El desarrollo o la alteración del proceso que apunta a un } \\
\text { bajo costo, Puntualidad en la prestación de servicios y } \\
\text { garantía de calidad. Acciones para reducir residuos. }\end{array}$ \\
\hline & Calidad & $\begin{array}{l}\text { Satisfacer las expectativas de los clientes en los } \\
\text { servicios. Adoptar programas para controlar y reducir } \\
\text { errores. }\end{array}$ \\
\hline & Rapidez & $\begin{array}{l}\text { Administre el tiempo para asegurar la Velocidad de la } \\
\text { entrega del servicio; Responder rápidamente a los retos } \\
\text { y problemas. Reduzca el flujo de información, } \\
\text { materiales y operaciones para optimizar el tiempo. }\end{array}$ \\
\hline & $\begin{array}{l}\text { Tecnología de la } \\
\text { información y la } \\
\text { comunicación }\end{array}$ & $\begin{array}{l}\text { Para evitar riesgos, controlar, registrar y gestionar las } \\
\text { informaciones para crear soluciones. tienen sistema } \\
\text { para calcular datos y facilitar la comunicación. }\end{array}$ \\
\hline
\end{tabular}

Fuente: Adaptación de Maurer y Silva (2014) y Roman et al. (2012).

Los enlaces de enlace mostrados en el cuadro 5 tienen la capacidad de desarrollar modelos de trabajo y gobernanza para remediar los problemas, generar conocimientos que promuevan los beneficios sociales o económicos, y que puedan ser diseminados a otros contextos. Cuando Esta lógica se aplica para reducir costos, mejorar el servicio o la calidad del proceso, reducir el tiempo de solución de problemas y las tecnologías están disponibles para minimizar el riesgo, control y la información de registro, facilitar la comunicación son Establecido en las condiciones de organización que impulsan la competitividad como en el Cuadro 4.

Cuadro 4- Relación de la dimensión de innovación con los factores de competitividad

\begin{tabular}{|c|c|c|}
\hline $\begin{array}{l}\text { Descripción de la } \\
\text { dimensión de la } \\
\text { innovación }\end{array}$ & $\begin{array}{l}\text { Factores de } \\
\text { competitividad }\end{array}$ & Descripción de los Factores Competitividad \\
\hline \multirow{2}{*}{$\begin{array}{l}\text { Innovación a nivel local } \\
\text { del tipo técnico, } \\
\text { sociotécnico, social, } \\
\text { organizacional o } \\
\text { institucional, orientada a } \\
\text { la producción de un } \\
\text { bien común, a la } \\
\text { asistencia de intereses } \\
\text { generales y colectivos } \\
\text { por una lógica de } \\
\text { cooperación. }\end{array}$} & Innovación & $\begin{array}{l}\text { Adoptar posturas innovadoras en procesos y estrategias } \\
\text { para desarrollar acciones, resolver problemas, estimular } \\
\text { la creatividad y mejorar los resultados. Es una economía } \\
\text { basada en la innovación y el conocimiento que pretende } \\
\text { producir eficiencia dentro y fuera de las operaciones. }\end{array}$ \\
\hline & $\begin{array}{l}\text { Responsabilidad } \\
\text { social }\end{array}$ & $\begin{array}{l}\text { Sostenibilidad en los procesos productivos con el } \\
\text { objetivo de mejorar el desempeño ambiental, la } \\
\text { resolución de problemas sociales, el uso de tecnologías } \\
\text { limpias y el uso adecuado de los recursos. }\end{array}$ \\
\hline
\end{tabular}

Fuente: Adaptación de Maurer y Silva (2014) y Roman et al. (2012).

La relación del cuadro 4 se llevó a cabo observando la Capacidad para crear y refinar productos, servicios, modelos de negocio o trabajar para cumplir con objetivos generales, tecnológicos o mejorar las condiciones de trabajo. El diferencial de La innovación social está en valorar el aspecto local, reconciliando los objetivos individuales y colectivos, la implicación de los actores a través de una gobernanza cooperativa que tiene como objetivo el bien común, como en el Cuadro 5. 
Cuadro 5- Cociente de la dimensión de los agentes con los factores competitividad

\begin{tabular}{|c|c|c|}
\hline $\begin{array}{l}\text { Descripción de la } \\
\text { dimensión de la } \\
\text { innovación }\end{array}$ & $\begin{array}{l}\text { Factores de } \\
\text { competitividad }\end{array}$ & Descripción de los Factores Competitividad \\
\hline \multirow{4}{*}{$\begin{array}{l}\text { Constituyen miembros } \\
\text { de la sociedad civil, } \\
\text { movimientos } \\
\text { cooperativos, } \\
\text { asociaciones } \\
\text { comunitarias que se } \\
\text { relacionan con el } \\
\text { desarrollo e } \\
\text { implementación de una } \\
\text { innovación social que } \\
\text { abarque los aspectos } \\
\text { sociales, } \\
\text { organizacionales, } \\
\text { institucionales o } \\
\text { intermedios. }\end{array}$} & $\begin{array}{l}\text { Factores del } \\
\text { Culturales }\end{array}$ & $\begin{array}{l}\text { Considerar la cultura para tomar decisiones, la } \\
\text { organización y las partes interesadas. }\end{array}$ \\
\hline & $\begin{array}{l}\text { Alianzas } \\
\text { estratégicas }\end{array}$ & $\begin{array}{l}\text { Articular relaciones con competidores, proveedores, } \\
\text { distribuidores. }\end{array}$ \\
\hline & Confiabilidad & $\begin{array}{l}\text { Se relacionan con los proveedores y clientes } \\
\text { manteniendo Previsión de plazos, planificación, control } \\
\text { de recursos y seguimiento de las actividades } \\
\text { productivas. }\end{array}$ \\
\hline & $\begin{array}{l}\text { Relación con los } \\
\text { clientes }\end{array}$ & $\begin{array}{l}\text { Satisfacer y satisfacer las necesidades y expectativas } \\
\text { de los clientes internos y externos. }\end{array}$ \\
\hline
\end{tabular}

Fuente: Adaptación de Maurer y Silva (2014) y Roman et al. (2012).

Existe una relación entre la dimensión de los actores y los factores de competitividad descritos en el cuadro 7 . Se refiere a la capacidad de hacer alianzas con las comunidades, la sociedad civil, la Unión, los clientes Para resolver problemas y satisfacer necesidades o buscar soluciones. Esta acción requiere la capacidad de respetar estándares, valores y cultura de diferentes instituciones o grupos, actuando con fiabilidad y cooperación, como en el Cuadro 6.

Cuadro 6- Relación de los procesos de dimensión con los factores de competitividad

\begin{tabular}{|c|c|c|}
\hline $\begin{array}{l}\text { Descripción de la } \\
\text { dimensión de los } \\
\text { procesos }\end{array}$ & $\begin{array}{l}\text { Factores de } \\
\text { competitividad }\end{array}$ & Descripción \\
\hline \multirow{2}{*}{$\begin{array}{l}\text { Es la forma en que se } \\
\text { coordina la innovación } \\
\text { social, se movilizan } \\
\text { conjuntamente los } \\
\text { medios necesarios y se } \\
\text { enfrentan las } \\
\text { limitaciones. }\end{array}$} & Flexibilidad & $\begin{array}{l}\text { Adaptarse y posicionarse en relación con el medio } \\
\text { ambiente. Adopción de factores que desarrollan la } \\
\text { capacidad de respuesta Rápido para cambiar. }\end{array}$ \\
\hline & Conocimiento & $\begin{array}{l}\text { Capacidad de retener, reutilizar y poner a disposición de } \\
\text { las personas para construir y mantener habilidades. } \\
\text { Combinando iniciativas técnicas y organizativas para } \\
\text { gestionar el conocimiento. }\end{array}$ \\
\hline
\end{tabular}

Fuente: Adaptación de Maurer y Silva (2014) y Roman et al. (2012).

La consonancia presentada en el cuadro 8 está en la capacidad de movilizar la participación de los actores para coordinar la innovación, una actitud guiada sobre la flexibilidad y la capacidad de adaptarse rápidamente al medio ambiente.

\subsection{PAUTAS DE GESTIÓN DE LA INNOVACIÓN SOCIAL VÁLIDAS PARA LA COMPETITIVIDAD ORGANIZACIONAL}

Para la identificación de las directrices para la gestión de la innovación social se evaluaron los documentos institucionales, las respuestas de los stakeholders, seguido del análisis crítico de las dimensiones de la gestión de la innovación social válidas para el alcance de la de competitividad. La recopilación de datos a la luz de la bibliografía permitió identificar las principales debilidades organizacionales y que condujeron a las indicaciones de la de mejorías en el Cuadro 7. 
Cuadro 7- Indicativo de mejoras en el alcance de la competitividad de la organización

\begin{tabular}{|c|c|}
\hline $\begin{array}{l}\text { Factores de } \\
\text { competitividad }\end{array}$ & Dimensiones de la innovación social \\
\hline \multirow{3}{*}{$\begin{array}{l}\text { Relación con los } \\
\text { clientes }\end{array}$} & Conocer los problemas y Satisfacer las necesidades del cliente. \\
\hline & Realizar acciones para minimizar la exclusión y la marginación. \\
\hline & Para buscar la satisfacción de las necesidades de la Unión. \\
\hline \multirow{6}{*}{ Capital Humano } & Invertir en la motivación y capacitación de los empleados para conocer al cliente. \\
\hline & Identifique un problema o necesidad de su propio empleado y tercerizado. \\
\hline & Reconociendo el papel de las personas \\
\hline & Identificar las actitudes y necesidades de las personas. \\
\hline & Considere la motivación de la gente. \\
\hline & Preocuparse por la calidad de las relaciones Interpersonales. \\
\hline \multirow{4}{*}{ Costo } & Dimensión innovadora del carácter \\
\hline & Busque la satisfacción del cliente reduciendo el costo del servicio prestado. \\
\hline & Adoptar acciones para reducir costos en la organización. \\
\hline & Realizar compras a un precio compatible con el mercado. \\
\hline \multirow{3}{*}{ Calidad } & Para buscar la satisfacción del cliente con la calidad del servicio rendida. \\
\hline & Desarrollar modelos de trabajo para remediar problemas internos y externos. \\
\hline & Desarrollar modelos de trabajo para remediar los problemas externalizados. \\
\hline \multirow{3}{*}{ Rapidez } & Innovar para resolver un problema Del cliente, los empleados y la comunidad. \\
\hline & Cumplir con los plazos con las demandas del sindicato. \\
\hline & Resuelva el problema y satisfaga la necesidad del cliente más rápidamente. \\
\hline TIC & Disponer de tecnología para facilitar el servicio al cliente y la comunicación. \\
\hline \multirow{3}{*}{ Innovación } & Dimensión de la innovación \\
\hline & Desarrollar innovaciones para satisfacer las necesidades de los clientes y de la Unión. \\
\hline & Desarrollar un modelo para gestionar la innovación de forma integrada. \\
\hline \multirow{2}{*}{$\begin{array}{l}\text { Responsabilidad } \\
\text { social }\end{array}$} & Para educar a los clientes sobre la importancia de invertir en Sostenibilidad. \\
\hline & Priorizar la compra de recursos y suministros de la comunidad local. \\
\hline \multirow{4}{*}{ Factores culturales } & Dimensión de los actores \\
\hline & Establecer una relación de cooperación con los clientes. \\
\hline & Modificar o reconstruir su cultura a nivel regional para enfrentar Problemas. \\
\hline & Respetar la ideología y los valores de la Unión. \\
\hline \multirow{5}{*}{$\begin{array}{l}\text { Alianzas } \\
\text { estratégicas }\end{array}$} & Garantizar la seguridad del cliente en el uso de sus datos. \\
\hline & Crear alianzas con actores de diferentes identidades. \\
\hline & Considere los valores de los subcontratados en las decisiones. \\
\hline & Establecer una relación de cooperación con los clientes y la Unión. \\
\hline & Gestionar conflictos de intereses. \\
\hline
\end{tabular}


Continuação...

\begin{tabular}{|c|c|}
\hline $\begin{array}{l}\text { Factores de } \\
\text { competitividad }\end{array}$ & Dimensiones de la innovación social \\
\hline \multirow{2}{*}{ Fiabilidad } & Transmita a la seguridad del cliente en la información proporcionada. \\
\hline & Establecer una relación de confianza con la Unión. \\
\hline \multirow{3}{*}{ Flexibilidad } & Dimensión de proceso \\
\hline & Mantenga una postura flexible ante el medio ambiente para lograr sus objetivos. \\
\hline & Buscar la flexibilidad para negociar con la Unión, el cliente y el empleado de su propio. \\
\hline \multirow{3}{*}{ Conocimiento } & Desarrollar innovaciones en conjunto con el cliente. \\
\hline & Movilizar La Unión a innovar en beneficio del trabajador. \\
\hline & Ofrecer espacio diseñado para evaluar y reflexionar sobre las experiencias. \\
\hline
\end{tabular}

Fuente: Datos de búsqueda (2017).

A partir del indicativo de mejora, se propusieron directrices para la gestión de la innovación social válidas para la competitividad organizacional indicada en la figura 1, contribuyendo al desarrollo de un entorno propicio para la innovación social y la competitividad.

\section{Cuadro 8- Descripción de las directrices de gestión de la innovación social}

\section{Directrices de gestión}

1. Administre los factores internos y externos de Forma participativa

\section{Adoptar una} estrategia flexible que incluya la responsabilidad social corporativa

3. Promover el valor compartido

4.Gestionar la innovación

5. Gestión de la innovación social

\section{Descripción}

Con base en Chiavenato (2014a) la organización debe ser sistémica y considerar las diferentes relaciones entre las partes. Hay influencias externas que deben ser reconciliadas con factores internos. El programa de transformación está en las personas y El proceso debe ser participativo.

Es la creación de estrategias como un proceso continuo y emergente. Uso de estrategias no planificadas que dan lugar a acciones coherentes Que conducen a resultados coherentes. Para Porter y Kramer (2006) requiere flexibilidad, adaptabilidad y un vínculo con la sostenibilidad.

Sobre la base de Porter y Kramer (2011) las cuestiones sociales deben estar enfocadas. Es necesario generar valor económico con valor para la sociedad, relacionar el crecimiento de la empresa con el progreso social. El liderazgo necesita ser entrenado para entender la necesidad de la comunidad y repensar el propósito del negocio con un enfoque para la generación de valor en la economía global.

Para Tidd y Bessat (2017) depende de la búsqueda de nuevas ideas en el escenario interno y externo; Selección y elección estratégica que centra en la competitividad; Implementación en la realidad y generación de valor. Debe romperse con modelos mentales automáticos asistiendo en el proceso de aprendizaje organizacional. El proceso debe ser integrado con el aprendizaje continuo y gradual que exige evaluación y reflexión sobre las experiencias.

Según João (2014) Es un conjunto de rutinas que empodera la capacidad de la organización para innovar socialmente. El modelo incluye los pasos del proceso de innovación social Que son: mapeo, selección, movilización de conocimiento, implementación, evaluación, difusión y cambio sistémico. La estructura de la innovación social es dinámica, debe crearse en un entorno virtual que facilite la interacción y colaboración de los actores, la estructura organizacional debe tener una gestión participativa, puede aplicarse en cualquier organización y renunciar al apoyo de una institución de apoyo y de una cultura cooperativa. 


\section{CONSIDERACIONES FINALES}

Esta investigación se propuso a para evaluar la gestión de la innovación social como factor de promoción de la competitividad. El curso del trabajo permitió identificar, describir y determinar in loco las cinco dimensiones de la innovación social y los quince factores de competitividad. Para lograr los resultados se llevó a cabo un análisis crítico de las dimensiones de la gestión de la innovación social. Todas estas directrices válidas para el alcance de la competitividad organizacional. El estudio propuso la gestión de la innovación social directrices de gestión para la innovación social para la competitividad organizacional, que incluye la gestión de los factores internos y externos de forma participativa, adoptando una estrategia flexible e integrando responsabilidad social empresarial, la promoción del valor

\section{REFERENCIAS}

[1]. AMADO, João da Silva. (2000). A Técnica de Análise de Conteúdo. Revista Referência. n.5, Novembro.

[2]. ANDREW, Caroline. KLEIN, Juan-Luis. (2010). Social Innovation: What is it and why is it importante to understand it better. Cahier du Centre de recherche sur les innovations sociales CRISES. Collection Études théoriques, no ET1003.

[3]. BAUER, Martin W. GASKELL, George. (2010). Pesquisa qualitativa com texto, imagem e som: um manual prático. Tradução de Pedrinho A. Guareschi. 8 Ed. Petropolis, RJ: Vozes.

[4]. BENEVIDES. Sâmia L. M. (2017) gestão da inovação social como fator de competitividade: estudo de caso em uma distribuidora do setor elétrico. (Dissertação). Pós Graduação Mestrado em Administração da Universidade Federal de Rondônia - PPGMAD UNIR. Porto velho.

[5]. BIGNETTI, Luiz Paulo. (2011). As inovações sociais: uma incursão por ideias, tendências e focos de pesquisa. Revista Ciências Sociais Unisinos. São Leopoldo, Vol. 47, N1, p. 314, janeiro/abril.

[6]. CAJAIBA-SANTANA, Giovany.(2014). Social innovation: Moving the field forward. A conceptual framework. Technological Forecasting \&Social Change, 42-41.

[7]. CASTRO, Mario; SANTOS, Fernando César Almada; SILVA, Eliciane Maria.(2008). A Relação entre Prioridades Competitivas e Indicadores de Desempenho: Survey em Empresas Moveleiras. Simpósio de Administração da Produção, Logística e Operações Internacionais, 11. São Paulo. compartido, la gestión de la innovación. Todas estas directrices contribuyen al desarrollo de un entorno propicio para la innovación social.

Dadas las bases teóricas conceptuales presentadas y por los resultados obtenidos en la recopilación de datos es posible concluir que la gestión de la innovación social contribuye a la gama de ventajas competitivas al permitir las necesidades, problemas y expectativas de los clientes externos e internos; estimulando el cambio de cultura organizacional centrándose en la flexibilidad; fomentando el desarrollo de acciones de responsabilidad social corporativa; contribuyendo a la generación de valor compartido entre organización y sociedad; al incentivar los procesos de innovación participativa y la creación de plantillas de gestión.

[8]. CORREIA, Suzanne E. N. FALÇÃO, Mariana C. OLIVEIRA, Verônica, M. CASTILLO, Leonardo A. G.(2015). Turismo de Base Comunitária como Inovação Social: congruência entre constructos. Revista de Turismo y Patrimônio Cultural - PASOS. Vol. 13, n. 5. Págs. 1213-1227.

[9]. CRESWEL, John W.(2010). Projeto de Pesquisa: métodos qualitativo, quantitativo e misto. 3 ed. Porto Alegre: Artmed.

[10]. CRESWELL, J.(2014). Investigação Qualitativa e Projeto de Pesquisa: escolhendo entre cinco abordagens. 3 ed. Porto Alegre: Penso.

[11]. CHIAVENATO, Idalberto.( 2014a.). Administração nos novos tempos: os novos horizontes em administração. Barueri: Manole.

[12]. CHIAVENATO, Idalberto.( 2014b). Introdução à teoria geral da administração. 9 Ed. Barueri, SP: Manole.

[13]. DIAS, Reinaldo. ZAVAGLIA, Tércia. CASSAR, Maurício.(2013). Introdução à administração: da competitividade à sustentabilidade. 3를. Alínea: Campinas.

[14]. EMMENDOERFER, Magnus Luiz. SILVA, Fernanda Cristina da. LIMA, Afonso Augusto T. de F. de C.(2013). Evidências de Inovação social na Gestão Pública do turismo em Minas Gerais Brasil: O modelo de circuitos turísticos em análise. PASOS - Revista de Turismo y Patrimônio Cultural. Vol. 9, n. 2. Pgs. 397-410.

[15]. GABRIELE, Pedrita D. TREINTA, Fernanda T. FARIAS FILHO, José R. SOUZA, Maurício C. de. TSCHAFFON, Pâmela B. BRANTES, Sonia R.( 2012). Sustentabilidade e vantagem competitiva estratégica: um estudo exploratório e bibliométrico. 
Revista científica eletrônica de engenharia da produção. Vol. 12. № ‥ 3. Pgs729-755. Florianópolis.

[16]. GIL, Antônia Carlos.(2010). Como Elaborar Projetos de Pesquisa. 5 Ed. São Paulo: Atlas.

[17]. HAMEL, Gary; PRAHALAD, C. K.( 2010). Competindo pelo Futuro: estratégias inovadoras para obter o controle do seu setor e criar os mercados de amanhã. Tradução de Outras Palavras. Rio de Janeiro: Campus.

[18]. JOÃO, Iraci de Souza.( 2014). Modelo de gestão da inovação social para empresas sociais. (Tese). Pós-Graduação em Administração de Organizações da Faculdade de Economia, Administração e Contabilidade de Ribeirão Preto da Universidade de São Paulo. FEA-RP/USP. Ribeirão Preto.

[19]. JULIANI, Douglas.(2014). Inovação Social: uma revisão sistemática de literatura. $X$ Congresso Internacional de Excelência em Gestão. Agosto.

[20]. KLEIN, Estaneslau. (2015). Licença Social: Caminho para a Sustentabilidade do Negócio. 1 ed. Curitiba: Appris.

[21]. MAURER, Ângela Maria.( 2011). As dimensões da inovação social em empreendimentos econômicos solidários do setor de artesanato gaúcho. Dissertação. (Mestrado em Administração). Programa de Pós-Graduação em Administração da Universidade Federal do Rio Grande do Sul: Porto Alegre.

[22]. MAURER, Ângela Maria. SILVA, Tânia Nunes da. (2014). Dimensões Analíticas para Identificação de Inovações Sociais: Evidências de Empreendimentos Coletivos. Brazilian Business Review - BBR. V 11, n. 6. Vitória, Nov-Dez.

[23]. MULGAN, Geoff. (2006). The Process of Social Innovation', Innovations, Spring, pp. 145162.

[24]. MUNCK, Luciano. MUNCK, Mariana G. M.; BARIM-DE-SOUZA, Rafael. (2011).Sustentabilidade Organizacional: a proposição de uma framework representativa do agir competente para seu acontecimento. Revista Interinstitucional de Psicologia. Edição Especial. Dezembro, 147-158.

[25]. MURRAY, Robin. GRICE-Caulier, Julie. MULGAN, Geoff.( 2011). Social Innovator Series: Ways to Design, Develop and Grow Social Innovation. The Open Book of Social Innovation. The Young Foudation. March.

[26]. OLIVEIRA, Tânia M. Veludo de.(2001). Amostragem não-probabilística: Adequações de
Situações para uso e Limitações de amostras por Conveniência, Julgamento e Quotas. Administração On Line FEA/USP. Volume 2, número 2. Setembro de. Recuperado em 29 de set de 2017 de < http://www.fecap.br/adm_online/art23/tania2.htm>

[27]. PATIAS, Tiago Zardin. GOMES, Clandia M. BOBSIN, Debora. LISZBINSKI, Bianca B.( 2017$).$ Modelos de análise da inovação social: o que temos até agora? Revista Brasileira de Gestão e Inovação. V. 4, n.2, Janeiro/Abril.

[28]. PORTER, Michael; KRAMER, Mark R.(2006). Estratégia e Sociedade: o elo entre vantagem competitiva e responsabilidade social empresarial. Harvard Business Review Brasil. Dezembro.

[29]. PORTER, Michael; KRAMER, Mark R.(2011). Criação de Valor Compartilhado. Harvard Business Review Brasil. Janeiro. Recuperado em 07 de mar de 2017 de <http://hbrbr.uol.com.br/criacao-de-valorcompartilhado/>

[30]. ROMAN, Darlan José; PIANA, Janaina; LOZANO, Marie Anne S. P. e L. MELLO, Nelson Ruben; ERDMANN, Rolf Hermann.(2012). Fatores de competitividade organizacional. Revista Brazilian Business Review - BBB. V. 9, n.1, Vitória, Jan-Mar, p. 27-46.

[31]. SANMARTIN, Stela Maris.( 2012). Criatividade e Inovação na Empresa: do potencial à ação criadora. São Paulo: Trevisan.

[32]. SANCHES, Cida; MEIRELES, Manuel; SORDI, José Osvaldo.( 2011). Análise Qualitativa por meio da Lógica Paraconsistente: método de interpretação e sínteses de informação obtida por Escarla Likert. III Encontro de Ensino e Pesquisa em Administração e Contabilidade. ENEPQ. João Pessoa, 20 a 22 de novembro de.

[33]. SOUZA, Ana Clara Aparecida Alves de. SILVA FILHO, José Carlos Lázaro da.(2014) Dimensões da Inovação Social e Promoção do Desenvolvimento Econômico Local no Semiárido Cearense. Encontro da EnANPAD. Rio de Janeiro, setembro de.

[34]. TIDD, Joe. BESSANT, John.( 2015). Gestão da Inovação. Bookman: Porto Alegre.

[35]. YIN, Robert K.(2010). Estudo de Caso: Planejamento e Métodos. 4ํㅡㄹ Ed. Porto Alegre: Bookman,. 


\section{Bapítulo 15}

\section{DESAFIOS DA CAPTAÇÃO DE RECURSOS PARA INOVAÇÃO: ANÁLISE A PARTIR DO FILME "WALT ANTES DA DISNEY"}

\section{Sonia Regina Amorim Soares de Alcantara}

Rafael Lucas Russo Daniel

Resumo: O presente artigo objetiva identificar os desafios da captação de recursos para a inovação no Brasil, mapeando as formas disponíveis de levantamento de capital, as competências necessárias, e também comparando desafios presentes no Brasil e Estados Unidos. Esse estudo fundamenta-se na abordagem qualitativa de pesquisa, utilizando o estudo observacional de uma narrativa filmica, partindo-se da análise de uma produção fílmica que possui similaridade com a realidade, e também em revisão bibliográfica. O desafio central identificado é a percepção da viabilidade da inovação por parte do investidor. O inovador precisa de competências para ser percebido e influenciar o mercado, além de ser criativo, saber trabalhar em equipe e ser inovador constantemente. O Brasil vem ampliando investimentos em inovação, porém, ainda bem abaixo do volume norte americano. A tendência é o uso de capital de risco apoiado nas universidades, e parcerias entre publico e privado.

Palavras-chave: Empreendedorismo, Inovação, Investimentos, Financiamento. 


\section{INTRODUÇÃO}

O cenário econômico precisa de pessoas que consigam identificar novas oportunidades de negócios, que criem novos produtos e melhorem os já existentes, usando os recursos que estão à sua disposição e suas habilidades inovadoras, com isso, gerando bens e serviços para a sociedade e retorno para as empresas.

A Inovação exerce um papel fundamental neste contexto. Segundo Simantob e Lippi (2003), o inovador é aquele que propaga ideias novas, que se mostra insatisfeito com o rumo e o ritmo das coisas e pretende criar uma nova ordem. O inovador é capaz de enxergar um novo mercado em que possa se diferenciar e sobressair, tendo como seu maior desafio, ser inovador constantemente (SIMANTOB; LIPPI, 2003). Drucker (1986) define empreendedores como pessoas que inovam, porém, segundo Ferreira (2017), a relação existente entre esses dois conceitos é muitas vezes percebida de maneira confusa, chegando à conclusão que, os inovadores são todos empreendedores, porque estão diretamente ligados aos consumidores por meio de suas atividades comerciais. Vale salientar, no entanto, que o empreendedor inovador não inova sozinho. Ou seja, todo inovador é empreendedor, mas não necessariamente o empreendedor é inovador.

O inovador nem sempre possui o capital necessário, com isso irá recorrer a algumas alternativas para dar início à inovação. Um investimento em inovação implica assumir uma incerteza maior do que em investimentos ordinários. Isso vale tanto para a incerteza do mercado quanto para a incerteza técnica (Melo, 2010). Nesse sentido, quando não se possui o capital necessário, conseguir um financiamento para iniciar a inovação será mais difícil que um investimento em um empreendimento tradicional no mercado.

Ante ao exposto, surge o questionamento de quais são os desafios em se conseguir o capital necessário para a inovação? Essa pesquisa tem o objetivo geral de identificar esses desafios, com os seguintes objetivos específicos: mapear formas disponíveis de levantamento de capital para a inovação; identificar as competências necessárias para a obtenção de capital financiado; e realizar uma comparação de desafios da captação no Brasil e nos Estados Unidos, por este segundo país ser considerado uma das maiores potências econômicas mundiais.

\section{METODOLOGIA}

Para responder ao questionamento da pesquisa e dar conta de atingir seus objetivos foi escolhido o estudo observacional em uma narrativa fílmica. O intuito é contribuir com estudos já realizados neste campo, analisando por meio de pesquisa qualitativa, a partir da análise do cinema comercial.

A utilização de filmes comerciais em estudos observacionais traz, dentre outros benefícios, a possibilidade de depuração das cenas com microanálises estruturadas, baseadas em dados indireta e diretamente observáveis dessas cenas. Assim, os filmes adquirem para si um encargo que ultrapassa as fronteiras da utilização didática, incorporando o papel de fonte de dados narrativos e, por meio desses dados, tornando-se como que um espelho/reflexo da realidade a qual pertence o fenômeno ou objeto observado. (Machado; Matos, 2012, p. 11)

Utilizando produções fílmicas como fonte de dados, é necessário reconhecer a influência que as imagens apresentadas nos veículos de comunicação exercem sobre a sociedade contemporânea, fato, que, de acordo com Flick (2004), atribui valor a pesquisas que se utilizam dessa abordagem. Com relação ao uso desses tipos de dados, Bergmann (1985 apud FLICK, 2004, p. 168) afirma:

Comparando às entrevistas, eles fornecem o componente não verbal dos eventos e das práticas, que, não fossem assim, somente poderiam ser documentados em protocolos de contexto. Comparados à observação tradicional, esses meios oferecem vantagens do acesso repetido: enquanto a situação observada tem o seu final irreversível, os filmes podem ser vistos e analisados sem limite de repetição, podendo transpor as limitações da percepção e da documentação, características da observação.

Espera-se, com a análise do filme Walt antes do Mickey, baseado em fatos reais, e a partir de dados coletados, identificar os desafios para o levantamento de capital necessário à criação e/ou manutenção da inovação. A relevância desse estudo está em esclarecer quais os desafios e com isso contribuir com reflexões sobre como superá-los, incentivando a disseminação da inovação. 


\section{A INOVAÇÃO E O FILME}

A escolha do filme Walt antes do Mickey baseia-se na importância da biografia do personagem principal, Walter Elias Disney (1901-1966), para a inovação. Segundo Frazão (2014), Walt Disney foi produtor cinematográfico, cineasta, roteirista, dublador, animador, empreendedor e inovador, fundador da The Walt Disney Company. Inovador pelo pioneirismo em animações e criação de diversos personagens presentes na infância das gerações desde o início dos anos 1930. Idealizador e empreendedor dos parques temáticos nos Estados Unidos Disneylândia e Walt Disney World Resort, depois expandidos para a França, Japão e Hong Kong. Ainda como legado, Disney deixou uma universidade (California Institute of the Arts-CalArts), filmes e documentários, além da Walt Disney Company, considerada um dos ícones do entretenimento mundial.

A trajetória de Walt Disney, segundo o filme Walt antes do Mickey, inicia no Kansas (EUA), em uma pequena fazenda, onde o jovem Disney desenhava em um celeiro. Seria aí o início da inovação? Para Disney a resposta é sim, porém, para se dar início a inovação é mais complexo do que apenas se ter ideias.

Não basta apenas ter ideias, sendo única ou não. O que importa é como se utiliza a ideia, de maneira a transformá-la em um produto ou serviço que faça o empreendimento crescer (DORNELAS, 2017, p. 48). Langdon Morris afirma que o primeiro passo da inovação é o pensamento estratégico. O processo de inovação começa com o objetivo de criar uma vantagem estratégica no mercado, por isso nesta fase pensa-se especificamente sobre como a inovação vai somar valor aos propósitos estratégicos, e assim o foco mira nas áreas alvo onde a inovação tem o maior potencial (MORRIS, 2011, p.140).

De acordo com Davila, Epstein e Shelton (2007), a estratégia de inovação precisa de ajustes com o passar do tempo. Alguns fatores podem afetar a escolha inicial. Dentre estes fatores, destacam-se as capacidades organizacionais, sucesso atual do modelo de negócios e os financiamentos.

Disney não possuía as condições organizacionais e gerencias necessárias para o sucesso da inovação, não possuía habilidades de negociação, com isso, acaba tendo prejuízo, como no caso de sua primeira venda, que o valor apenas cobria as despesas da produção do produto. O sucesso do personagem Gato Félix, que dominava o cinema da época, foi um dos maiores obstáculos na carreira de Walt, já que ninguém estava disposto a trocar o seu lucro garantido. "Quanto maior o sucesso, tanto maior será a resistência potencial à mudança." (DAVILA, EPSTEIN e SHELTON, 2007, p. 94)

Contar com os recursos adequados ao projeto é uma necessidade óbvia. O filme mostra a importância e a dificuldade em se conseguir esses recursos em toda sua obra e quando se obtinha o investimento, eram valores insuficientes. No entanto, por vezes essa falta de recursos pode contribuir para a empresa, evitando desperdícios e maiores dívidas futuras com os investidores. "Uma disponibilidade de recursos menos generosa incentiva as equipes de inovação a planejar e testar com o máximo cuidado os pressupostos de um novo modelo, antes de passarem a depender dele" (DAVILA, EPSTEIN e SHELTON, 2007, p 94).

Segundo Davila, Epstein e Shelton (2007), existem 3 tipos de inovação: disruptiva, incremental e radical. As inovações disruptivas são fruto de investigações científicas ou da engenharia, criam algo que as pessoas acreditavam ser impossível. A inovação incremental é entendida por explorar ou melhorar conceitos, tecnologias já existentes, porém, com o intuito de servir a outro propósito. Drucker (1986) sustenta a possibilidade de se redesenhar um antigo processo, por meio de novos conhecimentos adquiridos que serão adicionados a um conhecimento já existente. Já a inovação radical em oposição à incremental origina-se de algo novo para o mundo partindo de tecnologias ou métodos existentes. Luecke (2003) pontua que inovações radicais e incrementais são comumente vistas lado a lado, uma vez que após uma inovação radical segue-se um período de inovações incrementais que aprimoram a primeira inovação. Mesmo se concentrando no aperfeiçoamento do processo, Drucker (1986) destaca que um antigo processo apresentará novas necessidades que serão satisfeitas a partir de uma inovação.

As afirmações de Drucker (1986) e Luecke (2003) estão demonstradas no filme. Walt Disney tentou romper com o padrão do cinema mudo da época, partindo de tecnologias já existentes. No início Disney usava apenas inovações incrementais, 
criando desenhos da mesma maneira, porém, abordando temas diferentes, com novos personagens. Após alguns anos, Walt imaginou um desenho no qual um ator ao vivo era colocado no mundo de desenho animado, contratou uma jovem atriz e criou Alice's Wonderland, caracterizando a inovação radical.

\section{CAPTAČ̃̃O DE RECURSOS: COMPETÊNCIAS E RESULTADOS}

Toda organização precisa de recursos para se sustentar. Excetuando os institutos corporativos, ou fundações familiares, que possuem orçamento próprio garantido, as demais necessitam desenvolver uma estratégica específica para conseguir recursos, sendo esses recursos financeiros, materiais, humanos, entre outros. Cabe ao inovador desenvolver as competências necessárias para a obtenção de apoiadores à sua inovação, criando seu projeto da melhor forma possível. Um plano de negócios é a melhor forma de apresentar o projeto aos investidores em potencial, criando o plano de acordo com o tipo de investimento mais adequado ao negócio. (DEUTSCHER, 2010)

\subsection{COMPETÊNCIAS}

A inovação não acontece ao acaso, é um processo que transforma ideias novas em realidade de sucesso, que deve ser organizada e administrada. Bessant e Tidd (2009) afirmam que as competências gerenciais estão em todo o processo da inovação, seja na iniciação, renovação ou na reinvenção de uma empresa. Existe um conjunto de habilidades básicas que um inovador precisa possuir, que inclui: compreensão clara do processo e seus diferentes elementos; planejamento e gerenciamento de projeto contra cenários de incertezas; saber trabalhar em equipe; possuir visão e ser capaz de compartilhá-la; capacidade de aprender com o erro, melhorando seu desempenho na próxima oportunidade (BESSANT; TIDD, 2009, p. 45)

Walt Disney possuía algumas dessas competências, sabia o valor de seus funcionários e do trabalho em equipe, tentava ao máximo que todos tivessem a mesma visão, a da empresa. Walt montou um grande time de funcionários, todos trabalhavam em busca do sucesso da empresa, em tempos de crise alguns aceitaram trabalhar sem receber salário. Toda essa equipe composta por Disney foi essencial para o sucesso de sua organização no futuro, que mesmo após a falência, essa equipe retornou quando foi oportuno

Walt apresentava dificuldades com as competências gerenciais, não conseguia organizar, planejar ou gerenciar sua empresa e seus produtos, por isso, recorreu ao seu irmão Roy Disney, que demonstrava grande conhecimento administrativo, assumindo o controle financeiro da empresa.

\subsection{PLANO DE NEGÓCIOS}

A pessoa ou empresa que deseje conseguir investidores deve preparar e submeter a eles um plano de negócios. O plano de negócio é um documento de planejamento de comunicação da empresa com seus públicos interno e externo. Deutscher (2010) afirma que público interno são os executivos e gestores das unidades de negócios, já os externos são os fornecedores e clientes estratégicos, executivos que a empresa deseja contratar, investidores entre outros (DEUTSCHER, 2010)

O plano de negócio deve ser compartilhado com toda a empresa, criando um comprometimento das partes. Deutscher (2010) afirma ainda que, os investidores buscam empresas com diferenciais competitivos e claros, com uma equipe diferenciada e comprometida. Deve haver uma clara expectativa de demanda do mercado, os investidores querem saber como irão sair de seu investimento com um retorno aceitável.

O propósito de um plano de negócios é comunicar um projeto e como ele pode ser implementado. Uma das motivações da criação do plano de negócios é justamente a venda de um projeto, seja para potenciais investidores ou para investidores internos.

\subsection{TIPOS DE INVESTIMENTO}

No início da inovação existem diversas formas para se conseguir o capital necessário. Mariano e Mayer (2008) afirmam que dependendo do negócio, variam as diferentes alternativas para financia-lo. Para novos empreendimentos voltados ao setor tradicional, sem inovações, a forma utilizada é o financiamento próprio ou empréstimos com amigos e familiares (Mariano e Mayer, 2008). No caso de Disney, ele recorreu inicialmente 
aos seus pais como fonte de capital inicial. Com o passar dos anos, buscou diferentes formas de financiamento, nem sempre com êxito em face da dificuldade de apoiadores para novas ideias.

Nos dias de hoje, para empreendimentos inovadores surgem tipos de financiamentos específicos como os investidores anjo, crowndfunding, entre outros. Porém, não se descarta a utilização de métodos de captação tradicionais. A seguir, a descrição de formas disponíveis de levantamento de capital para a inovação:

\subsubsection{CROWDFUNDING}

Trata-se de um dos modelos mais recentes de captação de recurso. No Brasil, também é conhecido como financiamento coletivo. Nessa modalidade, o investimento é realizado a partir de contribuições vindas de doações, porém, os doadores não conquistam direitos legais sobre $\mathrm{o}$ produto ou empresa financiada. Geralmente é usado para captação de recursos em iniciativas de interesse coletivo, agregando várias fontes de financiamento, em maioria, pessoas físicas que possuem interesse em seu negócio. Trata-se de ações na internet com o objetivo de arrecadação de recursos para pequenos negócios e start-ups (empresas iniciantes que buscam explorar atividades inovadoras no mercado, em modelo de negócio escalável e que seja repetível). De modo geral, caso atingida a meta projetada, o empreendedor recebe o valor e começa a operar a sua ideia; quando não atingida a meta, o empreendedor devolve o arrecadado para os investidores. (PERIN, 2016, p. 58)

\subsubsection{INVESTIDOR ANJO}

São pessoas físicas que investem seu capital próprio em empresas nascentes com alto potencial de crescimento. O termo "anjo" foi originado nos inícios de 1900, e referia-se aos investidores que faziam investimentos de risco para apoiar as produções teatrais da Broadway (PRESTON, 2004). O investidor Anjo tem como objetivo aplicar em negócio com alto potencial de retorno. Não é apenas um investidor exclusivamente financeiro, mas ele apoia a ideia e aplica seus conhecimentos, experiências e network para aumentar suas chances de sucesso. Ressalte-se que o investimento anjo não é atividade filantrópica e/ou com fins puramente sociais. O investidor "anjo" torna-se sócio da empresa, recebendo uma quantidade de cotas do seu capital social em troca do investimento feito. Sendo sócios assumem os lucros e os riscos inerentes ao negócio. Sua expectativa é que com o crescimento da empresa, as suas cotas se valorizem, e ele possa vender a sua parte, com grande lucro (MARIANO e MAYER, 2008).

\subsubsection{INSTITUTO EMPREENDER ENDEAVOR}

É uma entidade internacional, sem fins lucrativos que atua no suporte ao empreendedorismo em países em desenvolvimento. Sua missão é eliminar os fatores que limitam o surgimento de empreendimentos inovadores, como a dificuldade de acesso ao capital, por exemplo. O instituto atua por meio de trocas de conhecimentos com os mentores da rede Endeavor, parceiros globais e conexões estratégicas, gerando nessa troca de conhecimento inspiração e capacitação dos atuais e futuros empreendedores. O instituto oferece uma variedade de casos bemsucedidos no Brasil, relatados no site do Endeavor. (ANDRÉ NETO et al., 2013)

\subsubsection{FORNECEDORES, CLIENTES E FUNCIONÁRIOS}

Uma empresa que está começando deve usar todas as possíveis alternativas ao seu favor. De acordo com Dornelas, uma boa negociação com fornecedores, como o parcelamento da compra de matéria-prima pode ajudar substancialmente a empresa. Existem ainda clientes que antecipam o pagamento das mercadorias em troca de descontos, esses estão financiando indiretamente a produção (Dornelas, 2017). A base de toda empresa, são seus funcionários e não poderia ser diferente na inovação visto que, muitos deles possuem espírito empreendedor e estão dispostos a abrir mão de um salário maior em troca de participação nos resultados ou ações, ficando mais motivados e trabalhando além do normal (Dornelas, 2017). No filme observa-se a participação da equipe no financiamento dos negócios, inicialmente até com a abdicação de salários e depois, com o sucesso, na participação societária.

\subsubsection{CAPITAL DE RISCO:}


Segundo a Associação Brasileira de Venture Capital (ABVCAP, 2017). O termo venture capital é a tradução de capital de risco em inglês. Esse tipo de investimento é provido por investidores individuais ou institucionais, a empresas emergentes, de pequeno, ou médio porte, voltadas para um produto, processo, ou serviço inovador, de grande potencial de crescimento e rentabilidade na forma de compra de ações, debêntures e/ou outros ativos patrimoniais (equity). Está associado a altos níveis de risco, por um prazo de 2 a 10 anos. É possível afirmar que a caracterização do investimento em capital de risco se dá por ser um tipo de investimento em empresas inovadoras, ou seja, empresas diferenciadas, que geram valor e vantagens aos seus produtos e serviços, além de obterem os maiores lucros. (STEFANINI, 2010). O inovador deve estar ciente que ao optar por essa alternativa não será mais 100\% independente e terá de aceitar os conselhos dos investidores, mesmo não concordando. Essa aliança entre o capitalista e o inovador é abordada de uma forma conflituosa no filme, onde o empreendedor Charles Mintz da Winkler Pictures, começa a fazer alterações nos trabalhos de Disney, para os padrões de sua empresa. No fim Charles tenta ao máximo fazer Walt ceder os direitos autorais de suas obras, argumentando que o mesmo não possuía influência no ramo.

\subsubsection{CAPITAL PRÓPRIO:}

Um dos tipos de investimentos mais comum na inovação, muitos empreendedores recorrem a empréstimos de parentes e conhecidos, porque no início da sua organização, os juros são bem altos para financiar uma empresa que não sabe se dará retorno. Além disso, geralmente no início não há ativos para serem dados em garantia de empréstimos (MARIANO e MAYER, 2008). No Brasil ainda é um dos mais procurados segundo Wollheim e Nuccio (2016). Walt recorreu ao capital próprio no primeiro momento para a fundação da sua empresa e início da prática de suas ideias. A quantia enviada pelos seus pais era pouca, mas suficiente para realizar a criação da empresa. Com esse dinheiro ele contratou funcionários e conquistou a sede da empresa, dando início a suas primeiras criações e apresentando-as aos clientes em potencial.

\subsubsection{LINHAS DE CRÉDITO BANCÁRIO:}

Além das despesas com juros serem dedutíveis para fins de imposto de renda, financiar um negócio com linhas de crédito é uma das formas mais seguras, pois não há perda de participação acionária. Em contrapartida, as desvantagens são a exigência de garantias patrimoniais, as taxas de juros elevadas e o aumento do risco da empresa, o que pode ser um obstáculo para conseguir novos empréstimos. No Brasil as taxas são muito altas e é comum a exigência de garantia real.

Vários desses tipos de investimentos não foram abordados no filme Walt antes do Mickey, pois por se tratar de um filme que retrata a primeira metade do século XX alguns investimentos citados ainda não existiam ou não eram comuns. Com isso, constata-se a ampliação de opções de financiamento e apoio à inovação.

\section{INVESTIMENTOS EM INOVAÇÃO: ESTADOS UNIDOS E BRASIL}

Com relação ao empreendedorismo no Brasil, Dornelas (2001) pontua que o mesmo começou a formar movimento por volta de 1990, quando foram criadas entidades como - Sebrae (Serviço Brasileiro de Apoio a Novas Empresas) e Softex (Sociedade Brasileira para Exportação de Software). Como o ambiente político-econômico do país não era favorável antes desse período, não se falava em empreendedorismo e criação de pequenas empresas; o empreendedor praticamente não encontrava informações para auxiliá-lo. Constata-se então que o empreendedorismo é muito novo no Brasil, logo, a inovação também é recente.

De acordo com Marzano (2011), estima-se que cerca de $90 \%$ dos financiamentos iniciais de firmas nos Estados Unidos seja proveniente do capital de risco. Empréstimos e linhas de créditos adicionais são opção para empresas iniciantes, porém, pela falta de garantia, esses empréstimos dificilmente atendem à demanda primária das empresas nascentes.

A opção por investidores anjos é muito presente nos EUA, atingindo cerca de US\$23 bilhões ao ano. No entanto, nessa mesma pesquisa Marzano (2011) afirma que 90\% dos projetos apoiados por investidores anjos são 
recusados antes mesmo de uma entrevista pessoal.

Apesar dos riscos inerentes à inovação, nos Estados Unidos as empresas contam com diversidade de apoios públicos e privados, pois além das várias fontes de capital, como fundos de pensão, universidades e fortunas particulares, existe ainda uma oferta permanente de empreendedores com novas ideias e empresas em fases de formação. $\mathrm{O}$ governo americano também atua como garantidor de fundos de entidades privadas, com a criação das empresas públicas de capital de risco. Essa parceria entre público e privado acabou criando um equilíbrio entre os objetivos sociais e financeiros, como estímulo ao empreendedorismo, inovação, desenvolvimento regional e criação de novos empregos. (Marzano, 2011)

Marzano (2011) mostra ainda que em 2007, os fundos de risco investiram US\$1,7 bilhões no Brasil. Portanto, a crítica que se faz é que no Brasil este tipo de investimento ainda responde por pequena parcela de financiamento da inovação. A atividade de capital de risco é ainda um enigma para grande parte do mercado brasileiro, apesar de iniciativas da Financiadora de Estudos e Projetos (FINEP) - como o Programa Inovar, por exemplo, da Associação Brasileira de Venture Capital (ABVCAP). Os principais instrumentos financeiros de apoio à inovação são geridos pelo Ministério da Ciência e Tecnologia, que repassa os recursos disponíveis às empresas através de duas agências, a FINEP e o Conselho Nacional de Desenvolvimento Científico e Tecnológico (CNPq). Para expandir a disponibilidade de capital de risco, a Unidade de Apoio a Financiamentos e Capitalização do Sebrae Nacional ajudou a criar o Programa de Capital de Risco, que vem estabelecendo fundos em vários estados. No entanto, é preciso um aperfeiçoamento, pois segundo Marzano (2011), em 2007 os investimentos do Brasil foram aproximadamente 5 vezes menores do que os do EUA em 1975.

Silva e Biagini (2015) mostram que em 2014 Já existia um total de US\$ 51 bilhões de capital de risco no Brasil, o equivalente a $2,2 \%$ do produto interno bruto (PIB) brasileiro naquele ano. Caracterizando uma grande evolução desde 2007. Porém, por mais que o Brasil tenha tido esse avanço, continua abaixo daqueles mercados que possuem tradição, como os Estados Unidos, por exemplo. (Silva; Biagini 2015 p.104).
A infraestrutura brasileira de inovação apresenta inúmeras características positivas. Existe uma agência específica, a Finep, que atua no campo de incubação, capital de risco e incentivo à pesquisa (Dornelas, 2017). No entanto, ainda apresenta inúmeras lacunas. O País possui relevante capacidade criativa, mas sua inserção no mundo dos negócios vem sendo lenta e dificultosa. Os instrumentos em prática atualmente são insuficientes para a disseminação da inovação no país (Marzano, 2011).

As universidades são essenciais no processo de inovação. Lester (2005) afirma que a participação da universidade implica em uma maior aproximação com a sociedade e com sua problemática econômica e social. Uma das grandes vantagens da universidade é o fluxo continuo de indivíduos que garante a qualificação, mas também a concepção de ideias inovadoras. (LESTER, 2005, p. 10). Portanto, a universidade tem a responsabilidade pela sólida formação no ensino Superior e no desenvolvimento de empreendedores e idéias inovadoras. Com isso, a educação superior tem uma função social específica: ser locus de capacidades empreendedoras e de inovação (CASTELLIS, 1997). O EUA possui as 10 melhores universidades do mundo, o rigor da seleção nessas universidades é reconhecido mundialmente. As universidades privadas dos Estados Unidos ainda recebem contribuições do Estado, para ajuda-las a evoluir constantemente. (CALDAS, 2001, p.14).

Mais uma vez ressalta-se a necessidade da harmonia entre público e privado, com isso, percebe-se que compete ao governo brasileiro ampliar investimentos na educação superior, contribuindo para a criação de novos inovadores, visto que, a universidade é também fonte de investimento, inovação e empreendedorismo.

Nos EUA a realidade da inovação é outra, as empresas não têm que arcar com toda a responsabilidade, visto que o governo também investe, logo, as captações dos investimentos são maiores e mais acessíveis. A criação de instituições públicas de capital de risco, a alta demanda de novas ideias a qualquer momento, criam uma segurança no apoiador. As competências necessárias são praticamente as mesmas nos Estados Unidos e no Brasil, porém, essa falta de segurança acaba influenciando a falta de investimentos. Com isso, constata-se o importante papel dos 
governos para incentivo à criação e manutenção dos inovadores.

\section{CONCLUSÃO}

O artigo teve como problema identificar os desafios do levantamento de capital à inovação no Brasil, com objetivos de abordar as competências necessárias para se obter investidores, mapeando formas existentes no Brasil e realizando uma comparação dos desafios a obtenção de capital no Brasil e Estados Unidos.

A inovação é essencial para evitar o engessamento de uma empresa, porém, o inovador enfrenta desafios desde mercado, aceitação e captação de recursos. No Brasil o levantamento do capital necessário teve uma melhora com o passar dos anos, porém, continua pouco evoluído comparado com países desenvolvidos. Com isso, os investimentos em inovação tendem a ser feitos em uma parceria com o público e o privado criando, gerando maior segurança para o investidor.

Cabe ao inovador evoluir constante e aprimorar as competências necessárias para

\section{REFERÊNCIAS}

[1]. ABVCAP. Associação Brasileira de Venture Capital. Disponível em: http://www.abvcap.com.br/. Acesso em Jun. 2017.

[2]. ANDRÉ NETO, Antonio et al. Empreendedorismo e desenvolvimento de novos negócios. Rio de Janeiro: Editora Fgv, 2013.

[3]. BESSANT, John; TIDD, Joe. Inovação e Empreendorismo. Porto Alegre: Bookman, 2009.

[4]. CALDAS, Marília Junqueira. A USP e seus desafios: I fórum de políticas universitárias. São Paulo: Editora da Universidade de São Paulo, 2001.

[5]. CASTELLS, M. The rise of the network society - the information age: economy, society and culture. Vol 1. Oxford: Blackell, 1997.

[6]. DAVILA, Tony; EPSTEIN, Marc J.; SHELTON, Robert. As regras da Inovação. Como gerenciar, como medir e como lucrar. Porto Alegre: Artmed Editora, 2007.

[7]. DEUTSCHER, Jose Arnaldo. Plano de negócios: um guia prático. Rio de Janeiro: Editora Fgv, 2010.

[8]. FRAZÃO, Dilva. Walt Disney: empresário norte-americano. 2014. Disponível em conquistar a credibilidade do investidor. É necessário saber trabalhar em equipe, possuir criatividade e mostrar como sua ideia irá agregar valor ao mercado. O filme por mais que retrate o século passado, traz uma base para análise do assunto pesquisado, visto que muito do que foi abordado no artigo está presente no filme.

Cabe ao inovador identificar os tipos de captação de recursos que melhor satisfazem as necessidades do seu projeto, sendo os investimentos dos tipos mais inovadores aos tradicionais. O grande desafio do inovador é conseguir o capital necessário e ser inovador constantemente, logo, a criatividade e aprender com o erro é essencial. Como o próprio Walt Disney afirma "Aqui, no entanto nós não olhamos para trás por muito tempo, nós continuamos seguindo em frente, abrindo novas portas e fazendo coisas novas, porque somos curiosos... e a curiosidade continua nos conduzindo por novos caminhos. Siga em frente.".

Indica-se para futuras pesquisas ampliar a análise da comparação da captação de recursos à inovação entre Brasil e Estados Unidos, ante a relevância deste país e suas inovações para o a sociedade global.

https://www.ebiografia.com/walt_disney/. Acesso em 26jul.2017.

[9]. DORNELAS, José Carlos. Empreendedorismo: transformando idéias em negócios. Rio de Janeiro: Campus, 2001

[10]. Empreendedorismo: transformando ideias em negócios. 6. ed. São Paulo: Empreende/atlas, 2017.

[11]. DRUCKER, Peter Ferdinand. Inovação e Espirito Empreendedor: práticas e princípios. São Paulo: Pioneira, 1986

[12]. FERREIRA, Laércio de Matos. OS PAPÉIS DESEMPENHADOS PELO EMPREENDEDOR E PELO INOVADOR NO ECOSSISTEMA DE INOVAÇÃO. 2017. Disponível em: <https://www.facebook.com/notes/inova-mundo/ospapéis-desempenhados-pelo-empreendedor-epelo-inovador-no-ecossistema- deinov/494592113997910>. Acesso em: 20 jun. 2017.

[13]. FLICK, U. Uma introdução à pesquisa qualitativa. 2. Ed. Porto Alegre: Bookman, 2004

[14]. LESTER, R. Universities, innovation and the competitiveness of local economies. Local Innovation Systems Project-Phase I, 13 dez. 2005. 
Disponível em: <http://web.mit.edu/lis/ Acesso em 15 jul de 2017

[15]. LUECKE, Richard. Managing Creativity and Innovation. Harvard Business School Press: Boston, 2003.

[16]. MACHADO, Diego de Queiroz; MATOS, Fátima Regina Ney. ESTUDOS OBSERVACIONAIS EM LINGUAGEM FÍLMICA. Curitiba: Editora Crv, 2012.

[17]. Mariano, Sandra R. H.; Mayer, Verônica Feder. Empreendedorismo e inovação: criatividade e atitude empreendedora. Rio de Janeiro: Fundação CECIERJ, 2008.

[18]. MARZANO, Fábio Mendes. Políticas de inovação no Brasil e nos Estados Unidos: a busca da competitividade - oportunidades para a ação diplomática. Brasília: Fundação Alexandre de Gusmão, 2011.

[19]. MELO, Luiz Martins de. O financiamento das empresas inovadoras: alternativas para discussão. Revista Economia \& Tecnologia, [s.l.], v. 6, n. 1, p.139-148, 31 mar. 2010. Universidade Federal do Parana. http://dx.doi.org/10.5380/ret.v6i1.27029.

[20]. MORRIS, Langdon. The Innovation Master Plan: The CEO's Guide to Innovation. Walnut Creek: Innovation Academy, 2011.

[21]. PERIN, Bruno. A Revolução das Startups: O Novo Mundo do Empreendedorismo de Alto Impacto. Rio de Janeiro: Alta Books, 2016.
papers/LIS05-010.pdf>. Acesso em: 16 jul. 2017. p. 10.

[22]. PRESTON, Susan L., Angel Investment Groups, Networks, and Funds: A Guidebook to Developing the Right Angel Organization for Your Community. The Ewing Marion Kauffman Foundation, August 2004. Disponível em: www.kauffman.org/pdf/angel_guidebook.pdf. Acesso em 20 de jun. 2017

[23]. SILVA, Filipe Borsato da; BIAGINI, Fabio Luiz. Capital de risco e o desenvolvimento de empresas de base tecnológica no Brasil: a experiência dos fundos Criatec e perspectivas. BNDES Setorial, Rio de Janeiro, n. 42 , p. [101]130, set. 2015.

[24]. SIMANTOB, Moysés; LIPPI, Roberta. Guia valor econômico de inovação nas empresas. Globo Livros, 2003.

[25]. Stefanini, Claudio José. Capital de risco: um estudo sobre os critérios de avaliação e escolha nos fundos de investimentos em capital de risco em empresas inovadoras de São Paulo e grande,São,Paulo,Disponível<em:

http://www.ead.fea.usp.br/Semead/10semead/siste ma resultado/trabalhosPDF/122.pdf. Acesso em 17 de jun 2017.

[26]. WOLLHEIM, Bob; NUCCIO, Dony de. Nasce um empreendedor: Dicas, provocações e reflexões para quem quer começar um negócio próprio. São Paulo: Portfolio-penguin, 2016. 


\section{Capítulo 16}

\section{A GESTÃO DO CONHECIMENTO APLICADA NO SETOR DE CORTE DIAMANTADO - NIVEL DE SIMILARIDADE}

\section{Daniel Brioschi Machado}

Raoni Rocha Simões

Resumo: Em um contexto remoto extrativista de alto risco, aplica-se a gestão do conhecimento tácito para testar a capacidade de uma microempresa mineradora em qualificar e "quantificar" a experiência dos seus funcionários no setor de corte de fio diamantado em uma pedreira de quartzito e distribuí-la de forma a tornar o processo o mais eficiente e seguro. Para isso é de fundamental importância a aplicação de uma "unidade de medida" para aferir-se o conhecimento incorporado desses trabalhadores. Esse conceito, denominado por Ribeiro (2012) como "Níveis de similaridade", foi configurado a partir de observações, entrevistas, análises curriculares, e um workshop, e serviu de base para a distribuição dos funcionários pelo setor, definindo o "mix de similaridade". Essa proposta entregou à empresa a possibilidade de organizar seu contingente/materiais de forma mais eficiente, planejar suas contratações baseada em algo tangível, e melhorar o processo de corte de fio diamantado.

Palavras chave: Gestão do conhecimento tácito, níveis de similaridade, ergonomia, atividade, Corte de fio diamantado. 


\section{INTRODUÇÃO}

O Brasil lidera o fornecimento de rochas ornamentais para o mundo todo. Informações sobre o desenvolvimento técnico mostram que o setor bate recorde após recorde em faturamento, impulsionado principalmente pelas exportações (REVISTA M\&T, 2015). Exemplo dessa vitalidade foi em 2013, ano em que, mesmo sob a influência de uma grave crise econômica, o setor registrou faturamento recorde de $\mathrm{R} \$ 1,3$ bilhão com exportações, somando o envio de blocos ou rochas já processadas ao exterior. Em 2014, o valor foi um pouco menor, chegando a $R \$ 1,28$ bilhão, mesmo assim superando os demais exercícios, inclusive o biênio 2006 e 2007, quando a economia estava em alta (REVISTA $M \& T$, 2015). Um mercado que se torna atraente mesmo cercado de grandes dificuldades e em regiões muito distantes dos polos industriais minerários e carente de recursos. Fazendo da implantação de empresas nesses locais um verdadeiro desafio tanto técnico/administrativo quanto social/ político.

Dentre os maiores exploradores de rochas ornamentais no país, destacam-se os estados de Minas Gerais, Rio de Janeiro e Espírito Santo. Juntos, eles detêm grande parte do parque industrial dessa atividade e uma fatia de quase $63 \%$ da produção desse material no país (LOPES, 2016).

Essencialmente as rochas ornamentais são formações rochosas, onde na natureza são compostas principalmente por minerais tais como o Quartzo, Mica e o Feldspato. A proporção que cada um desses minerais tem numa mesma rocha irá definir, além de sua dureza e resistência, a forma como esta será extraída, transportada e processada, seja ela para decoração de interiores, exteriores, obras de arte, calçamentos, construções e até mesmo matéria prima (REVISTA M\&T, 2015).

Tratando-se dos setores de uma jazida de rocha ornamental, destaca-se o setor de corte de fio. Os "Fioristas", como são denominados os funcionários dessa área, tem de lidar com um campo onde há uma grande necessidade de conhecimentos técnicos, atrelados a um alto grau de risco. Dentro desse espaço, o menor erro pode se traduzir em grandes perdas econômicas, materiais, atrasos nos prazos de entrega e até mesmo acidentes.

A abordagem aqui referida procura desenvolver-se nos pilares do conhecimento tácito, utilizando-se dos "Níveis de Similaridade" para estabelecer e testar a capacidade de uma microempresa mineradora capitalizar a experiência e o conhecimento tácito dos seus trabalhadores de uma maneira sistematizada. E dessa forma expropriar o conhecimento individual dos atores sociais (estes capazes de propor para cada conjuntura um determinado expediente) de uma forma sistematizada, e apropriá-los de maneira a tornar o processo o mais eficiente e seguro possível, especificamente no setor de "Corte de Fio".

Investiga-se também a aplicabilidade desses conceitos até aqui referidos em um novo contexto remoto extrativista: o da mineração de rochas ornamentais na região sudoeste da Bahia. Anseia-se com essa pesquisa ser capaz de aplicar esse ensaio e elucidar um quadro conceitual que possibilite identificar os diferentes níveis de similaridade presentes na força de trabalho e que torne os processos referentes a escolha e contratação de funcionários muita mais efetiva. Além disso, à atividade mais eficiente e segura frente a integração/interação de sujeitos com diferentes graus de conhecimento.

\section{CONTEXTO}

O trechos a seguir foi retirado do processo de licitação ambiental onde a empresa garante o uso de mão de obra local e, logo, o desenvolvimento da região perante a Secretaria de Meio Ambiente do estado da Bahia e o conselho municipal de Tanque Novo-BA (Município onde está localizada a pedreira). Compromisso que visando os âmbitos econômicos e logísticos seria benéfico para a empresa visto que, os salários e o custo de deslocamento dos funcionários para respectivas casas, assumido pela empresa, seriam muito menores. 
FIGURA 1- Trecho da licença Ambiental

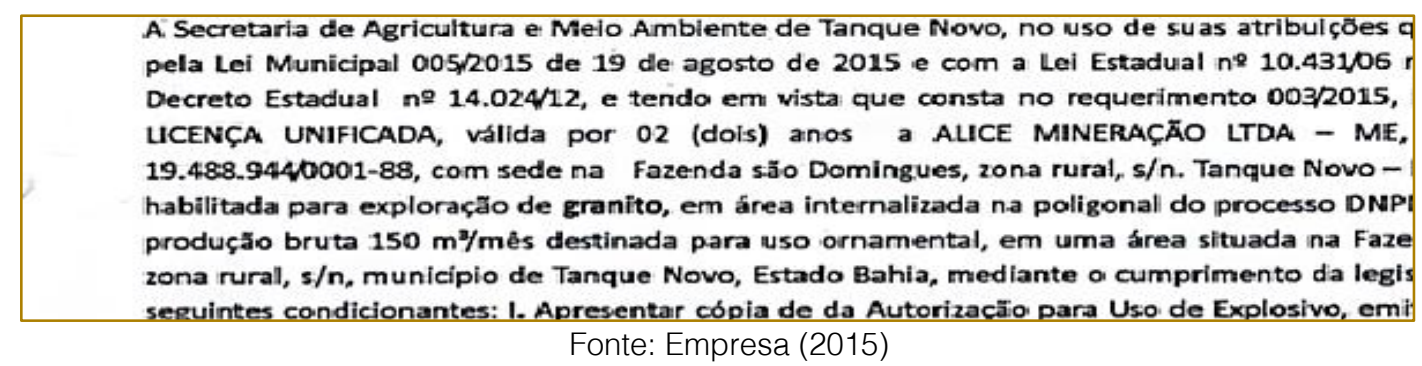

$\mathrm{O}$ ato de contratar profissionais de outras regiões do Brasil, locais estes muitas vezes com um grau de desenvolvimento e qualidade de vida muito superiores, e trazê-los para uma região remota, demanda recursos e benefícios bem acima da média. Lembra-se, ainda, que dados do DATASUS (2008) mostram uma região que sofre com a exiguidade de serviços públicos e uma migração não planejada poderia pôr em cheque esse cenário já precário.

Em detrimento da situação, não se encontra no local ou região próxima mão de obra qualificada. A pedreira em análise situa-se numa área de cerrado de difícil acesso a $23 \mathrm{~km}$ do centro do município de Tanque Novo- BA, sendo Vitoria da Conquista a cidade próxima de maior porte, a $313 \mathrm{~km}$ de distância. Tanto Tanque Novo, quanto Paramirim - Segundo Município em proximidade, são cidades de pequeno porte, com uma população entre 15 e 59 anos, possuindo, respectivamente, 9.632 e 13.721 pessoas. Em ambas as taxas de escolaridade são extremamente baixas. Em Tanque novo, segundo o IBGE (2010), temos um número de analfabetos entre homens e mulheres com mais de 15 anos de 3.087 pessoas. Paramirim conta com um "número de analfabetos entre homens e mulheres com mais de 15 anos" de 3019 pessoas.

A Microempresa instalou-se na região em 2014 sem experiências prévias nesse setor. Devido a atrasos na obtenção das licenças teve suas atividades iniciadas apenas em maio de 2015. Houve dois meses de paralização em junho e julho de 2015 e desde então já conta com uma taxa de rotatividade de $71,5 \%$. A empresa hoje conta com 14 funcionários dos quais apenas 4 mantiveramse desde o startup. Para o começo optou-se por uma equipe montada por 10 integrantes vindos de regiões com características mineradoras do Espírito Santo e Minas Gerais e que já haviam trabalhado em Pedreiras por pelo menos 2 anos. Estes seriam a demanda qualificada e experiente do coletivo de trabalho que seria complementado por mais 4 ajudantes locais.

No decorrer do projeto surgiram as primeiras dificuldades. Distância, falta de lazer e a remuneração, foram algumas das variáveis que levaram a empresa a confrontar uma altíssima taxa de rotatividade e buscar uma possível solução. Além disso, não era surpresa que devido a distância grande parte dos funcionários que foram contratos de longas distâncias não iriam querer ficar na região por mais de 2 ou 3 anos. Era indispensável uma forma de trabalhar essa "experiência" aos novatos que iniciavam a sua atividade na empresa. A partir de dados coletados juntos ao o $\mathrm{RH}$ verificou-se que a empresa já contava com uma taxa de rotatividade de $71,5 \%$. Mais da metade dos funcionários já havia sido demitido ou pedido afastamento. Distância, falta de lazer e a remuneração, foram algumas das variáveis que levaram a empresa a confrontar uma altíssima taxa de rotatividade e buscar uma possível solução.

\section{OBJETIVOS GERAIS}

A abordagem aqui referida procura desenvolver-se nos pilares do conhecimento tácito, estabelecendo e testando a capacidade de uma microempresa mineradora capitalizar a experiência e o conhecimento tácito dos seus trabalhadores de uma maneira sistematizada. Criando uma espécie de "estoque de conhecimento" que seja apto a conduzir eficientemente e "combinar" seu efetivo humano/material por dentre os riscos e dispares contextos provindos de tal atividade (RIBEIRO, 2012), especificamente no setor de "Corte de Fio".

Investiga-se também a aplicabilidade desses conceitos até aqui referidos em um novo 
contexto remoto extrativista: o da mineração de rochas ornamentais na região sudoeste da Bahia. Anseia-se com essa pesquisa ser capaz de aplicar esse ensaio como forma de expropriar o conhecimento individual dos autores sociais (estes capazes de propor para cada conjuntura um determinado expediente) de uma forma sistematizada, e apropriá-los (conhecimento) em novos funcionários.

\section{1-OBJETIVOS ESPECÍFICOS}

Verificar as variáveis responsáveis pela justificativa da escolha do setor "Corte de Fio" para análise.

Definir um padrão de "níveis de similaridade" para o setor de "Corte de Fio". Este deverá ser pautado sobre os currículos profissionais de cada. O currículo de trabalho e as experiências profissionais irão fundamentar os dados e classificá-los em 3 níveis -Alto, médio e baixa similaridade- e ainda fornecer uma conjectura sobre a quantidade mínima de tempo necessário para o ator ter controle sobre o que the foi especificado em cada nível.

Elaboração de um Workshop/Reunião onde possa ser confrontado com precisão os níveis de similaridade a serem encontrados. Será de fundamental importância a confrontação de dados de todas as partes envolvidas no processo diretamente e indiretamente. Diretores, Gerentes, Supervisores, Engenheiros de Minas, Técnicos e Auxiliares.

- Confrontar os dados da primeira análise com a identificada após o Workshop.

- Aplicar e testar o conceito de "níveis de similaridade" em contexto remoto extrativista de Rochas Ornamentais.

- Elucidar um quadro conceitual que possibilite identificar os diferentes tipos de níveis de similaridade presentes na força de trabalho.

- Criar um escopo de contratação acertado para a micro-empresa.

Espera-se com este estudo ser capaz de tornar os processos referentes a escolha e contratação de funcionários muita mais acertada. E à atividade e treinamentos mais eficientes e seguros frente a integração/interação de sujeitos com diferentes graus de conhecimento. E com isso, melhorar a gestão de pessoas e índices de SST.

\section{JUSTIFICATIVA}

Exatamente por tratar-se de um tipo de rocha pouco explorada não havia disponível na região trabalhadores habilitados exatamente para aquele determinado tipo de rocha. Dessa forma seria necessário apropriar-se de colaboradores que detivessem uma habilidade prévia da atividade, esta como expediente de moldagem do meio infiel, objeto de prescrição (GUERIN, F. et al, 2001), que fosse suficiente para operacionalizar todos os diferentes setores da jazida. Houve então a busca em outras regiões por profissionais que detivessem experiência prévia para essa atividade de alta complexidade e risco, e que veio a se tornar ainda mais crítica em um local distante. Ainda que considerados experientes pelos gestores, não eram todos que já haviam trabalhado com aquele padrão de rocha.

Devido a este cenário ficou claro que era indispensável pensando-se a longo prazo uma forma de transformar essa "experiência" contida na qualificação, no conhecimento explícito e no tácito coletivo em algo sistêmico que pudesse ser transferido e apropriado por um trabalhador novato e que fosse de feitio tangível. A reposta se origina em Ribeiro (2012) que define tal capacidade como "níveis de similaridade". Onde o conhecimento tácito é compreendido dentro de um autor social pelo decurso da experiência qualificada.

\section{REFERENCIAL TEÓRICO}

\subsection{FENOMENOLOGIA DA PERCEPÇÃO}

A Fenomenologia da Percepção, de MerleauPonty (1945) retratada por Ribeiro (2014) sugere uma comparação entre dois tipos de situações: A primeira seria a percepção como uma fundamentação generalizada, em que todo ser humano é naturalmente marcado com instintos que o auxiliarão durante a sua vida. E a segunda seria a que se vive, em que esse mesmo indivíduo em "sincronização" com o mundo é marcado com um "corpo histórico". Esta seriam as experiências de cada um e que dessa forma tornaria cada indivíduo um ser único.

A "Sincronização" proposta por Ribeiro (2014) em uma análise de Merleau- Ponty (1945) 
refere-se ao processo pelo qual a percepção de algo se torna personalizada. Quando ela realmente significa algo para o indivíduo, não significa, no entanto, que já está situado (preparado) para todas as situações que venham a aparecer. Acresça-se a présincronização como definição do estado anterior a ação paradoxal de incorporar a experiência e a sincronização que nos leva a um "corpo histórico", de um sujeito que baseia suas ações em situações já vividas por exemplo, de um agora, autor social provido de "macetes".

A experiência é o que permite ao indivíduo procurar diferentes saídas e que garante uma sincronização com a atividade de maneira positiva. Distinguir ao aproximar-se da máquina de fio (Corte de Fio) se essa é uma situação perigosa ou segura, se uma trinca na prancha que está sendo cortada é relevante ou irrelevante na continuação do corte, se há similaridade ou não entre outras configurações já presenciadas (RIBEIRO, Rodrigo, 2014). A sincronização sugere um corpo que é afetado pelas experiências a quais percebe, que vivencia.

$\mathrm{Na}$ prática, apropriando-se de um experimento dirigido por Merleau-Ponty (1945) e explicitada por Ribeiro (2014), dois indivíduos expostos a um mesmo cenário podem divergir quanto a conclusão. Logo, em um cenário no qual a percepção toma forma mostra que o mesmo indivíduo pode divergir quanto ao desenlace da situação antes e depois de uma sincronização.

\subsection{ABORDAGEM ERGONÔMICA}

Indiferentemente da empresa ou setor, as gestões atuais baseiam-se principalmente em dois tipos de modelos e estratégias como forma de padronizar um conhecimento mínimo necessário para um bom funcionamento da organização em seus funcionários. Primeiramente a visão prescritiva, fundamentada em normas, regras, padrões e "regras de ouro" por assim dizer (GUERIN, F. et al, 2001). Desta maneira, seria possível, pela organização, articular o conhecimento entre os funcionários, armazenar e partilhá-lo por meio da linguagem formal. As empresas que creem nessa versão apoiam suas teorias em um reforço e treinamento diário para atingir o esperado. Todavia, fica claro o quão escasso e insuficiente esse modelo se torna ao se compará-lo com a atividade, com o que realmente acontece no chão de fábrica (GUERIN, F. et al, 2001).

Em segundo lugar há a abordagem baseada na prática. Diretamente entrelaçada ao "saber fazer" de cada funcionário, com as regulações diversas que levam a possibilidade de antecipação do inesperado, com a gestão das variabilidades e imprevistos. Nessa abordagem as regulações quentes -provindas do campo, da observação dos autores sociais em atividade, ou até mesmo como recomendação deles próprios surgem como resultado de um ambiente com mais autonomia onde os autores sociais tem uma maior liberdade para julgar e propor medidas - abastecem os procedimentos e normas, tornando o contexto da atividade de trabalho muito mais seguro e produtivo (GUERIN, F. et al, 2001).

A gestão do conhecimento com seus preceitos fundados nos pilares de ergonomia tenta propor então uma maneira de se gerenciar esse conhecimento tácito. Isso significa, definir quais os trabalhadores são considerados experientes e colocá-los de forma a se distribuir esse conhecimento aplicado entre as diversas áreas e pessoas da organização. Elucidar o tempo necessário para cada autor social se tornar experiente, detentor desse conhecimento específico. E dessa forma, analisando os fatores culturais, linguísticos, sociais, econômicos, o coletivo de trabalho, o contexto de trabalho, cada trabalhador em sua dimensão singular, ser capaz de tornar muito mais eficiente essa transferência de conhecimento dentre os autores sociais.

\subsection{GESTÃO DO CONHECIMENTO TÁCITO NO PROCESSO DE APRENDIZAGEM}

A experiência que os seres humanos adquirem ao decorrer da vida, e em nosso caso específico na atividade de trabalho, e algo que desperta relevância entre pesquisadores e cientistas. A forma como cada indivíduo lida com uma situação e o motivo pelo qual ele escolheu determinado caminho e, principalmente, a justificativa de "menos experientes" escolherem outra opção, nos leva à busca pelo que se define conhecimento tácito.

Nonaka e Takeuchi (1995) evidenciam um experimento na manufatura de uma máquina de fazer pão. O qual uma máquina se apropria do conhecimento de um padeiro com 
perfeição. Tem-se, o que seria denominado conhecimento tácito, algo que pudesse ser baseado em normas, um "Saber" que estava implícito, escondido no indivíduo. Este passa a ser estruturado em uma linguagem formal baseada em regras e rotinas pertinentes à atividade, tornando- o dessa forma hábil a ser explicitado a uma máquina.
A partir daí deriva-se a espiral do conhecimento (NONAKA; TAKEUCHI, 1997) o qual por definição sugere em etapas a forma pelo qual o conhecimento pode ser transferido de uma pessoa a outra, e incorporado ou transformado de conhecimento tácito em explicito, tácito em tácito, explicito em explicito e explicito em tácito. A Figura 2 demonstra esse sistema:

FIGURA 2- Espiral do conhecimento

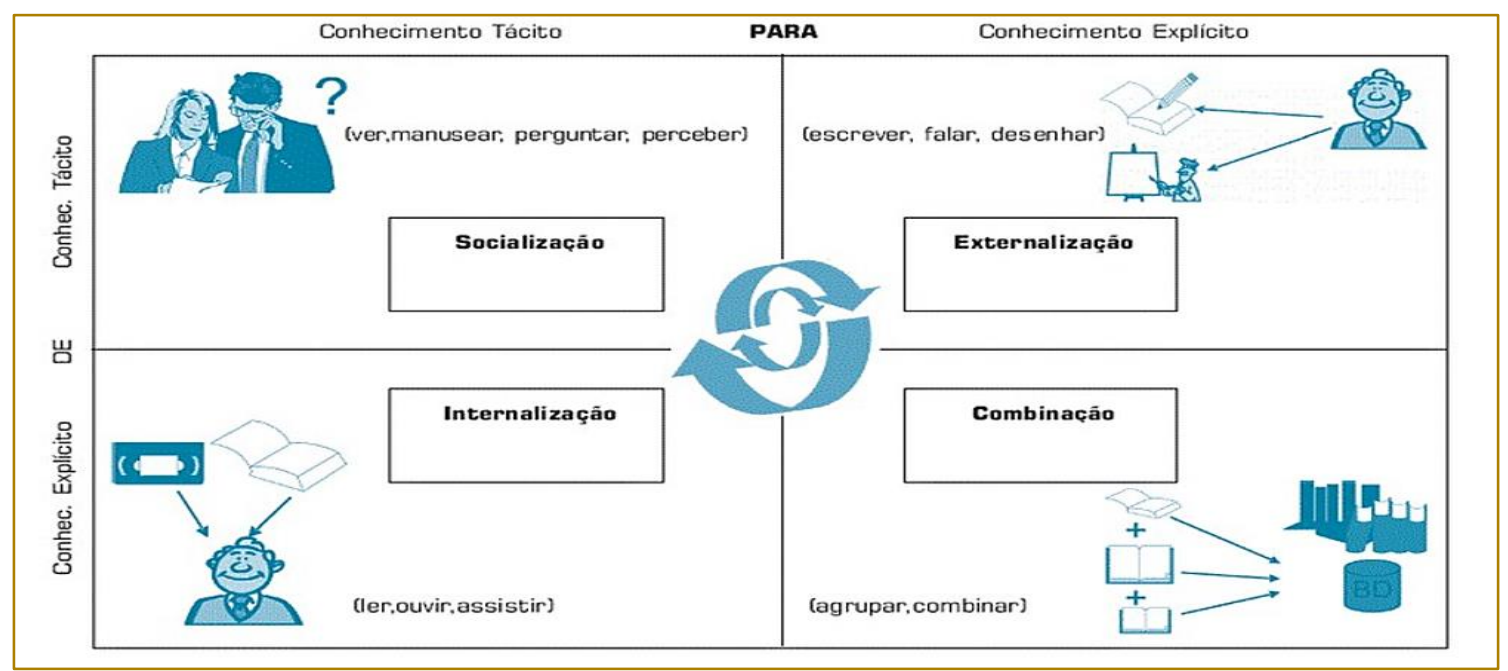

Fonte: Nonaka e Takeuchi (1997)

Entretanto, Ribeiro e Collins (2007), manifestam uma outra visão analisando o mesmo experimento de Nonaka e Takeuchi (1995). O conhecimento tácito não fora explicitado e incorporado pela máquina. A notoriedade do aparelho e seu manual contou com o auxílio de diversos atores sociais que tiveram de estar presentes com o mestre padeiro para aprenderem a fazer o pão e serem capazes de "adaptar" aquelas ações à prótese social. A vista dessa conjuntura emerge a ideia de quão limitado seria a transferência desse conhecimento via observação, "linguagem formal, expressões matemáticas, sentenças gramaticais, especificações, manuais etc." (NONAKA; TAKEUCHI, 1995, p. viii). O conhecimento tácito figura-se muito além do que e cabível de explicitação e definição.

Com o tempo surgem então novas definições e estudos sobre o assunto. Adiciona-se ao conhecimento explícito o conhecimento tácito coletivo (RIBEIRO, R; COLLINS, H, 2007). Um conhecimento transeunte que agrega as regras sociais de um grupo especifico, às regras informais -que dificilmente serão observadas por terceiros externos-, o conhecimento somático e o conhecimento tácito individual. Algo que fosse construído a partir da interação de diversos indivíduos sociais praticantes da atividade com percepções e experiências distintas, mas que convergindo para um mesmo objetivo fossem capazes de gerir as variabilidades de um meio infiel.

A vista disso, conhecimentos integralmente complementares atingem 0 que seria determinado por "experiência aplicada in loco em uma deliberada situação". Isto posto, dentro de uma conjuntura inesperada ser capaz de agir naturalmente e arquitetar uma solução dentro de certa cultura (RIBEIRO, 2007). Inclua-se ainda a capacidade do autor social de construir uma nova resposta "apropriada" frente a uma problemática.

Lima (2000) diz que "(...) A aprendizagem de uma habilidade prática só pode ocorrer por meio da prática e de forma progressiva durante a prática". Nessa abordagem fica claro o alto valor significativo da prática como forma de aprendizado. Este realmente acontecendo unicamente em meio a atividade e a processos situados no espaço temporal e 
físico como parte de um contexto coletivo eminente cultural. Essa aprendizagem pautada na abordagem social pode ser chamada de aprendizagem situada. O aprender como parte do processo de construção social da realidade. Transportando esse conceito para a atividade de trabalho faz-se emergir os "macetes". "Macetes" não são explicitados ou tomam forma, não se ensinam, se aprendem. O caráter particular de uma "improvisação" transcende a sua incorporação para ir além. "Usá-lo" de formar correta significa confrontar as normas, as regras antecedentes, as situações vividas para então dessa forma saber momento exato e o motivo de apropriarse do saber.

A prática situada paralelamente associada com as comunidades práticas, onde um mesmo grupo social compartilha o mesmo objeto de trabalho, torna-se então um organismo de relações entre indivíduos singulares aptos a decidir e inferir com diferentes saberes. Espera-se que as comunidades práticas tornem os indivíduos fies as condições das estradas e não aos mapas (BROWN, 1991).

\subsection{NÍVEIS DE SIMILARIDADE}

Em um mundo utópico pode se dizer que qualquer organização optaria por pessoas experientes como garantia de um início de operações seguro. Todavia, por questões financeiras, legais e a dificuldade em prospectá-los isso muitas vezes não é possível.

Esses trabalhadores tidos como experientes já desenvolveram uma urdidura em seus corpos, a prática já está incorporada neles.
Mas como definir quem é experiente? Experiente em que? Quais atividades de trabalho que estão relacionadas à jazida de quartzito? $O$ nível de similaridade desenvolvido por Rodrigo Ribeiro surge como uma forma de qualificar o histórico de experiências e estimar o conhecimento tácito agregado a ele (RIBEIRO, Rodrigo, 2012).

Ribeiro (2012) afirma que é inconcebível um indivíduo ter conhecimento tácito em tudo. Há a possibilidade de este ter conhecimento em uma determinada tarefa dentro de um contexto específico. Para poder analisar e julgar as situações apropriadamente, ser capaz de usar os "macetes" é necessário ao autor social estar inserido naquele contexto exato. Portanto ressalta-se que para um ator social definir-se experiente ou de alta similaridade na pedreira de quartzito não há outro feitio que não seja estar presente naquelas circunstâncias.

Pretende-se que o conceito de nível de similaridade (RIBEIRO, Rodrigo, 2012) consiga identificar a experiência dos autores sociais e definir quais delas tem similaridade e podem ser consideradas válidas para a atividade de mineração de rochas ornamentais (Quartzito), quais não estão relacionadas mas podem auxiliar e quais dos trabalhadores não possuem o conhecimento tácito necessário para a atividade.

\subsection{O SETOR DE CORTE DE FIO DIAMANTADO}

Para entender o contexto desse setor é fundamental conhecer um pouco da tarefa de um Fiorista, o responsável pela corte de fio diamantado. A Figura 3 ilustra essa conjuntura: 
FIGURA 3- Máquina de fio diamantado

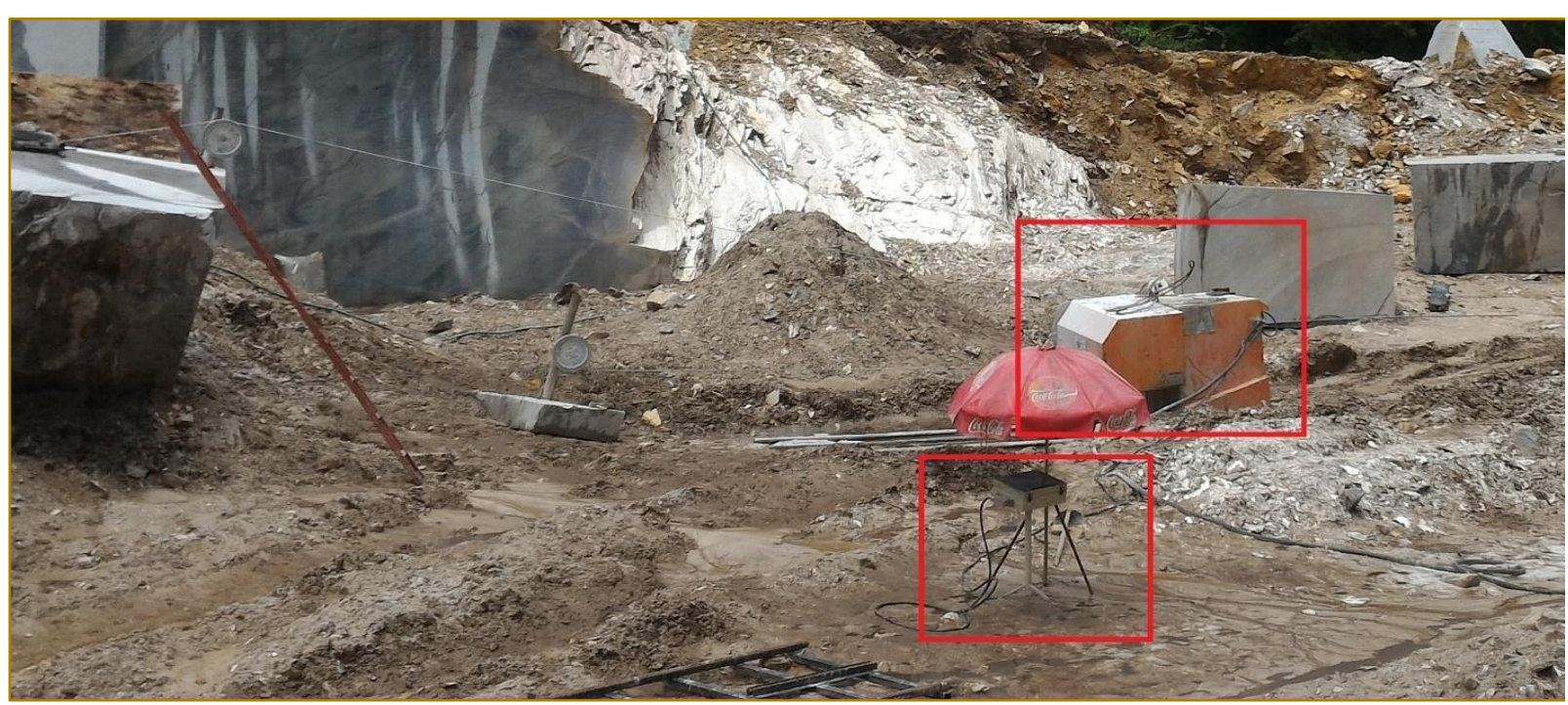

Fonte: Autoria própria (2017)

O quadrado em vermelho superior mostra uma máquina de corte de fio diamantado. A marcação inferior mostra o painel de controle da respectiva máquina.

O fio diamantado é composto por um cabo de aço com pérolas de diamantes regularmente espaçados por um material especiais de plástico e borracha. Esses fios são colocados e tensionados pela polia da máquina que fazem com que o mesmo se atrite com a rocha e ao mesmo tempo seja tracionado no sentido do corte desejado, produzindo o corte. O movimento do fio é feito pela polia maior e o tracionamento do fio é feito pelo andar da máquina sobre trilhos e por um outro sistema de acionamento que não o do fio (CAVAZZANA, 2005). Toda essa operação é controlada pelo painel de controle. Outras variáveis como a água usada, torres de alinhamento, roldanas e a movimentação da máquina com o decorrer do corte também devem ser controladas pelo Fiorista.

Tratando-se dos setores de uma jazida de rocha ornamental, destaca-se o setor de corte de fio. Os "Fioristas", como são denominados os funcionários dessa área, tem de lidar com um campo onde há uma grande necessidade de conhecimentos técnicos, atrelados a um alto grau de risco. Dentro desse espaço, o menor erro pode se traduzir em grandes perdas econômicas, materiais, atrasos nos prazos de entrega. Elucida-se na conjuntura econômica o corte impreciso dos blocos que gera descontos no valor por parte dos compradores, e ainda pode originar um retrabalho.
Apesar de ser considerada uma tecnologia inovadora nos âmbitos dessa atividade no brasil, a máquina de fio já está bastante difundida no contexto nacional (REGADAS, I.C, 2006). Contudo, por se tratar de uma atividade que utiliza um cabo de aço tensionado, e é a translação deste, sob tensão, quando enlaçado no mássico rochoso que irá efetuar o corte, há sempre o risco atrelado ao processo de rompimento do fio. $\mathrm{O}$ que pode ocasionar perdas enormes. Além disso, cita-se os riscos de deslizamentos de rochas, panes elétricas, entrave do fio diamantado da rocha que pode ocasionar uma parada brusca no equipamento.

Tendo em vista tais cenários, ressalta-se a importância de uma organização do efetivo pessoal de maneira a propor um mix dos níveis de similaridades onde colaboradores com diferentes saberes possam atuar em prol da produção e da segurança da melhor maneira possível.

\section{METODOLOGIA}

Apropria-se dos saberes desenvolvidos por Ribeiro (2012) em Tacit knowledge management. Phenomenology and the cognitive sciences, onde houve o estudo, na implantação de uma grande mineradora de níquel em uma área afastada, a respeito do gerenciamento do conhecimento tácito e sua a distribuição entre a força de trabalho de tal modo que os atores com diferentes graus de experiência, conhecimento tácito incorporado, fossem dispostos a acelerar a transferência 
desse "SABER-FAZER" entre as diferentes classes (DREYFUS, 2000).

E ainda ascender os níveis de segurança e produtividade no desenvolvimento de projetos sustentáveis em áreas remotas. Para isso é de fundamental importância a aplicação de uma "unidade de medida" para aferir-se o conhecimento incorporado desses trabalhos e estimar sua aplicabilidade. Esse conceito denominado "Níveis de similaridade", proposto por Ribeiro (2012), qualifica a experiência -Extrativista em Rochas Ornamentais de Quartzito- e demonstra a fidedigna capacidade de sistematizar essa transferência. Adiciona-se, a capacidade do sujeito, este moldado de forma complementar posto ao conhecimento explícito e tácito coletivo, em julgar o cenário acertadamente.

Inicialmente foi realizada uma observação geral e de análise organizacional do contexto produtivo, definição das tarefas e escolha da atividade a ser analisada. Tendo em vista o curto período de tempo em campo não houve a possibilidade de se incluir todos os setores no estudo. A pesquisa foi realizada no período entre julho de 2016 e abril de 2017. Durante esse tempo 4 meses foram dedicados ao campo conduzindo reuniões, análise da atividade, coletas de dados e entrevistas. Posteriormente, houve o estudo de cada funcionário baseado nas informações do $\mathrm{RH}$.

Dando sequência ao trabalho, um workshop irá esclarecer todo o trabalho e conceitos da pesquisa além de explicitar o material baseado no $\mathrm{RH}$ e confrontá-lo com os saberes de todos os indivíduos que tenham uma relação com o setor de "Corte de Fio Diamantado". E à vista disso, utilizando de todos os critérios e "Saberes" desse coletivo imerso na atividade, definir os "níveis de similaridade" e o mix de similaridade mais efetivo. Como parte da pesquisa também foi levado em consideração conversas informais que contribuíram o trabalho. Esses registros foram feitos por meio de gravações individuais e coletivas6.1-Etapa 1: Análise curricular

Para a definição dos "Níveis de Similaridade" foi necessário, em um primeiro momento, 194valia-los de acordo com seus currículos formais, alicerçada sobre os diversos contatos, entrevistas, conversas informais presentes na pesquisa. Essa análise teve a função de separar, do ponto de vista externo do pesquisador, os diferentes "níveis de similaridade": Alta, Média, ou Baixa, em função da quantidade de anos de profissão em cada serviço e nas experiências laborais em contextos semelhantes.

Com o currículo em mãos as perguntas norteadoras para a análise e estudo aprofundado do conhecimento tácito específico de cada um foram: Onde já trabalharam? Com que material já trabalharam? Por quanto tempo desempenharam aquela função? Essa crítica norteou uma definição primária do "nível de similaridade". Este foi o ponto de partida para um segundo momento, descrito a seguir.

\subsection{ETAPA 2: WORKSHOP E DEFINIÇÃO DOS NIIVEIS DE SIMILARIDADE}

O próximo passo foi em direção à confrontação do conceito empregado com os diferentes graus hierárquicos da empresa que tivessem relação com o campo em questão, permitindo assim formas mais concretas e diretamente ligadas à prática de gerir o conhecimento tácito. -Um workshop foi realizado para esclarecer todo o trabalho e conceitos da pesquisa, além de explicitar o material baseado no RH e confrontá-lo com os saberes de todos os indivíduos que tinham uma relação com o setor de "Corte de Fio Diamantado". À vista disso, foi necessário definir os "níveis de similaridade" das atividades e uma estimativa de tempo mínimo em anos para que se possa dominar as funções para aquele nível.

Foi realizada uma reunião com os 7 funcionários responsáveis pelo setor de corte, o proprietário da empresa, o engenheiro responsável, o supervisor de campo, o fiscal de qualidade, e o proprietário da empresa compradora. Devido ao alto grau de conhecimento de todo o setor de rochas ornamentais aliado ao elevado interesse das rochas provenientes daquela jazida.

A reunião foi iniciada com uma explicação sobre a proposta de pesquisa, os objetivos, uma apresentação da primeira tabela montada a partir dos currículos. E entre os motivos que levaram a escolha dessa classificação, cita-se, a ideia de um indivíduo que fosse capaz de operar uma máquina de fio em dispares contextos com a mesma competência levantou uma sombra de dúvidas por entre os participantes.

Funcionário 1: "Uai, mas isso aí não é verdade so, se fosse assim era fácil. Eu to falando por mim, mas olha, já trabalhei mais de 5 anos no 
granito de Fiorista e quando comecei a trabalhar no quartzo era tudo diferente, eu era novato de novo (...)".

Apesar de um conceito novo, a ideia do contexto de trabalho similar ou "nível de similaridade" já estava intrínseca nesse grupo. Uma prova disso é que este se apresentava no cotidiano da atividade, como apresentado abaixo.

\subsubsection{O CONCEITO ENRAIZADO}

Era fim de noite quando um novo funcionário se apresenta no alojamento. Após minutos de alguma conversa dirige-se ao dormitório para se preparar para a atividade logo pela manhã. O supervisor de campo relata que o funcionário tem boas referências e também bastante experiência. Mas que quer vê-lo no trabalho, com a "mão na massa".

Supervisor de campo: "Eles chegam aqui falando que sabem isso, que já fizeram aquilo, já trabalharam não sei quantos anos com pedreira. Mas essa pedreira aqui é diferente, o material é único. Não tem como saber sem vir e trabalhar aqui".

A ideia de que cada pedreira e única por parte do supervisor e baseada nas características e especificidades de cada rocha. Por exemplo, as fraturas que o mássico rochoso pode apresentar define como será a frente de trabalho. Essas características são de caráter morfológico das rochas e podem também estar relacionadas com ao intemperismo. Apesar de naquela época o conceito de nível de similaridade não ter sido apresentado para esse coletivo de trabalho, vê-se que de certo modo já existia entre os trabalhadores uma imagem da diferença de similaridade, a diferença entre ter experiência e ter a experiência situada (LOIOLA e THERRIEN, 2001).

Imediatamente, foram divididos em três grupos de acordo com seus "níveis de similaridade" e apresentados à tarefa. Era fundamental que eles mostrassem todas as características necessárias a um Fiorista, e contextos de atividades de trabalho que consideravam importantes para que um Fiorista pudesse ser considerado de Alta similaridade em uma pedreira de Quartzito. E posteriormente, estimar o tempo necessário em cada atividade.

\subsection{ETAPA 3: O MIX DE SIMILARIDADE}

Com a tabela de classificação dos níveis de similaridade construída e com os currículos dos funcionários em mãos, os gestores com apoio da equipe encontraram 0 mix de similaridade correto para cada turno. Não foi surpresa que um turno com somente pessoas de Alta similaridade fosse a preferência de grande parte dos gestores, visto que, funcionários de Alta similaridade dominavam o processo com superioridade aos demais níveis. No entanto, a classificação dos "níveis de similaridade" deveria mostrar exatamente qual o nível de funcionário necessário para cada grupo de trabalhadores para formar o mix correto. Isto é, funcionários capazes de lidar com as variabilidades da atividade, com qualidade de produção e segurança no processo, ao menor custo por funcionário.

\section{CRONOGRAMA}

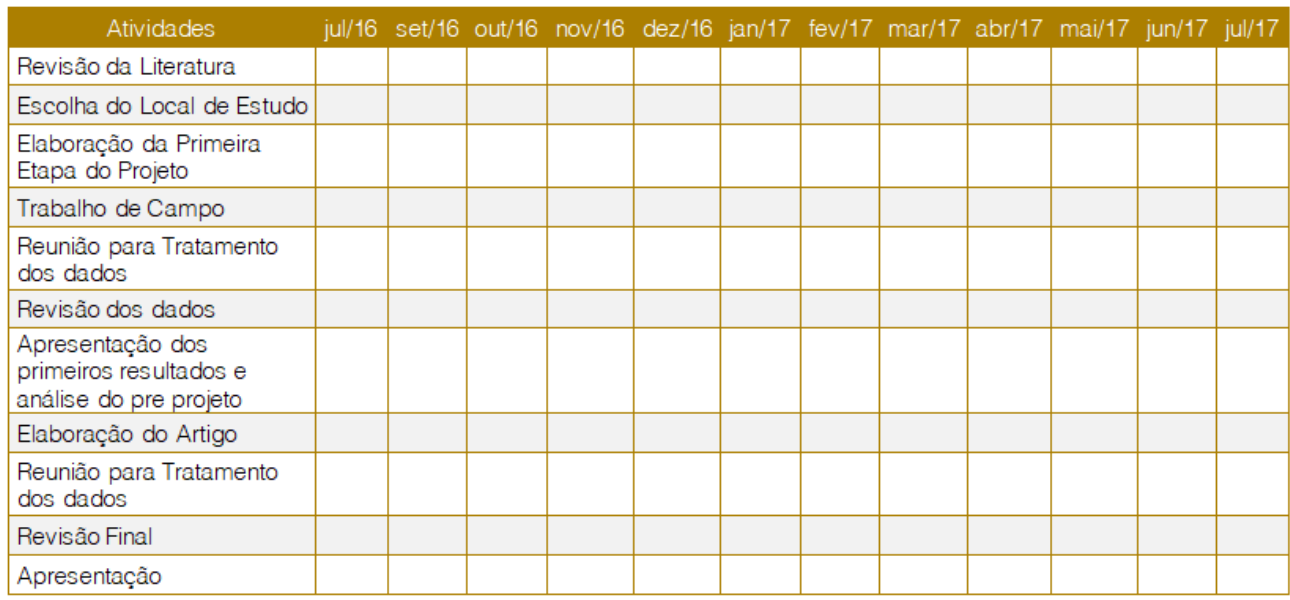




\section{RESULTADOS E DISCUSSÃO}

\subsection{RESULTADOS DA ANÁLISE CURRICULAR}

De acordo com a Etapa 1, a Tabela 1 foi criada para avaliar os funcionários de acordo com seus currículos e classificados de acordo com as atividades de trabalho $x$ anos de serviços. Partiu-se do pressuposto que qualquer experiência com máquinas de fio, seja ela em minas subterrâneas ou obras de infraestrutura, poderiam ser consideradas "similares". Logo, a classificação entre Alta, Média e "Baixa similaridade" ocorreram fundamentalmente de acordo com os anos de experiências. A título de exemplo, baseado em entrevistas, observações e análises de campo, uma pessoa que houvesse trabalhado com uma máquina de fio em qualquer contexto por mais de 5 anos poderia ser considerada de "Alta similaridade", entre 3 e 4 anos seria de Média, e menos que 3 anos, "Baixa similaridade". O que no futuro provouse completamente equivocado.

TABELA 1- Atividade $x$ Anos de serviços

\begin{tabular}{|c|c|c|c|c|c|}
\hline & \multicolumn{2}{|c|}{ Quartzo } & Granito & Arenito & TOTAL \\
\hline André & 6 anos & 7 anos & & & 13 anos \\
\hline Vagner & 3 anos & 5 anos & & 6 anos \\
\hline Roberto & & & & 3 anos & 6 anos \\
\hline Jean & & & & 1 ano & 3 anos \\
\hline Pedro & & & & 1 ano & 1 ano \\
\hline Gilson & & & & & $-1 .--$ \\
\hline
\end{tabular}

Fonte: Autoria própria (2016)

"Outros" Denomina todas as atividades exercidas envolvendo uma máquina de fio mas que não necessariamente são relacionadas a rochas ornamentais.

GRÁFICO 1- Nível de similaridade baseado em informações do RH

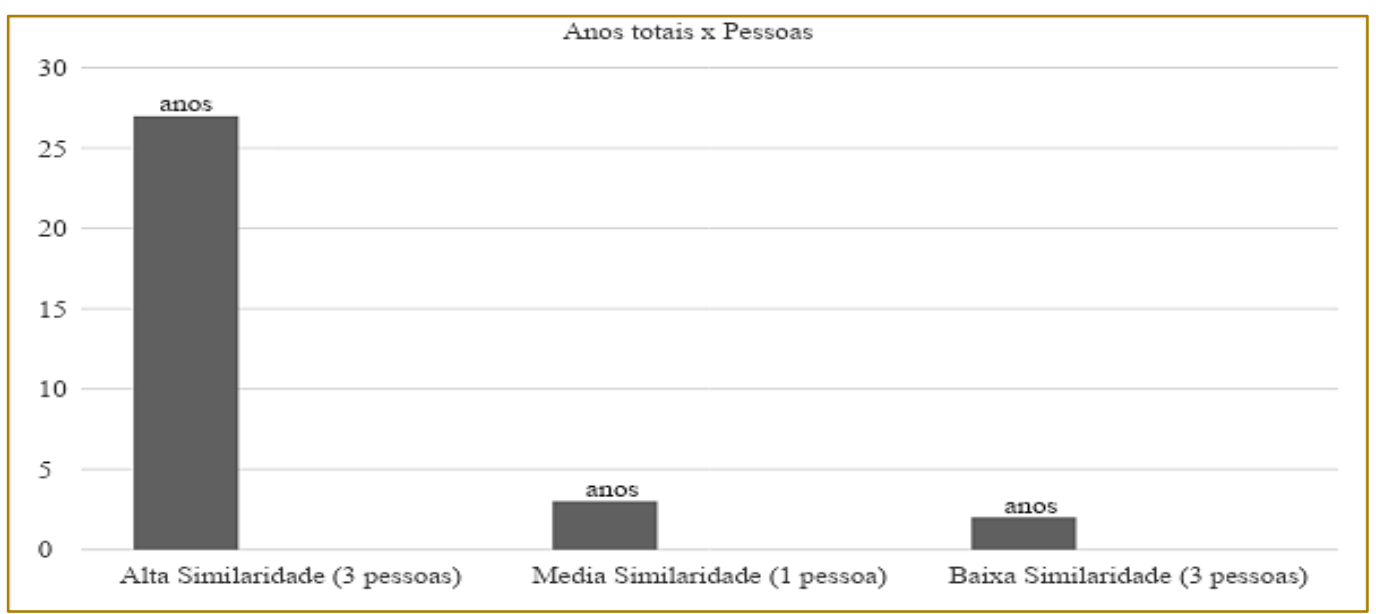

Fonte: Autoria própria (2016)

Foram analisados 7 funcionários que juntos obtiveram um total de 32 anos trabalhados. Destes, 27 anos foram classificados como sendo de "Alta similaridade" correspondendo a $84 \%$ dos anos de experiência em 3 funcionários. Na "média similaridade", obteve- se 3 anos ou aproximadamente 10\% dos anos de experiência desse setor. E, por último, 3 integrantes se encaixaram como sendo de Baixa similaridade com uma relação de $6 \%$ dos anos totais. Um "nível de alta similaridade" em $42 \%$ dos funcionários nesse 
respectivo setor pode parecer um bom início. Todavia, deve atentar-se para o elevado grau de risco e dificuldade que esse setor enfrenta.

Questões surgiram através desses números que começavam a confrontar e questionar os saberes e respostas obtidas. Eram esses números suficientes para uma operação segura? Um Fiorista que já houvesse trabalhado 8 anos em uma pedreira de granito com máquina de fio poderia ser considerado de alta similaridade para o contexto do quartzito? Os níveis iriam definir quais os funcionários mais aptos a trabalhar o quartzito? Ainda havia diversos outros degraus a se percorrer para atingir tais objetivos.

\subsection{RESULTADOS DO WORKSHOP}

A definição de "níveis de similaridade" tem seus alicerces na ideia de que quanto mais similar a experiência prévia for da atual, maior o seu nível de similaridade, ou seja, mais experiente ele pode ser considerado. Assim, todos os grupos deveriam apresentar situações em que ficasse clara a diferença entre "níveis de similaridade". Assim, todos os 3 grupos deveriam apresentar situações em que ficasse clara essa diferença.

TABELA 2- Classificação dos "níveis de similaridade"

\begin{tabular}{|l|l|l|l|l|l|l|}
\hline \multicolumn{7}{|c|}{ "Nível de Similaridade" } \\
\hline & Baixa & $\begin{array}{l}\text { Mínimo } \\
\text { (anos) }\end{array}$ & Média & $\begin{array}{l}\text { Mínimo } \\
\text { (anos) }\end{array}$ & Alta & $\begin{array}{l}\text { Mínimo } \\
\text { (anos) }\end{array}$ \\
\hline $\begin{array}{l}\text { Corte } \\
\text { de Fio }\end{array}$ & $\begin{array}{l}\text { Construção } \\
\text { civil e outros }\end{array}$ & 3 & Pedreira de Quartzo & 2 & Pedreira de Quartzito & 2 anos \\
& & & Pedreira de Granito & 3 & & \\
\cline { 4 - 5 } & & & Pedreira de Arenito & 3 & & \\
\hline
\end{tabular}

Fonte: Autoria própria (2016)

Os "níveis de similaridade" mostraram-se uma forma viável de identificar os quadros em que as atividades com as máquinas de fio fossem similares as de Quartzito, desde que, feito sobre a capacidade de pessoas imersas no contexto prático. Um exemplo foi em uma discussão nos grupos sobre o discernimento dos níveis e o que seria necessário em cada um. O que para nós mostrava-se como sendo um alto "nível de similaridade", um Fiorista que já tivesse trabalhado em uma pedreira de Granito por 8 anos, para eles se encaixava no máximo como "Média similaridade". Para esse trabalhador, ser considerado de "Alta similaridade" na extração de rochas ornamentais (Quartzito) ele deveria ter pelo menos 2 anos de experiência em rochas de Quartzito ou 2 anos em uma pedreira de Quartzo e 6 meses no Quartzito. Apesar de ambas serem a céu aberto e poderem ter até mesmo a mesma forma de produção e as mesmas máquinas, as características morfológicas das rochas são tão diferentes que tornam cada uma um contexto ímpar.
Sendo assim, a atividade de máquina de fio no contexto da construção civil foi considerada de baixa similaridade se comparada a extração de rochas ornamentais de quartzito. Na média similaridade atenta-se para um caso em específico, as pedreiras de quartzo. Apesar de ser classificada como media similaridade as características morfológicas da rocha, como sua dureza e textura, a tornam mais semelhantes com as pedreiras de quartzito. $\mathrm{E}$ isso leva a uma adaptação mais rápida de uma atividade a outra. Nesse caso especifico, 6 meses.

A rocha que é formada principalmente por Quartzo tem uma dureza muito maior do que os granitos em geral. Como ato de comparação, um rolo de fio diamantado usados em máquinas de fio chega a cortar até $3000 \mathrm{~m} 2$ de granito, enquanto no quartzo a mesma máquina faria $800 \mathrm{~m} 2$. E no Quartzito $400 \mathrm{~m} 2$. Por ter uma dureza muito maior as rochas de Quartzo são mais similares as de Quartzito, logo, trabalhadores que tiveram experiências nesses tipos de jazidas tem mais 
facilidade para pegar o "jeito" do Quartzito. Com base na Tabela podemos afirmar que muitos anos de experiência não são garantia de um alto "Nível de similaridade". O que acaba por refutar a tradição de que quanto mais experiente melhor. Os níveis de similaridade trazem o novo conceito de que experiência sim é importante, mas uma experiência situada, de conhecimento tácito situado.

\subsection{RESULTADOS DO MIX DE SIMILARIDADE}

Após o workshop surgiu o "Mix de similaridade" para o setor de corte. A equipe conseguiu definir a melhor maneira de se organizar o contingente de funcionários. De maneira a sempre se manter um grau elevado de similaridade durante o corte, e dessa forma uma qualidade produtiva elevada, agregada a segurança no processo do corte de fio diamantado.

Um Fiorista de Alta similaridade poderia ficar encarregado de no máximo duas máquinas, desde que contasse com uma equipe de dois ajudantes. Sua tarefa deveria ser acompanhar os painéis das duas máquinas, garantindo seu funcionamento adequado e, no decorrer do corte, fazer os ajustes necessários com o apoio dos dois ajudantes. Por exemplo, enquanto o funcionário de Alta similaridade observa o painel, o outro funcionário é direcionado ao alto da rocha para diminuir, aumentar ou reposicionar a vazão de água para o corte, ou ajustar uma torre de corte.

No período noturno, no qual como descrito anteriormente, só ocorria o corte dos blocos da prancha já derrubada no chão- Maciço rochoso. Por se tratar de uma atividade com risco menor, uma equipe composta por um funcionário de media similaridade e um de baixa foi considerada suficiente. Entenda-se por "risco menor": quebra do fio, desgaste excessivo das pérolas de diamante, e em contraste com o turno do dia não havia a necessidade de subir na pedra em si o que se tornava um risco pela altura.

De acordo com o mix de similaridade, e sabendo que a empresa contava no momento com 4 máquinas de fio, o período diurno da pedreira precisaria de 2 Fioristas de alta similaridade e 4 de baixa ou média. Enquanto o período noturno, um funcionário de média e um de baixa similaridade. A indiferença sobre baixa ou média, tratando-se do período diurno, deve-se à atividade que eles serão responsáveis, todas realizadas a partir das instruções dos atores de alta similaridade.

\section{ANÁLISE}

Tratando-se da atividade de trabalho, dos treinamentos e cursos especializados, referencia-se Ribeiro (2013b) que trata a importância da Imersão Física, o trabalho como unicidade da atividade de trabalho, das condições únicas e particulares da atividade (GUERIN, F. et al, 2001), em detrimento da Socialização Linguística como forma de aprimorar treinamentos e especializações em um quadro de alto risco extrativista, como o de rochas ornamentais. Concebido por Merleau-Ponty (2012), a "Fenomenologia da Percepção" com o conceito de Sincronização, demonstrou-se que cada indivíduo deve passar por um processo característico pelo qual irá adquirir a experiência necessária. Para a partir deste ponto, por exemplo, ponderar corretamente as situações imprevisíveis no setor de "Corte de Fio".

Pontua-se ainda, que além dos contextos similares de produção, a metodologia aplicada por Ribeiro (2012) no contexto da mineração de níquel explicitou as características e unicidades em cada nível de similaridade. Em quais aspectos da qualidade da produção, da organização, da segurança no trabalho um indivíduo de Alta similaridade tinha de diferença para um de média e baixa. Nessa pesquisa houve a definição de contextos de trabalho similares que podem ser úteis para a uma pedreira de quartzito. Contudo, as habilidades e características de cada nível ficaram implícitas. Acredita-se, contudo, que um maior refinamento dos resultados faria esses aspectos aflorarem.

\section{CONCLUSÃO}

Uma das principais preocupações era deixar claro que a proposta poderia levar a empresa a organizar seu contingente/materiais de forma mais eficiente e também planejar melhor suas contratações. Com a análise do "mix de similaridade" por parte dos gestores, ficou claro que, apesar de contarem com um número suficientes de fioristas, havia a demanda de mais um funcionário de "média similaridade". Isto se explica pelo fato de que durante o período noturno apenas uma das máquinas de fio funcionava e não havia a necessidade de se gastar recursos com um funcionário de alta similaridade. Após feita a 
constatação, um escopo foi enviado ao $\mathrm{RH}$ com as sugestões para a contratação. Requeria-se um fiorista de "média similaridade", ou seja, aquele que já houvesse trabalhado por pelo menos 2 anos em uma mina de quartzo, conforme identificado nos workshops deste estudo.

A pesquisa procurou ampliar a organização e a capacidade da empresa em gerir o REFERÊNCIAS

[1]. CAVAZZANA, Erlon. Modelo teórico de um fio diamantado para corte de mármore e granito. Vitória. 2005. Disponível em: http://projgradufes.xpg.uol.com.br/documentos/PG 2005_1/erloncavazzana.pdf. Acesso em: 28 Set 2016.

[2]. COLLINS, Harry; RIBEIRO, Rodrigo. A máquina de fazer pão: Conhecimento tácito e dois tipos de ação. 2007.

[3]. GUERIN, F. et al. Compreender o trabalho para transformá-lo: a prática da ergonomia. São Paulo: Edgard Blücher; Fundação Vanzolini, 2001.

[4]. INSTITUTO BRASILEIRO DE GEOGRAFIA E ESTATISTICA. Cidades. Disponível em: http://cidades.ibge.gov.br/xtras/perfil.php?lang=\&c odmun=292360\&search=Ilinfogr\%E1ficos:-

informa\%E7\%F5es-completas. Acesso em: 23 Set 2016.

[5]. LIMA, Francisco; RIBEIRO, Rodrigo. Interactional Expertise Revisited. Belo Horizonte. 2016.

[6]. LOIOLA, Francisco; THERRIEN, Jacques. Experiência e competência no ensino: Pistas de reflexões sobre a natureza do saber-ensinar na perspectiva da ergonomia do trabalho docente. Educação \& Sociedade. 2001

[7]. LOPES, Marcos. As principais rochas ornamentais exploradas no Brasil. Disponível em: http://tecnicoemineracao.com.br/principais-rochasornamentais-exploradas-no-brasil/. Acesso em: 15 Set 2016.

[8]. Ministério da Saúde. DATASUS. Disponível em: conhecimento tácito e, dessa forma, tornar mais eficiente os princípios de contratação, formação de equipes, distribuição entre turnos e setores, e até mesmo o planejamento das férias. Na busca pela qualificação do conhecimento tácito, todo o contexto da atividade tende a se tornar mais seguro e produtivo, facilitando o processo de desenvolvimento do projeto de exploração mineral em uma área tão longínqua.

http://www.datasus.gov.br/DATASUS/index.php?ar ea $=0206$. Acessado em: 31/07/2016.

[9]. NONAKA, Ikujiro; TAKEUCHI, Hirotaka. The knowledge-creating company. Oxford: Oxford University Press. 1995

[10]. NONAKA, Ikujiro; TAKEUCHI, Hirotaka. Criação de conhecimento na empresa: como as empresas japonesas geram a dinâmica da inovação. Rio de Janeiro: Campus, 1997

[11]. RIBEIRO, Rodrigo. Tacit knowledge management. Phenomenology and the cognitive sciences. Springer Science. Belo Horizonte. 2012. Disponível em: https://link.springer.com/article/10.1007/s11097011-9251-x. Acessado em: 13 Set 2016.

[12]. RIBEIRO, Rodrigo. The Role of Experience in Perception. Springer Science. Belo Horizonte. $2014 . \quad$ Disponível em: https://link.springer.com/article/10.1007/s10746014-9318-0. Acessado em: 12 Set 2016

[13]. RIBEIRO, Rodrigo. The role of interactional expertise in interpreting: the case of technology transfer in the steel industry. Belo Horizonte: Elsevier Ltd. 2007

[14]. REGADAS, Isaura. Aspectos relacionados as lavras de granitos ornamentais com fio diamantado no norte do estado do Espírito Santo, Brasil. São carlos. 2006.

[15]. SANTOS, Rodrigo. Brasil lidera fornecimento de rochas ornamentais. Manutenção \& Tecnologia. 2015. Disponível em: http://www.revistamt.com.br/index.php?option=com _conteudo\&task=viewMateria\&id=2088. Acesso em: 15 Set 2016. 


\section{Capítulo 17}

\section{REFLEXÕES SOBRE OS POSSÍVEIS IMPACTOS DO MARKETING RELIGIOSO NO MUNICÍPIO DE BOM JESUS DA LAPA.}

\section{Deyse Queiros Santos}

Neivande Dias da Silva

Cassiana Santos da Silva Farias

Resumo: Eficazes estratégias de marketing têm sido utilizadas por todos os segmentos empresariais. Nesse artigo, temos por objetivo mostrar como o marketing também está atualmente presente nas instituições religiosas modernas, que despertaram para a importância de atender desejos e necessidades dos consumidores potenciais da religião cristã. Para isso, tais instituições investem cada vez mais em estratégias mercadológicas para obtenção do crescimento numérico dos seus fiéis, atendendo, de forma eficiente, uma considerável demanda do mercado religioso. Para os estudos que foram realizados que trata-se de uma pesquisa básica de natureza qualitativa, foi contemplada a pesquisa descritiva e como procedimentos de coleta de dados foram feitos estudos através de pesquisa Bibliográfica e Documental que permitiram inferir sobre o papel do marketing no desenvolvimento do turismo religioso do município de Bom Jesus da Lapa. A cidade investigada adquiriu uma importância na rede urbana regional em função da sua oferta de serviços e de comércios modernos. Isso tem favorecido a expansão das atividades econômicas, muito influenciada pelo o incremento do numero de fiéis e a evolução do perfil dos romeiros.

Palavras-chave: (Turismo religioso; Marketing; Desenvolvimento regional) 


\section{INTRODUÇÃO}

A religião, que outrora possuía mera função espiritual e dogmática, atualmente tem um papel diferenciado em nossa sociedade. Essa diferenciação ocorreu, sobretudo, após o crescimento e a internacionalização do protestantismo norte-americano e o surgimento de novos movimentos católicos em meados do século XX, como a teologia da libertação e a renovação carismática católica (Machado, 2015). Essa nova orientação religiosa transformou os templos religiosos em espaços que, além de agradecer a deuses, buscar o perdão dos pecados, ou realizar sacramentos tornam-se um lugar de entretenimento, de bem-estar afetivo e social.

Associados com frequência aos templos estão às novas formas de relacionar-se com os fiéis e também da prática dos cultos. Um dos possíveis caminhos atualmente é o turismo e os locais onde há templos religiosos ou onde houve alguma manifestação de importância religiosa há visitação do turismo religioso. Nestes locais são criadas estruturas receptivas que podem gerar aspectos positivos como o aumento da arrecadação financeira, a geração de empregos, a qualificação da mão-de-obra e o desenvolvimento urbanístico, dentre outros. Entretanto, há também problemas sociais, econômicos e urbanísticos que o turismo proporciona, principalmente quando a localidade não possui planos e estratégias de gestão (Santos, 2010)

O Turismo Religioso tem um importante papel na economia, na cultura e na sociedade onde ocorrem. Os impactos políticos costumam ocorrer na gestão e divulgação da um determinado atrativo. Além disso, é papel do Estado garantir saúde, educação, transporte, saneamento básico e melhores condições de vida para os moradores de uma localidade, mesmo que seus atrativos não sejam geridos pela esfera pública (Teixeira \& Junior, 2003). Os impactos culturais abordam a mudança na estrutura da sociedade (Machado, 2015). Os impactos econômicos costumam se manifestar mais claramente e geralmente são os mais citados pelos administradores e autoridades locais para abordar um sucesso/ fracasso de um atrativo. Já os impactos sociais são consequência direta do processo de turistificação local, e costumam ser os mais difíceis de obter resultados positivos (Ribeiro, 2010).
Outro fator relevante são as estratégias de marketing que, independente do setor de atuação visam estabelecer as melhores formas de propagação, aceitação e venda de um produto ou serviço em um mercado específico de forma a atender as necessidades e desejos de seus consumidores (Silva, 2005). As religiões possuem um cenário atual de intensa competição mercadológica, disputando entre si a busca da aquisição, preservação e manutenção de novos e antigos seguidores (Mariano, 2004). Um exemplo é o atual crescimento das religiões protestantes frente ao catolicismo, que tem mobilizado a Igreja Católica a encontrar uma forma para evitar a evasão de fiéis (Fernandes, 1996).

A abordagem da religião sob os enfoques estratégicos e mercadológicos vêm sendo efetuados nos últimos anos, destacando-se levantamento de opinião da Igreja sobre os meios de comunicação de massa (Fadul, 1986), análise do processo de comunicação na Igreja (Dellacava \& Monteiro, 1991), princípios básicos de marketing religioso (Kater Filho, 1993), análise das formas de comunicação das Religiões (Gomes, 1987), estratégias de marketing religioso (Matayoshi, 2000) e análise do comportamento do consumidor religioso (Salvi \& Giglio, 2003).

Neste sentido, este trabalho procura entender aspectos relacionados às estratégias de fidelização para o aumento do grau de envolvimento pessoal dos católicos com a religião, bem como avaliar as possíveis consequências do marketing religioso no desenvolvimento da cidade de Bom Jesus da Lapa-Ba.

\section{MARKETING RELIGIOSO}

Hoje não causa mais espanto saber que todas as atividades humanas foram despertadas para a necessidade de persuasão e conquista. É assim no comércio, na indústria, nos serviços, na educação, na informação, na religião etc. Para as religiões que se encontram irremediavelmente submersas numa parafernália de símbolos e apelos, e mergulhadas na aberta permissão para a existência de uma "incômoda" pluralidade religiosa, o marketing passa a ser adotado nas diversas denominações religiosas com muita facilidade, e normalmente é visto como um instrumento eficaz no competitivo mercado religioso (Campá, 1998). 
Num contexto de globalização como este, onde a oferta religiosa é cada vez mais diversificada, onde a informação se difunde a uma velocidade estonteante e onde cada pessoa se torna mais livre relativamente às escolhas que faz, o marketing surge como uma ferramenta útil para adequar a oferta que temos e para melhor definir aquela que é a nossa marca (Katter Filho, 1995). Estes consumidores da religião têm muitas necessidades de ordem espiritual, psíquica e emocional insatisfeitas, e podem perfeitamente satisfazê-las através da "compra de promessas religiosas" (Patriota, 2003).

Pautando-se nessas oportunidades, alguns religiosos encontram o nicho, e compreendem a religião como um produto extremamente vendável na atual sociedade de consumo. Campos (1998) afirma que essa percepção:

Propaga-se numa sociedade pluralista e com tendências à secularização, cujo campo religioso concorrencial e turbulento facilita o surgimento de instituições ágeis, sintonizadas com as necessidades e desejos de um público devidamente segmentado, formando assim seu próprio mercado, empregando para isso estratégias de marketing e de propaganda, as quais se exteriorizam em ritos, retórica, teologia, formas administrativas e organizacionais, adaptáveis aos interesses de uma sociedade capitalista em processo de globalização. (Campos, 1998)

O "nicho mercadológico" achado pelas igrejas cristãs que investem em marketing tem sido explorado de forma impressionante com a rapidez peculiar ao atual desenvolvimento tecnológico, e com os instrumentais da comunicação, elas desenvolveram um discurso próprio, uma teologia própria e uma linguagem padronizada e eficaz, invadindo sem cerimônia alguma, muitos lares através do rádio e da televisão (Patriota, 2000).

O marketing é uma ciência social que tem por base uma teoria provinda da mais antiga ciência: a economia (Barna, 1997). Desta forma, a par do que acontece na economia com o fenómeno da determinação do valor, em que existe uma estreita relação com a troca, também o marketing estuda as transações que remetem para a necessidade da troca de valores entre os intervenientes ("clientes" e organização).

O Marketing Religioso consiste na aplicação do marketing a um campo específico: a todas as organizações religiosas que têm como fundamento da sua existência a satisfação das necessidades espirituais e religiosas da pessoa (Abreu, 2004 \& Barna, 1997). O seu objetivo prende-se com o desenvolvimento das organizações religiosas, procedendo-se para o efeito, à boa gestão das relações de troca que estabelece com os intervenientes, por forma a conseguir alcançar eficientemente a sua missão.

No marketing tradicional uma empresa oferece, ou torna disponível, produtos físicos, previamente guiados pela observação dos "anseios" do cliente. Nestes produtos, a empresa acrescenta "valores intangíveis", que se prontificam a satisfazer de imediato as necessidades latentes do consumidor (Hoffman \& Bateson, 2001). No entanto, mesmo que estas necessidades não sejam verdadeiramente latentes, o marketing, lançando mão da propaganda, se encarregará de convencer o possível cliente de que ele necessita realmente do produto oferecido. Partindo dessa premissa, podemos analisar a materialidade de alguns discursos religiosos e ver que eles reproduzem integralmente o discurso publicitário no item persuasão. Nestes discursos, a argumentação religiosa parte de se dar aos "produtos da fé", uma vantagem competitiva sobre os oferecidos por outras igrejas que não têm a preocupação de trabalhar as suas embalagens.

Além disso, o marketing religioso, tal como outras concepções dentro do conceito de marketing remete-nos para a importância de bem servir as pessoas, havendo por isso que desvalorizar a associação depreciativa que ainda se faz do marketing às campanhas publicitárias, ou seja, ao comércio, aspecto menos bem avaliado (Gronroos, 1997).

Com efeito, sendo de crucial importância conhecer os públicos para dessa forma melhor se poder agir sobre eles, torna-se imperativo iniciar as atividades de marketing estratégico que se podem sumariar nos seguintes procedimentos: segmentação, escolha do alvo, posicionamento.

\subsection{TURISMO RELIGIOSO NO BRASIL}

O Ministério do Turismo (MTur), órgão responsável por gerir e promover o turismo dentro do território brasileiro, traz na publicação Turismo Cultural: Orientações Básicas (2010) o seu próprio conceito para a 
atividade. De acordo com o MTur (2010), o turismo religioso:

[...] configura-se pelas atividades turísticas decorrentes da busca espiritual e da prática religiosa em espaços e eventos relacionados às religiões institucionalizadas, independentemente da origem étnica ou do credo [...] Está relacionado às religiões institucionalizadas, tais como as de origem oriental, afro-brasileiras, espíritas, protestantes, católica, composta de doutrinas, hierarquias, estruturas, templos, rituais e sacerdócio. (Brasil, 2010, p. 19).

Os critérios utilizados para processar a segmentação podem incluir a idade, nível de renda, meio de transporte, duração da permanência, distância do mercado consumidor, tipo de grupo, sentido do fluxo turístico, condição geográfica da destinação turística, aspecto cultural, grau de urbanização da destinação turístico (Ignarra, 2003).

$\mathrm{Na}$ atualidade a segmentação do mercado de turismo, uma vez que esta responde a demandas historicamente localizadas, se apresenta com os seguintes seguimentos: turismo científico, cultural, de estudos, de intercâmbio, pedagógico, de raízes, de eventos, de negócios, comercial, e no turismo, de golfe, espacial (Trigo et al, 2005). Despontam ainda como importantes seguimentos específicos do mercado turístico o turismo religioso e o turismo social.

O turismo religioso como fato social, gerador de deslocamento, que envolve públicos emissor e receptor, tem sua origem em tempos remotos, tendo em vista que peregrinações, romarias, festas religiosas desde muito antes do nascimento de Jesus Cristo já mobilizavam pessoas que viajavam motivados por suas crenças e por objetivos ligados ao transcendente. De acordo com dados preliminares do Departamento de Estudos e Pesquisas do MTur, em 2015, cerca de 17,7 milhões de brasileiros viajaram pelo país levados pela fé. Cerca de 10 milhões fizeram viagens sem pernoitar no destino (excursionistas) e outros 7,7 milhões permaneceram pelo menos uma noite no local.

Entre os destinos de turismo religioso consolidados no país também estão o Círio de Nazaré (Belém, PA), uma das maiores festas religiosas do mundo, que reúne cerca de um milhão e meio de pessoas em outubro; a Romaria à Juazeiro (Juazeiro do Norte, CE), que recebe cerca de dois milhões de devotos de Padre Cícero por ano; a Romaria de Bom Jesus da Lapa, com cerca de um milhão de peregrinos todo ano.

\subsection{ROMARIA DE BOM JESUS DA LAPA}

Caminhar, peregrinar, fazer romarias não é algo novo para o povo católico. Há séculos existem santuários nacionais, regionais e locais espalhados por todo o Brasil. Multidões continuam acorrendo a eles, apesar das grandes mudanças que se verificam no campo religioso brasileiro (Azzi, 1979). São tradições arraigadas em antigos costumes, repassados de geração a geração. Rosendal (2002) em suas pesquisas sobre três santuários populares, diz que as festas, procissões e romarias são as práticas mais sensacionais da religião popular, um tempo forte de imensa vivência religiosa, no qual ocorre visivelmente o encontro simbólico do santo com o povo, num controle direto, sem intermediários.

Romaria do Bom Jesus teve seu inicio no final do século XVII e tem seu ponto alto no dia 06 de agosto com a celebração da missa do romeiro na Esplanada do Santuário. É o evento religioso que reúne o maior número de fiéis na cidade e mobiliza todo espaço urbano da Hierópolis. As grutas, o morro e a água que brota das rochas são elementos naturais revestidos de sacralidade (MICEF, 2006).

As tradições de culto aos santos vêm da Europa, mas são recriadas pelos crentes, que utilizam uma linguagem simbólica e litúrgica peculiar para cultuar os seus santos protetores nos lugares sagrados (Souza, 1991). A missa, a confissão e a eucaristia fazem parte da liturgia formal da Igreja, da qual o romeiro participa. Entretanto, práticas como a subida do morro, a via sacra, a promessa e vários cânticos, dos quais muitos são desconhecidos pelos párocos locais, fazem parte do amplo e diverso leque de atividades religiosas dos meios populares, muito utilizadas pelos peregrinos do Bom Jesus.

A vida econômica e social da cidade de Bom Jesus da Lapa está estruturada em torno da romaria do Bom Jesus, assim, os afluxos de romeiros ao longo de todo o ano trazem dividendos, influencia a forma de organizar a vida familiar, influencia também o calendário civil da cidade (escolar, semanas temática, atividades recreativas) e estabelece o ritmo 
cotidiano da vida das pessoas que ali residem (Steil, 1996). Nos festejos do Bom Jesus, onde a participação popular aumenta exponencialmente o número de pessoas na cidade em relação ao número de habitantes, os moradores locais deixam as suas próprias casas a fim alugá-las aos romeiros/turistas e auferir algum lucro durante a peregrinação.

Embora o público que frequenta o santuário, na romaria-turismo do Bom Jesus, seja pobre e vítima de exclusão socioeconômica não deixa de influenciar no aporte financeiro que a cidade arrecada como também concorre para aquecer a economia do município e da região em seu entorno (Micef, 2006). Durante seis meses um considerável número de comerciantes se coloca na expectativa da realização dos eventos tendo em vista os benefícios daí advindos, ou seja, a intensificação do consumo por parte dos visitantes e a consequente obtenção de lucros. Há uma tendência de se explorar ao máximo as atividades comerciais, na esperança de se ter assegurada a sobrevivência por mais um período, reproduzindo-se dessa forma o ciclo da "economia da romaria". Durante os outros seis meses, diante das limitações do mercado de trabalho, manifesta-se um aparente estado de apatia (Santos, 2010).

A romaria do Bom Jesus da Lapa, de 29 de julho a 06 de agosto, não é a única que acontece durante o ano para o Santuário, existem outras que reúnem um número expressivo de devotos e que vão de julho a janeiro de cada ano. Conforme o site do Santuário (www.bomjesusdalapa.org.br), são elas: Romaria da Terra e das Águas, sempre no primeiro semestre de cada ano; 28 de julho a 06 de agosto, novenário do Senhor Bom Jesus; 15 de agosto, Romaria Diocesana dos Coroinhas; 05 a 06 de setembro, Romaria da Pastoral da Criança; 08 a 15 de setembro, setenário de Nossa Senhora da Soledade; 18 a 20 de setembro, Romaria dos Agentes Comunitários de Saúde e Endemias; 04 de outubro, festa do fundador do Santuário, Francisco de Mendonça Mar; 12 de outubro, festa de Nossa Senhora Aparecida, com a visita da imagem (2009); 18 de outubro, Romaria da Renovação Carismática; 25 de outubro, Romaria da Legião de Maria; 08 de dezembro, Festa da Imaculada Conceição; 13 de dezembro, Festa de Santa Luzia; 31 de janeiro, festa de Bom Jesus dos Navegantes. Dessas podemos destacar três como sendo as principais, por conta da quantidade de pessoas que participam - a romaria da Terra e das Águas, organizada pela CPT (Comissão Pastoral da Terra) do regional da CNBB (Conferência Nacional dos Bispos dos Brasil) da Bahia e de Sergipe e pelas CPTs diocesanas das Dioceses da Barra, Barreiras, Lapa, Irecê, Caetité e da arquidiocese de Vitória da Conquista; a Romaria do Bom Jesus da Lapa (em agosto) e a de Nossa Senhora da Soledade (em setembro)

O fluxo de peregrinos, com festas, rezas e todo um conjunto de atos rituais e devocionais, os números e estatísticas, teve início com um homem apenas, chamado Francisco Mendonça Mar, nascido em Portugal e que veio para o Brasil e desempenhou as funções de ourives e pintor e, em dado momento de sua história, foi o pivô da devoção ao Bom Jesus e Nossa Senhora da Soledade (Santos, 2010). Francisco de Mendonça Mar, nascido em Portugal, em 1657, era filho de um ourives, em Lisboa. Além de exercer a profissão do pai, era também pintor. Com vinte e poucos anos de idade, em 1679, chegou à Bahia, onde se instalou, tendo sua própria oficina e serventes - escravos. (Micef, 2006 \& SteiL, 1996).

A presença desses religiosos na região e a devoção em torno das figuras de Jesus e Maria, representadas nas imagens do Crucificado e de Nossa Senhora, deram início à povoação do entorno da gruta e posteriormente à ereção da vila e da cidade. A cidade de Bom Jesus da Lapa fica distante mil trezentos e vinte e quatro quilômetros de Salvador- Ba e está situada à margem direita do Rio São Francisco (Souza, 1991).

A festa do Bom Jesus da Lapa é, para os seus participantes, a vivência anual do extraordinário, do rompimento da rotina, da vivência de eventos simbólicos de capilaridade social que, pela extensão alcançada envolve diversas sociedades (oeste baiano, sul da Bahia, além de outros estados da federação), propiciando momentos extraordinários de interpretação, comunicação e transformação, produzindo condições de lançar um olhar diferenciado sobre a própria sociedade onde estes indivíduos estão inseridos, levando-os a refletir sobre as múltiplas realidades que os abarca (Mota, 2008). 


\section{ROMARIA DE BOM JESUS DA LAPA ASPECTOS ECONÔMICOS}

O turismo brasileiro apresenta, a cada ano, números mais expressivos em relação ao segmento religioso. De acordo com dados preliminares do Departamento de Estudos e Pesquisas do Ministério do Turismo (MTur), em 2014, cerca de 17,7 milhões de brasileiros viajaram pelo país levados pela fé (Abeoc, 2016).

Um levantamento realizado pelo MTur mostrou que mais de 344 municípios brasileiros promovem eventos que envolvem a fé, totalizando 96 eventos religiosos, entre eles pontos de peregrinação de fiéis e celebrações que atraem milhares de visitantes. Essas localidades se apropriaram de aspectos religiosos regionais e os transformaram em produtos turísticos, gerando uma fonte de desenvolvimento econômico e cultural para a comunidade local. O turismo religioso representa mais de $3 \%$ de toda a movimentação do turismo nacional, movimentando em torno de 15 bilhões de reais anualmente, evidenciando sua importância para a economia nacional, sobretudo em tempos de crise (Abeoc, 2016). Ainda de acordo com este levantamento, este segmento tem impulsionado economias locais e atraído pequenos negócios, além de movimentar setores da indústria, comércio, serviços e artesanato, gerando emprego e renda no país, e, tornando esse, um dos segmentos mais promissores do turismo nacional.

De acordo com cifras do Vaticano, o Brasil é o país com o maior número de católicos do mundo - mais de $12 \%$ da população católica mundial. Isso corresponde a 137 milhões de pessoas, quase a população da Rússia. Ainda segundo o Relatório de Tendências 2015 da WTM Latin America, apontou que 7,7 milhões de viagens domésticas feitas no Brasil em 2014 foram relacionadas à fé. Para efeito de comparação, essa cifra é equivalente ao número total de viagens domésticas realizadas no Uruguai em 2012.

O fluxo de romeiros, presente na cidade durante $\mathrm{O}$ ano todo, tem uma grande importância para as atividades econômicas, principalmente os serviços de hospedagem e de comércio (este será analisado posteriormente). Atualmente há aproximadamente 11 mil leitos distribuídos entre hotéis, pousadas, rancharias e dormitórios destinados ao aluguel diário
(Santos, 2015). Com este total de leitos, Bom Jesus da Lapa ocupa o quarto lugar na Bahia, depois de Salvador, Porto Seguro e Feira de Santana, respectivamente.

Há uma forte concentração dos hotéis e pousadas nas proximidades do Santuário, são os chamados "hotéis para romeiros". Uma característica típica desses hotéis é que a maioria é familiar, nos quais é comum a família, além de trabalhar, residir no próprio estabelecimento, compartilhando com o hóspede a sua sala de estar. Dividir o espaço da residência com o local de trabalho é uma das características do circuito inferior da economia urbana (Silva, 2001).

Há alguns anos atrás foi criada a agência internacional do Vaticano, e esta agência de viagens oficial da igreja católica classificou algumas cidades do mundo para o seu roteiro turístico religioso internacional (Santos, 2015). No Brasil, foram classificadas as cidades de Aparecida (SP), Senhor do Bonfim e Bom Jesus da Lapa (BA). Isso quer dizer que essas cidades têm que passar por um padrão internacional de qualificação, principalmente em prestação de diversos tipos de serviços para receber essa "clientela" mais exigente e seleta.

Estas recentes transformações da romaria lapense favorecem $\mathrm{o}$ crescimento de atividades econômicas mais modernas. No entanto, vale destacar a importância das romarias como reduto do circuito inferior da economia urbana lapense, em função da proliferação de formas de trabalho e de geração de renda que ocorre apenas no período de maior fluxo. Neste sentido, a expansão de atividades típicas do circuito superior da economia urbana parece apontar para uma "invasão progressiva do mercado pobre pelas maiores empresas" (Montenegro, 2011).

A cidade se destaca na rede urbana regional por oferecer diversos comércios e serviços modernos, especialmente os serviços públicos em função da presença de instituições tais como: Superintendência Regional da CODEVASF, Justiça do Trabalho, Promotoria Regional do Ministério Público, Juizado Especial, Justiça Federal, Inspetoria Fazendária, Unidade Avançada do INCRA, presença de instituições administradas pela Marinha, Aeronáutica e o Exército, Bancos (Banco do Brasil, Caixa Econômica Federal, Bradesco, Nordeste, Itaú, Bonsucesso e CredNordeste, etc.), Instituições de Ensino 
(UNEB, IFBAIANO, UBA, UNIP, UNISA e UNOPAR), serviços de saúde (SAMU, UPA, Maternidade), presença de grandes lojas como a Insinuante, Novo Mundo e Magazine Luiza e de algumas franquias como Microlins, FISK, Cacau Show, Subway, O Boticário, etc. Atualmente, grande parte desses serviços e comércio é encontrada no oeste da Bahia apenas nas cidades de Bom Jesus da Lapa e Barreiras. Estes dados apontam a importante expansão do circuito superior (Santos, 2015) na cidade, especialmente a partir da década de 1990, mas, sobretudo na última década.

Com a presença destas atividades econômicas anteriormente apresentadas, a cidade de Bom Jesus da Lapa além de se tornar relativamente conhecida no âmbito nacional por acolher o terceiro maior santuário do país (depois dos santuários de Aparecida/SP e Juazeiro do Norte/CE, respectivamente), também adquiriu uma importância significativa na rede urbana regional devido à sua oferta de serviços e de comércios modernos, bem como em função da sua rede de transportes que opera diariamente na região e no estado através de rodovias que ligam essa cidade aos centros urbanos mais importantes da rede urbana da Bahia. Essas recentes mudanças tiveram fortes implicações no espaço urbano de Bom Jesus da Lapa, a exemplo da expansão da mancha urbana do município (Silva, 2001).

O tipo de economia e o fato do turismo religioso estar atrelado à história do desenvolvimento do município, além de outros fatores contemporâneos que levaram a diminuição das áreas rurais e ao aumento da urbanização, atingiram o município de Bom Jesus da Lapa (Ibge, 2010). Entretanto, o grau de urbanização deste município (68\%) é inferior a Juazeiro do Norte (96\%), AparecidaSP $(99 \%)$ e do estado da Bahia (72\%). O Território de Cidadania Velho Chico, onde está localizado o município de Bom Jesus da Lapa, tem forte presença da agricultura familiar. Além disso, com a instalação do Perímetro Irrigado do Formoso nas ultimas décadas, situado a 30 quilômetros da cidade, houve uma expansão da agricultura no município. Nos anos de 2011 e 2012, Bom Jesus da Lapa foi o município que apresentou a maior produção de banana no Brasil, cujo valor bruto de comercialização foi de $\mathrm{R} \$ 112$ milhões (quase um terço do PIB municipal) e também na geração de empregos, uma vez que, no perímetro irrigado são mantidos sete mil empregos diretos e 10,5 mil empregos indiretos, (Codevasf, 2013).

Com relação aos domicílios permanentes, segundo dados do IBGE (2010), 78\% de agua encanada, $94 \%$ de energia elétrica e $27 \%$ com esgotamento sanitário. Esses valores são inferiores aos observados em Juazeiro do Norte que dispõe de 93\% de agua encanada, $100 \%$ de energia elétrica e 34\% com esgotamento sanitário; Aparecida-SP com $98 \%$ de agua encanada, $100 \%$ de energia elétrica e 95\% com esgotamento sanitário; e o estado da Bahia com $80 \%$ de agua encanada, $96 \%$ de energia elétrica e $45 \%$ com esgotamento sanitário.

Em 2010, do total da população, 44\% foram consideradas economicamente ativas, sendo $77 \%$ desta ocupadas e $12 \%$ desocupadas. Estes dados são similares aos encontrados no Estado da Bahia, com 89\% e 11\%, respectivamente e contrastantes com os regionais, que apresentaram 91\% e 9\%, respectivamente, para os mesmos indicadores. Entre 2006 e 2014, o numero de pessoas ocupadas cresceu linearmente no município, com incremento de 51\% neste período (IBGE, 2010). Esses resultados tiveram reflexos também no numero de pessoas assalariadas, com acréscimos de $61 \%$.

O salário médio mensal de todo município é composto de 1,9 salários mínimos e a renda per capta de $\mathrm{R} \$$ 443,16 (Figura 02). Comparando com a renda de Aparecida-SP e Juazeiro do Norte, pode-se observar que ela é inferior aos dois municípios, com valores de, respectivamente, $R \$ 852,15$ e $R \$ 509,05$, e menor que a do Estado $\mathrm{R} \$ 559,77$ (IPEA, 2016). Comparando-se com os anos de 2006 até 2014, percebe-se pouca variação em ganhos médios mensais. Desta forma, mesmo com bom índice de emprego, o salário dos moradores é mais baixo que o do estado e da região, caracterizando por empregos nas atividades de serviços voltadas ao turismo. Assim, pode-se observar que na geração de emprego e renda para a população, o turismo como impacto é positivo quanto à empregabilidade, mas não quanto à remuneração destes empregos, que é baixo em relação à média do Estado. Também se considera alto o peso que o turismo religioso tem na economia do município e, por conseguinte, a sua dependência, não aparecendo muitas oportunidades de renda e geração de empregos em outros setores. 
Figura 01 - Média de salário mensal dos municípios de Bom Jesus da Lapa- Ba, Juazeiro do NorteCE e Aparecida-SP. IBGE, 2010.

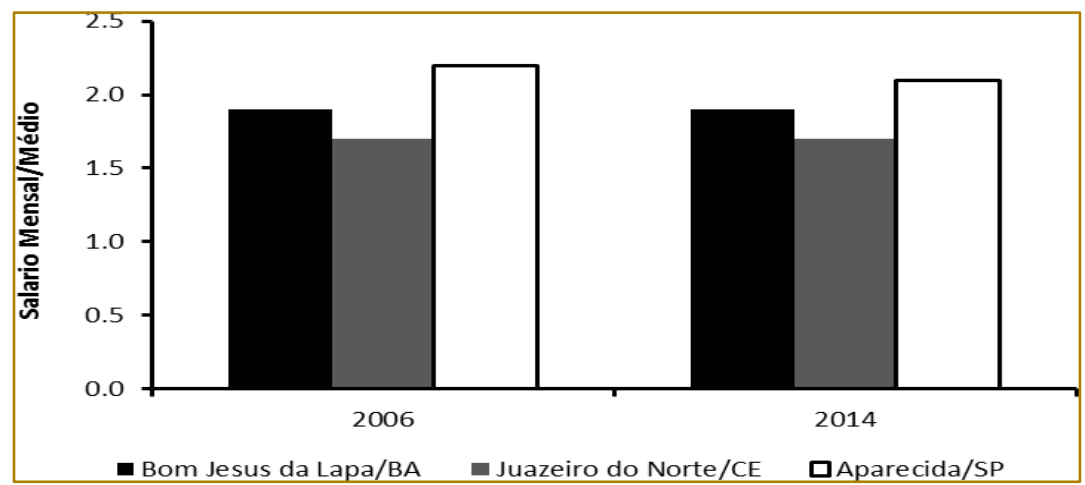

Segundo o IBGE (2010) no município de Bom Jesus da Lapa $12 \%$ das residências sobreviviam com até $1 / 2$ de salário mínimo mensal por morador (1988 domicílios), 24\% sobreviviam com $1 / 2$ até um salário mínimo por pessoa (3878 domicílios), 28\% recebiam entre um a dois salários (4500 domicílios), 20\% tinham rendimento mensal entre 2 a 5 salários mínimos (3301 domicílios) e 9\% não tinham rendimento (1414 domicílios). Estes resultados contrastam com o Estado da Bahia, onde $41 \%$ das residências sobreviviam com menos de $1 / 2$ salário mínimo mensal por morador, $29 \%$ sobreviviam com $1 / 2$ até um salário mínimo para cada pessoa, 14\% recebiam entre um a dois salários, $7 \%$ tinham rendimento mensal entre 2 a 5 salários mínimos e apenas 5\% não tinham rendimento. $\mathrm{Na}$ região do Nordeste, 38,1 \% das residências sobreviviam com menos de $1 / 2$ salário mínimo por morador, 29,9\% sobreviviam com $1 / 2$ até um salário mínimo por pessoa, $16 \%$ recebiam entre um a dois salários, 6,5\% tinham rendimento mensal entre 2 a 5 salários e apenas 2,9\% não tinham rendimento.

O PIB de Bom Jesus da Lapa, segundo o IBGE (2013) foi de R\$348.399.00, sendo o setor de serviços responsável por 72\%, seguido por setor Agropecuário (20\%) e Industrial (8\%) (Figura 03). Em Juazeiro do Norte, o setor de serviços contribuiu com $84 \%$ ( $R \$ 2,284,884.0$ ) do PIB, contra 16\% $(R \$ 423,994.0)$ da indústria e $1 \%$ do setor agropecuário ( $R \$ 18,953.0)$. Em Aparecida$\mathrm{SP}, 88 \%$ da produção interna esta associado ao setor de serviços ( $R \$ 606,905.0), 11,8 \%$ ao setor industrial $(R \$ 81,057.0)$ e apenas $0,2 \%$ ( $\mathrm{R} \$ 1,480.00)$ ao setor agropecuário.

Figura 02 - Distribuição do Produto Interno Bruto do município de Bom Jesus da Lapa-Ba. IBGE

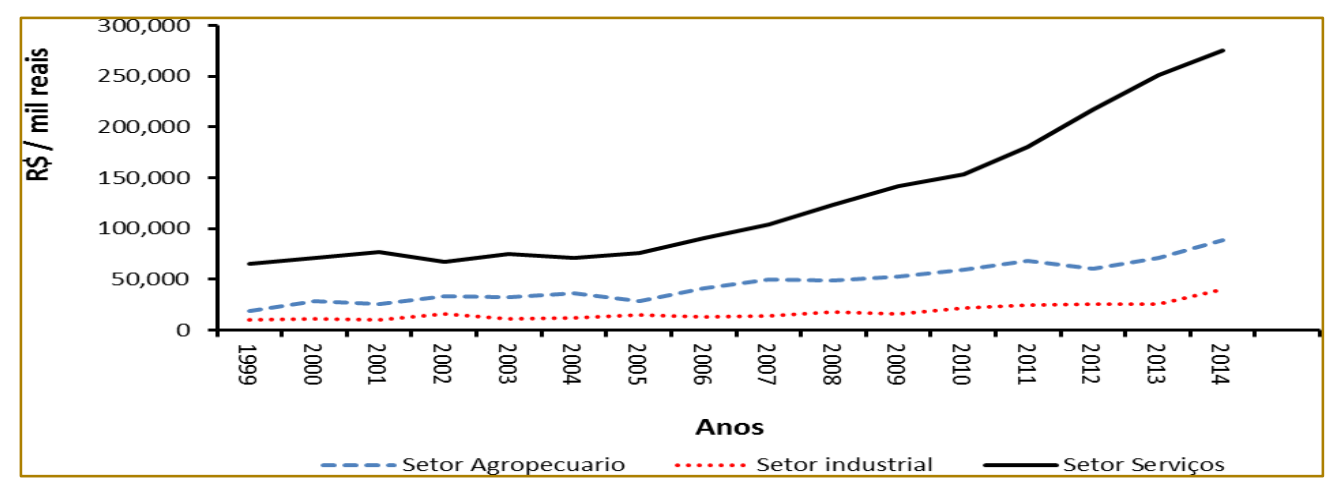

2013.Entre 2006 e 2014, o numero de empresas atuantes cresceu de forma lenta no município de Bom Jesus da Lapa, com oscilações durante os anos e acréscimo não superior a $12 \%$. Esses resultados foram similares em Aparecida-SP e inferiores a Juazeiro do Norte, que em 2013 apresentou crescimento de $24 \%$ e 2014 valores chegaram a 14\% (IBGE, 2016). 
O comércio e o setor hoteleiro e alimentício, associados ao turismo religioso gerido ao redor de Bom Jesus da Lapa, representaram as principais fontes de renda da cidade segundo dados do IBGE (2013), com 46\% do total das fontes de renda per capita do município. Somam-se ainda a pecuária e a agricultura, que acrescentou $\mathrm{R} \$ 70.822$ mil reais na economia (13\%), Impostos, líquidos de subsídios, sobre produtos, a preços correntes (8\%), Administração, saúde e educação públicas e seguridade social, a preços correntes (29\%) e Industria (5\%).

O circuito inferior em Bom Jesus da Lapa também tem papel importante na economia do município. Grande parte concentra-se na área central da cidade, onde existe maior fluxo de consumidores, a saber: principais avenidas, praças, mercado municipal, santuário, hospital, agências bancárias, etc. Dentre os pequenos comércios que pagam taxas ao poder público consta no setor de tributos da Prefeitura Municipal, um total de 395 estabelecimentos compostos por barracas ou bancas nas calçadas, ruas e praças para comercialização de qualquer produto; constam também 238 permissionários que atuam no mercado municipal, cujos produtos comercializados apresentam uma enorme diversidade (raízes medicinais, açougue, hortifrúti, peixaria, restaurante etc.). Estes dois tipos de estabelecimentos ocupam o segundo e o terceiro lugar, respectivamente, entre aqueles (sejam do circuito superior ou inferior) que pagam taxas à Prefeitura Municipal de Bom Jesus da Lapa (Santos, 2016).

Além destes pequenos negócios que são os mais representativos, podem-se observar ainda diversos tipos de pequenos estabelecimentos comerciais tanto na área central quanto nos bairros visitados. Nestes últimos, a economia popular encontra os seus consumidores na vizinhança, pois não conta com os mesmos fluxos de pessoas presentes na área central da cidade. Segundo (Santos, 2010), junto ao setor de tributação da Prefeitura Municipal de Bom Jesus da Lapa, para as romarias de 2014 foram emitidos 435 alvarás temporários distribuídos entre as atividades denominadas como: barracas ou pontos para comercialização de qualquer produto, tendas, vendedores de carrinho ambulante, carro de rapadura ou alho, diversões, parques de diversões, carro de rede, ambulante, etc.
Além dos agentes que atuam sazonalmente, nas romarias de Bom Jesus da Lapa também têm grande importância os trabalhadores do comércio de rua permanente, já os meses de julho a outubro, período em que ocorrem as grandes romarias, são considerados os meses de maiores vendas no comercio, o que demonstra a importância das romarias para o comércio sazonal, mas, sobretudo para a economia local.

De acordo com os estudos de Santos (2015) que traçou um perfil dos visitantes durante os eventos festivos de Bom Jesus da Lapa, $90,9 \%$ dos turistas tiveram como principal motivo da viagem o próprio evento religioso, e apenas $9,1 \%$ visitaram as localidades por outros motivos. O próprio estado da Bahia foi o maior emissor de turistas domésticos aos municípios de pesquisa, com $78,8 \%$ do total de entrevistados. Observa- se também a incidência de turistas residentes em outros estados, como Minas Gerais (6,0\%) e São Paulo (4,6\%). A permanência média dos turistas entrevistados foi de 3,8 pernoites no estado da Bahia e 3,1 pernoites na localidade, fato explicado pela duração média dos festejos, que ocorriam ao longo de cinco dias a uma semana em ambas as cidades pesquisadas.

O gasto médio per capita efetivado somente dentro da localidade pesquisada pelos turistas que visitaram as cidades ao longo da etapa foi de $R \$ 625,05$, sendo distribuídos entre hospedagem (31,0\%), alimentação $(13,8 \%)$, diversão noturna $(11,9 \%)$, compras de artigos religiosos (11,7\%), compras pessoais $(10,2 \%)$, atrativos e passeios $(10,0 \%)$, transporte local $(4,5 \%)$ e outros $(6,9 \%)$.

Os dados também apontam que mais da metade dos turistas $(72,0 \%)$ já tinha participado por outras vezes dos eventos religiosos pesquisados, um dado positivo, já que o retorno indica, muitas vezes, a satisfação do turista. Esse parecer ainda é reforçado com o dado de que $83,6 \%$ dos turistas tiveram suas expectativas superadas ou atendidas. A pesquisa mostra que cerca de $93,0 \%$ dos turistas entrevistados retornariam aos eventos pesquisados, e que mais de $98,0 \%$ os recomendariam a outras pessoas (IBGE, 2016).

Em relação à estrutura turística e de serviços das localidades, a maioria dos itens tiveram a avaliação positiva ("bom" ou "muito bom") de mais de $50,0 \%$ dos turistas, com exceção dos 
guias de turismo (avaliação negativa de $62,7 \%$ ), serviços de comunicação (avaliação negativa de 53,9\%), serviços médicos (avaliação negativa de 51,1\%) e sanitários públicos (avaliação negativa de 72,5\%). O destaque das avaliações positivas fica com a religiosidade $(99,7 \%)$, programação religiosa (98,9\%), patrimônio histórico/cultural (95,2\%), manifestações populares (95,7\%) e hospitalidade/povo (98,1\%).

Entre os aspectos que mais agradaram aos visitantes das localidades pesquisadas destacaram-se a programação religiosa, as missas, as procissões e a religiosidade e hospitalidade do povo.

\subsection{APECTOS SOCIAIS}

O turismo apresentou-se como um importante segmento para a dinâmica econômica de uma localidade. As teorias de desenvolvimento endógeno apresentaram- se como fortes aliadas do desenvolvimento local através do turismo, pois a oferta turística está em função não apenas dos atores locais, mas também da maneira como atuam conjuntamente, levando em consideração valores intangíveis: cultura local e identidade territorial (Guillaumon, 2011).
A população economicamente ativa no município gira em torno de $61,4 \%$, valor bem próximo ao observado em Juazeiro do Norte $62,8 \%$, entretanto inferior a Aparecida-SP $67 \%$. No estado da Bahia e na região do Nordeste, os valores são similares, $61,9 \%$ e $62,3 \%$, respectivamente.

O Índice de Desenvolvimento Humano (IDH) aumentou entre os anos de 1991 a 2010, elevando o patamar de classificação de baixo (menos que 0,555) para médio (de 0,555 a 0,699) (Figura 04). Esses resultados também poderão ser observados em Juazeiro do Norte, de 0,42 para 0,69 (IBGE, 2016). Em Aparecida-SP, os resultados foram ainda melhores, com o município evoluindo do IDH médio para o elevado. Os países com IDH médio apresentam um grupo heterogêneo, e em geral vêm apresentando relativas melhoras em seus IDHs ao longo dos últimos anos, combatendo problemas sociais de saúde e educação, mas ainda estão muito longes de promover uma democrática distribuição de renda. Os países com baixo IDH são aqueles com graves problemas socioeconômicos, e muitos convivem com dificuldade no acesso a recursos básicos, como água e alimentos.

Figura 04 - Evolução do Índice de Desenvolvimento Humanos dos municípios de Bom Jesus da Lapa-Ba, Juazeiro do Norte-CE e Aparecida-SP. IBGE, 2016.

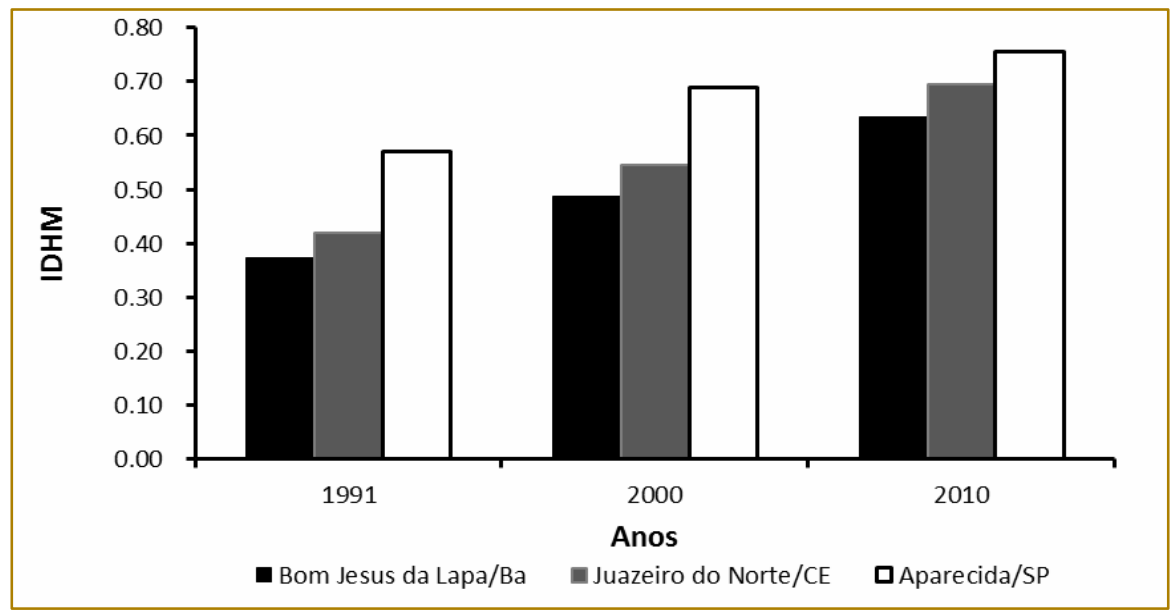

As taxas de analfabetismo em Bom Jesus da Lapa e Aparecida cairam entre os anos de 2000 e 2010, saindo de $25,4 \%$ para $19,2 \%$ $(3,43 \%)$ e $5,5 \%$ para $3,4 \%$, respectivamente. Estes resultados foram ainda mais expressivos em Juazeiro do Norte- CE, 25,0\% para $16,2 \%$. No estado da Bahia, taxa de pessoas que não sabem ler e escrever é de $16,6 \%$ contra $16,9 \%$ no Nordeste. Outro indicador educacional positivo é a população alfabetizada corresponde $72,4 \%$, contra os $76,7 \%$ do Juazeiro do Norte e $89,9 \%$ de Aparecida-SP. 
A expectativa de vida ao nascer era de 71,51 anos, a taxa de mortalidade infantil de 23,0 por mil nascimentos e a taxa de fecundidade de 2,4 filhos por mulher. Segundo dados do Ministério da Saúde, 78 casos de AIDS foram registrados em Bom Jesus da Lapa entre 1990 e 2013 e, de 2001 a 2011, foram notificados 1582 casos de dengue, um caso de malária e 252 de leishmaniose (IBGE, 2010).

Segundo o Mapa da Violência de 2014, com dados relativos a 2012, divulgados pelo Instituto Sangari, dos municípios com mais de vinte mil habitantes, a taxa de homicídios no município foi de 20,1 para cada 100 mil habitantes, ficando na $1159^{a}$ posição a nível nacional. O índice de suicídios para cada 100 mil habitantes foi de 0,0, com apenas três mortes confirmadas entre 2008 a 2012. Já em relação à taxa de óbitos por acidentes de trânsito, o índice foi de 21,6 para cada grupo de 100 mil habitantes, o $846^{\circ}$ a nível nacional. Em Aparecida-SP, no mesmo ano, foi registrada uma taxa de 37,1 homicídios para cada 100 mil habitantes, sendo o oitavo maior índice do estado de São Paulo e o 511으 maior do Brasil. O índice de acidentes de trânsito neste mesmo ano foi de 25,7 ocorrências para cada 100 mil residentes, ocupando a $67^{a}$ colocação a nível estadual e a $666^{\mathrm{a}}$ a nível nacional. Em relação à ocorrência de suicídios, a taxa foi de 2,9 ocorrências a cada 100 mil habitantes, sendo a $181^{\text {a }}$ maior taxa a nível estadual e a $1117^{\mathrm{a}}$ a nível nacional.

A frota municipal de Bom Jesus da Lapa no ano de 2015 era de 11585 motocicletas, 4 310 automóveis, 1631 caminhonetes, 964 motonetas, 484 caminhões, 183 camionetas, 166 ônibus, 79 micro-ônibus, 54 caminhõestrator, 59 utilitários, além de 313 em outras categorias, totalizando 19828 veículos. No transporte rodoviário, a cidade possui um terminal rodoviário de alcance interestadual. Bom Jesus da Lapa também conta com um aeroporto (IBGE, 2010).

Bom Jesus da Lapa, em termos rodoviários, é servida por quatro rodovias e desempenha importante função na área. $A$ cidade é cortada pelas federais BR-349 e BR- 430. Com a construção da Ponte Gercino Coelho, em 1990, com a intenção de facilitar o escoamento da produção do Projeto Formoso, a cidade ganhou mais força no oeste baiano. Outra rodovia, a BA-161, liga Bom Jesus da
Lapa à Sítio do Mato. Outra estrada, outrora de terra, foi criada. A BA-160 liga o município à Paratinga. Em contrapartida, em avaliações da Confederação Nacional do Transporte (CNT), recebeu o status de "péssima" durante vários anos consecutivos sendo que, em 2010, foi considerada a pior rodovia do Brasil.

\section{CONCLUSÃO}

Com base nos resultados alcançados nas pesquisas, verifica-se que o desenvolvimento do turismo religioso tem influência direta na economia do município de Bom Jesus da Lapa, revelando-se como uma das principais fontes de emprego e renda. O turismo ocasionou também benefícios à comunidade local com a valorização do patrimônio cultural e melhoria dos indicadores sociais.

A cidade investigada adquiriu uma importância na rede urbana regional em função da sua oferta de serviços e de comércios modernos. Isso possibilitou à presença de fluxos populacionais locais/regionais, além dos fluxos já existentes ligados a ocorrência de romarias, porém, estes têm aumentado significativamente graças aos novos meios de comunicação e à melhoria no acesso à cidade. Ambos os fluxos têm favorecido a expansão das atividades econômicas, atraindo grandes varejista e principalmente o circuito inferior, características de grande parte dos romeiros que visitam a cidade, isto é, populações pobres e tipicamente consumidoras desse circuito.

Admitindo-se a aplicabilidade do conceito de marketing dentro das organizações religiosas, onde o fundamento da sua existência consiste na satisfação das necessidades espirituais e religiosas dos fiéis, percebe-se que as estratégias mercadológicas utilizadas pela Igreja ao longo dos anos têm possibilitado o incremento do numero de fiéis, com reflexo direto na evolução do perfil dos romeiros. A romaria, enquanto um movimento ou uma atividade oriunda do catolicismo popular valoriza a fé dos fiéis que encontram no santuário o espaço sagrado de sua devoção especial. Uma vez atingido pela palavra anunciada no santuário, o romeiro se encarrega de difundir sua fé para outras localidades, espalhando os conceitos e valores do catolicismo. 


\section{REFERÊNCIAS}

[1]. ABEOC - Associação Brasileira de Empresa de Eventos. (2015) Turismo religioso em pauta na EMBRATUR. Recuperado de: http://www.abeoc.org.br/2015/04/turismoreligioso-em-pauta-na-embratur/ ( $10 \mathrm{dez}$ de dezembro de 2016)

[2]. Abreu, M., M., (2004). O Uso do Marketing nas Organizações Religiosas. Departamento de Gestão e Economia da Universidade da Beira Interior. 30p..

[3]. Azzi, R. (1979). As Romarias no Brasil., Petrópolis, n. 79, Revista Vozes p. 3954. Barna, G.(1997). O Marketing a Serviço da Igreja. São Paulo, Abba Press.

[4]. Campá, W.( 1998). O empresário e a fé: "homens de negócio" e a expansão pentecostal - Trabalho apresentado no seminário temático ST01 "Os pentecostais". VIII Jornadas sobre Alternativas Religiosas na América Latina São Paulo.

[5]. Campos, L. (1998). Teatro, Templo e Mercado: A Igreja Universal do Reino de Deus $\mathrm{e}$ as mutações no campo religioso protestante. São Paulo, UMESP.

[6]. CODEVASF (Companhia de Desenvolvimento dos Vales do Rio São Francisco e do Parnaíba). (2012) Recuperado de:

http://www.codevasf.gov.br/principal/publicac oes/publicacoes- atuais/producao-de-bananacresce-17-no-perimetro-irrigado-de-formosoba-e-alcanca-r- 112-mi-em-2012>. (15 jan. 2017).

[7]. Dellacava, R. \& Monteiro, P. (1991). E o verbo se fez imagem: a igreja católica e os meios de comunicação no Brasil: 1962-1989. Petrópolis, Vozes.

[8]. Fadul, A. (1986) Os meios de comunicação de massa: um desafio para a Igreja. Petrópoles, Vozes.

[9]. Fernandes, R. C. (1996). Novo Nascimento: os evangélicos em casa, na igreja e na política. Rio de Janeiro, Iser.

[10]. Gomes, P G. (1987) Cultura, Meios de Comunicação e Igreja. São Paulo, Loyola.

[11]. Gronroos, C. (1997) Services marketing: the case of a missing product. Journal of Business and Industrial Marketing, v. 13, n. $4 / 5$, p. $56-58$.

[12]. Guillaumon, S. (2011). Turismo em Territórios de Grande Densidade Religiosa. In:
Organizações \& Sociedade: O\&S. Salvador. UFBA: NPGA/EDUFBA, 2012, n. 63, p. 679 696.

[13]. Hoffman, K; \& Bateson, D.( 2001). Princípios de Marketing de Serviços. Tradução de Bazán Tecnologia Lingüística. São Paulo: Thomson.

[14]. IBGE, Instituto Brasileiro de Geografia e Estatística - Censo. (2010). Recuperado de: http://www.ibge.gov.br/home/estatistica/popul acao/censo2010/tabelas_pdf/total_popula cao_ceara.pdf>. (10 dez. 2016).

[15]. IBGE, Instituto Brasileiro de Geografia e Estatística - Censo. (2016). Recuperado de: http://www.ibge.gov.br/home/estatistica/popul acao/censo2010/tabelas_pdf/total_popula cao_ceara.pdf >. (10 dez. 2016.)

[16]. IBGE, Instituto Brasileiro de Geografia e Estatística - Produto Interno Bruto. ( 2010). Recuperado de: em:<http://www.ibge.gov.br/home/estatistica/ populacao/censo2010/tabelas_pdf/total_popul a cao_ceara.pdf>. (10 dez. 2016)

[17]. Ignarra, L, R. (2003) Fundamentos do Turismo. São Paulo. Pionera Thompson Learning.

[18]. IPEA. (2010). Recuperado de: < http://ipea.gov.br/>. (01 dez. 2016).

[19]. Kater Filho, A. (1995). O Marketing aplicado à Igreja Católica. São Paulo, Loyola.

[20]. Machado, C. S. (2015). Impactos do turismo religioso nos moradores da estância turística de Aparecida/SP. 76p. Rio de Janeiro. Dissertação (Mestrado em Ciências Sociais Aplicadas) Universidade Federal Fluminense.

[21]. Mariano, R. (2004). Expansão pentecostal no Brasil: o caso da Igreja Universal. Estudos. Avançados, vol.18, o․ 52, São Paulo Sept./Dec.

[22]. Matayoshi, L. Y. (2000). Bem aventurados aqueles que se comunicam como marca: A igreja renascer em cristo. São Paulo. Dissertação de Mestrado - ECA-USP,. 120p.

[23]. Micek, F. (2006). Bom Jesus da Lapa. 2.ed. Bom Jesus da Lapa: Gráfica Bom Jesus.

[24]. Ministério do Turismo. (2010). Turismo Cultural: orientações básicas. / Ministério do Turismo, Secretaria Nacional de Políticas de Turismo, Departamento de Estruturação, 
Articulação e Ordenamento Turístico, Coordenação-Geral de Segmentação - 3ㅜㅡ. ed. - Brasília: Ministério do Turismo.

[25]. Montenegro. M. (2011). Globalização, trabalho e pobreza no Brasil metropolitano. O circuito inferior da economia urbana em São Paulo, Brasília, Fortaleza e Belém. Tese (Doutorado em Geografia Humana) Universidade de São Paulo, São Paulo.

[26]. Patriota, K. O. (2003). Fenômeno do Marketing Religioso: Análise do Discurso da Igreja Renascer em Cristo na Mídia. Dissertação de mestrado em Comunicação, UFPE,. 145p.

[27]. Patriota, K. R. M. P. (2000). Fé na prateleira de vendas: A Sedução do Marketing Religioso.. 15p.

[28]. Ribeiro, C. M. (2010) Turismo religioso: fé, consumo e mercado. E-Revista Facitec, v.5, n.1, Art.6, ago-dez.

[29]. RosendaL, Z. (2002). Hierópolis: O sagrado e o urbano. Rio de Janeiro: Editora UERJ.

[30]. Salvi, R. D. \& Giglio, E. M. (2003). Aplicação dos modelos de comportamento do consumidor a católicos praticantes. Revista da ESPM, São Paulo, ano 9, n.4, p.58-72, jul./ago.

[31]. Santos Filho, M. (1989). O processo de urbanização no Oeste-Baiano. SUDENEDPG. PSU - URB. Recife.

[32]. Santos, J. R. A. (2010). Turismo, romaria e inclusão social no sul da Bahia. Dissertação (Mestrado em Cultura e Turismo), Universidade Estadual de Santa Cruz, Ilhéus.124p.

[33]. Santos, J. R. A. (2010). Turismo, romaria e inclusão social no sul da Bahia. Dissertação (Mestrado em Cultura e Turismo), Universidade Estadual de Santa Cruz, Ilhéus.
[34]. Santos, S. A. (2015). Circuito inferior da economia urbana na "capital baiana da fé. XIV Simpósio Nacional de Geografia Urbana: Perspectiva e Abordagens da Geografia Urbana no Seculo XXI. Fortaleza, CE. 2015. $20 \mathrm{p}$.

[35]. Silva A. M. B. (2001). A contemporaneidade de São Paulo. Produção de informações e reorganização do território brasileiro. Tese de doutorado. Departamento de Geografia, Faculdade de Filosofia Ciência, Letras e Ciências Humanas, USP. São Paulo.

[36]. Silva, J. C da. O Show da Fé: carisma e mídia na Igreja Internacional da Graça de Deus. 2005. Dissertação de Mestrado em Ciências Sociais, Universidade do Estado do Rio de Janeiro. Rio de Janeiro. 150p.

[37]. Souza, J. E. (1991). Catolicismo Popular e Evangelização na Diocese de Bom Jesus da Lapa - Bahia. Dissertação de Mestrado em Teologia, Instituto Santo Inácio Centro de Estudos Superiores: Belo Horizonte:. 140p.

[38]. Steil, C.A. (1996). O Sertão das Romarias: Um Estudo Antropológico Sobre o santuário de Bom Jesus da Lapa - Bahia. Vozes. Petrópolis.

[39]. Teixeira, M. S. G. \& Junior, M. C. R. (2003). Turismo religioso: Uma alternativa econômica para municípios do Seridó - RN.. $20 \mathrm{p}$.

[40]. Trigo, L. G. G. et al. (2005). Análises regionais e globais do turismo brasileiro. Roca. São Paulo.

[41]. Waiselfsz, J. J. (2016) Mapa da Violência: Homicídios por armas de fogo no Brasil.

Recuperado: http://flacso.org.br/files/2016/08/Mapa2016_ar mas_web.pdf. (05 dez. 2016). 


\section{Capítulo 18}

\section{A PERCEPÇÃO DOS CLIENTES EM RELAČ̃o AO ATENDIMENTO APLICANDO-SE A METODOLOGIA DISNEY EM UM HOTEL}

\section{Layna de Azevedo Pereira da Silva}

\section{Ueliton da Costa Leonidio}

\section{Humberto Medrado Gomes Ferreira}

Vanessa Cristina dos Santos

Resumo: Com o modelo de gestão de atendimento excepcional do Walt Disney World como um caso de sucesso, o presente trabalho tem como objetivo avaliar a percepção dos clientes em relação ao atendimento da metodologia Disney aplicada em um hotel na cidade de Petrópolis, RJ. Para isso, foram realizadas pesquisas bibliográficas sobre marketing de serviços e marketing de relacionamento e elaborado um questionário aplicado aos clientes para realizar um diagnóstico da percepção dos mesmos. Assim, foi possível identificar pontos a melhorar o atendimento. Com base nos resultados obtidos através dos dados coletados, foi realizada a análise da média. Por fim, observou-se propostas de melhoria que possibilitarão o hotel a alcançar a excelência no atendimento, superando as expectativas das clientes.

Palavras-Chave: Atendimento, Marketing de Relacionamento, Walt Disney World 


\section{INTRODUÇÃO}

Ao longo dos últimos 100 anos, a relação de forças entre a indústria, o varejo e o consumidor sofreu grandes mudanças, tendo como base a competitividade. Primeiro, o domínio foi da indústria, depois do varejo e, finalmente, do consumidor. No início do século $X X$, as indústrias pioneiras em seus segmentos possuíam o controle do mercado. A oferta de produtos era baixa e não havia pressão da concorrência. A partir da metade do século até a década de 80 , a indústria passou a privilegiar a eficiência dos canais de distribuição, com o objetivo de ampliar seu número de consumidores. Dentro do mesmo segmento, começaram a surgir uma grande variedade de produtos fornecida por diversos fabricantes. O número de competidores aumentou, e o eixo da força passou a deslocar -se da indústria para o varejo, que por sua vez aumentou seu poder de barganha deixando de ser apenas um canal de venda de produtos para tornar-se um potente centralizador do relacionamento com o consumidor, que evoluiu conforme a demanda de informações e se tornou cada vez mais exigente (AZEVEDO e POMERANZ, 2004, p. 7).

Com o surgimento da tecnologia, e consequentemente, de novos canais de venda, o consumidor se torna mais consciente da disponibilidade de opções e do poder do mercado. Neste novo cenário, o marketing de relacionamento passou a desempenhar um papel fundamental na recolocação das forças, centralizando-a nas mãos do consumidor, o que faz com que as ações de marketing priorizem 0 relacionamento com ele (AZEVEDO e POMERANZ, 2004, p. 9).

O marketing de relacionamento procura o diálogo com os clientes, e para isso, é preciso conhecer o público-alvo, suas preferências de consumo, seus hábitos pessoais e seus valores socioculturais para que se possa criar mensagens individuais com a forma e a linguagem apropriadas para estimular a resposta do consumidor e personalizar a comunicação (AZEVEDO e POMERANZ, 2004, p. 8).

Segundo Barreto (2013, p.11), o que se busca com o marketing de relacionamento não é vender mais para o maior número de clientes, e sim vender mais para cada cliente atual.

Um exemplo de organização que utiliza com maestria o marketing de relacionamento e uma forma diferenciada de gerir pessoas para alcançar resultados notáveis é a Walt Disney World. A magia que rodeia a maior empresa de entretenimento do mundo é, para os clientes, sinônimo de encanto e de lazer, já para a empresa, trata-se de uma questão muito mais prática. A Disney tem muito dos mesmos desafios que qualquer empresa e está voltada para o mesmo objetivo: atender com excelência as pessoas que compram os seus produtos e serviços. Todo negócio tem processos baseados em atendimento, portanto, todos precisam saber como criar a magia do atendimento. (DISNEY INSTITUTE, 2011, p. 19).

Para realizar programas de treinamento, a empresa criou o Disney Institute e atualmente é um dos centros de treinamento mais requisitados, pelo fato de abordar de maneira simples os princípios da empresa aos gestores de vários setores. Os programas são elaborados com foco em cinco áreas centrais: liderança, cultura, serviço, marca e inovação. A Disney mostra para os gestores como a implantação de práticas de atendimento aos clientes podem trazer vantagens competitivas, econômicas e mercadológicas. O próprio Walt Disney se interessava pelos talentos de seus funcionários e os inspirava através de sua visão, motivando as pessoas e sempre inovando. A base da empresa é a educação, gerando sabedoria, humanidade e conhecimento aos seus funcionários por meio de treinamentos e entretenimento (DISNEY INSTITUTE, 2011, p. 11).

O grupo Disney possui um dos maiores e melhores indicadores de satisfação de clientes do mundo. Com isso a empresa fideliza seus clientes, carinhosamente chamados de convidados e consegue gerar nesses clientes a vontade de voltar aos parques e estúdios.

Diante deste cenário, esse trabalho tem como problema de pesquisa a seguinte pergunta: Qual a percepção dos clientes em relação ao atendimento através da aplicação da metodologia Disney? Para responder a essa pergunta, a pesquisa teve como objetivo geral replicar a metodologia Disney adaptada ao cenário corporativo, buscando entender qual a percepção dos clientes em relação ao padrão de atendimento Disney. Para chegar neste objetivo geral, foram delineados os objetivos específicos do trabalho a partir dos conceitos de marketing, apresentando as definições e características da gestão de 
marketing sob a ótica de serviços e marketing de relacionamento, culminando com a verificação de como se dá o conceito Disney de atendimento. Foi selecionada a escala likert, para calcular estatisticamente a percepção dos clientes de um hotel em relação aos 4 pilares de atendimento Disney.

\section{FUNDAMENTAÇÃO TEÓRICA}

Durante a primeira década do século XXI, muitas empresas se viram obrigadas a prosperar financeiramente e até mesmo, sobreviver devido o difícil momento econômico vivido na época. Diante deste cenário, o marketing desempenha um papel de destaque para enfrentar esses desafios, uma vez que, outras funções organizacionais como contabilidade, finanças e operações não farão sentido se não houver uma demanda por produtos que seja suficiente para que a empresa obtenha lucro. (KOTLER E KELLER, 2014, p. 4).

Foi através do marketing que novos produtos foram introduzidos no mercado e passaram a serem aceitos e consumidos, por facilitarem ou melhorarem a vida das pessoas. Um marketing bem-sucedido gera demanda por produtos, e consequentemente, cria oferta de trabalho (KOTLER E KELLER, 2014, p.5).

O marketing abrange a identificação e a satisfação das necessidades humanas e sociais. Uma das mais breves e melhores definições de marketing é a de suprir necessidades gerando lucro (KOTLER E KELLER, 2014, p. 5).

Nesse contexto, o marketing de serviço se tornou parte fundamental da economia mundial, pois representa grande parcela significativa do PIB de vários países, principalmente dos industrializados (ZEITHAML et al, 2013, p. 4).

Segundo Zeithaml et al (2013, p. 5), com o crescimento do setor, do lucro e do potencial para a geração de vantagens competitivas, ao lado do declínio generalizado na satisfação do cliente com os serviços, fica evidente que nunca foram tão grandes o potencial e as oportunidades para as empresas se sobressaírem no marketing, na gestão e na execução de serviços.

De acordo com esse ponto de vista, a qualidade do produto percebido é um item da satisfação do cliente. A figura 1 ilustra a relação entre os dois conceitos, a qualidade do serviço é uma avaliação sistematizada, percebida pelo cliente referente a confiança, segurança, responsabilidade, a empatia e os tangíveis. Já a satisfação é mais abrangente: ela é influenciada pelas percepções da qualidade do serviço, do produto e pelo pre ço, além de fatores situacionais, como o clima, e pessoais, como o estado emocional do cliente (ZEITHAML et al, 2013, p. 79).

Lovelock (2005, p. 107) diz que antes de comprar um serviço, os clientes criam uma expectativa em relação a qualidade do serviço, se baseando em suas necessidades, experiências passadas, indicação de terceiros e propaganda do próprio contratado do serviço. Logo após utilizarem o serviço, os clientes comparam o que esperaram com o que realmente obtiveram. Os serviços que encantarem os clientes por superar a expectativa dos serviços que eles desejaram, serão percebidos como de qualidade superior, mas se os clientes se decepcionarem com o serviço recebido em relação ao que esperaram, ocorrerá uma discrepância entre o funcionamento do fornecedor do serviço e as expectativas do cliente.

Quando as percepções são consideradas, é imprescindível reconhecer que os clientes têm percepções a partir de contatos individuais e distintos, além de suas percepções baseadas em suas experiências como um todo (ZEITHAML et al, 2013, p. 79). 
Figura 1: A satisfação e as percepções do cliente sobre a qualidade do serviço

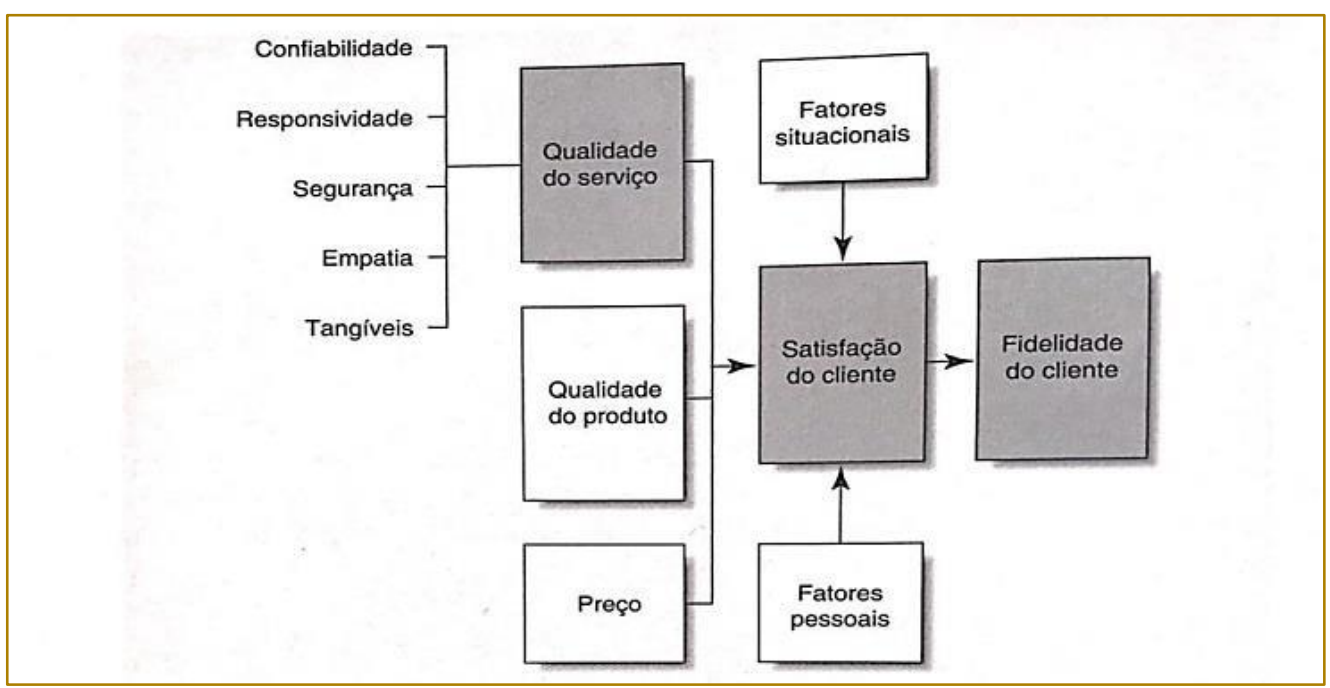

Fonte: ZEITHAML et a/ (2013, p. 78)

As pesquisas mostram que a percepção do cliente não é unidimensional, pois eles se baseiam em diversos fatores para julgar a qualidade. As cinco dimensões na qualidade do serviço, que representam como as informações sobre a qualidade do serviço, são organizadas na mente dos consumidores, da seguinte maneira:

- Confiabilidade: É a mais importante entre as cinco, pois é a capacidade de execução do serviço prometido de forma confiável e precisa, quando a organização cumpre o que foi prometido. Os clientes tendem a fechar negócios com empresas que cumprem as suas promessas.

- Responsividade: É quando a empresa se dispõe a auxiliar os seus clientes e fornecer ligeiramente 0 serviço. Esta dimensão se propõe a resolver rapidamente as solicitações do cliente, dando-Ihe toda a atenção necessária.

- Segurança: É o nível de conhecimento e cortesia dos funcionários, quando inspiram confiança e certeza. Esta dimensão é importante para serviços que os clientes percebem alto risco ou insegurança. Exemplo: Serviços bancários, de seguro, corretagem, médicos etc.

- Empatia: É tratar os clientes de modo individual, personalizado, co $\mathrm{m}$ cautela. Fazer com que os clientes se sintam únicos e especiais, e que a empresa compreende as suas necessidades.

- Tangíveis: São a aparência das instalações físicas, dos equipamentos, do quadro de pessoal e dos materiais de comunicação. São a representaç ão física ou as imagens que os clientes usam para avaliar a qualidade. Grande parte das empresas utilizam tangíveis junto a outra dimensão, com o objetivo de ter uma estratégia de qualidade em serviço. (ZEITHAML et al, 2013, p. 90).

Com o objetivo de definir quais são as fontes das impressões favoráveis e desfavoráveis dos clientes, os pesquisadores conduziram vários estudos sobre encontros de serviços em diversos contextos, devido a importância dos mesmos para a construção das percepções pelos clientes, e que, de certa forma, deu origem ao marketing de relacionamento (ZEITHAML et al, 2013, p. 98).

O marketing de relacionamento surgiu como resultado de uma série de fatores, como a diminuição do ritmo de crescimento do mercado, aumento da competitividade, desenvolvimento tecnológico e a mudança no comportamento do consumidor. Com tantas mudanças, nenhuma empresa pode perder os seus clientes atuais, porque definitivamente, estes não serão facilmente reconquistados (BARRETO, 2013, p.19).

Segundo Bogmann (2000, p.23) conforme a tecnologia avança e se sobrepõe, nenhuma empresa sozinha tem a capacidade e os conhecimentos necessários para levar produtos e soluções ao mercado na hora certa e de forma eficaz em relação aos custos. Portanto, é preciso trazer o cliente externo para dentro da empresa, ajudando-o a definir seus próprios interesses. 
Segundo Barreto (2013, p.10) Berry foi o primeiro a citar "marketing de relacionamento" e a classificar as principais características do marketing de relacionamento como o desenvolvimento de um serviço que constrói e personaliza um relacionamento para clientes individuais, estimula a fidelidade do cliente, investe na comunicação com os funcionários para que eles atendam melhor os clientes, cria benefícios extras entre outros. Também destaca três características principais do marketing de relacionamento:

- Personalizar o relacionamento para clientes individuais: O relacionamento deve ser construído para cada cliente individual e não para a massa. Pode ser aplicado através da utilização de banco de dados e manutenção da comunicação entre cliente e empresa.

- Oferecer benefícios extra: Para o cliente escolher ser fiel a sua empresa, deve ser oferecido benefícios relevantes.

- Comunicar-se com os funcionários: Para que o marketing de relacionamento seja uma ação bem-sucedida, os funcionários precisam estar envolvidos no processo.

O objetivo do marketing de relacionamento não é vender para grandes quantidades de clientes, mas sim vender mais para cada cliente individual. A empresa que objetiva participação no mercado, identificam as necessidades para o maior número de clientes, e atendem de forma padrão e uniformizada, já empresas focadas em identificar as necessidades de cada cliente individual, consegue ter um conhecimento íntimo de cada cliente e oferecer seu serviço de forma personalizada (BARRETO, 2013, p. 11).

Atualmente, o marketing deve se preocupar em atingir muito mais qualidade do que quantidade. Conhecer, encantar, servir e corresponder aos anseios dos clientes é fundamental para o sucesso da empresa e exige uma gestão sistemática desse relacionamento (BOGMANN, 2000, p. 23). Inicia-se assim o conceito de "magia Disney".

Walt Disney, era definitivamente capaz de realizar os seus sonhos. Ele fez a Disney Studios se tornar líder mundial em animações, concretizou sua visão pessoal construindo seu primeiro parque temático, a Disneylândia, e fez a marca Disney ser referência em entretenimento familiar. A empresa Disney possui 7 parques temáticos, 27 hotéis, dois navios de cruzeiro, 728 lojas, uma rede de rádio e tv, 10 emissoras de televisão, 42 estações de rádio, um portal de internet, cinco grandes sites e participação em nove redes de cabo nos EUA. A Disney possui ativos que produzem alto retorno sobre os investimentos feitos. No ano de 1999, fechou o faturamento em US\$ 24 bilhões de dólares, sendo mais de US\$ 6 bilhões gerados somente pelos parques temáticos. O Walt Disney World é o maior empregador em uma única localidade nos EUA, com funcionamento diário, durante todo o ano. Conta com uma força de trabalho de mais de 55 mil "membros do elenco" como a Disney nomeia seus funcionários. Os membros do elenco da Disney servem todo ano milhões de "convidados" - como a Disney chama seus clientes. A energia que movimenta essa cidade se chama magia (DISNEY INSTITUTE, 2011, p. 27).

"Magia" não é um termo muito utilizado no mundo corporativo, mas é uma palavra comum entre os círculos executivos da The Walt Disney Company. A magia é facilmente encontrada nos negócios da Walt Disney World, é só observar os convidados, como a criança que vê o Mickey pela primeira vez, em tamanho natural e pessoalmente, o adolescente que acaba de sair da queda livre de 13 andares do The Twilight Zone Tower of Terror, ou os pais que quando retornam para o hotel, encontram um ursinho Pooh de pelúcia com leite e biscoitos na cama dos filhos. Cada um desses momentos, representam um vínculo mágico entre o cliente e a empresa. Cada um contribui para um índice de fidelização de 70\% dos clientes com a Walt Disney World. A surpresa feliz que um cliente bem atendido sente é o resultado de muito empenho por parte da empresa e seus funcionários. Para o cliente, a magia é uma fonte de encantamento e prazer. Para a empresa e seus funcionários é uma questão prática (DISNEY INSTITUTE, 2011, p. 28).

A magia que envolve a Disney pode ser adequada a qualquer negócio, pois a Disney enfrenta exatamente os mesmos desafios de qualquer empresa: concorrência, dificuldades com mão-de-obra, aprender a firmar parcerias com mais eficácia, satisfação do cliente, entre outros (DISNEY INSTITUTE, 2011, p. 27). 
As empresas têm o mesmo objetivo que a Disney - atender bem as pessoas que compram os seus produtos e serviços. Não importa se você os chama de clientes, colaboradores ou pacientes, todas devem satisfazer os convidados, ou arriscar perdeIos (DISNEY INSTITUTE, 2011, p. 19).

Até as empresas mais tradicionais de produtos têm percebido que estão também, no ramo de serviços, pois toda negociação é baseada no atendimento. Todas possuem clientes e precisam saber como criar a magia do atendimento.

Atualmente, se vive a era de economia da experiência, onde produtos e serviços são apenas acessórios para envolver o cliente, que buscam viver experiências memoráveis e as empresas devem se tornar as provedoras dessas experiências (DISNEY INSTITUTE, 2011, p. 20) e, para tal, surge a Guestologia, que é o termo utilizado pela Disney para pesquisa de mercado e cliente, é entender quem são os convidados e o que eles esperam ao fazer uma visita. É possível identificar a importância dessa pesquisa para o sucesso da Disney, com tempo e o empenho dedicados (DISNEY INSTITUTE, 2011, p. 38).

O orçamento dedicado a guestologia é aplicado a diversas técnicas, como:

- Levantamentos nos portões do parque e outros pontos de acesso;

- $\quad$ "Postos de escuta" são criados para responder as perguntas dos convidados, solucionar problemas e coletar informações;

- Cartões de comentários são tão comuns quanto sorrisos;

- Coleta e a disseminação das opiniões e observações dos convidados pelos membros do elenco espalhados;

- Análise e comparação dos padrões de utilização e visitação (Os convidados parecem visitar certa atração mais cedo ou mais à tarde? Quantos convidados utilizam os sistemas de transporte a cada hora?);

- Cliente ocultos fazem compras para conferir o atendimento nas lojas;

- Levantamentos telefônicos são utilizados para coletar informações tanto de amostras aleatórias quanto de convidados recentes;
- Cartas e e-mails d convidados são avaliados em busca de dicas para melhorar $\mathrm{o}$ atendimento;

- Grupos de foco são usados para colher informações para o desenvolvimento futuro e a melhoria de atrações e brinquedos existentes.

As informações coletadas na guestologia são usadas de diversas maneiras, utilizando as opiniões dos seus convidados para implantar melhorias, como dizia Walt Disney "Você não constrói nada sozinho. Você descobre o que as pessoas querem e constrói para elas." (DISNEY INSTITUTE, 2011, p. 40).

Uma vez que um tema do atendimento está enraizado nos funcionários, e atua como promessa para os clientes e propósito para os funcionários, para cumprir essa promessa e concretizar esse propósito, deve-se estabelecer um padrão de atendimento de qualidade, guiado por quatro elementos básicos, que conforme o Disney Institute (2011, p.50) são:

- Segurança: O padrão de atendimento da segurança, assegura o bem-estar e a paz de espírito dos convidados, tratando-o como prioridade.

- $\quad$ Cortesia: O padrão de atendimento da cortesia faz com que todos os convidados sejam tratados como VIP's. Tratá-las como elas desejam serem tratadas, com reconhecimento e respeito por suas emoções, habilidades e culturas. O elenco é treinado para proporcionar felicidade para $\mathrm{O}$ convidado.

- $\quad$ Espetáculo: O padrão de atendimento do espetáculo aborda que o entretenimento deve ser dado aos convidados de maneira interrupta e excepcional.

- Eficiência: O padrão de atendimento da eficiência é cuidar para que não existam percalços nos parques, para que os convidados possam apreciar o que quiserem.

Conforme o Walt Disney World definia e ajustava seus quatro padrões de atendimento, o programa Traditions também dedicou cada vez mais tempo a ensinar os membros do elenco como praticá-los, focando nos elementos dos quatro padrões, que pode ser aplicado universalmente por toda a organização. Depois, a Disney University define a cortesia e explica como a mesma contribui para uma experiência positivo do 
convidado. O resulto desse conjunto de esforços é combinado a uma lista de ações chamada dicas de apresentação, que cada funcionário do Walt Disney World aprende no programa Traditions. Abaixo seguem as dicas de apresentação como um manual que garante que os membros do elenco saibam como agir com cortesia e respeitar cada convidado como indivíduo:

- $\quad$ Faça contato visual e sorria!

- Cumprimente e dê boas-vindas a cada e todo convidado

- Busque o contato com o convidado: Ouça as necessidades dos convidados, ofereça ajuda e responda a perguntas

- $\quad$ Proporcione imediata recuperação do atendimento: É a responsabilidade de cada membro do elenco tentar, na medida do possível, solucionar imediatamente uma falha no atendimento ao convidado antes de se tornar um problema de atendimento ao convidado e sempre descobrir a resposta para o convidado ou encontrar um membro do elenco que possa ajudar o convidado

- Mantenha linguagem corporal apropriada o tempo todo: Boa postura, aparência atenciosa e expressão facial apropriada

- $\quad$ Preserve a experiência mágica para o convidado: Sempre se concentrar no positivo, em lugar de regras e normas e nunca conversar sobre assuntos pessoais ou trabalho na frente dos convidados

- $\quad$ Agradeça cada e todo convidado

Essas diretrizes para o atendimento ao convidado, definem o comportamento com base nos convidados e comunicam as responsabilidades dos funcionários (DISNEY INSTITUTE, 2011, p. 73).

\section{MÉTODO DE PESQUISA}

Quanto aos fins este trabalho refere-se a uma investigação exploratória, que é aquela realizada em área na qual há pouco conhecimento acumulado e sistematizado. Por sua natureza de sondagem, não comporta hipóteses que, todavia, poderão surgir durante ou ao final da pesquisa (VERGARA, 2000, p. 47).

Também se trata de uma investigação descritiva, pois expõe características de determinada população ou de determinado fenômeno. Pode também estabelecer correlações entre variáveis e definir sua natureza. Não tem compromisso de explicar os fenômenos que descreve, embora sirva de base para tal explicação. Pesquisa de opinião insere-se nessa classificação (VERGARA, 2000, p. 47).

Quanto aos meios trata-se de uma pesquisa de campo, pois representa uma investigação empírica, realizada na empresa objeto de estudo. Segundo Vergara (2000 p.47) pode incluir entrevistas, aplicação de questionários, testes e observação participante ou não.

Também é uma pesquisa bibliográfica, pois é um estudo sistematizado desenvolvido com base em material publicado em livros, revistas, jornais, redes eletrônicas, isto é, material acessível ao público em geral (VERGARA, 2000, p. 47).

A pesquisa foi realizada por meio de questionário no qual foi apresentado um número determinado de questões ao entrevistado, aplicado através da plataforma Google Forms, com o qual as questões são fechadas e o respondente teve que avaliar qual era a resposta mais adequada.

O questionário apresentava questões fechadas, para traçar um perfil demográfico onde foram solicitadas as seguintes informações: idade, sexo e escolaridade e o instrumento da pesquisa. Foram aplicados 45questionários, para 45 pessoas, no período compreendido entre 25 a 29 de maio de 2017, em um hotel na cidade de Petrópolis.

Foi realizado um pré-teste do questionário referente a percepção dos clientes do hotel sobre o atendimento baseado nos 4 pilares da metodologia Disney, em maio de 2017 com 08 pessoas. Não foi observada nenhuma dificuldade na hora de responder as questões propostas pela mesma.

\section{ANÁLISE DOS RESULTADOS}

Utilizou-se de dados tratados por métodos estatísticos. Neste trabalho será utilizada a análise estatística. No presente estudo serão utilizadas para a análise dos dados coletados, estatísticas descritivas, além de tabulações cruzadas de perfis, apresentando as médias das respostas, além do perfil demográfico dos respondentes (VERGARA, 2010, p. 52).

Os dados foram coletados em uma escala likert, onde as respostas variam de 1 a 5 , sendo 1 correspondente a "Discordo 
totalmente", 2 a "Discordo", 3 a "Não concordo nem discordo", 4 a "De acordo", e 5 "Totalmente de acordo" indicando a frequente constante do fator.Foram utilizados por "meio de estatísticas descritivas" realizadas com planilhas do MS- Excel. Foram calculadas as médias de cada item do questionário para avaliar a percepção dos clientes do hotel sobre o atendimento baseado nos 4 pilares da metodologia Disney.
Baseando-se no referencial teórico e fundamentando-se nos 4 pilares do padrão de atendimento da Disney, foram elaboradas 3 percepções referentes a cada pilar do atendimento Disney, que são: Espetáculo, cortesia, segurança e eficiência. E para cada percepção, foi elaborado uma questão, totalizando 12 questões, sendo 3 questões referentes ao pilar espetáculo, 3 a cortesia, 3 a segurança e 3 a eficiência conforme a Tabela 1 e a Tabela 2.

Tabela 1: Fatores avaliados no questionário sobre a qualidade no atendimento ao cliente.

\begin{tabular}{|c|c|c|c|}
\hline $\begin{array}{l}\text { Elementos } \\
\text { padrão } \\
\text { Atendimento } \\
\text { Disney }\end{array}$ & $\begin{array}{l}\text { Importância } \\
\text { no contexto } \\
\text { Disney }\end{array}$ & Objetivo & Perguntas \\
\hline \multirow{3}{*}{ Espetáculo } & Estrutura & $\begin{array}{l}\text { "O cenário é ambiente no qual o atendimento é prestado aos } \\
\text { clientes, todos os objetivos nesse ambiente e os procedimentos } \\
\text { utilizados para melhorar a manter o ambiente e os objetos do } \\
\text { atendimento (DISNEY INSTITUTE, 2011, p.95) }\end{array}$ & 1 \\
\hline & Identidade & $\begin{array}{l}\text { "Cada detalhe e cada cenário devem sustentar e estender a } \\
\text { missão e a identidade organizacional (DISNEY INSTITUTE, 2011, } \\
\text { p.99)" }\end{array}$ & 2 \\
\hline & $\begin{array}{l}\text { Entreteniment } \\
\text { o }\end{array}$ & $\begin{array}{l}\text { "Para diminuir o tempo de espera, é necessário otimizar não } \\
\text { somente a operação do produto, mas também o fluxo de } \\
\text { convidados. (DISNEY INSTITUTE, 2011, p.127)" }\end{array}$ & 3 \\
\hline \multirow{3}{*}{ Cortesia } & Respeito & $\begin{array}{l}\text { "Todos os clientes exprimem uma grande necessidade de serem } \\
\text { reconhecidos e tratados com dignidade. (DISNEY INSTITUTE, } \\
\text { 2011, p129)" }\end{array}$ & 4 \\
\hline & Pro-atividade & $\begin{array}{l}\text { "Ter respostas rápidas para as perguntas é um componente } \\
\text { importante da satisfação do cliente. Deve-se proporcionar ao } \\
\text { elenco informações corretas da maneira certa no momento certo. } \\
\text { (DISNEY INSTITUTE, 2011, p 147)" }\end{array}$ & 5 \\
\hline & Expectativas & $\begin{array}{l}\text { "Trate todos os convidados como VIP's - pessoas muito } \\
\text { importantes e muito individuais. (DISNEY INSTITUTE, 2011, p, } \\
\text { 147)" }\end{array}$ & 6 \\
\hline \multirow{3}{*}{ Segurança } & Bem-estar & $\begin{array}{l}\text { "O padrão de atendimento da segurança reuqer que o bem-estar e } \\
\text { a paz de espírito dos convidados sejam sempre prioridade } \\
\text { (DISNEY INSTITUTE, 2011, p 51)" }\end{array}$ & 7 \\
\hline & Confiança & $\begin{array}{l}\text { "Quando a experiência é uniforme, ininterrupta e de alta qualidade, } \\
\text { Os convidados se sentem seguros em retornar (DISNEY } \\
\text { INSTITUTE, 2011, p.26)" }\end{array}$ & 8 \\
\hline & Segurança & $\begin{array}{l}\text { "Sentir segurança ao ser atendido, também implica no bem estar e } \\
\text { na paz de espírito do cliente (DISNEY INSTITUTE, } 2011 \text { p.51)" }\end{array}$ & 9 \\
\hline \multirow{3}{*}{ Eficiência } & Tempo hábil & $\begin{array}{l}\text { "Proporcione imediata recuperação do atendimento: Sempre } \\
\text { descubra a resposta para o convidado ou encontre outro membro } \\
\text { que possa ajudar (DISNEY INSTITUTE, 2011, p.74)" }\end{array}$ & 10 \\
\hline & $\begin{array}{c}\text { Funcionalidad } \\
\mathrm{e}\end{array}$ & $\begin{array}{l}\text { "A empresa analisa o fluxo de convidados e os padrões de } \\
\text { utilização para proporcionar equipamentos e níveis adequados } \\
\text { (DISNEY INSTITUTE, 2011, p. 53)" }\end{array}$ & 11 \\
\hline & Flexibilidade & $\begin{array}{l}\text { "É de responsabilidade de cada membro do elenco procurar } \\
\text { convidados que precisem de ajuda ou assistência (DISNEY } \\
\text { INSTITUTE 2011, p. 71)" }\end{array}$ & 12 \\
\hline
\end{tabular}
Fonte: Disney Institute 
Tabela 2: Perguntas referentes aos fatores avaliados no questionário sobre a qualidade no atendimento ao cliente

\begin{tabular}{|c|c|c|}
\hline & & Perguntas \\
\hline \multirow{3}{*}{ Espetáculo } & Estrutura & 1. A estrutura da empresa acrescenta qualidade ao atendimento? \\
\hline & Identidade & $\begin{array}{l}\text { 2. Reconheço a identidade da empresa em seus produtos, serviços e } \\
\text { funcionários? }\end{array}$ \\
\hline & Entretenimento & 3. A empresa se preocupa em tornar o tempo de espera agradável? \\
\hline \multirow{3}{*}{ Cortesia } & Respeito & $\begin{array}{l}\text { 4. Durante o atendimento, sinto que os funcionários reconhecem as minhas } \\
\text { necessidades e as atendem de maneira digna? }\end{array}$ \\
\hline & Pro-atividade & $\begin{array}{l}\text { 5. Os funcionários interrompem suas atividades para dar atenção ao } \\
\text { quesolicito? }\end{array}$ \\
\hline & Expectativas & 6. A qualidade do atendimento atende as minhas expectativas? \\
\hline \multirow{3}{*}{ Segurança } & Bem-estar & $\begin{array}{l}\text { 7. Me sinto seguro e protegido durante todo o processo do } \\
\text { atendimento/aquisição do produto/serviço? }\end{array}$ \\
\hline & Confiança & 8. Baseado no atendimento que recebi, retornaria outras vezes? \\
\hline & Segurança & $\begin{array}{l}\text { 9. Os funcionários estão preparados para me fornecer informações com } \\
\text { precisão e segurança? }\end{array}$ \\
\hline \multirow{3}{*}{ Eficiência } & Solicitações & 10. Minhas solicitações foram atendidas em tempo adequado? \\
\hline & Funcionalidade & $\begin{array}{l}\text { 11. Os canais de comunicação e acesso a empresa funcionam de forma } \\
\text { eficiente? }\end{array}$ \\
\hline & Flexibilidade & $\begin{array}{l}\text { 12. Durante o atendimento, o funcionário agiu com flexibilidade para com as } \\
\text { minhas necessidades? }\end{array}$ \\
\hline
\end{tabular}

Fonte: Disney Institute

Os questionários apresentavam questões fechadas, para traçar um perfil demográfico onde foram solicitadas as seguintes informações: idade, sexo e escolaridade e a aplicados 45 questionários, no período compreendido entre 25 a 28 de maio de 2017 , na cidade de Petrópolis. Os dados foram tabulados de maneira que foi possível analisálos e determinar conclusões as quais serão apresentadas a seguir.

Para a realização dessa parte do projeto, primeiramente, foi preciso calcular o universo da pesquisa. Para tanto, considerou-se o atendimento realizado em um período de 4 dias, período autorizado pela empresa para realizar a pesquisa.

Durante a aplicação da pesquisa, que aconteceu em maio de 2017, 45 (quarenta e cinco) pessoas responderam às perguntas de acordo com as interações do atendimento que receberam durante a hospedagem, no check-out. As médias obtidas estão representadas na Tabela 3. 
Tabela 3: Média dos resultados obtidos na pesquisa direcionada aos clientes do hotel

\begin{tabular}{|c|c|c|c|c|}
\hline & & Perguntas & Médias & $\begin{array}{l}\text { Total } \\
\text { das } \\
\text { Médias }\end{array}$ \\
\hline \multirow{3}{*}{ Espetáculo } & Estrutura & $\begin{array}{l}\text { 1. A estrutura da empresa acrescenta } \\
\text { qualidade ao atendimento? }\end{array}$ & 3,98 & \multirow{3}{*}{3,72} \\
\hline & Identidade & $\begin{array}{l}\text { 2. Reconheço a identidade da empresa } \\
\text { em seus produtos, serviços e } \\
\text { funcionários? }\end{array}$ & 3,87 & \\
\hline & Entretenimento & $\begin{array}{l}\text { 3. A empresa se preocupa em tornar o } \\
\text { tempo de espera agradável? }\end{array}$ & 3,31 & \\
\hline \multirow{3}{*}{ Cortesia } & Respeito & $\begin{array}{l}\text { 4. Durante o atendimento, sinto que os } \\
\text { funcionários reconhecem as minhas } \\
\text { necessidades e as atendem de maneira } \\
\text { digna? }\end{array}$ & 4,09 & \multirow{3}{*}{4,41} \\
\hline & Pro-atividade & $\begin{array}{l}\text { 5. Os funcionários interrompem suas } \\
\text { atividades para dar atenção ao que } \\
\text { solicito? }\end{array}$ & 4,6 & \\
\hline & Expectativas & $\begin{array}{l}\text { 6. A qualidade do atendimento atende } \\
\text { as minhas expectativas? }\end{array}$ & 4,53 & \\
\hline \multirow{3}{*}{ Segurança } & Bem-estar & $\begin{array}{l}\text { 7. Me sinto seguro e protegido durante } \\
\text { todo o processo do } \\
\text { atendimento/aquisição do } \\
\text { produto/serviço? }\end{array}$ & 4,07 & \multirow{3}{*}{4,21} \\
\hline & Confiança & $\begin{array}{l}\text { 8. Baseado no atendimento que recebi, } \\
\text { retornaria outras vezes? }\end{array}$ & 4,69 & \\
\hline & Segurança & $\begin{array}{l}\text { 9. Os funcionários estão preparados } \\
\text { para me fornecer informações com } \\
\text { precisãoe segurança? }\end{array}$ & 3,87 & \\
\hline \multirow{3}{*}{ Eficiência } & Solicitações & $\begin{array}{l}\text { 10. Minhas solicitações foram atendidas } \\
\text { em tempo adequado? }\end{array}$ & 4,24 & \multirow{3}{*}{4,14} \\
\hline & Funcionalidade & $\begin{array}{l}\text { 11. Os canais de comunicação e acesso } \\
\text { a empresa funcionam de forma } \\
\text { eficiente? }\end{array}$ & 3,71 & \\
\hline & Flexibilidade & $\begin{array}{l}\text { 12. Durante o atendimento, o funcionário } \\
\text { agiu com flexibilidade para com as } \\
\text { minhas necessidades? }\end{array}$ & 4,47 & \\
\hline
\end{tabular}

Fonte: Os autores

Baseando-se nesses dados, nota-se que as maiores médias se referem, respectivamente, as perguntas $8(4,69), 5(4,60), 6(4,53)$ e 12 $(4,47)$. A partir da pergunta 8 , em relação a se o cliente retornaria outras vezes baseado no atendimento que recebeu, define-se que a confiança (fator da segurança) é bem percebida, com grandes chances de fidelização. A pergunta 5, sobre se os funcionários interrompem as suas atividades para dar atenção ao que o cliente solicita e a pergunta 6 , sobre se a qualidade do atendimento atende as expectativas do cliente, tratam sobre pró-atividade e expectativa respectivamente (fatores da cortesia) sinal de que os funcionários estão se preocupando em se antecipar as necessidades dos clientes e a atender as suas expectativas. A pergunta 12, sobre se durante o atendimento, o funcionário agiu com flexibilidade para com as necessidades do cliente, está relacionada a flexibilidade (fator da eficiência) e pode-se perceber que o funcionário atende em um nível satisfatório.

Por outro lado, pôde-se perceber que as menores médias foram nas perguntas relacionadas ao pilar "Espetáculo". O menor, 3,31 (Pergunta 3), refere-se a preocupação da 
empresa em tornar o tempo de espera agradável. Em seguida, vem a média da pergunta 2 que trata sobre a identidade da empresa percebida, e recebeu média 3,87. Por final, a média da pergunta $1(3,98)$ que avalia a percepção do cliente em relação a estrutura que a empresa oferece. Percebe-se que as médias mais baixas foram em relação ao pilar espetáculo de atendimento, o que indica a necessidade da empresa em oferecer uma forma de entreter o seu cliente enquanto ele aguarda ser atendido, melhorar a sua estrutura fazendo com que cada ambiente tenha a identidade e os valores da empresa.

Em relação aos pilares do atendimento Disney, pode-se observar uma sequência da maior para menor média geral, respectivamente: Cortesia $(4,41)$, Segurança $(4,21)$, Eficiência $(4,14)$ e Espetáculo $(3,72)$. Onde, nota-se que a percepção dos clientes em relação à respeito e pró- atividade e as suas expectativas atendidas, possuem níveis satisfatórios. Mostra também, que a empresa deve se preocupar em manter o espetáculo acontecendo, repensando em maneiras mais agradáveis e atrativas para sua estrutura, promover a sua identidade, compartilhando seus valores, missão e visão em cada detalhe através de pesquisas e planejamento e buscar entreter o seu cliente, fazendo com que todas as interações referentes ao espetáculo atinjam níveis de satisfação mais altos.

A identidade e os valores da empresa podem ser melhor adaptados em seus produtos, serviços e funcionários, em uma reestruturação para agregar os seus valores ao espaço da empresa oferecido aos clientes

Segundo Lovelock (2005, p. 114) se a maioria das notas de satisfação entram na faixa entre 2 e 3 provavelmente existe um problema na entrega do serviço básico da empresa, ou seja, os benefícios básicos que os clientes esperam de uma empresa. Clientes indiferentes ou satisfeitos (notas 3 e 4) possivelmente estão felizes com o serviço básico, mas gostariam que tivesse serviços suplementares que tornem o produto básico mais eficaz e fácil de utilizar, já clientes inteiramente satisfeitos (nota 5) acreditam que uma empresa compreende e atende todas as suas preferências, necessidades, expectativas e problemas pessoais.

A empresa transmite mensagens a seus clientes por meio dos cenários nos quais operam, tais mensagens alteram as percepções dos clientes em relação ao produto e serviços vendidos, por isso, é imprescindível que os cenários sejam arquitetados e administrados para transmitir mensagens corretas aos clientes e atendê-los com eficácia, o que podemos evidenciar na percepção dos clientes em relação as perguntas $1(3,98)$ e $2(3,87)$ sobre a estrutura e identidade da empresa, respectivamente, pergunta $9(3,87)$ sobre se os funcionários estão preparados para fornecer informações com precisão e segurança. Outro encontro de serviço, é o encontro mediados pela tecnologia, que são aquele cujos canais de comunicação são baseados na tecnologia como site, e-mail, telefone etc., onde a eficiência e eficácia ao lidar com as necessidades do cliente são fatores importantes ao julgar a qualidade nesse encontro, onde podemos observar a média da pergunta $11(3,71)$ sobre a funcionalidade da empresa, se os canais de comunicação funcionam de forma eficiente, possui melhorias a serem feitas pois é um fator muito importante no julgamento do cliente em relação ao serviço.

Ou seja, apesar da empresa possuir médias acima de 3, é preciso suplementar de forma consistente os serviços básicos de forma que o torne mais eficaz, como de acordo com a pesquisa, a estrutura e a identidade da empresa, a preocupação em tornar o tempo de espera agradável, a segurança dos funcionários em fornecer informações e a otimizar os canais de comunicação e acesso. $\mathrm{E}$ os fatores que possuem média 4 precisam ser melhorados, pois são índices de satisfação indiferentes e podem ser atraídos pelo concorrente.

\subsection{ANÁLISE DEMOGRÁFICA: GÊNERO FEMININO}

Verificou-se que 44,4\% da amostra correspondem pessoas do gênero feminino, com as seguintes faixas etárias: $5 \%$ entre 20 - 25 anos, $20 \%$ entre 25 - 30 anos, $40 \% 30$ 40 anos e $35 \%$ acima de 40 anos. Sendo que $55 \%$ possuem graduação e $45 \%$ pósgraduação. Podemos observar que com tais dados a predominância da amostra do gênero feminino, são mulheres com pós-graduação e acima de 40 anos 
4.1.1 ANÁLISE DA PERCEPÇÃO DO ATENDIMENTO DE MULHERES ENTRE 20- 25 ANOS

Avaliaram média 3,0 as perguntas 1 que avalia se a estrutura acrescenta qualidade ao atendimento que receberam, a pergunta 2 sobre se o cliente reconheceu a identidade da empresa em seus produtos, serviços e funcionários, a pergunta 3 em relação a preocupação da empresa em tornar o tempo de espera agradável, a pergunta 4 que avalia se durante $\mathrm{O}$ atendimento os funcionários reconheceram as reis necessidades do cliente e as atenderam de maneira digna e a pergunta 11 sobre se os canais de comunicação e acesso a empresa funcionam de forma eficiente.

As maiores médias foram nas perguntas 5 $(5,00)$ sobre pro-atividade, se os funcionários interrompem as atividades para atender as solicitações do cliente, e a pergunta $8(5,0)$ relacionada a confiança que avalia se 0 cliente retornaria outras vezes baseado no atendimento que recebeu.

Portanto, mulheres com idade entre 20 - 25 anos, percebem que todos os fatores do pilar espetáculo (estrutura, identidade e entretenimento), devem ser melhorados, ressaltando a diferença da menor média recebida $(3,0)$ para a maior $(5,0)$.

Tabela 4: As percepções de mulheres com idade entre 20 - 25 anos sobre os pilares do atendimento Disney

\begin{tabular}{|c|c|c|c|}
\hline \multirow{3}{*}{ ESPETÁCULO } & Estrutura & 3 & \multirow{3}{*}{3,00} \\
\hline & Identidade & 3 & \\
\hline & Entretenimento & 3 & \\
\hline \multirow{3}{*}{ CORTESIA } & Respeito & 3 & \multirow{3}{*}{4,00} \\
\hline & Proatividade & 5 & \\
\hline & Expectativa & 4 & \\
\hline \multirow{3}{*}{ SEGURANÇA } & Bem estar & 4 & \multirow{3}{*}{4,33} \\
\hline & Confiança & 5 & \\
\hline & Segurança & 4 & \\
\hline \multirow{3}{*}{ EFICIÊNCIA } & Solicitações & 4 & \multirow{3}{*}{3,67} \\
\hline & Funcionalidade & 3 & \\
\hline & Flexibilidade & 4 & \\
\hline
\end{tabular}

\subsubsection{ANÁLISE DA PERCEPÇÃO DO ATENDIMENTO DE MULHERES ENTRE 25- 30 ANOS}

Avaliaram com as menores médias a pergunta $2(3,5)$, que trata o reconhecimento da identidade da empresa em seus produtos, serviços e funcionários, a pergunta $3(3,75)$, que avalia se durante 0 atendimento, os funcionários respeitam as reais necessidades dos clientes e as atendem de maneira digna.

As maiores médias foram nas perguntas 8 $(5,00)$ sobre confiança, baseado no atendimento recebido se o cliente retornaria a empresa, e as perguntas $5(4,75)$ que avalia se os funcionários interrompem as suas atividades para dar atenção ao que o cliente solicita, e a pergunta $6(4,75)$ sobre se o atendimento atende as expectativas do cliente. Ou seja, mulheres com idade entre 25 - 30 anos, percebem que a identidade, a eficiência dos canais de comunicação e acesso da empresa e a preparação dos funcionários para fornecer informações e a distração para o tempo de espera possuem pontos a melhorar, conforme mostra as figuras a seguir.

Em relação aos pilares do atendimento Disney, pode se observar uma sequência da maior para menor média geral, respectivamente: Cortesia $(4,50)$, Segurança $(4,42)$, Eficiência $(4,33)$ e Espetáculo $(3,92)$. Onde, percebe-se que a percepção das mulheres em relação a cortesia, segurança e eficiência possui níveis satisfatórios, e sobre o 
Tabela 5: As percepções de mulheres com idade entre 25 - 30 anos sobre os pilares do atendimento Disney

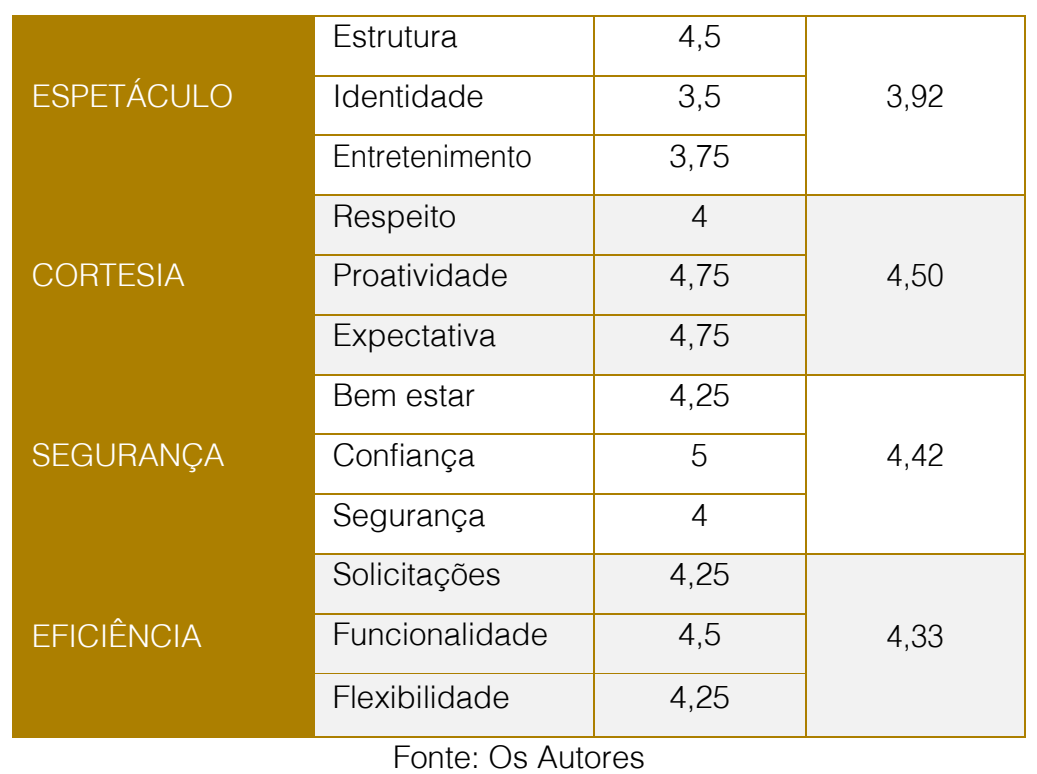

\subsubsection{ANÁLISE DA PERCEPÇÃO DO ATENDIMENTO DE MULHERES ENTRE 30- 40 ANOS}

Percebe-se que mulheres entre 30 - 40 anos, $90 \%$ possuem graduação e $10 \%$ possuem pós- graduação.

Avaliaram com as menores médias a pergunta $3(2,0)$, que avalia se a empresa se preocupa em tornar o tempo de espera agradável, a pergunta 9 (3,25), que avalia se os funcionários são preparados para fornecer informações com precisão e segurança, a pergunta 2 que avalia se o cliente reconheceu a identidade da empresa em seus produtos, serviços e funcionários e a pergunta $11(3,38)$ que avalia se os canais de comunicação e acesso a empresas funcionam de forma eficiente.

As maiores médias foram nas perguntas 8 $(4,75)$ sobre confiança, se baseado no atendimento recebido retornaria a empresa, a pergunta $5(4,63)$ relacionada a pro atividade, que avalia se os funcionários interrompem as suas atividades para dar atenção ao que o cliente solicita. Ou seja, mulheres com idade entre 30 - 40 anos, percebem que a identidade da empresa, a eficiência dos canais de comunicação e acesso da empresa e a preparação dos funcionários para fornecer informações e a distração para tempo de espera possuem pontos a melhorar.

Em relação aos pilares do atendimento Disney, pode-se observar uma sequência da maior para menor média geral, respectivamente: Cortesia $(4,21)$, Segurança $(3,96)$, Eficiência $(3,92)$ e espetáculo $(3,00)$. Onde, percebe-se que a percepção das mulheres com idade entre 30 - 40 anos em relação a pro-atividade por parte dos funcionários, e se o atendimento atende as suas expectativas, possuem níveis satisfatórios. Mostra também, que a percepção das mesmas em relação a eficiência, segurança e espetáculo da empresa possuem níveis mais baixos de acordo com as tabelas abaixo. 
Tabela 6: As percepções de mulheres com idade entre 30 - 40 anos sobre os pilares do atendimento Disney

\begin{tabular}{|c|c|c|c|}
\hline \multirow[b]{2}{*}{ ESPETÁCULO } & Estrutura & 3,63 & \multirow[b]{2}{*}{3,00} \\
\hline & Identidade & 3,38 & \\
\hline \multirow{4}{*}{ CORTESIA } & Entretenimento & 2 & \\
\hline & Respeito & 3,63 & \multirow{3}{*}{4,21} \\
\hline & Proatividade & 4,63 & \\
\hline & Expectativa & 4,38 & \\
\hline \multirow{3}{*}{ SEGURANÇA } & Bem estar & 3,88 & \multirow{3}{*}{3.96} \\
\hline & Confiança & 4,75 & \\
\hline & Segurança & 3,25 & \\
\hline \multirow{3}{*}{ EFICIÊNCIA } & Solicitações & 3,88 & \multirow{3}{*}{3,92} \\
\hline & Funcionalidade & 3,38 & \\
\hline & Flexibilidade & 4,5 & \\
\hline
\end{tabular}

Fonte: Os autores

Pode-se perceber que $75 \%$ das mulheres que responderam ao questionário possuem idade a partir de 30 anos, supondo que esse perfil é o predominante do gênero feminino da amostra.

Nota-se que $71,5 \%$ das mulheres acima de 40 anos possuem pós-graduação, e avaliam com a menor média a funcionalidade dos canais de comunicação da empresa, fator esse que pode ser entendido por ser um público que dificuldade com as tecnologias oferecidas, e com a maior média a pro-atividade dos funcionários em interromper as suas atividades para atender as solicitações, talvez por ser um perfil que aprecie um bom atendimento.

Já as mulheres que possuem entre 30 - 40 anos, a maioria (90\%) possui graduação e avaliam com a menor média o entretenimento, a preocupação da empresa em tornar o tempo de espera agradável, fator esse que pode ser entendido por ser um públicoque precise economizar tempo, visto que se encontram em vida profissional ativa. Avaliaram com a maior média a segurança, sobre retornar a utilizar os serviços da empresa baseado no atendimento recebido. Em ambos os casos, podemos observar médias satisfatórias no pilar cortesia, e médias razoáveis para eficiência, no caso de mulheres acima de 40 anos, e espetáculo para as mulheres entre $30-40$ anos.

O perfil de mulheres que possuem graduação como escolaridade predominante, avaliaram a percepção dos 4 pilares do atendimento Disney com médias razoáveis, enquanto as mulheres que possuem pós-graduação como escolaridade dominante, avaliaram com médias altas.

\subsection{ANÁLISE DEMOGRÁFICA: GÊNERO MASCULINO}

Verificou-se que $55,6 \%$ da amostra correspondem pessoas do gênero masculino, com as seguintes faixas etárias: $4 \%$ entre 20 - 25 anos, $12 \%$ entre 25 - 30 anos, 28\% 30 40 anos e

$52 \%$ acima de 40 anos. Sendo que 40\% possuem graduação, 32 \% pós-graduação, $24 \%$ técnico e $4 \% 2^{\circ}$ grau. Pode-se observar que com tais dados a predominância da amostra do gênero masculino, são homens com graduação e acima de 40 anos. Abaixo os gráficos que ilustram tais dados.

\subsubsection{ANÁLISE DA PERCEPÇÃO DO ATENDIMENTO DE HOMENS ENTRE 30 - 40 ANOS}

Nota-se que homens com idade entre 30 - 40 anos ou mais, 29\% possuem técnico, 29\% possuem graduação e 42\% possuem pósgraduação.

De maneira geral, a percepção possui níveis razoáveis, sendo as menores médias referentes a pergunta $3(2,89)$, que avalia se a 
empresa se preocupa em tornar o tempo de espera agradável e a pergunta $11(3,33)$ que avalia se os canais de comunicação e acesso a empresa funcionam de forma eficiente.

As maiores médias foram nas perguntas 8 $(4,44)$ e pergunta $6 \quad(4,11)$ sobre, respectivamente, se retornaria a empresa baseado no atendimento que recebeu, e se a qualidade do atendimento atende as expectativas. Ou seja, homens com idade entre 30 - 40 anos, percebem que a empresa pode repensar em maneiras de tornar o tempo de espera mais agradável e otimizar os canais de comunicação e acesso que representa um encontro mediado pela tecnologia (via e- mail, site, telefone, internet) que envolve a eficiência e a eficácia ao lidar com as necessidades dos clientes.

Em relação aos pilares do atendimento Disney, pode-se observar uma sequência da maior para menor média geral, respectivamente: Segurança (3,89), Cortesia $(3,85)$, eficiência $(3,67)$ e espetáculo $(3,37)$. Onde, percebemos que homens com idade entre 30 - 40 anos possuem uma percepção do atendimento de nível razoável, visto que a as médias não chegam a 4,0, como a figura ilustra abaixo.

Tabela 7: As percepções de homens com idade entre 30 - 40 anos sobre os pilares do atendimento Disney

\begin{tabular}{|c|c|c|c|}
\hline & Estrutura & 3,56 & \multirow{3}{*}{3,37} \\
\hline \multirow[t]{2}{*}{ ESPETÁCULO } & Identidade & 3,67 & \\
\hline & Entretenimento & 2,89 & \\
\hline \multirow{4}{*}{ CORTESIA } & Respeito & 3,44 & \multirow{3}{*}{3,85} \\
\hline & Proatividade & 4,00 & \\
\hline & Expectativa & 4,11 & \\
\hline & Bem estar & 3,56 & \multirow{3}{*}{3,89} \\
\hline \multirow[t]{3}{*}{ SEGURANÇA } & Confiança & 4,44 & \\
\hline & Segurança & 3,67 & \\
\hline & Solicitações & 3,78 & \multirow{3}{*}{3,67} \\
\hline \multirow[t]{2}{*}{ EFICIÊNCIA } & Funcionalidade & 3,33 & \\
\hline & Flexibilidade & 3,89 & \\
\hline
\end{tabular}

Fonte: Os autores

\subsubsection{ANÁLISE GERAL DA PERCEPÇÃO DO ATENDIMENTO DE CLIENTES DO GÊNERO MASCULINO}

Pode-se perceber que homens acima de 40 anos possuem como escolaridade dominante, a graduação e avaliam a percepção do atendimento baseado nos 4 pilares de atendimento Disney com médias altas, tendo como menor média em relação ao espetáculo, e mais precisamente do entretenimento, da preocupação da empresa em tornar o tempo de espera agradável, e como maior média o pilar cortesia, que possui médias bastante satisfatórias.

Homens com idade entre 30 - 40 anos, que representa $28 \%$ da amostra do gênero masculino, a maioria possui pós-graduação e avaliam a percepção do atendimento baseado nos 4 pilares da Disney com médias razoáveis.

\subsection{ANÁLISE GERAL DA PERCEPÇÃO GÊNERO FEMININO X GÊNERO MASCULINO}

Nota-se que os homens representam 55\% da amostra, enquanto as mulheres, $45 \%$. A predominância em relação a idade de ambos é de 30 anos pra cima.

Percebe-se que homens com idade acima de 40 anos avaliaram com menor média a preocupação da empresa em tornar o tempo de espera agradável $(3,92)$ e com maior média o atendimento das solicitações dos mesmos atendidas em tempo adequado $(4,62)$, enquanto as mulheres com idade acima de 40 anos avaliaram com menor 
média a funcionalidade dos canais de comunicação e acesso da empresa $(3,43)$, e com maior média a pro-atividade dos funcionários em interromper as suas atividades para dar atenção ao que é solicitado $(4,86)$.

Já os homens com idade entre 30-40 anos avaliaram com menor média a preocupação da empresa em tornar o tempo de espera agradável (2,89), e com maior média se baseado no atendimento recebido, se retornariam a empresa $(4,44)$,enquanto as mulheres com idade entre 30-40 anos avaliaram com menor média também a preocupação da empresa em tornar o tempo de espera agradável $(2,0)$, e com a maior média sobre retornar a utilizar os serviços da empresa baseado no atendimento que recebeu $(4,75)$.

Com tais dados pode-se observar que a percepção de homens com idade acima de 40 anos, que representam a predominância da amostra, em relação a ter um sentimento de segurança em relação ao produto ou serviço que ele adquire possui pontos a melhorar, enquanto as mulheres com idade acima de 40 anos percebem que os canais de comunicação e acesso a empresa são razoavelmente eficientes.

\section{CONCLUSÕES}

Este trabalho tem como problema de pesquisa: Qual a percepção dos clientes em relação ao atendimento através da aplicação da metodologia Disney?

Por meio de pesquisas bibliográficas e de campo foi possível identificar os pontos fortes e os pontos a serem melhorados no atendimento da empresa.

Os resultados da pesquisa, em função do nível de satisfação da percepção dos clientes em relação ao atendimento baseado nos pilares de atendimento Disney, indicam que a organização possui níveis satisfatórios, mas que podem ser melhorados para que se alcance uma gestão de excelência no atendimento.

Pode-se observar que a percepção geral do público sobre o atendimento do hotel em relação a metodologia Disney possui níveis satisfatórios, confirmados pelos dados obtidos sobre "Confiança", "Pro - atividade", "Expectativas" e "Funcionalidade", que se encontram em um nível bastante satisfatório. Isso demonstra que a empresa possui grandes chances de fidelizar os seus clientes, e que deve continuar as suas ações de treinar os seus funcionários para que o atendimento cortês e proativo que atenda as expectativas de seus clientes permaneçam. Em relação a percepção dos clientes em relação aos 4 pilares de atendimento Disney, observa-se que a sequência da maior para a menor média, respectivamente "Cortesia", "Segurança", "Eficiência" e "Espetáculo. Onde conclui-se que a percepção dos clientes em relação a sentir que os funcionários entendem as suas reais necessidades e as atendem de maneira digna, a pro atividade dos mesmos e a ter as suas expectativas atendidas possuem um nível satisfatório.

Entretanto, evidencia que a empresa pode melhorar os fatores do pilar "Espetáculo", como a "Estrutura", que corresponde aos aspectos físicos, as mensagens que a empresa transmite através do ambiente que opera a "Identidade", em compartilhar os seus valores em cada detalhe da empresa, e por fim, o "Entretenimento", em fazer com que o tempo de espera seja agradável.

Verificou-se também que, o gênero do perfil do cliente dominante da empresa são homens, e a faixa etária do perfil dominante é a partir de 30 anos.

Constatou-se que mulheres com idade a partir de 30 anos, avaliaram o pilar "Cortesia" com média alta, e o pilar "Eficiência" com média mais baixa, enquanto os homens com idade a partir de 30 anos avaliaram com maior média o pilar "Confiança" e com menor média o pilar "Entretenimento".

Pode-se observar com tais dados que as mulheres com idade a partir de 30 anos, clientes do hotel, possuem uma boa percepção quanto a cortesia da empresa, que corresponde ao respeito dos funcionários em atender e entender suas reais necessidades, a pro atividade dos mesmos ao interromper as suas atividades para dar atenção ao que solicitado e a qualidade do atendimento atender as suas expectativas. Por outro lado, possuem uma percepção razoável quanto aos canais de comunicação da empresa, como acesso ao site, contato por e-mail, telefone etc., quanto a flexibilidade por parte da empresa em atender as suas necessidades, e por último, quanto a atender as suas solicitações em tempo adequado. Enquanto os homens com idade a partir de 30 anos, 
cliente do hotel, percebem a confiança em relação a empresa positivamente, que corresponde a retornar outras vezes na empresa, baseado no atendimento que receberam.

Em relação as mulheres com idade a partir de 30 anos pode-se observar também, que as mesmas, possuem pós-graduação perceberam os pilares do atendimento Disney com médias mais altas, enquanto as que possuem graduação avaliaram com médias razoáveis.
Portanto, é fundamental compreender que atender ao cliente com qualidade não é apenas tratá-lo bem, com cortesia. Mais do que isso, atender com qualidade significa acrescentar benefícios a produtos e serviços, se preocupando com cada detalhe do processo, de todas as interações que o cliente obtém durante todo o processo do atendimento e objetivando a superar as expectativas dos clientes, criando experiências únicas e memoráveis.

\section{REFERÊNCIAS}

[1]. AZEVEDO, A;Pomeranz. Marketing de resultados. $1^{\circ}$ edição, São Paulo: M. Books do Brasil Editora Ltda, 2004.

[2]. BARRETO, I. Marketing de relacionamento. $1^{\circ}$ edição, São Paulo: Education do Brasil, 2013.

[3]. BOGMANN, I.M; Marketing de relacionamento: estratégias de fidelização e suas implicações financeiras. $1^{\circ}$ edição, São Paulo: Nobel, 2000.

[4]. DISNEY INSTITUTE. O jeito Disney de encantar os clientes. $1^{\circ}$ edição, São Paulo: Saraiva, 2011.

[5]. KOTLER, P.; KELLER, K. L. Administração de marketing. 14를 edição, São Paulo: Pearson Education, 2014.

[6]. LOVELOCK, C; WRIGHT, L. Marketing de Serviços. $1^{\circ}$ edição, São Paulo: Saraiva, 2005.

[7]. VERGARA, S.C. Projetos e Relatórios de Pesquisa em Administração. 12ª Edição, São Paulo: Atlas, 2000

[8]. ZEITHMAL, A.; BITNER, M.J; GREMLER, D.D. Marketing de serviços. $6^{\circ}$ edição, Porto Alegre: AMGH, 2013. 


\section{Capítulo 19}

\section{DIFERENCIAÇÃO DO PRODUTO: O CASO SAPATOS LENDS}

\section{Camila Andrade Silva Souza}

\section{Camila Silva Damasceno}

Stephania Aparecida Freitas Pedrosa

Joyce Gonçalves Altaf

Resumo: A exigência dos consumidores do mercado de luxo é crescente e isso faz com que as empresas se preocupem cada vez mais com as estratégias que serão utilizadas para conseguir atingir o seu público alvo e consequentemente fidelizálos. O objetivo desse artigo foi analisar o mercado de luxo sob a visão estratégica genérica de Porter (1980), a Diferenciação do Produto. No presente artigo foi desenvolvido o conceito, as bases e as vantagens da diferenciação, que nada mais é que a procura por oferecer ao produto ou serviço uma identidade própria e que seja reconhecida pelos consumidores. A empresa de luxo tratada nesse estudo, Lends, tem sua estratégia à Diferenciação do Produto. Para a realização da pesquisa trata-se de uma pesquisa de campo, com aplicação de questionários online, via WhatsApp com objetivo de observar o comportamento da clientela da marca pesquisada, identificando quais as fontes de Diferenciação do Produto que mais as atingem, além de analisar o que é luxo para as mesmas. Conclui-se que através da análise dos questionários as lojas buscarão aprimorar suas estratégias de diferenciação para adquirirem vantagem competitiva perante as lojas concorrentes.

Palavras chave: Estratégias, Diferenciação do Produto, Mercado de Luxo. 


\section{INTRODUÇÃO}

Nas últimas décadas o mercado vem se destacando pela competitividade ascendente e pela busca incansável de novidades, que se tornem tendências mundialmente conhecidas, de modo a gerar melhores resultados dentro das organizações. Considerando esse acirramento, as empresas necessitam avaliar constantemente seu posicionamento no mercado e trabalhar arduamente em seus diferenciais competitivos. Dentre eles o uso da estratégia de Diferenciação do Produto, que em sua essência torna uma marca ou empresa reconhecida por suas particularidades diante da concorrência, evidenciando vantagens competitivas (PORTER, 1980).

Ressalta-se que embora as corporações frequentemente alterem as propriedades de seus produtos ou serviços para implementar uma estratégia de Diferenciação do Produto, a existência dessa diferenciação, no final, é sempre uma questão de percepção do consumidor (BARNEY,2007). Quando se pensa no mercado de luxo isso se torna ainda mais relevante. Afinal, entender o conjunto de atitudes, emoções e motivos que levam estes a consumirem tais produtos e serviços é vital para um bom desempenho organizacional. Entretanto, a definição de luxo não é uma das tarefas mais simples afinal, o que é luxo para uns pode ser absolutamente comum para outros.

O presente artigo objetiva entender 0 comportamento do consumidor dos produtos da marca Lends que tem como finalidade desenvolver sapatos, bolsas e acessórios valorizando o design, materiais de alta qualidade, conforto e tecnologia de ponta. Atualmente, comercializa mais de 9 milhões de pares de calçados ao ano, além de bolsas e acessórios (ENICK, 2015).

Assim, para atender esse propósito foi desenvolvida uma pesquisa, eminentemente quantitativa, com o intuito de obter mais informações sobre a marca abordada e de seus consumidores no que se refere à Diferenciação do Produto. Para isso, foi desenvolvido um questionário por meio da ferramenta Google Drive composto por quatorze questões, onde foram coletados dados necessários para responder à questão problema proposta no trabalho. A pesquisa foi aplicada via WhatsApp, aplicativo que permite interação rápida e imediata por meio de mensagens de texto e enviadas via celular.
É importante ressaltar que a pesquisa foi operacionalizada durante quatorze dias e contou com a participação de 45 respondentes consumidoras da marca.

Ressalta-se que este estudo está desmembrado em quatro partes, além da presente introdução: 1) referencial teórico sobre o mercado de luxo, comportamento do consumidor de luxo e diferenciação do produto; 2) o método escolhido, o campo da pesquisa, as técnicas utilizadas para coleta de dados e o estudo de caso da marca Lends; 3) análise dos resultados da pesquisa realizada; e por fim, 4) as considerações finais do estudo.

\section{BREVE EMBASAMENTO TEÓRICO}

Neste tópico serão abordados assuntos que embasam a teoria acerca do estudo realizado. Inicialmente, será apresentado o tema de Estratégia Empresarial. Em seguida, serão introduzidos o referencial teórico da estratégia de Diferenciação do Produto. E então, para finalizar conceitos e noções de Mercado de Luxo.

\subsection{ESTRATÉGIA EMPRESARIAL}

Segundo Porter (2004) a competição se intensificou de forma drástica ao longo das últimas décadas. A competitividade empresarial surge quando empresas que oferecem produtos e serviços semelhantes, disputam os mesmos consumidores e desejam crescer e se destacar em meio aos seus concorrentes. Conhecer o mercado é fundamental para saber com que tipo de concorrência a empresa estará lidando.

De acordo com Silva (2001) o resultado da concorrência não depende só da firma, mas de vários fatores, fatores internos e externos, que podem ser controlados ou não por ela. Cada fator tem a sua importância e peso dentro de um ambiente de competição, e, em alguns mercados, um fator pode ser mais representativo que outro, formando-se no contexto da interação dos fatores sistêmicos, estruturais e internos à firma.

Para uma empresa manter-se competitiva é necessário a busca de novas tecnologias, novos mercados e novos métodos de gerenciamento, produto e serviços de qualidade, diferenciais comerciais e de integração total das cadeias de valor da empresa, clientes e fornecedores. 
Porter (2004) diz que o desenvolvimento de uma estratégia competitiva é, em essência, o desenvolvimento de uma fórmula ampla para o modo como uma empresa competirá quais deveriam ser as suas metas e quais as políticas necessárias para levar-se a cabo essas metas. As Estratégias genéricas de Porter, liderança em custo, diferenciação e enfoque foram criadas para a empresa obter vantagem competitiva mediante ao mercado, que pode ser analisado através do modelo das 5 forças ou ameaças competitivas, a rivalidade entre concorrentes, barreiras à entrada de concorrentes, poder de barganha dos compradores, poder de barganha dos fornecedores e a ameaça de produtos ou bens substitutos.

Segundo Porter (1980) as empresas que apresentariam melhor desempenho seriam aquelas que conseguissem aplicar uma, e apenas uma, das duas estratégias genéricas, liderança em custos e diferenciação do produto, mais a estratégia de enfoque.

Carneiro, Cavalti e Silva (1997) propuseram que a liderança em custo, que é uma estratégia usada pelas empresas para fazer com que seu custo total seja menor do que o de seus concorrentes, o custo mais baixo funciona como mecanismo de defesa da empresa contra a rivalidade de seus concorrentes, já o enfoque é uma estratégia que se baseia no fato de que a empresa será capaz de atender melhor ao seu alvo estratégico do que aqueles concorrentes que buscam atender a toda à indústria, e por último a estratégia de diferenciação procura por oferecer ao produto ou serviço uma identidade própria e que seja reconhecida pelos consumidores.

\subsection{DIFERENCIAÇÃO DO PRODUTO}

A estratégia de Diferenciação do Produto, que segundo Hunt e Morgan (1995), pressupõe que a empresa ofereça, no âmbito de toda a indústria, um produto que seja considerado único pelos clientes, ou seja, cujas características o distingam daqueles oferecidos pela concorrência. Porter (1980) destaca ainda que possa haver várias empresas perseguindo e obtendo sucesso com uma estratégia de diferenciação, desde que cada uma delas se especialize em características ou atributos distintos das demais, e que haja um número suficiente grande de cliente que valorizem distintamente cada um destes atributos e características.

De acordo com Caves e Williamson (1985) existem doze maneiras, denominadas bases em que as empresas podem diferenciar seus produtos, conforme ilustra o quadro 1. Vale ressaltar após este breve exposto e defesa de alguns autores sobre as etapas necessárias para diferenciar um produto a pesquisa em questão optou por trabalhar com o legado de Caves e Williamson (1985).

\section{QUADRO 1 - Maneiras de se diferenciar o produto ou serviço}

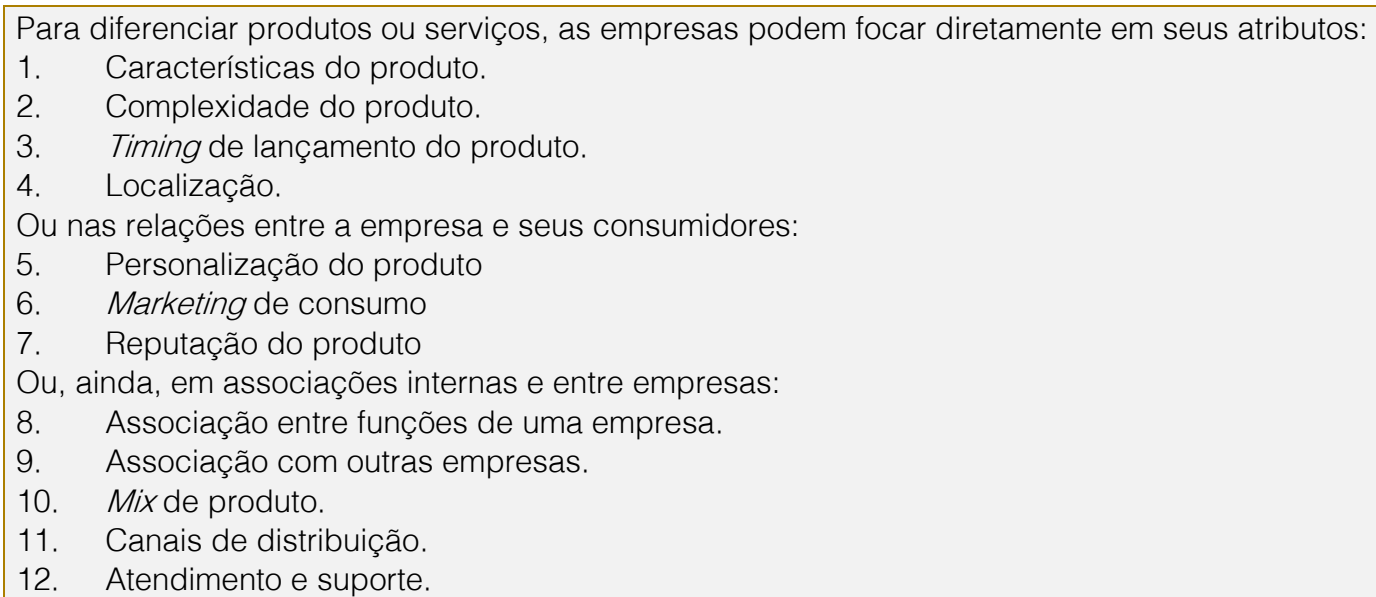

Fonte: Caves e Williamson (1985, p.113-132)

Para Barney (2007), diferenciar produtos ou serviços, as empresas podem focar diretamente em seus atributos, destacando: características do produto (a empresa modifica as características do produto, com o objetivo de diferenciá-lo dos produtos existentes), complexidade do produto (por essa a empresa tenta convencer os 
consumidores que o seu produto é mais valioso que os outros, pois possui mais componente que os concorrentes), timing de lançamento do produto (com o pioneirismo em sua indústria a empresa pode criar vantagem competitiva, já que pode instituir uma percepção junto aos consumidores de que seus produtos são mais valiosos) e localização (localização física). Ou nas relações entre empresa e consumidor, como: personalização do produto (customização do produto de acordo com o perfil do cliente), marketing de consumo (busca criar desejo para adquirir o produto), ou pela reputação do produto (se não a mais, uma das mais importantes bases de diferenciação, podendo ser duradoura). Por fim, pode ainda ocorrer por associação interna ou entre empresas: associação entre funções de uma empresa (integração entre diferentes produtos, ou entre funções dentro de uma mesma empresa), associação com outras empresas (nessa base empresas distintas unem seus produtos em um conjugado só, geralmente essa união é realizada por uma aliança estratégica), mix de produto (quanto maior a variedade no portfólio da empresa, maior o mix de produtos que a mesma possui), canais de distribuição (essa base de diferenciação pode ser realizada pela própria empresa ou por empresas distintas, ou seja, terceirização e diz respeito como distribuir seus produtos) e por último atendimento e suporte (o pós venda, o tipo atendimento e serviço oferecido ao consumidor, quanto melhor e mais completo, melhor tende a ser a percepção do comprador quanto a empresa).

De acordo com Barth (1996), os motivos que levam 0 consumidor a desejar e consequentemente a adquirir um produto de luxo são objeto de extensos estudos. Muitas vezes disfarçadas em reais vantagens, como qualidade, diferenciação, conforto, entre outros fatores, claramente, em contrapartida à motivação do consumidor do produto de lixo. Apesar de toda esta caracterização fascinante que distingue o mercado de luxo dos demais mercados, toda a teoria e prática tradicionais do marketing constituem as ferramentas básicas para a estratégia e posicionamento destes produtos ou serviços.

\subsection{MERCADO DE LUXO}

De acordo com Altaf (2009), convenciona-se denominar de luxo todo aquele produto ou serviço dotado de qualidade, de estética, de preço e de imagem de marca superior aos convencionais, podendo pertencer a várias categorias de bens - embora algumas delas, naturalmente, estejam mais associadas ao conceito.Para muitos, luxo significa algo caro e não democrático, de acesso restrito. Altaf (2009) destaca que a definição do termo não se limita a isto. Afinal, de acordo com Castarède (2005, p. 24), "Luxo é o que não é corriqueiro e está relacionado ao talento, ao garbo, à magnificência e à celebração. É tudo que não é necessário".

Segundo Alléres (2000), o luxo pode ser definido como algo que vá além da necessidade, pois os consumidores compram produtos de luxo também por desejo, pelos sonhos, pela vontade de aparecer socialmente e pela autoestima. Nesse mercado, a imagem social dos consumidores é definida pelos produtos que compram, e é através deles que se sentem realizados. Este autor divide o luxo em três categorias: O luxo inacessível, caracterizado como patrimônio tornando se, por exemplo, uma herança de família passada por gerações; o luxo intermediário, que é produzido em pequena escala; e o luxo acessível, abrangendo um maior número de pessoas, priorizando a qualidade e o bem-estar dos mesmos, como roupas, acessórios, perfumes, carros, entre outros.

O mercado de luxo existe até hoje devido ao elevado padrão de vida de uma parcela da população e seu alto poder aquisitivo para adquirir produtos mais caros e raros, tornando se um importante mercado em termos globais. Este que já fatura na casa dos bilhões de dólares. Para Lipovetsky e Roux (2005), porém, o luxo hoje, não se restringe a apenas a parcela da população com padrões de vida mais altos, mais sim a outros indivíduos que possuindo uma renda mínima buscam também inserção social a partir da compra de artigos de luxo e do consumo de produtos diferenciados.

Para, contudo, definir quais são os objetivos desse mercado ascendente é importante ressaltar quais os principais aspectos que os tornam produtos de luxo. Dentre eles, a qualidade dos produtos, tradição, seu público alvo (classes mais altas), produção limitada, diferenciação do produto perante os concorrentes, preços altos (que indicam alto valor agregado), marca reconhecida, além do valor hedônico que os bens de luxo trazem aos seus consumidores (GEARGEOURA, 1997). Tendo em vista esses aspectos 
essenciais que tornam os produtos e serviços de luxo e diferenciados, há uma série de categorias desses que são oferecidas nesse mercado de luxo como, roupas, sapatos, acessórios, perfumes, cosméticos, joias, carros, dentre outros.

Para o mercado de artigos de luxo, um dos pontos importantes nesse contexto diz respeito à história da marca. É através da mesma que são passados aos consumidores as tradições e os conceitos. Segundo Barth (1996), a legitimidade de uma marca de luxo está na qualidade intrínseca do produto ou serviço e seu refinamento. Pode se dizer que a marca é o principal ativo de uma empresa ligada a artigos de luxo. Criar uma identidade para a marca de luxo depende, principalmente, de aspectos dos produtos como, design, materiais raros, caros e refinados, tradição da marca, estilo e para qual usuário ela será produzida.

Ainda segundo Barth (1996), a dimensão da imaginação é uma parte fundamental da marca de luxo, pois está deve apresentar personalidade. É através dos aspectos emocionais, que as pessoas deixam de adquirir um produto ou serviço para comprar um comportamento ou emoção.

Existem alguns fatores e subfatores que influenciam o comportamento de compra do consumidor, segundo Kotler (2000). São eles: fatores culturais, pessoais, sociais e psicológicos. Os culturais estão ligados aos valores de cada indivíduo, os sociais referemse ao status que os consumidores passam a ter quando compram produtos de luxo, os sociais ao estilo de vida e circunstâncias econômicas e os psicológicos seria a melhor forma de motivar o consumidor a usar produtos de luxo.

\section{METODOLOGIA}

A metodologia é vista como um conjunto de atividades sistemáticas, que permite alcançar o objetivo, traçando o caminho a ser seguido, detectando erros e auxiliando as decisões científicas (LAKATOS; MARCONI, 1992). Com o intuito de identificar as características precisas de consumidoras que fazem uso de peças de marca de luxo, foi realizada uma pesquisa com abordagem quantitativa que tem como foco a dimensão mensurável dos fenômenos, buscando traduzir em números, opiniões e informações. Segundo Richardson (2012) a pesquisa caracteriza-se pelo emprego da quantificação, tanto nas modalidades de coleta de dados, quanto no tratamento deles por meio de técnicas estatísticas. Através de um questionário (Vide Apêndice I), composto por quatorze questões, sendo quatro abertas e dez fechadas, foram coletados os dados necessários para responder à questão problema proposta no trabalho, ou seja, entender o comportamento do consumidor dos produtos da marca Lends. A elaboração do mesmo foi feita por meio da ferramenta fornecida pelo Google, denominada Google Drive. A conta é totalmente gratuita, permitindo o livre acesso de qualquer lugar que a pessoa a acessar, seja por smartphone, computador ou tablet. A aplicação aconteceu por meio do WhatsApp, aplicativo que permite uma maior interação entre o pesquisador e os pesquisados, via mensagens de texto pelo celular. É importante ressaltar que a pesquisa foi aplicada durante quatorze dias (nos meses de setembro e outubro de 2017) e obteve retorno de 45 questionários respondidos dos 60 enviados.

Após aplicação dos questionários as respostas obtidas ficam armazenadas na própria ferramenta Google Drive, que organiza as respostas e logo em seguida exporta para a Microsoft Excel, programa no qual é realizada a tabulação, cruzamento de dados e criação de gráficos.

\section{CONTEXTUALIZAÇÃO DA EMPRESA}

A marca Lends, os nomes foram alterados para preservar a organização, foi criada pelo filho do fundador de uma grande empresa do ramo de sapatos. Iniciou suas atividades em agosto de 1995. A mesma integra o grupo X\&Co, que participam também diversas outras marcas. Hoje, este grupo é líder no setor de calçados, bolsas e acessórios femininos no Brasil, que, atualmente tem sua fábrica no estado do Rio Grande do Sul e alcança patamares internacionais.

Com mais de 41 anos de história, o conceito da marca Lends é desenvolver sapatos, bolsas e acessórios valorizando o design, materiais de alta qualidade, conforto e tecnologia de ponta. Atualmente, comercializa mais de 9 milhões de pares de calçados ao ano, além de bolsas e acessórios, segundo afirma o site institucional da marca (ENICK, 2015). Com o intuito de internacionalizar a marca, a Lends em setembro de 2012 inaugurou sua primeira loja 
fora do país, localizada em Nova York, com o objetivo de interagir com o mercado norte americano, onde ficou conhecida por lançar tendências com atitude e inovação.

A Lends tem como missão oferecer a seu público um conceito de produtos conectados ao design, qualidade, moda e liberdade de expressão. A marca tem como proposta lançar no mercado produtos de luxo que atendam a suas consumidoras, que neste caso, são caracterizadas como mulheres jovens, contemporâneas que possuem classe e estilo próprio (OLIVEIRA, 2017). Para isso, a mesma conta com uma ampla linha de calçados, bolsas e acessórios femininos elaborados para agradar esse público alvo.

Como meio de divulgar seus produtos de luxo e alcançar seu mercado consumidor, a Lends investe na criação de um site próprio da marca, onde é disponibilizado para suas clientes e visitantes suas coleções, sua trajetória, e shop online, para realizar as compras. Além desse meio, a marca também divulga seus produtos através de propagandas em redes sociais como, o Instagram, muito utilizado, e em revistas de moda. É a partir do modo como as marcas divulgam seus produtos e de seu

GRÁFICO 1 - Produto mais consumido.

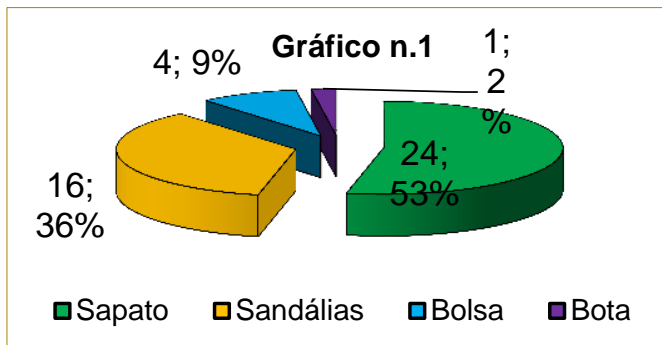

Fonte: Resultados da Pesquisa (2017) planejamento, que esta conquista sucesso no mercado, segundo Oliveira e Porto (2015).

Atrelado a essa estratégia que a Lends utiliza para ganhar seus consumidores e diferenciar sua marca das demais nesse mercado de luxo, é imprescindível afirmar que os benefícios inerentes à marca para o consumidor estão relacionados com algumas características, que são: conforto, durabilidade, inovação e valor. Para Chernatony (2005), os benefícios fazem com que os donos das marcas estimulem suas habilidades, conhecimentos e ideias na perspectiva de posicionar a marca criativamente e diferencialmente ao consumidor.

\section{RESULTADOS}

Por meio da aplicação dos questionários foi possível realizar o esboço do perfil de 45 consumidoras de produtos de luxo. A idade das mesmas varia entre 21 a 64 anos, sendo $80 \%$ dos valores menor ou igual a 48 anos. Destaca-se também diferentes profissões das respondentes como advogadas, empresárias, engenheira, médicas e entre outras. E no que se refere à renda mensal a média das entrevistadas foi acima de $R \$ 7.496,01$ reais.

GRÁFICO 2 - Motivo de comprar produto da marca

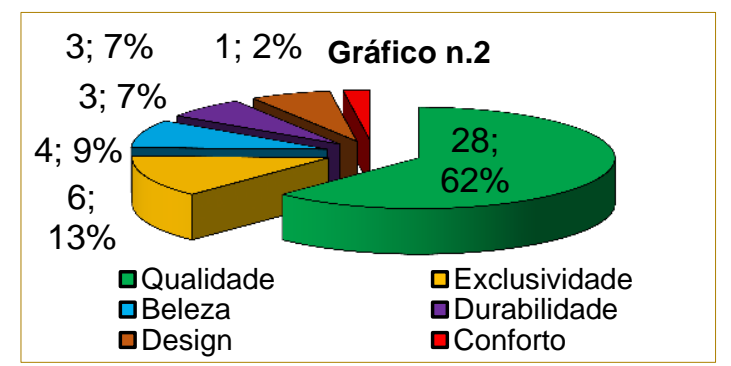

O gráfico n.1 mostra ao produto mais consumido da marca de luxo Lends, o mais citado pelas respondentes foi sapato com $53 \%$, seguido pela sandália com $36 \%$. Já o gráfico n.2 foi questionando as entrevistadas, o motivo que levam as mesmas a comprarem produtos de luxo, e com isso destacaram adjetivos como qualidade com 62\% e exclusividade com $13 \%$. 
GRÁFICO 3 - Local de compra.

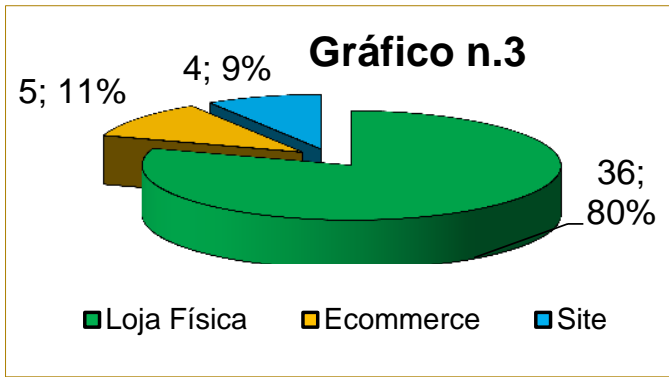

GRÁFICO 4- Grau de satisfação do atendimento.

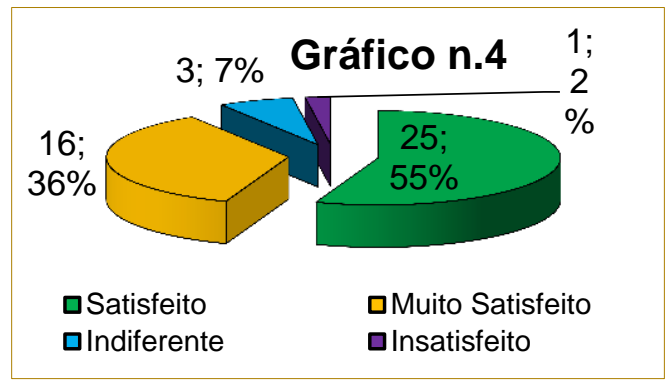

Fonte: Resultados da Pesquisa (2017)

O gráfico n.3 diz respeito ao local onde as respondentes costumam realizar a comprar de produtos da marca, que as lojas físicas têm de longe o maior valor citados pelas mesmas com $80 \%$, sendo um ponto forte na diferenciação da marca. No gráfico n.4, foi questionado as entrevistadas o grau de satisfação das mesmas com relação ao atendimento na loja da marca de luxo. Das respondentes 55\% marcaram a opção

GRÁFICO 5 -Meios de divulgação.

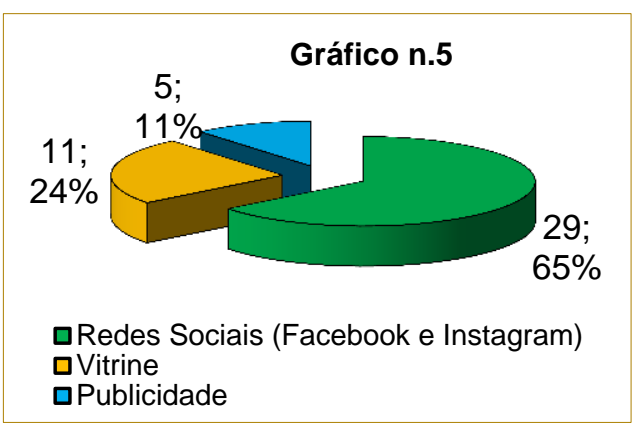

"satisfeita", seguida de "muito satisfeita" com $36 \%$. Dentre as consumidoras que demonstraram "indiferença", "insatisfação" ou "muita insatisfação" com o atendimento destacaram comentários como: Atendimento normal, sem nenhuma surpresa ou diferenciação (Entrevistada n.30) e compras feitas em lojas da zona sul do Rio de Janeiro falta qualidade no atendimento (Entrevistada n.32).

GRÁFICO 6- Atratividade do produto.

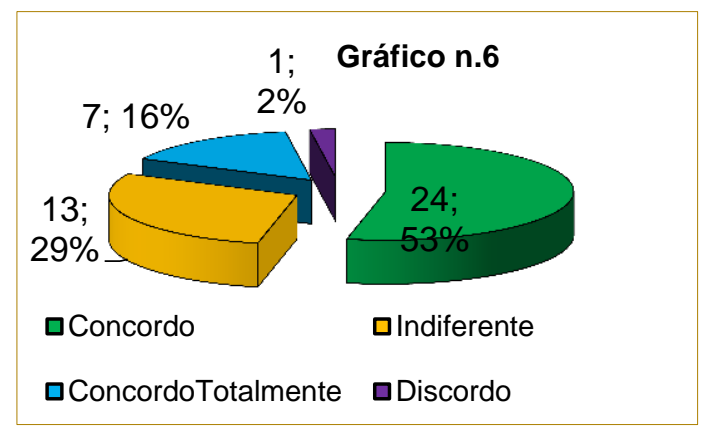

Fonte: Resultados da Pesquisa (2017)

No gráfico n.5 foram analisados os meios de divulgação que são utilizados pela Lends, as redes sociais (Facebook e Instagram) são os meios que mais impactam e atraem as consumidoras na decisão de comprar com $65 \%$. O gráfico n.6 mostra que as consumidoras escolheram comprar produtos da marca, devido à atratividade do produto, que é possuir mais componentes que o produto dos concorrentes, destaca-se com $53 \%$ a opção "concordo" e com 29\% "indiferente". 
GRÁFICO 7 -Personalização do produto.

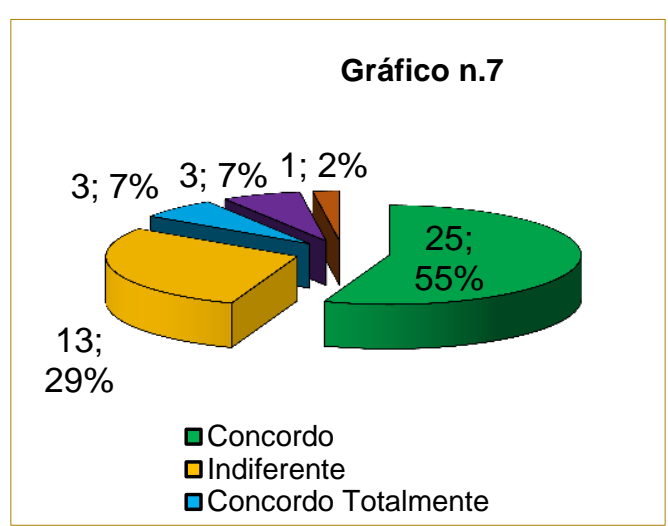

GRÁFICO 8 - Reputação da marca.

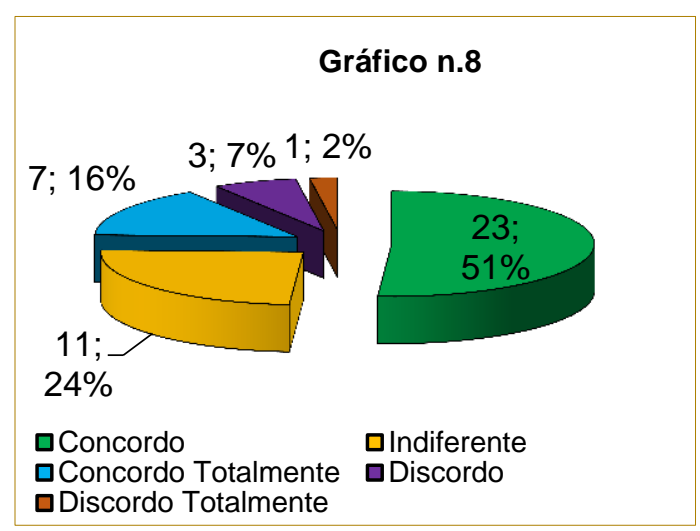

Fonte: Resultados da Pesquisa (2017)

$\mathrm{Na}$ questão sobre escolherem consumir produtos da marca de luxo Lends devido à personalização do produto, ou seja, peças exclusivas, iniciais de nomes, modificação na cor, gráfico n.7, as respondentes optaram pela opção "concordo" com 55\% e "indiferente" com 29\%. No gráfico n.8, em relação a consumir os produtos da Lends devido à reputação da marca, ou seja, a imagem que a mesma apresenta perante o mercado de luxo, as entrevistadas marcam a opção "concordo" com 51\%, seguido da opção "indiferente" com 24\%.

GRÁFICO 9 - Mix de produtos.

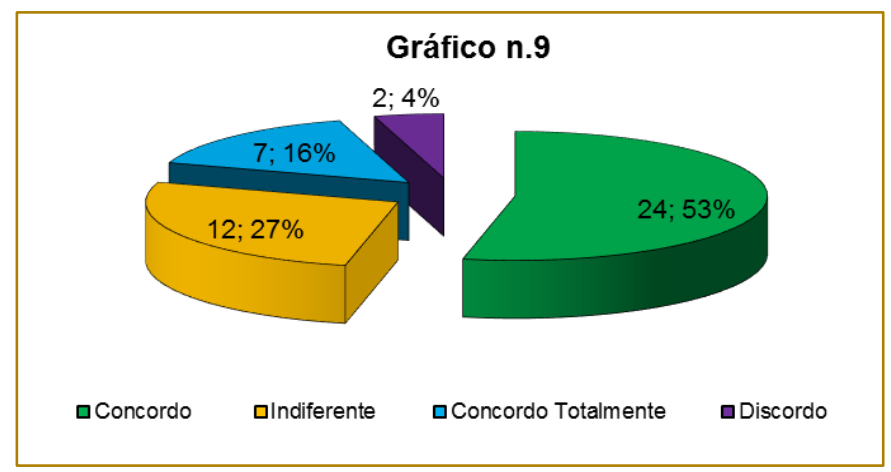

Fonte: Resultados da Pesquisa (2017)

E por fim, em relação ao mix de produtos, gráfico n.9, 53\% optaram pela opção "concordo", enquanto, 27\% por "indiferente" ao analisar a variedade de produtos que a Lends oferece.

\section{CONSIDERAÇÕES FINAIS}

Considera-se que o presente artigo tenha contribuído significamente para o estudo do comportamento das consumidoras da marca de luxo apresentada. O mesmo serviu para conhecer as estratégias de Diferenciação do Produto que são mais utilizadas pela marca de luxo Lends, além de demonstrar as principais características e expectativas das consumidoras que compram os produtos da marca.

Levando em conta o quadro 1 (página 4), onde estão descritas as 12 bases de Diferenciação do Produto que, segundo Porter (1980) definiu as para garantir uma visão estratégica a nível do negócio, pôde-se destacar na pesquisa algumas delas sendo 
apontadas pelas consumidoras entrevistadas. Dentre as bases citadas que podemos ressaltar como mais importantes temos, a característica do produto (o design), a personalização do produto (o que o torna diferenciado e exclusivo perante as outras marcas de luxo), o marketing de consumo (que busca atrair as consumidoras através da divulgação de seus produtos de forma eficiente) e a reputação da marca (a forma como a marca é reconhecida no mercado de luxo).

Outra informação importante foi que, as consumidoras da marca apontaram como principal meio de divulgação, isto é, a forma como as mesmas conhecem e acompanham os produtos desejados, as redes sociais como, Instagram e Facebook, que hoje, são consideradas novas fontes e as mais utilizadas pelas empresas para fazer o marketing digital de seus produtos e serviços.

No mercado de luxo, a imagem social dos consumidores é definida pelos produtos que compram, e é através deles que se sentem realizados. Constatou-se na pesquisa que, as

\section{REFERÊNCIA}

[1]. ALTAF, J. A relação entre o eu estendido do público homossexual masculino e seu consumo de vestuário de luxo. Dissertação (Mestrado). Universidade Estácio de Sá, Mestrado em Administração de Empresas,2009, 161p.

[2]. ALTAF, J. G et al. Eu Estendido e Marcas de Luxo: Associação Aplicada ao Consumidor Homossexual Masculino. In: VII CONVIBRA ADMINISTRAÇÃO - CONGRESSO VIRTUAL BRASILEIRO DE ADMINISTRAÇÃO, 2010. Disponível em: http://www.convibra.com.br/upload/paper/adm/ad m_830.pdf. Acesso em: 10 abr.2017.

[3]. BARNEY, J. B. Administração Estratégica e Vantagem Competitiva. São Paulo: Pearson Prentice Hall, 2007.326p.

[4]. BARTH, C. A. S. M. Marketing de Produtos de Luxo: Simbolismo, Marcas e Estratégia.123p.Tese (Mestrado em Administração). Fundação Getúlio Vargas Escola de Administração de Empresas de São Paulo, 1996.

[5]. CAPPELLARI, G. et al. Atitudes, Emoções e o Comportamento de Compra dos Consumidores dos Produtos e Serviços de Luxo. Revista de Administração da FATEA, Universidade Regional do Noroeste do Estado do Rio Grande do Sul UNIJUÍ/RS, p. 85-100, jan./jun. 2016. Disponível consumidoras da marca Lends consomem os produtos não só pela necessidade, mas também pelo desejo e status que a mesma proporciona para seus clientes. Além de possuir produtos com preços elevados, de alta qualidade e reduzida escala de produção, são considerados altamente exclusivos e adquiridos por uma parcela menor da sociedade de alto poder aquisitivo, que neste caso, é seu público alvo. Por isso, a marca estudada apresentou características essenciais para estar inserida no mercado de luxo brasileiro.

Por fim, seria interessante que fosse realizada uma pesquisa qualitativa para aprofundar esse estudo, de forma a entender e interpretar comportamentos, atitudes, e motivações que influenciam ou determinam a escolha dos produtos pelas consumidoras da marca LENDS. Além disso, outras marcas do mercado de luxo podem utilizar desse método de pesquisa do artigo em questão para conhecer como seus consumidores se comportam e quais diferenciais são essenciais para que estes sejam clientes fiéis da marca.

em:

http://publicacoes.fatea.br/index.php/raf/article/vie w/1727/1273. Data de acesso: 15/05/2017.

[6]. CARNEIRO, J. M. T. Porter Revisitado: Análise Crítica da Tipologia Estratégica do Mestre. Revista de Administração Contemporânea - RAC, Rio de Janeiro, v.1, n.3, p.7-30, set./dez.1997. Disponível em: http://www.scielo.br/scielo.php?script=sci_arttext\& pid $=$ S1415$65551997000300002 \& \operatorname{lng}=p t \& n r m=i s o \& t \operatorname{lng}=p t$. Data de acesso: 18 ago.2017.

CASTARÈDE, J. O luxo - os segredos dos produtos mais desejados do mundo. São Paulo: Barcarolla, 2005.

[8]. CHERNATONY, Leslie de. Construção de marca. In: BAKER, Michael John. Administração de Marketing. Rio de Janeiro: Campus, 2005, p.263279.

[9]. D'ANGELO, A. C. Precisar, não precisa: um olhar sobre o consumo de luxo no Brasil. São Paulo: Lazuli, 2006.191p.

[10]. DA SILVA, C. L. Competitividade e Estratégia Empresarial: Um Estudo da Indústria Automobilística Brasileira na Década de 1990. Revista FAE Centro Universitário, Curitiba, v.4, n.1, p.35-48, jan./abr.2001. Disponível em: https://revistafae.fae.edu/revistafae/search/search? 
simpleQuery=.+Competitividade+e+Estrat\%C3\%A 9 gia+Empresarial\%3A+Um+Estudo+da+Ind\%C3\% BAstria+Automobil\%C3\%ADstica+Brasileira+na+D \%C3\%A9cada+de+1990.\&searchField=query. Acesso em:18 ago.2017.

[11]. DE ALMEIDA, A. F. Análise das Estratégias Competitivas de Quatro Bancos sob Diferentes Enfoques Teóricos. Revista O\&S, Bahia, v.7, n.17, jan./abr.2000. Disponível em: http://www.adm.ufba.br/pt-br/publicacao/revista-os20. Acesso em: 18 ago.2017.

[12]. ENICK, L.S.M. A Utilização do Instagram na Gestão do Relacionamento com Consumidores e Possiveis Consumidores: Caso LENDS. 75p. TCC (Trabalho de conclusão do Curso de Comunicação Social - Relações Públicas). Universidade Federal do Rio Grande do Sul, Porto Alegre , 2015.

[13]. KOTLER, P. Administração de Marketing 10ª Edição. São Paulo: Pearson Prentice Hall, 2000.

[14]. LIPOVETSKY, G. O Luxo Eterno: da Idade do Sagrado ao Tempo das Marcas. São Paulo: Cia das Letras, 2005.

[15]. OLIVEIRA, E. R.O Desafio da Contrução das Marcas: Proposta de um Modelo.95p.Tese (Doutorado em Administração). Pontificia Universidade Católica de São Paulo PUC-SP, 2017.

[16]. PIANARO, L. Estratégias de Marketing no Mercado de Roupas e Acessórios de Luxo. Revista
FACES R. Adm, Belo Horizonte, v. 7, n. 1, p. 103122, jan./mar. 2008. Disponível em: http://www.fumec.br/revistas/facesp/article/view/11 2/109. Acesso em: 10 abr.2017.

[17]. PORTER, M. E. Estratégia Competitiva: Técnicas para Análise de Indústrias e da Concorrência. Rio de Janeiro: Campus, 1980.

[18]. PORTER, M. E. Estratégia Competitiva: Técnicas para Análise de Indústrias e da Concorrência.7. ed. Rio de Janeiro: Elsevier, 2004.

[19]. RICHARDSON, R. J. Pesquisa Social: Métodos e Técnicas. São Paulo: Atlas, 2011.

[20]. TAVARES, M. C. Segmentação de Mercado, Diferenciação de Produto e a Perspectiva da Antropologia de Consumo. Revista Gestão e Tecnologia, Pedro Leopoldo, v. 11, n. 1, p. 106-122, jan./jun. 2011. Disponível em: https://revistagt.fpl.edu.br/get/article/view/276/363. Acesso em: 25 abr.2017.

[21]. VIEIRA, M. F. Consumo de Produtos de Luxo: Um Estudo Teórico Sobre o Mercado da Moda. Revista da Unifebe (Online), Santa Catarina, v. 1, n.9 jan./jul. 2011. Disponível em: http://periodicos.unifebe.edu.br/index.php/revistael etronicadaunifebe/article/view/63/52. Acesso em: 18 abr.2017. 
1) Idade:

2) Profissão:

3) Renda Familiar:

Até $\mathrm{R} \$ 937,00$

De $R \$ 937,01$ à $R \$ 1874,00$

De $R \$ 1874,01$ à $R \$ 3748,00$

De $R \$ 3748,01$ à $R \$ 7496,00$

Acima de $R \$ 7496,01$

4) Qual produto consome da marca?

Sapato

Sandálias

Bolsa

Acessórios

Outros:

5) Qual motivo a leva a comprar produtos de luxo?

Durabilidade

Qualidade

Conforto

Exclusividade

Outros:

6) Onde costuma realizar a compra, quando adquire produtos da marca LENDS?

Loja Física

Site

Ecommerce

Lojas revendedoras da marca

Outros:

7) Como você avalia o atendimento na loja da marca de luxo? (Caso responda Indiferente, Insatisfeito ou Muito Insatisfeito, responder a próxima questão).

Muito Satisfeito

Satisfeito

Indiferente

Insatisfeito

Muito Insatisfeito

Por quê? 
8) Além da marca LENDS, qual outra marca você costuma consumir?

9) Dentre os meios de divulgação utilizados pela marca de luxo, qual mais te atrai?

Redes Sociais (Facebook e Instagram)

Publicidade

Boca a Boca

Vitrine

Outros:

10) Você escolhe comprar produtos da marca LENDS, devido à atratividade do produto? (Possuir mais componentes que os produtos dos concorrentes).

Concordo Totalmente

Concordo

Indiferente

Discordo

Discordo Totalmente

11) Você escolhe consumir produtos da marca LENDS devido à personalização do produto? (Peças exclusivas, iniciais de nomes, modificação da cor).

Concordo Totalmente

Concordo

Indiferente

Discordo

Discordo Totalmente

12) Você opta pela marca LENDS devido à reputação do produto? (Imagem perante ao mercado de luxo).

Concordo Totalmente

Concordo

Indiferente

Discordo

Discordo Totalmente

13) Você escolhe consumir a marca LENDS devido ao mix de produtos que ela oferece? (Variedade de produtos).

Concordo Totalmente

Concordo

Indiferente

Discordo

Discordo Totalmente 


\section{Gapítulo 20}

\section{COMPORTAMENTO DO CONSUMIDOR: FATORES QUE GERAM A NECESSIDADE DA AQUISIÇÃO DE COSMÉTICOS E DE SERVICOOS ESTÉTICOS}

\section{Tatiana Moreira Clemente}

\section{Hérica Landi de Brito}

\section{Gleidson Caetano da Silveira Pinto}

Resumo: Este artigo visa estudar os fatores que geram a necessidade da aquisição de cosméticos e de serviços estéticos, tendo em vista que o mercado de beleza tem se mostrado promissor no Brasil. Para atender ao objetivo proposto utilizou-se a pesquisa com abordagem qualitativa, classificada quanto aos objetivos como um estudo exploratório. É uma investigação de corte transversal e com utilização de técnicas de estatística descritiva. Após avaliar os fatores que geram a necessidade da aquisição de cosméticos e de serviços estéticos de alguns moradores das cidades de Sobradinho e Planaltina, no Distrito Federal, os relatos indicam que os principais motivos de compras nesse segmento estão vinculados a autoestima e a possibilidade de melhoria da aparência.

Palavras-chave: comportamento do consumidor, cosméticos, estética e aparência. 


\section{INTRODUÇÃO}

Estudar o consumidor ajuda a melhorar ou lançar novos produtos e serviços, determinar preços, elaborar mensagens, melhorar os meios de comunicação e desenvolver outras atividades voltadas para a administração mercadológica. É o campo do comportamento do consumidor que estuda como as pessoas, grupos e organizações selecionam, compram, usam e descartam produtos, serviços, ideias ou experiências. Tudo isso com o objetivo de ter uma visão abrangente do cotidiano e das mudanças do consumo, com o intuito de entender o consumidor a fundo, ajudando a organização a comercializar os produtos e serviços certos para os clientes certos e de maneira correta, satisfazendo suas necessidades e desejos (KOTLER; KELLER, 2006). Complementando, Nalini, Cardoso e Cunha (2013) salientam que a conduta do consumidor é diversificada e complexa. E que para cada tipo de produto ou serviço o processo de compra pode ser diferente.

Posto a afirmação dos autores acima sobre a diversificação e complexidade da conduta do consumidor para uma gama vasta de produtos e serviços na qual são disponibilizados no mercado, optou-se neste artigo analisar os fatores que geram a necessidade para adquirir cosméticos e serviços estéticos. Portanto, entende-se que a definição dos produtos de higiene pessoal, perfumaria e cosméticos (HPPC), de acordo com a Resolução da Diretoria Colegiada RDC 07, de 10 de fevereiro de 2015, da Agência Nacional de Vigilância Sanitária (Anvisa) é caracterizada como:

“... preparações constituídas por substâncias naturais ou sintéticas, de uso externo nas diversas partes do corpo humano, pele, sistema capilar, unhas, lábios, órgãos genitais externos, dentes e membranas mucosas da cavidade oral, com o objetivo exclusivo ou principal de limpá-los, perfumá-los, alterar sua aparência e ou corrigir odores corporais e ou protegê-los ou mantê-los em bom estado" (ANVISA, 2005).

Por sua vez, os serviços estéticos, segundo a publicação sobre: Como montar um Centro de Estética, no Portal do Sebrae (2017) são serviços de tratamento corporal e facial, por meio de cosméticos e equipamentos diversos, que tem o propósito de melhorar a aparência pessoal, de realizar algum tipo de reabilitação, que permite o relaxamento e até mesmo proporciona e mantem a saúde. É pertinente mencionar que conforme a publicação sobre Tendências do Segmento da Beleza, no Portal do Sebrae (2017) esse segmento de produtos e técnicas de beleza incluem, atualmente, negócios de salões de beleza, clínicas de estética, SPA's e laboratórios.

Após entendimento do conceito de cosmético e de serviços estéticos, que englobam o ramo da beleza, é importante salientar sobre sua influência econômica no país. Hoje, aproximadamente $1,5 \%$ do orçamento familiar é voltado para obter cosméticos e similares, mesmo mediante a recessão atual do país. No ranking mundial de consumo deste segmento, o Brasil fica atrás apenas dos Estados Unidos, China e Japão, respectivamente (ABIHPEC, 2017). Apesar da crise econômica no Brasil, as fábricas de produtos de beleza não se encontram abaladas com tal situação. A Euromonitor, provedora global de inteligência estratégica de mercado, aponta que 0 segmento de estética tende a crescer 16,6\% entre 2015 e 2020, no país (apud, ANUÁRIO ABIHPEC, 2017).

Nesse contexto, o referido tema foi escolhido para estudo tendo em vista que o mercado de beleza tem se mostrado promissor no Brasil, fazendo necessário entender melhor os fatores que influenciam as escolhas do consumidor na hora de realizar uma compra ou adquirir um serviço nesse ramo.

Vários fatores contribuem para que o Brasil seja considerado um mercado com grande potencial nesse ramo: a adesão cada vez maior dos homens em adquirir cosméticos e realizar procedimentos estéticos, a participação crescente da mulher brasileira no mercado de trabalho, o investimento em tecnologia de ponta nas indústrias deste segmento, a redução dos preços praticados no mercado, o lançamentos de novos produtos voltados às necessidades do cliente e o aumento da expectativa de vida (ANUÁRIO ABIHPEC, 2017).

A mídia também é outro fator relevante, pois tem imenso poder de influência entre as pessoas, e por meio dela o consumo de cosméticos se expandiu e tornou a aparência uma dimensão essencial da identidade de homens e mulheres (GOLDENBERG, 2002).

Além da influencia econômica, há também a influencia social. Mulheres que utilizam cosméticos são visualizadas como mais saudáveis e mais confiantes (NASH et al., 2006). As que não aderem aos padrões de 
aparência impostos pela sua sociedade são afetadas profissionalmente e financeiramente, pois se deve considerar que algumas organizações veem a aparência como um requisito fundamental para 0 sucesso empresarial (YWCA, 2008).

Tendo em vista que o segmento da beleza é relevante para a sociedade e para a economia brasileira é importante analisar o comportamento dos consumidores deste mercado. Entretanto, por meio de uma revisão teórica realizada junto a livros de marketing, livros de beleza e em bases de dados renomadas, tais como: Elsevier Science Direct, Google Scholar, Capes, Spell e Scielo, não foi encontrado nenhum estudo com foco específico em comportamento do consumidor de cosméticos e de serviços estéticos e foram encontradas pouquíssimas pesquisas com assuntos similares. Constatando-se, desse modo, uma lacuna na literatura para responder ao seguinte questionamento: $\mathrm{O}$ que gera a necessidade de adquirir cosméticos e serviços estéticos? Desta forma, procurando responder à questão apresentada, esse trabalho tem o seguinte objetivo: investigar os fatores que geram a necessidade do segmento feminino e do segmento masculino em comprar cosméticos e em realizar procedimentos estéticos.

\section{REFERENCIAL TEÓRICO}

\subsection{COMPORTAMENTO DO CONSUMIDOR}

Conforme o Art. $2^{\circ}$ da Lei 8.078 , de 11 de setembro de 1990 "o consumidor é toda pessoa física ou jurídica que adquire ou utiliza produto ou serviço como destinatário final". De acordo com o Art. 3ํ da Lei já mencionada o produto é caracterizado como: "qualquer bem, móvel ou imóvel, material ou imaterial". Serviço, por sua vez, é caracterizado como: "qualquer atividade fornecida no mercado de consumo, mediante remuneração, inclusive as de natureza bancária, financeira, de crédito e securitária, salvo as decorrentes das relações de caráter trabalhista" (BRASIL, 1990).

Cada consumidor tem percepções diferentes, algumas positivas e outras negativas com relações a produtos, serviços, propagandas, lojas e até mesmo das pessoas. O consumidor é um ser social, que está passível a circunstâncias culturais e pressões que podem afetar seu comportamento. (KARSAKLIN, 2004).
"A diversidade e a complexidade são aspectos característicos de processos comportamentais de consumo. Um indivíduo pode realizar comportamento de compra para os mais diversos produtos ou serviços, sendo que, para cada produto ou serviço, o processo pode ser de tipo diferente. Uma mulher pode comprar um par de sapatos para si mesmo, um jogo eletrônico para o filho adolescente, a revista sobre futebol para o marido. Em todos os casos ocorre comportamento de consumo, mas, em cada um deles há características diferentes quanto a, dentre outros fatores, as motivações e os fatores ambientais que levaram a obtenção do produto desejado" (NALINI, CARDOSO E CUNHA, 2013).

\subsection{RECONHECIMENTO NECESSIDADES}

O reconhecimento da necessidade é o primeiro passo do processo de decisão de compra de um cliente. Ele ocorre quando o consumidor sente falta de algo; é a percepção de que existe um estado de desconforto, físico ou psicológico, que pode ser amenizado com a compra de um produto ou aquisição de um serviço, fazendo com que - referido estado volte ao estado normal (KOTLER, 2009; LAS CASAS, 2012; CROCCO et al., 2013; ROCHA, 2015). Esse reconhecimento de desejo, por parte do consumidor, refere-se ao primeiro passo do processo de decisão de compra de um produto ou serviço.

Posto isso, pode-se observar que na pesquisa "O comportamento da consumidora de cosméticos" (CORRÊA, 2006) foi constatado que as consumidoras de cosméticos buscam esses produtos devido à necessidade de aumentar a autoestima; ser mais feliz; sentirse melhor, mais de bem com a vida e com mais bem estar; para se defender melhor nos desafios da vida, evitando ser rejeitada; para ter melhor higiene pessoal, para se apresentar nos círculos sociais imediatos; para ter melhores chances no mercado de trabalho e para realização pessoal.

Corroborando, Sant'anna (2014) afirma que muitos concordam com a ideia de que a boa aparência aumenta a autoestima e o bem estar, e que muitas mensagens publicitárias embasam-se na expectativa de sanar a baixa estima com o consumo de cremes cosméticos, alegando o rejuvenescimento e eliminando a tristeza. Para Masiero (2015) 
aumentar a autoestima e conquistar a boa aparência são algumas motivações que levam as pessoas a submeterem-se a procedimentos estéticos.

Nos resultados do estudo "A vaidade impulsiona o consumo de cosméticos e de procedimentos estéticos cirúrgicos nas mulheres? Uma investigação exploratória" (STREHLAU, CLARO e NETO, 2015) concluise que as mulheres vaidosas tem a necessidade de utilizar cosméticos e de realizar procedimentos estéticos, com 0 objetivo de realçar seus atrativos e alterá-los. $\mathrm{E}$ que quanto maior a vaidade, maior a autoestima corporal, confirmando assim, que a vaidade impulsiona o consumo nesse segmento da beleza.

A aparência física tem uma influência sobre como as outras pessoas percebem os indivíduos. A aparência percebida tem efeitos poderosos. Exemplo disso é se uma mulher é atraente, as pessoas não só pensam que ela tem apenas uma aparência mais agradável que as demais, porém pelo simples fato da mulher ser bonita as pessoas deduzem que a mesma pode ser melhor profissionalmente do que as desprovidas de uma aparência ideal (OGHAZI, 2015). Posto isso, é evidente a necessidade de uma boa aparência em prol de uma boa aceitação social.

Por fim, outro fator que gera a necessidade pela busca de cosméticos e procedimentos estéticos que foi muito citado por diversos autores é a autoestima (STREHLAU, CLARO e NETO, 2015; DOESCHKA et al. 2008, YAMAMIYA et al. 2004; MASIERO 2015; CORRÊA, 2006; SANT'ANNA, 2014). De acordo com Doeschka et al. (2008), a satisfação corporal e a autoestima das mulheres tendem a diminuir após a visualização de imagens de padrões de beleza ideal imposta na mídia, enquanto o humor negativo tende a aumentar, abalando assim o psicológico dessas pessoas. Corroborando, Yamamiya et al. (2004) cita em seus estudos que a exposição da mulher a imagens de mídia de pessoas magras e bonitas afetam negativamente a sua visão corporal e seu estado de humor.

\subsection{MERCADO DE COSMÉTICOS E DA ESTÉTICA NO BRASIL}

Segundo o anuário de 2016 da ABIHPEC aproximadamente $1,5 \%$ do orçamento familiar é voltado para obter cosméticos e similares, mesmo mediante a recessão atual do país. Em 2015 o Brasil perdeu sua posição de 3o lugar para $4^{\mathrm{Q}}$ lugar no ranking mundial de consumo deste segmento, ficando atrás apenas dos Estados Unidos, China e Japão, respectivamente. O ocorrido foi influenciado pelo aumento de carga tributária, alta do dólar e a crise política, mas ainda assim os fatos não foram suficientes para diminuir a estabilidade da indústria deste segmento (ANUÁRIO ABIHPEC, 2017).

É relevante ressaltar que o referido setor brasileiro industrial tem representatividade de $6,6 \%$ no mundo. Tratando-se de representação na América Latina, o Brasil tem 49,1\% nesse segmento e no Mercosul o país é dominante, com $82,5 \%$. É O $2^{\circ}$ setor industrial que mais investe em inovação e o $1^{0}$ setor industrial que mais investe em publicidade. E ao referir-se ao campo de oportunidade de trabalho a indústria estagnou de 2013 para 2014 e teve uma pequena queda de 2014 para 2015 e de 2015 para 2016. Já os estabelecimentos de serviços estéticos mesmo com a atual conjuntura do país desde 2006 teve cenário favorável no quesito oportunidade de trabalho (ANUÁRIO ABIHPEC, 2017).

Portanto, essa incessante procura pela boa aparência, bem-estar, autoestima e saúde tem aumentado a criação de novos estabelecimentos nesse setor, tem gerado crescimento de demanda de clientes em clínicas estéticas e despontado significativamente o consumo de cosméticos e afins, fatores estes que contribuem significativamente na economia do Brasil.

\section{METODOLOGIA}

Participaram do estudo, 129 moradores de ambos os sexos, de duas cidades do Distrito Federal. A escolha da localidade foi realizada com base nas premissas da amostra não probabilística por acessibilidade, na qual o pesquisador seleciona os elementos pela facilidade de acesso a eles (VERGARA, 2013). Participaram da pesquisa pessoas de ambos os sexos, com idade igual ou superior a 12 anos e que residiam em Sobradinho-DF ou em Planaltina-DF.

A pesquisa foi aplicada por intermédio de questionário, Porém, a aplicação do questionário, para a amostra dos 129 pesquisados, foi realizada sem a presença da pesquisadora, em papel impresso, utilizando 
o método bola de neve, que segundo Vinuto (2014) é uma maneira de utilizar cadeias de referência, ou seja, onde os indivíduos selecionados para serem estudados indicam novos participantes da sua rede de contatos para responder ao questionário. O método bola de neve na cidade de Sobradinho teve início na Clínica de Estética Glamour e na cidade de Planaltina em uma Instituição na Instituição de Ensino Superior. Portanto, tendo em vista a ausência da pesquisadora e devido ao método bola de neve foi necessário anexar um texto explicativo junto ao questionário, com o objetivo de informar sobre a natureza da pesquisa, sua importância e, ainda, ter a oportunidade de despertar a colaboração dos participantes, bem como, solicitar a devolução da pesquisa dentro do tempo hábil pré-estabelecido.

Finalizando, a análise de dados foi realizada no software de análise textual chamado Iramuteq, explorando a análise lexicográfica clássica e análise de nuvem de palavras, que corresponde ao agrupamento de palavras e organiza as mesmas em função da sua frequência.

\section{RESULTADOS}

$\mathrm{Na}$ indagação dos fatores que geram a necessidade da aquisição de cosméticos e serviços estéticos parte do segmento masculino alega não buscar tais produtos e serviços, fato este comprovado na aplicação estatística de frequência absoluta, sendo as palavras "não busco" citadas por 12 vezes nos questionários dos entrevistados. Sendo relevante mencionar que os que fizeram menção a essas palavras deixou evidente que não buscam serviços e produtos, exceto os relacionados à corte de cabelo por tratar-se de produtos e serviços essenciais do dia a dia.

$\mathrm{Na}$ sequência temos o termo "para ficar bonito", com a frequência absoluta $=7$; seguido do "bem estar", com frequência absoluta = 6; posteriormente "elevar autoestima, "melhorar aparência" e "saúde", ambos com frequência absoluta $=4$, "cultural", com frequência absoluta $=3$ e por fim, a expressão "inclusão social", que devido a frequência ser inferior a 3 não foi mencionada no gráfico de nuvens, conforme pode-se observar abaixo.

Figura 1 - Fatores que geram a necessidade de aquisição de produtos e serviços estéticos no segmento masculino

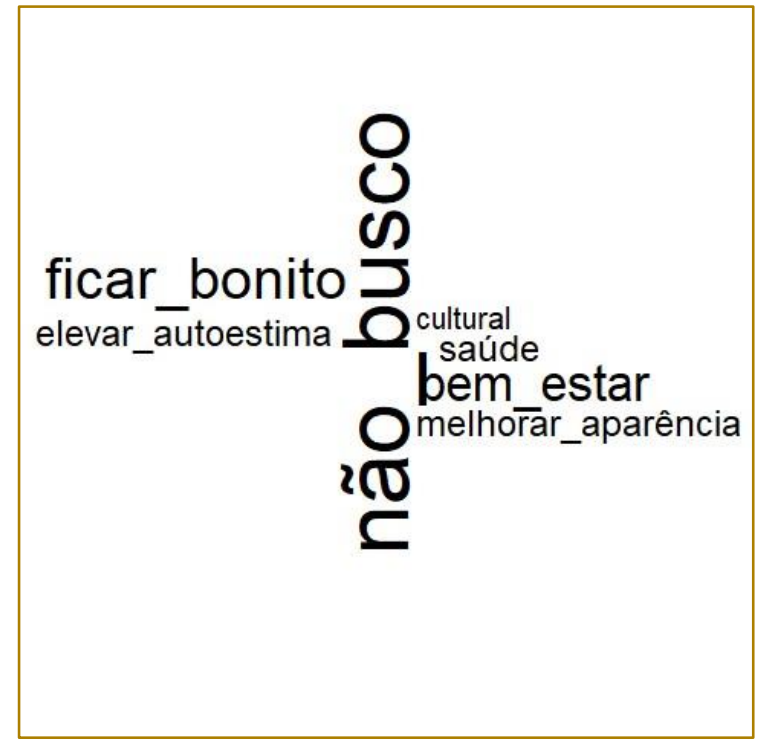

Fonte: Dados da pesquisa (Iramuteq)

Com relação ao segmento feminino os principais motivadores para a busca de cosméticos e de serviços estéticos são: "elevar a autoestima" e melhorar a aparência, com frequência absoluta $=20$. Posteriormente foi confirmado que essa motivação esta relacionada a "melhoria e equilíbrio da saúde", com frequência absoluta = 19; seguido da imposição da "mídia", com frequência = 17; " bem estar", com frequência 
=16; "ficar mais bonita", com frequênica = 15, "para ser melhor inserido socialmente", com frequência $=14$ e por fim, as frequências menos relevantes, devido ao baixo índice, tais como: não busco produtos e serviços, obrigatoriedade cultural, qualidade de vida, para relaxar, motivação e rejuvenescer.

Figura 2 - Fatores que geram a necessidade de aquisição de produtos e serviços estéticos no segmento feminino

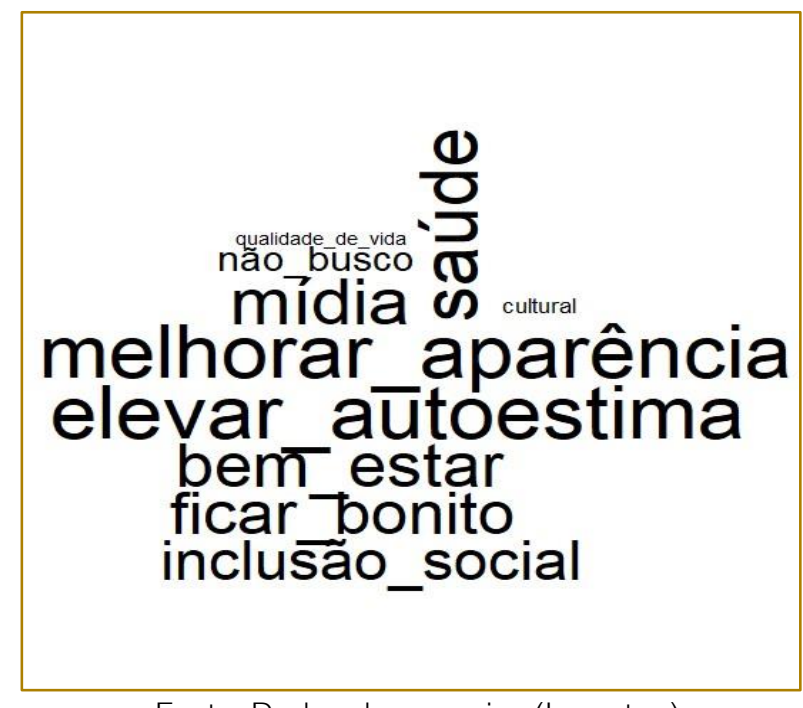

Fonte: Dados da pesquisa (Iramuteq)

\section{DISCUSSÕES}

Tratando-se dos fatores que geram a necessidade da aquisição de cosméticos e de serviços estéticos, as mulheres mencionam em seus relatos que o principal motivo está vinculado a autoestima e a possibilidade de melhoria da aparência

De acordo com Branden (1998), quando têm autoestima elevada, as pessoas estão mais preparadas para a vida, para as adversidades do dia a dia, tendem a ser mais criativas nas atividades de negócio, com maior probabilidade para o sucesso nas organizações, possuem melhores relacionamentos interpessoais, são mais otimistas, vivendo com maior entusiasmo, mais leveza e tolerância.

Atualmente muitos concordam com a ideia de que a beleza aumenta a autoestima e o bem estar. Muitas mensagens publicitárias embasam-se na expectativa de sanar a baixa estima com o consumo de cremes cosméticos, alegando o rejuvenescimento e eliminando a tristeza. (SANT'ANNA, 2014). Posto isso, a renomada autora salienta que a oportunidade de se libertar de uma aparência que não combina com o indivíduo pode alavancar a autoestima e potencializar sua fisionomia facial e corporal.
Na sequência, a segunda denominação de maior frequência absoluta foi "para ficar bonito(a), mas apesar da nomenclatura com palavras diferentes, pode-se inserir sua interpretação no contexto da expressão "melhoria da aparência", por tratar-se de termos diferente, mas com ênfases semelhantes. Tal situação teve apenas o propósito de prezar as falas das pessoas entrevistadas, não permitindo junções de expressões.

Outras motivações estão direcionados a saúde, imposição da mídia e inclusão social. Sant'anna (2014) diz que a partir da década de 50 a aparência tornou-se um gênero de primeira necessidade, dando ênfase a atividades físicas, alimentação saudável e uso de cosméticos, abrindo espaço para as indústrias destes segmentos.

Fatores estes que também foram evidenciados no estudo qualitativo elaborado para a ABIHPEC, onde se constatou que 95\% dos entrevistados entendem os produtos de Higiene Pessoal, Perfumaria e Cosméticos como essenciais e indispensáveis para os cuidados básicos com a saúde, bem-estar e qualidade de vida.

Compreender da onde surge a necessidade da aquisição de produtos e serviços estéticos 
é fundamental para os gestores atuantes no ramo e para quem pretende abrir um negócio neste segmento. É constatado nesta pesquisa e ratificado por diversos autores no decorrer do embasamento teórico deste trabalho que o culto à beleza, à juventude e à saúde passou a ser uma grande tendência dos hábitos e costumes modernos da população brasileira. É concernente que os empreendedores de estética assimilem que os serviços que podem proporcionar neste setor é uma necessidade básica e principalmente cultural da população brasileira (ABIHPEC, 2016). Posto isso, ao disponibilizar serviços deste segmento no mercado os empresários estarão deixando ao dispor dos seus consumidores a possibilidade de seus clientes terem bem estar, qualidade de vida, saúde, inclusão social, proporcionando-lhes mais sucesso, entre outros benefícios que não envolvem exclusivamente o consumidor final do produto ou serviço, indo muito além, proporcionando um bem social (SEBRAE, 2017). E por tratarse de um segmento relevante, por já fazer parte da necessidade básica e estar arraigado na cultura do Brasil, este mercado nacional tem crescido mais proporcionalmente do que o mercado mundial. Hoje, os brasileiros são considerados um dos povos mais vaidosos do mundo (SEBRAE, 2017). E a ABIHPC (2017) sinaliza que as mulheres lideram o mercado, mas atualmente $25 \%$ dos homens brasileiros já são usuários de tratamentos de beleza e $61,9 \%$ acreditam que cuidar da beleza é uma necessidade constante e não um luxo.

Para Kury (2003) as pessoas que procuram esses procedimentos de embelezamento tem a necessidade de seguir padrões que são impostos nas mídias. Os indivíduos tendem a realizar cortes de cabelo semelhantes a pessoas famosas, maquiagens idênticas a de atrizes que estão no auge etc. Complementando, Flor (2010) referencia que a textos públicos deixam nítido que ter uma aparência apresentável e um corpo perfeito é representação de poder econômico e social. A aparência, na contemporaneidade, é sinal de melhor aceitação social e satisfação pessoal (SANT'ANNA, 2014).

A aparência física tem uma influência sobre como as outras pessoas percebem os indivíduos. A beleza percebida tem efeitos poderosos. Se uma mulher é atraente, as pessoas não só pensam que ela tem apenas uma aparência mais agradável que os demais, porém pelo simples fato da mulher ser bonita as pessoas deduzem que a mesma pode ser melhor profissionalmente do que as desprovidas de uma beleza ideal (OGHAZI, 2015).

Mulheres que utilizam cosméticos são visualizadas como mais saudáveis e mais confiantes (NASH et al., 2006). As que não aderem aos padrões de aparência impostos pela sua sociedade são afetadas profissionalmente e financeiramente, pois deve-se considerar que algumas organizações veem a aparência como um requisito fundamental para o sucesso empresarial (YWCA, 2008).

Ao tratar do mesmo questionamento referente a essas necessidades para o segmento masculino, é nítido no gráfico de nuvens de palavras que a maior frequência é a descrição dos entrevistados informando que não buscam o serviço, porém os que buscam rodeiam das mesmas necessidade do segmento feminino, porém com uma frequência menos significante.

Ao analisar e discorrer sobre os fatores que geram a necessidade das pessoas adquirirem produtos e serviços do segmento de beleza é importante compreender que os gestores desta área tem o poder de influenciar, por meio de seus serviços e de seus produtos a elevação da autoestima de seus clientes, a oportunidade de seus consumidores estarem inseridos na sociedade com maior êxito, proporcionar felicidade, saúde, prazer e juventude. Fatores estes considerados por alguns autores, já mencionados, como necessidade básica da população brasileira atual. Novamente, surge aqui a reflexão da importância desse mercado na atualidade.

\section{CONCLUSÃO}

O setor que abrange as áreas de beleza e estética é favoráveis e está em constante expansão e devido a esse crescimento contínuo, que faz-se necessário estudos referente ao tema.

O presente trabalho conseguiu atingir seu objetivo, tendo em vista que constatou que os fatores que geram a necessidade da aquisição de cosméticos e de serviços estéticos estão relacionados à autoestima e a possibilidade de melhoria da aparência. A pesquisa evidenciou, também a necessidade desses produtos para a sociedade, e ratificou, ainda, a inferência que os produtos e serviços do embelezamento desenvolvem na vida 
afetiva e social dos indivíduos e que tais produtos e serviços são tachados na atualidade como necessidades básicas. Fatores estes que demostram com clareza que os negócios nesse setor são muito rentáveis, basta estudar seu mercado, entender seu cliente e acima de tudo, satisfaze-lo em seus anseios e necessidades almejadas.

Neste estudo, ao referir-se as implicações gerencias com base nos resultados apresentados é possível identificar que as maiores demandas do ramo da beleza é o segmento feminino, porém o segmento masculino está sendo visto como um grande alvo de oportunidade e um novo nicho de mercado, podendo proporcionar um crescimento ainda mais ousado para o referido setor. Com relação aos fatores que geram as necessidades da aquisição de produtos e serviços de beleza, é notório que o segmento da estética privilegia a sensação do amor próprio, da autoestima elevada, da valorização das pessoas frente a si mesma e diante da sociedade. Cabendo aos marqueteiros e aos empreendedores utilizarem dessas informações não apenas para pensarem em maior lucratividade, mas também para proporcionar a sociedade

\section{REFERÊNCIAS}

[1]. ABIHPEC. Disponível em $<$ https://abihpec.org.br/publicacao/caderno-detendencias-2014-2015/>. Acesso em: 18 janeiro 2017.

[2]. ABIHPEC. Anuário. Disponível em: < https://abihpec.org.br/publicacao/panorama-dosetor-2017/>. Acesso em: 18 janeiro 2017.

[3]. ABIHPEC. Mercado Brasileiro de HPPC: quarta posição mundial com sensação de terceira. Disponível em: $<$ https://abihpec.org.br/2017/02/mercadobrasileiro-de-hppc-quarta-posicao-mundial-comsensacao-de-terceira/>. Acesso em: 18 janeiro 2017.

[4]. ANVISA. Legislação. Disponível em: < http://portal.anvisa.gov.br/documents/10181/28676 85/RDC_07_2015_.pdf/c2a1078c-46cf-4c4b-888a092f3058a7c7>. Acesso em: 26 setembro 2017.

[5]. BRANDEN, Nathaniel. Autoestima: como aprender a gostar de si mesmo. São Paulo: Saraiva, 1998.

[6]. BRASIL. Lei no 8.078 , de 11 de setembro de 1990. Dispõe sobre a proteção do consumidor e dá outras providências. Disponível em: < brasileira uma vida mais prazeirosa, amavél, feliz e saudável.

Algumas limitações deste trabalho devem ser reconhecidas. As de maiores destaque são: o corte transversal, a utilização de amostra não probabilística e a obtenção de um perfil geral mais jovem e estudante, que embora tenham satisfeito o objetivo do trabalho, futuramente podem adquirir uma amostra mais abrangente, tendo em vista que o tema é relevante e de acordo com a literatura a terceira idade além de refletir o perfil demográfico do país foi tachado como um nicho de mercado no ramo de beleza pelo Sebrae.

Finalizando, como porposição para estudos futuros é apropriado investigar sobre o comportamento dos consumidores da terceira idade, comportamento do consumidor em clínicas estéticas, segmento masculino como consumidor de embelezamento, estratégias de marketing que diferenciam o segmento masculino e o feminino no ramo da beleza e por fim, como as pré-adolescentes observam esse segmento da beleza e como as mesmas se beneficiam dele. Tendo em vista que o referido ramo está continuamente em expansão e o tema torna-se cada vez mais relevante e próspero.

http://www.planalto.gov.br/ccivil_03/Leis/L8078.htm >. Acesso em: 28 junho 2017.

[7]. CORRÊA, Jorge de Paula. Comportamento da consumidora de cosméticos. 2006. $117 f$. Dissertação (Mestrado em Administração) - PósGraduação em Administração, Universidade FUMEC, Belo Horizonte, 2006.

[8]. CROCCO, Luciano et al. Fundamentos de marketing. São Paulo: Saraiva, 2013.

[9]. CURY, Augusto Jorge. A ditadura da beleza e a revolução das mulheres. Rio de Janeiro: Sextante, 2005

[10]. DOESCHKA, J. Anschutz et al. The bold and the beautiful. Influence of body size of televised media models on body dissatisfaction and actual food intake. 2008. Disponível em: <http://www.sciencedirect.com/science/article/pii/S 0195666308001396 > . Acesso em: 04 abril 2017.

[11]. FLOR, Gisele. Beleza à venda: o corpo como mercadoria. Revista Eletrônica de PósGraduação da Faculdade Cásper Libero, São Paulo, v.2, n. 2, dezembro 2010. Disponível em: $<$ http://www.revistas.univerciencia.org/index.php/c 
omtempo/article/viewFile/7493/6914>. Acesso em: 07 março 2017

[12]. GOLDENBERG, Mirian. Nu e Vestido: Dez antropólogos revelam a cultura do corpo carioca. Rio de Janeiro: Record, 2002.

[13]. KARSAKLIAN, Eliane. Comportamento do consumidor. São Paulo: Atlas, 2004.

[14]. KOTLER, Philip; KELLER Kevin Lane. Administração de marketing. São Paulo: Pearson, 2006

[15]. KOTLER, Philip. Administração de marketing: análise, planejamento, implementação e controle. São Paulo: Atlas, 2009.

[16]. KURY, Lorelai. Ritos do corpo. Rio de Janeiro: Senac, 2003.

[17]. LAS CASAS, Alexandre Luzzi. Administração de marketing. São Paulo: Atlas, 2012

[18]. MASIERO, Luciana Maria. Mudanças culturais: uma reflexão sobre a evolução das cirurgias plásticas. Revista del Grupo Internacional de Investigacion de Antropología del cuerpo, Salamanca, n. 0, p. 62-77, jul./dec., 2015.

[19]. NALINE, Eugênio Guimarães; CARDOSO, Michel de Melo; CUNHA, Sinthia Rodrigues. Comportamento do consumidor: uma introdução ao Behavioral Perspective Model (BPM). Fragmentos de cultura, Goiânia, v. 23, n. 4, p. 489-505, out./dez., 2013.

[20]. NASH, Rebecca et al. Cosmetics: They Influence more than Caucasian female facial attractiveness. Journal of Applied Social Psychology, v. 36 n. 2, p. 493-504, 2006.

[21]. OGHAZI, Pejvak. Beautiful teaching and good performance. 2015. Disponível em: < http://www.sciencedirect.com/science/article/pii/S0 14829631500497X>. Acesso em: 07 abril 2017.

[22]. ROCHA, Marcos (Org.). Marketing estratégico. São Paulo: Saraiva, 2015.

[23]. Marketing: novas tendências. São Paulo: Saraiva, 2015.

[24]. SANTA'ANNA, Denise Bernuzzi. História da Beleza no Brasil. São Paulo: Contexto, 2014.

[25]. SEBRAE. Como montar um centro de estética. Disponível em: Disponível em: <
http://www.sebrae.com.br/sites/PortalSebrae/ufs/m g/artigos/como-abrir-um-centro-de-estetica-emminas-

gerais,68b79889ce11a410VgnVCM1000003b7401 OaRCRD>. Acesso em: 17 dezembro 2017.

[26]. SEBRAE. Disponível em: $<$ http://www.sebraemercados.com.br/a-novaconsumidora-modifica-o-mercado-de-beleza-eestetica/>. Acesso em: 06 julho 2016.

[27]. SEBRAE. Disponível em: < http://www.bibliotecas.sebrae.com.br/chronus/ARQ UIVOS_CHRONUS/bds/bds.nsf/5de09fe521b18f7b 92b7e20a734ee57a/\$File/5741.pdf>. Acesso em: 18 março 2017

[28]. SEBRAE. Disponível em: <http://www.sebraemercados.com.br/tendenciasdo-segmento-de-beleza/>. Acesso em: 17 dezembro 2017

[29]. SEBRAE. Tendências do Segmento da beleza. Disponível em: <http://www.sebraemercados.com.br/tendenciasdo-segmento-de-beleza/>. Acesso em: 17 dezembro 2017.

[30]. SEBRAE. Disponível em: $<$ http://www.sebrae.com.br/sites/PortalSebrae/artig os/tendencias-para-o-mercado-debeleza,65acae21e224f410VgnVCM1000004c00210 aRCRD>. Acesso em: 17 dezembro 2017.

[31]. STREHLAU, Vivian Lara; CLARO, Danny Pimentel; NETO, Silvio Abrahão Laban. A vaidade impulsiona o consumo de cosméticos e de procedimentos estéticos cirúrgicos nas mulheres? Uma investigação exploratória. R.Adm, São Paulo, v.50, n.1, p. 73-88, jan/fev/mar, 2015.

[32]. VERGARA, Sylvia Constant. Projetos e relatórios de pesquisa em administração. São Paulo: Atlas, 2013

[33]. YAMAMIYA, Yuko et al. Women's exposure to thin-and-beautiful media images: body image effects of media-ideal internalization and impactreduction interventions. 2004. Disponivel em: < http://www.sciencedirect.com/science/article/pii/S1 740144504000737> . Acesso em: 06 abril 2017.

[34]. YWCA USA. Washington: August, 2008. Disponível em: <http://www.ywca.org/atf/cf/\%7B711d5519-9e3c4362-b753-ad138b5d352c\%7D/BEAUTY-AT-ANYCOST.PDF >. Acesso em: 11 julho 2016. 


\section{Capítulo 21}

\section{O APELO AMBIENTAL COMO INFLUENCIA NA DECISÃO DE COMPRA DO CONSUMIDOR DE PRODUTOS COSMÉTICOS}

\section{Eliane Santos Vargas}

\section{Lívia Maria de Pádua Ribeiro}

\section{Daniel Brianezi}

\section{Laércio Antônio Gonçalves Jacovine}

Resumo: Em resposta ao aumento da preocupação dos clientes com o meio ambiente, as empresas estão modificando e desenvolvendo novos produtos menos prejudiciais para o ambiente, em que seus anúncios utilizam uma variedade de apelos para convencer os consumidores a comprarem. Alguns destes anúncios com apelos verdes enfatizam a relação entre os atributos do produto e do ambiente, enquanto outros usam os recursos mais tradicionais, como benefícios financeiros (SCHUHWERK; LEFKOFF-HAGIUS, 1995). Diante disso, procurou-se investigar o seguinte problema de pesquisa: Qual a relação entre apelo ambiental e preço de produtos de cosmético? Para responder a essa pergunta de pesquisa foi utilizado o contexto de consultores de cosméticos de venda direta, que foram questionados se percebem que o apelo ambiental incentiva seus clientes a compra independente do fator preço. O objetivo geral deste estudo foi investigar a relação entre o apelo ambiental e o fator preço em produtos de cosmético na percepção dos consultores de uma marca. O método utilizado foi survey, com aplicação de questionário. Os resultados do estudo demonstram que os produtos que contêm um apelo ecológico como argumento de venda não conduzem a um estímulo de compra significativamente mais favorável.

Palavras Chave: Apelo Ambiental; Atitude dos Consumidores; Preço Produtos Verdes 


\section{INTRODUÇÃO}

A preocupação dos consumidores com 0 meio ambiente tem aumentado nos últimos anos conforme Moser (2015); Lin e Hsu (2015) e Gonçalves; Lourenço; Silva, (2015). Esta preocupação tem criado muitas oportunidades, assim como ameaças, para todas as empresas como apontam Walley; Custance; Parsons (2000) e BOZTEPE (2012). Em resposta, as empresas estão modificando e desenvolvendo novos produtos menos prejudiciais para o ambiente, em que seus anúncios utilizam uma variedade de apelos para convencer os consumidores a comprar. Alguns destes anúncios com apelos verdes enfatizam a relação entre os atributos do produto e do ambiente, enquanto outros usam os recursos mais tradicionais, como benefícios financeiros (SCHUHWERK; LEFKOFF-HAGIUS, 1995). Diante desses pressupostos, procura-se investigar 0 seguinte problema de pesquisa: Qual a relação entre apelo ambiental e preço de produtos de cosmético?

Para responder a essa pergunta de pesquisa foi utilizado o contexto de consultores de cosméticos de venda direta, que foram questionados se percebem que 0 apelo ambiental incentiva seus clientes a compra independente do fator preço.

O objetivo geral deste estudo foi investigar a relação entre o apelo ambiental e o fator preço em produtos de cosmético na percepção dos consultores de uma marca.Nessas condições o estudo propôs analisar as seguintes hipóteses:

Hipótese 1: Na visão do consultor de vendas, o apelo ambiental interfere na atitude do consumidor, e os mesmos estão dispostos a dar preferência e/ou pagar um valor maior por produtos com este apelo.

Hipótese 2: Na visão do consultor de vendas, o apelo ambiental interfere na atitude do consumidor, e os mesmos estão dispostos a dar preferência para produtos com este apelo, desde que não paguem um valor a mais por eles.

Hipótese 3: Na visão do consultor de vendas, o apelo ambiental não interfere na atitude do consumidor, uma vez que os clientes estão mais preocupados com a qualidade do produto, praticando um consumo utilitarista.

O tema ainda é incipiente, uma vez que para Moser (2015), ainda não está claro se as atitudes do consumidores verdes são consistentes com seus comportamentos de compra e quais os fatores que desempenham um papel importante no processo de tomada de decisão, o que justifica essa pesquisa.

Este artigo está dividido em cinco partes. Além da introdução, na segunda parte encontra-se o referencial teórico, na terceira parte é apresentada a metodologia, na quarta vislumbram-se os resultados e discussão e na última parte, concluí-se com as considerações finais.

\section{REFERENCIAL TEÓRICO}

\subsection{APELO AMBIENTAL}

Sistemas de gestão ambiental e programas de marketing verdes ganharam popularidade crescente nas economias de mercado ocidentais. Eles são vistos como custoseficientes, eficazes e apenas meios de combate aos problemas associados ao impacto da atividade econômica no ambiente (MERILAINEN; MOISANDER; PESONEN, 2000).

Para Prothero e Fitchett (2000), o Marketing não só tem o potencial para contribuir para o estabelecimento de formas mais sustentáveis de sociedade, mas, como um agente de princípio na operação e na proliferação do discurso de commodities, também tem uma responsabilidade considerável para fazê-lo.

Kilbourne (2004) acrescenta que a relação entre o marketing e o ambiente foi examinada desde o início da década de 1970, mas começou a se concentrar em publicidade no início da década de 1990. Anúncios ambientalmente relacionados foram frequentemente analisadas quanto ao teor, em seguida, um quadro para a publicidade verde foi desenvolvido, ampliando o domínio de investigação ao nível de paradigmas.

Pereira e Ayrosa (2004) definem o argumento ecológico como qualquer estímulo mercadológico que forneça informações sobre a produção ecologicamente correta de determinado produto, se associando a uma marca ou empresa, e que tenha a intenção de alterar o comportamento, ou a atitude do consumidor.

Para Manrai et al. (1997) publicidade verde é definida como a publicidade que enfatiza o equilíbrio ambiental do produto. Atributos como degradabilidade, reciclagem, menor poluição e outros, são considerados amigos do ambiente. 
Santos (2010) afirma que o discurso ecológico está hoje totalmente incorporado às campanhas publicitárias, e o apelo ecológico na propaganda se apresenta de diversas formas e temáticas ambientais. Vários desses apelos - emocional, euforia e gerenciamento podem ser descritos como "verde" porque enfatizam os atributos ambientais ou implicações ecológicas do produto (SCHUHWERK; LEFKOFF-HAGIUS, 1995).

Hartmann, Apaolaza Ibáñez e Forcada Sainz (2005) sugerem que uma estratégia de posicionamento verde bem implementada pode levar à uma percepção mais favorável da marca, dando assim apoio à abordagem de marketing verde em geral.

Para Pereira e Ayrosa (2004), a avaliação que consumidores fazem dos argumentos ecológicos presentes em anúncios ou embalagens pode ser uma fonte para os estrategistas de marketing no momento de comunicar informações sobre o produto.

Teixeira (2008) propõe que o marketing ambiental contribui para a conscientização ambiental por parte do mercado consumidor, em que, ao adotar este tipo de marketing, a organização deve informar a seus consumidores acerca das vantagens de se adquirir produtos e serviços ambientalmente responsáveis, estimulando e despertando o desejo do mercado por esta categoria de produtos.

Santos (2010) esclarece que as ações do marketing "verde", ou ambiental, não se destinam a eliminar a exploração ambiental, uma vez que o próprio consumo humano é naturalmente uma exploração dos recursos naturais, mas sim direcionar-se no sentido de minimizar o impacto do consumo no meio ambiente.

No mesmo pensamento, Pereira e Ayrosa (2004) declaram que pessoas expostas a anúncios publicitários e que se sintam pouco envolvidas com a marca ou produto podem ter suas atitudes afetadas pela aceitação ou não de pistas com argumento ecológico.

Já Schuhwerk; Lefkoff-Hagius (1995) sugerem que, ao dirigir a atenção aos atributos ambientais através de destaque, um apelo verde pode gerar respostas positivas por parte dos consumidores, independentemente do seu nível de envolvimento com o meio ambiente.

Para Moura (2003), a maior dificuldade das empresas é repassar os custos ambientais, pois o consumidor exige produtos "verdes", mas não concorda em pagar o custo por esse diferencial, o que torna a empresa menos competitiva.

Bliss (1978) também chama a atenção para o fato de que os apelos do marketing, independente do veículo, podem ser recebidos de forma bastante deturpados e podem não ser percebidos, pois o simbolismo do apelo se perde para algumas classes sociais. Ele afirma que aptidões para perceber abstrações, para ser objetivo, para ser articulado e para empatia varia conforme o nível de educação, status ocupacional e riqueza do ambiente residencial.

Teixeira (2008) destaca que no Brasil marcado por uma baixa distribuição de renda e por diversos planos econômicos malsucedidos, que deixaram o mercado em situação instável - os consumidores ainda têm orientado seus hábitos de consumo de acordo com a melhor relação custo-benefício que um artigo pode trazer. $\mathrm{O}$ que dificulta transplantar o Marketing "verde" para a nossa cultura, ou seja, o lucro do marketing ambiental vem a longo prazo, com a adoção da referida comunicação de atitude. As empresas só serão fortalecidas perante o mercado, se o mesmo já tiver consciência das questões ecológicas.

\subsection{COMPORTAMENTO DO CONSUMIDOR}

Boztepe (2012) caracteriza consumidores verdes como as pessoas que visam a proteger a si mesmos e o ambiente com seu poder de compra. Ele afirma em contrapartida a estas atitudes dos consumidores, as empresas começaram a formar suas estratégias de marketing, de modo a apelar pelo aumento da sensibilização para o tema.

Peattie (2001) afirma que profissionais de marketing e acadêmicos estão tentando identificar e compreender os consumidores verdes e as suas necessidades e desenvolver ofertas de mercado que atendam a essas necessidades.

Ottman (2004) enfatiza que a utilidade do produto pode fazer a diferença, aumentando a probabilidade de que os consumidores irão comprar o produto mais verde.

Para Lin e Hsu (2015) comportamento do consumidor verde pode induzir indústrias a desenvolverem métodos de produção verdes e converter padrões de desperdício de 
consumo para os padrões de consumo verde, e a sanção social tem uma influência significativa mais do que alterações climáticas e os meios de comunicação.

Gonçalves, Lourenço e Silva (2015), acrescentam que os gerentes de marketing que querem atingir a venda verde devem desenvolver e promover produtos ambientalmente corretos, de boa qualidade que satisfaçam as expectativas e desejos dos consumidores, apelando para o lado emocional do consumidor, as consequências sociais, e o desejo de conhecimento e novidade. Eles acrescentam que nas estratégias de comunicação, os gestores devem tentar não só transmitir as características dos produtos, mas poderia informar os consumidores sobre o impacto positivo da redução do consumo de energia sobre o meio ambiente ou os benefícios para a saúde de alimentos orgânicos.

De Oliveira e Waissman (2002) sugerem que as empresas abram as portas para o público com maior consciência das questões ambientais, uma vez que os mesmos não estão interessados somente em embalagens não poluentes. Estes consumidores estão interessados na garantia de uma qualidade de vida melhor e de respirar ar puro, desejam saber quem é e como é a empresa/indústria/fábrica que estão comprando os produtos.

Schlegelmilch, Bohlen e Diamantopoulos (1996), destacam que as medidas de consciência ambiental estão intimamente ligadas ao comportamento de compra ambientalmente responsável. Santos (2010) afirma que a propaganda pode influenciar as atitudes dos consumidores, e estas podem determinar as intenções de compra futura. Ele procurou medi-las em relação ao apelo ecológico na propaganda, em relação à marca, ao preço e à intenção de compra. Para isso, focou nas atitudes do consumidor diante de propagandas com apelos ecológicos, que, para ele, têm por objetivo precípuo o de estimular o consumo, a venda de produtos e serviços, e nem tanto uma preocupação com o meio ambiente.

Para Hartmann, Apaolaza Ibáñez e Forcada Sainz (2005) os melhores efeitos perceptivos são obtidos através de uma estratégia de posicionamento verde que combinava atributos funcionais com benefícios emocionais. Os gerentes de marca devem proporcionar benefícios emocionais através da marca, ao mesmo tempo, certificando-se de que os grupos alvo percebem os benefícios ambientais reais.

Ginsberg e Bloom (2004) descrevem que os consumidores preferem escolher um produto verde à um que é menos amigável ao ambiente, quando todas as outras coisas são iguais, mas os consumidores não são susceptíveis de comprometer a atributos tradicionais de produtos, tais como a conveniência, disponibilidade, preço, qualidade e desempenho.

Bliss (1978) afirma que a atitude deriva da composição de componentes cognitivos, afetivos e conativos.

- Cognitivo: agrupam-se as crenças e conhecimento que a pessoa possui referente a um objeto.

- Afetivo: congrega os sentimentos de uma pessoa sobre determinado objeto da atitude.

- Conativo: é representado pelas tendências de comportamentos da pessoa quanto ao objeto da atitude.

Santos (2010) destaca que a mudança de atitude acontece a partir do momento em que o indivíduo passa a ter outras experiências de vida ou passa a frequentar outras atmosferas. Assim, ele acredita que a influência ambiental é preponderante para a mudança de atitude de um indivíduo.

Após pesquisarem atitudes dos consumidores mediante apelo ecológico na embalagem de um determinado produto, Pereira e Ayrosa (2004) concluíram que os sujeitos que foram expostos ao argumento ecológico apresentam uma avaliação significativamente mais positiva em relação à marca do que os do grupo que não foram expostos ao argumento ecológico. Para eles, o resultado sugere que o argumento ecológico pode funcionar indiretamente como um facilitador dos efeitos da marca, em que se não gera atitudes mais positivas, ao menos parece potencializar os efeitos de atitudes positivas já existentes em relação à marca.

Para De Oliveira e Waissman (2002), o hábito de usar produtos "verdes" tem o poder de fazer dos consumidores agentes de mudança ambiental. Entretanto, segundo os mesmos autores:

... há afirmações de mudanças de atitudes no que se refere às intenções, porém o discurso não acompanha a prática real, o que seria um 
sinalizador efetivo de mudança de comportamento. Há engajamento sim, mas não há a mesma resposta factual, efetiva.

Costa e Silva (2010) apontam o choque entre sacrifícios individuais - diretos - e sacrifícios coletivos - indiretos. Para eles, o consumidor submetido a pagar sacrifícios individuais, pode simplesmente se negar a tal sacrifício e escolher não participar da busca de qualidade de vida no planeta, através da tomada das preocupações ambientais.

O atributo renda é geralmente relacionado positivamente para a sensibilidade ambiental. A justificativa mais comum para esta crença é que os indivíduos podem, em níveis de renda mais altos, suportar o aumento marginal nos custos associados a apoiar causas verdes e favorecendo a oferta de produtos verdes (STRAUGHAN; ROBERTS, 1999).

Cunha (2011) propõe que o consumidor verde está disposto a pagar mais pelo produto e até mesmo abrir mão de algumas comodidades da vida moderna (como um carro mais potente). O grande desafio das empresas seria entender o que motiva um consumidor a aderir à sustentabilidade, a um modo de vida e de consumo mais "verde", ecológico e nãopoluente. Com relação a isso Schuhwerk; Lefkoff-Hagius (1995) afirma que os consumidores com pouco conhecimento ou interesse no ambiente acreditam que produtos verdes geralmente custam mais do que os produtos regulares.

Pereira e Ayrosa (2004) destacam que o consumidor brasileiro parece olhar com certa simpatia as causas ambientais, mas que não se pode afirmar que este consumidor avalie criteriosamente os produtos e que tenha consciência do impacto que seu ato de compra pode ter no meio ambiente.

Bertolini e Possamai (2005) observam que empresas que oferecem ou pretendem oferecer produtos ecologicamente corretos, precisam conhecer os critérios de compra utilizados pelo público alvo e o grau de consumo ecológico de seus clientes ou potenciais clientes. Contudo, para que existam esses consumidores, eles necessariamente precisam possuir uma consciência ambiental.

Eles afirmam que o consumidor "verde" é fiel e consciente e dá preferência para:

- Embalagens recicláveis e com selos indicando a procedência ecologicamente correta do produto;
- Opta pelas marcas que informam a composição da embalagem dos seus produtos:

- $\quad$ Utiliza refil; e
- Evita adquirir produtos em isopor.

Teixeira (2008) esclarece que no Brasil, o mercado para os produtos ecológicos ainda é constituído por uma elite que possui condições financeiras para optar por empresas e produtos ambientalmente responsáveis. Reforçando que:

A educação ambiental assume um importante papel como uma ferramenta do marketing verde capaz de fazer o mercado internalizar mensagens de conteúdo informativo e participar do processo de construção das relações de troca do futuro, onde produtos existirão não somente para satisfazer as necessidades e expectativas humanas, mas também as necessidades da natureza em todas as suas formas.

Cunha (2011) cita indicações quanto às características dos consumidores "verdes", baseando-se em diferentes pesquisas realizadas em vários países:

- Habitantes de países mais desenvolvidos tendem a ser mais conscientes ecologicamente do que a população de países emergentes, quer seja por razões culturais, econômicas ou governamentais;

- Pessoas mais jovens, com maior grau de instrução e maior renda, assim como do sexo feminino, são consumidores mais "verdes" do que outros perfis; e

- Moradores de áreas rurais e pessoas da geração Baby Boom (Norte Americanos pessoas nascidas logo após o término da II Guerra Mundial) que tenham bom poder aquisitivo, também tendem a incorporar produtos ambientalmente corretos às suas compras com mais facilidade.

Para Ribas e Smith (2006), os brasileiros estão muito atrás dos europeus e dos norteamericanos quanto às atitudes ambientais, devido a questões econômicas em que a responsabilidade ambiental fica nos últimos planos do dia a dia dos consumidores. No Sudeste e Sul do país é possível encontrar uma maior conscientização por parte dos formadores de opinião em relação ao consumo sustentável. Verifica-se que este 
padrão acontece geralmente nas camadas sociais de poder econômico mais elevado e com maior grau de instrução.

Eles acrescentam que qualquer mudança de comportamento que ocorra em uma sociedade leva algum tempo para ser consolidada, pois a parcela maior da sociedade incorpora os novos padrões de consumo após a modificação e incorporação pelos formadores de opinião.

Teixeira (2008) destaca que no contexto brasileiro, pesquisas indicam que as motivações consumistas ainda não abarcam completamente a qualidade ambiental dos produtos - quando comparadas ao fator "preço", afirmando que apenas uma pequena parcela do mercado já começa a se preocupar com a questão ambiental.

\section{METODOLOGIA}

A natureza dessa pesquisa é quantitativa, que utilizou o método survey com formulários que tem a finalidade de responder o problema da pesquisa, compreendendo o seu objetivo e, consequentemente, atender aos objetivos intermediários (BOTELHO; ZOUAIN; ALMEIDA, 2006).

A pesquisa foi realizada com os consultores de cosméticos de venda direta de uma marca multinacional na cidade de Ipatinga. Inicialmente, foram aplicados cento e dezoito (118) formulários aos consultores de vendas, sendo que, nove (9) destes foram invalidados, ficando na amostra desse estudo, noventa e nove (99) formulários preenchidos.

As questões 6, 8, 10, 17 e 19 do formulário buscaram verificar a percepção do consumidor quanto ao apelo ambiental, na visão dos consultores e se este apelo estimulava ou motivava a compra de produtos cosméticos. Já as questões 11 a 15 e 20 a 24 checaram a influência do fator preço e de forma indireta o contexto social. Enquanto as questões 1, 3, 4, 5, 7, 9, 16 e 18 averiguaram se os representantes da empresa entendem e repassam com eficácia a filosofia ambiental para o consumidor final, que será analisado e discutido em outro artigo.

Para medir as atitudes, tanto do consumidor na visão do consultor de venda quanto em relação ao fator preço, foi aplicada a escala de Likert (ou somatória), em que os entrevistados informaram o grau de concordância e discordância das perguntas, que podem ser pontuadas de diversas formas (Mattar 1996), mas que, neste caso, foi utilizado de forma decrescente em uma escala de 4 a 0 para as atitudes e para 0 preço alto da linha "E", e de forma crescente 0 a 4 para o preço baixo da linha "S".

Segundo Gelinski e Padilha (2009), esta empresa preocupa-se com o meio ambiente desde sua fundação (1969), tendo o cuidado de usar em seus produtos ativos naturais e vegetais. Em 2000, lançou a linha voltada para questões ecológicas, em que iniciou o trabalho com matérias-primas que não prejudicavam o meio ambiente; embalagens biodegradáveis; programa de certificação dos fornecedores; e gastou $\mathrm{R} \$ 11$ milhões em pesquisas e marketing.Neste trabalho, esta linha será denominada como "E".

Olivetti (2013) informou o lançamento em 2013 de outra linha da empresa, denominada neste trabalho como linha "S", que de acordo com a proposta desenvolvida pela empresa, convida a consumir de um jeito novo, conciliando o prazer individual com a vida do planeta. Com relação a logística, a embalagem deste novo produto proporciona menos transporte, uma vez que podem ser dispostas em maior quantidade nos veículos, o que significa menos gasto de combustível e poluição.

O apelo ambiental dessas duas linhas foi descrito no Quadro 1. 
Quadro 1: Apelo ambiental específico

\begin{tabular}{|c|c|c|}
\hline \multicolumn{3}{|c|}{ APELO AMBIENTAL ESPECÍFICO } \\
\hline LINHA & "E" & "S" \\
\hline Ano de lançamento & 2000 & 2013 \\
\hline Apelo ambiental & $\begin{array}{l}\text { Programa de Certificação de Fornecedores de } \\
\text { Produtos Florestais para as áreas e reservas com } \\
\text { as quais se relaciona, visando garantir que os } \\
\text { recursos da flora brasileira sejam extraídos de } \\
\text { forma social e ambientalmente correta. O } \\
\text { Programa tem como essência o retorno } \\
\text { econômico para as reservas extrativistas, além } \\
\text { de respeitar o modo de vida das populações } \\
\text { locais, agregando valor ao trabalho e ao produto } \\
\text { final comercializado pelas comunidades. "... é a } \\
\text { biodiversidade brasileira, qual é a riqueza do } \\
\text { nosso povo da floresta, qual a riqueza desta } \\
\text { floresta, que por sua vez só conhecemos porque } \\
\text { tem gente lá dentro, como fazemos tudo isto de } \\
\text { forma certa virar produto..." (RIBAS e SMITH, } \\
\text { 2006) }\end{array}$ & $\begin{array}{l}\text { Produtos desenvolvidos a } \\
\text { partir de um processo } \\
\text { inteligente, que reduz } \\
\text { materiais para gerar menos } \\
\text { lixo, menos desperdício e } \\
\text { menos impacto ambiental. } \\
\text { As embalagens têm um } \\
\text { design inteligente, que } \\
\text { utiliza menos matéria-prima } \\
\text { e aproveita até a última gota } \\
\text { de cada produto. O formato } \\
\text { da embalagem exige } \\
\text { menos transporte, o que } \\
\text { significa menos gasto de } \\
\text { combustível e poluição } \\
\text { (OLIVETTI, 2013). }\end{array}$ \\
\hline Possui refil? & Sim & $\begin{array}{l}\text { Não, mas a embalagem tem } \\
\text { características do próprio } \\
\text { refil }\end{array}$ \\
\hline
\end{tabular}

Fonte: Elaborado pelos autores, baseado em Ribas e Smith (2006) e Olivetti (2013).

O formulário sobre apelo ambiental foi desenvolvido baseado no portfólio da 6a maior empresa de vendas diretas no mundo (EXAME, 2014), em que questiona aos consultores da marca sobre a percepção do consumidor quanto ao apelo ambiental, e se este apelo estimula ou motiva a compra de produtos cosméticos, verificando também a influência do fator preço. Ribas e Smith, (2006) entrevistaram a gestora da Linha "E" com relação a disposição para compra de produtos ambientalmente corretos, sendo relatado o seguinte:

As pesquisas nos dizem que sim, que 0 consumidor está evoluindo para a compra de produtos ambientalmente corretos, pois ele tem uma percepção muito positiva das empresas que assim o fazem, porém, este mesmo consumidor que valoriza, que acha interessante, ..., nem sempre está predisposto a pagar mais por isso. Então você verifica uma ruptura nesta valorização do consumidor. O fator econômico é a parte mais sensível deste consumidor.

No Quadro 2 pode-se observar a diferença de preço entre os produtos da Linha "E" e "S", sendo predominante o valor mais caro o da linha "E".

Quadro 2: Comparação de preços entre linha "E" e "S"

\begin{tabular}{|c|c|c|c|}
\hline \multicolumn{4}{|c|}{ COMPARAÇÃO DE PREÇOS ENTRE LINHA "E" e "S" } \\
\hline PRODUTOS & PREÇO LINHA “E” & PREÇO LINHA "S" & $\begin{array}{c}\text { DIFERENÇA ENTRE LINHA "E" e } \\
\text { "S" }\end{array}$ \\
\hline SHAMPOO & $\begin{array}{l}\mathrm{R} \$ 15,90-300 \mathrm{ml} \\
\mathrm{R} \$ 0,05 \text { por } \mathrm{ml}\end{array}$ & $\begin{array}{l}\mathrm{R} \$ 6,20-200 \mathrm{ml} \\
\mathrm{R} \$ 0,03 \text { por } \mathrm{ml}\end{array}$ & $\mathrm{R} \$ 0,02$ por ml \\
\hline CONDICIONADOR & $\begin{array}{l}\mathrm{R} \$ 19,50-300 \mathrm{ml} \\
\mathrm{R} \$ 0,07 \text { por } \mathrm{ml}\end{array}$ & $\begin{array}{l}\mathrm{R} \$ 7,5-200 \mathrm{ml} \\
\mathrm{R} \$ 0,04 \text { por } \mathrm{ml}\end{array}$ & $\mathrm{R} \$ 0,03$ por ml \\
\hline SABONETE LÍQUIDO & $\begin{array}{l}\mathrm{R} \$ 24,80-250 \mathrm{ml} \\
\mathrm{R} \$ 0,10 \text { por } \mathrm{ml}\end{array}$ & $\begin{array}{l}\mathrm{R} \$ 07,30-200 \mathrm{ml} \\
\mathrm{R} \$ 0,04 \text { por } \mathrm{ml}\end{array}$ & $\mathrm{R} \$ 0,06$ por ml \\
\hline SABONETE BARRA & $\begin{array}{l}\mathrm{R} \$ 14,90-300 \mathrm{~g} \\
\mathrm{R} \$ 0,05 \text { por } \mathrm{g}\end{array}$ & $\begin{array}{l}R \$ 12,00-450 \mathrm{~g} \\
\mathrm{R} \$ 0,03 \text { por } \mathrm{g}\end{array}$ & $\mathrm{R} \$ 0,02$ por $\mathrm{g}$ \\
\hline HIDRATANTE CORPO & $\begin{array}{l}\mathrm{R} \$ 44,80-400 \mathrm{ml} \\
\mathrm{R} \$ 0,11 \text { por } \mathrm{ml}\end{array}$ & $\begin{array}{l}\mathrm{R} \$ 10,90-200 \mathrm{ml} \\
\mathrm{R} \$ 0,05 \text { por } \mathrm{ml}\end{array}$ & $\mathrm{R} \$ 0,06$ por ml \\
\hline
\end{tabular}

Fonte: Elaborado pelos autores, baseado na revista da marca campanha 10/2016. 


\section{RESULTADOS E DISCUSSÃO}

A marca é respeitada no Brasil e já ganhou o prêmio de empresa mais ética do mundo pela EthiSphere em 2011 na categoria Saúde e Beleza (RELATÓRIO, 2012), e não tem em sua história casos de greenwashing (maquiagem verde). O greenwashing é um fenômeno em que os falsos apelos ambientais induzem a falsas conclusões sobre o produto ou serviço (GOERG et al., 2014).

Apesar de não praticar o greenwashing, a gerente de Meio Ambiente da empresa estudada destaca a dificuldade da comunicação ambiental para com os consumidores, pois esta comunicação tem um jargão próprio muito forte. Um dos casos de falha de comunicação admitidos foi do refil do buriti que tinha a seguinte citação: "Protege a sua pele das agressões do dia a dia"; "Usa menos recursos naturais e protege 0 planeta".A frase está errada, pois o refil não protege o planeta. Então a empresa utilizou a frase: "Usa menos recursos naturais para conservar o planeta" (RIBAS e SMITH, 2006).

Após o fato ocorrido, a empresa fez uma pesquisa que revelou que o consumidor entendia conservar e proteger como sinônimos. Então, a gerente de vendas concluiu que, traduzir uma linguagem técnica para a linguagem de pessoas que não tem nenhuma educação ambiental é complicado, pois neste caso o consumidor precisava entender que a compra do refil é algo interessante para ele, para o planeta, que tem um impacto menor, uma análise de ciclo de vida menor (RIBAS e SMITH, 2006).

Apesar de Goerg et al. (2014) relatar que a proporção de brasileiros que premiam corporações por seus comportamentos socialmente e ambientalmente mais responsáveis subiu de $12 \%$ para $22 \%$ nos últimos quatro anos, não vislumbra-se nesta pesquisa a força do apelo ambiental.

Os consultores, em sua maioria, que utilizam do apelo ambiental para a venda, percebem que este apelo incentiva a compra do produto em apenas 34\% (soma de 'Sempre' e 'Quase sempre') na linha "E" e 38\% (soma de 'Sempre' e 'Quase sempre') na linha "S" (Figuras 1 e 2).

Figura 1 - Frequência com que o consultor percebe que a propaganda ambiental incentiva o cliente a comprar os produtos da linha "E"

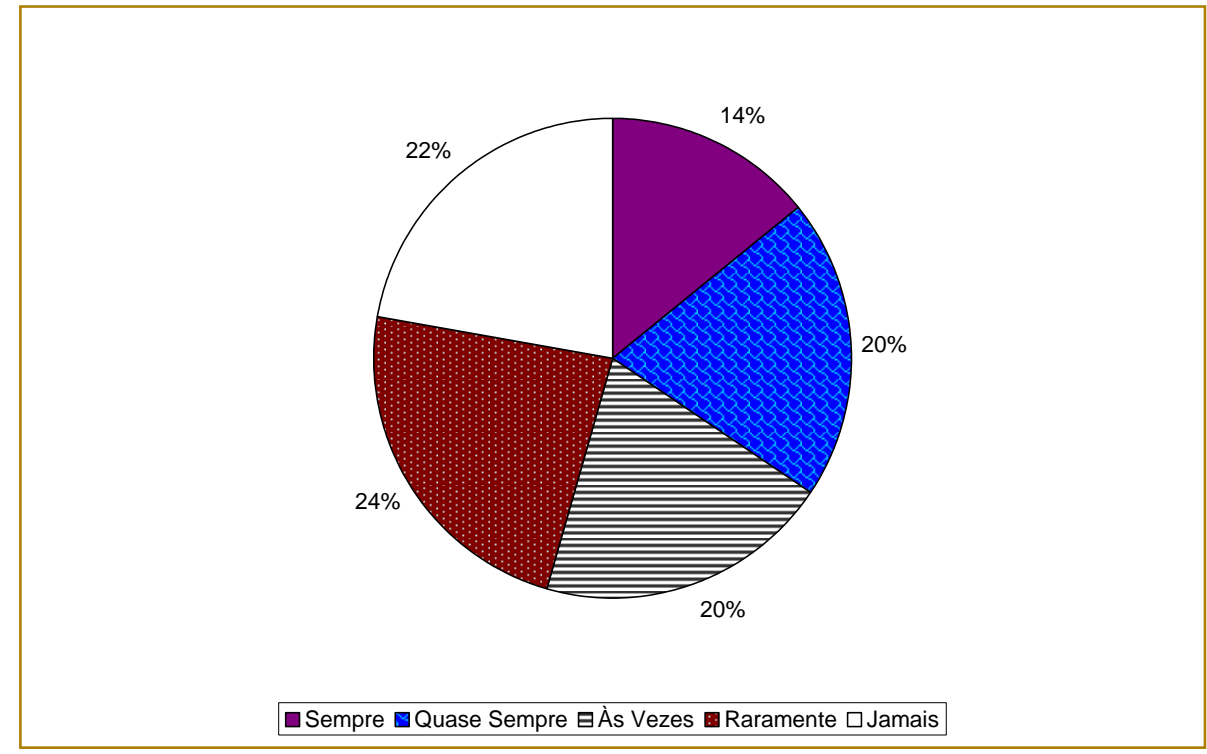


Figura 2 - Frequência com que o consultor percebe que a propaganda ambiental incentiva o cliente a comprar os produtos da linha "S"

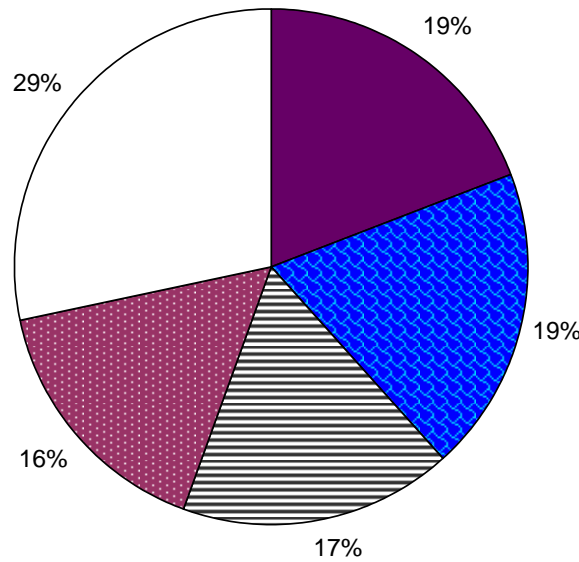

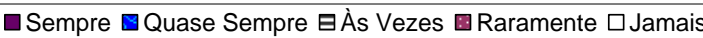

Este resultado condiz com a pesquisa de Santos (2010) em que a atitude do consumidor foi mais favorável à anúncio sem apelo ecológico.

Durante a aplicação do formulário deste artigo, algumas consultoras disseram que acreditam que os clientes não estão interessados em saber sobre o meio ambiente, e sim sobre a qualidade e fragrância dos produtos.

Herzog (2002) relata uma história ocorrida com a bióloga mineira Ilka Fioravante Altoé que não gostou quando viu caixas de chá de uma madeira não identificada num catálogo de produtos cosméticos da marca estudada. Ao entrar em contato com a empresa, descobriu que as caixas eram de imbuia espécie da flora brasileira ameaçada de extinção - e recebeu uma cópia dos documentos do IBAMA que autorizavam a venda do produto, mas mesmo assim deixou de ser consumidora da marca.

Quatro meses depois, a empresa decidiu parar de comprar as caixas de imbuia e destinar para projetos de reflorestamento todos os recursos arrecadados com a comercialização das 5 mil embalagens adquiridas do fornecedor, uma vez que a empresa de Curitiba que fornecia a madeira ao fabricante das caixas em Campinas não tinha total controle sobre sua origem. O projeto ajudou a empresa de cosmético estudada a reforçar sua imagem de empresa amiga da natureza e ganhou uma consumidora de volta (Herzog, 2002).

Mas em Ipatinga, a pesquisa demonstra através da percepção dos consultores que os consumidores desta marca são, em sua maioria, nada "verdes" (46\%) e que apenas $6 \%$ são "verdes" (figura 3 ). 
Figura 3- Clientes na Visão do Consultor

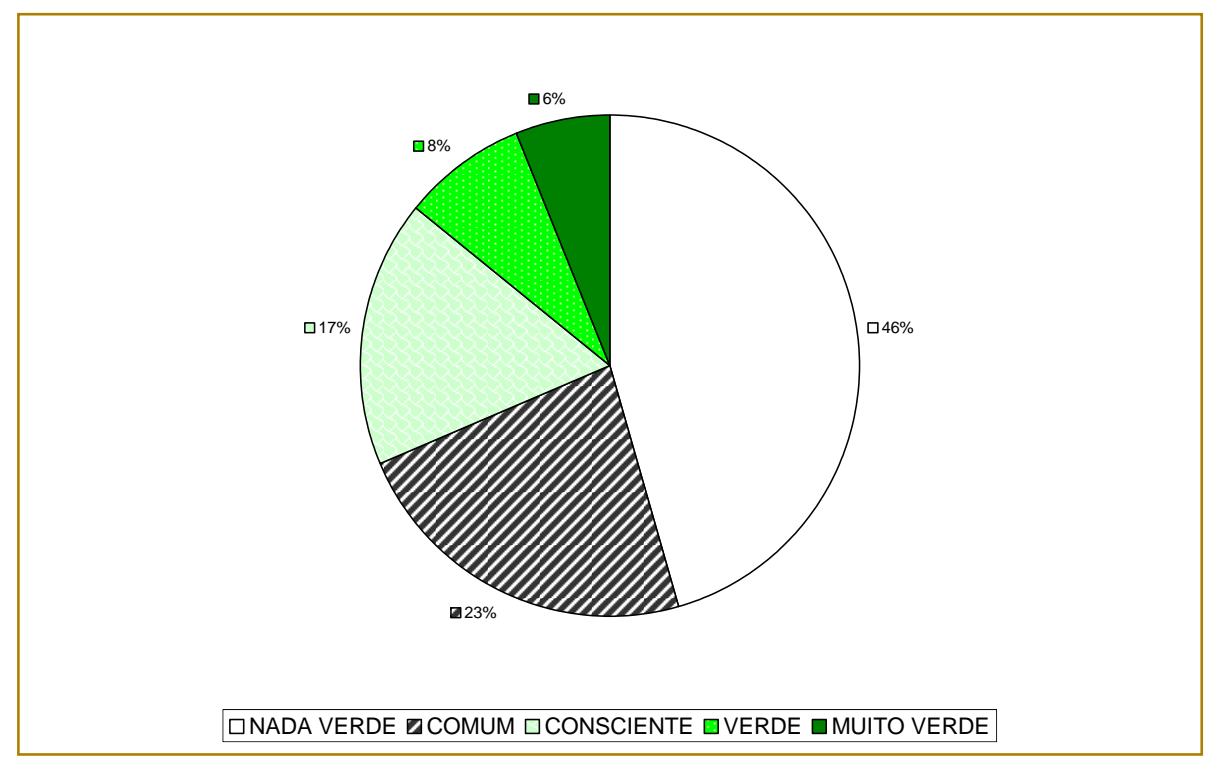

Os consumidores que têm fortes convicções sobre o meio ambiente são susceptíveis de prestar atenção aos atributos ambientais dos produtos. Mas os consumidores que não têm fortes convicções sobre o meio ambiente também podem tender a prestar atenção aos atributos ambientais dos produtos, através de uma variedade de fatores, tais como publicidade, venda pessoal e de boca em boca (SCHUHWERK; LEFKOFF-HAGIUS, 1995).

Meyer (2001) destaca que produtos verdes são comprados somente se os clientes percebem que os produtos possuem atributos superiores às ofertas dos concorrentes, daí surge a necessidade de identificar como os consumidores percebem custo e os benefícios dos produtos, buscando salientar suas vantagens.

Muitas consultoras disseram: "Compra porque gosta do produto, da qualidade, não olha preço e nem apelo". Pode-se relacionar esta visão à pesquisa de Santos (2010) no tocante ao poder da marca, em que, independente desta utilizar apelo ambiental ou não, a atitude do consumidor é mais favorável se a marca for conhecida.

Cunha (2011) destaca a dificuldade de encaixar os consumidores "verdes" em perfis demográficos, dificultando encontrar uma linguagem única ou mesmo um meio de comunicação padrão para atingi-los. Para ele, isso ocorre porque implica em mudanças no estilo de vida da pessoa antes de quererem aderir a produtos e serviços ecologicamente corretos.
A literatura apresentada caracteriza o apelo ambiental como uma ferramenta fundamental para o sucesso das empresas, mas a realidade brasileira é que a proporção de consumidores que praticam o consumo consciente continua em $5 \%$ da população (INSTITUTO AKATU, 2013).

\subsection{ANÁLISE DO PREÇO DA LINHA "E" E "S"}

Kotler e Armstrong (2007) destacam que na última década houve uma mudança no comportamento do consumidor com relação ao preço e à qualidade em que as empresas modificaramsuas abordagens de preço para alinhá-los com a mudança nas condições econômicas e nas percepções de preço do consumidor.

Moser (2015) enfatiza que o fator preço é um dos pontos críticos no contexto de compra ecológica. Ele acrescenta que os consumidores têm de valorizar os benefícios de produtos verdes e entender porque eles são mais caros. As empresas podem aplicar preços e estratégias promocionais que abordam as normas pessoais e induzindo uma "vontade de pagar" maior para capitalizar as oportunidades do segmento de mercado verde.

Ribas e Smith (2006) destacam o fator preço no caso dos refis dos produtos disponibilizados pela marca, em que, segundo a opinião de uma promotora de vendas, o preço mais baixo é o principal incentivo para a compra dos refis da linha "E". No entanto ela acrescenta que, com o tempo, 
o consumidor se acostuma com a ideia de que o refil tem um impacto ambiental e um ciclo de vida menor, sendo bom para o Planeta.

Figura 4 - Preço Alto da Linha "E" Atrapalha a Compra do Produto

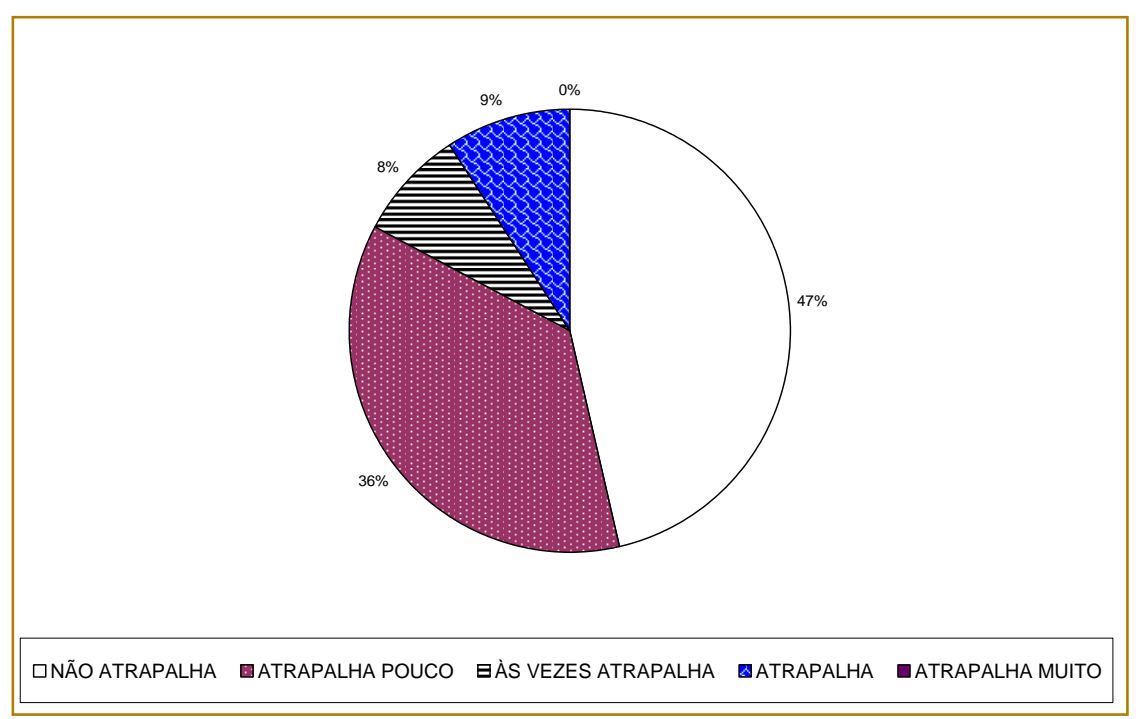

O fato da linha "E" ter produtos com o preço elevado não é fator que prejudique a venda, conforme demonstra a Figura 4, em que 83\% (soma de 'Não Atrapalha' e 'Atrapalha Pouco') dos consultores disseram que o preço não atrapalha. Este resultado também está de acordo com a pesquisa de Santos (2010) em que à atitude em relação ao preço apresentou a melhor média no tratamento sem apelo ecológico.

$\mathrm{Na}$ determinação de preço para linhas de produtos é estabelecido gradações de preços em que deve-se levar em conta as diferenças de custo entre as linhas, as avaliações de suas diferentes características pelos clientes e os preços dos concorrentes. Em muitos setores, a gerência de marketing estabelece níveis de preço bem definidos para as linhas. Então, seuma empresa estabelece três níveis de preço, é provável que o cliente associe os preços baixos, médios e altos à qualidade baixa, média e alta. A tarefa da empresa é estabelecer diferenças na qualidade percebida que justifiquem as diferenças de preço (KOTLER e ARMSTRONG, 2007).
Um produto é de qualidade quando ele oferece um desempenho ou conformidade a um preço que seja aceitável pelo consumidor. As organizações procuram produzir os produtos com qualidade, mas com um custo baixo para ter uma aceitação no mercado e com um baixo preço para obter lucro (VERAS, 2009).

Mas, quando o preço é mantido ao mesmo nível de produtos não verdes, as propriedades positivas do produto sobre o meio ambiente podem ser usadas como um elemento de uma vantagem competitiva, como enfatizado por Boztepe (2012).

Como se pode verificar no Quadro 2 os produtos da linha "S" têm um preço muito abaixo da linha "E", em que seu apelo ambiental está voltado para uma embalagem que gere menos impacto ambiental e ao mesmo tempo menos custo. Diante deste fato, este trabalho verificou que o preço baixo da linha "S" foi associado em algum momento pelos clientes como produto de baixa qualidade em apenas 22\% (soma de 'Atrapalha' e 'Atrapalha Muito') dos casos (Figura 5). 
Figura 5 - Preço Baixo da Linha "S" Incentiva a Compra do Produto

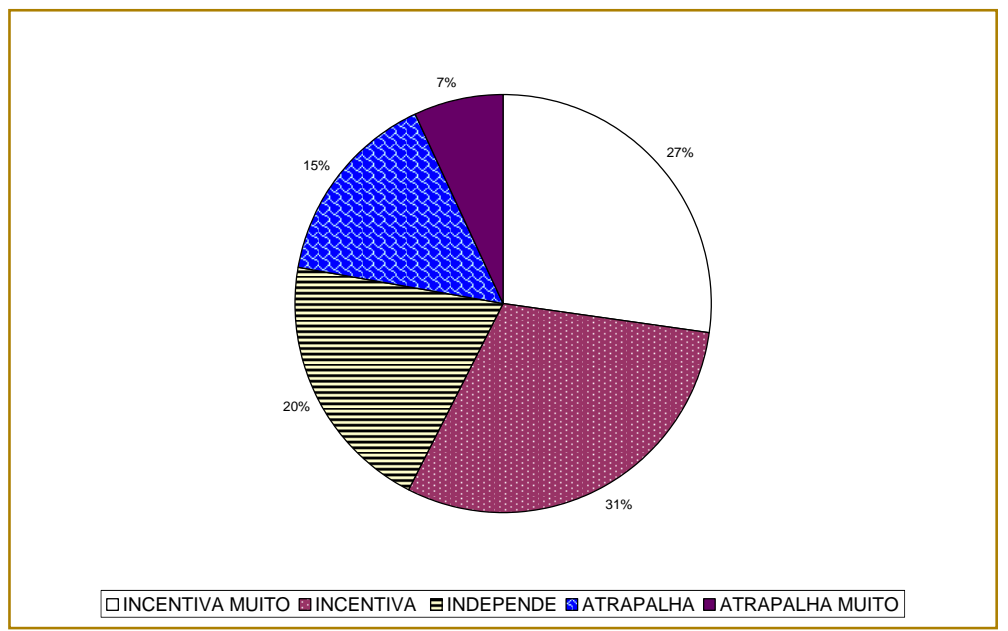

Para a maioria dos consultores, o preço baixo da linha "S" incentiva a compra dos produtos em 58\% (soma de 'Incentiva' e 'Incentiva Muito') dos casos (Figura 5). A linha "S" apresenta-se como uma exceção, pois conforme visto no Quadro 2, os custos ambientais no Brasil são altos e variados, mas mesmo assim, a empresa conseguiu praticar um preço acessível a maioria da população brasileira sem perder a qualidade, contrariando um pensamento de Cunha (2011):

Embora a demanda deva continuar crescente, a questão dos preços mais elevados é um desafio a ser enfrentado, pois boa parte dos consumidores atuais e potenciais não está disposto ou não pode pagar um diferencial de até $40 \%$ pelos produtos ecologicamente responsáveis.

Não é de se surpreender que uma marca tão forte não consiga influenciar ambientalmente seus consumidores, uma vez que o contexto social em que está inserido não é educado ecologicamente. Já que a empresa admite praticar lobby político (RELATÓRIO, 2012), seria interessante praticá-lo na educação de ensino básico ao médio.

Devido a limitação da amostra e o fato da linha "S" ser muito nova, apenas conclusões provisórias podem ser extraídas do estudo. No entanto, verificou-se que através dos números apresentados nas figuras acima, que o resultado tende a validar mais a hipótese de que o apelo ambiental não interfere na atitude do consumidor, uma vez que os clientes estão mais preocupados com a qualidade do produto, praticando um consumo utilitarista.
Das dificuldades encontradas, destaca-se a resposta falsa obtida através do formulário aplicado com respostas fechadas, pois, segundo Santos (2010) os entrevistados podem fornecer este tipo de resposta que não traduz o que de fato fazem, dando apenas respostas socialmente corretas, as chamadas de viés da desejabilidade social.

\section{CONCLUSÃO}

Os resultados do estudo demonstram que os produtos que contêm um apelo ecológico como argumento de venda não conduzem a uma estímulo de compra significativamente mais favorável. A atitude do consumidor, na visão do consultor, em relação ao preço da linha "S" é maior do que a atitude em relação ao apelo ambiental. Assim como, a predisposição em pagar por um produto de uma linha mais cara - linha "E" - é relacionada à qualidade e não ao apelo ambiental.

No caso dos consumidores brasileiros, não se pode deixar de levar em consideração o fator educação ambiental. Com a ascensão econômica de muitos, o que se vislumbra é o prazer em poder consumir, mas ao mesmo tempo, estes consumidores não possuem renda e consciência "verde" suficientes para dar preferência a um produto com custo ambiental.

Os representantes da empresa estudada classificaram seus clientes como nada verdes ou comum em sua maioria, que não percebem a influência do apelo ambiental na venda de ambas as linhas estudadas.

Diante dos fatos apresentados, constatou-se que a hipótese confirmada foi a de que o 
consumo praticado pelos clientes da marca é o utilitarista, ou seja, o apelo ambiental não interfere na atitude do consumidor e estes clientes estão mais preocupados com a qualidade do produto do que com os impactos no meio ambiente.

Os resultados deste estudo levantam questões como a dificuldade em traduzir a linguagem "verde" para pessoas que não tem nenhuma educação ambiental. Outro questionamento é se o apelo ambiental é um equívoco no contexto Brasil, uma vez que o Marketing "verde" deve ser usado como fator de educação ambiental para seus

\section{REFERÊNCIAS}

[1]. BERTOLINI, Geysler Rogis Flor; POSSAMAI, Osmar. Proposta de Instrumento de Mensuração do Grau de Consciência Ambiental, do Consumo Ecológico e dos Critérios de Compra dos Consumidores. Revista de Ciência \& Tecnologia.V. 13, n. 25/26, jan-dez, 2005

[2]. BLISS, Perry. Administração de Marketing e o Comportamento do Meio Ambiente. São Paulo: Atlas, 1978.

[3]. BOTELHO, Delane; ZOUAIN, Deborah Moraes; ALMEIDA, Alda Rosana. Pesquisa quantitativa em administração. São Paulo: Atlas, $2006229 \mathrm{p}$.

[4]. BOZTEPE, Aysel. Green marketing and its impact on consumer buying behavior. European Journal of Economic and Political Studies, v. 5, n. 1 , p. 5-21, 2012

[5]. COSTA, Marcone Freitas da; SILVA, Naira Luan Sousa. Marketing Verde e Consciência do Consumidor: Realidade ou Utopia de Consumo? Anais do XIII SEMEAD - USP. São Paulo: 2010.

[6]. CUNHA, Reynaldo Dannecker. Projeto Inteligência de Mercado. Boletim de Tendências: 2011. SEBRAE 2011

[7]. DE OLIVEIRA, José Antônio Puppim; WAISSMAN, Vera. Integrando ação e comunicação para uma estratégia de marketing ambiental: o caso Aracruz Celulose. Revista Eletrônica de Administração, v. 8, n. 6, 2002.

[8]. GELINSKI, Karen Gisele Franciosi; PADILHA, Valéria Wisniewski. O Marketing Verde ou Eco Marketing - Um Estudo em Algumas Empresas Brasileiras. Anais da SIEPE - Semana de Integração Ensino, Pesquisa e Extensão: 2009.

[9]. GINSBERG, Jill Meredith; BLOOM, Paul N. Choosing the right green-marketing strategy. MIT Sloan Management Review, v. 46, n. 1, p. 79, 2004.

[10]. GONÇALVES, Helena Martins; LOURENÇO, Tiago Ferreira; SILVA, Graça Miranda. consumidores, ao invés de estímulos persuasivos.

Como a pesquisa foi direcionada para venda direta de cosméticos, sugere-se novos estudos para outros segmentos, até mesmo na área de prestação de serviço. Sugere-se também a reaplicação do formulário com os consumidores da linha "E" e "S" para verificar suas percepções.

Sugere-se ainda pesquisas com relação à educação ambiental no Brasil, tanto por parte dos governantes quanto de empresas e ONGs.

Green buying behavior and the theory of consumption values: A fuzzy-set approach. Journal of Business Research, v. 69, n. 4, p. 1484-1491, 2015.

[11]. HARTMANN, Patrick; APAOLAZA IBÁÑEZ, Vanessa; FORCADA SAINZ, F. Javier. Green branding effects on attitude: functional versus emotional positioning strategies. Marketing Intelligence \& Planning, v. 23, n. 1, p. 9-29, 2005.

[12]. HERZOG, Ana Luiza. Recall de árvores. Exame. Disponível em: < http://exame.abril.com.br/revista-

exame/edicoes/0760/noticias/recall-de-arvoresm0052368>. Acesso em: Junho. 2014.

[13]. INSTITUTO AKATU. Sumário de Conclusões - Pesquisa Akatu 2012: Rumo À Sociedade Do Bem-Estar. São Paulo: Instituto Akatu, 2013.

[14]. KILBOURNE, William E. Sustainable communication and the dominant social paradigm: can they be integrated?. Marketing Theory, v. 4, n. 3, p. 187-208, 2004.

[15]. KOTLER, Philip; ARMSTRONG, Gary. Princípios de Marketing. 12. ed. São Paulo: Pearson Prentice Hall, 2007.

[16]. LIN, Hsiu-Yi; HSU, Meng-Hsiang. Using social cognitive theory to investigate green consumer behavior. Business Strategy and the Environment, v. 24, n. 5, p. 326-343, 2015.

[17]. MATTAR, Fauze Najib. Pesquisa de Marketing. São Paulo: Editora Atlas, 1996. 1 ed.

[18]. MERILAINEN, Susan; MOISANDER, Johanna; PESONEN, Sinikka. The masculine mindset of environmental management and green marketing. Business Strategy and the Environment, v. 9, n. 3, p. 151, 2000.

[19]. MOSER, Andrea K. Thinking green, buying green? Drivers of pro-environmental purchasing 
behavior. Journal of Consumer Marketing, v. 32, n. 3, p. 167-175, 2015.

[20]. MOURA, Luiz Antônio Abdalla de. Economia Ambiental: gestão de custos e investimentos. 2. ed., rev e atual. São Paulo: J. de Oliveira, 2003. 232 p.

[21]. Natura é a $6^{\mathbf{a}}$ empresa de vendas diretas do mundo. Exame.com. Disponível em < http://exame.abril.com.br/negocios/noticias/naturae-a-6a-empresa-de-vendas-diretas-domundo-vejalista>. Acesso em: Abril. 2014

[22]. GOERG, P. et al. Greenwashing no Brasil: um Estudo sobre os Apelos Ambientais nos Rótulos dos Produtos. Anais do VII Encontro Nacional de Estudos do Consumo. PUCRJ/Rio de Janeiro, Sept, v. 24, p. e 26, 2014

[23]. MANRAI, Lalita et al. How Green-Claim Strength and Country Disposition Affect Product Evaluation. Psychology \& Marketing, v. 14, n. 5, p. 511-537, 1997.

[24]. MEYER, Arnt. What's in it for the customers? Successfully marketing green clothes. Business Strategy and the Environment, v. 10, n. 5, p. 317-330, 2001.

[25]. OLIVETTI, Sabrina. Linha Sou de Natura e novidades da semana \#4 maio. Disponível em: < http://www.coisasdediva.com.br/2013/05/novidade s-da-semana-4-maio-2/ >. Acesso em: Maio. 2014.

[26]. Ottman, J.A. (2004). Removing the Barriers.In Business, 26(1), January/February, p.31. PEATTIE, Ken. Golden goose or wild goose? The hunt for the green consumer. Business Strategy and the Environment, v. 10, n. 4, p. 187, 2001.

[27]. PEREIRA, Severino Joaquim Nunes; AYROSA, Eduardo André Teixeira. Atitudes Relativas a Marcas e Argumentos Ecológicos: Um Estudo Experimental. Revista Eletrônica de Gestão.V. 2, n. 2, mai-ago, 2004.

[28]. PROTHERO, Andrea; FITCHETT, James A. Greening capitalism: Opportunities for a green commodity. Journal of Macromarketing, v. 20, n. 1, p. 46-55, 2000.

[29]. RELATÓRIO. Relatório Natura \#11. Disponível em: < http://natura.infoinvest.com.br/ptb/3996/ra_2011_co mpleto_gri_port.pdf>. Acesso em: Junho. 2014.
[30]. REVITA NATURA. Ciclo 10 2016. Plural Indústria Gráfica LTDA. 2014.

[31]. RIBAS, José Roberto; SMITH, Sandra Burle Marx. Gestão com Sustentabilidade: O caso da linha Ekos da Natura. III SEGeT-Simpósio de Excelência em Gestão e Tecnologia, Rio de Janeiro, Brasil, 2006

[32]. SANTOS, João Maurício. O Apelo Ecológico na Propaganda Como Fator de Influência na Atitude de Compra do Consumidor: Um Estudo Experimental. 2010.

[33]. SCHLEGELMILCH, Bodo; BOHLEN, Greg; DIAMANTOPOULOS, Adamantios. The link between green purchasing decisions and measures of environmental consciousness. European journal of marketing, v. 30, n. 5, p. 35-55, 1996.

[34]. SCHUHWERK, Melody E.; LEFKOFFHAGIUS, Roxanne. Green or non-green? Does type of appeal matter when advertising a green product?. Journal of advertising, v. 24, n. 2, p. 4554, 1995.

[35]. STRAUGHAN, Robert D.; ROBERTS, James A. Environmental segmentation alternatives: a look at green consumer behavior in the new millennium. Journal of consumer marketing, v. 16, n. 6, p. 558-575, 1999.

[36]. TEIXEIRA, Alessandra. O marketing verde. São Paulo, 2009

[37]. Venda Direta: O que é? AMBEVD. Disponível em < http://www.abevd.org.br/htdocs/index.php?secao= venda_direta\&pagina=venda_direta_o_que_e>. Acesso em: Junho. 2016

[38]. VERAS, Carlos Magno dos Anjos. GESTÃO DA QUALIDADE. Disponível em: < http://www.ifma.edu.br/proen/arquivos/artigos.php/ gestao_da_qualidade.pdf $>$. Acesso em: Junho. 2014.

[39]. WALLEY, Keith; CUSTANCE, Paul; PARSONS, Stephen. UK consumer attitudes concerning environmental issues impacting the agrifood industry. Business Strategy and the Environment, v. 9, n. 6, p. 355, 2000. 


\section{Capítulo 22}

\section{LOGISTICA REVERSA COMO ESTRATÉGIA DE FIDELIZACCÃO NO SETOR DE PRODUTOS DE BELEZA: UMA REVISÃO SISTEMÁTICA DA LITERATURA}

\section{Thaís Testoni}

\section{Patricia Guarnieri}

\section{Raphael Salviano de Souza}

Amanda Cristina Gaban Filippi

Resumo: O Brasil é o quarto maior mercado consumidor de cosméticos e produtos de beleza, estando atrás apenas dos Estados Unidos, Japão e China (ABIHPEC, 2017). Com o aumento da venda, aumenta também a geração dos resíduos, o que requer da sociedade e empresas práticas de descarte sustentáveis. Com a sanção da Lei 12.305/2010 a logística reversa de embalagens em empresas de diversos segmentos no Brasil passa a ser obrigatória. Indo além do atendimento à legislação empresas passam a utilizar a logística reversa na obtenção de vantagens econômicas, captação e manutenção de clientes. Esse trabalho teve como objetivo analisar a o estado da arte relacionada à logística reversa e fidelização de consumidores de produtos de beleza. Assim, foi realizada uma pesquisa aplicada, exploratória, descritiva, cujo procedimento técnico foi a revisão sistemática da literatura. Os resultados demonstraram o a escassez de artigos que tratem dos temas logística reversa e fidelização de consumidores associados, bem como identificou oportunidades de estudos futuros. Destaca-se ainda que alguns estudos enfatizam a necessidade de que as empresas percebam a logística reversa não apenas como uma estratégia para atender a legislação, mas também como estratégia de conquista e manutenção de clientes

Palavras-chave: Embalagens; Fidelização; Logística Reversa; Produtos de Beleza. 


\section{INTRODUÇÃO}

Por muito tempo, as empresas não mostravam interesse nos resíduos e produtos pósconsumo que geravam, de forma a providenciar o descarte apropriado, mas esse fator começa a mudar com a ampla quantidade de produtos utilizados mundialmente e, consequentemente, a criação de legislações ambientais restritivas (SILVA; LEITE, 2012).

A Logística Reversa tornou-se uma área de atuação de grande interesse. Seu conceito pode ser definido como o retorno de produtos, embalagens ou materiais ciclo logístico, para ser utilizados como matéria prima reciclável, reutilizados ou ainda na venda para o mercado secundário. A logística reversa trata do processo de planejamento, implantação e controle eficiente e eficaz dos resíduos que retornam ao ciclo logístico, os quais podem ser bens pós-consumo, sem mais utilidade ao primeiro consumidor, e bens pós-venda, os quais se caracterizam por bens pouco ou nada consumidos pelo cliente (LEITE, 2009). Como um dos objetivos do recolhimento de bens ou embalagens, está a recuperação de valor ou realização do descarte adequado do produto (SHIBAO; MOORI; SANTOS, 2010).

Existe, também, um objetivo estratégico da logística reversa, o que possibilita agregar valor a um produto logístico constituído por bens inservíveis ao proprietário original, ou que ainda possuam condições de utilização, por produtos descartados por terem atingido o fim de vida útil e por resíduos industriais (LEITE, 2002). Assim, a logística tem sido uma útil ferramenta para o gerenciamento empresarial na obtenção de vantagens econômicas (ROGERS; TIBBEN-LEMBKE, 1998).

Atualmente, as empresas devem adequar-se para atender às novas legislações, uma vez que a responsabilidade dos impactos ambientais dos resíduos sólidos recentemente passou a ser dos fabricantes. Além da responsabilidade legal das empresas, o aumento da consciência ambiental exige o melhor conhecimento de seus clientes e, assim, possibilitam a implementação de políticas na melhoria da satisfação e fidelização dos clientes por meio da cadeia de suprimentos, uma oportunidade ainda negligenciada por diversas empresas (LAMBERT et al., 2011).
Algumas empresas de produtos de beleza já possuem iniciativas com relação à logística reversa de embalagens, como por exemplo: Mac, Maria Helena Misturinhas e Grupo Boticário (Moreira e Guarnieri, 2016). Devido a maior evidência dos impactos ambientais e maior conscientização da sociedade, surgem legislações que impelem as empresas a adotar práticas de logística reversa, como é o caso da Política Nacional de Resíduos Sólidos - PNRS, a qual foi sancionada em 2010 por meio da Lei 12.305. Esta legislação obriga as empresas geradoras de embalagens, de quaisquer tipos, a implementar programas de logística reversa, viabilizando seu retorno ao setor produtivo por meio da reciclagem (GUARNIERI, 2011).

Nesse caso a indústria de produtos de beleza também devem se adequar para atender a legislação, visto que os produtos comercializados por esse setor, além de possuir embalagens, são compostos por produtos químicos, que podem causar impactos ambientais e para a saúde.

Considerando esses aspectos, o descarte de resíduos tem sido foco estratégico de várias empresas. Um exemplo de abordagem estratégica está na relação entre a logística reversa e o relacionamento com o cliente. Assim, uma cadeia de relacionamentos é formada pela empresa juntamente com a transformação em valor agregado transmitido ao cliente, podendo também ser gerado pela integração entre empresa e cliente no momento após a venda, sendo tão importante quanto à venda em si (ZENONE, 2007).

O objetivo deste trabalho é analisar o estado da arte no que se refere ao tema logística reversa, fidelização e indústria de produtos de beleza por meio de uma revisão sistemática da literatura, com base no protocolo proposto por Cronin, Ryan e Coughlan (2008).

Existem poucos estudos que relacionem logística reversa e relacionamento com cliente no mesmo cenário, além de serem quase inexistentes os estudos sobre descarte de produtos de beleza e fidelização dos consumidores. São citadas algumas pesquisas mais recentes de forma cronológica:

Cardoso (2011) promoveu uma escala de avaliação para o comportamento de descarte de produtos de cosméticos por parte de seus consumidores. Silva e Leite (2012) realizaram uma revisão de estudo sobre Logística Reversa de retorno de embalagens como 
forma estratégia nas empresas brasileiras. Cerqueira, Oliveira e Honorio (2013) analisaram a percepção de consumidores e vendedores sobre o processo de compra de cosméticos.

Corrêa e Silva (2013) analisaram o processo de logística reversa de pós-consumo da empresa O Boticário, enxergando a logística reversa como uma ferramenta utilizada para redução dos impactos produzidos por ela, a fim de alcançar o desenvolvimento sustentável. Bánkuti e Bánkuti (2014) identificaram e analisaram ações ambientais estratégicas implantadas por empresas nacionais do setor de cosméticos.

Thode-Filho et al (2015) analisaram os impactos associados à logística reversa e descarte inadequado de pós-consumo do esmalte de unhas em Duque de Caxias. Moreira e Guarnieri (2016) promoveram uma análise de uma política de fidelização de clientes atrelada à logística reversa de embalagens de cosméticos em indústrias de cosméticos brasileiras.

São percebidas algumas semelhanças entre os artigos em questão, porém não foram encontrados estudos que integrem a percepção sobre logística reversa pós consumo de produtos de beleza e a relação entre fidelização de clientes. Assim esse estudo torna-se relevante ao sintetizar o conhecimento existente por meio de uma revisão sistemática da literatura.

\section{REFERENCIAL TEÓRICO}

\subsection{LOGÍSTICA REVERSA}

Para compreender o ciclo logístico, direto ou reverso, é necessário entender que o canal de distribuição gerencia e movimenta os produtos do fornecedor até o cliente final (OLIVEIRA; ALMEIDA, 2013). Os canais logísticos de distribuição, segundo Bowersox e Closs (2010), são caracterizados como entidades que viabilizam a troca de produtos durante o processo de comercialização, do fornecedor inicial até o comprador final.

A Logística Reversa, segundo Rodrigues et al. (2002), trata dos produtos no sentido inverso da logística tradicional, ou seja, é o processo de reintegração dos produtos ao ciclo produtivo, a fim de reaproveitar seus componentes e materiais constituintes. De uma forma mais profunda, Rogers e TibbenLembke (1998) afirmam que a Logística Reversa é um processo que deve planejar, implementar e controlar o fluxo de recursos e respectivas informações, desde o ponto de consumo até o ponto de origem, a fim de recapturar valor ou adequar o seu destino. A figura 1 apresenta os processos logísticos diretos e reversos

Figura 1: Processo Logístico Direto e Reverso - Área de atuação, atividades e etapas.

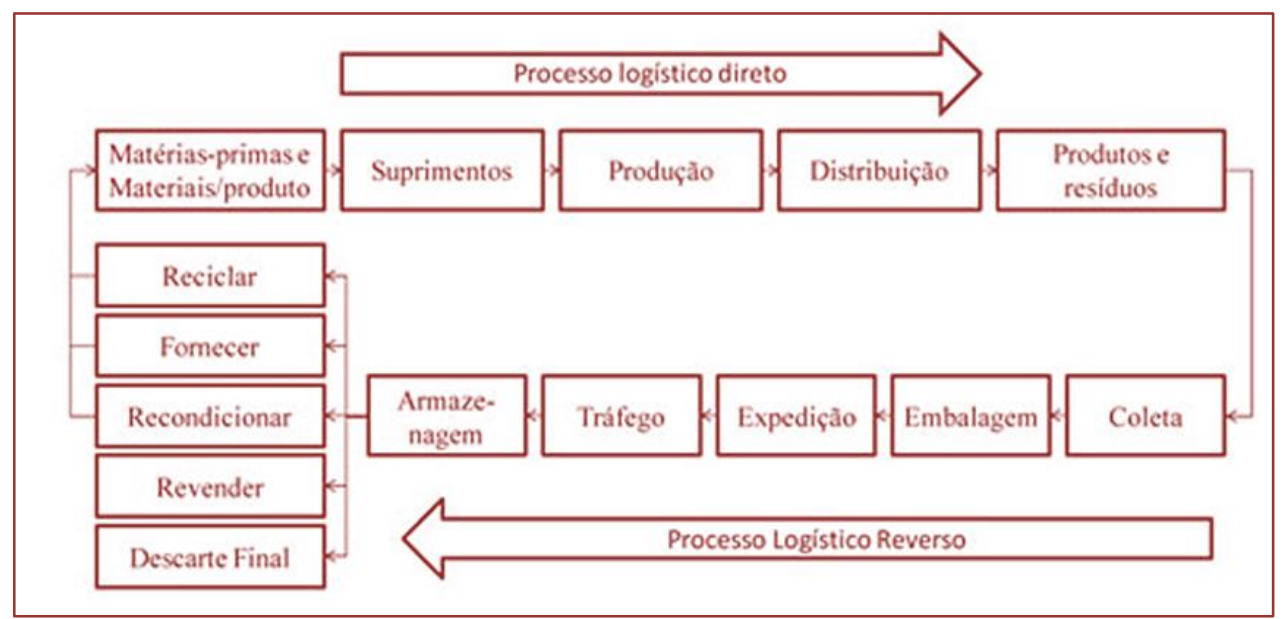

Fonte: Kruglianskas, Aligleri e Aligleri (2009). 
Como mostrado na Figura 1, o processo Logístico Direto é visto como uma continuidade de todas as tarefas de movimentação do fluxo de produtos, desde o fornecedor até o ponto de consumo final, assim como as trocas de informações que colocam os produtos em movimento (BALLOU, 1995). Contudo, os descartes inadequados de produtos, assim como a globalização e a escassez de recursos, geraram a necessidade das empresas adotarem medidas com o objetivo de praticar o inverso desse processo, complementando o processo de logística empresarial (OLIVEIRA; ALMEIDA, 2013).

Para compreender o surgimento da Logística Reversa, deve-se lembrar do aumento significativo do volume de resíduos sólidos, bem como a consciência ecológica da população atual que prega a preservação do meio ambiente e a diminuição do desperdício (RODRIGUES; RODRIGUES; LEAL; PIZZOLATO, 2002). Deste modo, a logística reversa é diretamente relacionada às questões legais, ambientais e econômicas, permitindo maior eficiência ecológica das empresas que a praticam em seu processo produtivo e, consequentemente, agregando valor por meio de uma imagem corporativa da empresa (LEITE, 2002; SOUZA e VIEIRA, 2015).

O Council of Supply Chain Management Professionals - CSCMP (2010) definiu a Logística Reversa como um segmento da logística que foca o movimento e gerenciamento de produtos e materiais após a venda e após a entrega ao consumidor. Inclui produtos retornados para reparo e/ou reembolso financeiro. $O$ gerenciamento reverso dos bens de pós-consumo e pósvenda pode ser observado no ponto de vista estratégico e econômico, sendo uma motivação para obtenção de resultados financeiros (LEITE, 2003). Esse conceito se mostra apropriado para a pesquisa uma vez que engloba o pós-venda e pós-consumo e busca atender a importância social, ambiental e econômica da logística reversa.

Sabendo que a logística reversa é a área da logística empresarial que visa gerenciar aspectos de retorno de bens ao ciclo produtivo, é possível afirmar que os canais de distribuição reversos podem ser tanto de pósvenda quanto de pós-consumo (SOUZA; VIEIRA, 2015).A logística reversa de pósvenda relaciona-se a produtos com pouca ou nenhuma utilização, que por diferentes motivos retornaram à cadeia de distribuição direta, sendo consequência de erros no processamento dos pedidos, garantia dada pelo fabricante, defeitos ou falhas de funcionamento no produto, avarias no transporte, entre outros motivos (LEITE, 2002). A logística reversa de pós-consumo, é formada por planejamento, controle e disposição dos bens que estão no final de sua vida útil, podendo ter sua utilidade prolongadas para outro propósito, recicladas ou apenas destinadas à coleta de lixo urbano (GUARNIERI et al., 2006). Leite (2003) afirma que o fluxo de retorno esses bens de pósconsumo podem ser destinados a fins tradicionais, como a incineração ou os aterros sanitários, ou retornar ao ciclo produtivo por meio de reciclagem ou reutilização em uma extensão de sua vida útil.

\subsection{Legislações de Resíduos Sólidos}

Visto que o surgimento da logística reversa é diretamente ligado à preocupação com o descarte final de bens, é possivel compreender a importância do tema. De acordo com preocupações por parte dos cidadãos e de empresas, foram criadas legislações ambientais que exigem maior responsabilidade por parte das organizações na geração e descarte de resíduos (SOUZA; VIEIRA, 2015).

De acordo com Donato (2008), o desenvolvimento sustentável surgiu a partir da constatação da necessidade de encontra um equilíbrio ecológico por parte das empresas, gerando diversos conceitos atuais sobre sustentabilidade. Dessa forma, acredita-se que, para alcançar o desenvolvimento social e econômico é importante atentar-se às implicações referentes às questões ambientais (OLIVEIRA; ALMEIDA, 2013).

Como um meio de buscar o equilíbrio ecológico, Conselho Nacional do Meio Ambiente (CONAMA) vigorou a resolução no 001 em 1986, definindo como impacto ambiental qualquer alteração físicas, químicas e biológicas do meio ambiente, causada por qualquer atividade humana. Além disso, foi definido que qualquer atividade que possa interferir do meio ambiente deverá ser analisada para aprovação do órgão estadual competente. Podem, também, ser citadas diversas outras resoluções do CONAMA e ANVISA - Agência Nacional de Vigilância Sanitária - a respeito de descartes de resíduos possivelmente perigosos o meio ambiente em geral (GUARNIERI, 2011), tais 
como proibição da utilização de substâncias que destroem a Camada de Ozônio, controle do teor de fósforo e outras substancias tóxicas utilizadas das produções, dentre outros.

Outra medida diretamente impactante ao descarte de embalagens foi a Política Nacional de Resíduos Sólidos (PNRS). Esta foi instituída pela Lei 12.305/2010 em dois de agosto de 2010, estabelecendo um regime que permite o enfrentamento dos principais problemas ambientais, sociais e econômicos decorrentes do manejo inadequado dos resíduos sólidos. A PNRS divide a responsabilidade de geração de resíduos sólidos importadores, distribuidores, comerciantes, o cidadão e titulares de serviços de manejo dos resíduos sólidos urbanos na Logística Reversa dos resíduos e embalagens pós-consumo e pós-consumo (BRASIL, 2010).

Tais práticas de sustentabilidade impactaram na geração oportunidades de criação de instrumentos de gestão para retorno de resíduos, focos da logística reversa, impactando em ganhos de diversas naturezas (GUARNIERI, 2011). O que antes poderia ser um problema transforma-se em uma oportunidade estratégica para sobreposição de posicionamento organizacional, quando relacionado a outras empresas do mesmo ramo (SOUZA; VIEIRA, 2015).

Os programas socioambientais podem impactar na maior produtividade das empresas, causando lucro ao mesmo tempo em que gera uma harmonia ambiental (DONATO, 2008). Assim sendo, a sustentabilidade econômica é suportada pelo possível crescimento econômico, partindo do pressuposto que não haja impactos negativos para a população ou gerações futuras (BRUNDTLAND, 1987; OLIVEIRA; ALMEIDA, 2013). Esta visão buscada pelas legislações é imposta a longo prazo, demonstrando que tanto a decisão quanto gestão vão além do interesse microeconômico imediato (DOWBOR, 2008).

Alguns autores afirmam não haver uma definição conclusiva para desenvolvimento sustentável, ao passo que não possuem um padrão absoluto, variando de acordo com setor industrial ou a sociedade inserida (VILHA; CARVALHO, 2005). Apesar de serem existentes legislações sobre descarte de matérias, busca-se observar são aplicadas na indústria de produtos de beleza como foco de captação de clientes, sendo a questão de pesquisa do estudo presente.

\subsection{DESCARTE DE PRODUTOS DE BELEZA}

Para compreender o impacto da logística reversa em embalagens de produtos de beleza é necessário saber que, no Brasil, o comportamento de descarte teve crescimento de $16,3 \%$ em 2010, de acordo com o Instituto Brasileiro de Economia da Fundação Getúlio Vargas (IBRE/FGV, 2010), estimando um faturamento de 40 bilhões de reais anuais. Vale lembrar que o Brasil ocupa a quarta posição mundial no consumo de produtos de beleza, equivalendo a $7,1 \%$ do consumo de cosméticos (EUROMONITOR, 2016).

Sabe-se que existem cerca de 2.642 empresas no Brasil que são regularizadas pela ANVISA, onde 20 são de grande porte e representam $75 \%$ do faturamento do setor de higiene pessoal, perfumaria e cosméticos (ABIHPEC, 2017). Dentre empresas deste setor, foram pesquisadas na internet as que divulgam suas práticas de sustentabilidade e logística reversa de suas embalagens e foram encontradas sete empresas que se enquadram neste requisito.

Dentre as empresas de produtos de beleza que oferecem políticas de devolução de embalagens aos seus clientes, tem-se empresa de cosméticos canadense MAC, sendo uma das pioneiras no Brasil em programas de retorno de embalagens de produtos cosméticos, atrelado ao relacionamento com o cliente. Seu programa de fidelização troca seis embalagens vazias por um batom da loja, colaborando com o descarte adequado de suas embalagens usadas (MAC, 2015).

As quatro marcas do Grupo Boticário possuem um programa de logística reversa de suas embalagens, possibilitando que os clientes retornem seus produtos vazios em qualquer época do ano. Uma dessas marcas, a O Boticário, iniciou há pouco tempo uma ação semelhante, trocando embalagens vazias por produtos novos, incentivando os consumidores ao descarte consciente, além de promover um melhor relacionamento com eles (O BOTICÁRIO, 2017). Assim, o cliente pode de cadastrar em um site da promoção para entregar suas embalagens em uma loja por um período estipulado.

A empresa Quem Disse, Berenice? - outra marca do Grupo Boticário - promoveu um dia 
de troca de batons usados de qualquer marca por novos. Este é outro programa desenvolvido pela Boti Recicla, fazendo parte do programa de reciclagem da indústria que inclui as marcas O Boticário, Quem disse, Berenice?, The Beauty Box e Eudora. Todas as embalagens vazias recolhidas são enviadas para - cooperativas de catadores de material reciclável, o que contribui para a geração de renda das famílias envolvidas na atividade e reduz o impacto do descarte inapropriado das embalagens no meio ambiente (BOTI RECICLA, 2017).

Como já citado anteriormente, a marca de esmaltes Maria Helena Misturinhas também possui um programa de retorno de embalagens, além de oferecer aos seus consumidores uma redução no custo dos produtos a serem comprados futuramente (MARIA HELENA MISTURINHAS, 2012). Assim, é possível perceber que a preocupação das empresas com a Logística Reversa de suas embalagens tem sido visível, através de planos de ação estratégicos de recuperação do valor econômico, ou até como melhorias na imagem e relacionamento com seus consumidores (SILVA; LEITE, 2012).

Outra empresa conhecida pela sustentabilidade de suas embalagens é a Lush, uma empresa britânica que produz seus próprios recipientes fabricados com plástico polipropileno, um material reciclável e reutilizado para novas embalagens da marca, além de utilizar plástico PET, outro material reciclável (LUSH, 2017). Como prática de sustentabilidade e fidelização de clientes, a empresa troca suas embalagens pósconsumo por alguns produtos selecionados, além de oferecer embalagens de presente (caixa, fitas e adesivos) de produtos reciclados e que podem ser reutilizadas pelos seus clientes.

Para demonstrar essa preocupação vigente das empresas em prol da sustentabilidade, no último ano trinta e três empresas receberam o selo do Programa de Qualificação de Fornecedor, realizado pela Associação Brasileira da Indústria de Higiene Pessoal, Perfumaria e Cosméticos (ABIHPEC) em São Paulo. O modelo, já utilizado nos Estados Unidos, qualifica os fornecedores de cosméticos de embalagens e serviços para o setor de higiene pessoal, perfumaria e cosméticos, sendo avaliados em cinco quesitos: 1. Qualidade de produtos e serviços; 2. Atendimento comercial; 3. Desenvolvimento de produtos e/ou serviços de forma consciente e inovadora; 4. Entrega e 5. Assistência Técnica. (ABIHPEC, 2015). Deste modo, o programa busca contribuir para o melhoramento da cadeia produtiva, ampliando a preocupação com excelência em todo ciclo logístico.

Outro programa estipulado pela ABIHPEC em 2006 tem como objetivo buscar melhorias para o descarte de embalagens pós-consumo atrelado ao incentivo de parcerias de empresas brasileiras e de reciclagem. De tal modo, o Programa "Dê a Mão para o Futuro" foi apresentado ao Ministério do Meio Ambiente afim de atender a Política Nacional de Resíduos Sólidos, sendo praticado nos estados de Santa Catarina, São Paulo, Rio de Janeiro e Paraná (ABIHPEC, 2006).

Todos esses programas de incentivo à logística reversa criados são impactos da exigência dos consumidores por serviços e produtos que incluem as preocupações ambientais, criando uma diferenciação na fidelização dos clientes (BATALHA; CHAVES, 2006). Assim, Batalha e Chaves (2006), Demo (2015) e Guarnieri (2015) afirmam que a mudança na cultura de consumo dos clientes influencia diretamente nas estratégias de marketing em logística reversa, possibilitando guiar o relacionamento com o cliente por meio de práticas de sustentabilidade.

\subsection{Marketing de Relacionamento}

As organizações que adotaram práticas de relacionamento com os clientes passaram a ter vantagem competitiva sobre as outras. D’Angelo, Shneider, Larán (2006) consideram que o marketing de relacionamento tem como objetivo a manutenção do relacionamento com o consumidor em longo prazo. Deste modo, uma organização deve desenvolver estratégias para construir um bom relacionamento com o cliente e mantê-lo (MIQUEL-ROMERO; CAPLLIURE-GINER; ADAME-SÁNCHEZ, 2014).

Payne (2012) afirma que quando se conhece a demanda e comportamento do consumidor, a organização passa a obter vantagem competitiva, passando a utilizar a Gestão de Relacionamento para potencializar as estratégias de relacionamento com $\mathrm{O}$ consumidor. Portanto, marketing de relacionamento pode ser visto como a construção do relacionamento entre organização e consumidor de forma duradoura (BERRY, 2005; PARVATIYAR, SHETH, 2000). McKenna (1999) afirma que a fidelização do consumidor gera 
competitividade do mercado ao reter clientes, ao mesmo tempo que gera vantagem competitiva para a organização construir e manter um relacionamento a longo prazo.

Como afirmam Kotler e Keller (2012), o marketing também deve continuar após a venda e seguir o ciclo de vida do produto, uma vez que a satisfação ou não dos consumidores somente ocorre com o desempenho do produto adquirido. Assim, é necessário manter uma ação coletiva entre a logística reversa e o marketing para suprir as necessidades do cliente, ao mesmo tempo em que se busca manter um longo relacionamento entre ele e a empresa (GUARNIERI, 2015).

De acordo com Ottman (1994) a coleta de produtos e embalagens usadas, pode impactar no aumento de fidelidade dos clientes e aprofundamento do relacionamento entre eles. Este pode ser um meio de manter uma vantagem competitiva, visto que se traduz como a eficiência da organização em suas atividades ao mesmo tempo em que é capaz de gerar valor aos clientes (PORTER, 1991).

Ao mesmo tempo em que existe um aumento de exigências sustentáveis com as empresas, os consumidores estão cada vez mais conscientes ecologicamente e considerando cada vez mais aspectos ambientais para efetuar suas compras (GUARNIERI, 2015). Assim, só será possível implementar qualquer estratégia de marketing com a compreensão do pensamento e comportamento de seu consumidor (FOURNIER et al., 1998).

\section{MÉTODOS E TÉCNICAS DE PESQUISA}

Quanto à classificação da pesquisa, trata-se de uma pesquisa aplicada, exploratória, descritiva e qualitativa. $O$ procedimento técnico utilizado foi a revisão da literatura. Ressalta-se que existem basicamente dois tipos de revisão da literatura: revisão tradicional ou narrativa da literatura e revisão sistemática da literatura. A revisão sistemática da literatura utiliza uma abordagem mais rigorosa e definida para revisar a literatura em uma área especifica, portanto, fornece a análise crítica de artigos publicados e não publicados da área de estudo em questão, não podendo ser restrita apenas ao resumo dos resultados de uma série de estudos (CRONIN; RYAN; COUGHLAN, 2008).
Foi utilizada a técnica meta-síntese para interpretar os estudos encontrados, uma vez que podem ser combinados para identificar temas em comum de acordo com a análise de elementos-chave em cada estudo, transformando essas descobertas individuais em novas interpretações (POLIT; BECK, 2006).

A elaboração de um roteiro de seleção de artigos é necessária para demonstrar a lacuna existente no escopo das pesquisas, além de auxiliar a produção deste estudo. Para isso, foi utilizado o Protocolo de Cronin, Ryan e Coughlan (2008), um procedimento metodológico composto por cinco etapas, são elas: 1. Formulação da questão de pesquisa; 2. Estabelecer conjunto de critérios de inclusão e exclusão; 3. Seleção e acesso da literatura; 4. Avaliação da qualidade da literatura incluída na revisão.

Etapa 1 - Definição da pergunta de pesquisa: Deve-se definir um elemento específico de interesse que seja encontrado nos estudos de forma comum. Sabendo que quanto mais específica a questão de pesquisa, mais coerente o resultado poderá ser, a revisão sistemática seguiu os critérios de filtros propostos de seleção de artigos. Vale ressaltar que a pesquisa visa responder à pergunta: Existe preferência, e consequentemente, fidelização dos consumidores de empresas de produtos de beleza que praticam a logística reversa de embalagens pós-consumo?

Etapa 2 - Definição de critérios de inclusão e exclusão: foram definidos de acordo com as bases de pesquisas a serem exploradas, sendo adotadas as plataformas Scielo, Google Scholar, Science Direct e Spell, uma vez que contribuem com os principais periódicos, estrangeiros e brasileiros, que abarcam o tema de pesquisa. A seleção teve como base os resumos das publicações, pela combinação das seguintes palavras chaves: consumidor de produtos de beleza, relacionamento com marca, gestão ambiental estratégica, logística reversa, setor de beleza e também as palavras-chave em inglês: brandloyalty, cosmetics, reverse logistics, customer, innovation, relashionship marketing, satisfaction e loyalty. $O$ período para a seleção de pesquisa foi de cinco anos, ou seja de 2011 a 2016, tendo como resultado um total de sete pesquisas empíricas 
realizadas que se mostram diretamente relevantes ao presente estudo. Com esse período, pretendeu-se buscar os artigos mais recentes sobre o tema, mostrando que ainda há uma lacuna de estudo a ser preenchida.

Etapa 3 - Seleção e acesso da literatura: Após o recolhimento de todos os estudos encontrados e condizentes com os filtros, foi necessário realizar a leitura dos artigos que foram coletados para que sejam analisados criticamente. Primeiramente, foram encontrados dezoito artigos que se mostravam compatíveis com todos os filtros: margem temporal, bases de pesquisa e palavras-chave comuns. Foram pesquisados artigos específicos para o tema, tratando da logística reversa, consumidores de produtos de beleza e fidelização.

Etapa 4 - Avaliação da qualidade da literatura - Foram excluídos artigos que integravam os temas em comum de forma muito abrangente, mantendo poucos assuntos em comum com a pesquisa atual, por exemplo, artigos que estudavam outros segmentos que não o de produtos de beleza, como eletroeletrônicos, embalagens de agrotóxicos, embalagens em geral, entre outros. Assim, buscou-se a maior quantidade possível de temas específicos e compatíveis com o estudo presente, relacionando logística reversa e empresas de produtos de beleza, bem como fidelização de clientes por meio da logística reversa pósconsumo. Após a leitura e análise destes, a quantidade de artigos diretamente relevantes ao tema caiu para sete. Isso se justifica por possuírem focos diferentes da pretensão de estudo presente, mesmo mostrando algumas semelhanças.

Etapa 5 - Análise, síntese e disseminação dos resultados: Com base em uma análise de conteúdo dos artigos, foram ressaltados os principais autores, universidades, anos de publicação, objetivo dos estudos, procedimentos metodológicos adotados e relevância, além de serem destacadas as lacunas da literatura encontradas nos trabalhos analisados, o que embasou a seção 4 que trata da apresentação dos resultados e sua discussão.

\section{APRESENTAÇÃO E ANÁLISE DOS RESULTADOS}

De acordo com os estudos encontrados, observa-se que há um crescimento da abordagem dos assuntos pesquisados nos cinco anos, além da existência de diversas pesquisas tendo como temas a logística reversa e relacionamento com clientes. Entretanto observou-se que são insuficientes no Brasil estudos que relacionem ambos os temas em conjunto, possibilitando sintetizar e correlacionar os assuntos neste presente estudo.

A principal linha de pesquisa a ser estudada trata-se da fidelização de clientes por meio da logística reversa de embalagens em indústrias de produtos de beleza no Brasil. Assim, com relação à procura de estudos sobre os temas propostos, são apresentados os seguintes artigos mais relevantes para a pesquisa.

Após a análise da quantidade de publicações ao longo do período definido de cinco anos, observou-se que a pesquisa se faz necessária uma vez que busca preencher uma lacuna referente à falta de pesquisas brasileiras sobre o assunto, já que os artigos empíricos encontrados não relacionam Logística Reversa e Fidelização com empresas de produtos de beleza, sendo restrito à empresas de cosméticos. 
Quadro 2. Revisão Sistemática da Literatura: artigos relevantes para pesquisa

\begin{tabular}{|c|c|c|c|c|c|}
\hline Autores & Instituição & Publicação & Objetivo do Estudo & Método & Relevância \\
\hline $\begin{array}{l}\text { Corrêa e } \\
\text { Silva } \\
(2013)\end{array}$ & $\begin{array}{l}\text { Universidade } \\
\text { Federal de } \\
\text { Pernambuco } \\
\text { (UFPE) }\end{array}$ & $\begin{array}{l}\text { Revista de } \\
\text { Gestão } \\
\text { Ambiental e } \\
\text { Sustentabili- } \\
\text { dade. }\end{array}$ & $\begin{array}{l}\text { Analisar o processo de } \\
\text { logística reversa de } \\
\text { pós-consumo da } \\
\text { empresa O Boticário. }\end{array}$ & $\begin{array}{l}\text { Estudo de } \\
\text { caso e } \\
\text { entrevista com } \\
\text { consumidores } \\
(n=10)\end{array}$ & $\begin{array}{l}\text { Processo } \\
\text { logístico da O } \\
\text { Boticário } \\
\text { através das } \\
\text { percepções de } \\
\text { clientes e } \\
\text { funcionários }\end{array}$ \\
\hline $\begin{array}{l}\text { Silva } \\
\text { Leite } \\
(2012)\end{array}$ & $\begin{array}{l}\text { Universidade } \\
\text { Presbiteriana } \\
\text { Mackenzie } \\
\text { (UPM) }\end{array}$ & $\begin{array}{l}\text { Revista de } \\
\text { Gestão } \\
\text { Social e } \\
\text { Ambiental }\end{array}$ & $\begin{array}{l}\text { Realizar uma revisão } \\
\text { de estudo sobre } \\
\text { Logística Reversa e } \\
\text { relaciona-la aos } \\
\text { motivos de retorno e as } \\
\text { políticas empresariais } \\
\text { estratégicas }\end{array}$ & $\begin{array}{l}\text { Survey com } \\
\text { executivos } \\
(n=195)\end{array}$ & $\begin{array}{l}\text { Relação entre } \\
\text { de Logística } \\
\text { Reversa e } \\
\text { estratégia } \\
\text { empresarial }\end{array}$ \\
\hline $\begin{array}{l}\text { Bánkuti e } \\
\text { Bánkuti } \\
(2014)\end{array}$ & $\begin{array}{l}\text { Universidade } \\
\text { Estadual de } \\
\text { Maringá (UEM) }\end{array}$ & $\begin{array}{l}\text { Revista } \\
\text { Gestão da } \\
\text { Produção }\end{array}$ & $\begin{array}{l}\text { Identificar e analisaram } \\
\text { ações ambientais } \\
\text { estratégicas } \\
\text { implantadas por } \\
\text { empresas nacionais do } \\
\text { setor de cosméticos. }\end{array}$ & $\begin{array}{l}\text { Entrevista e } \\
\text { estudo de } \\
\text { caso }(n=1)\end{array}$ & $\begin{array}{l}\text { Analisou ações } \\
\text { ambientais } \\
\text { estratégicas no } \\
\text { setor de } \\
\text { cosméticos }\end{array}$ \\
\hline $\begin{array}{l}\text { Thode- } \\
\text { Filho et al. } \\
(2015)\end{array}$ & $\begin{array}{l}\text { Universidade do } \\
\text { Estado do Rio } \\
\text { de Janeiro } \\
\text { (UERJ); } \\
\text { Universidade } \\
\text { Federal do } \\
\text { Estado do Rio } \\
\text { de Janeiro } \\
\text { (UNIRIO) }\end{array}$ & $\begin{array}{l}\text { Revista } \\
\text { Eletrônica } \\
\text { em Gestão, } \\
\text { Educação e } \\
\text { Tecnologia } \\
\text { Ambiental }\end{array}$ & $\begin{array}{l}\text { Analisar os impactos } \\
\text { associados à logística } \\
\text { reversa e descarte } \\
\text { inadequado de pós- } \\
\text { consumo do esmalte } \\
\text { de unhas em Duque de } \\
\text { Caxias. }\end{array}$ & $\begin{array}{l}\text { Metodologia } \\
\text { qualitativa de } \\
\text { fontes } \\
\text { secundárias. }\end{array}$ & $\begin{array}{l}\text { Estudou a } \\
\text { evolução do } \\
\text { consumo } \\
\text { comparando } \\
\text { com o } \\
\text { crescimento da } \\
\text { LR e PNRS. }\end{array}$ \\
\hline $\begin{array}{l}\text { Moreira e } \\
\text { Guarnieri } \\
(2016)\end{array}$ & $\begin{array}{l}\text { Universidade de } \\
\text { Brasillia (UnB) }\end{array}$ & $\begin{array}{l}\text { Revista } \\
\text { Gestão } \\
\text { Industrial }\end{array}$ & $\begin{array}{l}\text { Promover uma análise } \\
\text { de uma política de } \\
\text { fidelização de clientes } \\
\text { atrelada à logística } \\
\text { reversa de embalagens } \\
\text { de cosméticos em } \\
\text { indústrias brasileiras. }\end{array}$ & $\begin{array}{l}\text { Survey com } \\
\text { consumidores } \\
\text { de cosméticos } \\
(n=504)\end{array}$ & $\begin{array}{l}\text { Relacionaram a } \\
\text { preferência dos } \\
\text { consumidores } \\
\text { por empresas } \\
\text { de cosméticos } \\
\text { brasileiras que } \\
\text { praticam a LR. }\end{array}$ \\
\hline $\begin{array}{l}\text { Cardoso } \\
(2011)\end{array}$ & $\begin{array}{l}\text { Universidade de } \\
\text { Brasillia (UnB) }\end{array}$ & $\begin{array}{l}\text { Não houve } \\
\text { (trabalho de } \\
\text { conclusão } \\
\text { de curso) }\end{array}$ & $\begin{array}{l}\text { Promover uma escala } \\
\text { de avaliação para o } \\
\text { comportamento de } \\
\text { descarte de produtos } \\
\text { de cosméticos por } \\
\text { parte de seus } \\
\text { consumidores. }\end{array}$ & $\begin{array}{l}\text { Metodologia } \\
\text { qualitativa de } \\
\text { dados } \\
\text { secundários }\end{array}$ & $\begin{array}{l}\text { Avaliou o } \\
\text { comportamento } \\
\text { de descarte dos } \\
\text { consumidores } \\
\text { de cosméticos. }\end{array}$ \\
\hline $\begin{array}{l}\text { Cerqueira, } \\
\text { Oliveira e } \\
\text { Honorio } \\
(2013)\end{array}$ & $\begin{array}{l}\text { Universidade } \\
\text { Federal de } \\
\text { Sergipe (UFS); } \\
\text { Universidade } \\
\text { Federal da } \\
\text { Bahia (UFBA); } \\
\text { Universidade } \\
\text { Federal da } \\
\text { Paraíba (UFPB) }\end{array}$ & $\begin{array}{l}\text { XXXIII } \\
\text { Encontro } \\
\text { Nacional De } \\
\text { Engenharia } \\
\text { De } \\
\text { Produção }\end{array}$ & $\begin{array}{l}\text { Analisar a percepção } \\
\text { de consumidores e } \\
\text { vendedores sobre o } \\
\text { processo de compra } \\
\text { de cosméticos. }\end{array}$ & $\begin{array}{l}\text { Entrevistas e } \\
\text { questionários } \\
(n=229)\end{array}$ & $\begin{array}{l}\text { Mostrou as } \\
\text { preferências e } \\
\text { percepções de } \\
\text { consumidores } \\
\text { de produtos } \\
\text { cosméticos }\end{array}$ \\
\hline
\end{tabular}

Tal revisão da literatura é fundamental para o processo de pesquisa e ajuda a refinar uma questão de pesquisa através da determinação de um corpo de conhecimento, ao criar uma maior compreensão sobre um tópico (CRONIN; RYAN; COUGHLAN, 2008). Desta forma, o presente trabalho se justifica também pela falta de estudos que tratam sobre a fidelização de clientes relacionados à logística reversa de produtos de beleza, correlacionando ambos os temas em um mesmo patamar, visto que a preocupação acerca deste tema no Brasil é recente. 
Para analisar se há ou não escassez de artigos nos últimos anos que integrem os assuntos de logística reversa e fidelização de consumidores, apresenta-se a Figura 2:

Figura 2. Quantidade de artigos relevantes publicados de 2011 a 2016.

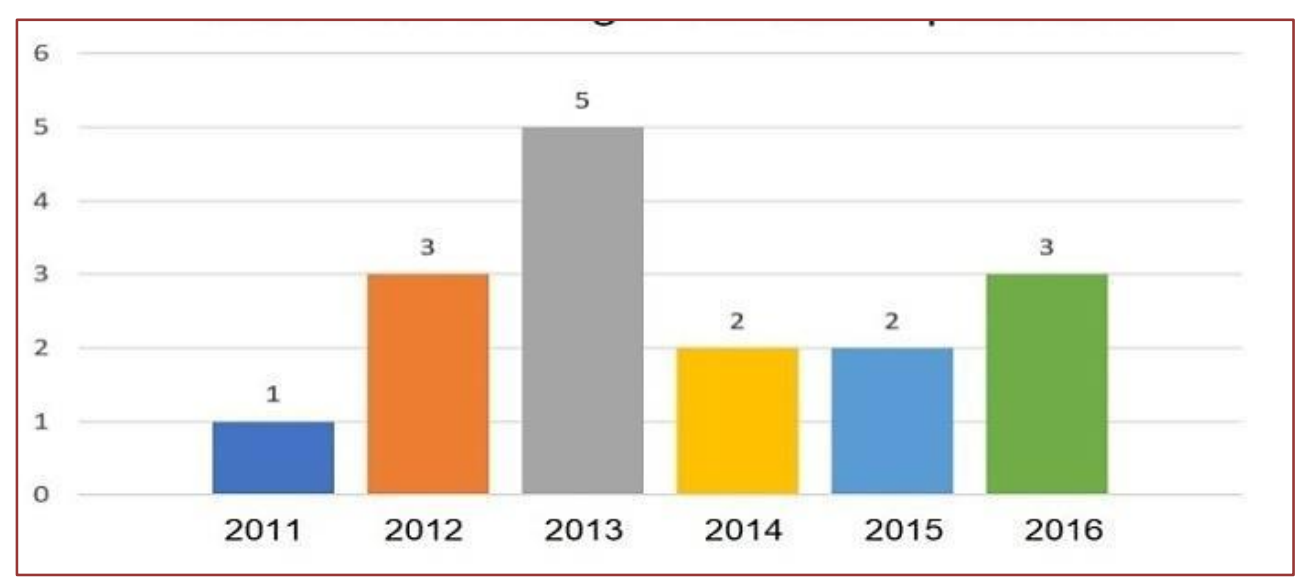

A Figura 2 mostra a quantidade de artigos que abordam temas semelhantes publicados nos últimos cinco anos, margem temporal definida anteriormente. Como apresentado nesta seção, dentre os 16 artigos encontrados, apenas 7 apresentaram alto grau de semelhança com o estudo presente, abordando os temas interligados de logística reversa, fidelização de clientes e empresas de produtos de beleza. Assim, a quantidade de publicações nos últimos anos mostrou ser de baixa frequência, visto que maior quantidade de artigos publicados no ano foi em 2013, sendo publicados cinco artigos sobre Logística Reversa feita com consumidores de empresas de diversos setores.

Este fator mostra a relevância deste estudo para estimular a expansão deste campo de pesquisa. Ademais, foram analisadas as universidades de origem dos autores dos sete artigos mais relevantes para o estudo presente, conforme a Figura 4.

Figura 3. Universidades de origem dos autores filtrados na revisão sistemática

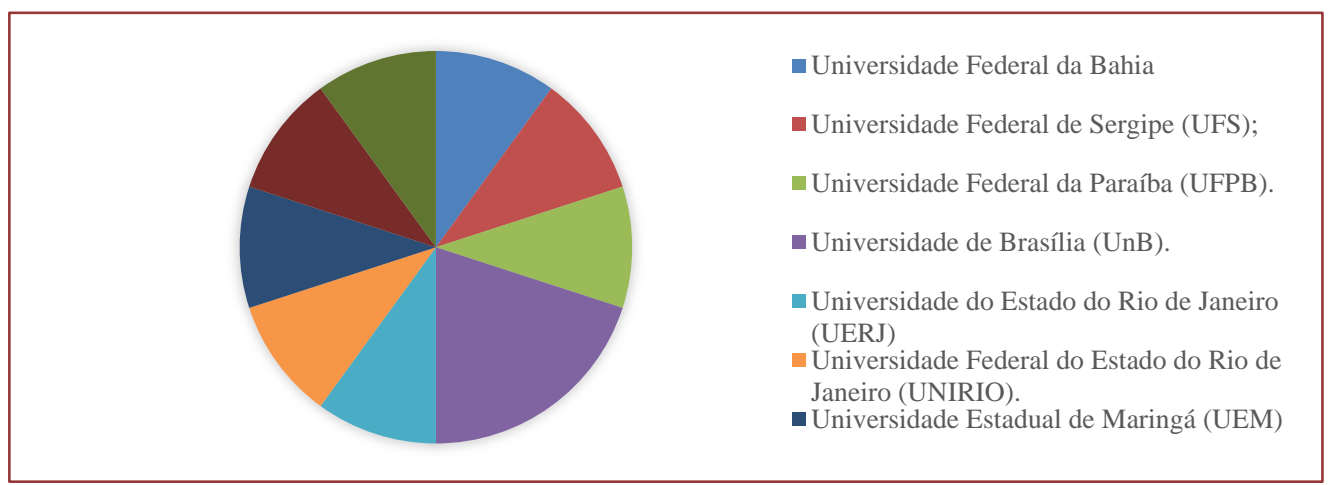

Ao analisar a Figura 3, é possível perceber que existe uma grande variedade de universidades de origem dos autores filtrados. Dentre as sete pesquisas que compõem a revisão sistemática da literatura, apenas a Universidade de Brasília foi a única instituição repetida por ser a origem de estudo de dois autores. Ao observar as regiões das universidades em questão, observa-se que os estudos sobre logística reversa foram foco em diversos locais, mostrando que é um tema relevante de estudo no Brasil todo. Sobre os métodos de pesquisa utilizados nos sete estudos em questão, apresenta-se a Figura 4: 
Figura 4. Métodos utilizados pelos estudos filtrados na revisão sistemática

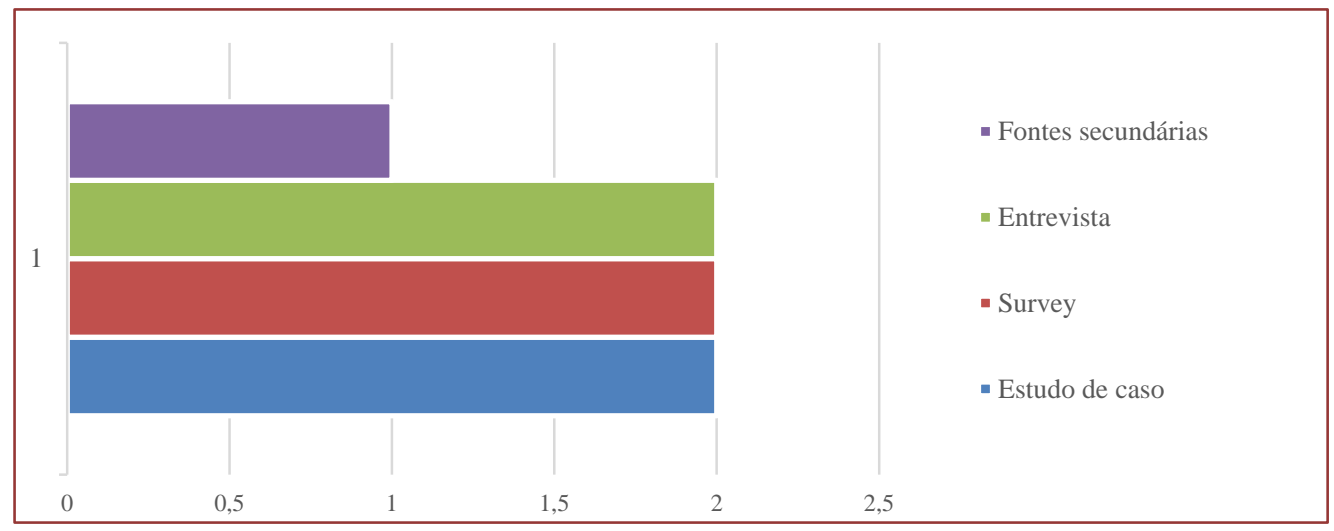

Como se percebe na figura 4 , os estudos selecionados na revisão sistemática tiveram como foco quatro tipos de procedimentos técnicos de pesquisa, sendo escolhido mais de um procedimento em alguns estudos. Assim, foram utilizadas fontes secundárias, entrevistas, survey e estudo de caso. Nota-se que não houve destaque para um procedimento específico, visto que entrevista, survey e estudo de caso foram apontados em dois estudos, enquanto apenas um estudo efetuou a análise de fontes secundárias.

Foram identificadas também as lacunas encontradas nos artigos analisados na revisão sistemática da literatura. Foi apontado que por alguns autores a necessidade de estudar as diferentes frentes da Logística Reversa, de acordo com o tipo de empresa, tamanho, valor agregado na devolução de embalagens e outros diversos assuntos (SILVA; LEITE, 2012).

Observou-se também a sugestão de estudos que abordem a avaliação sobre a logística reversa e a PNRS e as diferentes propostas implementadas com a utilização da Logística Reversa (THODE-FILHO, 2015). Por outro lado, há a oportunidade de investigar as diferenças das características no comportamento de compra de produtos de beleza, de acordo com gêneros de consumidores e nas estratégias de marketing oferecidas por essas empresas de produtos de beleza (CERQUEIRA; OLIVEIRA; HONORIO, 2013).

Moreira (2015) sugeriu buscar os motivos pelos quais os consumidores em geral não apresentarem atitudes ambientalmente responsáveis, além de fomentar estudos sobre as áreas de logística, logística reversa, marketing e marketing de relacionamento, além de estudos que correlacionem essas áreas, visto que há escassez destes.

Moreira e Guarnieri (2016) destacam a necessidade de pesquisas sobre empresas que atuam como operadoras de logística reversa, bem como estudos que analisem o comportamento do consumidor quanto quanto ao descarte, tem termos de consciência e atitude.. Também destacam a importância de estudos que relacionem de forma integrada diferentes áreas da administração.

Ademais, foi percebido que existe uma baixa quantidade de estudos publicados sobre os temas logística reversa e fidelização nos últimos cinco anos, sendo essa uma oportunidade para fomentar pesquisas que relacionem o consumidor de produtos de beleza e a logística reversa utilizada pelas empresas como meio de fidelização de clientes.

\section{CONCLUSÕES E RECOMENDAÇÕES}

A indústria da beleza no Brasil é o quarto maior mercado consumidor dos produtos de beleza do mundo (ABIHPEC, 2017) e, consequentemente, aumenta-se o número de embalagens de pós-consumo descartadas. Ao mesmo tempo, nota-se um aumento de legislações que visam diminuir o impacto do descarte inadequado de resíduos, como é o caso da Política Nacional de Resíduos Sólidos.

Esta pesquisa teve como objetivo principal analisar o estado da arte, com base nos critérios de inclusão e exclusão detalhados na seção de métodos e técnicas de pesquisa, no que tange aos temas logística reversa e fidelização de clientes, no setor de produtos de beleza. Foram identificadas as empresas 
que possuem tais práticas, bem como estudos que abordam os temas relacionados. No entanto, percebe-se uma carência de estudos que abordem tais aspectos em conjunto. Destaca-se que alguns estudos enfatizam a necessidade de que as empresas percebam a logística reversa não apenas como uma estratégia para atender a legislação, mas também como estratégia de conquista e manutenção de clientes.

Esse trabalho limitou-se a analisar a literatura dos últimos cinco anos acerca dos temas citados, usando um protocolo específico de revisão sistemática, limitando-se também aos critérios de inclusão e exclusão citados na seção de métodos e técnicas de pesquisa.

Como sugestão para estudos futuros, sugerese um estudo quantitativo para obter a

\section{REFERÊNCIAS}

[1] ABIHPEC. Panorama do Setor 2017: panorama do setor de higiene pessoal, perfumaria e cosméticos. São Paulo, 2017. Disponível em $<$ https://abihpec.org.br/publicacao/panorama-dosetor-2017/> . Acesso em fevereiro de 2017.

[2] BÁNKUTI, S. M. S.; BÁNKUTI, F. I. Gestão ambiental e estratégia empresarial: um estudo em uma empresa de cosméticos no Brasil. Gest. Prod., São Carlos, v. 21, n. 1, p. 171-184, 2014. BALLOU, R.H. Logística Empresarial. São Paulo: Atlas, 1995

[3] BRASIL. Lei 12.305/2010, de 02 de agosto de 2010.Institui a Política Nacional de Resíduos Sólidos. Brasília, DF, 02 ago. 2010. Disponível em: <http://www.planalto.gov.br/ccivil_03/_ato20072010/2010/lei/l12305.htm>. Acesso em: 12 mar. 2017.

[4] BRUNDTLAND, G. H. (Org.). Nosso futuro comum. Rio de Janeiro: FGV, 1987.

[5] BOWERSOX, D. J.; CLOSS, D. J. Logística empresarial: o processo de integração da cadeia de suprimento. 1. ed. São Paulo: Atlas, 2010.

[6] CARDOSO, M.T.. Descarte de cosméticos: uma proposta de escala de avaliação do comportamento dos consumidores. 2011. $54 \mathrm{f}$. Monografia (Bacharelado em Administração), Universidade de Brasília.

[7] CERQUEIRA, Aline de; OLIVEIRA, Rodrigo de; HONORIO, José. Comportamento do consumidor de cosméticos: alinhando a percepção dos consumidores e vendedores sobre o processo de compra. In: XXXIII Encontro Nacional de Engenharia de Produção, Salvador, BA, 2013.

[8] CHAVES, G.; BATALHA, M.. Os consumidores valorizam a coleta de embalagens recicláveis?:um estudo de caso da logística reversa em uma rede de hipermercados. Gestão \& percepção dos consumidores quanto às questões relacionadas à fidelização e logística reversa e também que seja realizado um estudo qualitativo, trazendo percepções, hábitos e preferências de consumidores por meio de entrevistas pessoais. Outro fator interessante a ser estudado são as ações de novas e pequenas empresas e suas relações com o descarte de embalagens, logística reversa e relacionamento com o cliente. Deste modo, é possível buscar insumos profundos através de entrevistas com estas empresas.

Este estudo contribui ao sintetizar os trabalhos que abordam tal temática e também apontar oportunidades de pesquisa, com base nos estudos analisados.

Produção, São Paulo, v. 13, n.3, set.-dez., 2006, p.423-434.

[9] CONAMA. Resolução CONAMA no 1 de 23 de janeiro de 1986. Dispõe sobre critérios básicos e diretrizes gerais para o Relatório de Impacto Ambiental - RIMA. Disponível em: $<$ http://www.mma.gov.br/port/conama/legiano.cfm? codlegitipo=3>. Acesso em: 23 set. 2015.

[10] CORREAA, A.; SILVA, M. A logística reversa sob a perspectiva produção-mercado-consumo: o caso O Boticário. Revista Gestão Ambiental e Sustentabilidade. São Paulo, v. 2,n. 1, 2013.

[11] CRONIN, P.; RYAN, F.; COUGHLAN, M. Undertaking a literaturereview: a step-by-step approach. British Journal of Nursing, 2008, p. 3843.

[12] DEMO, G.. Marketing de relacionamento e comportamento do consumidor. São Paulo: Atlas, 2015.

[13] DEMAJOROVIC, J.; AUGUSTO, E.; SOUZA, M. Logística reversa de REEE em países em desenvolvimento: desafios e perspectivas para o modelo brasileiro. Ambiente \& Sociedade. São Paulo v. XIX, n. 2, 2016, p. 119-138. Disponível em: <http://www.redalyc.org/html/317/31746369007/>.

[14] DEMAJOROVIC, J.; MIGLIANO, J. Política nacional de resíduos sólidos e suas implicações na cadeia da logística reversa de microcomputadores no Brasil. Gestão \& Regionalidade (Online), São Caetano do Sul, 2013, p. 29-87.

[15] DONATO, V. Logística Verde. Rio de Janeiro: Editora Ciência Moderna Ltda., 2008. 276 p.

[16] DOWBOR, L. Democracia Econômica: novas tendências da gestão social. Petrópolis: Ed. Vozes, 2008. 
[17] GUARNIERI, P. et. al. A logística reversa de pós-venda e pós-consumo agregando valor econômico, legal e ecológico às empresas. In: ADM 2005 Congresso de Administração, Ponta Grossa: UEPG, 2005.

[18] GUARNIERI, P. Logística reversa: em busca do equilíbrio econômico e ambiental. Recife: Editora Clube de Autores, 2011.

[19] A importância da logística reversa no comportamento pós-compra do consumidor. In: DEMO, Gisela. Marketing de relacionamento e comportamento do consumidor.São Paulo: Atlas, 2015.

[20] GRUPO BOTICARIO. Nossa história. Disponível em:

http://www.grupoboticario.com.br/ptbr/institucional/Paginas/nossahistoria.aspx> Acesso em: 19 de maio. 2017

[21] Sustentabilidade: MatériasPrimas e embalagens. Disponível em: < http://www.grupoboticario.com.br/ptbr/sustentabilid ade/Paginas/materias-primas-e-embalagens.aspx > Acesso em: 19 de maio 2017.

[22] HERNÁNDEZ, C.; MARINS, F.; CASTRO, R. Modelo de gerenciamento da logística reversa. Gestão \& Produção, São Carlos, v. 19, n. 3 , 2012, p. 445-456.

[23] KRUGLIANSKAS, I.; ALIGLERI, L.; ALIGLERI, L.A. Gestão socioambiental: responsabilidade e sustentabilidade do negócio. São Paulo: Atlas, 2009

[24] LAMBERT, S.; RIOPEL, D.; ABDULKADER, W. A reverse logistics decisions conceptual framework.Computers \& Industrial Engineering, v. 61, 2011, p. 561-581.

[25] LEITE, P. Logística reversa: nova área da logística empresarial. Revista Tecnologística, São Paulo, mai. 2002.

[26] Logística reversa: meio ambiente e competitividade. São Paulo: Pearson, 2009.

[27] MAC. Back tom.a.c. Disponível em: $<$ https://www.maccosmetics.com/giving_back/back _to_mac.tmpl> Acesso em: 20 de maio 2017.

[28] MOREIRA, I.F. Fidelização de clientes por meio da logística reversa: um estudo com consumidores de indústrias de cosméticos brasileiras. 2015. 116 f. Monografia (Bacharelado em Administração), Universidade de Brasília.

[29] MOREIRA, I.F.; GUARNIERI, P. Preferência dos consumidores por empresas que implementam práticas de logística reversa como meio de fidelização: estudo na indústria de cosméticos brasileira. Revista Gestão Industrial: revista de pósgraduação em Engenharia de Produção de Ponta Grossa, UTFPR, v. 12, n. 4, 2016.

[30] OLIVEIRA, L. G.; ALMEIDA, M. L. Logística reversa de embalagens como estratégia sustentável para redução de custos: um estudo em uma engarrafadora de bebidas. Revista Metropolitana de Sustentabilidade - RMS. v. 3, n. 3, 2013

[31] POLIT D; BECK C. Essentials of nursing research: methods, appraisal and utilization. Philadelphia: Lippincott Williams and Wilkins, 6. ed., 2006.

[32] QUEM DISSE BERENICE. Conheça o programa de fidelidade. Disponível em <http://www.quemdisseberenice.com.br/fidelidade >. Acesso em: 19 de maio 2017.

[33] RODRIGUES, D. et al. Logística Reversa: conceitos e componentes do sistema. XXII Encontro Nacional de Engenharia de Produção. Curitiba, PR: ENEGEP, 2003. Disponível em: http://www.abepro.org.br/biblioteca/EN ROGERS, D. S. \&

[34] RODRIGUES, G.; PIZZOLATO, N.; SANTOS, V.Logística Reversa dos Produtos de pós-venda no Segmento de Lojas de Departamento.XVIII Congresso de Pesquisa e Ensino em Transportes, 2002.

[35] ROGERS, D.; TIBBEN-LEMBKE, R. Going back wards: reverse logistics trends and practices. In: Reverse Logistics Executive Council, Reno: University of Nevada, 1998. Disponível em: <http://www.abrelpe.org.br/imagens_intranet/files/lo gistica_reversa.pdf>. Acesso em: 19 jun. 2017.

[36] SHIBAO, F.; MOORI, E.; SANTOS, M. A logística reversa e a sustentabilidade empresarial.In: XIII Seminário em Administração (SEMEAD), set. 2010. Disponível em: <http://webresol.org/textos/a_logistica_reversa_e_a_sustentabi lidade_empresarial.pdf.>. Acesso em: 19 jun. 2017.

[37] SILVA, A.; LEITE, P. Empresas brasileiras adotam políticas de logística reversa relacionadas com o motivo de retorno e os direcionadores estratégicos?.Revista de Gestão Social e Ambiental, São Paulo, v. 6, n. 2, maio/ago. 2012, p. 79-92.

[38] SILVA, E.; MENEZES, E.. Metodologia da Pesquisa e Elaboração da Dissertação. 2005. 138 f. Dissertação - Universidade Federal de Santa Catarina, Florianópolis, 2005.

[39] SOUZA, B.; VIEIRA, G. Análise dos procedimentos de logística reversa aplicados em duas plantas de uma indústria multinacional atuante no segmento de petróleo e gás. Organizações em Contexto, São Bernardo do Campo, v. 11, n. 22, jul.-dez. 2015

[40] THODE FILHO, S. et al. Gestão de resíduos pós consumo: uma proposição de logística reversa para o esmalte de unhas. In: Eletronic Journal of Management, Education and Environmental Technology, v. 19, n. 3, 2015.

[41] VILHA; A. CARVALHO, R. Desenvolvimento de novas competências e práticas de gestão da inovação voltadas para o 
desenvolvimento sustentável: estudo exploratório da Natura. IngeñariaAmbiental, v. 9 n. 1, 2013.

[42] YOUNGER, P.Using the internet to conduct a literature search. Nurs Stand, 2004, p. 45-51.
[43] ZENONE, L. Customer relationship management: gestão do relacionamento com o cliente e a competitividade empresarial: em busca do equilíbrio econômico e ambiental. [S.L]: Novatec, 2007. 


$$
\text { Alutary }
$$




\section{ADEMIR CLEMENTE}

Graduado em Economia e Engenharia pela UFPR $(1974,5)$. Mestre em Engenharia de Produção pela COPPE / UFRJ (1977). Doutor em Engenharia de Transportes pela COPPE / UFRJ (1982). Lecionou em graduação e em pós-graduação nos Estados Unidos da América. Pós-doutorado pela Universidade de Londres na área de Economia do Trabalho, 1989. Pósdoutorado em Lógica Fuzzy Aplicada pela COPPE/UFRJ, 2012. Editor adjunto da Revista de Contabilidade e Controladoria da UFPR entre 2010 e 2012. Professor Associado do Departamento de Ciências Contábeis da UFPR. Docente Permanente do Programa de PósGraduação em Contabilidade (Nível 5). Nove livros publicados nas áreas de Economia, Administração, Finanças e Estatística. Ocupou a vice-direção do Setor de Ciências Sociais Aplicadas da UFPR entre 2013 a 2017. Avaliador de artigos da International Review of Financial Analysis (Qualis-CAPES A1) e de outros 10 periódicos. ademir@ufpr.br Currículo: http://lattes.cnpq.br/3021828547126069

\section{ADRIANA REGINA MARTIN}

Bacharelado e Licenciatura em Química pela UFSCar, Mestrado e Doutorado em Ciência e Engenharia dos Materiais pela UFSCar, Doutorado Sandwich na Universidade de WisconsinMadison/USA com Bolsa Fulbright, Pós Doutorado em Inovação Tecnológica pela UFSCar, Pós Graduação em Política e Estratégia pela ADESG, Foi professora na Faculdade Oswaldo Cruz (FOC) e na Faculdades Nove de Julho (Uninove) ministrando disciplinas relacionadas a Polímeros e Química e na Universidade de Santo Amaro (Unisa) e na Fundação Escola de Sociologia e Política de São Paulo (FESPSP) ministrando disciplinas relacionadas a Gestão. Foi professora Visitante na Unicamp ministrando a disciplina Inovação Tecnológica para os cursos de Engenharia e de Gestão. Foi Gerente de Desenvolvimento de Produto e Assistência Técnica para América Latina nas empresas multinacionais, Huntsman Química Brasil e Mash Plásticos, atuou em PD\&I na Startup Orbys e na empresa BRF atuou na diretoria de PD\&I sendo responsável pela gestão do portfólio de projetos de PD\&l, pela prospecção e gestão de projetos de PD\&I em parceria com ICTs, pela transferência de tecnologia e pela captação de recursos financeiros para desenvolvimento de projetos de PD\&I junto a Embrapii, BNDES, FINEP, CNPq. Atuou no CLAEQ-Pieracciani Consultoria de Inovação auxiliando as empresas a captarem recursos financeiros para desenvolvimento de projetos de PD\&I, a utilizarem incentivos fiscais (Lei do Bem) e também desenvolverem projetos por meio da Inovação Aberta. Foi Professora Visitante na UnB na área de Gestão da Inovação no Dep. de Engenharia de Produção e Gerente de Negócios Tecnológicos no CDT/UnB e também atuou no Mestrado em Transferência de Tecnologia e Inovação. Foi consultora ad hoc no MCTIC Comitê de Auxílio Técnico dos Setores Transversais (CAT-TRANSVERSAL) - Lei do Bem e na EMBRAPA - no comitê Técnico do Macroprograma 1. Atualmente é Diretora do Departamento de Políticas de Desenvolvimento e Inovação em Tecnologias Estruturantes - DETEC- da Secretaria de Desenvolvimento Tecnológico e Inovação - SETEC/MCTIC e Professora Colaboradora no Mestrado em Transferência de Tecnologia e Inovação na UnB. É consultora ad hoc das seguintes instituições: CNPq - no comitê de avaliação do Programa RHAE Pesquisador na Empresa e no comitê de avaliação de Produtividade em Desenvolvimento Tecnológico e Extensão Inovadora - Bolsa DT; FAPESP - no comitê do Programa de Inovação em Pequenas Empresas; SENAI - no comitê de avaliação do Edital de Inovação na Industria; e MACKPESQUISA - no comitê do Fundo Mackenzie de Pesquisa da Universidade Mackenzie/SP

\section{ADRIANE CARINE MALDANER VORPAGEL}

Graduação em Ciências Contábeis pela Universidade Estadual do Oeste do Paraná UNIOESTE 


\section{AMANDA CRISTINA GABAN FILIPPI}

Doutoranda em Agronegócios pela UFG, profa. colaboradora na UNB, membro do Grupo de Operações, Logística e Métodos de Apoio à Decisão da UnB (GOMETA), do Grupo de Estudos e Pesquisas Avançadas em Logística e Supply Chain Management (GEALOGS) e do Grupo de Estudos em Agronegócio (GEA/UFG), revisora de periódicos nacionais e internacionais sobre temas ligados ao Agronegócio e Desenvolvimento Rural. Trabalha com Agronegócio, Logística Empresarial, Logística Agroindustrial, Armazenagem Agrícola, Supply Chain, Condomínios de Armazéns Rurais e Condomínios Rurais. Mestre em Agronegócios pela UNB e Engenheira Agrônoma pela ESALQ/USP. Foi analista/pesquisadora do Grupo de Pesquisa e Extensão em Logística Agroindustrial (ESALQ-LOG), realizou Prática Profissionalizante em \&quot;Sistemas Logísticos Agroindustriais\&quot; (ESALQ/USP), foi membro do grupo de pesquisa Diversidade Genética e Melhoramento ? USP, Grupo de Estudos \&quot;Luiz de Queiroz\&quot; 2013 (GELQ 2013) da ESALQ e chefe do Evento de Energia Renováveis. Atuou com pesquisa na área de Educação no Departamento de Economia, Administração e Sociologia da ESALQ/USP. Realizou intercâmbio na Universidade de Trás-os-Montes e Alto Douro (UTAD/Portugal-ESALQ/USP).

\section{ANDERSON GIOVANE SONTAG}

Mestre em Administração pelo Programa de Pós-Graduação em Administração da Universidade Estadual do Oeste do Paraná - PPGADM / UNIOESTE (2016). Especialista em Contabilidade, Perícia e Auditoria pela UNOPAR (2014). Especialista em Direito Empresarial pela UNIOESTE (2011). Bacharel em Ciências Contábeis pela Universidade Estadual do Oeste do Paraná - UNIOESTE (2007). Atualmente é professor da União de Ensino Superior do Paraná (UESPAR). É sócio quotista - Escritório Contábil Rondon Ltda. Tem experiência na área de Administração, com ênfase em Contabilidade, atuando principalmente em Contabilidade Intermediária, Contabilidade de Custos, Gerencial, Tributária e Tópicos Especiais em Contabilidade.

\section{ANTONIO SÉRGIO EDUARDO}

Graduação em Ciências Contábeis - Faculdades de Ciências Contábeis e Atuariais da Alta Noroeste - SALESIANO. Especialização em Controladoria, Gerência Contábil e Financeira, Auditoria (UFMS). Mestrado em Geociência (UNICAMP). Doutorando em Meio Ambiente e Desenvolvimento Regional - Universidade Anhanguera (UNIDERP - MS). Professor Efetivo nos cursos de Administração e Gestão Financeira da UFMS, campus de Nova Andradina

\section{CAMILA ANDRADE SILVE SOUZA}

Possui graduação em Engenharia de Produção pela Faculdade Machado Sobrinho e cursa pós-graduação em Gerenciamento de Projetos pela PUC Minas Gerais. Possui experiência no desenvolvimento de plano de negócio e implantação do programa 5S.

\section{CAMILA SILVA DAMASCENO}

Possui graduação em Engenharia de Produção pela Faculdade Machado. Experiência no desenvolvimento de projetos como Pesquisa de Mercado, Plano de Negócios e na área de Gestão de Pessoas.

\section{CASSIANA SANTOS DA SILVA FARIAS}

Graduanda em Administração pela Universidade do Estado da Bahia. 


\section{DANIEL BRIANEZI}

Engenheiro Florestal, mestre e doutor em Ciência Florestal pela Universidade Federal de Viçosa (UFV). Professor efetivo do Departamento de Ciência e Tecnologia Ambiental (DCTA) do Centro Federal de Educação Tecnológica de Minas Gerais (CEFET-MG). Atua na área de Economia Ambiental, em que desenvolve pesquisas relacionadas a Serviços Ambientais e Pagamento por Serviços Ambientais (PSA), com ênfase em projetos de carbono, biomassa e carbono florestal, inventário e neutralização de gases de efeito estufa. Além disso, possui experiência em certificações ambientais, em especial ISO 14.001, certificação florestal FSC e padrões de certificação agrícola. O pesquisador é parecerista Ad hoc de periódicos nacionais e agências de fomento.

\section{DANIEL BRIOSCHI MACHADO}

Graduado em Engenharia de Saúde e Segurança pela Universidade Federal de ItajubáCampus Itabira

\section{DANIELA CINTIA DE CARVALHO LEITE MENEZES}

Possui Mestrado em Ciências Contábeis pelo Programa Muitiinstitucional e Inter-regional de Pó-graduação em Ciências Contábeis - UnB / UFPB / UFRN (2004) e Graduação em Ciências Contábeis pela Universidade Federal da Paraíba - UFPB (2002). Atua como Docente e Orientadora no Curso de Ciências Contábeis da UFPB, Campus IV, Litoral Norte, onde atualmente é Professora do Departamento de Ciências Sociais Aplicadas (DCSA), do Centro de Ciências Aplicadas e Educação (CCAE). Possui experiência didática na docência desde 2002, com várias orientações em cursos de graduação e especialização. É avaliadora dos periódicos e pesquisadora na área de contabilidade com ênfase na Contabilidade para Usuários Internos, possuindo estudos publicados nos principais congressos e periódicos de contabilidade do país.

\section{DENIZAR LEAL}

Doutor em Administração - COPPEAD/UFRJ. Mestre em Educação - UnB. Professor Adjunto da Universidade Federal do Espírito Santo

\section{DEYSE QUEIROS SANTOS}

Professora da Universidade do Estado da Bahia - Campus UNEB / Bom Jesus da Lapa. Graduada em Administração de Empresas. Pós Graduado em Gestão de Varejo e MBA em Marketing ,Mestranda em Educação de Jovens e Adultos. Grupo de pesquisa: Grupo de Estudos Multidisciplinares em Educação, Psicologia e Administração - GEMPA, do (a) Universidade do Estado da Bahia. e do grupo de pesquisa em Educação Contextos e cognição na Educação de Jovens e Adultos-CCEJA da Universidade do Estado da Bahia.

\section{DIEGO VINICIUS DIAS}

Pós Graduado no MBA de Gestão Empresarial pelo Centro Universitário Municipal de Franca. Graduado em Engenharia Elétrica pela Unifran. Eletricista do grupo CPFL Paulista, atuação em Franca, SP. 


\section{EDER ANGELO SANCHES}

Graduação em Engenharia Elétrica pela Universidade Estadual Paulista - Unesp (1997), cursando mestrado na área de Sistemas Mecatrônicos na Universidade de Brasília - UnB (2018), Licenciatura Complementar de Física pela Universidade Cruzeiro do Sul (2015), especialização em Gerência de Projetos pela Fundação Getúlio Vargas - FGV (2007) e especialização em Gestão de Marketing pelo Centro Universitário Central Paulista - Unicep (2003). Atualmente, é servidor público efetivo do Governo Federal, em Brasília - DF, do Ministério da Ciência, Tecnologia, Inovações e Comunicações (MCTIC), exercendo a função de Tecnologista, atuando nas seguintes áreas de inovação e empreendedorismo. Atuou na área de incentivos fiscais (Lei do Bem, Programa Inovar-Auto, Lei para o Desenvolvimento Regional); área de Bens Sensíveis e na área de Inclusão Digital e projetos de infraestrutura. Tem 15 anos de experiência no setor privado na área de engenharia elétrica, manutenção e projetos, atuando em 4 empresas multinacionais de grande porte, principalmente nas seguintes áreas: metalúrgica, automotiva e mineração.

\section{ELIANE SANTOS VARGAS}

Possui graduação em Administração (2009) e Ciências Contábeis (2010) pelo Centro Universitário do Leste de Minas Gerais, pós graduação lato sensu em Gestão Ambiental (2014), Gestão Pública Municipal (2014) pela e Gestão Pública (2016) pela Universidade Federal de Viçosa. Mestranda em Administração (início 2016) CEFETMG. Tem experiência na área de tesouraria pública e fiscalização de tributos municipais.

\section{ELZA HOFER}

Doutorado em Administração pela Pontifícia Universidade Católica do Paraná - PUCPR (2012); Mestre em Controladoria Contabilidade Estratégica pelo Centro Universitário Álvares Penteado UNIFECAP - (2004); Mestre em Ciências Sociais Aplicadas área de concentração Contabilidade - Faculdades Reunidas de Administração, Ciências Contábeis e Econômicas de Palmas (2000) e graduação em Ciências Contábeis pela Faculdade de Ciências Humanas de Marechal Cândido Rondon - FACIMAR (1986).

\section{EMERSON ANDRADE GIBAUT}

Mestre em Ciências Contábeis pela Universidade Federal da Bahia (UFBA). Contador, Graduado em Ciências Contábeis pela Universidade Federal da Bahia (UFBA) e Graduando em Direito pela Universidade Católica do Salvador (UCSAL). Atuou como Contador da Fundação de Amparo à Pesquisa do Estado da Bahia (FAPESB). Atualmente, exerce o cargo de Coordenador Financeiro da Superintendência de Proteção e Defesa do Consumidor (PROCON). Atua como Professor de Ciências Contábeis da Faculdade Ruy Barbosa (WYDEN) e da Pós Graduação em Auditoria e Consultoria Contábil da CAIRU.

\section{ERIC FERNANDO BOECK DAZA}

Doutorando em Engenharia Elétrica pela Universidade Federal de Santa Maria (conclusão prevista para 2019), Mestrado de Economia da Universidade do Vale do Rio dos Sinos (2014), Mestrado em Negócios de Energia pelo Instituto Español de Energia (2011) concluído em Madri - Espanha e Mestrado em Engenharia Elétrica pela Universidade Federal de Santa Maria (2010). MBA em Gestão Empresarial pela Escola Superior de Propaganda e Marketing (2010). Graduação em Engenharia Elétrica - Universidade Federal de Santa Maria (2007). Atua em empresas nacionais e multinacionais do setor de energia desde 2007. Professor dos cursos de engenharia na Universidade Luterana do Brasil (ULBRA) desde 2014. Com interesse e atuação nas áreas de energia, econometria e regulação econômica. 


\section{FABIANO FERREIRA BATISTA}

Doutorando em Ciências Contábeis pela Universidade Federal da Paraíba. Mestre em Ciências Contábeis pela Universidade Federal da Paraíba. Graduado em Ciências Contábeis. Professor de Ciências Contábeis na Universidade Federal de Campina Grande.

\section{FÁBIO BIASOTTO FEITOSA.}

Psicólogo graduado pela Universidade Estadual Paulista/UNESP (2000). Doutor em Relações Interpessoais pelo PPGEEs da Universidade Federal de São Carlos/UFSCar (2007). Cumpriu período de doutorado sanduíche na Universidade Técnica de Lisboa/UTL (2006) pela CAPES, com ênfase em comportamento, desenvolvimento cognitivo e saúde. Formação complementar para o tratamento da Depressão pela abordagem interpessoal em Leicestershire/NHS Trust, Inglaterra. Pós-doutorado em tratamento e prevenção psicológica na University College London/UCL (2015) pela CAPES. Professor do Departamento de Psicologia/DEPSI da Universidade Federal de Rondônia/UNIR

\section{FLÁVIO DE SÃO PEDRO FILHO.}

É Pós-Doutor em Gestão e Economia pela Universidade da Beira Interior (UBI), Covilhã, Portugal. É Doutor em Administração (2010), pela Universidade de São Paulo (USP). É Mestre em Engenharia de Produção pela Universidade Federal de Santa Catarina; possui especialização em Planejamento pela UFBA e em Engenharia de Produção pela UFSC. É Bacharel em Administração pela EAUFBA. Atualmente é Professor Associado e Pesquisador na Universidade Federal de Rondônia (UNIR).

\section{FRANCISCO XAVIER SOARES FILHO}

Bacharel em Administração Pública (2013), Analista em Desenvolvimento de Sistemas (2008), Especialista em Gestão Pública (2011), Especialista em Contabilidade Pública e Responsabilidade Fiscal (2015), Especialista em Políticas Públicas (2016), Mestre em Ciência, Gestão e Tecnologia da Informação pela Universidade Federal do Paraná (2014). Currículo: http://lattes.cnpq.br/6970166653258204.

\section{FRANCISCO DAÊNNIO CASIMIRO DE OLIVEIRA}

Contador. Mestre em Sistemas Agroindustriais pela Universidade Federal de Campina Grande - UFCG. Especialista em Direito Tributário, pela Faculdades Integradas de Patos FIP. Bacharel em Ciências Contábeis pela Universidade Federal de Campinda Grande UFCG.

\section{FRANCISCO JEAN CARLOS DE SOUZA SAMPAIO}

Graduado em Ciências Contábeis pela Universidade do Estado do Rio Grande do Norte UERN. Especialista em Auditoria Contábil - UERN. Mestre em Ciências Contábeis pela Universidade Federal de Pernambuco - UFPE. Professor do Curso de Administração da Universidade do Estado do Rio Grande do Norte - UERN. Professor do Curso de Ciências Contábeis da Universidade Federal de Campina Grande - UFCG. Membro dos Grupos de Pesquisa: Núcleo de Estudos Organizacionais do Alto Oeste Potiguar - NEOP/UERN e Grupo de Estudos e Pesquisas em Economia, Cultura e Território - GEPECT/UERN.

\section{GEMAEL CHAEBO}

Graduação em Administração (UNAES - MS). Mestrado em Administração (UFMS). Doutorado em Administração (UNB). Professor Efetivo nos cursos de Administração e Gestão Financeira da UFMS, campus de Nova Andradina 


\section{GENIVAL JARDEL TRAJANO TEIXEIRA}

Graduado em Comércio Exterior pelo Instituto Federal de Educação, Ciência e Tecnologia do Rio Grande do Norte/IFRN (2017). Concluiu o Curso de Formação em Programação Básica pelo Instituto Metrópole Digital/UFRN (2014). Participou como pesquisador no Núcleo de Estudos de Tecnologia e Gestão na Indústria e Serviços (TGIS), no Instituto Federal de Ciência e Tecnologia do Rio Grande do Norte (IFRN), onde executou pesquisas sobre os determinantes do grau de dependência de fertilizantes para a balança comercial brasileira.

\section{GIANINNI MARTINS PEREIRA CIRNE}

Professora da Universidade Federal de Campina Grande do Curso de Ciências Contábeis. Mestre em Sistemas Agroindustriais. Especialista em Contabilidade de Custos para Gestão, pela Universidade Estadual da Paraíba. Membro do Grupo de Pesquisa GEPCON, da Universidade Federal de Campina Grande.

\section{GLEIDSON CAETANO DA SILVEIRA PINTO}

Mestre em Administração pela Faculdade Alves Faria - ALFA/GO, Especialista em Tecnologia de Redes de Computadores pela Universidade Federal de Lavras - UFLA/MG e Graduado em Administração pela Faculdade de Ciências e Educação de Rubiataba - FACER/GO. Atua como Professor no Instituto Federal Goiano, no Campus Ceres/GO.

\section{GUILHERME FREITAS CAMPOS}

Bacharel em Ciências Contábeis - Ufes. Mestrando em Ciências Contábeis - Ufes

\section{HÉRICA LANDI DE BRITO}

Doutora em Psicologia pelo Programa de Pós-graduação em Processos de Desenvolvimento Humano e Saúde (PGPDS) do Instituto de Psicologia da Universidade de Brasília (UnB), com bolsa CAPES (2016). Mestre em Psicologia pela Pontifícia Universidade Católica de Goiás (2011), com Área de Concentração em Psicopatologia Clínica e Psicologia da Saúde. Graduada em Psicologia (Licenciatura e Bacharelado) pela Pontifícia Universidade Católica de Goiás (2009) e pós-graduada em Psicoterapia Cognitivo-Comportamental (2013). Atualmente é Coordenadora do Curso de Psicologia do UNIALFA - Centro Universitário Alves Faria e professora do Mestrado Profissional em Administração desta mesma instituição.

\section{HUMBERTO MEDRADO GOMES FERREIRA}

Doutor em Administração ( USCS/SP, 2017), Mestre em Administração (Ibmec-RJ/2006), PósGraduado em Administração (FGV-RJ/2001), Graduado em Economia (UCP-RJ/1989) e Graduado em Administração (Estácio de Sá/2014)

\section{IGOR ALEXANDRE CLEMENTE DE MORAIS}

Pos doutor em estatística aplicada a finanças pela Universidade da Califórnia e mestre em ciência de dados, inteligência artificial, machine learning e deep learning aplicada. Sócio em startup na área de criptomoeda, blockchain e inteligência artificial. Diversos artigos e livros publicados tratando de finanças com uso de econometria e deep learning. 


\section{ISABELLE CARLOS CAMPOS REZENDE}

Possui Mestrado em Ciências Contábeis pelo Programa Muitiinstitucional e Inter-regional de Pó-graduação em Ciências Contábeis - UnB / UFPB / UFRN (2009) e Graduação em Ciências Contábeis pelo Centro Universitário de João Pessoa - UNIPÊ (2006). Atua como Docente e Orientadora no Curso de Ciências Contábeis da UFPB, Campus IV, Litoral Norte, onde atualmente é Professora do Departamento de Ciências Sociais Aplicadas (DCSA), do Centro de Ciências Aplicadas e Educação (CCAE) e Atual Chefe do DCSA/CCAE/UFPB. Foi tutora e orientadora do Curso de Especialização em Gestão Pública da UFPB (CEGESP-EAD). Trabalhou em empresa pública. Possui experiência didática na docência desde 2009, com várias orientações em cursos de graduação e especialização. É avaliadora dos periódicos e pesquisadora na área de contabilidade com ênfase na Contabilidade para Usuários Externos, possuindo estudos publicados nos principais congressos e periódicos de contabilidade do país.

\section{JACKSON JOSÉ SALES MIRANDA JÚNIOR}

Mestrando em Políticas Públicas e Desenvolvimento na Universidade Federal da Integração Latino-Americana (Unila). Pós-Graduando em Planejamento na Gestão Pública pelo Instituto Federal de Rondônia-IFRO.(2017). Graduado em Administração pela Universidade Federal de Rondônia (UNIR), membro do Grupo de Pesquisa em Gestão da Inovação e Tecnologia GEITEC, pesquisador do Grupo de Estudos e Pesquisa em Inovação e Sustentabilidade da Amazônia - GEPISA e do Grupo de Espaços Deliberativos e Governança Pública, da Universidade Federal de Viçosa

\section{JÉFERSON RODRIGO STRÖHER}

Mestrado em Ciências Contábeis pela Unisinos, possui especialização (MBA) em Controladoria, Finanças e Auditoria pela Fundação Getúlio Vargas, (2013). Possui graduação em Ciências Contábeis pela Pontifícia Universidade Católica do Rio Grande do Sul, (2008). Atuou como coordenador administrativo da Associação Antônio Vieira (ASAV) - Colégio Anchieta. Posteriormente, estruturou e organizou a controladoria da Associação Nóbrega de Ação e Assistência Social - ANEAS. Áreas de atuação: gestão orçamentária, finanças empresariais, análise das demonstrações financeiras, uso de indicadores de desempenho na gestão organizacional, custos para controle, determinação do lucro e tomada de decisões.

\section{JOSÉ MOREIRA DA SILVA NETO}

Possui graduação em ciências contábeis pela Faculdade de Administração e Ciências Contábeis Campos Salles de São Paulo (1982), especialização em contabilidade: análise e auditoria pala Universidade Federal de Rondônia (1988), especialização em contabilidade e controladoria pela Universidade de São Paulo (1993), mestrado em ciências contábeis e controladoria pela Universidade de São Paulo (1998) e doutorado em engenharia de produção pela Universidade Federal de Santa Catarina (2004). É Professor Titular, atua nos programas de graduação e pós-graduação, respectivamente, dos cursos de ciências contábeis e mestrado em administração da Universidade Federal de Rondônia (UNIR). É, coordenador da linha de pesquisa: estratégias e competências organizacionais e líder do grupo de estudo e pesquisa em organizações (GepOrg).

\section{JOSE SIMÃO DE PAULA PINTO}

Analista de Sistemas (1989), Administrador (1997), Especialista em Sistemas Distribuídos (1999), mestre em Informática - Bancos de Dados (2001) e doutor em Informática Aplicada ao Ensino e Pesquisa em Cirurgia - Medicina (2005). É professor adjunto na Universidade Federal do Paraná - simao@ufpr.br. Currículo: http://lattes.cnpq.br/7514178774795860. 


\section{JOSÉ SOARES RIBEIRO}

Graduação em Ciências Contábeis (UCDB - MS). Especialização em administração financeira, contabilidade e auditoria pelo Instituto Nacional de Pós-graduação. Mestrado em Psicologia (UCDB - MS). Professor Efetivo nos cursos de Administração, Gestão Financeira e Ciências Contábeis da UFMS, campus de Nova Andradina

\section{JOSÉ RIBAMAR MARQUES DE CARVALHO}

Professor doutor do Programa de Pós-graduação em Administração (PPGA/UFCG) e do Mestrado Profissional em Administração Pública - PROFIAP/UFCG. Líder do Grupo de Pesquisa GEPCON/UFCG.

\section{JOSE TIAGO ANGELICO DA SILVA}

\section{Contador}

Graduado em Ciências Contábeis pela Universidade Federal de Campina Grande.

\section{JOYCE GONÇALVES ALTAF}

Doutoranda em Ciencias Empresariales y Sociales pela Universidad de Ciencias Empresariales y Sociales - UCES (2018). Possui mestrado em Administração e Desenvolvimento Empresarial pela Universidade Estácio de Sá - MADE (2009), curso de extensão em Marketing e Liderança pelo Marietta College (2005), pós graduação em História Econômica pela Universidade Federal de Juiz de Fora (2003), graduação em Administração de Empresas pela Faculdade Metodista Granbery (2007) e graduação em Serviço Social pela Universidade Federal de Juiz de Fora (2002). Atua como coordenadora do curso de Administração da Fundação Educacional Machado Sobrinho e professora dos cursos de Administração, Engenharia de Produção e Ciências Contábeis ministrando diversas disciplinas em nível de graduação, elaboração de projetos acadêmicos e publicação de trabalhos científicos na área de Administração e afins. Exerce a função de professora no curso de Pós Graduação em Administração Pública da UAB/UFF. Possui experiência na área de Administração, com ênfase em Estratégia e Marketing, atuando principalmente nos seguintes temas: marketing,comportamento do consumidor, estratégias empresariais, grupos estratégicos e redes de relacionamento.

\section{LAÉRCIO ANTÔNIO GONÇALVES JACOVINE}

Possui graduação em Engenharia Florestal pela Universidade Federal de Viçosa (1993), mestrado em Ciência Florestal pela Universidade Federal de Viçosa (1996) e doutorado em Ciência Florestal pela Universidade Federal de Viçosa (2000). Atualmente é professor associado da Universidade Federal de Viçosa. Tem experiência na área de Recursos Florestais e Engenharia Florestal, com ênfase em Economia Ambiental, atuando principalmente nos seguintes temas: créditos de carbono, sequestro de carbono, certificação florestal, desenvolvimento sustentável e gestão ambiental.

\section{LAYNA DE AZEVEDO PEREIRA DA SILVA}

Bacharel em Marketing pela Universidade Católica de Petrópolis I Certificada em Business strategy and marketing management pela Fondazione CUOA Business school, IT I Certificada em Estratégias de Marketing digital 


\section{LÍVIA MARIA DE PÁDUA RIBEIRO}

Doutorado em Administração pela Universidade Federal de Lavras (2014), mestrado em Administração pela Universidade Federal de Lavras (2006), especialização em Gestão Estratégica pela Universidade Federal de Minas Gerais (2003) e graduação em Ciências Contábeis pela Universidade Federal de Minas Gerais (2002). Atualmente é professora efetiva do Centro Federal de Educação Tecnológica de Minas Gerais (CEFET-MG), leciona na graduação em Administração e no Programa de Pós-graduação em Administração (PPGA). Tem experiência na área de Administração e Contabilidade, atuando principalmente no seguinte tema: controladoria e gestão de custos; administração pública e contabilidade pública.

\section{LUIZ ALBERTO MANGONI}

Mestre em Ciências Contábeis - Linha de pesquisa em Finanças - pela Universidade do Vale do Rio dos Sinos - UNISINOS, concluído em março/2015. Com especialização em Administração Financeira pela Universidade de Caxias do Sul (2001). Possui graduação em Ciências Contábeis pela Universidade de Caxias do Sul (1989). Atua no Departamento Financeiro de empresa nacional de grande porte e como professor na Faculdade CNEC Farroupilha (RS). Também é professor convidado para cursos de Pós-Graduação em Controladoria e Finanças na Universidade de Caxias do Sul.

\section{MÁRCIO LUIZ RIBEIRO}

Possui graduação em Ciências Econômicas pela Universidade Estadual do Oeste do Paraná (2016) e aluno do Mestrado em Teoria Econômica na Universidade Estadual do Oeste do Paraná (2017). Tem interesse nos seguintes temas: distribuição de renda e desigualdade social.

\section{MARCOS PEDRINHO ZUCK}

Bacharel em Ciências Econômicas pela Universidade Estadual do Oeste do Paraná (UNIOESTE), campus de Cascavel (2016)

\section{MARINES SANTANA JUSTO SMITH}

Doutora em Ciência da Informação pela UNESP/Marília, Mestre em Administração pelo UniFACEF. Docente dos Cursos de Ciências Contábeis, Administração e Engenharia de Produção. Docente no Curso de Pós-Graduação - Lato Sensu e Stricto Sensu - no Centro Universitário Municipal de Franca.

\section{MÔNICA ALMEIDA GAVILLAN}

Graduada em Administração de Empresas pela Universidade de Brasília - UNB, Especialista em Gestão de Pessoas pela Universidade Castelo Branco e Mestra em Turismo pela Universidade Federal do Rio Grande do Norte - UFRN. Atua como docente da Universidade Potiguar- UNP e Instituto Federal do Rio Grande do Norte(temporário)IFRN, curso de especialização em Gestão Pública, modalidade EAD.

\section{NEIVANDE DIAS DA SILVA}

Mestre em Gestão de Negócios Turísticos pela Universidade Estadual do Ceará e graduada em Administração pela Universidade Estadual do Sudoeste da Bahia. Pós-graduada em Gerenciamento de Micro e Pequenas Empresas pela Universidade Federal de Lavras. Docente da Universidade do Estado da Bahia (UNEB), campus XVII, no curso de Administração. Exerceu a função de Coordenadora Local do curso de Letras do Plano Nacional de Formação de professores da Educação Básica (PARFOR/ Plataforma Freire), 
pólo de Bom Jesus da Lapa. Coordena e atua como professora do curso de pós-graduação lato sensu em Gestão Estratégica das Organizações, como também coordena o Núcleo de Ensino Pesquisa e Extensão - NUPE - campus XVII.

\section{PATRICIA GUARNIERI}

Professora adjunta do curso de Administração da Universidade de Brasilia (UnB). Professora e orientadora no Programa de Pós-Graduação em Agronegócio e no Programa de PósGraduação em Administração da Universidade de Brasília (UnB). Doutora em Engenharia de Produção pela Universidade Federal de Pernambuco (UFPE), 2012. Mestre em Engenharia da Produção, com ênfase em Gestão Industrial, pela Universidade Tecnológica Federal do Paraná (UTFPR), 2006. Especialista em Gestão Empresarial pela Faculdade de Ciências Sociais e Aplicadas de Cascavel e Instituto Brasileiro de Pesquisas Sócio-Econômicas, 2002 e, Especialista em Docência no Ensino Superior pela União Panamericana de Ensino, 2005. Bacharel em Ciências Contábeis pela Universidade Estadual do Oeste do Paraná (UNIOESTE), 2000. Tem experiência em Gestão de Empresas, atuando principalmente nas seguintes áreas: Logística de Suprimentos e Logística Reversa, Gestão de parcerias e relacionamentos colaborativos no SCM e Análise de decisões. É autora do livro Logística Reversa: em busca do equilíbrio econômico e ambiental. Possui artigos publicados em eventos e periódicos nacionais e internacionais, capítulos em livros nacionais e internacionais. Editora executiva da Revista em Gestão, Inovação e Sustentabilidade (Regis). Referee de periódicos nacionais e internacionais, além de eventos nacionais e internacionais. É pesquisadora dos grupos de pesquisa: Grupo de Pesquisa em Operações, Logística e Métodos de Apoio à Decisão (GOMETA) e Grupo de Pesquisas e Estudos Avançados em Logística e SCM (GEALOGS).

\section{RAFAEL LUCAS RUSSO DANIEL}

Discente da Universidade Federal do Ceará (UFC), vinculado ao curso de Ciencias Econômicas, desenvolvendo pesquisa sobre empreendedorismo e financiamento da inovação. Participou como membro do Nucleo de Estudo e Pesquisa em Secretariado Executivo. Atualmente exerce a função de caixa executivo no Banco Bradesco, com certificação pela Associação Brasileira de Capitais (ANBIMA).

\section{RAFAEL ARAÚJO SOUSA FARIAS}

Graduado em Administração pela UniNovafapi - Certificado Fundação Getúlio Vargas - FGV; Graduado em Ciências Contábeis pela Universidade Federal do Piauí - UFPI; Mestre em Contabilidade pela Universidade Federal de Santa Catarina - UFSC; Doutorando em Administração pela Universidade de Brasília - UnB; e Contador CRC/DF.

\section{RAONI ROCHA SIMOES}

Doutor em Ergonomia e Organização do Trabalho pela Universidade de Bourdeax e Professor Adjunto da Unifei-Itabira

\section{RAPHAEL SALVIANO DE SOUZA}

Graduado em Administração pela Universidade de Brasília - UnB

\section{RICHELIEL ALBERT RODRIGUES SILVA}

Técnico em Agropecuária, Técnico em Comércio Exterior, Engenheiro Florestal e Mestre em Ciências Florestais (2007-2017) pela Universidade Federal do Rio Grande do Norte (UFRN), Doutorando em Ciências Florestais pela Universidade Estadual do Centro-Oeste (UNICENTRO). Desenvolve pesquisas de biologia reprodutiva, genética de populações e manejo de espécies florestais. 


\section{RODRIGO MACKSSUEL SILVA DE MELO}

Bacharel em Administração Pública pela UFRN e Tecnólogo em Comércio Exterior pelo IFRN.

\section{SÂMIA LAÍSE MANTHEY BENEVIDES}

É Psicóloga, Mestre em Administração e Pesquisadora no Grupo de Pesquisa Gestão da Inovação e Tecnologia vinculado a Universidade Federal de Rondônia. Vice coordenadora da Linha de Pesquisa Gestão da Inovação Social e Sustentabilidade na Amazônia e docente em cursos de Pós Graduação na Faculdade Católica de Rondônia.

\section{SANDERSON CESAR MACEDO BARBALHO}

Possui graduação em Engenharia Elétrica pela Universidade Federal do Rio Grande do Norte (1993), mestrado em Engenharia Mecânica pela Universidade Federal do Rio Grande do Norte (1997) e doutorado em Engenharia Mecânica pela Universidade de São Paulo (2006), ambos, mestrado e doutorado, desenvolvidos na área de Engenharia de Produção. É profissional em gestão de projetos com certificado PMP (Project Management Professional), pelo Project Management Institute (PMI). Atualmente é professor adjunto do Departamento de engenharia de produção da Universidade de Brasília e Diretor do Centro de Desenvolvimento Tecnológico (CDT) da UnB. Atuou entre janeiro de 2003 e janeiro de 2008 como engenheiro de desenvolvimento sênior e gerente de projetos, e entre janeiro de 2008 e agosto de 2012 como Gerente do Escritório de Projetos da OPTO ELETRÔNICA S.A. Tem experiência nas áreas de Engenharia Eletrônica, Processos de Fabricação, Gerência da Produção e em Desenvolvimento de Produto. Atua principalmente nos seguintes temas: gestão da produção de produtos ETO, inovação e desenvolvimento de produto, gestão de projetos, planejamento e controle da produção, processos de fabricação, análises de confiabilidade, falhas e riscos de segurança de equipamentos eletro-eletrônicos, mecatrônica, ensino de engenharia, modelos de referencia e melhoria de processos.

\section{SÉRGIO LOPES}

Graduação em Ciências Econômicas pela FECIVEL/UNIOESTE-Universidade Estadual do Oeste do Paraná/Cascavel. Especialização em Teoria Econômica pela UFPR-Universidade Federal do Paraná, Mestrado em História Contemporânea pela UFF-Universidade Federal Fluminense. Doutorando em Economia na Universidad Nacional de Córdoba-AR. Professor do curso de Ciências Econômicas da UNIOESTE-Universidade Estadual do Oeste do Paraná, campus de Cascavel. Autor do livro sobre a história do Paraná, O Território do Iguaçu no contexto da Marcha para Oeste, pela Edunioeste, Cascavel, PR.

\section{SONIA REGINA AMORIM SOARES DE ALCANTARA}

Mestre em Administração de Empresas, com pesquisa sobre Empregabilidade e Maturidade. Especialista em Administração de Recursos Humanos. Graduada em Serviço Social. Experiência em gestão nos segmentos de educação, atendimento ao público, relacionamento com fornecedores e planejamento de serviços, com ênfase no setor da saúde suplementar. Formação em Consultoria. Atuação como facilitadora de treinamentos corporativos para formação, educação e desenvolvimento de talentos e de equipes. Foi Superintendente de Relacionamento com Prestadores na Camed Saude. Integrou a Diretoria da Unidas-CE União das Instituições de Autogestão em Saúde. Atualmente é Professora da Universidade Federal do Ceará, vinculada ao Departamento de Administração. Membro do GEPES-Grupo de estudos e pesquisas em Secretariado, cadastrado no CNPQ desde 2014. Área de pesquisa: gestão de pessoas, empreendedorismo e inovação. Lattes: http://lattes.cnpq.br/4973711675622354, orcid.org/0000-0002-7158-7246 . 


\section{STEPHANIA APARECIDA FREITAS PEDROSA}

Possui graduação em Engenharia de Produção pela Faculdade Machado Sobrinho em Juiz de Fora. Possui experiência no desenvolvimento de projetos de Plano de Marketing, Pesquisa de Mercado, Plano de Negócio e Gestão de Pessoas.

\section{TATIANA MOREIRA CLEIMENTE}

Mestra em Administração pela Faculdade Alves Faria - ALFA/GO, Especialista em Gestão de Pessoas pela União Pioneira da Integração Social - UPIS/DF, Especialista em Gestão Estratégica em Logística pela Faculdade Juscelino Kubitschek - JK/DF, Especialista em Gestão Empresarial pela Faculdade Juscelino Kubitschek - JK/DF, Graduada em Administração pela Faculdade Michelangelo - DF e Graduada em Pedagogia pela Faculdade de Ciências de Wenceslau Braz, FACIBRA. Atualmente é Coordenadora e Professora dos Cursos de Administração, Gestão de Recursos Humanos e Gestão Pública da Faculdade Ideal - DF e Consultora Administrativa da Empresa Glamour Esthetic Center/DF.

\section{THAÍS NOGUEIRA DA SILVA}

Graduada em Gestão Financeira (UFMS)

\section{THAÍS TESTONI}

Graduada em Administração pela Universidade de Brasília - UnB.

\section{THAÍS NICOLE PEREIRA GOMES}

Possui graduação em Ciências Contábeis pela Universidade Federal da Paraíba (UFPB), Campus IV - Litoral Norte, Mamanguape-PB. Atualmente, trabalha numa Indústria de materiais para Sinalização Viária.

\section{THALISA MARIA JATI GILBERTO}

Mestre em Administração pelo Centro Universitário Municipal de Franca (UniFACEF), Graduada em Administração pelo UniFACEF e Direito pela FDF, docente dos cursos de graduação Administração, Ciências Contábeis e Engenharia de Produção e cursos de pós graduação Lato Sensu do UniFACEF. Proprietária e Diretora Financeira da empresa Solocon.

\section{UELITON DA COSTA LEONÍDIO}

Mestre em Administração - IBMEC, linha de pesquisa em Marketing. Bacharel em Administração (UCP). Atua como vice-diretor do Centro de Ciências Sociais Aplicadas (CCSA) da UCP e coordenador do Curso de Administração. Líder do grupo de pesquisa de estratégias de marketing e consultor de empresas.

\section{VANESSA CRISTINA DOS SANTOS}

Doutora em Economia (UFF) com ênfase em Desigualdade da Distribuição de Renda e Welfare State. Mestre. em Economia (UEM). Economista (UCP). Diretora do Centro de Ciências Sociais Aplicadas (CCSA) da UCP. Coordenadora do Curso de Ciências Econômicas. . Coordenadora do Núcleo de Estudos sobre Pobreza, Desigualdade, Justiça Distributiva e Desenvolvimento (NEPO). 


\section{VÍTOR CARDOSO DA SILVEIRA}

Graduação em Ciências Contábeis (UNP - RN). MBA em Administração Financeira (UNI RN). Mestrado em Administração (UFMS). Doutorando em Administração (UFMS). Professor Efetivo nos cursos de Administração e Gestão Financeira da UFMS, campus de Nova Andradina

\section{YARA MAGALY ALBANO SOARES}

Doutoranda no Programa de Pós-graduação de Ciências Contábeis da UFPB (PPGCC). Linha de pesquisa, usuário interno. Mestrado em Ciências Contábeis pela Universidade de Brasília (2007). Possui graduação em Ciências Contábeis pelo Centro Universitário do Rio Grande do Norte (2004) e graduação em Cooperativismo pela Universidade Federal do Rio Grande do Norte (1992). Atualmente é professor assistente da Universidade Federal da Paraíba. Tem experiência na área de Contabilidade, com ênfase em Contabilidade Gerencial. 


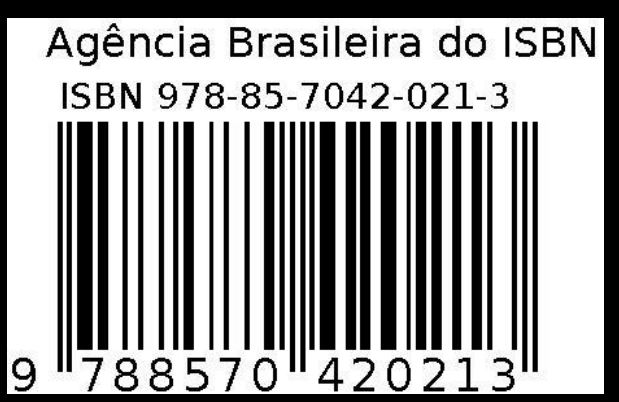

